Nils Bernstein und Charlotte Lerchner (Hg.)

\title{
Ästhetisches Lernen im DaF-/DaZ-Unterricht
}

Literatur - Theater - Bildende Kunst - Musik - Film

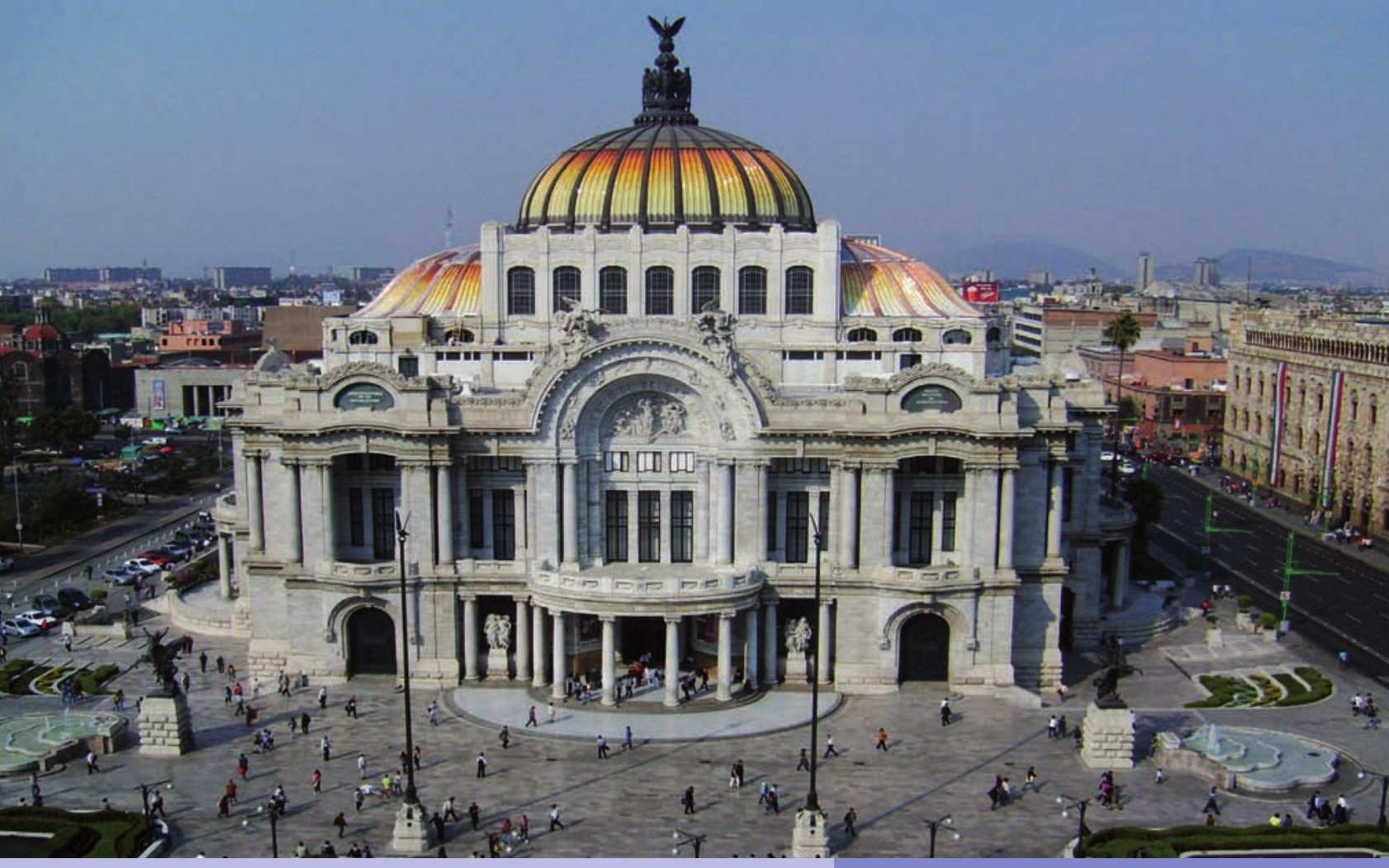

\section{Band 93}

Materialien

Deutsch als Fremdsprache 

Nils Bernstein und Charlotte Lerchner (Hg.) Ästhetisches Lernen im DaF-/DaZ-Unterricht

Dieses Werk ist lizenziert unter einer Creative Commons Namensnennung - Weitergabe unter gleichen Bedingungen 4.0 International Lizenz.

(c) (1) (2) 
erschienen als Band 93 in der Reihe „Materialien Deutsch als Fremdsprache“ in den Universitätsdrucken im Universitätsverlag Göttingen 2014 
Nils Bernstein und

Charlotte Lerchner (Hg.)

Ästhetisches Lernen im DaF-/DaZ-Unterricht

Literatur - Theater -

Bildende Kunst - Musik - Film

Materialien

Deutsch als Fremdsprache Band 93

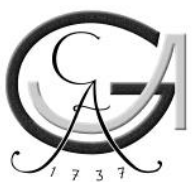

Universitätsverlag Göttingen 2014 


\section{Bibliographische Information der Deutschen Nationalbibliothek}

Die Deutsche Nationalbibliothek verzeichnet diese Publikation in der Deutschen Nationalbibliographie; detaillierte bibliographische Daten sind im Internet über $<$ http://dnb.ddb.de $>$ abrufbar.

Die „Materialien Deutsch als Fremdsprache“ sind eine Reihe des Fachverbands Deutsch als Fremdsprache e.V. $(\mathrm{FaDaF})$, in der Tagungsergebnisse, Dissertationen und andere wichtige Einzeldarstellungen aus dem Bereich Deutsch als Fremdsprache veröffentlicht werden.

http://www.fadaf.de/de/Publikationen/mat_daf/

\section{fadaf}

Schriftleitung: Annett Eichstaedt; Annegret Middeke

Gedruckt mit freundlicher Unterstützung von

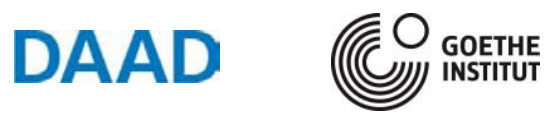

Dieses Buch ist nach einer Schutzfrist auch als freie Onlineversion über die Homepage des Verlags sowie über den GUK (Göttinger Universitätskatalog) bei der Niedersächsischen Staats- und Universitätsbibliothek (http://www.sub.uni-goettingen.de) erreichbar. Es gelten die Lizenzbestimmungen der Onlineversion.

Satz und Layout: Nils Bernstein und Charlotte Lerchner Umschlaggestaltung: Jutta Pabst

Titelabbildung: Reproduktion des Palacio de Bellas Artes, autorisiert durch das Instituto Nacional de Bellas Artes y Literatura, 2012

(C) 2014 Universitätsverlag Göttingen http://univerlag.uni-goettingen.de ISBN: 978-3-86395-183-2

ISSN: $1866-8283$ 


\section{Inhaltsverzeichnis}

\section{Nils Bernstein \& Charlotte Lerchner}

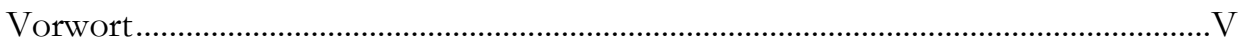

\section{Literatur}

\section{Carmen Schier}

Ästhetische Bildung in DaF und im fremdsprachlichen Literaturunterricht als Grundlage für eine nachhaltige Allianz zwischen Denken und Empfinden................3

\section{Michael Dobstadt \& Renate Riedner}

Dann machen Sie doch mal etwas anderes -

Das Literarische im DaF-Unterricht und die Kompetenzdiskussion

\section{Julia Collazo}

Migrationsliteratur hören, sprechen und erleben -

Hörspielproduktion im DaF-Unterricht

\section{Heidi Hahn}

Bühne frei für große Gefühle: Ästhetisches und theatrales Lernen im

DaF-/DaZ-Unterricht am Beispiel von Heinrich Heines Der arme Peter in der Bilderbuchadaption von Peter Schössow

\section{Almut Hille \& Johann Georg Lughofer}

Einfach mal dichten. Slam Poetry im Unterricht Deutsch als Fremdsprache 


\section{Christiane Hochstadt}

Der is im Heræen müd - Mimetisch-ästhetisches Lernen im gemeinsamen

Deutschunterricht mit L1 - und L2-Lernenden an den Beispielen der

literarischen Gesprächs- und der Leseförderung 75

\section{Dietrich Rall}

Die Farbe Blau: Literatur und Kunst im DaF-Unterricht

\section{Angelika Weber}

Literatur bewegt Grammatik. Ästhetisches Lernen im Grammatikunterricht des Deutschen als Fremdsprache

\section{Anke Stöver-Blahak}

Ästhetische Kommunikation im DaF-Unterricht

Ich babe es eher als ein Arbeitswerkzeng betrachtet als ein ricbtiges Gedicht

\section{Antje Dohrn}

Leseförderung mit literarischen Texten im DaZ-Unterricht

Ulrike Pleß

Übersetzen von Liedern im DaF-Unterricht

\section{Theater}

\section{Manfred Schewe}

Für das Ästhetische einen Ort schaffen. DaF als Baubaus - ein Vorentwurf 167

\section{Micha Fleiner}

Zur Notwendigkeit einer performativ-ästhetischen Fremdsprachenlehrerausbildung im deutschsprachigen Hochschulraum: Zusammenfassende Einblicke in Theorie und Praxis

\section{Susanne Even}

Dramapädagogik und Ästhetisches Lernen im Fremdsprachenunterricht 191

\section{Birgit Oelschläger}

Bühne frei für Deutsch! - Rückbesinnung auf das Wesen des Theaters 207

\section{Magdalena Haftner \& Anne-Marie Kuhfuß}

Ich hab gar nicht gemerkt, dass ich Deutsch spreche - Wie die theatrale Erfahrung des Improvisationstheaters freies und authentisches Sprechen erlebbar macht und die kommunikative Kompetenz fördert

\section{Maik Walter}

Mit Worten Räume bauen: Improvisationstheater und szenische

Wortschatzvermittlung 


\section{Bildende Kunst}

\section{Eva Veronika Chen}

Die Sprache der Dinge: Ästhetisches Lernen und Visual Literacy in der Ausbildung von DaF-Lehrenden - Über die Arbeit mit Bildern und Objekten

\section{Tristan Lay}

Kunstbilder im DaF-/DaZ-Unterricht - Die Porträts des Malers

Gerhard Richter und seiner Kinder Betty, Ella und Moritz

\section{Musik}

\section{Camilla Badstübner-Kizik}

Text - Bild - Klang

Ästhetisches Lernen im mehrsprachigen Medienverbund.

\section{Matthias Perner}

Musik im DaF-Unterricht: Von der Sprache zur Musik - und zurück

\section{Kathrin Wild}

Neue Töne im Ausspracheunterricht 335

\section{Film}

\section{Tina Welke}

Die Etablierung eines Geheimnisses -

Titelsequenzen im Unterricht Deutsch als Fremdsprache.

Nils Bernstein

Ästhetisierte Faktualität im Film. Über die filmisch-literarische Vermittlung von Initiationsszenen des bundesrepublikanischen Terrorismus in den beiden Filmen Wer wenn nicht wir (2011) und Der Baader Meinhof Komplex (2008)... 



\section{Vorwort}

In dem Roman Der unsichtbare Apfel lässt Robert Gwisdek seinen Protagonisten Igor an den schulischen Gegebenheiten verzweifeln. In einem Gespräch mit dem Schuldirektor versucht der Grundschüler diesen zum Überdenken des verwendeten Lehransatzes zu bringen:

[Igor] schlug ihm vor, dass es ein Fach geben sollte, welches mit verbundenen Augen abgehalten würde. Er sagte, dass er nun schon zwei Jahre zum Unterricht komme, aber nichts finden könne, was den Tastsinn oder das Gehör trainiere. Auch sein Geruchssinn werde nicht geübt [...]. Darüber hinaus müsse das lange Sitzen aufhören, da es hochgradig ungesund sei (Gwisdek 2014: 20).

Der Direktor reagiert auf diesen Vorschlag mit einem Lachen. Ganz ähnlich wurden alternative Ansätze wie die Waldorf- oder die Montessoripädagogik jahrelang belächelt, die - wie hier beschrieben - unter anderem auf die Einbindung aller Sinne in den Lernprozess beharrten. Die Ansicht, dass Lernen ganzheitlich sein muss, also nicht nur den Kopf, sondern den gesamten Menschen einbeziehen muss, ist aber in den letzten Jahren ins Zentrum der wissenschaftlichen Auseinandersetzung gerückt worden. Grund dafür ist die Beobachtung, dass das rein kognitive Bildungssystem nicht mehr mit den Herausforderungen einer globalisierten, sich ständig wandelnden Welt in Einklang zu bringen ist.

Stattdessen muss der Mensch in seiner Ganzheitlichkeit im Lernprozess berücksichtigt werden, wie es beim Ansatz des ästhetischen Lernens der Fall ist und wie

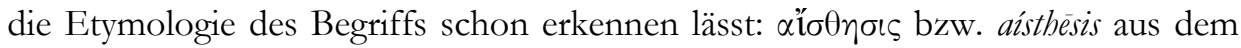
Griechischen bedeutet sinnliche Wahrnehmung und Empfindung. ${ }^{1}$ Ästhetisches

${ }^{1}$ Zur Wort- und Begriffsgeschichte vgl. Zabka 2010: 452f. und Lehnerer 1993: $38 \mathrm{f}$. 
Lernen heißt also nichts anderes als mit allen Sinnen und Gefühlen lernen. Klassischerweise wird die Ästhetik mit den Künsten in Verbindung gebracht, da sie die ästhetische Wahrnehmung schulen. Es ist aber zu beachten, dass diese sich auch auf Alltagssituationen beziehen kann, insofern sie nicht „Zweckorientiertpragmatisch“ (Spinner 2008: 9), sondern ästhetisch ist. Die Bedeutung der sinnlichen Wahrnehmung für den Menschen hatte Friedrich Schiller bereits 1795 in seiner philosophisch-ästhetischen Schrift Über die ästhetische Erziehung des Menschen formuliert. Die Menschwerdung, so Schiller im sechsten Brief, sei nur erreicht, wenn „die Sinne und der Geist" (Schiller 2009: 24) miteinander in Einklang stehen. Dass die Bildung der Weg hin zur Persönlichkeitsbildung ist, ergibt sich von selbst, ebenso dass in dieser Ästhetik eine große Rolle spielen muss.

Bis vor wenigen Jahren wurde diese Erkenntnis, abgesehen von einigen Ausnahmen, wie die bereits oben genannten pädagogischen Nischen, aber in den Bildungssystemen weltweit ignoriert und ihre Verfechter wurden wie der Protagonist in Gwisdeks Buch ob ihrer abweichenden Ideen belächelt. Stattdessen fokussierte man sich auf eine rein kognitiv ausgerichtete Didaktik. Der Fremdsprachenunterricht im Allgemeinen und Deutsch als Fremdsprache bilden hierbei keine Ausnahme. Zu sehen ist diese Entwicklung hin zur Kompetenzorientierung im Fremdsprachenbereich unter anderem am Gemeinsamen Europäischen Referenzrahmen ( $G e R)$, in dem ,affektive und ästhetische Aspekte kaum angemessen berücksichtigt werden“ (Rösler 2012: 269) und der aus diesem Grund unter anderem verstärkt in die Kritik geraten ist, sowie an der mit dem $G e R$ verbundenen zunehmenden Bedeutung von Zertifizierungen.

Selbstverständlich fordern die VertreterInnen einer ästhetisch ausgerichteten Didaktik aber nicht die Abschaffung der kognitiven Herangehensweise. Vielmehr geht es darum, beide Ansätze miteinander zu verbinden. Für den literarischen Bereich wurde schon empirisch nachgewiesen, dass eine solche Verknüpfung keinerlei Widerspruch darstellt, sondern im Gegensatz produktiv sein kann und die Thematisierung von Literatur durchaus mit einem kompetenzorientierten Lernen in Verbindung stehen kann (vgl. Preußer 2012: 285; Albrecht; Hornberger 2014: 58).

Betrachten wir das Ästhetische im Bereich Deutsch als Fremdsprache, wird schnell klar, dass Künste - wie auch in den anderen Fremdsprachen - schon lange eine Rolle gespielt haben - sei es als landeskundliche Objekte oder zur Vermittlung von Inhalten wie Grammatik, Lese- und Hörverstehen. Dennoch bringt der Ansatz des ästhetischen Lernens eine Neuerung mit sich, da bis dato die Eigenheiten der Künste kaum beachtet wurden und somit ihr besonderes Potenzial nicht ausreichend genutzt wurde. Oft findet man in Lehrwerken beispielsweise Lieder, die als Hörverstehensübung eingesetzt werden, wobei Melodie und Rhythmus gar keine Rolle spielen. Ein anderes Beispiel ist der Einsatz des Spielfilms als „VerlegenheitsLückenbüßer" (Spinner 2008: 12) am Ende eines Kurses oder aber auch die weit- 
verbreiteten Didaktisierungen zu Filmen, die nur Hörverstehensaufgaben beinhalten, anstelle die audiovisuelle Bildsprache des Mediums miteinzubeziehen. Diese Beispiele zeigen, dass der Einsatz von Kunst häufig ein instrumentalisierender ist, denn die Kunst wird den Zwecken des kognitiven Spracherwerbs untergeordnet.

Doch wie steht es aktuell um die Künste im DaF-Unterricht? Und wie kann man dem ästhetischen Lernen im DaF-Unterricht angesichts der zunehmenden Kompetenzorientierung gerecht werden? Diese zwei Fragestellungen beschäftigten die Teilnehmenden des Kongresses „Ästhetisches Lernen im DaF-Unterricht. Musik Kunst - Film - Theater - Literatur “' ${ }^{\text {, }}$, der vom elften bis 13. März 2013 am Fremdsprachenzentrum Centro de Enseñanza de Lenguas Extranjeras (CELE) der Universidad Nacional Autónoma de México (UNAM) stattfand und vom Goethe-Institut Mexiko, dem Deutschen Akademischen Austauschdienst (DAAD), dem Österreichischen Austauschdienst (OeAD), dem österreichischen Bundesministerium für Unterricht, Kunst und Kultur (BMUKK) dem mexikanischen Deutschlehrerverband Asociación Mexicana de Profesores de Alemán ( $A M P A L)$ sowie der deutschen und österreichischen Botschaft in Mexiko unterstützt wurde. ${ }^{3}$ Ziel des Kongresses war es, die verschiedenen Kunstformen unter Beachtung ihrer jeweils eigenen Ästhetik in den Mittelpunkt zu stellen.

Der vorliegende Band vereint nun Beiträge des Kongresses sowie eine Vielzahl weiterer Artikel, die dank eines zusätzlichen Call for Papers in Zusammenarbeit mit dem Fachverband Deutsch als Fremd- und Zweitsprache e.V. (FaDaF) gewonnen werden konnten. Zu beachten sind bei der Gliederung zwei Dinge. Zum einen, dass die vom Kongress übernommene Aufzählung „Musik - Kunst - Film - Theater - Literatur" keine Vollständigkeit anstrebt. Grund dafür ist, dass ästhetisches Lernen weit darüber hinausgeht, wie weiter oben schon konstatiert wurde. Zum anderen muss beachtet werden, dass Kunstformen in jedem Fall synästhetische Betrachtung ermöglichen und fördern. Dies zeigt sich daran, dass einige Beiträge nicht unbedingt einer einzelnen Kunstform zuzuordnen sind, sondern Brücken zwischen verschiedenen Bereichen schlagen. So treffen beispielsweise Theater und Musik oder Literatur und Film aufeinander.

Bedanken möchten wir uns insbesondere bei Dr. Annegret Middeke und Annett Eichstaedt vom Fachverband Deutsch als Fremd-und Zweitsprache e.V. (FaDaF), Helmut

\footnotetext{
2 Die Einteilung basiert auf den Vorlesungen über Ästhetik, in denen Hegel eine Einteilung der ästhetischen Künste vornimmt und die sechs Disziplinen Architektur, Malerei, Skulptur, Musik, Tanz und lyrische Dichtkunst nennt. Wir haben ausgehend von diesen die Kategorien etwas vereinfacht und zusammengefasst, wobei wir uns vor allem an den in der Fremdsprachendidaktik bereits berücksichtigten Bereichen orientiert haben. Unserer Auffassung nach können Architektur, Malerei und Skulptur als Bildende Kunst gefasst und Tanz dem Theater zugeordnet werden. Da der Film zu dem Zeitpunkt noch nicht existierte, wird er in Hegels Aufzählung nicht berücksichtigt, wird aber später in Anlehnung an diese als die siebte Kunst bezeichnet.

3 Vgl. die Kongresshomepage (online: www.cele.unam.mx/dafkongress) und den Bericht in Scenario 2013, Ausgabe 1, Jahrgang VII. Online: http://publish.ucc.ie/journals/scenario/2013/01/ BernsteinLerchner/07/de (Stand 27.05.2014).
} 
Schippert vom Goethe-Institut und außerdem bei Karoline Merz für die Unterstützung bei der nicht immer einfachen Formatierungsarbeit.

Nils Bernstein und Charlotte Lerchner

Hamburg und Mexiko-Stadt im Juni 2014

\section{Literatur}

Albrecht, Christian; Hornberger, Johannes (2014): Empirische Zugänge zu ästhetischer Erfahrung. In: Jahraus, Oliver; Liebau, Eckart; Pöppel, Ernst; Wagner, Ernst (Hrsg.): Gestalten und Erkennen. Ästhetische Bildung und Kompeten₹. Münster: Waxmann, 49-61.

Gwisdek, Robert (2014): Der unsichtbare Apfel. Köln: Kiepenheuer \& Witsch.

Lehnerer, Thomas (1993): Ästhetische Bildung. In: Staudte, Adelheid (Hrsg.): Ästhetisches Lernen auf neuen Wegen. Weinheim u.a.: Beltz, 38-43.

Preußer, Ulrike; Kreft, Florian (2012): Aphorismen lesen - Aphorismen verstehen. Kurze Textanalysen von B.A.-Studierenden der Germanistik. In: Preußer, U1rike; Sennewald, Nadja (Hrsg.): Literale Kompetenzentwicklung an der Hochschule. Frankfurt a.M. u.a.: Lang, 285-303.

Rösler, Dietmar (2012): Deutsch als Fremdsprache. Eine Einführung. Stuttgart u.a.: Metzler.

Schiller, Friedrich (2009): Über die ästhetische Erįiehung des Menschen in einer Reihe von Briefen. Kommentar von Stefan Matuschek. Frankfurt a.M.: Suhrkamp.

Spinner, Kaspar H. (2008): Perspektiven ästhetischer Bildung. Zwölf Thesen. In: Vorst, Claudia; Grosser, Sabine; Eckhardt, Juliana; Burrichter, Rita (Hrsg.): Ästhetisches Lernen. Fachdidaktische Grundfragen und praxisorientierte Konzepte im interdisziplinären Kontext von Lebrerbildung und Schule. Frankfurt a.M. u.a.: Lang, $9-23$.

Zabka, Thomas (2010): Ästhetische Bildung. In: Frederking, Volker; Krommer, Axel; Meier, Christel (Hrsg.): Taschenbuch des Deutschunterrichts Bd. 2. Literaturund Mediendidaktik. Baltmannsweiler: Schneider Verlag Hohengehren, 452-468. 


\section{Literatur}





\section{Ästhetische Bildung in DaF und im fremdsprachlichen Literaturunterricht als Grundlage für eine nachhaltige Allianz zwischen Denken und Empfinden}

\section{Carmen Schier}

Auf der Grundlage eines pragmatischen Bildungsverständnisses und der zunebmenden Standardisierung von Bildungsinhalten stehen im gegenwärtigen Fremdsprachenunterricht eindeutig rationale Denkprozesse mit Blick auf abprüfbare Kompetenzen im Fokus. Der Beitrag geht der Frage nach, inwiefern gerade die Förderung ästhetischer Kompetenzen in der Arbeit mit Literatur im Rahmen von Deutsch als Fremdsprache und des fremdsprachlichen Literaturunterrichts zur Entfaltung innerer Bilder beitragen kann und dadurch individuelle und kulturelle Lemprozesse in Gang gesetzt und reflektiert werden, in denen durch die Entwicklung eigener Ausdrucks- und Gestaltungsfähigkeit auch die Entwicklung der Sprache profitiert.

\section{Einleitung}

Seit der Umsetzung des Bologna-Prozesses mit dem Ziel der Schaffung eines einheitlichen europäischen Hochschulraumes stehen der Bildungsbegriff und das Verhältnis von Bildung und Ausbildung immer wieder im Fokus des gesellschaftlichen Diskurses. Realität ist derzeit ein pragmatisches Bildungsverständnis, das sich - nicht nur beim Erwerb einer Fremdsprache - u.a. in der Standardisierung von Bildungsinhalten und deren Reduzierung auf abprüfbare Kompetenzen zeigt. Nach der Grundschule ist der Unterricht in der Sekundarstufe bereits weitgehend einseitig ausgerichtet an rationalen Denkprozessen und Faktenwissen und relativ wahrnehmungsarm (vgl. Kirchner u.a. 2006: 9). In der Erwachsenenbildung und im 
universitären Bereich bleibt ohnehin nur wenig Raum für ein sinnlich orientiertes Wahrnehmen und subjektbezogenes Interpretieren von Wirklichkeit. Genau dies aber ist das Ziel ästhetischer Bildung, die als Äquivalent zu einem vorrangig begrifflich ausgelegten Zugang zur Welt dient.

Ästhetische Bildung ist ausgelegt auf ein sinnlich orientiertes und subjektbezogenes Wahrnehmen und Deuten von Wirklichkeit [, in dessen Kontext sollen] Sensibilität, Fantasiefähigkeit, Imaginationskraft und Kreativität ebenso entfaltet werden wie das kritische und emanzipierte Zurechtfinden und Verhalten in einer von Bildern und (audio-)visuellen Medien bestimmten Welt (ebd.: 11).

Wenn man Bildung nicht nur durch die Brille der ökonomischen Verwertbarkeit im Blick hat, wird in diesem Kontext zwangsläufig auch die Frage nach dem Zusammenhang zwischen Bildungsauftrag und Persönlichkeitsbildung relevant. Der nachfolgende Beitrag möchte zeigen, inwiefern gerade die Förderung ästhetischer Kompetenzen in der Arbeit mit Literatur im Rahmen von Deutsch als Fremdsprache und des fremdsprachlichen Literaturunterrichts zur Entfaltung innerer Bilder beitragen kann und dadurch individuelle und kulturelle Lernprozesse in Gang gesetzt und reflektiert werden, in denen durch die Entwicklung eigener Ausdrucksund Gestaltungsfähigkeit auch die Entwicklung der Sprache profitiert.

\section{2 Ästhetische Bildung und Lernkultur der emotionalen Beteiligung}

Der ökonomischen Verwertbarkeit von Bildungsinhalten stehen international durchaus andere Entwicklungstendenzen gegenüber. So war ein Ziel der Agenda der zweiten UNESCO-Weltkonferenz 2010 in Seoul (Südkorea),

$[\mathrm{k}]$ ünstlerische und kulturelle Bildung als Basis für eine ausgeglichene kreative, kognitive, emotionale, ästhetische und soziale Entwicklung von Kindern, Jugendlichen und lebenslang Lernenden [zu] bekräftigen (Zweite Weltkonferenz: 3).

Mehr als 2.000 ExpertenInnen aus 120 Ländern verständigten sich auf die Bedeutung kultureller Bildung als Grundlage von Lernen und Forschen mit dem Ziel, spezielle Entwicklungsziele festzulegen und Strategien zu diskutieren, um durch kulturelle Bildung Menschen bessere Entwicklungschancen zu bieten (vgl. Merkel 2010). Durch künstlerische und kulturelle Bildung soll das kreative und innovative Potential der Gesellschaft gesteigert werden (vgl. ebd.: 7). Damit werden international künstlerische und ästhetische Bildung einer mathematischen und naturwissenschaftlichen als gleichwertig zur Seite gestellt. Vor allem die Transferforschung macht deutlich, 
dass ästhetische Bildung eine Reihe von Kompetenzen (wie Kreativität, flexibles Denken, räumliches Vorstellungsvermögen, akademische Leistungsfähigkeit oder emotionale Intelligenz) fördert (Rittelmeyer 2012: 20).

Die neuere Hirnforschung belegt „die milieuabhängige Plastizität des menschlichen Gehirns" (ebd.: 46) und damit seine Fähigkeit zur Veränderung, die u.U. sogar bis zu einer Neubildung von Zellen reichen kann, abhängig von den Erfahrungen und Handlungen des einzelnen Individuums. Somit sind wir in gewisser Weise auch aktive Mitgestalter unserer organischen Voraussetzungen für emotionale und geistige Fähigkeiten (vgl. ebd.). Demgegenüber können lange ungenutzte Hirnareale auch verarmen.

Wenn wir anerkennen, dass Lernen etwas mit Lebensbewältigung zu tun hat, so bezieht es sich nicht nur auf kognitive Dimensionen. Durch Lernen wird das Verhältnis zu sich selbst, zu anderen und zur Welt verändert. Der Einzelne wirkt aktiv an der Konstruktion von Wahrnehmung und Erfahrung mit. Wenn wir den Menschen ganzheitlich betrachten, so entsteht Erfahrung durch Aktivität, durch Tun. In einer von Bildern dominierten Lebenswelt gibt es aber auch einen Verlust an Erfahrung bzw. eine Reduzierung ihrer Dimensionen. Ein Lernen mit allen Sinnen ist jedoch vorrangig nur noch in der Grundschule ein den Lernprozess durchziehender Gedanke.

\section{Wahrnehmung als Grundlage ästhetischer Rezeptionserfahrung ${ }^{1}$}

Sinnliche Wahrnehmung bildet die Grundlage ästhetischer Erfahrung. Es ist bekannt, dass schon frühe sinnliche Wahrnehmungen quasi gespeichert werden und durch ihr Weiterwirken spätere Wahrnehmungen beeinflussen, beispielsweise im Sinne einer verstärkten Aufmerksamkeit für bestimmte Phänomene (z.B. Geräusche, Gerüche, Farben, Formen o.̈.). Die ästhetische Wahrnehmung bezieht sich dabei nicht nur auf Objekte der Künste, sondern auch auf Phänomene und Situationen des Alltags. Eine intensive Wahrnehmung ist die Grundlage jeder ästhetischen Rezeptionserfahrung (vgl. Spinner 2008: 12). „Ästhetisches Wahrnehmen ist [...] kein sinnliches, selbstvergessenes Wahrnehmen, sondern schließt eine gesteigerte geistige Präsenz ein" (ebd.: 10). Sie ist meist nicht nur auf einen Sinneskanal beschränkt; so ruft eine Musik möglicherweise auch die Bilder der Situation wach, in der man zu ihr getanzt hat, verbinden sich Farben oder Gerüche mit bestimmten Bildern einer Reise oder regt ein Text den Geschmackssinn an. Zur ästhetischen Erfahrung wird eine Wahrnehmung erst, wenn sie nachhaltig erlebt wird. Für eine intensive ästhetische Erfahrung braucht man Zeit. Bei der Rezeption von

\footnotetext{
1 Die nachfolgenden Schwerpunkte sind auch Teil meines Artikels in: Altmayer, Claus; Dobstadt, Michael; Riedner, Renate; Schier, Carmen (Hrsg.) (2014): Neue Konzepte zur Rolle der Literatur in Deutsch als Fremdsprache und internationaler Germanistik. Tübingen: Stauffenburg Verlag.
} 
literarischen Texten, Filmen oder Theaterstücken gehören Neugier und Staunen genauso dazu wie Irritationen und Widerstand. Gerade auch aus diesem Grund lesen wir, gehen wir ins Kino, leihen wir Filme aus und versinken in die Handlung. Eine Grundvoraussetzung für ästhetische Erfahrung ist Imaginationsfähigkeit, weil es erst durch die Verknüpfung unserer Vorstellungskraft gelingt, beim Betrachten eines Bildes das Rauschen des Meeres zu hören oder uns beim Lesen einer Geschichte auch visuell in eine andere Welt zu versetzen.

In der Transferforschung finden sich viele Belege zur bereichernden Wirkung und zum Potential von Musik, Tanz oder Theater im Hinblick auf die Förderung von Eigenschaften wie Aufmerksamkeit, Imagination und Reflexionsfähigkeit. Empirische Belege für solche Effekte, ausgehend von der Lektüre belletristischer Texte, findet man bisher dagegen kaum (vgl. Rittelmeyer 2012: 95). Bietet aber nicht gerade auch Literatur einen Einblick in mögliche Lebensmuster und zeigt metaphernreich und in ganzer Breite und Tiefe Welten, Handlungen, die uns anregen, sensibler machen und bewusstseinsbildend wirken?

\section{Lesemotivation als eine Voraussetzung zur Entwicklung eines fremden Blicks und zum Perspektivenwechsel als Teil ästhetischer Bildung}

Fremdsprachliche Lesekompetenz und die Förderung von Lesemotivation gehören eng zusammen. Studien belegen, dass sich das Leseverhalten junger Leute stark verändert hat. Nach meinen Erfahrungen wird im fremdsprachlichen Literaturund DaF-Unterricht viel weniger als im muttersprachlichen Literaturunterricht überhaupt hinterfragt, wie viel die Lernenden lesen, was sie lesen (wollen) und schon gar nicht, wie sie lesen. Die Studie Lesen in Deutschland 2008 der Stiftung Lesen zeigt, dass der Kern der Vielleser (mehr als 50 Bücher im Jahr) mit rund $25 \%$ über die letzten Jahre relativ gleich geblieben ist (vgl. Lesen in Deutschland 2008). Dagegen hat die Zahl der Gelegenheitsleser abgenommen. Seit dem Jahr 2000 wurden 2500 Jugendliche und Erwachsene dazu repräsentativ befragt. Von den 14-19-jährigen Befragten haben 45\% angegeben, als Kind selten oder nie ein Buch als Geschenk erhalten zu haben. Dieser Gruppe fehlt schon einmal ein Leseimpuls oder eine oft vorausgesetzte Lesekultur, wobei davon auszugehen ist, dass diese Entwicklung nicht nur auf Deutschland zutrifft. Interessanterweise werden Deutsch sprechende Migranten als eine besondere „Lese-Mittelschicht“ (ebd.) ausgemacht.

Das Lesen am Bildschirm war auch 2008 schon im Alltag angekommen. In den letzten fünf Jahren nach dieser Erhebung hat sich jedoch der Markt bereits wieder rasant verändert. Die neue Vorlesestudie der ZEIT, der Deutschen Bahn und der Stiftung Lesen 2012 widmet sich daher dem Markt der Bilder- und KinderbuchApps und dem Stellenwert von Smartphones, Tablets und E-Readern (vgl. Vorlesestudie 2012). 
Ausgehend von der Erkenntnis der Studie 2011, dass Vorlesen für die ganzheitliche Entwicklung von Kindern einen sehr großen Stellenwert hat, wurde 2012 der Frage nachgegangen, wie die neuen technischen Möglichkeiten die Familiensituation - in Bezug auf das Vorlesen für zwei-achtjährige Kinder - verändern. Nach dieser Untersuchung nutzt jede dritte Familie mit Tablet im Haus Kinder- und Bilderbuch-Apps. Viele Eltern sehen darin ein Potential, das Kinder zum Lesen anregt, das Buch aber nicht verdrängt, sondern eher ergänzt. Dabei stehen besonders Väter der neuen Technik aufgeschlossen gegenüber. Und die Jugendlichen, die Studierenden? Inwiefern wären sie lesefreudiger und offener, wenn auch im DaF-Unterricht Lesen und die Auseinandersetzung mit Literatur ergänzend zur klassischen Buch- bzw. Textlektüre stärker unter Nutzung digitaler Medien erfolgen würde?

Literarische Texte eröffnen den Lernenden neue Räume und bieten ihnen spezifische Erklärungen von Welt, die auch zur Überprüfung der eigenen Lebenswelt und für das Verstehen unserer Erfahrungen dienen können. Schon die Rezeptionsästhetik hat gezeigt, dass Lesende gar nicht anders können, als den Text für sich zu adaptieren: Sie spielen mit, bringen beim Lesen automatisch ihre Subjektivität ein und sind somit beteiligt an der Herstellung des Textsinns. Als MitspielerInnen nehmen die Lesenden die Innenperspektive ein, sie versetzen sich in die Figuren, knüpfen dabei an ihre eigenen Lebenserfahrungen an und sind auch emotional involviert, denn sie bangen, hoffen, leiden oder freuen sich mit den HeldenInnen. Als Lesender muss man sich nicht selten in Figuren hineinversetzen, die nicht unbedingt nach eigenen und vertrauten Mustern agieren oder anders denken und fühlen als man selbst.

Ästhetische Erfahrung, die neue, bisher nicht gekannte Möglichkeiten des Lebens erschließt, ermöglicht Vorstellungen von dem, was anders und wie es anders sein könnte (Kirchner u.a. 2006: 15).

Gleichzeitig reagieren die Lesenden auf die ProtagonistenInnen in den Texten, beurteilen ihr Handeln und werden dadurch ästhetisch-kritische BeobachterInnen. Es geht also auch um eine ästhetische Urteilsbildung.

Da Imaginationen stark subjektiv geprägt sind, befördern sie Individualität in Lernprozessen und regen gerade im Auseinandersetzungsprozess mit Literatur auch zum Fremdverstehen an. Unaufdringlich machen Sie deutlich, dass Fremdheit durch die Ambivalenz von Zugehörigkeiten entsteht und keineswegs nur durch interkulturelle Kontexte eine Bedeutung erfährt. Zunächst erlauben die unterschiedlichen Bilder und die jeweils sehr verschiedenen ästhetischen Anregungen, die vom Text ausgehen, die Lesart der einzelnen Lernenden kennen zu lernen und die differenzierten Zugänge zum Text auszumachen, die im fremdsprachlichen Deutschunterricht oder in DaF nicht allein an sprachliches Wissen der Lernenden geknüpft sind. Allerdings kann es im Unterricht nicht allein darum gehen, vielfältige und differenzierte Imaginationen zu entwickeln, sondern vor allem das „Wechselspiel zwischen subjektiver Imagination und genauer Wahrnehmung fruchtbar zu 
Carmen Schier

machen“ (Spinner 2008: 14). Dennoch hinterfragt Abraham zu recht die Annahme, „[d] as zu Erschließende, zu Erklärende, zu Deutende sei ,der Text“" (Abraham 2010: 14). Er plädiert für ein poetisches Verstehen und wendet sich damit gegen eine Funktionalisierung von Literatur im Unterricht (vgl. ebd.: 16f.).

Im DaF-Unterricht mag zunächst erschwerend erscheinen, dass bei komplexen Texten Verständnis erst einmal grundsätzlich (sprachlich) hergestellt und gesichert werden muss. Jeder literarische Text nimmt Einfluss auf den Lesenden und vertieft bzw. verändert seine Vorstellungen von Welt und damit dem Zusammenleben von Menschen. Diese Erfahrungen und Einblicke schärfen nicht nur das Bewusstsein für die kulturelle Bedingtheit von Handlungen, sondern sensibilisieren auch für die moralischen Dimensionen dieser, denn Literatur konfrontiert uns auch immer wieder mit moralischen Konflikten und ethischen Ansprüchen. Bedenken und nutzen wir diese Dimension hinreichend im Zuge der Auseinandersetzung mit Literatur im DaF-Unterricht oder fokussieren und reduzieren wir noch allzu oft die ästhetische Erfahrung auf das Wiedererkennen von Stilmitteln, Stilformen und Bildern und messen der Autorintention größere Bedeutung bei als der des eigenen Urteils der Lesenden?

\section{Erfahrungsoffenes, ganzheitliches und interdisziplinäres Arbeiten in Rezeptions- und Produktionsprozessen}

Im Prozess einer angemessenen Auseinandersetzung mit Literatur muss es nach meiner Überzeugung auch Raum für emotional geprägte sinnliche Erfahrung und den Austausch darüber geben sowie Gelegenheiten für den eigenen gestaltenden Ausdruck. Letzteres gilt aus meiner Sicht gerade auch für den DaF-Unterricht, dabei kann dieses Gestalten von einer Rezitation über die Arbeit mit dramapädagogischen Mitteln bis hin zum kreativen Schreiben reichen. Dies setzt einen Unterricht voraus, in dem der Lehrende den Lernenden Platz zum Entwickeln und Erproben eigener Ideen lässt. Wenn Lernende

ihre emotionalen, imaginativen und kognitiv-rationalen Annäherungen an den ästhetischen Gegenstand einbringen, gemeinsam reflektieren und weiterentwickeln dürfen und sollen, bedarf es einer Lernsituation, die Individualisierung und Differenzierung zu ihren obersten Prinzipien erhebt (Büker 2008: 169).

Diese Forderung lässt sich in den oft festen Strukturen institutioneller Kontexte längst nicht ohne weiteres umsetzen. Darüber hinaus wird sie nicht selten als idealisierte Vorstellung mit dem Verweis auf Lehrpläne, Prüfungsanforderungen u.ä. abgetan oder belächelt von all jenen, die nur textanalytische Arbeit als wahre Beschäftigung mit Literatur (vor allem mit der Hochliteratur) gelten lassen bzw. ein solches Vorgehen für Erwachsene als überflüssig betrachten und einen nachhaltigen Lerneffekt anzweifeln. „Die Zweck- und Zwanglosigkeit des Ästhetischen 
widersetzt sich einem nur auf Nutzanwendung zielenden Lernbegriff“ (Kirchner u.a. 2006: 29). Aus didaktischer Perspektive ist zudem die Erkenntnis, dass insbesondere die Verbindung rezeptiver und produktiver Zugangsweisen besonders wirkungsvoll ist, keineswegs neu. Im DaF-Unterricht wird dieser handlungsorientierte Ansatz aber häufig auf Sprachhandlungen oder die Auswahl von Themen reduziert und damit verkürzt. Für die Arbeit in literarischen Seminaren im weltweiten Rahmen der Germanistikausbildung wird er, zumindest meiner Erfahrung in der Lehrerfortbildung nach, mit Blick auf den Anspruch von Wissenschaftlichkeit erst gar nicht vordergründig in Betracht gezogen.

Besonders für jugendliche Lernende spielt die ästhetische Bildung eine große Rolle, da ästhetische Erfahrung als Alteritätserfahrung nicht nur zum Nachdenken anregt, sondern auch im Rahmen der Identitätsbildung von besonderem Belang ist. Haußer meint: „Was einen emotional nicht berührt und kalt lässt, wird auch nicht identitätsrelevant“ (Haußer 1994: 9). Subjektive Bedeutsamkeit wirkt in diesem Verständnis wie ein Filter.

Fraglos muss im DaF-Unterricht bei komplexen literarischen Texten erst einmal Verständnis hergestellt und gesichert werden. In diesem Zusammenhang kann es sein, dass für einige Lernende so ein Zugang zu einer Welt ermöglicht wird, die vielleicht sonst nicht in ihren Blick geraten würde. Im DaF-Alltag gibt es auf der einen Seite eine ganze Reihe ästhetischer Produkte, die nicht zuletzt durch den produktorientierten Ansatz aufgewertet wurden. Sie reichen von Texten als Ergebnisse des kreativen Schreibens bis hin zur literarisch-ästhetischen Analyse poetischer Texte. Solche Produkte werfen natürlich auch die Frage nach angemessenen Möglichkeiten der Evaluierung auf, die sich für den Lehrenden nicht immer leicht gestaltet. Andererseits spielt die Arbeit mit Literatur im Gemeinsamen Europäischen Referenzrahmen für Sprachen (GER) bekanntermaßen eine untergeordnete Rolle und findet erst ab B2-Niveau überhaupt Erwähnung.

\subsection{Masken als möglicher ästhetischer Zugang und Element der Auseinandersetzung mit dem literarischen Text}

Unbestritten besitzt der menschliche Körper Kulturen und Mentalitäten übergreifende Relevanz im gegenwärtigen gesellschaftlichen Diskurs. In den westlichen Kulturen ist der Körper der Ort des Selbst und seine mehr oder minder ständige Präsenz in den Medien macht ihn zum Gegenstand allgemeiner Aufmerksamkeit. Weltweit drücken wir unsere Meinungen, Haltungen und Einstellungen nicht nur verbal, sondern auch nonverbal durch unsere Körpersprache aus. Vor allem in unserem Gesicht spiegelt sich unsere innere Welt wider. Olschanski unterstellt ihm gar, „Organ der ,Aufrichtigkeit““ (Olschanski 2001: 29) zu sein. Der Spaß des Menschen an der Verwandlung seines Gesichtes hat eine lange historische Tradition. Parallel zur Gesichts- und Körperbemalung entwickelten sich auch Masken, die anfangs vor allem kultische Bedeutung besaßen und eine religiös-mythische Funktion erfüllten. Im sozialen Kontext übersieht die häufig negative Konnotation der 
Maske die Notwendigkeit, in der Gesellschaft eine oder mehrere Rollen zu spielen und die entsprechenden Masken zu tragen, denn die Rolle, so wie sie verbirgt, „dient [dazu], [...] die persönliche Integrität zu schützen, soziale Distanz herzustellen und nicht zuletzt das soziale Prestige der eigenen Rolle zu sichern" (Eisermann 1991: 253). Bereits Mitte der neunziger Jahre habe ich auf dieser Grundlage gemeinsam mit einer Kollegin an der Universität Coimbra in Portugal begonnen, im Prozess der Auseinandersetzung mit Literatur mit Masken zu arbeiten und ihr Potential für die ästhetische Bildung zu nutzen (vgl. Jahn; Schier 2005, Schier 2011). Ästhetische Objekte wie Masken erfordern vom Lernenden auch eine Offenheit für die Wirkung von Material, Farben und Motiven und nicht zuletzt kann die Auseinandersetzung mit Masken dazu beitragen, sich selbst als Person zu erkennen.

\subsubsection{Herstellung der Masken}

Für die Arbeit mit Masken muss zunächst in Partner- oder Gruppenarbeit von einigen Lernenden ein einfacher Abdruck des Gesichtes aus Gips hergestellt werden; ein Prozess, der etwa eine halbe Stunde dauert. Dazu braucht man nicht mehr als zerschnittene Teile handelsüblicher Gipsbinden, etwas Wasser und eine möglichst fettige Creme zur Grundierung des Gesichtes. Die Arbeit am Abdruck bietet bereits die Möglichkeit zu variieren: Augen und/oder Mund geschlossen oder offen zu halten, sein neutrales Gesicht abbilden zu lassen oder bereits unter der Maske mimisch in eine Rolle zu schlüpfen. Das Spiel mit der Verfremdung steht dabei von Anfang an im Vordergrund und lädt auf ungezwungene Weise ein, genauer über das eigene Maskentragen, die eigene und fremde Körperwahrnehmung und sein Rollenverhalten zu reflektieren. Personen, die sich nicht immer gut kennen, müssen zulassen, sehr lange und relativ intensiv berührt zu werden bzw. sich wagen, jemanden zu berühren. In diesem Zusammenhang müssen sie eigene Formen der Verständigung finden. Die getrocknete weiße Gipsmaske kann später bemalt oder anderweitig bearbeitet werden.

\subsubsection{Verwendung der Masken in Verbindung mit ausgewählten Themen}

An einigen Beispielen möchte ich zeigen, wie sinnvoll vor allem im Rahmen eines projektorientierten Unterrichts die Arbeit mit Masken sein kann und wie diese interdisziplinär für die Entwicklung ästhetischer Kompetenz genutzt werden kann ${ }^{2}$. Unter projektorientierter Arbeit verstehe ich hier die Konzipierung kleinerer oder größerer Unterrichtseinheiten, die - integriert in den Sprach- und Landeskundeunterricht - als Block gehalten werden (beispielsweise 4-5 Unterrichtsstunden) oder über einen längeren Zeitraum (z.B. ein Semester mit je einer Stunde pro

\footnotetext{
${ }^{2}$ Die genannten Themenvorschläge wurden weitgehend aus meinem Artikel in Fremdsprache Literatur entnommen vgl. Schier 2011.
} 
Woche) der ausschließlichen Arbeit mit Literatur gewidmet sind. Die inhaltliche Klammer bildet ein Themendach, unter diesem können je nach Wunsch und Bedarf verschiedene literarische Genres miteinander kombiniert, Literatur epochenübergreifend herangezogen und/oder in einer Mischung aus Hochliteratur und populären literarischen Formen verschiedene Zugänge zum Thema geschaffen und individuelle Lernerinteressen eingebunden werden. Es bildet darüber hinaus eine gute Grundlage für die Verknüpfung der verschiedenen Teilbereiche der Germanistik und für eine Zusammenarbeit mit anderen Disziplinen wie Kunst oder Musik. Das thematische Prinzip spielt im Literaturunterricht inzwischen eine große Rolle.

Vorschlag 1: Das Männerbild in der neueren deutschsprachigen Literatur von Frauen (für ältere Jugendliche oder Erwachsene, ab B1-Niveau)

Die Lernenden bilden mit Hilfe der Masken ihr eigenes Bild von Männern ab, gestalten Gesichter von Textcharakteren oder stereotype Männerbilder mit dem Ziel der inhaltlichen Auseinandersetzung mit dem Thema Männlichkeit im Vorfeld der Textrezeption oder der intensiven Auseinandersetzung mit den Textcharakteren während oder nach der Rezeption der Texte

Vorschlag 2: Lyrik und Prosa zum Leben in der Großstadt (alle Zielgruppen, ab A2Niveau)

Mit Hilfe der Masken gestalten die Lernenden die Gefühle verschiedener lyrischer Ichs in Großstadtgedichten (z.B. Einsamkeit, Anonymität, Kälte, Reizüberflutung) und rezitieren später selbst diese Gedichte hinter vorgehaltener Maske. Passende Musik könnte die Beiträge ankündigen und ergänzen. Im Vorfeld kann eine Diskussion über die Zuordnung der Masken zu den Gedichten und eine damit verbundene Auseinandersetzung über mögliche Sinnzuschreibungen durch Klang und Rhythmus stattfinden.

Vorschlag 3: Auf der Suche nach der blauen Blume oder von der Sebnsucht der Menschen, glücklich zu sein (ältere Jugendliche und Erwachsene, ab B1-Niveau)

Die Lernenden gestalten Masken zu unterschiedlichen Textsequenzen auf dem Weg der Helden bei ihrer Suche nach Glück.

Vorschlag 4: Zwischen Liebe und Liebe - literarische Texte zu einem großen Gefühl (Jugendliche und Erwachsene, ab B1-Niveau)

Die Lernenden gestalten die Masken und kombinieren sie mit ausgewählten Textstellen zu einer kleinen Ausstellung. Andere Lernende schreiben möglicherweise zu den entstandenen Masken kleine neue Texte.

Vorschlag 5: Sprachgewitter - kleine Texte mit großer Wirkung (Jugendliche und Erwachsene, ab B1-Niveau)

Unter diesem Dach versuchen die Lernenden in der Gestaltung der Masken die Sprachgewalt des jeweiligen Textes (Rap, Lyrik, Essay) bildlich umzusetzen und dort thematisierte Gefühle (Wut, Zorn, Ablehnung, Verunsicherung, Enttäuschung 
u.ä.) deutlich zu machen. Dies kann aber genauso für die Umsetzung und Verbildlichung sprachgewaltiger Textauszüge und -stellen umfangreicher literarischer Werke genutzt werden, von Goethes Faust über Kafkas Die Verwandlung bis zu Brechts Furcht und Elend des dritten Reiches.

Ästhetische Bildung versteht sich in diesem Kontext nicht in erster Linie als Prozess der Wissensaneignung, sondern als Ergebnis sinnlicher Erfahrung und des Austausches darüber als eigenständige Quelle von Wissen und Erkenntnis. In diesem Rahmen spielt auch die symbolische Sinnzuweisung eine Rolle.

\section{2 Ästhetischer Zugang zum literarischen Text durch die (didaktische) Nutzung anderer Medien}

\subsubsection{Zur Arbeit mit Hörbüchern}

In den letzten Jahren erfreuen sich Hörbücher einer immer stärkeren Beliebtheit, neben belletristischen Texten schließt der neuerliche Trend bereits Sachhörbücher ein. Der Begriff Hörbuch kann sehr weit gefasst werden. Hier sei in erster Linie an das originäre Hörbuch gedacht, das sich durch Texttreue auszeichnet. Gelesen werden vor allem Prosatexte. Normalerweise beschränkt sich im Unterschied zum Hörspiel und anderen dramaturgisch bearbeiteten Aufzeichnungen, z.B. von Theateraufführungen, die akustische Dimension auf die Stimme der Sprechenden (oder der AutorenInnen), die mitunter durch kleine musikalische Einspielungen ergänzt wird. Die erzählten Begebenheiten werden hörbar gemacht. Es sei an dieser Stelle kurz daran erinnert, dass das Erzählen und Hören von Geschichten nicht nur zum Ursprung der Begegnung mit Literatur zurückgeht, sondern dass Erzählen auch eine der wichtigsten Kommunikationsformen im Alltag ist und ihm damit eine allgemeine kulturelle Bedeutung zukommt.

Zunächst, so könnte man meinen, wird es für die Hörenden schwieriger als für die Lesenden. Das Tempo ist vorgegeben, ein kurzes Verharren oder Zurückblättern ist nicht möglich. Verweise auf zusätzliche unmittelbare Erklärungen (Fußnoten, Glossare o.ä.) stehen nicht zur Verfügung. Andererseits unterstützen die Stimmführung und der Klang der Stimme das Textverständnis. Pausen, Betonung und Lautstärke lenken den Zuhörer, erreichen ihn u.U. viel eher auch auf einer emotionalen Ebene. Das Interesse am Text kann dadurch gesteigert werden, die Erlebnisintensität erhöht. Dazu kommt die Schulung einer differenzierten Wahrnehmung der Sprechausdrucksmerkmale. Die Empathie des Hörenden kann durch das Vorlesen verstärkt und als Voraussetzung für einen Perspektivenwechsel genutzt werden. Vorgelesene Texte sind allerdings nicht ganz unproblematisch, denn ein vorgelesener Text ist immer ein interpretierter Text, der bereits eine Lesart vorgibt, die dem des Lesenden/Hörenden nicht entsprechen muss. Allerdings eröffnet diese Lesart des Textes auch die Chance, auf der Grundlage dieser Interpretation leichter über mögliche andere Auslegungen und Deutungen ins Gespräch zu kommen. Wenn es dem Lehrenden gelingt, für eine angenehme akustische Um- 
gebung zu sensibilisieren, kann für den Lernenden eine sehr konzentrierte Atmosphäre geschaffen werden, in der Raum für ein Hinhören und bewusstes Zuhören entsteht, bei dem sich rezeptives und produktives Handeln und damit Wahrnehmung und Interpretation verschränken (vgl. Heudecker 2006: 88f.).

Die Arbeit mit Hörbüchern ermöglicht eine Fokussierung auf individuelle auditive Wahrnehmung und eine kontrastierende Zusammenschau mit der individuellen Wahrnehmung anderer (ebd.: 88).

Anhand der Hörbucharbeit kann gut veranschaulicht werden, dass , nicht nur der Text bestimmt, was er bedeutet, sondern auch der Rezipient“ (Travkina 2009: 94).

Der Einsatz von Hörbüchern bietet gute Anknüpfungspunkte für ein ganzheitliches, emotionales und prozessorientiertes Lernen. Durch Hörbücher wird den Lernenden sehr stark die Rolle der Stimme bewusst. Während es bei herkömmlichen Hörverstehensübungen, die ja Teil jedes DaF-Unterrichts sind, ganz vordergründig um das Verstehen im Sinne des Erfassens bestimmter Fakten, Zahlen und inhaltlicher Aussagen oder um phonetische Übungen geht, steht beim HörbuchEinsatz die Stimme als Einflussfaktor auf die Interpretation des Gesagten im Fokus. In diesem Zusammenhang kann an der sprechkünstlerischen Kompetenz der Lernenden gearbeitet werden, die für eine gelingende Kommunikation im SenderNachricht-Empfänger-Kontext immer Bedeutung hat. WIE etwas gesagt wird, spielt im Kommunikationsprozess ja eine nicht unerhebliche Rolle. Das Hörbuch kann den Einstieg in das Erlesen eines literarischen Textes bieten. Die Herausarbeitung von Textstrukturen und die Konkretisierung von Sinn- und Bedeutungszuschreibung können in Verbindung mit Hörbüchern in besonderem Maße genutzt werden, auf diese Weise können auch LeseanfängerInnen und Leseschwache unterstützt werden. Es gelingt eine literarische und ästhetische Erfahrung ohne Schriftlektüre ${ }^{3}$.

\subsubsection{Beispiel Fotostrecke}

Nicht nur Bredella unterstreicht, dass Lesen als eine Art gelenkter Schaffensprozess durch interpretative und kreative Aufgaben gefördert werden kann (vgl. Bredella 2007: 79). Dramapädagogische Mittel (z.B. die szenische Gestaltung von Textpassagen oder die Inszenierung von Standbildern) können das inhaltliche Gespräch über den Text und die Arbeit am Text unterstützen, individuelle Zugangsweisen zu diesem befördern und das Bewusstsein für nonverbale und paraverbale Einflussfaktoren auf die Interpretation schärfen. In einer bilddominierten Welt vermag vielleicht gerade die Diskussion visueller Umsetzungsmöglichkeiten zu einem tieferen Textverstehen beizutragen. Viele Lernende haben heute ein Handy mit integrierter Kamera, es bietet die Option, selbst gemachte Fotos und kleine

3 Zur Hörkulisse als Ansatzpunkt für eine Hördidaktik siehe beispielsweise Moser-Pacher, Andrea; Wogrolly, Albert 2010. 
Fotostrecken in den Unterricht einzubinden. Diese Verbindung von rezeptiver Textarbeit auf der einen und produktiver Eigeninitiative beim Herstellen der Fotos auf der anderen Seite prägt sich als Methodenkombination nachhaltiger ins Gedächtnis der Lernenden ein. Die Umsetzungs- und Einsatzmöglichkeiten im Unterricht sind vielfältig:

Im Vorfeld der Lektüre:

- Fotoentwürfe für das Buchcover ausgehend vom Titel des Textes oder nach Teilen der ungelenkten Erstrezeption

Im Prozess der Lektüre und der Anschlusskommunikation:

- Fotos für ein Werbeplakat zu einer Lesung oder ergänzend zu einer Rezension

- Gestaltung eines Einbandes

- Fotos als Illustration bestimmter Textpassagen, zur Verbildlichung der HauptheldInnen etc.

- Fotoreihen zur Veranschaulichung bestimmter Gefühlsausdrücke der ProtagonistenInnen (zur Auswahl und zum Abgleich eigener innerer Bilder)

- Erstellung einer Fotogeschichte oder eines Fotoromans in Gruppenarbeit, möglicherweise in der Kombination mit selbst ausgewählten (oder vorgegebenen) tragenden Textpassagen

- Erarbeitung eines Comics auf der Grundlage des gelesenen Textes

- Fotoreihen vor dem Hintergrund der Idee, den Stoff zu verfilmen. Man stellt sich vor, die SchauspielerInnen haben sich bereits in einem Casting vorgestellt, die Fotos der BewerberInnen werden nun gesichtet und die Besetzung der Rollen wird diskutiert.

- Anfertigung von Fotocollagen

Jeder literarische Text verändert (bzw. verstärkt) die Vorstellungen eines Lesers vom sozialen Zusammenleben der Menschen, den Motiven ihres Handelns, von den sie umgebenden und bestimmenden (möglicherweise metaphysischen) Kräften und Energien oder von der kulturellen Bedingtheit ihrer Handlungen und Vorstellungen (Hallet 2007: 37).

Hallet spricht in diesem Kontext von der „Erfahrungshaftigkeit“ (ebd.: 37) narrativer Texte. Literatur konfrontiert uns mit anderen Lebens- und Handlungsmustern, mit moralischen Konflikten und sensibilisiert uns dadurch zum Hinterfragen eigener Urteile und Einstellungen.

Zur ästhetischen Erfahrung gehört aber nicht nur, dass wir emotional involviert sind, sondern auch, dass wir beurteilen und zur Reflexion über den Rezeptionsprozess angeregt werden, weil wir, indem wir nicht handelnd in ein Geschehen verstrickt sind, auch eine gewisse Distanz bewahren können (Bredella 2007: 82). 
Ziel der universitären Ausbildung muss es sein, Lehrende zu befähigen, in diesem Sinne zu unterrichten. Haben wir in unserer Ausbildung von Lehrenden für den DaF-Unterricht bzw. den fremdsprachlichen Literaturunterricht tatsächlich genug Raum für deren Wahrnehmensschulung, eine Schulung von Ausdrucks- und Urteilsqualitäten, Arbeit an und mit den Sinnen, die beim Lernenden letztendlich rationale und emotionale Erkenntnisprozesse anregen und miteinander verbinden soll?

In Deutschland ist die Schnittstelle zwischen Schule und Hochschule bzw. Universität relativ klein geworden. Neuere Konzepte der Literatur- und Kulturwissenschaften der letzten Jahre spiegeln sich bisher nur bedingt in Lehr- und Lernkontexten wider. Der Sprach- und Landeskundeunterricht in DaF folgt nach wie vor in erster Linie klassisch-traditionellen Mustern. Wenn wir in unserem Unterricht die Hinwendung zu dem wollen, was durch Literatur Menschen (Lernende) generell berührt, bewegt und für sie konkret greifbar wird, was sie interessiert und - wenn wir Erfolg haben - sie zum erkennenden Handeln bewegt, dann müssen wir auch in den Institutionen Schule und Hochschule dafür den Raum und die entsprechenden Rahmenbedingungen schaffen, gegen eine geistige Verarmung und eine Informationsvöllerei.

\section{Literatur}

Abraham, Ulf (2010): Poetisches Verstehen. Zur Eingemeindung einer anthro-pologischen Erfahrung in den kompetenzorientierten Deutschunterricht. In: Winkler, Iris; Masanek, Nicole; Abraham, Ulf (Hrsg.): Poetisches Verstehen. Literaturdidaktische Positionen - empirische Forschung - Projekte aus dem Deutschunterricht. Baltmannsweiler: Schneider Verlag Hohengehren, 9-22.

Bredella, Lothar (2007): Die welterzeugende und die welterschließende Kraft literarischer Texte: Gegen einen verengten Begriff von literarischer Kompetenz und Bildung. In: Bredella, Lothar; Hallet, Wolfgang (Hrsg.): Literaturunterricht, Kompetenzen und Bildung. Trier: WVT, 65-86.

Büker, Petra (2008): Zur Entwicklung eines fremden Blicks durch Unterrichts-forschung: Studierende auf dem Weg zum ästhetischen Lernen. In: Vorst, Claudia; Grosser, Sabine; Eckhardt, Juliane; Burrichter, Rita (Hrsg.): Ästhetisches Lernen. Fachdidaktische Grundfragen und praxisorientierte Konzepte im interdisziplinären Kontext von Lehrerbildung und Schule. Frankfurt a.M. u.a.: Lang, 169-186.

Eisermann, Gottfried (1991): Rollen und Masken. Tübingen: Mohr.

Fuchs, Max (2011): Ästhetisches Lernen und Lebren in Institutionen. Diskurse - Themen Zugänge. Werkstattbericht zur kulturellen Schulentwicklung 4/2011 (Entwurf vom 01.04.2011). Online: http://www.kultur-macht-schule.de/fileadmin/user_ 
upload/Wissensbasis/Aesthetisches_Lernen_und_Lehren_in_Institutionen_01 0411.pdf (Stand: 06.01.2014).

Hallet, Wolfgang (2007): Literatur, Kognition und Kompetenz. Die Literarizität kulturellen Handelns. In: Bredella, Lothar; Hallet, Wolfgang (Hrsg.) (2007), 31-64.

Haußer, Karl (1995): Identitätspsychologie. Berlin u.a.: Springer.

Heudecker, Sylvia (2006): Hörbücher - Annäherung an ein Medium und seine Didaktik. In: Wagner, Roland W.; Brunner, Andrea; Voigt-Zimmermann, Susanne (Hrsg.): bören - lesen - sprechen. München: Reinhardt, 81-91.

Jahn, Susanne; Schier, Carmen (2005): Projektarbeit und interkulturelles Lernen. Neue Arbeitsweisen im universitären Sprach- und Landeskundeunterricht. In: Das Fremde im Eigenen: Sprache, Literatur und Kultur des deutschen Sprachraums aus interkultureller Perspektive. Actas de la XI. Semana de Estudios Germánicos, Band II. Madrid: Ediciones del Orto 2005, 709-720.

Kirchner, Constanze; Schiefer Ferarri, Markus; Spinner, Kaspar H. (Hrsg.) (2006): Ästhetische Bildung und Identität. Fächerverbindende Vorschläge für die Sekundarstufe I und II. München: kopaed.

Lesen in Deutschland 2008. Online: http://www.stiftunglesen.de/institut-fuer-leseund-medienforschung/forschungsprojekte/lesen-in-deutschland-2008 (Stand: 06.01.2014).

Merkel, Christine (2010): Kulturelle Bildung gewinnt weltweit an Bedeutung. Zweite UNESCO-Weltkonferenz. zur kulturellen Bildung in Seoul. Online: http://www.unesco.de/4743.html (Stand: 06.01.2014).

Moser-Pacher, Andrea; Wogrolly, Albert (2010): Hör.Räume. In: ide. Lernräume. Zeitschrift für den Deutschunterricht in Wissenschaft und Schule, Heft 3, 91-98.

Olschanski, Reinhard (2001): Masken und Personen. Zur Wirklichkeit des Darstellens und Verbüllens. Göttingen: Vandenhoeck \& Ruprecht.

Rittelmeyer, Christian (2012): Warum und wozu ästhetische Bildung? Über Transferwirkungen künstlerischer Tätigkeiten. Ein Forschungsüberblick. Oberhausen: ATHENAVerlag.

Schier, Carmen (2011): Perspektivenwechsel als Tür zu anderen Welten. Zum Potential von Literaturprojekten in Deutsch als Fremdsprache. In: Fremdsprache Literatur. München: Goethe-Institut 2011, Fremdsprache Deutsch, Heft 44, 53-59.

Spinner, Kaspar H. (2008): Perspektiven ästhetischer Bildung. Zwölf Thesen. In: Vorst, Claudia; Grosser, Sabine; Eckhardt, Juliane; Burrichter, Rita (Hrsg.): 
Ästhetisches Lernen. Fachdidaktische Grundfragen und praxisorientierte Konzepte im interdisziplinären Kontext von Lehrerbildung und Schule. Frankfurt a.M. u.a.: Lang, 9-23.

Travkina, Elena (2009): Vorgelesene Prosa im Hörbuch. Untersuchungen zur Wirkung und zu Einsatzmöglichkeiten im Unterricht Deutsch als Fremdsprache. Dissertation. Halle/ Saale, 87-97.

Vorlesestudie 2012. Online: https://www.stiftunglesen.de/institut-fuer-lese-undmedienforschung/forschungsprojekte/vorlesestudie (Stand: 06.01.2014).

Winkler, Iris; Masanek, Nicole; Abraham, Ulf (Hrsg.) (2010): Poetisches Verstehen. Literaturdidaktische Positionen - empirische Forschung - Projekte aus dem Deutschunterricht. Baltmannsweiler: Schneider Verlag Hohengehren.

Zweite Weltkonferenz für kulturelle Bildung: Seoul Agenda: Entwicklungsziele für künstlerische/kulturelle Bildung. Online: http://www.unesco.de/fileadmin/ medien/Dokumente/Kultur/Kulturelle_Bildung/111024_Seoul_Agenda_DE _final.pdf (Stand: 06.01.2014) 



\title{
Dann machen Sie doch mal etwas anderes- Das Literarische im DaF-Unterricht und die Kompetenzdiskussion
}

\author{
Michael Dobstadt \& Renate Riedner \\ Ausgehend von der Debatte um die (Nicbt-)Messbarkeit literatur-und kulturbezogener Kompe- \\ tenzen und von Überlegungen der Verf. zur literarisch-ästhetischen Dimension von Sprache und \\ deren Bedeutung für den gesteuerten Fremdsprachenerwerb, setzt sich der Beitrag kritisch mit der \\ Kompetenzorientierung des modernen Fremdsprachenunterrichts auseinander. Seine These lautet, \\ dass diese Orientierung problematisch ist aufgrund ibrer Verankerung in einem instrumentellen, \\ dezidiert nicht-ästhetischen Verständnis von Sprache und Kommunikation. Die Kompetenzorien- \\ tierung ist demnach neu zu fassen auf der Basis eines komplexeren Verständnisses von Sprache \\ und Kommunikation, das insbesondere ibrer literarisch-ästhetischen Dimension Rechnung trägt.
}

\section{Einleitung}

Seit dem PISA-Schock ist es weitgehender Konsens, dass der Fremdsprachenunterricht kompetenzorientiert angelegt sein muss. Vor dem Hintergrund der Tatsache, dass in den 1960er-Jahren die kommunikative Kompetenz zum zentralen Lernziel des modernen Sprachunterrichts avancierte (vgl. Decke-Cornill; Küster 2010: 105), relativiert sich allerdings die Zäsur, die mit der Umstellung auf die Standard-, Output- und eben auch Kompetenzorientierung in der Ära nach PISA gemeinhin verbunden wird; diese Umstellung intensivierte vielmehr eine Entwicklung hin zu einem auf Effektivität ausgerichteten Sprachunterricht, für den - trotz ihrer ,ambitious educational agenda“" (Kramsch 2006: 250) - tendenziell schon die kommunikative Didaktik der 1960er- und 70er-Jahre mit ihrer Orientierung an den prakti- 
schen Bedürfnissen der Sprachlernenden stand. ${ }^{1}$ Auch die mit PISA Einzug haltende Fokussierung auf Messbarkeit, die es zuvor so nicht gegeben hatte, lässt sich in diese Entwicklung einordnen: Sie verdankt sich dem Bemühen, angesichts der enttäuschenden Ergebnisse der Lernstandsüberprüfungen das Sprachlehren und -lernen für alle beteiligten Akteure noch transparenter, optimierbarer, steuer- und planbarer zu machen (vgl. DGFF 2008: 9f.). Die Ausführungen des Gemeinsamen europäischen Referenzrahmens (GeR) - dem zentralen Dokument der Umstellung auf Kompetenzorientierung im Fremdsprachenbereich - zur ,ästhetischen Sprachverwendung" (Trim u.a. 2001: 51) wie auch seine Kompetenzskalen machen dabei deutlich, dass diese Entwicklung mit einem weitgehenden Ausschluss des Ästhetischen einher geht; der ästhetische Aspekt der Sprache spielt jedenfalls in dem Sprachkonzept, das dem GeR zugrunde liegt, keine Rolle (vgl. Decke-Cornill; Küster 2010: 336). Die Ambivalenz des Lernziels der kommunikativen Kompetenz und des ihm korrespondierenden kommunikativen Sprachunterrichts wurzelt in diesem Umstand: Einerseits war es fraglos ein Fortschritt, dass im Sprachunterricht nicht mehr die Erfüllung der grammatischen Norm im Vordergrund stand, sondern die Fähigkeit, in und mit der Fremdsprache erfolgreich zu handeln und die eigenen kommunikativen Ziele auch dann zu erreichen, wenn diese nicht native-like beherrscht wird. Die Bevorzugung authentischer Kommunikationssituationen und -anlässe und damit einher gehend der Bedeutungsverlust literarischer Textualität signalisieren aber zugleich eine Einengung auf ein Sprachverständnis, das in den letzten Jahren immer stärker in die Kritik geraten ist. ${ }^{2}$ Aus einer Perspektive, die die Handlungsorientierung des Fremdsprachenunterrichts zwar ausdrücklich teilt (vgl. Dobstadt; Riedner 2012), aber dennoch bzw. gerade deshalb das Literarische sowohl als Unterrichtsgegenstand als auch als didaktisches Prinzip (Didaktik der Literarizität) und als Dimension von Sprache für wichtig und relevant erachtet, haben wir die Nichtexistenz des Literarischen im aktuellen Sprachunterricht und seinen Konzepten bereits thematisiert (vgl. dazu Dobstadt; Riedner 2011). Im vorliegenden Aufsatz möchten wir dieser Problematik in Bezug auf die Kompetenzorientierung nachgehen. Dabei wollen wir das Spannungsverhältnis, das offensichtlich zwischen aktuellen Konzepten eines kompetenzorientierten Sprachunterrichts und dem Literarisch-Ästhetischen besteht, näher beleuchten. Kann man - so ließe sich pointiert fragen - Deutsch als Fremdsprache kompetenzorientiert unterrichten und dabei dem Literarisch-Ästhetischen Raum und Stellenwert geben? Ein solche Frage mag angesichts des real existierenden Sprachunterrichts und seiner Konzepte kurios klingen. Doch knüpfen wir mit ihr an eine bestehende Diskussion an, die vor allem in den schulischen Deutsch- und Fremdsprachendidaktiken ge-

\footnotetext{
${ }^{1}$ Es sei daran erinnert, dass die Einführung des kommunikativen Sprachunterrichts vor allem eine Reaktion auf die erste große Welle der ökonomischen Globalisierung nach dem Zweiten Weltkrieg war.

2 Zur Kritik des Sprachverständnisses, das dem Referenzrahmen zugrunde liegt und für den aktuellen Fremdsprachenunterricht prägend ist, siehe u.a. Barkowski 2003, mit spezifischen Fokus auf das Literarische siehe Dobstadt; Riedner 2011.
} 
führt wird; im Mittelpunkt dieser Diskussion steht der Begriff der literarischen Kompeten₹: Sein einschlägiges Gegenstück im Fach Deutsch als Fremdsprache hat dieser Begriff in dem von der US-amerikanischen Fremdsprachendidaktikerin Claire Kramsch in den Diskurs eingebrachten Begriff der symbolic competence. Beide Begriffe gehören - wie noch näher auszuführen sein wird - in den Kontext einer dezidiert kritischen Auseinandersetzung mit der Kompetenzorientierung des modernen (Fremd-)Sprach(en)unterrichts bzw. mit deren Grundlagen - das macht sie interessant. In der Auseinandersetzung mit diesen Begriffen wollen wir nach Umgangsweisen mit dem oben skizzierten Spannungsverhältnis fragen und danach, welche Konsequenzen aus ihm zu ziehen wären - aus der Perspektive des Faches Deutsch als Fremdsprache. Unser Aufsatz versteht sich dabei als eine erste, tastende Annäherung an eine Problematik, die angesichts der Bedingungen, unter denen Sprachunterricht heute stattfindet - sowohl was seine sprachenpolitischen Vorgaben als auch die „language ideology“ (Kramsch; Huffmaster 2008: 293) betrifft, die die Erwartungen der Sprachlernenden bestimmt - eine grundsätzliche ist, für die es eine schnelle und einfache Lösung nicht geben kann.

\section{Literarische Kompetenz}

Der Begriff der literarischen Kompetenz war in der schulischen Deutschdidaktik bereits vor den PISA-Tests bekannt und in Gebrauch (vgl. Frederking 2010: 332). Der bemerkenswerte Anstieg der Zahl der Veröffentlichungen dazu seit ca. 2005 (vgl. Abraham 2005, Spinner 2006, Kammler 2006 und 2010, Eggert 2009, Wintersteiner 2010, Frederking 2010, Froidevaux 2012) zeigt allerdings, dass er erst mit der im Anschluss an PISA erfolgenden Umstellung auf einen kompetenzorientierten Deutschunterricht zu einem prominenten Thema der literaturdidaktischen Reflexion geworden ist. ${ }^{3}$ Die Motive dafür sind vielschichtig. Zunächst einmal spiegelt sich in dieser Zunahme der Publikationen zum Gegenstand Literarische Kompetenz im Sinne der oben erläuterten Zielsetzung, die Effektivität von Unterricht zu erhöhen, das Bemühen der Literaturdidaktik wider, „klarer zu sehen, was Kernkompetenzen des literarischen Verstehens sind und wie man sie vermitteln kann" (Abraham; Kepser 2009: 74).4 Im Hintergrund stand und steht aber auch die Sorge, dass

das, was sich nicht als Kompetenz beschreiben, in Bildungsstandards formulieren und in Testaufgaben erfassen lässt, [...] zumindest mittelfristig aus dem Fokus der Lehrenden zu verschwinden und aus dem Zentrum des Unterrichts an dessen Rand gedrängt zu werden [droht; MD/RR] (Frederking 2008: 7).

\footnotetext{
3 Ähnliches lässt sich für die schulische Fremdsprachendidaktik konstatieren (vgl. Hallet 2010, Rössler 2010, Surkamp 2012).

${ }_{4}$ Vgl. auch Spinner 2006: 7, Surkamp 2012: 88f.
} 
Und genau das ist ja der Fall in Bezug auf das Lesen von Literatur, deren Rezeption sich - darin sind sich die Literaturdidaktiker/innen weitgehend einig - „einer gradlinigen Skalierung oder einfachen Bewertung entzieh[t]“ (Burwitz-Melzer 2008: 5). Nach Bonnet; Breidbach (vgl. 2013: 30) führte dies aber nicht zu einer Problematisierung der Kompetenzorientierung als solcher, sondern zu einer Problematisierung ihres Verhältnisses zur Standardisierung; demnach bemüht sich die eine Richtung der Literaturdidaktik um eine Modellierung der literarischen Kompetenz, die sie operationalisierbar macht; die andere Richtung lehnt dies ab und fordert, „neben dem Kompetenzdiskurs einem Bildungsdiskurs gleichberechtigte Geltung zu verschaffen“ (ebd.). Ein Beispiel für die erste Richtung ist das Projekt Literarische Rezeptionskompetenz als literarästhetische Urteilskompetenz. (LUK). Dieses Projekt versucht das Grundproblem, dass die konstitutive Mehrdeutigkeit des literarischen Textes eine „kompetenztheoretische Modellierung und empirische Erfassung ästhetischen Verstehens [...] schwierig“ (Frederking 2008: 52) macht, im Rückgriff auf Ecos semiotische Ästhetik und insbesondere seinen Begriff der intentio operis zu lösen; denn dieser erlaube es, bestimmte Interpretationen als inadäquat abzuweisen und somit die (Kompetenz-)Dimension des semantischen literarästhetischen Urteilens, die auf die Feststellung des Sinns eines literarischen Textes zielt, einer Bestimmung und Beurteilung zugänglich zu machen (vgl. ebd.). ${ }^{5}$ Problematisch an diesem Ansatz ist die fehlende Begründung für die Wahl seiner literaturtheoretischen Grundlage. Dabei ist die Unterscheidung zwischen intentio auctoris, intentio lectoris und intentio operis diskutabel, weil sie die essentialistische Vorstellung eines leserunabhängigen Textsinns nahelegt. Möglicherweise macht aber gerade diese Implikation die Attraktivität von Ecos Modell für LUK aus. Denn das Konstrukt einer intentio operis ermöglicht es, auf eine literaturtheoretisch bzw. -wissenschaftlich (vermeintlich) abgesicherte Weise die konstitutive Mehrdeutigkeit des literarischen Textes zwar grundsätzlich anzuerkennen, sie aber zugleich auch wieder zu begrenzen und letztlich zu neutralisieren - als Voraussetzung dafür, dass die Ergebnisse literarischen Lernens skalier- und messbar gemacht und objektiv bewertet werden können.

Solchen Versuchen steht Kaspar H. Spinner erkennbar skeptisch gegenüber. In seinem vielbeachteten Aufsatz zum literarischen Lernen von 2006 betont er, dass sich „literarisches Lernen von dem unterscheidet, was in der Regel in Lesetests abgeprüft wird“ (Spinner 2006: 12), denn Literatur sei von der „Unabschließbarkeit der Sinnbildung“ und von „Mehrdeutigkeit“ (ebd.) gekennzeichnet. Insofern kann er als ein Vertreter der zweiten Position gelten, zumal er die Kompetenzorientierung grundsätzlich gutheißt und literarische Kompetenz ausdrücklich als "Ziel“

\footnotetext{
${ }^{5}$ Weitere Dimensionen, die von dem Modell berücksichtigt werden, sind die des ideolektalen literarästhetischen Urteilens, bei der es darum geht, die formalen Spezifika eines literarischen Textes zu erfassen, sowie die Dimension des kontextuellen literarästhetischen Urteilens, womit die Verarbeitung von textexternen Informationen wie historische, epochenspezifische, gattungsgeschichtliche usw. Aspekte gemeint ist; auf diese Dimensionen können wir im Rahmen dieses Aufsatzes jedoch nicht weiter eingehen.
} 
(ebd.: 7) literarischen Lernens bezeichnet. Schaut man genauer hin, enthält sein Text allerdings Hinweise, die sein Bekenntnis zur Mehrdeutigkeit und unabschließbarer Sinnbildung relativieren. So ordnet er sprachlichen Gestaltungsmitteln eindeutige ästhetische Wirkungen und Funktionen zu (vgl. ebd.: 9), seine Empfehlung, „Perspektivenübernahme“ (ebd.) zu üben, impliziert die Annahme, man könne diese Perspektiven zweifelsfrei identifizieren; er ordnet Texte nach Schwierigkeitsgraden (vgl. ebd.: 12), ohne darauf einzugehen, dass auf diese Weise Deutungen vorgegeben und Deutungsspielräume eingeschränkt werden. Damit rückt Spinner näher an LUK heran, als ihm lieb sein dürfte. Deutlich wird an diesen beiden Beispielen, dass in der Debatte um den Begriff der literarischen Kompetenz neben dem Begriffsbestandteil Kompetenz. (und dem damit gegebenen Bezug auf Standardisierung, die je nach Standort entweder akzeptiert oder abgelehnt wird) auch der erste Begriffsbestandteil zu berücksichtigen ist, was in der literaturdidaktischen Diskussion indes kaum geschieht: Kritisch wird in der Regel nur auf den Kompetenzbegriff Bezug genommen, der (meist rezeptionsästhetisch modellierte) Literaturbegriff wird dagegen als unproblematisch vorausgesetzt. ${ }^{6}$

In diesem Zusammenhang lohnt es sich, einen Blick auf den Ursprung von Konzept und Begriff der literarischen Kompetenz zu werfen. Das Konzept geht auf die von der strukturalen Linguistik beeinflusste Poetikdiskussion der sechziger Jahre zurück (vgl. Barsch 2013); der Begriff wurde von Jonathan Culler in seinem 1975 veröffentlichten Buch Structuralist Poetics, das ein eigenes Kapitel zur „Literary Competence" enthält, profiliert (vgl. Hallet 2010). Literarische Kompetenz beschreibt demnach die Kenntnis und die Beherrschung der spezifischen (wenn auch historisch variablen) Konventionen für die Rezeption und die Produktion literarischer Texte (vgl. Culler 1975: 117f.). Dabei geht es ausdrücklich nicht um eine angemessene Interpretation des einzelnen, konkreten Textes (vgl. ebd.: 118). Es geht vielmehr darum, sich mit den - konventionsgeregelten - Bedingungen literarischer Bedeutungsproduktion auszukennen; also mit dem „how literature works“ (ebd.: 119). Damit ist zweierlei impliziert: Der literarische Text ist, wie rätselhaft und opak er sich im Konkreten - als einzelnes literarisches Werk - auch darbieten mag, in seiner Funktionsweise grundsätzlich transparent; und ein kompetenter Umgang mit diesem Text lässt sich von einem weniger kompetenten Umgang klar unterscheiden (vgl. ebd.: 121). Diese doppelte Transparenz - die der literarischen Funktionsweise eines Textes und die des kompetenten Umgangs mit ihm - könnte ein Grund für die intensive Rezeption sein, die der Begriff der literarischen Kompe-

\footnotetext{
${ }^{6}$ Wenn Bonnet; Breidbach darauf hinweisen, dass es „lohnend sein (könnte), die Debatte von der Rekonstruktion des Gegenstandes ,Literatur' her aufzurollen" (2013: 35), dann machen sie insofern auf ein Desiderat der literaturdidaktischen Kompetenzdebatte aufmerksam. So liegt ein Problem der Kompetenzkataloge von - beispielsweise - Burwitz-Melzer 2008, Hallet 2009 und Surkamp 2012 nicht zuletzt darin, dass das ihnen zugrundeliegende Verständnis vom literarischen Text - oder anders formuliert: die ihnen implizite Literaturtheorie - kaum transparent gemacht, nicht systematisch reflektiert und schon gar nicht begründet wird.
} 
tenz in der Literaturdidaktik nach PISA erfahren hat. ${ }^{7}$ Nun gesteht Culler am Ende des Kapitels allerdings zu, dass das Lesen von Literatur bisweilen an die Grenze zwischen dem „comprehensible“ (ebd.: 129) und dem ,incomprehensible“ (ebd.) führe und damit an einen Punkt, wo die interpretativen Modelle, ,which inform one's culture“ (ebd.: 130), brüchig würden. Dies bedeutet aber, dass literarische Kompetenz schlussendlich doch nicht im Befolgen von Regeln und Konventionen aufgeht. Denn diese können dort keine Orientierung mehr bieten, wo jene Zone des Literarischen betreten ist, in der unsere „procedures for making sense“ (ebd.) grundlegend subvertiert und unterminiert werden. Um sich in dieser Zone bewegen zu können, reicht die Kenntnis der literarischen Konventionen nicht aus; sie muss ergänzt - und d.h. auf eine paradoxe Weise relativiert und transzendiert werden durch kreative und im Wortsinn unkonventionelle Fähigkeiten zur Rezeption und Produktion von Bedeutung. Damit ist der von Culler eingeführte Begriff der literarischen Kompetenz gesprengt, und zwar von innen heraus. Sein Grundproblem hat Terry Eagleton sehr treffend folgendermaßen umschrieben:

Ein kompetenter Leser ist der, der bestimmte Regeln auf den Text anwenden kann; aber welches sind die Regeln, nach denen man Regeln anwendet? [...] Die Regel mag beispielsweise sein, Parallelismen im Gedicht aufzuspüren, aber was zählt als Parallelismus? Wenn Sie mit dem, was für mich als Parallelismus zählt, nicht einverstanden sind, haben Sie mit keiner Regel gebrochen [...]. Und wenn Sie mich fragen, warum ich gerade diese Regel überhaupt anwende, kann ich mich abermals nur auf die Autorität der literarischen Institution berufen und sagen: „So machen wir das eben.“ Worauf Sie immer erwidern können: „Dann machen Sie doch mal etwas anderes“ (Eagleton 1997: 109).

Diese Aufforderung kann sich auf ein Verständnis von Literatur berufen, demzufolge diese die Konventionen in einer unvorhersehbaren und nicht-antizipierbaren Weise bricht und verschiebt. Verschiebt sich damit aber nicht zugleich auch der Begriff der literarischen Kompetenz, anstatt - wie es Eagleton mit seinem Diktum beabsichtigt - des Scheiterns überführt zu werden? Könnte man es nicht als einen Aspekt des Literarischen auffassen, dass es auch die Spielregeln des eigenen Diskurses permanent in Frage zu stellen und zu verändern vermag? Als literarisch kompetent würde dann nicht mehr der- oder diejenige gelten, der/die den literarischen Konventionen gemäß rezeptiv oder produktiv Sinn bildet, sondern der/die sich in der von der Literatur aufgerissenen Lücke zwischen den Konventionen zu bewegen und ihnen damit sogar tendenziell voraus zu sein vermag. Der Begriff der literarischen Kompetenz, so verstanden, stünde dann aber nicht nur in Opposition zum standardorientierten Kompetenzdiskurs (vgl. Bonnet; Breidbach 2013: 33,

\footnotetext{
7 Im Lichte dieser Vermutung zeigen sich Berührungspunkte zwischen Ecos intentio operis - dem zentralen Baustein in der Theoriearchitektur von LUK - und Cullers ,conventions of plausibility“ (Culler 1975: 127).
} 
Hallet 2009, Hallet 2010), sondern auch zu einem Literaturdiskurs, der die Grenze zwischen Literatur und Nicht-Literatur; zwischen sog. literarischer und sog. Alltagssprache immer schon kennt (auch wenn er - wie Culler - durchaus anerkennt, dass sich diese Grenzen bisweilen ändern und verschieben).

Dieser Punkt führt zu der Frage, was der Begriff der literarischen Kompetenz für das Fach Deutsch als Fremdsprache leisten kann. Von seinem Ursprung her ist der Begriff auf Gegenstände und Ziele bezogen, die für das Fach Deutsch als Fremdsprache, dessen Gegenstand nicht die Literatur in einem traditionellen Sinne ist, nicht relevant sind. Hinzu kommt, dass der Begriff - wie wir am Beispiel von LUK gesehen haben - sowohl zum Literarischen als auch zum (standardorientierten) Kompetenzdiskurs ein ambivalentes und uneindeutiges Verhältnis aufweist. Auf der anderen Seite lenkt der Begriff - und zwar schon bei Culler - den Blick weg von den Ergebnissen literarischer Sinnproduktion - dem einzelnen literarischen Text - hin zu (den Bedingungen) ihrer Entstehung. Damit eröffnet sich die Möglichkeit, literarische Kompetenz als eine erweiterte Sprachkompetenz im Sinne von Claire Kramsch aufzufassen, nämlich als die Fähigkeit, „to understand the practice of meaning making itself“ (Kramsch 2006: 251). Voraussetzung dafür ist aber ein unkonventionelles und keineswegs selbstverständliches Verständnis des Literarischen, das es aus der konventionellen Bindung an den literarischen Text und die Sprache der Literatur löst und es als Aspekt und Dimension der Sprache selbst begreift. Wie sich der Begriff unter einer solchen Perspektive konkretisieren kann, hat Dobstadt (2010) aufgezeigt.

\section{Symbolic competence}

Anders als der Begriff der literarischen Kompetenz ist der Begriff der symbolischen Kompetenz nicht aus dem Diskussionszusammenhang der schulischen Literaturdidaktik heraus entstanden, sondern im Zusammenhang einer grundlegenden Neubestimmung der Zielsetzungen des Fremdsprachenunterrichts lokalisiert. ${ }^{8}$ Dass der Begriff der symbolic competence Anleihe an dem wirkungsmächtigen Begriff der kommunikativen Kompetenz nimmt, der den Fremdsprachenunterricht seit den 1970er-

\footnotetext{
8 Die Differenz des Diskurses im Schulzusammenhang und im außerschulischen Fremdsprachenunterricht ist jedoch keineswegs eine absolute - letztlich resultiert sie aus dem umfassenderen schulischen Bildungsanspruch, der Literatur zwar als in seinem Stellenwert bedrohten, jedoch als grundsätzlich einzubeziehenden Unterrichtsgegenstand sieht, während Literatur als möglicher Gegenstand im außerschulischen Fremdsprachenunterricht spätestens seit den 1950er-Jahren mit der Verschiebung der Funktion des Fremdsprachenerwerbs vom Zweck der Bildung hin zum Zweck der praktischen Kommunikation ihren Stellenwert verloren hat. Dies heißt aber nicht, dass die Hinterfragung des den unterrichtsmethodischen Konzepten zugrunde liegenden Sprachbegriffs nicht auch für die Schule von zentraler Relevanz sein könnte - zumal im Zusammenhang einer zunehmenden Auflösung der Differenz von DaM und DaZ. Umgekehrt sollte sich das Fach Deutsch als Fremdsprache fragen, ob es in der Diskussion um die „symbolic competence“ nicht auch um die Rückholung allgemeiner Bildungsziele in den Fremdsprachenunterricht geht - eine Frage, die auch bei Kramsch anklingt, wenn sie von einer „essential competence for youngsters“ (Kramsch 2009: 118) spricht und diese als Kombination von „,knowledge, experience and judgement" (ebd.) beschreibt.
} 
Jahren nachhaltig verändert und geprägt hat, wird bereits im Titel des 2006 erschienenen programmatischen Artikels From Communicative Competence to Symbolic Competence deutlich, in dem Claire Kramsch den Begriff erstmals in die Diskussion eingeführt hat. Das Konzept der kommunikativen Kompetenz und dessen Entwicklung in den letzten 25 Jahren unterzieht sie dabei einer kritischen Revision: Ihre Kritik gilt zum einen der Entwicklung kommunikativer Kompetenz von einem sich selbst als demokratisch verstehenden, emanzipatorischen Konzept hin zu einem Konzept, das (fremd-)sprachliche Kompetenz ausschließlich im Zeichen von Effektivität und Messbarkeit bestimmt und letztlich ökonomischen Prämissen folgt. Zum anderen sieht sie aber auch Anlass zu einer grundlegenden Revision des Sprach- und Kommunikationsbegriffes, der hinter dem Konzept der kommunikativen Kompetenz steht. Medialisierung und Globalisierung, die Alltäglichkeit multilingualer und multikultureller Biographien und das zunehmend kritische Bewusstsein gegenüber homogenisierenden Konzepten von Kultur und Nation bilden den Hintergrund ihrer Überlegungen: Sie lassen zum einen die dem Konzept der kommunikativen Kompetenz zugrunde liegende Vorstellung homogener soziokultureller Gruppen, die durch ein einheitliches Kommunikationsverhalten und ein gemeinsames Kontextwissen bestimmt sein könnten, obsolet erscheinen und mit ihm die Vorstellung eines in sich geschlossenen Systems kultureller Sinnbildung. Vor dem Hintergrund veränderter gesellschaftlicher Realitäten und komplizierterer Kommunikationsbedingungen verliert zum anderen die dem kommunikativen Ansatz inhärente optimistische Sicht individueller kommunikativer Handlungsmacht zunehmend an Überzeugungskraft; und mit ihr die Auffassung, dass das Subjekt grundsätzlich Herr seiner sprachlichen Handlungen ist, wenn man ihm nur die nötigen sprachlichen Mittel an die Hand gibt.

Dagegen setzt Kramsch ein komplexeres Konzept sprachlicher Bedeutungsbildung, das von der grundlegenden semantischen Nicht-Identität von sprachlichen Zeichen und damit von einer fortgesetzten Verschiebung von Sinn ausgeht, da die Resonanzen des Sprechens im Subjekt als grundlegend offen gedacht werden:

In teaching German, it is important to remember that the meanings expressed in the German language only exist in relation to other meanings, constructed in other codes in other places at other times (Kramsch; Huffmaster 2008: 296).

Seine erkenntnistheoretische Basis hat dieser - wie Kramsch in einer Reihe von weiteren Publikationen deutlich macht (Kramsch; Whiteside 2008, Kramsch; Huffmaster 2008, Kramsch 2009) - vor allem in der poststrukturalistischen Sprachphilosophie Derridas und deren Weiterentwicklung bei Judith Butler und in den erkenntniskritischen Prämissen der Kulturwissenschaft in der Nachfolge Foucaults. Als weitere prägende Konzepte nennt sie die language ecology und die linguistische Komplexitätstheorie, die vor allem in der angewandten Linguistik im anglophonen Bereich diskutiert werden. 
Wenn Bedeutungen nicht als fest gedacht werden, sind sie als solche letztlich auch nicht vermittelbar; die Aufgabe eines zeitgemäßen Fremdsprachenunterrichts kann sich dementsprechend auch nicht in der Vermittlung von (semantischem) Wissen und dem Wissen darum, wie dieses zu kommunizieren wäre, erschöpfen: „Today it is not sufficient for learners to know how to communicate meanings; they have to understand the practice of meaning making itself." (Kramsch 2006: 251). Symbolische Kompetenz wird dabei als Metakompetenz bestimmt („In this sense symbolic competence is the quintessential metacompetence of our postmodern times“" (Kramsch 2009: 114)); sie bildet ein komplexes Cluster symbolischer Fähigkeiten (,symbolic abilities"), das sowohl reflexive als auch produktive bzw. sprachkreative Komponenten umfasst:

awareness of the symbolic values of words, ability to find the most appropriate subject position, ability to grasp the larger social and historical significance of events and to understand the cultural memories evoked by symbolic systems, ability to perform and create alternative realities by reframing the issues (Kramsch 2009: 113).

Mit einer solchen explizit sprachbezogenen Bestimmung grenzt Kramsch ihr Konzept der symbolischen Kompetenz auch vom Konzept interkultureller Kompetenz $\mathrm{ab}$, das durch den Fokus auf die Akzeptanz fremder Werte und Überzeugungen primär moralisch ausgerichtet und damit als additiv zu den sprachbezogenen Kompetenzen im engeren Sinne konzipiert ist (vgl. hierzu ebd.: 118f.).

Der Argumentationszusammenhang, in dem das Konzept der symbolischen Kompetenz steht, bildet die Frage nach zeitgemäßen Konzepten für den Fremdsprachenunterricht und nicht die Frage nach der Rolle der Literatur in ihm - symbolische Kompetenz wird dementsprechend auch nicht als eine genuin literarische Kompetenz bestimmt. Allerdings schreibt Kramsch der Literatur ein besonderes Potential für die Ausbildung symbolischer Kompetenz zu: „Through literature, they [learners] can learn the full meaning making potential of language." (Kramsch 2006: 251). Durch sie können zentrale Komponenten symbolischer Kompetenz, die Kramsch mit den Begriffen „,production of complexity“, „,tolerance of ambiguity“ und ,appreciation of form as meaning“ (Kramsch 2006: 251) bestimmt, gefördert werden. Dass Kramsch die Rolle der Literatur für die Ausbildung symbolischer Kompetenz hervorhebt, ist insofern naheliegend, als Kramsch ihr Konzept im Zusammenhang der Diskussion um Rolle und Zielsetzungen des Fremdsprachenunterrichts an US-amerikanischen Colleges entwickelt, in denen Literatur traditionell eine weitaus größere Rolle spielt als im außeruniversitären Fremdsprachenunterricht in der Erwachsenenbildung. Ihr hoher Stellenwert liegt jedoch nicht in ihrer institutionellen Bedeutung, sondern primär in ihrer besonderen Affinität zum Symbolischen begründet: Durch die Arbeit mit ihr können - so die These Lernende in besonderer Weise für Mehrdeutigkeit, sprachliche Ambiguität und die symbolische Form, durch die Bedeutung konstituiert und vermittelt wird, sensibilisiert werden (vgl. Kramsch 2006 und 2011: 40). 
An das Konzept der symbolic competence lassen sich eine Reihe von Fragen richten: (1) So bleibt in den Ausführungen von Kramsch ein Stück weit in der Schwebe, wie sich symbolische Kompetenz und kommunikative Kompetenz zueinander verhalten. Handelt es sich bei der symbolischen Kompetenz um eine Fähigkeit, die die kommunikative Kompetenz auf einer höheren Ebene ergänzt und bereichert, wie z.B. das folgende Zitat nahe legt:

Symbolic competence does not do away with the ability to express, interpret and negotiate meanings in dialogue with others, but enriches it and embeds it into the ability to produce and exchange symbolic goods in the complex global context in which we live today (Kramsch 2006: 251)?

Oder bilden kommunikative und symbolische Kompetenz - wie der Titel des Aufsatzes From communicative competence to symbolic competence ja auch nahelegen könnte Gegenbegriffe? Hierfür spricht, dass die Sprachbegriffe, die beiden Konzepten zugrunde liegen, sich zwar aufeinander beziehen, sich aber letztlich grundlegend voneinander unterscheiden. Geht es - so wäre zu fragen - um eine grundlegende Kritik bestehender Konzepte des Fremdsprachenunterrichts bzw. um einen grundlegenden Paradigmenwechsel oder um die additive Ergänzung bzw. um eine weitere Zielsetzung? Oder handelt es sich um Konzepte, die jeweils in unterschiedlichen Phasen des Fremdsprachenunterrichts bzw. in unterschiedlichen institutionellen Zusammenhängen relevant bzw. für den Fremdsprachenerwerb funktional sind? (2) Zum anderen stellt sich die Frage, inwieweit symbolische Kompetenz vermittelt und getestet werden kann - eine Frage, die Kramsch in ihrem Artikel Discourse, the symbolic dimension of Intercultural Competence auch selbst explizit diskutiert hat, wobei sie zumindest in Bezug auf ihre Testbarkeit zu der klaren Schlussfolgerung kommt:

Trying to test symbolic competence with the structuralist tools employed by schools and businesses is bound to miss the mark. Instead, symbolic competence should be seen as the educational horizon against we measure all learners achievements (Kramsch 2009: 118).

Um angesichts der aktuellen Dominanz positivistischer Testverfahren in Fremdsprachenzusammenhängen, die das zu Lehrende und zu Lernende vorab der Selektion seiner Testbarkeit unterziehen, der Dimension des Symbolischen im Fremdsprachenunterricht einen entsprechenden Raum zu geben, muss - so die Schlussfolgerung - die politische Natur des Testens selbst, bzw. die Sprachideologie, die ihm zugrunde liegt, offen gelegt und damit auch kritisierbar gemacht werden: „We should then measure what can legitimately be measured and refuse to measure the rest, even though it is essential that we teach it" (ebd.: 116). Aber wenn symbolic competence von Kramsch hiermit für den Fremdsprachenunterricht als ebenso essentiell wie nicht operationalisierbar ausgewiesen ist, dann stellt sich schließlich (3) die praktisch-politische Frage, wie dieses fremdsprachendidaktische Kompetenzziel oder vielleicht besser: dieser Zielhorizont fremdsprachlichen Lehrens und Lernens in den aktuellen fremdsprachendidaktischen Konzepten, Curricula, Lehr- und 
Lernmaterialien abgebildet und verankert werden kann, insofern diese zumindest bzgl. der Operationalisierbarkeit einer konträren Logik folgen; und dafür ebenfalls den Kompetenzbegriff in Anspruch nehmen.

\section{Perspektiven}

Die Einführung der Begriffe und Konzepte der literarischen Kompetenz und der symbolischen Kompetenz in den Diskurs des Faches Deutsch als Fremdsprache ist nicht primär als Ausdruck des Unbehagens über eine zu geringe Beschäftigung mit literarischer Textualität bzw. über einen zu geringen Anteil literarischer Texte im Unterricht zu verstehen. Vielmehr geht es - viel grundsätzlicher - um das Verständnis der zu vermittelnden und zu erwerbenden Sprachkompetenz, und - damit zusammenhängend - um das dieser Kompetenz korrespondierende Verständnis von Sprache und Kommunikation. Insofern diese Merkmale aufweisen, die traditionellerweise der Literatur zugeschrieben werden - Unauslotbarkeit, Unabschließbarkeit, Opazität, Mehrdeutigkeit und Vielschichtigkeit usw. -, sprechen wir hier von einem literarisch-ästhetischen Sprachverständnis. Dieses steht zum instrumentellen Sprachverständnis, das den aktuellen Sprachunterricht dominiert, in Spannung und damit indirekt auch zum Begriff der Kompetenz, soweit dieser (siehe Gemeinsamer europäischer Referenzrahmen) mit dem instrumentellen Sprachverständnis verflochten ist. Am Begriff der Kompetenz festhalten kann man unter diesen Umständen nur, wenn man bereit ist, sich auf ein Paradox im Sinne der kritischen Theorie sprachlichen Handelns von Judith Butler einzulassen. Diese geht davon aus, dass sich „das Sprechen in gewissem Sinne unserer Kontrolle entzieht“ (Butler 2006: 31), weil das Subjekt nicht Souverän der Sprache ist, sondern von ihr konstituiert wird; doch resultiert seine sprachliche Handlungsmacht genau aus diesem Umstand:

Während einige Theoretiker die Kritik der Souveränität als Zerstörung der Handlungsmacht missverstehen, setzt meiner Ansicht nach die Handlungsmacht gerade dort ein, wo die Souveränität schwindet. Wer handelt (d.h. gerade nicht das souveräne Subjekt), handelt genau in dem Maße, wie er oder sie als Handelnde und damit innerhalb eines sprachlichen Feldes konstituiert sind, das von Anbeginn an durch Beschränkungen, die zugleich Möglichkeiten eröffnen, eingegrenzt wird (ebd.: 32).

Den Widerspruch eines solchen Verständnisses zum positivistischen Geist und Gestus der GeR-Kann-Beschreibungen haben Warner; Gramling (2014: 4) herausgestellt. Trifft dieser Widerspruch aber schlussendlich nicht auch die Begriffe der literarischen Kompetenz und der symbolic competence? Nur teilweise. Denn beide Begriffe verfügen mit den Adjektiven literarisch und symbolisch über ein implizites Widerlager, das zum jeweiligen zweiten Begriffsbestandteil Kompetenz in eine produktive Spannung tritt, diesen gleichsam in Anführungszeichen setzt und ihn damit 
in die nötige Schwebe bringt, die ihn im Diskurs hält. Der Begriff der literarischen Kompetenz kann dabei zudem unmittelbar mit dem Literarischen als Aspekt und Dimension von Sprache assoziiert werden, ${ }^{9}$ und damit mit dem ebenso wichtigen wie notorisch unterbelichteten Umstand, dass jeder, auch der vermeintlich alltäglichen (und folglich nicht-literarischen) Sprachverwendung ein unhintergehbar literarisches (poetisches, kreatives) Moment innewohnt; und zwar sowohl in der Sprachproduktion wie in der -rezeption, insofern auch diese ohne einen kreativen Anteil nicht auskommt. Eine so verstandene literarische Kompetenz würde - wiederum ganz im Sinne dessen, was Kramsch mit dem Begriff der symbolischen Kompetenz bestimmt - ein breites Spektrum von auf ganz unterschiedlichen Ebenen angesiedelten Fähigkeiten umfassen, zu denen beispielsweise die Wahrnehmungsfähigkeit für Rhythmus, für Form, für Neben- und Zwischentöne, für Uneigentliches, Ironisches und Intertextualität gehören; aber auch die Fähigkeit zu überraschenden, unkonventionellen sprachlichen Handlungen, die ebenso metakommunikativ wie metakreativ an den Grenzen und Rändern der Sprache operieren und diese verschieben und verändern. Mit dem an der Vorstellung einer exakten Mess- und Skalierbarkeit orientierten Verständnis von Kompetenz hat dieses Verständnis freilich nichts mehr zu tun. Insofern das erstere den heutigen Kompetenzdiskurs dominiert, bleibt der oben ausgeführte Widerspruch zumindest tendenziell erhalten und mit ihm die Diskussion um den Begriff der Kompetenz selbst. Angesichts des konstatierten Widerspruchs sollte diese Diskussion dabei auch für noch zu entdeckende bzw. zu kreierende Alternativen zum Begriff der Kompetenz offen sein, die den oben beschriebenen, erweiterten Zielsetzungen fremdsprachlichen Lernens womöglich gerechter zu werden vermögen. ${ }^{10}$

\section{Literatur}

Abraham, Ulf (2005): Lesekompetenz, literarische Kompetenz, poetische Kompetenz. Fachdidaktische Aufgaben in einer Medienkultur. In: Rösch, Heidi (Hrsg.): Kompetenzen im Deutschunterricht. Frankfurt a.M. u.a.: Lang, 13-26.

Abraham, Ulf; Kepser, Mathis (2009): Literaturdidaktik Deutsch. Eine Einführung. Berlin: Erich Schmidt.

Barkowski, Hans (2003): Skalierte Vagheit - der europäische Referenzrahmen für Sprachen und sein Versuch, die sprachliche Kommunikationskompetenz des Menschen für Anliegen des Fremdsprachenunterrichts niveaugerecht zu portionieren. In: Bausch, K.-Richard; Christ, Herbert; Königs, Frank G. (Hrsg.): Der Gemeinsame europäische Referenzrahmen für Sprachen in der Diskussion. Arbeits-

\footnotetext{
${ }_{9}$ Vgl. dazu auch Dobstadt 2010: 287.

10 Mögliche Begriffe, die bereits im Diskurs zirkulieren, sind beispielsweise „Diskursfähigkeit“ vgl. Hallet 2009 und „Multiliteralität“"vgl. Elsner 2007.
} 
papiere der 22. Frübjabrskonferenz zur Erforschung des Fremdsprachenunterrichts.

Tübingen: Narr, 22-35.

Barsch, Achim (2013): Kompetenz, literarische/poetische. In: Nünning, Ansgar (Hrsg.): Metzler Lexikon Literatur-und Kulturtheorie. 5., aktualisierte und erweiterte Auflage. Stuttgart u.a.: Metzler, 395.

Bonnet, Andreas; Breidbach, Stephan (2013): Blut ist im Schuh: Wie gut kleidet der Kompetenzbegriff die literarisch-ästhetische Bildung beim Tanz auf dem Hofball der Standardisierung? In: Grünewald, Andreas; Plikat, Jochen; Wieland, Katharina (Hrsg.): Bildung - Kompetenz - Literalität. Fremdsprachenunterricht zwischen Standardisierung und Bildungsanspruch. Stuttgart: Klett, 20-35.

Burwitz-Melzer, Eva (2007): Ein Lesekompetenzmodell für den fremdsprachlichen Literaturunterricht. In: Literaturunterricht, Kompetenzen und Bildung. Trier: WVT, 127-157.

Butler, Judith (2006): Haß spricht. Zur Politik des Performativen. Frankfurt a.M.: Suhrkamp.

Culler, Jonathan (1975): Structuralist Poetics. Structuralism, Linguistics and the Study of Literature. London: Routledge \& Kegan Paul.

Decke-Cornill, Helene; Küster, Lutz (2010): Fremdsprachendidaktik. Eine Einführung. Tübingen: Narr.

DGFF (2008): Kompetenzorientierung, Bildungsstandards und fremdsprachliches Lernen - Herausforderungen an die Fremdsprachenforschung. Positionspapier von Vorstand und Beirat der DGFF, Oktober 2008 (unter Mitarbeit von Daniela Caspari, Andreas Grünewald, Adelheid Hu, Lutz Küster, Günter Nold, Helmut J. Vollmer, Wolfgang Zydatiß). In: Zeitschrift für Fremdsprachenforschung 19, 2, 163-186.

Dobstadt, Michael (2010): Competencia literaria para docentes y estudiantes del Alemán como Lengua Extranjera. ¿Qué es? ¿Para qué sirve? ¿Y cómo se enseña? In: Formación e investigación en lenguas extranjeras y traducción: Actas de las Segundas Jornadas Internacionales: Buenos Aires, 2 al 4 de junio de 2010/Coordinado por Diana Ardissone, Patricia Willson y Laura Miñones. Buenos Aires: Instituto de Enseñanza Superior en Lenguas Vivas „Juan Ramón Fernández“ 2010 (CD-Rom), 282-288.

Dobstadt, Michael; Riedner, Renate (2011): Überlegungen zu einer Didaktik der Literarizität im Kontext von Deutsch als Fremdsprache. In: Ewert, Michael; Riedner, Renate; Schiedermair, Simone (Hrsg.): Deutsch als Fremdsprache und Literatumissenschaft. Zugriffe, Themenfelder, Perspektiven. München: iudicium, 99-115.

Dobstadt, Michael; Riedner, Renate (2012): Vieldeutige Texte - vieldeutige (Kon-) Texte. Von der Dynamisierung der Text-Kontext-Beziehung zur Erweiterung 
kultureller Handlungskompetenz. In: Albrecht, Corinna; Bogner, Andrea; Hess-Lüttich, Ernest (Hrsg.): Re-Visionen. Kulturwissenschaftliche Herausforderungen interkultureller Germanistik. Frankfurt a.M. u.a.: Lang, 371-388.

Eagleton, Terry (1997): Einführung in die Literaturtheorie. Stuttgart: Metzler.

Eggert, Hartmut (2009): Literarische Texte und ihre Anforderungen an die Lesekompetenz. In: Groeben, Norbert; Hurrelmann, Bettina (Hrsg.): Lesekompetenz: Bedingungen, Dimensionen, Funktionen. Weinheim u.a.: Juventa, 186-194.

Elsner, Daniela et al. (2007) (Hrsg.): Fremdsprachenkompetenzen für ein wachsendes Europa. Das Leitzicel,Multiliteralität'. Frankfurt a.M. u.a.: Lang.

Frederking, Volker (2008): Literarische bzw. (literar)ästhetische Kompetenz. Möglichkeiten und Probleme der empirischen Erhebung eines Kernbereichs des Deutschunterrichts. In: Frederking, Volker (Hrsg.): Schwer messbare Kompetenzen. Herausforderungen für die empirische Fachdidaktik. Baltmannsweiler: Schneider Verlag Hohengehren, 36-64.

Frederking, Volker (2010): Modellierung literarischer Rezeptionskompetenz. In: Kämper-van den Boogaart, Michael; Spinner, Kaspar H. (Hrsg.): Lese- und Literaturunterricht (Teil 1). Geschichte und Entwicklung; Konzeptionelle und empirische Grundlagen. Baltmannsweiler: Schneider Verlag Hohengehren, 324-380.

Froidevaux, Gérald (2012): Dimensionen und Modelle literarischer Kompetenzen im Fremdsprachenunterricht. In: Babylonia 2, 12, 25-30.

Hallet, Wolfgang (2009): Romanlektüre und Kompetenzentwicklung: Vom narrativen Diskurs zur Diskursfähigkeit. In: Hallet, Wolfgang; Nünning, Ansgar (Hrsg.): Romandidaktik. Theoretische Grundlagen, Methoden, Lektüreanregungen. Trier: WVT, 73-88.

Hallet, Wolfgang (2010): Literarische Kompetenz. In: Surkamp, Carola (Hrsg.): Metzler Lexikon Fremdsprachendidaktik. Stuttgart u.a.: Metzler, 200-201.

Kammler, Clemens (2006): Literarische Kompetenzen - Standards im Literaturunterricht. Anmerkungen zum Diskussionsstand. In: Kammler, Clemens (Hrsg.): Literarische Kompetenzen - Standards im Literaturunterricht. Modelle für die Primar-und Sekundarstufe. Seelze: Kallmeyer, 7-22.

Kammler, Clemens (2010): Literarische Kompetenzen beschreiben, beurteilen und fördern. In: Rösch, Heidi (Hrsg.): Literarische Bildung im kompetenzorientierten Deutschunterricht. Freiburg i.Br.: Filibach, 197-213.

Kramsch, Claire (2006): From Communicative Competence to Symbolic Competence. In: Modern Language Journal 90, 249-252. 
Kramsch, Claire (2009): Discourse, the symbolic dimension of Intercultural Competence. In: Hu, Adelheid; Byram, Michael (Hrsg.): Interkulturelle Kompetenz und fremdsprachliches Lernen. Modelle, Empirie, Evaluation. Tübingen: Narr, 107-121.

Kramsch, Claire (2011): Symbolische Kompetenz durch literarische Texte. In: Fremdsprache Deutsch 44, 35-40.

Kramsch, Claire; Huffmaster, Michael (2008): The political Promise of Translation. In: Fremdsprachen Lehren und Lernen 37, 283-297.

Kramsch, Claire; Whiteside, Anne (2008): Language Ecology in Multilingual Settings. Towards a Theory of Symbolic Competence. In: Applied Linguistics 29, 4, 645-671.

Rösch, Heidi (2005) (Hrsg.): Kompetenzen im Deutschunterricht. Frankfurt a.M. u.a.: Lang.

Rössler, Andrea (2010): Literarische Kompetenz. In: Meißner, Franz-Joseph; Tesch, Bernd (Hrsg.): Spanisch kompetenzorientiert unterrichten. Seelze: Klett; Kallmeyer, 131-136.

Spinner, Kaspar (2006): Literarisches Lernen. In: Praxis Deutsch 200, 6-16.

Surkamp, Carola (2012): Literarische Texte im kompetenzorientierten Fremdsprachenunterricht. In: Hallet, Wolfgang; Krämer, Ulrich (Hrsg.): Kompetenzaufgaben im Englischunterricht. Grundlagen und Unterrichtsbeispiele. Seelze- Velber: Klett; Kallmeyer, 77-90.

Trim, John; North, Brian; Coste, Daniel (2001): Gemeinsamer europäischer Referenzrahmen für Sprachen: lernen, lehren, beurteilen. Berlin: Langenscheidt.

Warner, Chantelle; Gramling, David (2014): Kontaktpragmatik - fremdsprachliche Literatur und symbolische Beweglichkeit. In: Deutsch als Fremdsprache 2, 1-10.

Wintersteiner, Werner (2010): Wir sind, was wir tun. Poetisches Verstehen als fachdidaktische Herausforderung. In: Winkler, Iris; Masanek, Nicole; Abraham, Ulf (Hrsg.): Poetisches Verstehen. Literaturdidaktische Positionen - empirische Forschung - Projekte aus dem Deutschunterricht. Baltmannsweiler: Schneider Verlag Hohengehren, 23-36. 



\title{
Migrationsliteratur hören, sprechen und erleben - Hörspielproduktion im DaF-Unterricht
}

\author{
Julia Collazo \\ Der vorliegende Beitrag stellt ein Projekt vor, in dem Migrationsliteratur als Ausgangspunkt für \\ eine Hörspielproduktion der Lernenden diente. Die Kreation von Hörspielen ermöglicht den \\ Lernenden einerseits eine motivierende (Neu-)Gestaltung von und andererseits eine intensiv- \\ handlungsorientierte Auseinandersetzung mit Literatur durch die Produktion von Paralleltexten. \\ Im Fokus stebt dabei, dass die Transformation von gelesener in gehörte Literatur die Lernenden \\ zu einer Auseinandersetzung mit Aspekten der ästhetischen Gestaltung anregt. Der Beitrag gibt \\ außerdem Hinweise zur unterrichtspraktischen und technischen Umsetzung solcher Projekte.
}

\section{Literatur soll zum Mitdenken anregen}

Die Reduktion literarischer Texte auf ein linguistisches Objekt bzw. auf Behälter zur Informationsentnahme im Fremdsprachenunterricht (FSU) weist Bredella in seiner Monographie Das Verstehen des Anderen zurück (vgl. Bredella 2010: 87, 72). Literarische Texte müssen stattdessen ,als Äußerungen [verstanden werden], die uns zum Mitdenken und Mitfühlen und zu Stellungnahmen anregen" (ebd.: 30). Die Ansprache der Lernenden auf emotionaler Ebene, die im engen Zusammenhang mit dieser Forderung steht, wird auch von Ehlers und Li als wichtiges Ziel des FSU angeführt (vgl. Ehlers 2010: 1531, Li 2007: 38). Obwohl die Sekundärliteratur konstatiert, dass Literaturvermittlung überwiegend am Erwerb kognitiver Fähigkeiten orientiert ist (vgl. Li 2007: 42), wird zunehmend die Notwendigkeit betont, in kreativitätsorientierten Verfahren kognitive Lernziele mit emotionalen zu verbinden (vgl. ebd.: 46). Literarische Texte bringen dafür auch die geeigneten Voraussetzungen mit: Zum einen möchten Lernende durch Literatur unterhalten 
werden, zum anderen liefert sie ihnen wichtige Anreize zu „echter Kommunikation“ (Ehlers 2010: 1531). Ein entscheidendes Argument für die stärkere emotionale Beteiligung der Lernenden beim Lesen ist auch die Betonung der subjektiven Zugänge zum literarischen Text durch die Rezeptionsästhetik ${ }^{1}$ (vgl. Schewe 2002: 41, Li 2007: 46). Wie soll nun aber Literatur im FSU vermittelt werden, um den genannten Ansprüchen zu entsprechen?

\section{Hörspielproduktion und die Umsetzbarkeit eines handlungs- und produktorientierten Unterrichts}

Ehlers und Schier betonen hierzu die Notwendigkeit eines handlungs- und produktorientierten Unterrichts, der die schöpferischen Momente des Lesens durch daran anknüpfende Aktivitäten fördert (vgl. Ehlers 2010: 1539, Schier 2011: 55). Die Lernenden werden so zu Mitspielenden: Sie können sich in die Figuren hineinversetzen, Geschichten weiter- oder umerzählen und sind dadurch emotional beteiligt sowie in ihrer Kreativität gefordert.

Eine Möglichkeit zur Umsetzung der genannten Forderungen ist die Hörspielproduktion ${ }^{2}$ im FSU. Verschiedene Aufsätze in Fachzeitschriften konnten bereits die Vielseitigkeit solcher Projekte im Hinblick auf Thematik und Anwendbarkeit auf verschiedene Niveaustufen zeigen (vgl. Bischof 2004, Blumensath 2004, Caspari 2012). In dem folgenden Vorschlag wird die Hörspielproduktion nicht nur als Möglichkeit verstanden, die vier Fertigkeiten integrativ zu schulen, sondern vor allem die Lernenden in ihrer „ästhetisch-kritischen Beobachter[position]“ (Schier 2011: 53) zu stärken.

\section{Projekt: Podcasten - auf Deutsch!?}

Das hier vorzustellende Projekt mit dem Titel Podcasten - auf Deutsch!? wurde von mir in der Factultad de Estudios Superiores Acatlán (FES)/Universidad Nacional Autónoma de México (UNAM) mit einer kleinen Gruppe von Studierenden fachfremder Studiengänge durchgeführt, deren Deutschkenntnisse zwischen B1 und B2 variierten. Der Kurs ergänzte von Februar bis Mai 2013 bei einer Dauer von 120 Minuten pro Woche den jeweiligen Deutschkurs der Lernenden. Das übergeordnete Thema des Projektunterrichts waren die kulturellen Differenzen zwischen Deutschland und Mexiko. Die Lernenden sollten bis zum Ende des Kurses in Gruppen jeweils eine Audioaufnahme zu diesem Thema anfertigen, die dann in Serie mit den anderen Kursproduktionen als Podcast ins Internet eingestellt wur-

\footnotetext{
${ }^{1}$ Die Rezeptionsästhetik versteht das literarische Werk als „Produkt einer Interaktion von Text und Leser" (Iser 1994: 229).

2 Beim Hörspiel handelt es sich laut Wermke um eine Form des Hörbuchs, bei der die Einbindung von Klängen und Geräuschen konstitutiv ist (vgl. Wermke 2004: 53).
} 
den. Ausgangspunkt für die Annäherung an das für die Lernenden sehr interessante Thema der kulturellen Differenzen war die Erzählung Rafik Schamis Eine deutsche Leidenschaft namens Nudelsalat (Schami 2011), die der Migrationsliteratur ${ }^{3}$ zuzuordnen ist. Die Lernenden erfassten zunächst den Inhalt, anschließend auch den Aufbau des Textes. In einem weiteren Schritt wurde darüber diskutiert, inwiefern ähnliche kulturelle Differenzen bezüglich der Pünktlichkeit, der Gastfreundschaft und der Esskultur auch in deutsch-mexikanischen Begegnungen denkbar wären. Nach einigen vorbereitenden Sprechübungen erfolgte zunächst die Vertonung des Erzähltextes von Rafik Schami durch die Lernenden im Sinne eines Hörbuchs als Lesung4. In einer anschließenden Reflexionsphase wurde im Gruppengespräch einerseits kritisch erläutert, inwieweit sich diese Erzählung in ihrer Originalform für eine Vertonung eignet. Zum anderen wurde diskutiert, welche Veränderungen bzw. Ergänzungen man vornehmen müsse, um ein mögliches Hörspiel zu gestalten. Dabei wurde in Bezug auf Ersteres die Variation des Textes durch Einbindung von Dialogen mit unterschiedlichen Sprechern/-innen und die Stimmmodulation hingewiesen. In Bezug auf die Hörspielproduktion tauschten die Lernenden Ideen zur Gestaltung mit Geräuschen und Musik aus. Dadurch wurden sie für die Unterschiede zwischen Hörbuch als Lesung und Hörspiel sowie deren Gestaltungsformen sensibilisiert. Zur Verdeutlichung dieser Unterschiede besteht die Möglichkeit, dass die Lernenden nun einen Teil der Erzählung als Hörspiel aufnehmen. ${ }^{5}$

In Erweiterung des Themas recherchierten die Lernenden weitere Beispiele für kulturelle Unterschiede zwischen Deutschland und Mexiko und präsentierten diese im Kurs. Dabei griffen einige Lernende auch auf Erfahrungen zurück, die sie persönlich in Deutschland gemacht hatten. Anschließend entschieden sich die Gruppen für ein gemeinsames Hörspielthema und entwickelten dazu ein Manuskript. Dieses kann man als Paralleltext bezeichnen, da es in der Struktur und dem Aufbau der Erzählung von Rafik Schami glich. Nach Fertigstellung des Manuskripts richtete sich die Aufmerksamkeit des Kurses erneut auf die Differenzen zwischen einem schriftlichen Text und seiner Vertonung als Hörbuch. Auch im Rückgriff auf die Erfahrungen der ersten Textaufnahme wurden konkrete Möglichkeiten besprochen, welche Gestaltungsmittel für die Produktion eines Hörbuchs als Lesung bzw. eines Hörspiels einzusetzen wären. Im nächsten Schritt arbeiteten die Lernenden

\footnotetext{
3 Rösch definiert Migrationsliteratur mit Biondi als Literatur, die „die Fremde als literarischen Ort zu gestalten sucht" (Rösch 2000: 376) Dabei bewegt sie sich zwischen zwei oder mehreren Kulturen, Sprachen oder Zeiten (vgl. ebd.: 367f.).

${ }^{4}$ Laut Frederking besteht noch keine systematische fachwissenschaftliche Aufarbeitung für das breite Begriffsspektrum zwischen Hörtext, Hörspiel und Hörbuch (vgl. Frederking; Krommer; Maiwald 2012: 106). Jedoch ist gegenwärtig auch in der Fachwissenschaft eine Tendenz zur Favorisierung des Begriffs Hörbuch zu beobachten. Dieser wird als Oberbegriff für alle ,akustisch-auditiven Speicherungen von stimmlichen sprachlichen Äußerungen“ (ebd.: 106) verwendet. Im vorliegenden Aufsatz wird jedoch im Sinne einer Präzisierung mit Wermke zwischen einem Hörbuch als Lesung, d.h. mit Beschränkung auf die Stimme des Lesers, und einem Hörbuch als Hörspiel, d.h. mit dem konstitutiven Charakter von Geräuschen und Stimmen, unterschieden (vgl. Wermke 2004: 53).

${ }^{5}$ Leider war es aufgrund der begrenzten Projektzeit nicht möglich, mit den Lernenden diese Übung durchzuführen.
} 
ihre Texte, den Spezifika des Hörspiels entsprechend, um. Die anschließende Korrektur aller Fehler im Hörspielmanuskript durch die Lehrende erfolgte in enger Absprache mit den Lernenden. Im Folgenden übten die Lernenden in verteilten Rollen die Dialoge. Sie ergänzten weitere Details in der Stimmmodulation und Pausen. Schließlich wurde das Manuskript mit dem kostenlosen Programm Audacity ${ }^{6}$ aufgenommen (vgl. Steinmann 2012: 253, Blumensath 2004: 36). Die entstandene Audiodatei wurde anschließend mit Geräuschen und Musik unterlegt. Die letzte Aufgabe bestand dann in der Didaktisierung der eigenen Hörspiele für andere Lernende. Die fertigen Audiodateien wurden später mit den entsprechenden Stichwörtern versehen und als Podcasts im Internet eingestellt. ${ }^{7}$

Mit diesem komplexen Projekt verbanden sich verschiedene Zielsetzungen:

1. Die Lernenden setzten sich produktiv mit einem Thema der Migrationsliteratur auseinander. Sie vertieften dabei ihr Wissen über kulturelle Differenzen. Außerdem konnten sie ihre eigenen Erfahrungen und ihr Wissen über Deutschland und Mexiko einbringen.

2. Die Lernenden bekamen einen Einblick in den Aufbau und die Stilistik schriftlicher Texte. Vergleichend lernten sie mögliche Gestaltungsmittel für die Vertonung eines literarischen Ausgangstextes als Hörbuch als Lesung bzw. Hörspiel kennen. Diese gestalterischen Mittel wendeten sie kreativ auf die eigene Hörspielproduktion an.

3. Vor und während des Aufnahmeprozesses trainierten die Lernenden ihre Aussprache im segmentalen sowie suprasegmentalen Bereich.

4. Die Lernenden übten integrativ alle vier Fertigkeitsbereiche.

An dieser Stelle möchte ich darauf hinweisen, dass dasselbe Projekt mit geringfügigen Veränderungen auch auf andere Themenebereiche problemlos übertragen werden kann. Der Einbezug von Migrationsliteratur bot sich jedoch besonders an, um die interkulturelle Kompetenz zu schulen (vgl. Tütken 2006: 54, Rösch 2000: 386). Sowohl Themen wie kulturell fremde Welten und Kulturkontakte (vgl. Ehlers 2010: 1536) als auch die spezifische Sprache der Migrationsliteratur (vgl. Rösch 2000: 377), sprechen DaF-Lernende emotional an und motivieren sie zur eigenen Textproduktion (vgl. Tütken 2006: 54). Der Erzähltext von Rafik Schami ist in seinem Umfang und seinen Anforderungen für das Sprachlernniveau B1/B2 geeignet. Mit der nötigen Vorentlastung der Lexik konnten die Lernenden den Text überwiegend selbstständig erfassen. Die Darstellung von Stereotypen, aber auch die ironische Reflexion des Autors über die eigene und die fremde Kultur bieten

\footnotetext{
6 Den kostenlosen Download finden Sie online unter: http://audacity.sourceforge.net/, (Stand: 03.10.13).

7 In der Podcast-Suchmaschine www.podster.de findet man nach Eingabe des Stichwortes „Mexiko“ den Podcast http://podcasting2013.podspot.de. Der Direktlink ist http://podster.de/view/13788, (Stand: 04.10.13).
} 
vielfältige Anlässe für anschließende Gespräche. Die Erzählung regte die Lernenden zudem an, vergleichend über eigene kulturelle Besonderheiten und Stereotypen zu reflektieren (vgl. Rösch 2000: 386). Der Text von Rafik Schami eignet sich also unter dem Blickwinkel der emotionalen Beteiligung der Lernenden auf besondere Weise, um in das Thema der kulturellen Differenzen einzusteigen.

\section{Schulung der ästhetischen Kompetenz}

Die beiden während des Projekts entstandenen Hörbuchtypen werden anschlieBend bezüglich ihres Potentials zur Stärkung einer „ästhetisch-kritischen Beobachter[position]" (Schier 2012: 53) bei den Lernenden geprüft.

Bei der ersten Aufnahme des literarischen Originaltextes von Rafik Schami handelte es sich um eine Produktion, die in ihrem Ergebnis einem Hörbuch als Lesung glich. Diese Übung diente einerseits der Vorentlastung bezüglich der technischen Details der Aufnahme, andererseits war mit ihr das Ziel verbunden, die Lernenden für die Besonderheiten auditiver Textgestaltung, hier besonders der Stimmmodulation, zu sensibilisieren, da diese auch beim Hörspiel eine wichtige Rolle spielt. Eine Voraussetzung für die Aufnahme literarischer Texte ist das sinnfassende Lesen ${ }^{8}$ im Vorfeld (vgl. Forster 2002: 241), auf dessen Relevanz auch Bredella in seiner Kritik an einem verengten Begriff literarischer Kompetenz hinweist (vgl. Bredella 2010: 72). Die Lesenden sind aus rezeptionsästhetischer Sicht bei der Sinnerschließung des Textes maßgeblich beteiligt. Das mehrmalige und sinnfassende Vorlesen kann darüber hinaus zu einer „Intensivierung der Wirklichkeit" (Folkvord 2011: 127) beitragen. Beim Vorlesen bringen die Lernenden bereits ihre eigene Interpretation, ihr subjektives Textverständnis, ein. Das kann auf den FSU vitalisierend und erkenntnisfördernd wirken (vgl. ebd.: 128). Diese Art des Vorlesens steht im Gegensatz zu dem häufig motivationslosen Lesen der Lehrbuchtexte im regulären FSU (vgl. Forster 2002: 237). Zudem eröffnet das Erarbeiten einer Sprechfassung bzw. das interpretierende Textsprechen einen neuen Zugang zum Text, seinem Stil und seinen Inhalten (vgl. ebd: 234). Forster nennt diese Form des Sprechens oder vielmehr Vorlesens ,ästhetische Kommunikation“ (ebd.: 234). Die Vorteile einer Aufnahme bestehen nun darin, dass durch das erneute Hören die Möglichkeit zur Autokorrektur der Aussprache besteht. Die Lernenden wurden zu einem Vergleich verschiedener Lesestile angeregt. Am Ende hatten sie einen eigenen Audiotext produziert, der ihnen auch als Motivation für das weitere Deutschlernen diente, da sie beispielsweise die hörbar verbesserte Aussprache auf sich selbst und ihr eigenes Handeln zurückführen konnten (vgl. Riemer 2010: 1153f.). Die Lernenden bekamen zudem einen konkreten Eindruck bezüglich ihres Sprachstandes. Ausgehend davon konnten sie sich neue Arbeitsbereiche in der Fremdsprache erschließen. Schließlich ermöglicht eine weitere Aufnahme, etwa zu

${ }^{8}$ Forster definiert das sinnfassende Lesen als „,angemessenes Vorlesen von Texten“ (Forster 2002: 237). Dabei steht die Schulung der Intonation im Vordergrund (vgl. ebd.). 
einem späteren Zeitpunkt, den unmittelbaren Vergleich und damit die Evaluation der eigenen Sprachentwicklung.

Bei der zweiten Aufnahme handelte es sich um eine produktorientierte „Anschlusshandlung“ (Ehlers 2010: 1539). Durch die Kreation eines eigenen Textes in Anlehnung an den literarischen Ausgangstext wurden die Lernenden selbst zu Schreibenden. Sie brachten ihre eigenen Ideen und Erfahrungen in Absprache mit der Gruppe ein. Zu einem selbstgewählten Schwerpunkt recherchierten sie im Internet oder befragten Deutsche bzw. Mexikaner/-innen. Sie konzipierten einen schriftlichen Text, den sie in einem ersten Schritt entsprechend der Spezifika des Hörbuchs und anschließend bezüglich der Gestaltungsmittel im Hörspiel modellierten. Dabei konzentrierten sie sich auf die ästhetischen Mittel des auditiven Mediums: Die Lernenden setzten sich intensiv mit den unterschiedlichen Gestaltungsmitteln schriftlicher und vertonter schriftlicher Texte auseinander. Die Lehrenden könnten darüber hinaus die Lernenden dazu ermutigt, deutsche Hörspiele zu rezipieren und deren Gestaltung im Vergleich zum Originaltext zu analysieren. In der Hörspieldatenbank des Deutschen Rundfunkarchivs (DRA) finden sich zahlreiche Beispiele für vertonte Literatur. ${ }^{9}$ Für jüngere Lernende wäre es auch denkbar, die gut im Internet zugänglichen Hörspielfolgen von Die Drei ??? mit dem Originaltext zu vergleichen. ${ }^{10}$ Hierbei sind besonders die Textkürzungen, aber auch die durchgängige Gestaltung mit Hintergrundgeräuschen zur Erzeugung einer lebendigen Hörspielumgebung auffällig.

Bei der anschließenden Aufnahme des Hörspielmanuskripts war einerseits entscheidend, dass die Lernenden zur Verbesserung ihrer eigenen Aufnahme die Vertonung immer wieder abhörten und korrigierten. Andererseits ermunterte die spätere Zugänglichkeit der Audiodateien als Podcasts im Internet die Lernenden, sich besonders auf die Aussprache zu konzentrieren. Sowohl Fehler im segmentalen als auch im suprasegmentalen Bereich wurden beim Abhören der Aufnahme häufig von den Lernenden selbst registriert und in Autokorrektur bzw. durch Mitlernende korrigiert. Lehrende können mit weiteren Phonetikübungen den Lernprozess zusätzlich unterstützen. Die Bedeutung der Stimmmodulation und der Pausen für eine lebendige Gestaltung des Hörtextes wurde während der Aufnahmen beson-

\footnotetext{
${ }^{9}$ Leider unterliegt die Hörspieldatenbank des DRA weiterhin einer Erneuerung und ist deswegen im Internet nicht für die freie Suche zugänglich. Jedoch besteht die Möglichkeit zu Rechercheanfragen: http:/ / www.ard.de/radio/hoerspielarchiv/ $/$ id $=570460 /$ nid $=570460 / \mathrm{cf}=42 / \mathrm{wrzwf3}$, (Stand: 20.10.13).

10 Als Beispiel könnte die Folge Die Drei ??? und die Silbermine genommen werden. Besonders geeignet erscheint dies, weil sowohl Textauszüge (http://www.buchhandel.de/WebApi1/GetMmo.asp? MmoId=1404777\&mmoType=PDF, (Stand: 20.10.13)) als auch das Hörspiel (http://www.youtube. $\mathrm{com} /$ watch? $_{\mathrm{v}}=\mathrm{RJxkb3JDMNQ}$ (Stand: 20.10.13)) frei im Internet zugänglich sind. Bei diesem Beispiel muss angemerkt werden, dass es den Fokus auf die Sensibilisierung für die Gestaltungsmittel legt und sich deswegen vom Thema der kulturellen Differenzen entfernt. Idealerweise könnten die Lehrenden ein Hörspiel suchen, das auf einen Text der Migrationsliteratur zurückgeht.
} 
ders deutlich. Im Sinne Forsters kann man also auch hier von ästhetischer Kommunikation ${ }^{11}$ sprechen.

Sowohl der Einsatz der Stimme als auch die Gestaltung der Texte mit Geräuschen und Musik sind stark subjektiv und ließen den Lernenden ein Höchstmaß an kreativen Freiräumen. Es erfolgte eine bewusste Zuwendung zu den gestalterischen Mitteln, in deren Konsequenz die Lernenden für die ästhetischen Aspekte der Hörspielgestaltung sensibilisiert wurden.

Die der Aufnahme folgende Veröffentlichung im Internet machte die sprachliche Leistung der Lernenden sichtbar (vgl. Steinmann 2012: 247). Die Möglichkeiten des Web $2.0^{12}$ erleichtern zudem die Kommunikation mit anderen Nutzenden, beispielsweise über Blogs und Foren (vgl. Wagner; Heckmann 2012: 9), sodass hier die Möglichkeit zu einer authentischen, inhaltsgeleiteten Kommunikation mit anderen Lernenden oder auch Muttersprachlern/-innen besteht (vgl. Peuschel 2009: 91).

Während des Projekts an der FES Acatlán entstanden zwei Texte zu den Themen Weihnachten und Pünktlichkeit mit einem Umfang von zwei bis vier Minuten. Beide Themen wurden von den Lernenden selbst gewählt. Das erste Thema erscheint mir als durchaus geeignet, um Differenzen und Gemeinsamkeiten im Bereich der Traditionen darzustellen. Pünktlichkeit jedoch ist ein Thema, das in engem Zusammenhang mit stereotypen Vorstellungen über Mexikaner/-innen bzw. Deutsche steht. Hier sollten die Lehrenden zur Auseinandersetzung mit Stereotypen anregen, die sich durch ein ironisches bzw. relativierendes Kommentar im Hörspiel äußern könnte.

\section{$5 \quad$ Möglichkeiten und Grenzen}

Das vorgestellte Projekt wurde von den Lernenden sehr positiv aufgenommen. Ein besonderer Vorteil des Projekts war die Möglichkeit der Einbindung von Lernenden mit unterschiedlichem Sprachstand (B1-B2) in den kooperativen Arbeitsformen der Sozialform Gruppenarbeit. Zur Herausforderung können je nach Interessen und Vorkenntnissen der Lernenden die technischen Details der Aufnahme werden, obwohl Audacity mit seiner sehr benutzerfreundlichen Oberfläche und einer Reihe von Handbüchern und Wikis die Anwendung deutlich erleichtert. ${ }^{13}$ Alternativ wäre es allerdings auch denkbar, die Aufnahmen mit Mikrofon und Kassettenrecorder zu machen.

\footnotetext{
${ }^{11}$ Forster definiert ästhetische Kommunikation als einen Teilbereich der Sprechwissenschaft, der „das Sprechen von dichterischen Texten für Hörer“ umfasst (Forster 2002: 234).

12 Der Begriff Web 2.0 meint das Aufkommen von Orten kooperativen Schreibens im Internet wie beispielsweise Chat und Blog (vgl. Rösler 2010: 1211).

13 Hinweise dazu und mögliche Hilfestellungen: http://audacity.sourceforge.net/help/, (Stand: 18.10.13).
} 
Das vorgestellte Projekt erlaubt die aktive Beteiligung der Lernenden am Leseprozess. Sie werden emotional, aber auch kognitiv einbezogen. Das Vorlesen regt zunächst zum Nachdenken über den literarischen Ausgangstext und schließlich zur kreativen Gestaltung eines eigenen Textes an. Im Einklang mit der Sekundärliteratur kann ich den „,immens[en]“ (Caspari 2012: 90) Zugewinn an Kompetenzen und die umfangreiche Schulung der Fertigkeiten bestätigen. Die Lernenden hoben in ihren Selbstevaluationen im Anschluss an das Projekt hervor, dass sie besonders im Bereich des sinnbetonenden Lesens, des globalen Hörens und der Aussprache deutliche Fortschritte gemacht hätten. Im Hinblick auf die Förderung der ästhetischen Kompetenz ${ }^{14}$ kann festgehalten werden, dass die Lernenden sich intensiv mit den Inhalten und dem Aufbau des Ausgangstextes auseinandersetzten. Die anschließende Hörspielproduktion sensibilisierte sie für die Klanggestalt des Textes. Sie lernten die künstlerische Qualität gesprochener literarischer Texte besser zu beurteilen (vgl. Forster 2002: 236) und konnten dadurch in ihrer „ästhetischkritischen Beobachter[position]“ (Schier 2012: 53) gestärkt werden.

\section{Literatur}

Bischof, Monika (2004): Sei doch mal still. Wie man aus einem Bilderbuch ein Hörspiel selber machen kann. In: Frühes Deutsch 3, 3-35.

Blumensath, Heinz (2004): Texte - Bilder - Töne. Ein Hörspiel-Film. In: Frühes Deutsch 3, 36-37.

Bredella, Lothar (2010): Das Verstehen des Anderen. Kulturwissenschaftliche und literaturdidaktische Studien. Tübingen: Narr.

Caspari, Martina (2012): Methoden des handlungs- und produktionsorientierten Fremdsprachenunterrichts am Beispiel eines innovativen DaF-Projekts. In: Babylonia 3, 87-90.

Ehlers, Swantje (1994): Gegenrede. In: Fremdsprache Deutsch. Zeitschrift für die Praxis des Deutschunterrichts 11, 60.

Ehlers, Swantje (2010): Die Rolle der Literatur im Fach Deutsch als Fremd- und Zweitsprache. In: Krumm, Hans-Jürgen; Fandrych, Christian; Hufeisen, Britta; Riemer, Claudia (Hrsg.): Deutsch als Fremd- und Zweitsprache. Ein internationales Handbuch. 2. Halbband. Berlin u.a.: de Gruyter, 1530-1544.

Frederking, Volker; Krommer, Axel; Maiwald, Klaus (2012): Mediendidaktik Deutsch. Eine Einführung. Berlin: Erich Schmidt.

\footnotetext{
${ }^{14}$ Ehlers definiert ästhetische Kompetenz als Wissen über literarische „Konventionen“ und „handlungsgeleitete Normen" (Ehlers 1994: 60).
} 
Folkvord, Ingvild (2011): Gehörte Geschichten im Literaturunterricht: Symbolische Kompetenz und Präsenzerlebnisse. In: Ewert, Michael; Riedner, Renate; Schiedermair, Simone (Hrsg.): Deutsch als Fremdsprache und Literaturwissenschaft: Zugriffe, Themenfelder, Perspektiven. München: iudicium, 116-129.

Forster, Roland (2002): Von der Leselehre zum Textsprechen: Ästhetische Kommunikation im DaF-Unterricht. In: Wolff, Armin; Lange, Hartmut (Hrsg.): Europäisches Jahr der Sprachen: Mehrsprachigkeit in Europa. Materialien Deutsch als Fremdsprache 65. Regensburg: FaDaF, 234-246.

Iser, Wolfgang (1994): Die Appellstruktur der Texte. In: Warning, Rainer (Hrsg.): Rezeptionsästhetik: Theorie und Praxis. München: Fink, 228-252.

Li, Yuan (2007): Wege zur „Schönheit“ durch Literatureinsatz im Fremdsprachenunterricht. In: Zielsprache Deutsch 34, 3, 35-50.

Peuschel, Kristina (2009): Integrierte Textentwicklung in einem Radioprojekt mit fortgeschrittenen DaF-Lernenden. In: Peuschel, Kristina; Pietzuch, Jan Paul (Hrsg.): Kaleidoskop der jungen DaF-/DaZ-Forschung. Göttingen: Universitätsverlag, 89-106.

Riemer, Claudia (2010): Motivierung. In: Krumm, Hans-Jürgen; Fandrych, Christian; Hufeisen, Britta; Riemer, Claudia (Hrsg.) (2010), 1152-1157.

Rösch, Heidi (2000): Migrationsliteratur im DaF-Unterricht. In: Info DaF 27, 4, 376-392.

Rösler, Dietmar (2010): Die Funktion von Medien im Deutsch als Fremdspracheund Deutsch als Zweitsprache-Unterricht. In: Krumm, Hans-Jürgen; Fandrych, Christian; Hufeisen, Britta; Riemer, Claudia (Hrsg.) (2010), 1199-1214.

Schami, Rafik (2011): Eine deutsche Leidenschaft namens Nudelsalat. In: Schami, Rafik (Hrsg.) (2011): Eine deutsche Leidenschaft namens Nudelsalat. München: dtv, 31-36.

Schewe, Manfred Lukas (2002): Literaturvermittlung auf dem Wege von gestern nach morgen - eine auslandsgermanistische Perspektive. In: German as a foreign language (GFL) 3, 25-47.

Schier, Carmen (2011): Perspektivenwechsel als Tür zu anderen Welten. Zum Potenzial von Literaturprojekten in Deutsch als Fremdsprache. In: Fremdsprache Deutsch. Zeitschrift für die Praxis des Deutschunterrichts 44, 53-59.

Steinmann, Cornelia (2012): Podcast-Projektbaukasten. In: Wagner, Jürgen; Heckmann, Verena (Hrsg.): Web 2.0 im Fremdsprachenunterricht. Ein Praxisbuch für Lehrende in Schule und Hochschule. Glückstadt: Werner Hülsbusch, 247-254. 
Tütken, Gisela (2006): Literatur im Unterricht Deutsch als Fremdsprache an der Hochschule im Ausland - aber wie? Ein Vorschlag am Beispiel Rußlands. In: Info DaF 33, 1, 52-90.

Wagner, Jürgen; Heckmann, Verena (2012): Vorwort. In: Wagner, Jürgen; Heckmann, Verena (Hrsg.) (2012), 9-11.

Wermke, Jutta (2004): Das Hörbuch im Rahmen einer Hördidaktik. In: Der Deutschunterricht 57, 4, 50-63. 


\section{Bühne frei für große Gefühle: Ästhetisches und theatrales Lernen im DaF-/DaZ-Unterricht am Beispiel von Heinrich Heines Der arme Peter in der Bilderbuchadaption von Peter Schössow}

\section{Heidi Hahn}

Der Aufsatz, möchte am Beispiel des Bilderbuchs Der arme Peter von Peter Schössow zeigen, wie im DaF-/DaZ-Unterricht ästhetisches und theatrales Lernen sprachgestütżt verwirklicht werden kann. Nach einleitenden Überlegungen zum Stellenwert literarischer Texte im Fremdund Zweitsprachunterricht wird das ausgewählte Bilderbuch binsicbtlich seiner medialen Verfasstheit vorgestellt und analysiert. Im Anschluss daran begründet die Verfasserin die Eignung des Mediums für ästhetische und theatrale Lemprozesse. Vorschläge zur methodischen Umsetzung beschließen den Beitrag.

\section{Literarische Texte im DaF-/DaZ-Unterricht}

Die Beteuerung, dass literarische Texte es schwer hätten im Fremd- und Zweitsprachunterricht, zieht sich seit Ende der 80er Jahre als Grundkonstante durch die Forschungsliteratur. ${ }^{1}$ Damit einher geht die Forderung, literarischen Texten im DaF-/DaZ-Unterricht auch in Zeiten des Gemeinsamen europäischen Referenzrahmens (GeR) einen größeren Stellenwert einzuräumen. Meist werden zur Begründung emotionale und motivationale Aspekte angeführt. Literatur könne Gratifikationserfahrungen liefern und so neben dem Sprachlernen der literarische Kom-

\footnotetext{
1 Vgl. Weinrich 1988, Koppensteiner 2001, Krenn 2003, Dohrn 2007, Piepho 2007, Hahn 2010, Rösch 2011. In jüngerer Zeit widmet die DaZ-Didaktik dem Literaturunterricht als Fachunterricht mehr Aufmerksamkeit (vgl. Rösch 2010).
} 
petenzentwicklung dienen. Nicht abschließend geklärt für den DaF-/DaZ-Kontext sind die Konsequenzen des immanenten Spannungsverhältnisses zwischen Ästhetik und Didaktik. Den Verstehensbemühungen der Fremdsprachdidaktik steht die prinzipielle Un(aus)deutbarkeit literarischer Texte als Merkmal ihrer spezifischen Ästhetik, ihrer Literarizität, gegenüber. Die Herausforderung liegt darin, genau diese Literarizität zum Gegenstand der Sprachbetrachtung im DaF-/DaZUnterricht zu machen (vgl. Dobstadt 2009), den grundsätzlichen Widerspruch von Ästhetik und Didaktik positiv zu wenden und das lernwirksame Potential von literarischen Texten für die Entwicklung von Sprachkompetenz zu nutzen. In der Forschungsliteratur wird in diesem Zusammenhang die besondere Bedeutung von produktiven Verfahren und textnahem Lesen herausgestellt (vgl. Rösch 2011: 105ff.), zu ergänzen wäre die Förderung von visual literacy (vgl. Dehn 2007; Lütge 2011).

\section{Das Bilderbuch Der arme Peter von Peter Schössow und Heinrich Heine}

\subsection{Text}

Das neun-strophige Erzählgedicht Der arme Peter, 1827 veröffentlicht in Heinrich Heines Buch der Lieder/Junge Leiden als viertes Stück der Abteilung „Romanzen“ (Heine 1827/1975: 73ff.), erschien erstmals am 16. Dezember 1821 in der Zeitschrift Das Sonntagsblatt (Minden), als Teil eines kleinen vierteiligen Zyklus' mit der Überschrift Der arme Peter ${ }^{2}$. Die Fassung von 1827 ist in drei bezifferte Teile à drei Strophen unterteilt, der Text hat den Charakter eines Miniatur-Dramas mit Exposition, Peripetie und Katastrophe. Der arme Peter ist eine Liebestragödie im Gewand eines Erzählgedichts. Der Erzähler stellt in der Exposition die drei Protagonisten/innen vor: Hans, Grete und Peter. Er tut dies im epischen Präsens, das der Vergegenwärtigung des Erzählten dient. Zeit und Ort der Handlung bleiben unbestimmt, ein Ortswechsel zwischen Stadt und Gebirge kann aber festgemacht werden. Bereits nach der ersten Strophe ist die Konstellation in ihrer Tragik klar: Nur zwei können zusammenkommen, schließen den Bund der Ehe. Der Dritte bleibt außen vor, als armer Peter. Am Ende der dritten Strophe erhält der Unglückliche das Wort. In einem Klagemonolog spricht er über drei Strophen von seinem Liebesleid und -schmerz. Schließlich sucht er Ruhe auf der Höhe des Berges und ergibt sich dort seinen Tränen. Ab der siebten Strophe übernimmt der Erzähler erneut die Führung und berichtet, dass sich Peter nun wieder auf der Straße zeige - ein Schatten seiner selbst. Während Passantinnen in ihm mitfühlend einen Rekonvaleszen-

\footnotetext{
2 Vorangestellt war den drei mal drei Strophen ein weiterer Text mit dem Titel Der arme Peter I, dieses Gedicht wird später im Buch der Lieder unter der Überschrift Der Traurige aufgeführt und eröffnet dort die Rubrik Romanzen.
} 
ten vermuten („Der stieg wohl aus dem Grab hervor.“) (V. 30), weiß es der Erzähler besser: „Der legt sich erst ins Grab hinein.“ (V. 32). Als Antwort auf die verlorene Liebe bleibt nur der Tod, der Schlaf „bis zum Jüngsten Tag“ (V. 36). Die formale Struktur des Gedichts korrespondiert in vielfacher Hinsicht mit dem Textinhalt. Jeweils drei vierzeilige Strophen weisen ihr eigenes Metrum und Reimschema auf. In der ersten Strophentrias dominiert der Daktylus, es wechseln vierund dreihebige Verse im Kreuzreimschema. Die zweite Strophentrias ist jambisch gehalten, auch hier wechseln vier- und dreihebige Verse im Kreuzreim. Durchgängig alternieren in den ersten sechs Strophen stumpfe und klingende Kadenzen. Die letzten drei Strophen differieren formal erheblich. Vorzufinden sind nun durchgehend paargereimte jambische vier-Heber. Während der Daktylus zu Beginn die Bewegtheit der hochzeitlichen Tanz-Szene unterstreicht, korrespondiert der schlichte alternierende Jambus der Strophen vier bis sechs (Volksliedstrophe) mit der Liebesklage des Protagonisten. In den letzten drei Strophen erzeugen der gleichmäßige Jambus und die Paarreime, verbunden mit den durchgängig stumpfen Kadenzen, eine dumpfe Atmosphäre. Die Figur des armen Peter kann in eine Reihe von weiteren literarischen Figuren mit negativer Liebeserfahrung in Heines Werk gestellt werden. ${ }^{3}$ Die Sprache der Romanze ist im einfachen Volkston gehalten. Kurze Parataxen werden gelegentlich durch ein nebenordnendes „und“ miteinander verbunden (so in V. 2, 4, 6 und 8), seltener durch untergeordnete Temporalund Kausalsätze erweitert. Der umgangssprachliche definite Artikel vor den Vornamen unterstreicht die konzeptionelle Mündlichkeit. Einige Archaismen verdienen Aufmerksamkeit; hierzu gehören „Hochzeitsgeschmeide“ (V. 6), „Werkeltagskleide“ (V. 8), ,von hinnen“ (V. 16), ,,sich etwas zuleide tun“ (V. 12), ,Jungfräulein“ (V. 31) und ,Jüngster Tag" (V. 36). Der lyrischen Sprache geschuldet sind sprachliche Normabweichungen wie Inversion (V.7, 17, 33), Elision (V.16, 18) und Ellipse (V. 21).

Peter Schössow versieht in seinem Bilderbuch den Heine-Text mit einem paratextuellen Vorsatz bzw. Motto. Er zitiert Heines vierzeiliges Gedicht „Anfangs wollt ich fast verzagen“ (Heine 1827/1975: 65) und kommentiert es knapp mit dem Satz „Kenn ich.“ (Schössow: Vorsatzblatt). Auf diese Weise tritt der Bilderbuchschöpfer Schössow in einen Dialog mit dem lyrischen Ich des HeineGedichts. Dass der moderne Künstler mit dem literarischen Protagonisten auch den Vornamen gemeinsam hat, legt Identifikationsprozesse nahe und kann als ein weiteres Spiel mit autobiographischen Bezügen gelesen werden.

\footnotetext{
3 Vgl. den bleichen Heinrich in der Romanze Die Fensterschan oder den kranken Wilhelm aus der Wallfahrt nach Kevlaar
} 


\subsection{Bilder}

Mit seiner 2013 im Hanser-Verlag veröffentlichten Adaption von Heines Gedicht gelingt dem renommierten zeitgenössischen Bilderbuchkünstler Peter Schössow eine Bild-Text-Kombination von herausragender Güte. Das Buchcover zeigt die Guckkastenbühne eines etwas altmodischen Theaters in der Totalen (vgl. Abb. 1). Die Betrachter/innen werden zu Zuschauer/innen. Auf der Bretterbühne, vor einer Steinballustrade, hinter der ein Prospekt mit Bäumen und Büschen zu sehen ist, spaziert im hellen Sonnenlicht ein junger Mann mit Hut und Brille, schlicht und altertümlich gekleidet. Unter beiden Armen trägt er Bücherstapel, sein Blick ist nach oben gerichtet, der Mund zu einem seligen Lächeln verzogen. Markantestes Requisit sind neun Schmetterlinge, die seinen Kopf umflattern. Die Vermutung, dass der junge Mann verliebt sei, liegt nahe, er zeigt alle Merkmale des romantischen Schwärmers. Auf neunzehn großformatigen Doppelseiten schildert Schössow in der weiteren Folge den Besuch einer Theateraufführung, in der Kinder für Kinder (und einige Erwachsene) den Heineschen Text als Bühnenstück inszenieren. Die Straßenszenen außerhalb des Theaters zeigen Kinder und Jugendliche in modischer Kleidung wie Baseball-Kappen und Chucks; Mobiltelefone und Skateboards verweisen ebenfalls auf das Hier und Heute. Dennoch baut Schössow augenzwinkernd Irritationen ein, so den Teddybär auf der ersten Doppelseite als phantastisches Element und Fiktionalitätssignal. Das Stück selbst spielt, in Übereinstimmung mit der Textvorlage, im 19. Jahrhundert. Biedermeierliche Kostüme und bürgerlicher Habitus markieren die historische Ferne. Die Schäferszene kann als Reminiszenz an stilisierte Naturidyllen des 18. Jahrhunderts verstanden werden. Die Rollen der Brautjungfern, Nonnen, Schafe, Engel, Marktfrauen und Passantinnen leitet Schössow aus der Schlussstrophe des Gedichts ab und bereichert so die Szenerie. Gleichzeitig übernehmen sie die beobachtende und kommentierende Funktion des Chores. Geschickt wird die Inszeniertheit der Bühnenhandlung hervorgehoben. So sind beispielsweise die Prothese des Nachtwächters wie auch sein Leibesumfang nur Schein, wie der Blick auf die Garderobenszene zeigt. Diese Doppelseite zum Geschehen in der Theatergarderobe ist ein Schlüssel für das Verstehen des fiktionalen Rollenspiels. Zur Gestaltung seiner Bildmotive nutzt Schössow die digitale Technik. Er verwendet insgesamt gedeckte Farben, differenziert jedoch deutlich. So haben die Tageslichtszenen ein helleres Kolorit, der Zuschauerraum ist etwas abgedunkelt, die Hochzeitsszene wird von einer künstlichen Sonne beleuchtet, der Kirchenraum ist mit Dämmerlicht erfüllt. In Peters Atelier (er ist offensichtlich auch Maler!) fällt Tageslicht. ${ }^{4}$ Die Winternacht im Gebirge ist in kaltes Blau getaucht ${ }^{5}$, Peters Gang durch die Gassen der Stadt ins trübe Zwie-

\footnotetext{
${ }^{4}$ Im Vergleich zur Textvorlage steigert Schössow die seelischen Qualen noch, die der Protagonist zu erleiden hat. Peter kommt die Aufgabe zu, das frisch getraute Paar zu malen. Auch die soziale Unterprivilegierung des Protagonisten wird auf diese Weise betont.

${ }^{5}$ Intramediale Anspielung: Vgl. Caspar David Friedrichs Gemälde Der Wanderer im Nebelmeer und Eismeer.
} 
licht der Regennacht. In der Kirchhofszene schließlich dominieren Braun- und Grautöne, doch die Morgenröte zieht bereits herauf („,bis zum Jüngsten Tag“) (V. 36). Die Figurenzeichnung ist klar und äußerst präzise. Anhand kleiner Details können die Personen mühelos voneinander unterschieden werden. Voran- und nachgestellt sind der Bilderzählung zwei Vignetten. Auf der ersten begegnet dem/der Betrachter/in ein Mädchen mit kurzen braunen Zöpfen, das sich offensichtlich für einen Theaterbesuch zurechtmacht. Die Theaterkarte klemmt zwischen den Lippen. Auf dem Boden liegt ein Bücherstapel. Die Schlussvignette zeigt dasselbe Mädchen, diesmal mit abgerissener Theaterkarte in der Hand. Es sitzt auf einem Schemel - es ist der Schemel aus Peters Atelier -, stützt den Kopf in die Hände und betrachtet eine weiße Rose, die im Topf auf dem Bücherstapel platziert ist. ${ }^{6}$ Der Mund ist zu einem nachdenklichen Lächeln geöffnet. Die Theateraufführung scheint nachzuwirken. Schössow erzählt auf den ersten fünf Doppelseiten ausschließlich monocodiert piktoral, der Text tritt erst auf der sechsten Doppelseite hinzu. Auf eine Straßenszene, die mit der Silhouette des Michels (St. Michaelis-Kirche) die Stadt Hamburg evoziert, folgt die Szene, in der sich Schauspieltruppe und Publikum ins Theater begeben, es schließt sich die an ein Wimmelbild erinnernde Doppelseite mit dem Geschehen in der Garderobe an, darauf eine Darstellung des noch fast leeren Zuschauerraums mit Blick auf den geschlossenen Bühnenvorhang und schließlich eine Doppelseite mit dem Darsteller des Peter, wie er sich anschickt, mit seinen Bücherstapeln vor das Publikum zu treten (Gegenansicht zum Cover); der Vorhang scheint sich gerade zu öffnen. Bild und Text sind im weiteren Verlauf der Erzählung genau abgestimmt und rhythmisiert. Jeder Strophe ist eine Doppelseite zugeordnet. Nach der dritten Strophe - hier endet der erste Akt - wechselt die Perspektive vom Bühnen- in den Zuschauerraum. Auch die Strophen vier bis sechs, die dem zweiten Akt entsprechen, sind jeweils einer Doppelseite zugeordnet. Die folgende Doppelseite zeigt abermals das Publikum - von Angst und Entsetzen ergriffen. Der Schnee auf der Bühne scheint auch den Zuschauerraum zu füllen, was sich freilich beim genauen Hinsehen als optische Täuschung erweist. Es folgen die Strophen sieben bis neun, die Peters psychischen und physischen Verfall schildern. Daran angefügt sind noch drei Doppelseiten ohne Text. Die Darsteller/innen treten an die Bühnenrampe und verbeugen sich (vgl. Abb. 2). Hier nimmt der/die Betrachter/in wieder die Zuschauerperspektive ein. Das letzte Bild zeigt Zuschauer/innen und Schauspieler/innen, wie sie das Thalia-Theater verlassen. Bei genauer Betrachtung können alle Darsteller/innen und einige wichtige Figuren aus dem Publikum anhand bestimmter Attribute (Frisur, Kleidung, Schuhe, Taschen) identifiziert werden.

\footnotetext{
${ }^{6}$ Intramediale Anspielung: Vgl. Walther von der Vogelweide Ich saz uf eime steine. In: Bergner 1983: 164; auch August Rodin Der Denker.
} 


\subsection{Intermedialität}

Das Bilderbuch Der arme Peter ist eine Medienkombination. Bild und Text werden miteinander verbunden (vgl. Rajewsky 2004: 14f.). Dem Text als Ausgangsmedium werden die Bilder als Folgemedium zur Seite gestellt (sekundäre Intermedialität). Der Text bleibt dabei durchweg im Original erhalten, wird nicht weiter in Dialoge umgewandelt. Auch wenn die Worte eine wichtige Funktion haben, dominieren doch eindeutig die Bilder. Dies zeigt sich bereits durch die einleitenden fünf Doppelseiten, die fast gänzlich ohne Text auskommen (partielle Intermedialität). Eingefügt sind lediglich vereinzelte Beschilderungen und Theaterplakate. Die graphische Erzählung nutzt zusätzlich die aus der Comic-Kunst bekannte Verwendung von Piktogrammen (Schmetterlinge ${ }^{7}$ sowie Doppelherzen und zerbrochenes Herz, vgl. Abb. 3). Medial gesehen liegt ein erzählendes Bilderbuch vor, konzeptionell dagegen eine Theateraufführung. Indem das Bilderbuch medienspezifische Merkmale des Theaters aufgreift und integriert, werden intermediale Bezüge hergestellt (vgl. Rajewsky 2004: 16f.) und es entsteht ein neuer ästhetischer Raum. So ahmt beispielsweise das in sattem Rot gehaltene Vorsatzblatt den roten Samtvorhang des Theaters nach. Der Darstellung des Bühnengeschehens wird durchgängig eine Doppelseite eingeräumt, die die Guckkastenbühne in der Totale erfasst, gerahmt durch den Seitenvorhang. Die Bilderbuchrezipienten/innen schlüpfen über längere Passagen in die Rolle der Zuschauer/innen. Genau wie die Theateraufführung liefert die Bilderbucherzählung eine Ansicht der Figuren, der Kostüme, Requisiten und Kulissen, sie imitiert auch die Lichtregie des Theaters. Durch die Rhythmisierung der neunzehn Doppelseiten wird die Strukturierung der Theateraufführung in drei Akte verdeutlicht. Was allerdings fehlt, ist das authentische Theatererlebnis im Raum, der Live-Effekt, die akustischen Eindrücke (Stimmen, Geräusche, Musik) und Bewegungselemente. Auch lässt Schössow den Originaltext unverändert, d.h. es führt ein Erzähler durch die Handlung, was dramenuntypisch ist. Durch die eingeschränkte direkte Rede bzw. Personenrede - es sprechen im Gedicht nur Peter, die drei jungen Frauen und der Erzähler - müssen die Figuren der Bilddarstellungen auch ohne Rollentext wirken. Das Bilderbuch bietet aber auch ästhetische Funktionen, die die Theateraufführung nicht leisten kann: Es führt zusätzlich eine Rahmenhandlung und unterschiedliche Perspektiven vor. Wie im Film gibt es Schnitte, die zu Orts- oder Perspektivwechsel führen: In die Garderobe, aber auch vom Bühnenraum in den Zuschauerraum und umgekehrt. Und vor allem kann im Bilderbuch geblättert werden, dieses Medium kann wiederholt und nach individuellen Bedürfnissen rezipiert werden. Um die raffinierten Details und Verweise in Peter Schössows bildkünstlerischer Adaption zu entdecken, ist ein solches Vorund Zurückblättern sogar unerlässlich, das Bilderbuch ist geradezu eine Herausforderung für die visuelle Wahrnehmungsfähigkeit. Durch die Einbeziehung von Zuschauerraum und Publikum in seine Bilddarstellung bekennt sich Schössow

\footnotetext{
${ }^{7}$ Abgeleitet von der Redewendung Schmetterlinge im Bauch baben.
} 
implizit zu performativen Tendenzen der Gegenwartskunst. Das Geschehen im Publikum nähert sich in seiner Bedeutsamkeit dem Bühnengeschehen an, die Interaktion zwischen Schauspielern/innen und Zuschauern/innen wird zum Gegenstand der künstlerischen Darstellung. Daraus ergibt sich nun die reizvollste Neuerung, die Peter Schössow hinzuerfindet. Der Liebestragödie der Bühnenhandlung wird eine zarte Romanze zwischen Darsteller und Zuschauerin zur Seite gestellt. Die junge Theaterbesucherin der Eingangsvignette hat offensichtlich ein Auge auf den Hauptdarsteller geworfen. Ob es die Liebe zu Büchern und Literatur ist, die sie verbindet? Als sie ihr Ticket an der Kasse zeigt, schlendert der Peter-Darsteller gerade recht locker von links ins Bild (blondes Haar, gelber Schal). Das Mädchen hat in der ersten Reihe Platz genommen (dritter Platz von links, von der Bühne aus gesehen) und verfolgt die Handlung des Stückes von Anfang an fasziniert. Als Peter die Trauung seiner Liebsten mit dem offensichtlich gut situierten Hans mit ansehen muss, hält es die kleine Zuschauerin nicht mehr auf ihrem Platz. Auch als er das jung vermählte Paar malen muss, erstarrt sie förmlich vor Schrecken. Das Mitfiebern hält an, bis sich am Ende des Spiels der Peter-Darsteller verbeugt. Jetzt endlich darf das Mädchen zur Bühnenrampe laufen und ihn anhimmeln. Auf dem Schlussbild der Bilderzählung sieht man die bezopfte Zuschauerin neben dem Peter- und dem Hans-Darsteller einhergehen, vertieft in ein lebhaftes Gespräch. Der Hans-Schauspieler telefoniert allerdings nebenbei, und zwar vermutlich mit dem großen Mädchen mit Pagenkopf und weiß-gelber Schiebermütze, die er auch schon in der Garderobe per Mobiltelefon kontaktiert hatte, und die im Stück eine der drei Brautjungfern/Nonnen/Schafe/Engel/Jungfräulein gemimt hat. In Wirklichkeit ist also alles ganz anders - und es stellt sich nur die Frage, woher die beiden Sträuße mit weißen Rosen kommen - auf der Bühne spielte nur einer eine Rolle, jetzt trägt der Peter-Darsteller auch einen Strauß. Zuhause bei der jungen Theaterbesucherin blüht indessen eine einzelne Rose im Topf. So gestaltet Schössow in seinem Bilderbuch nicht nur die für einen Theaterbesuch typische Anschlusskommunikation, sondern es gelingt ihm auch, die intensive Wirkung einer Theateraufführung bildkünstlerisch festzuhalten.

\section{Zum didaktischen Potential des Bilderbuchs}

\subsection{DaF-/DaZ-spezifische Anforderungen und Lernchancen}

Im DaF-/DaZ-Unterricht geht es vorrangig darum, Spracherwerbsprozesse zu befördern. Diese betreffen gemäß GeR die Bereiche Lese- und Hörverstehen, Sprechen und Schreiben. Im Hinblick auf sprachliches Lernen eignen sich Bilderbücher besonders gut. Die Textmenge ist meist stark reduziert, außerdem haben die Bilder häufig eine Semantisierungsfunktion und können so das Textverstehen unterstützen (vgl. Rösch 2011: 116). Ein Problem stellt sich allerdings im Hinblick auf die Adressatengruppe. Deshalb sollte sich der DaF-/DaZ-Unterricht darum 
bemühen, Bilderbücher ausfindig zu machen, die doppelsinnig konzipiert sind bzw. auch Jugendliche und Erwachsene interessieren (vgl. Weinkauff; Glasenapp: 170f.). Mit dem Bilderbuch Der arme Peter ist ein solches Medium gegeben. Das universelle Thema Liebe spricht Lernende unterschiedlicher Kulturen und Altersgruppen an.

Heines Gedicht Der arme Peter erzählt eine gut nachvollziehbare (Alltags-)Geschichte; gleichwohl handelt es sich um lyrisch verdichtete Sprache. Es liegen Überstrukturierungen auf lautlicher, lexikalischer, semantischer, syntaktischer und textueller Ebene vor. Diese typischen Elemente poetischer Sprache können auch im DaF-/DaZ-Unterricht erfahrbar gemacht werden. In seiner Kürze und stilisierten sprachlichen Einfachheit (vom Irrealis in V. 11/12 abgesehen) kommt der Text DaF-/DaZ-Lerndenden entgegen. Peter Schössows Bilderbuchadaption erweitert den literarischen Text von Heinrich Heine zu einem hochkomplexen ästhetischen Gebilde, dem es sich verstehend anzunähern gilt; das schließt die Artikulation von Nichtverstehen bewusst mit ein. Es ist außerdem ein Beispiel dafür, wie Bilderbücher auch eine eigene, vom Text abweichende Geschichte erzählen können. Der historische Text von Heinrich Heine wird so in einen Gegenwartskontext gerückt. Dies dürfte den Textzugang erheblich erleichtern und schließt eine Betrachtung unter literarhistorischen Fragestellungen dennoch nicht aus. Heinrich Heine gilt als einer der bekanntesten deutschen Dichter weltweit. Die Beschäftigung mit seinem Werk im Fremdsprachenunterricht ist auch im Hinblick auf kulturelles Lernen leicht zu rechtfertigen. Grundsätzlich stellt sich die Frage, welche Erfahrungen die Lerngruppe bereits mit Gedichten, Bilderbüchern, aber auch mit der Rezeption und Produktion von Theateraufführungen gemacht hat. Das Thema unglückliche Liebe wird ab einem Alter von neun oder zehn Jahren für Kinder relevant. Die Figur des unglücklichen Peter stellt fraglos Empathie-, vielleicht auch Identifikationsmöglichkeiten bereit und bedient so die personale Lernebene (vgl. Rösch 2011: 107). Auf sozialer Ebene bietet das Bilderbuch Anlass für Gespräche vor, während und nach der Rezeption. Entsprechend der Anschlusskommunikation nach einem Theaterbesuch können inhaltliche und aufführungs- bzw. bildbezogene Fragen diskutiert werden. Auf der Methodenebene ist zu überlegen, welche Lesarten das Bilderbuch ermöglicht. Ist der arme Peter existenziell und/oder materiell unterlegen? Soll der Blick auf die Handlung des Bühnenstücks und/oder auf dessen Inszenierung bzw. Inszeniertheit und Wirkungsdimension gerichtet werden? Welche Rolle spielt dabei die Historizität des Textes? Wie positioniert sich Peter Schössow zu seinem Gegenstand? Auf Sachebene geht es darum, die vorliegende intermediale Bild-Text-Kombination mit ihren spezifischen Merkmalen zu erkennen und zu nutzen. Das bedeutet in diesem Fall die genaue Wahrnehmung des Gedichttextes einschließlich seiner poetisch und historisch bedingten Fremdheitssignale wie auch ein aufmerksames Bildlesen sowie die Blickschärfung für die intermediale Bezugnahme des Bilderbuchs auf ästhetische Merkmale einer Theateraufführung. Für manche DaF-/DaZ-Lernende wird auch die kulturspezifische Darstellung eines traditionellen mitteleuropäischen Theaters und erst recht die Nutzung dieser öf- 
fentlichen Institution durch Kinderschauspieler/innen fremd sein. Hier kann (inter)kulturelles Lernen ansetzen.

\section{2 Ästhetisches und theatrales Lernen in der DaF-/DaZ-Perspektive}

Wenn auch gilt, dass unter der Zielsetzung von Spracherwerb grundsätzlich jede Literatur als Lerngegenstand in Frage kommt (vgl. Rösch 2011: 107), so stellt sich die Sachlage anders dar, wenn neben dem Sprachlernen ästhetische Lernprozesse ins Spiel kommen sollen. Thomas Zabka definiert ästhetische Bildung auf der Grundlage der Aisthesis und Ästhetik als Sinneserfahrung und als Erfahrung des „ästhetisch gelungenen Kulturprodukts“ (Zabka 2013: 472). Es gehe um den „Erwerb ästhetisch genannter Fähigkeiten, Kenntnisse und Einstellungen“ (ebd.: 471) sowie um die „Enkulturation in ästhetisch genannte Objekte des Alltagslebens, der Massenmedien und der Künste" (ebd.). Hierbei komme sowohl der Ausbildung des ästhetischen Werturteils als auch der ästhetischen Praxis, die Vermittlung, Aufführung und Gestaltung umfasst, besondere Bedeutung zu. Als zentrale Ziele ästhetischer Bildung formuliert Zabka „Wahrnehmungsfähigkeit, Genussfähigkeit, individuell-lebensgeschichtliche Symbolbildung, Denken in Ähnlichkeiten und ein Interpretieren ohne Nötigung zur abschließenden begrifflichen Fixierung“ (ebd.: 483). Ästhetische Bildung als Gesamtkonzept in den DaF-/DaZ-Unterricht zu integrieren, ist grundsätzlich ein gewagtes Unterfangen und bedarf ganz sicher der flankierenden sprachlichen Unterstützung. Bei der ästhetischen Erfahrung handelt es sich zwar um eine anthropologische Grundkonstante, die sich allenfalls kulturell unterschiedlich ausdifferenziert. Beachtet werden muss allerdings, dass das Sprechen über ästhetische Erfahrung für $\mathrm{DaF}$-/DaZ-Lernende eine ungleich höhere Hürde darstellt als für L1-Lernende. Es müssen also Redemittel bereitgestellt werden, die es ermöglichen, Wertungen, Empfindungen sowie die Funktionsweise medienspezifischer Gestaltungsmittel zu versprachlichen. Es wäre zu erproben, inwiefern sich zu dem Bilderbuch von Heine/Schössow Aufgabenstellungen im Sinne der oben genannten Bildungsziele entwickeln ließen.

Betrachtet man Schössows Bilderbuch als eine konzeptionelle Theateraufführung, stellen sich Fragen nach den Möglichkeiten theatralen Lernens. Gabriele Paule sieht die Theaterdidaktik im Kontext kultureller Sozialisation (vgl. Paule 2013). Ziel müsse die Heranbildung von Theatergänger/innen sein, die sensibel geworden sind für theatrale Ästhetik und die über entsprechendes Wissen verfügen, um theatrale Kunstwerke kompetent rezipieren zu können. Anders als der eindimensional codierte Lesetext eines Dramas ist die fertige Inszenierung eines Theaterstücks ein äußerst komplexer und vielschichtiger Text, bei dem das Zusammenwirken verschiedenster Zeichen simultan wahrgenommen wird. Wenn eine konkrete Theateraufführung (hier: eine ins bildkünstlerische Medium transferierte Aufführung) zum Unterrichtsgegenstand wird, stellen sich zunächst Probleme der Aufführungsbeschreibung und Aufführungsanalyse. Als didaktische Aufgabenfelder und Ziele nennt Paule zusammenfassend und teilweise in Übereinstimmung 
mit Zabka die Wahrnehmungsschulung, das Kennen- und Lesenlernen der Elemente verschiedener theatraler Zeichensysteme und ihres wechselseitigen Zusammenwirkens sowie die Äußerungskompetenz, d.h. das Redenlernen über Kunst. Zuschauen lernen, verstehen lernen, genießen lernen - auf diese drei Säulen müsse die Theaterdidaktik aufbauen (vgl. Paule 2013). Auch für Prozesse theatralen Lernens im DaF-/DaZ-Unterricht müssen spezifische Redemittel zur Verfügung gestellt werden, die die Entwicklung der geforderten Äußerungskompetenz erst ermöglichen. Diese betreffen z.B. den theaterspezifischen Wortschatz einschließlich eines Vokabulars zur Aufführungsbeschreibung und -analyse. Hinzu kommen Redemittel, die die Wirkungsdimension des Dargebotenen betreffen. Wie das Bilderbuch Der arme Peter zum Ausgangspunkt für DaF-/DaZ-spezifisches, d.h. sprachgestütztes theatrales Lernens werden kann, soll im Folgenden gezeigt werden.

\section{DaF-/DaZ-spezifische Aufgabenstellungen: Ästhetisches und theatrales Lernen im Kontext von Spracherwerb und (inter)kulturellem Lernen}

\subsection{Vor der Rezeption}

Die Vorerfahrungen der Lernenden werden abgerufen durch das Zeigen von verschiedenen Abbildungen, die unterschiedliche Theater und Theaterinnenräume zeigen. Hierzu sollten passende Redemittel angeboten werden. Anschließend berichten die Lernenden von Theaterbesuchen. Auch hierfür werden Formulierungshilfen bereit gestellt.

Anhand der Fotos werden Vokabeln und Redemittel zum Wortfeld Theater gesammelt.

Nach Piephos Konzept des Story tellings im Fremdsprachenunterricht hat es sich bewährt, vor der Präsentation des Gegenstands in Form eines setting a stage den imaginären Rahmen abzustecken, in dem sich die Handlung bewegt (vgl. Piepho 2007). Dies könnte geschehen durch eine kleine Einführung:

Heute werden wir eine besondere Theateraufführung erleben. Wir gehen aber nicht ins Theater, sondern schauen uns dieses Bilderbuch an. Der Hamburger Künstler Peter Schössow hat es im Jahr 2013 gezeichnet, den Text dazu hat der deutsche Dichter Heinrich Heine geschrieben, vor fast 200 Jahren. Das Stück heißst Der arme Peter. Es wird von Kindern für Kinder gespielt, in einem ganz normalen Stadttheater. Sicher habt ibr Ideen, weshalb das Stück diesen Titel trägt. Weiter: Es geht in dem Stück um jemanden, der Liebeskummer hat, denn seine Freundin heiratet einen anderen Mann. Überlegt: Was wird passieren? Eventuell kann hier die erste Strophe (vor)gelesen werden, möglicherweise unter Weglassung der vier Reimwörter „herum“ (V. 1), „Freude“ (V. 2), ,stumm“ (V. 3), „Kreide“ (V. 4). Die Wörter sollten als Hilfestellung vorgegeben werden. 
Der Text von Heinrich Heine ist schon etwas älter. Deshalb gibt es einige Wörter, die man heute nicht mehr oder selten gebraucht. Ordnet die Wörter zu (Vorentlastung des Textes).

\subsection{Während der Rezeption}

Bei der Betrachtung des Bilderbuchs sollten Bild- und Textrezeption miteinander verzahnt werden. Zentral ist die Bereitstellung von Redemitteln zur Förderung der Äußerungskompetenz. Die Beschreibung sollte zunächst wenig gelenkt werden, erst in einem zweiten Schritt wird der Blick auf unscheinbare Details gerichtet. Die Betrachtung des Covers bildet den Ausgangspunkt. Die Lernenden beschreiben das Bild möglichst genau.

Es ist naheliegend, in diesem Zusammenhang auf die Redewendung Schmetterlinge im Bauch haben für ,verliebt sein“ einzugehen. Das Mädchen mit den braunen Zöpfen sollte genau erfasst werden (Eingangsvignette). Hier kann ein kleiner Text entstehen. Wie heißt sie? Wie kann man ibre Frisur und Kleidung beschreiben? Was tut sie gerade? Als durchlaufende Aufgabenstellung sollten die Lernenden die Figur des Mädchens im Buch verfolgen.

Die ersten fünf Doppelseiten können durch Leitfragen und Impulse erschlossen werden.

Straßenszene: Beschreibe die Personen auf dem Bild. Wie viele gehen, wie viele stehen, wie viele sitzen? Versuche jede Person kurz zu beschreiben. Redemittel: Der Junge mit der runden Mütze und den rot-grauen Chucks/ Das Mädchen mit den halblangen Haaren und der weißgelben Kappe/ Der junge Mann mit dem Rucksack und dem Holzbrett auf der Schulter etc.

Szene vor der Theaterkasse: Was bedeuten die Schilder ,Eingang' und ,Bübne??

Szene in der Garderobe: Hier ziehen sich die Schauspieler/innen um und bereiten sich auf ibre Rollen vor. Erkennst du Personen aus der Straßenszene wieder?

Auch die nächste Szene, die den noch spärlich gefüllten Zuschauerraum zeigt, kann als Übung zur Personenbeschreibung und Anwendung von Ortsangaben genutzt werden. Hier sollte der Blick auf die Details gerichtet werden: Teddybär und Roboter im Zuschauerraum, Katze auf der Bühne.

Der Vorhang geht auf: Was siehst du? Beschreibe den Gesichtsausdruck der Zuschauer/ innen. Warum ist die Perspektive, die Peter Schössow hier wählt, ungewöhnlich?

Im weiteren Verlauf kann arbeitsteilig verfahren werden. Eine Gruppe konzentriert sich auf die Beschreibung der Mimik und Gestik bzw. Haltung der Darsteller/innen, eine auf die Kostüme, eine auf die Requisiten, eine auf die Beleuchtung. Der Text wird zunächst von der Lehrperson laut vorgelesen. Bei der wiederholten Betrachtung des Bilderbuches sollten Lernende diese Aufgabe übernehmen. Der Text wird so hörbar gemacht. Die Betrachtung der Doppelseite sollte möglichst auch genutzt werden, um das Sprachmaterial des Gedichts zu reflektieren und zu kontextualisieren. Woran erkennt man, dass Hans und Grete vor Freude jauchzen? Warum ist Peter blass wie Kreide? Denkbar wäre allerdings auch, den Text bei der ersten Betrachtung komplett zu vernachlässigen und die Handlung allein aus den 
Bildern zu erschließen. Hierzu müssten eventuell noch weitere Redemittel bereitgestellt werden.

In einem zweiten Schritt sollte über die Wirkung der Bilder gesprochen werden. Hierbei kann zunächst das Publikum im Buch betrachtet werden. Wie reagiert es (gespannt, gefesselt, mitfüblend, belustigt, entsetzt, gelangweilt, unkonzentriert, hochkonzentriert), wie finden die Zuschauer/innen das Stück (spannend, lustig, traurig, tragisch, komisch, langweilig)?

$\mathrm{Zu}$ den Publikumsbildern kann auch folgende Zusatzaufgabe gestellt werden: Verfolgt die Reaktionen einzelner Personen während des Stückes: Wie verhalten sich der Roboter, der Teddybär, die swei Brüder in der Mitte der zweiten Reibe und ibre Schwester (alle in grün-grauen Hemden), der Junge ganz, vorn in der Mitte (mit grün-gerändertem Pullunder), das Mädchen mit den braunen Zöpfen?

Zur letzten Doppelseite (vor dem Theater): Erkennst du die Darsteller/innen wieder? Auf dem Bild sind zwei Rosensträuße zu sehen, auf dem Schlussbild im Theater war es nur einer. Kannst du dir erklären, woher der zweite Strauß kommt?

Anschließend sollten die Lernenden selbst ihre Bildeindrücke äußern.

Möglich sind auch sogenannte Zwischenrufe. Die Lernenden schreiben auf Post-its kleine Botschaften an einzelne Personen (Zuspruch, Kritik etc.); diese Botschaften werden dann den entsprechenden Personen im Bild zugeordnet. Als handlungsorientierte Aufgabe können einzelne Personen oder Personengruppen von den Lernenden im Raum nachgestellt werden, die anderen Lernenden erraten, um wen es sich handelt, und beschreiben die Situation.

\subsection{Nach der Rezeption}

Ausgangspunkt für die Anschlusskommunikation kann die Betrachtung der Schlussvignette sein. Zu beschreiben wären Haltung und Gesichtsausdruck des Mädchens, spekuliert werden kann über seine Gefühle und Gedanken. Als produktionsorientierte Aufgabe bietet sich das Verfassen eines inneren Monologs an, eventuell auch einer Reizwortgeschichte, die das Motiv der Rose aufgreift. Um nochmals das Theaterstück in seiner Gesamtheit in den Blick zu nehmen, könnte eine Theaterkritik oder aber ein Brief an den Künstler Peter Schössow verfasst werden. Thematisiert werden sollten auch medienspezifische Unterschiede zwischen Theateraufführung und Bilderzählung. Anschlussaufgaben ließen sich in Bezug auf die Verfasser von Text und Bildern stellen. Wer war Heinrich Heine? Suche im Internet nach weiteren Gedichten dieses Autors. Lies auch den Text, der der Geschichte vorangestellt ist (,Anfangs wollt ich fast verzagen... ). Wie verstehst du den Kommentar von Peter Schössow (,Kenn ich.')? Suche im Internet oder in Bibliotheken nach weiteren Büchern dieses Künstlers und stelle sie der Lerngruppe vor. 


\section{Schluss}

Die vorgestellten Lernmöglichkeiten lassen sich bereits ab einem Sprachstand verwirklichen, der dem Niveau B1/B2 (GeR) entspricht. Durch seine Komplexität eignet sich die Heine-Adaption von Peter Schössow aber auch für literarische Gespräche auf C2-Niveau. Das Bilderbuch kann durch seine Doppelsinnigkeit und die qualitativ hochwertige künstlerische Ausführung auch von älteren Jugendlichen und Erwachsenen genussvoll rezipiert werden. Die Verbindung von genauem Text- und Bildlesen, Hörverstehen und produktiven Verfahren fördert zentrale Bereiche des fremd- und zweitsprachlichen Lernens und verknüpft sie mit ästhetisch-theatralen Erfahrungen. Durch die dreifache Auseinandersetzung mit der Aufführung als eigenständigem Theaterkunstwerk, mit dem Gedichttext als Sprachkunstwerk sowie mit dem Bilderbuch als intermedialem Kunstwerk werden Lernende im besten Fall dazu befähigt, ihr eigenes ästhetisches Urteil aus der Reflexion heraus autonom zu formulieren und „Anschauungen [...] unter Begriffe zu bringen“ (Kant 1781: 98).

\section{Literatur}

Bergner, Heinz (Hrsg.) (1983): Lyrik des Mittelalters II. Probleme und Interpretationen. Stuttgart: Reclam.

Dehn, Mechthild (2007): Visual literacy und Sprachbildung. In: kjl \& $m$ 59, 3 , 11-20.

Dobstadt, Michael (2009): „Literarizität“ als Basiskategorie für die Arbeit mit Literatur in DaF-Kontexten. Zugleich ein Vorschlag zur Neuprofilierung des Arbeitsbereichs Literatur im Fach Deutsch als Fremdsprache. In: Deutsch als Fremdsprache 46, 1, 21-30.

Dohrn, Antje (2007): Leseförderung mit literarischen Texten im DaZ-Unterricht. Bausteine für einen integrativen Deutschunterricht. Frankfurt a.M. u.a.: Lang.

Glasenapp, Gabriele von; Weinkauff, Gina (2010): Kinder- und Jugendliteratur. Paderborn: Schöningh.

Hahn, Heidi (2010): Deutsch lernen mit Sams \& Co. In: Knapp, Werner; Rösch, Heidi (Hrsg.): Sprachliche Lernumgebungen gestalten. Freiburg i.Br.: Fillibach, 85-98.

Heine, Heinrich (1827/1975): Historisch-kritische Gesamtausgabe der Werke. Hrsg. von Manfred Windfuir, bearbeitet von Pierre Grappin. Band I/1 Buch der Lieder. Text. Hamburg: Hoffmann und Campe.

Heine, Heinrich; Schössow, Peter (2013): Der arme Peter. München: Hanser. 
Kant, Immanuel (1781/1981): Kritik der reinen Vernunft. In: Weischedel, Wilhelm (Hrsg.): Kant, Immanuel. Werke in zehn Bänden. Sonderausgabe. Band 3. Darmstadt: Wissenschaftliche Buchgesellschaft.

Koppensteiner, Jürgen (2001): Literatur im DaF-Unterricht. Eine Einführung in produktiv-kreative Techniken. Wien: öbv \& hpt.

Krenn, Wilfried (2003): Garnierung oder Hauptgericht? Überlegungen zum Einsatz literarischer Kurztexte im Unterricht Deutsch als Fremdsprache. In: Krumm, Hans-Jürgen; Portmann-Tselikas, Paul (Hrsg.): Theorie und Praxis. Österreichische Beiträge zu Deutsch als Fremdsprache 6. Innsbruck: StudienVerlag, 15-40.

Lütge, Christiane (2011): Visual literacy. Bildung durch Bilder im Fremdsprachenunterricht. In: Praxis Englisch 5, 6-8.

Paule, Gabriela (2013): Didaktik und Ästhetik des Theaters: Lesen und Verstehen theatraler Texte. In: Frederking, Volker; Krommer, Axel; Meier, Christel Erika; Huneke, Hans-Werner (Hrsg.): Taschenbuch des Deutschunterrichts. Bd. 2. Literaturund Mediendidaktik. Baltmannsweiler: Schneider Verlag Hohengehren, 161-181.

Piepho, Hans-Eberhard; Börner, Otfried; Edelhoff, Christoph (Hrsg.) (2007): Narrative Dimensionen im Fremdsprachenunterricht. Braunschweig: Schroedel/Diesterweg/Klinkhardt.

Rajewsky, Irina O. (2004): Intermedialität - eine Begriffsbestimmung. In: Bönnighausen, Marion; Rösch, Heidi (Hrsg.): Intermedialität im Deutschunterricht. Diskussionsforum Deutsch 15. Baltmannsweiler: Schneider Verlag Hohengehren, 8-30.

Rösch, Heidi (2010): DaZ im Literaturunterricht. In: Ahrenholz, Bernt (Hrsg.): Fachunterricht und Deutsch als Zweitsprache. Tübingen: Narr, 219-237.

Rösch, Heidi (2011): Deutsch als Zweit- und Fremdsprache. Berlin: Oldenbourg Akademieverlag.

Trim, John; North, Brian; Coste, Daniel (2001): Gemeinsamer europäischer Referenzrahmen für Sprachen: lernen, lehren, beurteilen. Berlin: Langenscheidt.

Weinrich, Harald (1988): Deutsch für Köpfe. In: Die politische Meinung 32, 86-91.

Zabka, Thomas (2013): Ästhetische Bildung. In: Frederking, Volker u.a. (Hrsg.) (2013), 471-487. 


\section{Anhang: Abbildungen}

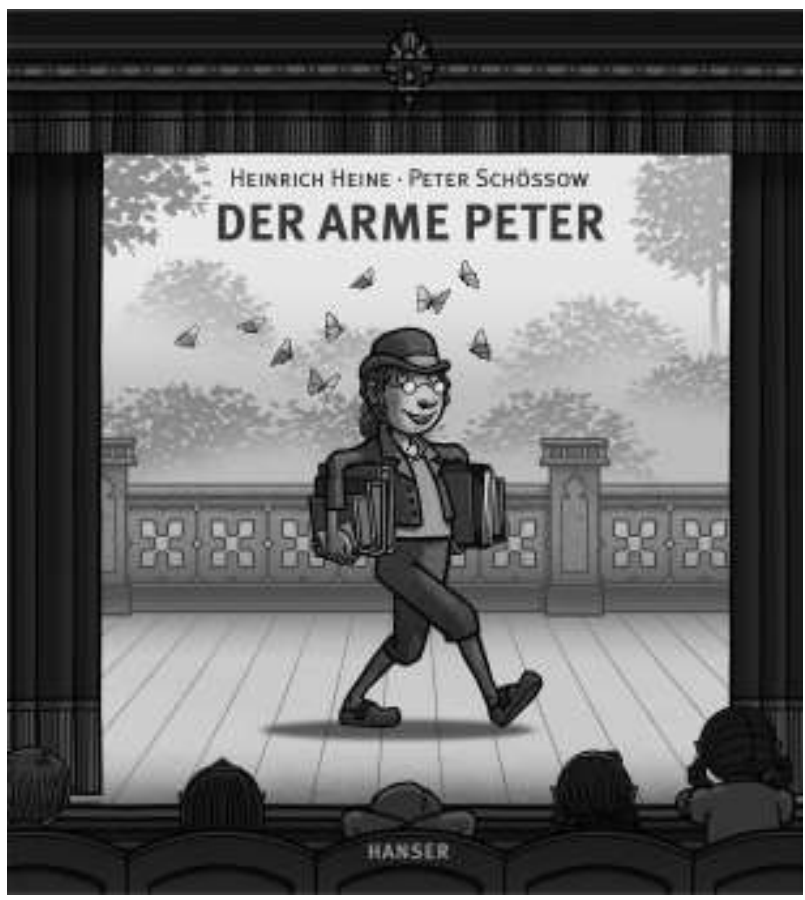

Abb. 1: Buchcover zu Der arme Peter von Peter Schössow mit frdl. Genehmigung des Autors

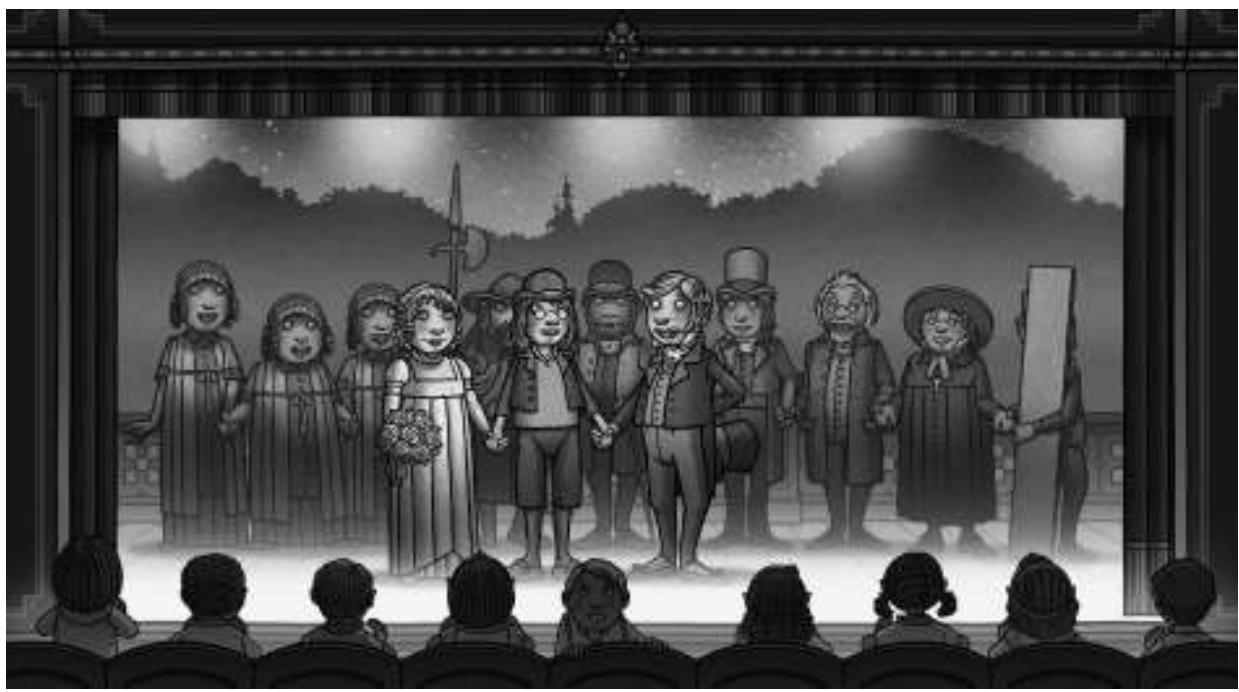

Abb. 2: Illustration aus Peter Schössows Der arme Peter mit frdl. Genebmigung des Autors 


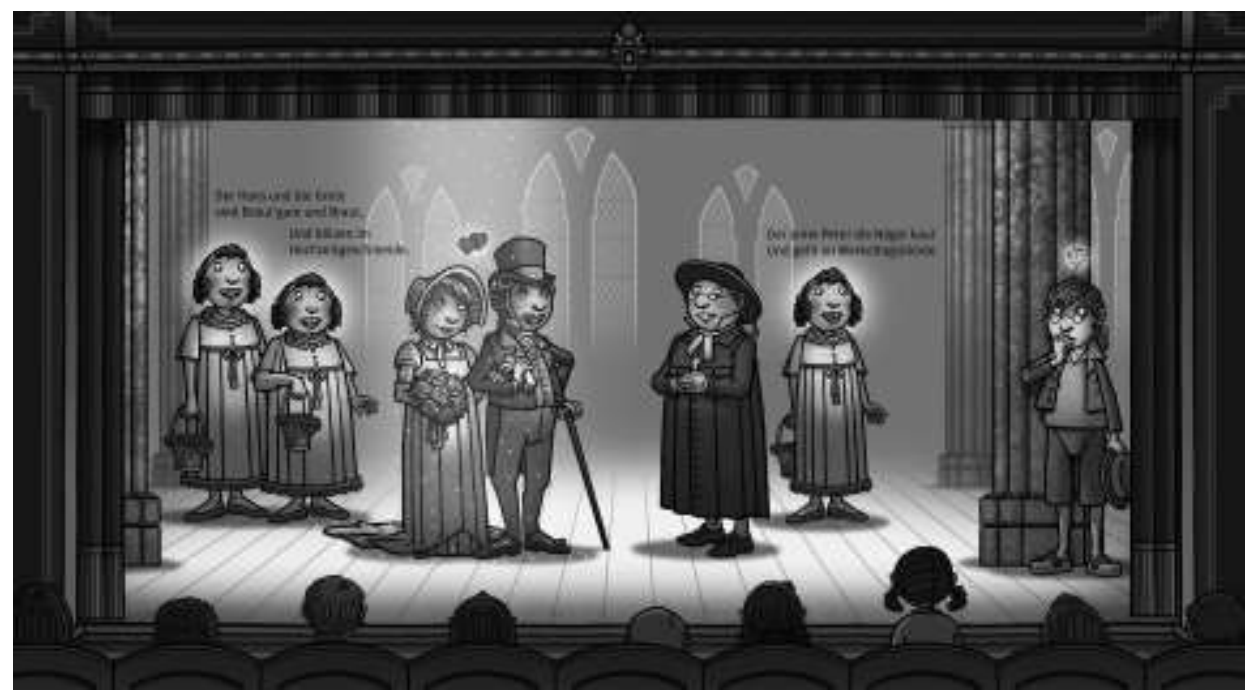

Abb. 3: Illustration aus Peter Schössows Der arme Peter mit frdl. Genehmigung des Autors 


\title{
Einfach mal dichten. Slam Poetry im Unterricht Deutsch als Fremdsprache
}

\begin{abstract}
Almut Hille \& Johann Georg Lughofer
Der Beitrag erschließt Slam Poetry als ein Text- und performance-Format, das vielfältige Anschlussmöglichkeiten für den Unterricht Deutsch als Fremdsprache bietet. Es ist im Internet und eventuell sogar auf Bühnen vor Ort immer verfügbar. Lernende können, lebendige' Texte hören, sehen, lesen, sprechen und schreiben. Sie können selbst als Autor/innen, Performer/innen, Juror/innen oder Kommentator/innen auftreten. Thematisch nebmen Slam-Texte oft aktuelle Tagesereignisse und Fragestellungen auf und kommentieren sie, verorten Themen wie Freundschaft, Liebe, Lebensentwürfe und Utopien im aktuellen Zeitgeist. Sie sind damit auch hervorragend für Prozesse golbalen Lernens - unter dem wir mit Klaus Seitz. 2002) in thematischer Hinsicht die Auseiandersetzung mit weltweiten Zusammenhängen und in methodischer Hinsicht ganzheitliche, interdisziplinäre und multiperspektivische Lernprozesse verstehen - sehr gut geeignet. Die Einsatzmöglichkeiten von Slam Poetry im DaF-Unterricht werden in diesem Beitrag mit Blick auf Lernziele und Kompetenzen diskutiert.
\end{abstract}

\section{Einleitung}

Nachdem nicht zuletzt die starke Orientierung auf Förderung sprachlicher Kompetenzen im Gemeinsamen Europäischen Referenzrahmen für Sprachen (GER) zwischenzeitlich zu einer Verengung der Perspektiven kulturellen und ästhetischliterarischen Lernens im Fremdsprachenuntericht führte (vgl. Beitrag von Dobstadt/Riedner in diesem Band), wird diesen inzwischen wieder größere Bedeutung zugemessen. Eine plurale (Persönlichkeits-)Bildung, die Ausprägung partizipativer Kompetenzen, fremdsprachige Diskursfähigkeit und in ihrem Zusammenhang die Sensibilisierung für verschiedene, auch ästhetische Sprachverwendungen 
und deren symbolische Funktionen werden als übergreifende Ziele des Fremdsprachenunterrichts definiert. ${ }^{1}$ In diesem Kontext gewinnen die kognitiven und affektiven Dimensionen literarischer Lektüre- und Schreibprozesse erneut Beachtung. Anhand literarischer Texte, die als Teil von Diskursen und nicht wie in der Fremdsprachendidaktik vielfach üblich als deren Abbildung aufzufassen sind, können Lernende die ästhetisch modellierten diskursiven Verhandlungen einer Gesellschaft erlesen und erleben. Sie können sich mit selbst verfassten und veröffentlichten Texten in sie einschalten.

Eine Textsorte, die dafür vielfältige Möglichkeiten bietet, ist Slam Poetry, die im Kontext des Faches Deutsch als Fremdsprache bislang eine erstaunlich geringe Rolle spielt. ${ }^{2}$ In Zeiten zunehmender Literaturmüdigkeit ist sie insbesondere bei jüngeren Leuten äußerst beliebt: Die 17. Deutschsprachigen Meisterschaften im Poetry Slam 2013 zogen wieder tausende Zuschauerinnen und Zuschauer an. Auf der Videoplattform youtube wurden einzelne deutschsprachige Bühnenmitschnitte von über 300.000 Usern angesehen, ${ }^{3}$ eine enorme Zahl an Videos mit Slam-Texten erreicht dort über 10.000 Klicks.

Ihre Popularität, ihre sprachlichen, performativen und inhaltlichen Merkmale lassen diese Literaturform für den Einsatz im Unterricht geeignet erscheinen: Slam Poetry bezieht in ihrer Konzentration auf Bühnenkompatibilität oftmals Alltagssprache, Interjektionen, Wiederholungen, Reime, Lautmalerei und Refrains ein, was für eine große Zahl von Übungen - von der Festigung der Aussprache bis zum generativen Schreiben ${ }^{4}$ - Anschlussmöglichkeiten bietet. Inhaltlich werden in den Texten individuelle Beobachtungen, Wahrnehmungen und Emotionen der Literaten/innen, Kommentare zu aktuellen Ereignissen und Fragestellungen auch in globalen Dimensionen präsentiert. Die Aufführungspraxis bietet hervorragende weiterführende Möglichkeiten für den Unterricht. Entsprechende methodische Überlegungen werden im Folgenden ausgeführt. Dabei wird anstelle von Unterrichtsrezepten eine Übersicht über eine größere Zahl von Texten, die für das sprachliche und kulturelle Lernen besonders geeignet erscheinen, präsentiert.

\section{Wo Jugendliche für Literatur Eintritt zahlen: Poetry Slams}

Für den Begriff Poetry Slam findet sich keine deutsche Übersetzung. Mitteralterlich oder antik anmutende Worte wie Dichterwettstreit bzw. Dichterschlacht werden zwar manchmal bemüht, können aber der aus den USA stammenden, modernen Performancepraxis keineswegs gerecht werden. Erst 1986 entstand diese Veranstal-

\footnotetext{
1 Vgl. etwa Küster 2003, Hallet 2006, Altmayer 2007 und Kramsch 2006, 2011.

2 Als erste Impulse vgl. Hille; Schönleber 2010 und Lughofer 2012.

${ }^{3}$ Online sein von Sebastian 23 zum Beispiel erreicht sogar über 350.000 Klicks (Stand: 23.9.13).

${ }^{4}$ Das generative Schreiben nach Belke 2008 meint die Verwendung eines grammatikalischen Gerüsts für eigene Texte. Also wird einerseits struktureller Halt geboten, andererseits kreativer Spielraum ermöglicht, wobei eine Verwendung spezifischer sprachlicher Strukturen gezielt gefördert werden kann.
} 
tungsform in Chicago; sie verbreitete sich in den letzten zwanzig Jahren weltweit so schnell, dass heute allein im deutschsprachigen Raum an über 80 Veranstaltungsorten regelmäßige Poetry Slams stattfinden. ${ }^{5}$ Damit ist die deutschsprachige Szene auch die zweitgrößte der Welt und so stark professionalisiert, dass eine gröBere Zahl von Künstlern/innen von den Einnahmen ihrer Auftritte, Workshops, Bühnenprogramme und Auftragsarbeiten leben kann. Zu den deutschen Größen und Gründungsvätern wie Bas Böttcher und Michael Lentz gesellen sich jüngere Kollegen wie beispielsweise Sebastian 23, Lars Ruppel, Julian Heun, Temye Tesfu, Jan Philipp Zymny und Marc Uwe Kling, darunter auch professionelle Performanceliteraten/innen wie Markus Köhle, Mieze Medusa, Stefan Abermann und Jasmin Hafedh aus Österreich oder Lara Stoll und Gabriel Vetter aus der Schweiz. Sogar ein eigener Verlag in Paderborn, Lektora, hat sich auf Slam Poetry spezialisiert. Dort und anderswo werden nicht nur Anthologien mit Slam-Texten verlegt, sondern auch Textsammlungen einzelner Slam-Künstler/innen. Den Veranstaltungen selbst ist mittlerweile der Sprung von alternativen Cafés und Musiksendern zu etablierten Medien wie ZDF, WDR, ARTE, Sat 1 und Einrichtungen der Hochkultur wie dem Admiralspalast Berlin, dem Schauspielhaus Hamburg, den Kammerspielen München oder dem Wiener Burgtheater gelungen. Das Phänomen Slam gilt als beispielhaft für die nahe Zukunft der Literatur: Es steht „paradigmatisch für eine Entwicklung des Literaturbetriebs in Richtung Popularisierung und Eventisierung“ (Porombka 2001: 20), einhergehend mit einem „Funktionswandel der Literatur für die Gesellschaft"(ebd.), hin zur Unterhaltung und Vernetzung, in der literarische Kommunikationsformen immer stärker mit Formen der Alltagskommunikation, der Wissenschaftssprache u.a. verschmelzen.

Das englische Wort slam bedeutet eigentlich schlagen, zuknallen, werfen - eine Verbildlichung der schnellen Auftrittspraxis, bei der dem Publikum ein Text zugeworfen wird, den es selbst ohne lange Reflexionsmöglichkeiten beurteilen soll. In der US-amerikanischen Alltagssprache wird slam auch für scharf kritisieren oder jemanden runtermachen verwendet, was zu den oft subversiven Texten passen könnte. Darüber hinaus bezeichnet slam im Sport auch einen Volltreffer oder ein wichtiges Turnier wie Grand Slam und dessen Sieg, was den Wettbewerbscharakter der Literaturveranstaltungen widerspiegelt.

Den großen Erfolg des Formats sichern vor allem die Offenheit und die Interaktivität der Veranstaltungen, bei denen zumeist die Zuhörer/innen die Sieger/innen küren. Dies lädt sie im Gegensatz zu klassischen Lesungen - in Slamkreisen gerne als Veranstaltungen mit Wasserglas und Leselampe abgetan - zu einem genauen Zuhören und Mitfiebern ein. Im deutschsprachigen Raum wird zumeist eine demokratische Beurteilung bevorzugt, bei der das Publikum beteiligt ist: Dies kann eine Punktewertung durch Juroren/innen aus dem Publikum oder

\footnotetext{
5 Vgl. www.myslam.net/de/ (Stand: 01.09.2013). Das Portal verzeichnet außerdem 330 Slamorte, darunter aber ebenso Lesebühnen und Einzelveranstaltungen. Auf der Slamkarte, einem Zählsystem, um in die deutschsprachigen Meisterschaften zu gelangen, werden über 130 Veranstaltungen gewertet.
} 
eine Abstimmung per Lautstärke des Applauses sein. In einzelnen Slams werden aber auch vorher ausgeteilte Rosen in die Höhe gehalten, Dichtungsringe über die jeweils dargebotenen Besenstiele der Poeten geschoben, Pfennige in beschriftete Gläser geworfen oder Wäscheklammern am Körper des auserwählten Dichters befestigt. Auf alle Fälle ist das Publikum in die Wertung maßgeblich einbezogen. Falls es - wie oft in der Heimat des Slams, den USA - eine Jury gibt, urteilt diese eher als Parodie einer konventionellen Wettbewerbsjury.

Auch über den evaluierenden Applaus hinaus ist das Publikum nicht längerfristig zur andächtigen Ruhe gezwungen. Die Länge der Beiträge darf zumeist gefüblte fünf Minuten nicht überschreiten. Entsprechend der Club-Atmosphäre kann das Publikum beim Poetry Slam durchaus Ge- oder Missfallen ausdrücken. Zweiteres ist in den deutschsprachigen Ländern jedoch kaum üblich. Doch auch im richtungsweisenden New Yorker Bowery Poetry Club erinnert die shut up-rule das Publikum daran, dass Zwischenrufe erst von der zweiten Minute der jeweiligen Auftritte an erlaubt sind.

Auch die aktive Teilnahme auf der Bühne ist bei den meisten Slams für alle Interessierten möglich. Bei einer offenen Liste kann sich jede/ $r$ vor Beginn der Veranstaltung eintragen, wobei die Reihenfolge der Auftritte ausgelost wird. Die Slammer/innen können aber genauso gut eingeladen werden. Ebenso treten Poeten/innen als Opferlamm außer Konkurrenz auf, um Publikum und Jury mit einer simulierten Wertung einzustimmen. Regeln für Texte und performance gibt es beim Slam nur wenige, aber stark fixierte: Selbstgeschriebene Texte müssen in einer bestimmten Zeit vorgetragen werden. Requisiten, Kostüme und Musikinstrumente sind nicht erlaubt. ${ }^{6}$ Die literarischen Genres und Formen variieren in Folge dieser Freiheit sehr stark - Lyrik, Rap, Kurzgeschichte, Minidramen, Kabarett- und Comedy-Beiträge sind zu erleben. Mitunter wird der Slam auf ein Thema festgelegt oder im Format variiert, zum Beispiel gibt es Dead or Alive-Slams, bei denen Autoren/innen aus der Slamszene mit ihren Texten gegen die von Schauspielern/innen vorgetragenen Texte bekannter toter Dichter/innen antreten müssen; es gibt $A c$ tionwriting, bei dem Gedichte in der Öffentlichkeit schreibend verfasst werden; Lyrikduelle, bei denen zum Beispiel zu einem Stichwort (aus dem Publikum) zwei Poeten/innen in kurzer Zeit Gedichte vortragen müssen; oder Deaf-Slams in Gebärdensprache. Auch Formate ohne Wettbewerbsdruck wie Lesebühnen und offene Bühnen, sogenannte Open Mics, haben sich durchgesetzt.

Trotz aller Unterschiede verfolgen erfolgreiche Slammer/innen die formale Grundidee, den Schwerpunkt ihrer Kunst auf den Prozess des Vortragens selbst zu legen. Dies führt zu inszenierten - geschrienen, geflüsterten oder gekeuchten Texten. Viele Poeten/innen tragen auswendig vor, was einen verstärkten Einsatz von direktem Blickkontakt, Mimik und Gestik zulässt. Es verwundert nicht, dass so gut wie allen Slam-Anthologien CDs oder DVDs beigelegt sind, damit zumin-

\footnotetext{
${ }^{6}$ Hierzu eine amüsante Erklärung auf youtube: Was ist Poetry Slam? erklärt von Felix Römer. Online: http://www.youtube.com/watch?v=nG5s2o6shZs (Stand: 05.09.2013).
} 
dest die Intonation gehört, im besten Fall die performance aber auch gesehen werden kann. Die Intermedialität dieser Literaturszene unterstreicht auch ihre Präsentation im Internet, in lebendigen interaktiven Internetportalen und Diskussionsforen, auf youtube mit Bühnenmitschnitten sowie mit Poetry Clips, einem Hybridmedium zwischen Live-Performance, Schauspiel, Verfilmung und Musikvideo, in dem die Gedichte ohne viel Aufwand verfilmt werden.

Wenn auch künstlerische Differenzen und Meinungsverschiedenheiten in der Szene herrschen und kein Manifest sie zusammenhält, besteht sie dennoch nicht ohne künstlerischen Zusammenhalt. Petra Anders (vgl. 2010: 65) verweist in diesem Zusammenhang auf die Intertextualität von Slamtexten. Die Poeten/innen beeinflussen sich durch ihre Reisetätigkeit im deutschsprachigen Raum und weltweit gegenseitig, so dass bestimmte Stilelemente und Themen immer wieder auftauchen und die Texte aufeinander Bezug nehmen. Bas Böttcher spricht vom Slamtourismus (vgl. Frederkring; Krommer 2009: 89), vom ständigen Reisen, das den intensiven literarischen Austausch der Szene - mit der Selbstbezeichnung Slamily - ermöglicht. Besonders stark ist das Phänomen der Intertextualität bei regelmäßigen lokalen Slams zu beobachten, da sich die ständig auftretenden Autoren/innen immer wieder aufeinander beziehen.

\section{Slam Poetry und Poetry Slams im Unterricht Deutsch als Fremdsprache}

Viele Vorteile der Slam Poetry für den Unterricht liegen in Zeiten des sinkenden Interesses an kanonisierter Literatur auf der Hand: Popularität, Intermedialität, Internetaffinität sowie die Möglichkeit zur Kooperation mit Slammern/innen in der eigenen Stadt. Insofern gilt die relative Reserviertheit gegenüber Slam Poetry im DaF-Unterricht schon seit längerem nicht mehr für den muttersprachlichen Deutschunterricht. Kooperationen zwischen Schule und Poetry Slam-Szene bilden sich seit mehreren Jahren heraus. Das lebendige Kulturformat stellt für junge Menschen eine im günstigen Fall mitreißende Motivation sowie einen niederschwelligen Eintritt in die Welt der Literatur dar. Die Mischform zwischen Mündlichkeit und Schriftlichkeit sowie ihre Nähe zur Populär- und Alltagskultur bieten ein großes Potenzial. So kann Slam Poetry in einer Brückenfunktion dem allgemeinen Desinteresse an Literatur entgegentreten. Darüber hinaus wird die Möglichkeit erkannt, durch Slam Poetry und verwandte Formen vermehrt die Grenzen einzelner Medien zu überwinden und den performativen Akt ins Zentrum eines Literatur- bzw. Sprachunterrichts zu stellen, der so fächerübergreifend und medienintegrativ gestaltet werden kann.

Slam wird als lebendige Vermittlungsform für Literatur vielfach an Schulen eingesetzt. Entsprechende Fortbildungen für Lehrkräfte sowie Workshops für Schüler/innen werden angeboten. Insbesondere in Projektwochen und außercurricularen Veranstaltungen wird Slam Poetry unterrichtet und mancher Slam durchge- 
führt. In mehreren Städten Deutschlands, der Schweiz und Österreichs existieren zumeist in der Nähe schulischer oder anderer pädagogischer Einrichtungen U20Poetry Slams für Teilnehmer/innen unter 20 Jahren. Seit 2004 ist U20 auch eine Kategorie der Deutschsprachigen Meisterschaften.

Von diesem Erfolg zeugt eine Reihe publizierter Unterrichtsmaterialien, welche vor allem motivierende Schreibanlässe sowie Tipps zum Vortrag und zur Organisation eines Poetry Slams bereithalten. 2007 erschien als erste umfassende Publikation in deutscher Sprache Petra Anders' Arbeitsbuch Poetry Slam. Live-Poeten in Dichterschlachten. Dieselbe Autorin gab im Reclam Verlag in der Reihe Texte und Materialien für den Unterricht die Anthologie Slam Poetry (2008) heraus. Sie war weiterhin federführend für die Ausgabe der Zeitschrift Praxis Deutsch: Poetry Slam \& Poetry Clip (vgl. Anders; Abraham 2008) tätig, in der in verschiedenen Beiträgen konkrete Ideen für den Unterricht präsentiert werden. Almut Hille und Matthias Schönleber (2009a, b) fügten dem Text-, Hör- und Filmbuch Die Poetry Slam Expedition: Bas Böttcher (Bekes; Frederking 2009) modularisierte Materialien und Arbeitsanregungen für den Literaturunterricht nebst Klausurvorschlag hinzu, welche Anschlussmöglichkeiten an kanonisierte Texte bieten: eine Kontextualisierung, die auf ein vernetztes Wissen und nicht zuletzt auf die Kompatibilität mit Rahmenlehrplänen zielt. Die erfahrene Workshopleiterin Xóchil A. Schütz gab das Lehrwerk Slam Poetry - eigene Texte verfassen und performen (2009) heraus, das sich explizit an Lehrende richtet und sich auf das persönlichkeitsfördernde Verfassen von Texten konzentriert.

Eine umfassende Übersicht zu den Möglichkeiten und dem derzeitigen Stand, die kulturelle Praxis Poetry Slam und deren Motivationspotential für den Deutschunterricht fruchtbar zu machen, legte Anders (2010) vor. Als Mitorganisatorin der Deutschsprachigen U20-Meisterschaften konnte sie für den Wettbewerb eingereichte Texte analysieren und die Poeten/innen zu Interviews treffen. In der Auswertung der Interviews belegte sie, dass sich Jugendliche vor allem mit der eigenen Person, dem eigenen Schreiben und gesellschaftlichen Problemen auseinandersetzen. Anders unterstreicht die individuelle aber auch die soziale und kulturelle Bedeutung von Slams für junge Leute. Vor allem individuelle Gratifikationen wie die ästhetische Verarbeitung des Alltags und das Finden eines eigenen Stils stehen im Mittelpunkt. Durch die Vorträge lernen die Jugendlichen, selbstbewusster und freier zu sprechen, was die mündliche Arbeit im Unterricht und die Gestaltung verschiedener Kommunikationssituationen nachweisbar fördere (ebd.: 147ff., 320ff.). Ähnliche Überzeugungen formuliert auch Alexander Willrich (2010) in seiner Übersicht zum Poetry Slam, inklusive einer sorgfältigen Auswahl von Texten nebst Unterrichtsvorschägen mit Arbeitsblättern.

Viele der erwähnten Vorteile und manche darüber hinaus können auch für den Unterricht Deutsch als Fremdsprache fruchtbar gemacht werden. Dem trugen Almut Hille und Matthias Schönleber Rechnung, indem sie zu dem genannten Band Die Poetry Slam Expedition (2010) auch Materialien für den Unterricht Deutsch als Fremdsprache herausgaben. In ihnen präsentieren sie vielfältige hin- und wei- 
terführende Übungsmöglichkeiten zur Phonetik, zum globalen Lese- und Hörverständnis, zum Wortschatz sowie zum strukturierten Schreiben.

Viele Arbeitsformen legt das Textformat Slam Poetry selbst nahe. Schon die Präsentation von Slamtexten in Lückentexten oder anderen Arbeitsvorlagen lässt sich mit dem reichhaltigen Angebot an Videos im Internet oder mit der Möglichkeit, aktive Slammer/innen einzuladen, besonders lebhaft gestalten. Slam Poetry lädt zum Weiterschreiben ein: sei es als offenes kreatives Schreiben, das zur eigenen Präsentation führt, oder als generatives Schreiben, das Belke (2008) für den Deutschunterricht fordert. Aufgrund seiner klaren Struktur und Zugänglichkeit wählten Döll, Hägi und Aigner (2012) beispielsweise den Slam-Text Jahreszeitengedicht von Clara Nielsen (vgl. Willrich 2010: 207ff.) ${ }^{7}$ als geeigneten Ausgangstext des generativen Schreibens zur diagnosegestützten Sprachförderung bei Problemen mit Satzverbindungen (vgl. Döll; Hägi; Aigner 2012: 122ff.). Für die Sprachförderung ist Slam Poetry wegen ihres Hangs zu Wiederholung und Refrain, zu Reimen und zur Onomatopöie hervorragend geeignet. Weitere für die Spracharbeit passende Textbeispiele wären Wenn alles einfach wäre von Sebastian 23, Wenn alles blau wäre von Fatima Moumoini, Wiegenlied von Markus Köhle (Medusa; Köhle 2013: 179) oder Gib mir und Sport ist... von Mieze Medusa (Medusa; Köhle 2013: 169). Sorgfältig präsentierte Beiträge wie Ich hasse das von Katja Hofman oder Verschlissen. Verschissen. Verlassen. Oder einfach ein meiner Ex gewidmeter Text mit dem Titel: Schleich di! von Markus Köhle (Medusa; Köhle 2013: 32) ermöglichen es auch, Alltagssprache mit Interjektionen und dialektalen Teilen gut zu verstehen. Manche Texte beschäftigen sich explizit mit den Schwierigkeiten beim Erlernen der deutschen Grammatik (z.B: Grummel Grammatik. Ein Kindheitstraumabewältigungstext von Markus Köhle; vgl. Medusa; Köhle 2013: 120) bzw. sind mehrsprachig (z.B. Nach dem Sturm von Fatima Moumoini), was sie für einen Fremdsprachenunterricht gut geeignet erscheinen lässt.

Slam-Texte erlauben im Unterricht Deutsch als Fremdsprache eine erfolgreiche Verbindung von sprachlichem, kulturellem und ästhetisch-literarischem Lernen, wobei auch nach der Funktion und Wirkung formaler Merkmale gefragt werden kann. Den Lernenden kann eine Form von Sprachverwendung nahegebracht werden, „die die ästhetische Dimension von Sprache sowohl (kalkuliert) nutzt als auch transparent macht und damit eine erweiterte Spracherfahrung ermöglicht" (Dobstadt; Riedner 2011: 111). Das komplexe Zusammenspiel von individuellen Beobachtungen und Erfahrungen, Textformen, (intermedialen) Präsentationen, Publikum und (spielerischer) Wertung und Konkurrenz erlaubt - auf analytischen sowie produktiven und handelnden Wegen - den Erwerb und Ausbau umfassender kommunikativer und partizipativer Kompetenzen.

In dem Sammelband Globalisierung und Gegenwartsliteratur bezeichnet Robert Stockhammer Slam Poetry (neben blogs) als eine der „typische[n] Ausprägungen

\footnotetext{
${ }^{7}$ So gut wie alle erwähnten Slamtexte sind im Internet auf der Videoplattform youtube leicht zu finden. Falls sie auch (oder in wenigen Fällen nur) in uns bekannter gedruckter Form vorliegen, wird dies angemerkt.
} 
einer globalisierten Literatur“ (Stockhammer 2010: 336), da sie schnell und im Gegensatz zu Büchern wirklich gegenwärtig sei. Sie reagiert unmittelbar auf gesellschaftliche Entwicklungen, meldet sich in diesen zu Wort, thematisiert Alltagserfahrungen und Lebensentwürfe einer jüngeren, zunehmend miteinander vernetzten Generation und korrigiert sich selbst immer wieder. Mit dieser Verfasstheit kann Slam Poetry auch zu einem Gegenstand globalen Lernens im Unterricht Deutsch als Fremdsprache werden.

Die Bezeichnung globales Lernen ist ein Sammelbegriff für verschiedene pädagogische Konzepte, die in Reaktion auf die Herausforderungen der Globalisierung in den letzten Jahrzehnten entstanden sind. Sie zielen im Gegenstandsbereich auf weltweite Zusammenhänge und die individuelle Verortung in ihnen sowie in methodischer Hinsicht auf interdisziplinäre, ganzheitliche und multiperspektivische Lernverfahren (vgl. Seitz 2002b: 10). Globales Lernen wird vorrangig als Persönlichkeitsbildung verstanden und konzipiert, orientiert an der Leitfrage „welche Fähigkeiten ein Mensch braucht, um unter den Bedingungen einer gefährdeten Weltgesellschaft ein gelingendes und zugleich solidarisches Leben führen zu können“ (Seitz 2002a: 10). Das Phänomen Globalisierung ist dabei als Prozess, der in allen Lebensrealitäten festgemacht werden kann, aufzufassen: Es

bezeichnet nicht, zumindest nicht nur, gigantische abstrakte Strukturen wie das Welthandelsregime der WTO [=World Trade Organization], die sich wie eine Käseglocke über uns stülpen. Globalisierung ereignet sich vielmehr durch jede alltägliche Aktivität, durch alles Lokale hindurch, sie vollzieht sich durch Verknüpfung konkreten lokalen Tuns (ebd.: 3).

Globales Lernen sollte also ,nicht auf eine Pädagogik der Weltprobleme reduziert werden“ (ebd.: 10), sondern eine Persönlichkeitsbildung im Welthorizont umreißen. Die ästhetische Bildung kann in ihr eine entscheidende Rolle spielen, spricht sie doch nicht nur kognitive Fähigkeiten und Grundlagen moralisch-ethischer Haltungen, sondern auch Vorstellungskraft, Emotionalität und Kreativität an. ${ }^{8}$

Werner Wintersteiner will globales Lernen zudem als Kritik an den gegenwärtigen Globalisierungsprozessen verstanden wissen bzw. als einen Beitrag zu einer , anderen' Globalisierung. In Lernprozessen solle die veränderbare ,Gemachtheit der Globalisierung bewusst werden. Er geht von der optimistischen Vorstellung aus „,(und Optimismus ist ja die Voraussetzung jeder Pädagogik), dass eine ,andere Globalisierung‘ möglich ist, dass wir, mit den Worten von Johan Galtung, die ,Globalisierung nicht als Schicksal, sondern als Projekt' betrachten sollen" (Wintersteiner 2003: 203).

Dies ist sicher möglich anhand der thematischen und performativen Konzeption vieler Slam-Texte und ihrer sozial- wie zeitkritischen Attitüde. Aktuelle Tagesereignisse werden aufgenommen und kommentiert, ewige Themen wie Freund-

\footnotetext{
8 Vgl. neben Küster 2003 auch Badstübner-Kizik 2006: 381ff. Zum globalen Lernen im Unterricht
} Deutsch als Fremdsprache vgl. auch Hille 2012. 
schaft, Liebe, Lebensentwürfe und Utopien im aktuellen Zeitgeist verortet. SlamTexte umkreisen die persönliche Positionierung und Perspektive in einer globalisierten Welt, wägen Möglichkeiten für „ein gelingendes und zugleich solidarisches Leben“ (Seitz 2002a: 10). Eine intensive Beschäftigung mit der eigenen Identität, Visionen einer nachhaltig gestalteten, zukunftsfähigen Weltgesellschaft und Prämissen für das individuelle Leben stehen immer wieder im Zentrum:

- So werden Konsumgesellschaft und Arbeitsleben in Texten wie Dran glauben, Fünffacher Wortwert, Füblothek, Nach dem Loop: Leben, Meine Paradiese von Bas Böttcher (vgl. Bekes; Frederking 2009: 16, 26, 34, 36, 44), Praktikanten von Marc Uwe Kling (vgl. Kling 2006) und Und wenn ich nur einfach nichts tue? von Nadja Schlüter thematisiert; ${ }^{9}$

- $\quad$ der respektlose Umgang mit der Natur in Alles in allem und Blumenblüten von Bas Böttcher (vgl. Bekes; Frederking 2009: 12, 32);10

- Genderfragen in Mama oder: aber nicht nur von Mieze Medusa (vgl. Medusa; Köhle 2013: 75), Wenn ich eine Frau wäre von Sarah Bosetti und Wach auf von Clara Felis;

- Migration und Xenophobie in Vorurteile oder Minderwertigkeitskomplexe von Jacinta Nandi, dem Beitrag von Fatima Moumoini bei den Poetry Slam Meisterschaft $2012^{11}$ und Ein Kanake sieht rot oder Auf der anderen Seite von Sulaiman Masomi;

- Neue Medien in Online sein von Sebastian 23;

- allgemeine Probleme der Weltgemeinschaft in Ich packe meine Koffer von Yasmin Hafedh, Jeder kann Proband sein von Kolja Reichert und Beginnen wir mit Schreibmaschinen von Ken Yamamoto.

Die Auseinandersetzung mit diesen Themen erfolgt oft in ironischer Distanzierung und mit wortgewandtem Humor, die für den Unterricht zusätzliche Herausforderungen, aber auch zusätzliches Potenzial bedeuten.

Die in methodischer Hinsicht in Konzepten globalen Lernens geforderten integrativen, ganzheitlichen, inter- und transdisziplinären Lernprozesse werden durch Slam als Literatur- und Veranstaltungsformat, das partizipatorische, kooperative, handlungsorientierte und multiperspektivische Zugänge fordert, nahegelegt.

\footnotetext{
${ }_{9}$ Arbeitsanregungen für den Unterricht Deutsch als Fremdsprache zu den Texten Dran glauben, Nach dem Loop: Leben und Meine Paradiese bieten Hille; Schönleber 2010: 30ff., 38f., 40f. Sie beziehen sich auf die Bedeutungen sprachlicher Wendungen, auf Phonetik, Wortschatzarbeit und Aspekte kulturellen Lernens.

10 Arbeitsanregungen bieten wiederum Hille; Schönleber 2010: 21ff., 26, 24f. Sie zielen zum Beispiel auf das (Weiter-)Schreiben und die Performance von Texten sowie auf das Bewerten von Texten in einer Jury.

11 Online: http://www.youtube.com/watch?v=Ts_PY-sgfM4 (Stand: 23.09.2013).
} 
Über die unmittelbare Textarbeit hinaus bietet das Ziel einer Slam-ähnlichen Bühnenpräsentation - eventuell gar vor einer gewissen Öffentlichkeit - besondere Möglichkeiten für den DaF-Unterricht. Die Textpräsentation (und mit ihr die Textproduktion) gewinnt dabei erheblich an Gewicht. Eine mehrfache Überarbeitung kann zur Selbstverständlichkeit statt zur aufoktroyierten Arbeit werden selbst für professionelle Slammer/innen bedeutet ein Vortrag nicht den endgültigen Abschluss des Schreibprozesses: Nach den Publikumsreaktionen werden weitere Modifikationen des Textes vorgenommen, für mögliche Publikationen werden die Texte immer weiter überarbeitet und liegen am Ende möglicherweise in verschiedenen Fassungen und mit unterschiedlichen Titeln vor. ${ }^{12}$ Slam ermöglicht eine Authentizität und unmittelbare Sinnhaftigkeit des Präsentierens, die sonst kaum im Fremdsprachenunterricht erreicht werden kann. Dass bei Präsentationstätigkeiten auf einzigartige Weise alle vier Fertigkeiten und Kompetenzen gebündelt und verknüpft werden, stellen Dannerer und Fandrych (2012: 4) dar. Wie andere Präsentationen, nur lebendiger und zumeist motivierter, stehen Slam-Performances im Fremdsprachenunterricht zwischen gesprochener und geschriebener Sprache, legen starkes Gewicht auf Gestik, Mimik, Körperhaltung, Bewegung, Intonation und Interaktion mit dem Publikum. Die Slam-Performance sollte nie ein reines Vorlesen werden. Wichtig ist es, in einzelnen kleinen Schritten - kurze Sequenzen und vorgefertigte Texte gemeinsam im Chor sprechen, Leseübungen in verschiedenen gespielten Stimmungen, phonetisches Training, Stimmübungen, etc. - zur Perfomance zu schreiten. Eine Angst beim Präsentieren sollte gar nicht erst aufkommen, sondern der spielerische Charakter überwiegen. Ein behutsames und differenziertes Hinführen zum eigenständigen Vortrag ist dabei essentiell. Dies kann Hand in Hand mit eigenständigen Textproduktionen passieren, wobei auch hier auf eine langsame Progression im kreativen Schreiben zu achten ist: vom Schreiben mit vorgegebenen grammatikalischen Strukturen über literarische Kleinformen (z.B. Elfchen, Haiku, Akrostichon) hin zu längeren Texten nach Inspirationen vom gesammelten Wortpool, von Bildern o.ä. Die Texte sollten zur Vorbereitung eines Slams in der DaF-Gruppe immer wieder laut vorgelesen werden, was nicht unbedingt durch den Verfassenden umgesetzt werden muss: Es erhöht zumeist den Spaß, wenn eine andere Person den Text eventuell vorher korrigiert und dann rezitiert; Diskussionen und Kommentare sollten folgen.

Die Sprachverwendung wird so nahezu vorbildlich handelnd und partizipativ umgesetzt. Die Präsentation wird nicht nur gespielt, es geht um die Mitteilung eines literarischen Textes - eventuell gar im Wettbewerbskontext. Solch ein Slam kann im Klassenverband inszeniert, doch genauso in einem öffentlichen Rahmen präsentiert werden. Die Regeln für einen eigenen Poetry Slam können in einem demokratischen Prozess selbst ausgehandelt werden. Diese eigene Festlegung von Regeln kann auch gewisse Risiken entschärfen mit Vereinbarungen wie Nach jeder

12 Vgl. zum Beispiel den Text Liebeserklärung an eine Chinesin und Kleine Einladung von Bas Böttcher in Bekes; Frederking 2009: 22f. und Hille; Schönleber 2009a: 7. 
Performance muss applaudiert werden oder Jedes Feedback nach einer Performance muss etwas Positives beinhalten.

Weiterhin werden Möglichkeiten intermedialen, auch die Medienkompetenz fördernden Lernens eröffnet, insbesondere bei den analytischen, rezeptiven und produktiven Beschäftigungen mit Poetry Clips. Hier können lyrische Muster erkannt und Textstruktur, Textaussage und filmische Mittel in Bezug zueinander gesetzt werden. Filmische Mittel wie Kameraführung und -einstellung können analysiert und in der Fremdsprache beschrieben werden. Bei der Produktion eigener Clips müssen Lösungen für die Umsetzung sprachlicher Bilder in bildliche Zeichen gefunden werden. ${ }^{13}$ Poetry Clips, die sich für den Unterricht eignen, sind zum Beispiel Alles in allem und Dran glauben von Bas Böttcher, ${ }^{14}$ Du baust einen Tisch von Nora Gomringer, Stillstand von Maximilian Humpet und Svenja Gräfen, meine generation von Sebastian 23 oder Bonn von Sebastian Krämer.

\section{$4 \quad$ Fazit und Ausblick}

Slam Poetry ist ein Textformat, das mit hohem Potenzial für Motivation und Bildungsförderung im Unterricht Deutsch als Fremdsprache eingesetzt werden kann. In Zeiten einer zunehmenden Literaturmüdigkeit bietet es als Mischform zwischen Mündlichkeit und Schriftlichkeit, durch seine Nähe zur Populär- und Alltagskultur, seine Internetaffinität und seine Intermedialität wie Intertextualität vielfältige Anknüpfungsmöglichkeiten für Lehr- und Lernprozesse. Slam-Texte und performances, die im Netz zu hören und zu sehen sind, können im Unterricht lebendig und aktuell präsentiert werden. Sie erlauben erfolgreiche Verbindungen von sprachlichem, kulturellem und ästhetisch-literarischem Lernen.

Die thematische und performative Konzeption vieler Slam-Texte legt zudem ein globales Lernen nahe. Slam Poetry reagiert unmittelbar auf Tagesereignisse und gesellschaftliche Entwicklungen, meldet sich kommentierend zu Wort, thematisiert Alltagserfahrungen und Lebensentwürfe einer jüngeren, zunehmend miteinander vernetzten Generation. In sozial- wie zeitkritischer Attitüde umkreisen viele Texte individuelle Verortungen, Lebensentwürfe und Utopien in einer globalisierten Welt. Methodisch fordert Slam als Literatur- und Veranstaltungsformat partizipatorische, kooperative, handlungsorientierte und multiperspektivische Zugänge. Die Präsentation eigener Texte - auf einer Bühne oder in Poetry Clips - ist nicht nur gespielt sondern erfolgt in einer authentischen Situation. Fremdsprachenlernende erhalten die Gelegenheit, als Autoren/innen, Performer/innen, Juroren/innen oder Kommentatoren/innen am literarischen Betrieb und damit an gesellschaftlichen Diskursen teilzuhaben.

\footnotetext{
${ }_{13} \mathrm{Zu}$ einer möglichen Schrittfolge bei der Produktion eigener Poetry Clips vgl. Hille; Schönleber 2009a: 60ff.

${ }^{14}$ Vgl. die DVD zu Bekes; Frederking 2009, Track eins und zwei.
} 
Slam Poetry kann für Literatur begeistern, auch in der Fremdsprache. Dafür stehen die Poetry Slams, die das Goethe Institut, das Österreichische Kulturforum und Pro Helvetia seit einigen Jahren weltweit in deutscher Sprache veranstalten und die in vielen Ländern zu den meistbesuchten deutschsprachigen Kulturveranstaltungen zählen.

\section{Literatur}

Altmayer, Claus (2007): Von der Landeskunde zur Kulturwissenschaft - Innovation oder Modetrend? In: Germanistische Mitteilungen 65, 7-21.

Anders, Petra (22007): Poetry Slam. Live-Poeten in Dichterschlachten. Ein Arbeitsbuch. Ilserlohn: Verlag an der Ruhr.

Anders, Petra (Hrsg.) (2008): Slam Poetry. Texte und Materialien für den Unterricht. Stuttgart: Reclam.

Anders, Petra; Abraham, Ulf (Hrsg.) (2008): Poetry Slam \& Poetry Clip. Praxis Deutsch, 208.

Anders, Petra (2010): Poetry Slam im Deutschunterricht. Aus einer für Jugendliche bedeutsamen kulturellen Praxis Inszenierungsmuster gewinnen, um das Schreiben, Sprechen und Zubören zu fördern. Baltmannsweiler: Schneider Verlag Hohengehren.

Badstübner-Kizik, Camilla (2006): Fremde Sprachen - Fremde Künste? Bild- und Musikkunst im interkulturellen Fremdsprachenunterricht. Das Fallbeispiel Deutsch als Fremdsprache in Polen. Gdansk: Wydawnictwo Uniwersytetu Gdanskiego.

Belke, Gerlind (2008): Mehrsprachigkeit im Deutschunterricht. Sprachspiele, Spracherwerb und Sprachvermittlung. Baltmannsweiler: Schneider Verlag Hohengehren.

Bekes, Peter; Frederking, Volker (Hrsg.) (2009): Die Poetry-Slam-Expedition: Bas Böttcher. Ein Text-, Hör- und Filmbuch. Braunschweig: Schroedel.

Dannerer, Monika; Fandrych, Christian (2012): ,Vorhang auf!', ,Beamer an!‘ oder einfach ,Alle mal herhören!'? Formen und Funktionen, Ansprüche und Leistungen des Präsentierens im Deutschunterricht. In: Fremdsprache Deutsch 47, 3-11.

Dobstadt, Michael; Riedner, Renate (2011): Überlegungen zu einer Didaktik der Literarizität im Kontext von Deutsch als Fremdsprache. In: Ewert, Michael; Riedner, Renate; Schiedermair, Simone (Hrsg.): Deutsch als Fremdsprache und Literaturwissenschaft. Zugriffe, Themenfelder, Perspektiven. München: iudicium, 99-115. 
Döll, Marion; Hägi, Sara; Aigner, Max (2012): Diagnose gestützte Sprachförderung in der Sekundarstufe: Profilanalyse und generatives Schreiben mit Slampoetry. In: ÖDaF-Mitteilungen 2, 115-129.

Hallet, Wolfgang (2006): Tasks in kulturwissenschaftlicher Perspektive. Kulturelle Partizipation und die Modellierung kultureller Diskurse durch tasks. In: Bausch, Karl-Richard; Burwitz-Melzer, Eva; Königs, Frank G.; Krumm, HansJürgen (Hrsg.): Aufgabenorientierung als Aufgabe. Arbeitspapiere der 26. Frühjabrskonferenz, zur Erforschung des Fremdsprachenunterrichts. Tübingen: Narr, 72-83.

Hille, Almut (2012): Globales Lernen im Unterricht Deutsch als Fremdsprache. In: DaF-Werkstatt 17-18, 59-70.

Hille, Almut; Schönleber, Matthias (2009a): Die Poetry-Slam-Expedition: Bas Böttcher. Texte, Tracks und Clips. Materialien und Arbeitsanregungen. Braunschweig: Schroedel.

Hille, Almut; Schönleber, Matthias (2009b): Die Poetry-Slam-Expedition: Bas Böttcher. Texte, Tracks und Clips. Informationen für Lehrerinnen und Lehrer. Braunschweig: Schroedel.

Hille, Almut; Schönleber, Matthias (2010): Die Poetry-Slam-Expedition: Bas Böttcher. Materialien Deutsch als Fremdsprache. Arbeitsheft. Braunschweig: Schroedel.

Kling, Marc Uwe (2006): Generation Praktikum. Online: http:/ /www.goethe.de/ges /soz/dos/arb/gpr/de1973735.htm (Stand: 23.09.2013).

Kramsch, Claire (2006): From Communicative to Symbolic Competence. In: The Modern Language Journal 90, 2, 249-252.

Kramsch, Claire (2011): Symbolische Kompetenz durch literarische Texte. In: Fremdsprache Deutsch 44, 35-40.

Küster, Lutz (2003): Plurale Bildung im Fremdsprachenunterricht. Interkulturelle und ästhetisch-literarische Aspekte von Bildung am Beispiel romanistischer Fachdidaktik. Frankfurt a.M. u.a.: Lang.

Lughofer, Johann (2012): Poetry Slam - ein ungehobener Schatz für DaF/DaZ? In: Dirim, Inci; Krumm, Hans-Jürgen; Schmölzer-Eibinger, Sabine; PortmannTselikas, Paul (Hrsg.): Theorie und Praxis. Österreichische Beiträge zu Deutsch als Fremdsprache 1. Innsbruck u.a.: Praesens, 201-214.

Medusa, Mieze; Köhle, Markus (2013): Ping Pong Poetry. Die neuen besten Slamtexte. Wien: Milena.

Porombka, Stephan (2001): Slam, Pop und Posse. Literatur in der Eventkultur. In: Harder, Matthias (Hrsg.): Bestandsaufnabmen. Deutschsprachige Literatur der neunziger Jahre aus interkultureller Sicht. Würzburg: Königshausen \& Neumann, 27-42. 
Preckwitz, Boris (2005): Spoken Word und Poetry Slam. Kleine Schriften zur Interaktionsästhetik. Wien: Passagen.

Seitz, Klaus (2002a): Globalisierung als pädagogisches Problem. Globales Lernen in Netrwerken. Online: http://www.tdh.de/fileadmin/user_upload/inhalte/11_Glo bales_Lernen/Dokumente_zu_Globales_Lernen/Globalisierung_als_paedago gisches_Problem.pdf (Stand: 04.09.2013), 1-10.

Seitz, Klaus (2002b): Bildung in der Weltgesellschaft. Gesellschaftstheoretische Grundlagen Globalen Lernens. Frankfurt a.M.: Brandes und Apsel.

Schütz, Xóchil A. (2009): Slam Poetry - eigene Texte verfassen und performen. Buxtehude: Persen.

Stockhammer, Robert (2010): und: Globalisierung, sprachig - Literatur (Gegenwart?, deutsch?) In: Amann, Wilhelm; Mein, Georg; Parr, Rolf (Hrsg.) (2010): Globalisierung und Gegenwartsliteratur. Konstellationen - Konzepte - Perspektiven. Heidelberg: Synchron Wissenschaftsverlag der Autoren, 333-352.

Westermayr, Stefanie (2010): Poetry Slam in Deutschland. Marbach: Tectum.

Willrich, Alexander A. (2010): Slam Poetry für Deutschland. Die Sprache. Die SlamKultur. Die mediale Präsentation. Die Chancen für den Unterricht. Paderborn: Lektora.

Wintersteiner, Werner (2003): Erziehung zur globalen Verantwortung. Globales Lernen als neues Paradigma der Friedenspädagogik? In: Lang-Wojtasik, Gregor; Lohrenscheit, Claudia (Hrsg.): Entwicklungspädagogik - Globales Lernen Internationale Bildungsforschung. Frankfurt a.M. u.a.: Lang, 198-207.

Wintersteiner, Werner (2006): Transkulturelle literarische Bildung. Die „Poetik der Verschiedenheit" in der literarturdidaktischen Praxis. Innsbruck u.a.: StudienVerlag. 


\title{
Der is im Herzen müd-Mimetisch-ästhetisches Lernen im gemeinsamen Deutschunterricht mit L1- und L2-Lernenden an den Beispielen der literarischen Gesprächs- und der Leseförderung
}

\begin{abstract}
Christiane Hochstadt
Der vorliegende Beitrag widmet sich dem mimetisch-ästhetischen Lernen. Dieses Lernen soll theoretisch erläutert und an Beispielen aus bestehenden deutschdidaktischen Unterrichtskonzeptionen veranschaulicht werden. An den Bereichen der literarischen Gesprächs- und der Leseförderung wird gezeigt, wie sich mimetisches Lernen als aisthetische und ästhetische Form des Lernens ideal dazu eignet, ästhetische Erfabrungen zu ermöglichen und zu versprachlichen und durch einen Zugang zu ästhetischem Lernen Sprachförderprozesse von Schülerinnen und Schülern mit Deutsch als Zweitsprache zu initiieren.
\end{abstract}

\section{Einleitung}

Menschen aller Kulturen lernen von Beginn ihres Lebens an, indem sie sich an Vorbildern orientieren. Diese Orientierung basiert auf einem mimetischen Begehren ${ }^{1}$ als menschlicher Grundfähigkeit. Kinder gehen mimetische Beziehungen zu Prozessen ein, zum Beispiel zu Handlungen von Personen. Die Grenze zwischen ästhetischen und nicht-ästhetischen Kontexten ist dabei fließend, was sich etwa in Lautspieldialogen zwischen Mutter und Kind oder in frühkindlichen Rollenspielen (vgl. Andresen 2002, 2007) zeigt.

\footnotetext{
${ }^{1}$ Der Begriff des mimetischen Begehrens wurde zuerst von Girard geprägt und wird auch von Wulf verwendet (vgl. Wulf 2001: 258).
} 
Christiane Hochstadt

Auch sprachliche Aneignungsprozesse werden weithin mimetisch vollzogen. Entsprechend lässt sich das Prinzip der Mimesis als relevanter Erwerbsmotor in Theorien des Erst- und Zweitspracherwerbs ausmachen. Besonders die interaktionistische Spracherwerbsforschung zeigt, dass die mimetische Bezugnahme wesentlich für sprachliche Aneignungsprozesse ist, was auch die Literacy-Forschung für das präliterale Vorlesen bestätigt.

Die Evidenz dafür, dass mimetisches Handeln nicht nur für weitgehend ungesteuerte Erwerbs-, sondern auch für zielgerichtete Lernprozesse zentrale Bedeutung hat, ist groß. Auch im Unterricht, so die These, tragen mimetische Beziehungen grundlegend zu sprachlichem (und nicht-sprachlichem) Lernen bei und stellen somit eine didaktische Chance auch für Sprachförderprozesse dar. Gerade für Lernende, die präliteral die entscheidenden mimetischen Prozesse in der Zielsprache nicht oder nur unzureichend vollziehen konnten, scheint ein dementsprechender Zugang elementar zu sein.

Zentrale Voraussetzungen, um mimetische Beziehungen zu begünstigen, sind meines Erachtens die Förderung ästhetischer Erfahrungen und die Schaffung entsprechender Lernkontexte in der Schule, um dem ästhetischen Lernen einen zentralen Platz im Regelunterricht und nicht nur außerhalb dessen (etwa in Arbeitsgemeinschaften) einzuräumen. Weil Mimesis und Ästhetik letztlich nicht mess- und erzwingbare und damit nur bedingt steuerbare Größen sind, kann es lediglich um das Ziel und den Versuch einer Begünstigung eines solchen Lernens gehen.

Wie die Verankerung ästhetischen Lernens aussehen kann, soll in Abschnitt 3 exemplarisch an zwei deutschdidaktischen Konzeptionen gezeigt werden, die unterschiedliche Formen mimetisch-ästhetischen Lernens anstreben. Zunächst wird in Abschnitt 2 der Begriff des mimetisch-ästhetischen Lernens theoretisch bearbeitet und das Verhältnis von Mimesis und Ästhetik erläutert.

\section{Mimetisch-ästhetisches Lernen}

Mimesis (vgl. für eine umfassende Begriffsrekonstruktion Gebauer; Wulf 1992; 2003) bezieht sich allgemein auf Darstellungs- und Ausdrucksformen menschlichen Handelns, das sich an vorgegebenen Mustern bzw. Modellen orientiert (vgl. Erhart 2000: 596). Die häufigste Vorstellung von Mimesis ist die der Nachahmung. Dabei greift mimetisches Handeln weiter: Es ist zugleich nachahmendes und kreatives Handeln. Im aristotelischen Sinne entsteht durch die Orientierung an einem mimetischen Impuls in einem schöpferischen Akt Neues, existieren zugleich Ähnlichkeit und Differenz, verschmelzen Bild und Abbild.

Als anthropologischer Grundbegriff gewinnt die Mimesis zunehmend auch in pädagogischen Kontexten an Bedeutung. Göhlich; Zirfas stellen sie als Motor des Können-Lernens dar, unter dem sie eine „reflexionslos reaktivierbare Handlungsfähigkeit“ (2007: 184) verstehen. Dieses praktische Wissen - Bourdieu (1980) spricht vom sens pratique - steht auch für Wulf im Zentrum seiner Theorie mimeti- 
schen Lernens, das definiert wird als musterorientiertes „Lernen durch Nachahmung“ (Wulf 2007: 91), das „nicht bloßes Imitieren oder Kopieren“ (ebd.) sei, sondern ein Prozess, ,in dem in der mimetischen Bezugnahme auf andere Menschen und Welten eine Erweiterung der Weltsicht, des Handelns und Verhaltens erfolgt" (ebd.). Wulf spezifiziert mimetisches als ästhetisches und soziales Lernen (vgl. 2007: 99ff.) und stellt so den engen Zusammenhang zwischen Mimesis und Ästhetik heraus, auf den bereits die Ursprünge des Mimesisbegriffs hinweisen: In vorplatonischer Zeit wird der Ausdruck Mimesis für eine bestimmte musik- und tanznahe Form des Handelns bzw. Aufführens verwendet (vgl. Else 1958: 79). Daucher (1979: 125f.) definiert Mimesis sogar als ein konstituierendes Merkmal des Ästhetikbegriffes. Als „elementare[s] menschliche[s] Bedürfnis“ (ebd.) bilde der Imitationsdrang des Menschen eine Grundlage ästhetischen Handelns. Ästhetisches Lernen steht einem rationalitätsgesteuerten Lernbegriff gegenüber (vgl. Staudte 1993: 8) und ermöglicht eine „,Wiederentdeckung' der ästhetischen Dimension der Bildung“ (ebd.). Ästhetisches Lernen beschränkt sich nicht auf die Auseinandersetzung mit Kunst, sondern schließt jegliche sinn-liche Lernprozesse mit ein. Dementsprechend versteht Welsch die Ästhetik als Aisthetik (vgl. Welsch 2003: 9). Diese Verbindung hat eine große Relevanz für die Organisation von Lernprozessen und deren Verknüpfung mit sinnlichem Lernen. Göhlich; Zirfas halten entsprechend fest: „Was und wie auch immer gelernt wird, geschieht - soweit es sich um individuelles Lernen handelt - in jedem Fall in, mit und durch den Leib“ (2007: 123).

Ich möchte mich den in diesem Abschnitt ausgeführten Positionen anschließen und ästhetisches Lernen als eine Kerndimension mimetischen Lernens verstehen. Unter den Begriff ästhetisches Lernen möchte ich Lernprozesse subsumieren, die sinnlich - also aisthetisch - motiviert sind (vgl. Kleimann 2002), auf Prozess- bzw. Phänomenstrukturen fokussieren (vgl. Welsch 2003: 10), Irritation (vgl. ebd., Seel 2004: 75) bzw. Faszination ausüben und zu mimetischer Angleichung drängen. Im ästhetischen Lernen werden ästhetische Erfahrungen gemacht und verarbeitet. Die erste Stufe ist hierbei stets die Perzeption durch objektgerichtete Aufmerksamkeit (vgl. Olsen; Blöchle 2010: 121ff.) ohne reflexive Steuerung.

Neben der ästhetischen Kerndimension sollen zwei weitere herausgestellt werden, die mit dieser ineinanderspielen und gemeinsam in einem Prozess wirksam werden: Mimetisches Lernen ist musterorientiertes und interpersonelles Lernen. Der Begriff Musterorientierung bezieht sich auf prozessuale Muster als kognitive, dynamische Einheiten (vgl. Funke 2005: 76), die als sprachliche Muster verschiedene Ebenen betreffen (z.B. die syntaktische, suprasegmentale, morphologische Ebene) und in unterschiedlichen Komplexitätsgraden auftreten können (vgl. Pracht 2010: $21 \mathrm{ff}$.$) . Die kognitiven Muster aktivieren sich bei mimetischen Prozessen, indem ein$ Mensch direkt auf ein rezipiertes Muster reagiert, quasi von diesem angesteckt wird. In geleiteten sprachlichen Lernarrangements geschieht dies in interpersonellen Prozessen. In Bezug auf diese Prozesse ist ein weiterer Begriff relevant, der des 
scaffolding (vgl. ausführlich Gibbons 2002)2 , der sich vom englischen scaffold, Baugerüst, ableitet und von Wood; Bruner; Ross (1976: 90) erstmals im Zusammenhang mit der Interaktion von Kindern mit ihren Bezugspersonen gebraucht wurde. Besonders im englischsprachigen Raum hat sich das scaffolding als grundlegendes zweitsprachdidaktisches Prinzip durchgesetzt, unter anderem durch die Monographie von Gibbons (2002). Als scaffolding-Prozesse können solche gelten, in denen ein Lernender zunächst bewusste Unterstützung durch einen Lehrenden erhält. Den Schülerinnen und Schülern wird ein Gerüst gebaut, das schrittweise wieder abgebaut werden kann (sogenanntes fading). Die Lehrkraft dient als Sprachvorbild, an dem sich die Lernenden orientieren können, die dadurch in der „Zone der nächsten Entwicklung“(Wygotski 1974: 237) zu handeln vermögen.

\section{Mimetisch-ästhetische Sprachförderung im Deutschunterricht - zwei Beispiele}

Der Begriff Sprachförderung spielt vornehmlich im Zusammenhang mit zweitsprachdidaktischen Fragestellungen eine Rolle und wird im deutschdidaktischen Diskurs in erster Linie in pragmatischen, außerästhetischen Kontexten gebraucht. Dies ist vor allem dann der Fall, wenn Sprache unter funktionalen Aspekten betrachtet wird. Ästhetische Spracherfahrungen und die poetische Funktion von Sprache (vgl. Jakobson 1972: 103ff.) bleiben dabei häufig zweitrangig. ${ }^{3}$ Ich möchte in Rekurs auf Barthes' Lust am Text (1974) von der Lust an der Sprache sprechen und dafür plädieren, einen erweiterten Begriff von Sprachförderung zu etablieren, der mimetisch-ästhetisches Lernen in Bezug auf Prozesse des Sprechen-, Zuhören-, Lesen- und Schreibenlernens einschließt und die Förderung sprachlicher Fähigkeiten an ästhetisches Handeln knüpft, womit gleichrangig neben produktivem rezeptives Handeln gemeint ist. Im Folgenden wird anhand zweier Ansätze - zum Sprechen und zum Lesen -, die Formen mimetisch-ästhetischen Lernens konzeptionell verankert haben, verdeutlicht, wie eine solche Sprachförderung im weiten Sinne aussehen kann. Im Rahmen der ersten Darstellung zum literarischen Gespräch soll an einem Transkriptauszug veranschaulicht werden, wie eine Ästhetisierung von Lernsituationen sich positiv auf das sprachliche Lernen von Schülerinnen und Schülern mit Deutsch als Zweitsprache auswirkt und Sprachförderung auch dort vollzogen werden kann, wo sie nicht explizit im Vordergrund steht. Die zweite Darstellung soll aufzeigen, wie mimetisch-ästhetische Prozesse auch beim Lesenlernen wirksam werden können.

\footnotetext{
2 Vgl. ebenfalls Kniffka; Siebert-Ott 2009: 9.

${ }^{3}$ Vgl. aber Belkes z.B. 2012 vorrangig auf Zweitsprachlernende ausgerichtete Konzeption eines integrativen Sprachunterrichts, der starke mimetisch-ästhetische Elemente enthält.
} 


\subsection{Mimetisch-ästhetisches Lernen, Sprachförderung und Literatur: Das Heidelberger Modell des Literarischen Unterrichtsgesprächs}

Im Zusammenhang mit literarischem Lernen kommt den Begriffen Mimesis und Ästhetik innerhalb der Deutschdidaktik immer wieder eine basale Rolle zu (z.B. Abraham 1996: 173ff., Ortner 1996: 89). Die jüngste umfassende Einbettung mimetisch-ästhetischen Lernens in konzeptionelle Überlegungen zum literarischen Lernen wird im Heidelberger Modell des Literarischen Unterrichtsgesprächs (vgl. Härle; Steinbrenner 2010; Steinbrenner 2010a und 2010b, Steinbrenner; Mayer; Rank 2011) geleistet. Mit dem Heidelberger Modell liegt ein literaturdidaktischer Ansatz vor, der auf der Grundlage verschiedener Bezugstheorien, u.a. der Hermeneutik, der Dekonstruktion, der Bruner'schen Spracherwerbstheorie und der Themenzentrierten Interaktion, eine Gesprächsform/-auffassung über Literatur ${ }^{4}$ vertritt, die u.a. (vgl. im Folgenden Steinbrenner; Wiprächtiger-Geppert 2010: 4ff.)

- $\quad$ eine Alternative zum traditionellen, stark gelenkten, fragend-entwickelnden Unterrichtsgespräch darstellt,

- $\quad$ die Verständigung über unterschiedliche Lesarten eines Textes fördert,

- Verstehen als gesprächsförmigen Prozess, als „,inneres Selbstgespräch, als Gespräch mit einem Text und als Gespräch mit einem realen Gegenüber“ (ebd.: 2) begreift,

- Irritation und Nichtverstehen als literaturdidaktische Zielsetzungen etabliert,

- Verstehens- bzw. Nichtverstehensprozesse als unabschließbar charakterisiert (Kein endgültiges $W_{\text {ort }}^{5}$ )

- den literarischen Text und seine Sprache mimetisch nachvollziehen lässt.

Im letzten Punkt werden mimetisch-ästhetische Angleichungsprozesse in Form des mimetischen Sprechens (vgl. ausführlich Steinbrenner 2009, 2011) betont. Mimetisches Sprechen wird unter anderem als expressiv, affektiv und sinnlich, also als aisthetisch, charakterisiert. Im mimetischen Sprechen werden also ästhetische Erfahrungen zugleich kommuniziert und erzeugt. Steinbrenner betont, dass es dabei nicht um einen pragmatisch-instrumentellen Sprachgebrauch gehe (vgl. Steinbrenner 2009: 657). Dieser Aspekt ist gerade für Lernende mit Deutsch als Zweitsprache entscheidend. Mimetisches Sprechen gibt die Möglichkeit, sich „,suchend, fragend, tentativ“ (ebd.: 656) - das heißt auch, ohne Druck, ohne normative Sprech-

\footnotetext{
${ }^{4}$ Literarische Gespräche beschränken sich nicht auf die Auseinandersetzung mit gedruckten Texten. Auch im Zusammenhang mit theatralen Texten spielt mimetisches Sprechen eine Rolle - vor allem im Rahmen von anschlusskommunikativen Prozessen (vgl. dazu Olsen 2010, 2011). Das scaffoldingPrinzip ist auch hier zentrales Prinzip, um Sprachförderprozesse zu initiieren und zu begleiten. Ein didaktisches Stufenmodell in Bezug auf rezeptive ästhetische Erfahrungen im Theater liegt mit Olsen; Blöchle 2010 vor.

${ }^{5}$ Kein endgültiges Wort (Härle; Steinbrenner 2010) ist der Titel des ersten Sammelbands, mit dem das Heidelberger Modell begründet wurde.
} 
vorgaben - zu äußern und zugleich eine sprachliche Orientierung, ein Gerüst ${ }^{6} \mathrm{zu}$ finden im Text und in den Äußerungen der anderen Gesprächsteilnehmerinnen und -teilnehmer. Beim mimetischen Sprechen fließen Elemente des literarischen Textes, über den gesprochen wird, in das eigene Sprechen einer Gesprächsteilnehmerin/eines Gesprächsteilnehmers ein (vgl. Steinbrenner 2009: 656).

Dass das mimetische Sprechen eine Brücke für Schülerinnen und Schüler mit Deutsch als Zweitsprache darstellen kann, wird im folgenden Auszug ${ }^{7}$ einer Unterrichtsstunde gezeigt. Eine vierte Klasse bespricht mit einer studentischen Praktikantin das Gedicht Der Panther von Rainer Maria Rilke. Die Studentin bezieht sich in ihrer schriftlichen Unterrichtsplanung zwar auf das Heidelberger Modell, räumt dem Gespräch in der Stundenverlaufsskizze aus Unsicherheitsgründen in Bezug auf das Gelingen eines solchen Gesprächs aber nur zehn Minuten ein (die tatsächliche Zeit betrug dann 13,51 Minuten). ${ }^{8}$

$\mathrm{L} \quad$ mich hat des gewundert als da das wort kraft stand. ging es euch auch so? maya

S1 ja aber ein PANther.. der is . hat ja kraft der is ja. ähm ein STARkes tier [L: ja] und ähm die kraft geht ja net weg

S2 nee aber sie meint weil der EINgesperrt is da im ZOO

S1 ((genervt)) ich WEISS mann

L ((berubigend)) tabea..

S3 ((laut zu S4)) (ey) voll so gegen die STÄbe boxen . ich will RAUS!

S4 ((lacht)) (muskeln)

S5 ((zieht das [ae] theatralisch lang und verstellt seine Stimme)) ST Äbe Gäbe .. ((sehr viel leiser)) stäbe gäbe . reim

L ok tabir

S5 für dem is langweilig da in sein käfig der will lieber rennen in die welt .. der is im berzen müd. traurig

L $\quad$ ja.. GUT.. maya

S1 derpanther ist halt . also so MÜD geworden dass er nichts/ dass er die kraft nicht

\footnotetext{
${ }^{6}$ Auch beim mimetischen Schreiben in Form von Nacherzählungen wirkt sich die Orientierung an einem Gerüst positiv auf die Leistungen von Schülerinnen und Schülern mit Deutsch als Zweitsprache aus. Dass dies nicht nur für den lexikalischen, sondern u.a. auch für den flexionsmorphologischen und syntaktischen Bereich gilt, wird in Hochstadt 2014 dargelegt.

${ }^{7}$ Hinweise zur Transkription:

. - kurze Pause

.. $\quad$ - längere Pause

(5sec) - Pause von 5 Sekunden

fin/ - Wort- oder Konstruktionsabbruch

STÄbe - betonte Silbe

(ey) - vermuteter Wortlaut

(...) - unverständliche Äußerung

$((\ldots))$ - Zusatzinformationen

[...] - Unterbrechung durch andere/n Gesprächsteilnehmer/in

8 Steinbrenner; Wiprächtiger 2010: 7 empfehlen in ihren Vorschlägen zum Gesprächsrahmen für ein literarisches Gespräch etwa 30 Minuten.
} 
mehr halten kann und sein wille is wie betäubt und des is auch mit der keraft so

S6 haja der will raus und der hat ge/ der denkt ich will $\mathrm{R} A U S$ und ich darf nich und es gibt keine welt mehr hinter den stäben und. ähm . er hat nur so stille .. und stäbe vor sein gesicht er fin/ fühlt.. wie betäubt

L ja ibr habt tolle sachen gesagt. aber adnan du hast grad gesagt dass/ was denkst du was betäubt bedeuten könnte?

S6 balt betäubt halt .. keine AHnung. kein kraft tausend stäbe keine welt mehr .. so wie er wär tot

Mit ihrer Äußerung stellt die Lehrerin ein Element aus dem Text, das Wort Kraft, in den Mittelpunkt. Gleichzeitig verbalisiert sie ihre Irritation und fordert die Schülerinnen und Schüler indirekt auf, zu diesem expressivem Sprechakt Stellung zu nehmen. Sie provoziert damit eine Auseinandersetzung mit dem Text, deren mimetischer Charakter zunehmend deutlich wird. Exemplarisch möchte ich das an den Äußerungen der Schüler 5 und 6 verdeutlichen:

Schüler 5, Tahir, der bis dahin keinen Gesprächsbeitrag geäußert hat, reagiert auf den Nebendialog zwischen den Schülern 3 und 4. Er spricht das Reimpaar Stäbe und gäbe spontan und scheint Gefallen daran zu haben. Nach einer kurzen Pause wiederholt er die Textelemente leise für sich. Offensichtlich tritt zur intuitiven Auseinandersetzung nun ein reflexives Moment: Der Schüler klassifiziert die Wörter, deren Klang für ihn offenbar eine ästhetische Erfahrung ist, für sich als Reimpaar. Die Studentin geht auf diese Äußerung nicht explizit ein, wird aber auf den Schüler aufmerksam und fordert ihn indirekt auf, weiterzusprechen. Zunächst antwortet der Schüler, was sich wie eine indirekte Begründung für die Äußerung von S3 liest. Dann formuliert er einen Gedanken, in dem er die Sprache des Textes zu seiner eigenen, einer neuen macht. Es gelingt ihm dadurch nicht nur, eine ÄuBerung zu formulieren, in der er den Kasus flexionsmorphologisch richtig kennzeichnet (Herzen), sondern er bringt durch die Zusammenführung zweier Textausschnitte (Herzen, müd) und seiner Erweiterung durch das Attribut traurig eine neue Bedeutungsdimension ins Gespräch ein. Die Studentin verpasst es an dieser Stelle, das mimetische Sprechen des Schülers aufzunehmen, daran anzuknüpfen und Tahir darin weiter zu fördern. Sie hätte ihn auf mehreren Wegen zu einer vertieften Auseinandersetzung mit dem Text und seinem eigenen Gesprächsbeitrag motivieren können: zum Beispiel durch Nachfragen (Wie meinst du das? W as macht deiner Meinung nach sein Herz müde und traurig?), durch eigene Gesprächsbeiträge oder durch den Bezug auf Beiträge anderer Teilnehmerinnen und Teilnehmer (Hat das für dich etwas damit zu tun, was S1 vorhin gesagt hat - dass die Kraft nicht weggeht?). Darüber hinaus hätte sie unterschiedliche Lesarten thematisieren können (Gibt es Textstellen, die deiner Auffassung widersprechen?).

Schüler 6, Adnan, ein Lerner mit Deutsch als Zweitsprache, übernimmt zunächst den Perspektivenwechsel, den Schüler 3 vollzogen hat (ich will raus), und wiederholt dessen Worte. Aus diesem Wechsel heraus baut er die Expressionen und Gedanken des Raubtieres in eigenen Worten aus und versucht, sie zu verbali- 
sieren. Im zweiten Teil seiner Äußerung bezieht er sich stärker auf den Text, was sich vorrangig lexikalisch zeigt (Stille, Stäbe, betäubt). Als die Lehrerin ihn schließlich bittet, zu erklären, wie betäubt zu verstehen sei, greift der Schüler auch hier wieder auf den Text zurück, sozusagen als Brücke, bevor er eine eigene Paraphrase, nämlich wie tot, hinzufügt. In seiner Äußerung zeigt sich aber noch etwas, was bereits in Tahirs Gesprächsbeiträgen deutlich wurde: Adnan bleibt dem Text nicht äußerlich, er verleibt ihn sich ein, geht mimetische Beziehungen zu ihm und darüber hinaus zu einem anderen Gesprächsteilnehmer (S3) ein. Die ästhetische Sprache des Textes hat eine große Anziehungskraft, sodass sie gleichsam immer wieder hineinfließt in das Sprechen der Lernenden. Sie dient als Gerüst und zugleich als Möglichkeit, sich von ihr abzusetzen.

Steinbrenner; Wiprächtiger-Geppert (2010: 1) betonen, dass das Heidelberger Modell „für eine bestimmte Haltung gegenüber den Schülern, dem Text und dem Gespräch steht“". Von dieser Haltung können Lernende mit Deutsch als Zweitsprache profitieren, ohne dass ein literarisches Gespräch auf eine Sprachfördermethode beschränkt und ihm sein ästhetischer Charakter genommen wird.

\subsection{Mimetisch-ästhetisches Lernen, Sprachförderung und Lesen: Lautleseverfahren}

Ein anderer Weg mimetisch-ästhetischen Lernens wird innerhalb der Lesedidaktik als Teil sogenannter Lautleseverfahren beschritten. Mit diesem Terminus werden Maßnahmen bezeichnet, die die Förderung der Leseflüssigkeit, der reading fluency, zum Ziel haben. Sogenannte hierarchieniedrige Leseprozesse, die die

Lesefähigkeit bei der Worterkennung, der Verbindung von Wortfolgen im Satzzusammenhang und bei der Herstellung von Relationen zwischen den einzelnen Sätzen (Rosebrock; Nix 2012: 27)

betreffen, stellen u.a. besonders für Lernende mit Deutsch als Zweitsprache, die über einen vergleichsweise geringen aktiven und passiven Wortschatz verfügen, eine Schwierigkeit dar. Durch die Förderung der Leseflüssigkeit wird der Grundstein für hierarchiehöhere Verstehensleistungen gelegt (z.B. Herstellung globaler Kohärenz, inhaltliche Gesamtvorstellung, Entschlüsselung rhetorischer, stilistischer und argumentativer Strategien, vgl. ebd.: 12ff.), die wiederum Voraussetzung sind für erfolgreiches Handeln in allen Schulfächern. Die Forschung hat zudem gezeigt, dass sich Vorlesen und damit auch die Lautleseverfahren positiv auf den Wortschatzerwerb9 auswirken (vgl. z.B. Elley 1989, Nix 2007, Nix 2011: 109, Birkle 2012: 56ff.).

\footnotetext{
${ }_{9}$ Ein spezifisch für Lernende mit Deutsch als Zweitsprache konzipierter Ansatz zur Wortschatzförderung ist das so genannte Robuste Wortschatztraining (vgl. Kurtz 2012), bei dem ebenfalls ästhetisches Handeln (z.B. das laute Rufen zu lernender Wörter) ein Teil des Konzepts ist.
} 
Inzwischen liegt eine große Anzahl an unterschiedlichen Lautleseverfahren vor, die sich jedoch zwei Grundformen zuordnen lassen: dem wiederholten Lautlesen und dem begleitenden Lautlesen.

Die Grundidee des wiederholten Lautlesens ist, dass

Schüler(innen), die nicht flüssig lesen können, [...] einem Tutor einen kurzen, für sie mittelschweren Text so lange immer wieder laut vor[lesen], bis sie einen zuvor festgelegten Standardwert an gelesenen Wörtern pro Minute erreicht haben (Rosenbrock; Nix 2012: 37).

Zahlreiche methodische Verfahren werden im Rahmen des wiederholten Lautlesens vorgeschlagen, die möglicherweise ästhetische Erfahrungen begünstigen können. Hier sei neben Vorlesearrangements für jüngere Schülerinnen und Schüler oder der Erstellung eines Hörbuchs vor allem das Verfahren des Lesetheaters genannt, wobei besonders auf die phonetische und expressive Seite des Vorlesens fokussiert wird. Beim Lesetheater werden aus epischen Vorlagen dramatische LeseScripts erstellt, die von den Lesenden wiederholt in der Gruppe geübt und klanglich inszeniert werden - immer mit der Zielsetzung, den Text für die Zuhörenden „möglichst bildhaft und einprägsam, eben ,lebendig““ (ebd.: 38) vorzutragen. Die Schülerinnen und Schüler erfahren den Text also wiederholt sinnlich-sprecherisch und machen ihn in interpersonellen Prozessen zu einer Erfahrung für Zuhörende, wobei eine aufmerksame Haltung von Sprechenden und Zuhörenden dem Vorleseprozess gegenüber durch den theatralen Rahmen unterstützt werden kann.

Der interpersonelle Aspekt spielt auch und besonders beim begleitenden Lautlesen die zentrale Rolle. Ein/e Schüler/in, der/die weniger gut liest (der/die Tutand/in), bildet mit einem/er stärkeren Leser/in (einem/er Tutor/in) ein LesePaar, auch Lese-Tandem genannt. Beide lesen - dicht beieinander sitzend - synchron, wobei der/die Tutor/in als Lesemodell fungiert, das „den Lesefluss des Schwächeren unterstützend begleitet" (ebd.: 39). Der/Die Tutor/in kann, dem scaffolding-Prinzip gemäß, im Leseprozess mehr oder weniger stark die Führung übernehmen. Wenn er/sie merkt, dass sein/ihr Partner/in sicherer wird, kann er/sie sich beispielsweise durch leiseres Lesen oder durch Aussetzen zurückhalten und bei Bedarf unterstützend eingreifen. ${ }^{10}$

\footnotetext{
10 Beim begleitenden Lautlesen (vgl. im Folgenden Rosebrock; Nix 2012: 39ff.) werden die LeseTandems auf der Grundlage der Ergebnisse eines Lesegeschwindigkeitstests von der Lehrkraft eingeteilt und die Rollen des Tutors/der Tutorin und des Tutanden/der Tutandin fest bestimmt. Für eine Einheit des begleitenden Lautlesens sind etwa 20 Minuten vorgesehen - das Training erfordert hohe Konzentrationsleistungen. Motivationale und soziale Schwierigkeiten können durch methodische Variationen abgefangen werden. Beispielsweise kann dem Lese-Training ein sportlicher Charakter verliehen werden, indem der Tutand bzw. die Tutandin die Rolle des Lese-Sportlers/der LeseSportlerin und der Tutor/die Tutorin die des Lese-Trainers/der Lese-Trainerin einnimmt. Der dahinterstehende und den Schülerinnen und Schülern zu vermittelnde Grundgedanke ist, dass LeseSportlerinnen und -Sportler ein kontinuierliches Training für die Leistungssteigerung brauchen. Zahlreiche empirische Untersuchungen zum begleitenden Lautlesen zeigen positive Effekte sowohl in Bezug auf die Leseflüssigkeit als auch auf das Textverstehen der Schülerinnen und Schüler (vgl. zusammenfassend ebd.: 42f.).
} 
Beide Formen sollen im vorliegenden Beitrag als mimetisch-ästhetisches Lernen interpretiert werden. In Anlehnung an den Begriff des mimetischen Sprechens möchte ich dafür den Begriff des mimetischen Lesens verwenden. Besonders das begleitende Lautlesen ist durch die interpersonelle Nähe, durch das Aufeinanderbezogensein in synchronen Prozessen auf mimetische Angleichung angewiesen. Die Lesenden können diese Angleichung als etwas Ästhetisches im Sinne eines Flow-Effekts erfahren, womit der Zustand bezeichnet wird,

in dem ein Mensch in seiner Tätigkeit aufgeht, in dem er so konzentriert ist, dass er sich selbst vergisst, mit der Umwelt verschmilzt und sich schließlich in neuer Form, selbsterweitert, sozusagen als Gelernt-Habender aus dem Geschehen herausgehoben, erfährt, was ein Gefühl des Glücks mit sich bringt (Göhlich; Zirfas 2007: 123). ${ }^{11}$

An einem weiteren Beispiel aus der Praxis, einem Transkriptauszug aus einem Interview mit dem Sechstklässler Fatih, soll verdeutlicht werden, wie der Schüler versucht, seine Erfahrungen mit dem Lesetandem zu verbalisieren. Er hatte zuvor neun Schultage lang einen Text in kurzen Lautlesetrainings mit seinem Tandempartner geübt. Ziel war die Aufführung als Tandemlesung auf einer Klassenzimmerbühne mit zwei Stellwänden. Die Schülerinnen und Schüler stellten sich auf Stühle - einer hinter die linke und einer hinter die rechte Stellwand -, sodass man sie nur bis zur Brust sehen konnte. An jeder der Stellwand wurde ein Mikrofon angebracht. Zugeschaut haben sowohl die eigene als auch die Parallelklasse. Insgesamt lasen sechs Lesetandems an diesem Tag ihre geübten Texte vor.

L also du hast jal mir ja mal gesagt dass du nicht magst wenn andere ZUbören wenn du vorliest .. jetrt war das ja $n$ bisschen anders mit dem the Ater und so und dass ibr/ dass du so viel üben konntest. aber du hast ja jetzt trotzdem vor ANdern geLEsen und jetzt würd mich interessieren was fürn geFÜHL das war und welches/ was du dazu sagst zu dem ganzen. wie das für dich war

$\mathrm{S} \quad$ baja des war schon voll krass mit zuschauer und so aber ich bin/ da warja die WAND und die haben nur mein kopf gesehn

L aber gebört hat man dich ganz ((lacht)) und du hast SEHR GUT gelesen

$\mathrm{S} \quad((\mathrm{klopft}$ sich theatralisch auf die Schulter)) bin champion

$\mathrm{L} \quad$ wie war das für dich dauernd mit dem artur zu lesen?

$\mathrm{S} \quad$ gut $\cdot j a \cdot g u t$

$\mathrm{L} \quad$ hat das am ende BESser geklappt als am anfang?

$\mathrm{S}$ weißnet

$\mathrm{L} \quad$ und in der aufführung?

$\mathrm{S} \quad$ da war ich net allein des war irgendwie gut weil ich hab gedacht wenn ich fehler mach dann merk.t des die leute net .. des wort. museumsaufsicht da hab ich immer FALSCH gelesen bei'n üben und da hab ich dann gelb gemacht auf den zettel und jetrt kann ich gut sagen des wort . auch gefühlsduselei

\footnotetext{
11 Vgl. dazu auch die Strukturmomente ästhetischer Erfahrungen nach Peez 2005: $14 f$.
} 
L damit du dran denkst. hast du's gelb gemacht mein ich .. [S: ja] hat dich das gar nicht gestört dass da noch ein zweiter gelesen hat? hat dich das nicht rausgebracht?

$\mathrm{S} \quad$ ich weiß net des war auch weil der raum mit mikeroFON und so des war voll geil .. des war dann so wie arturs stimme meine is .. oder beide sind eine stimme

$\mathrm{L} \quad$ hast du deine stimme noch gut gehört?

$\mathrm{S} \quad$ manchmal. wenn artur ein wort früher gesagt hat dann mehr aber irgendwann hab ich des nimmer gemerkt

Interessant für den vorliegenden Beitrag sind insbesondere die letzten drei Äußerungen des Schülers. Zunächst betont Fatih den unterstützenden und damit psychisch entlastenden Wert des gemeinsamen Lesens. Er drückt darüber hinaus aber auch seinen Lernfortschritt, sein Können ganz konkret am Beispiel zweier Textelemente aus, die er bei der Aufführung (und auch im Interview) fehlerlos ausgesprochen hat. Anschließend bewertet Fatih das mikrofongestützte Sprechen positiv, das für ihn, wie später im Interview deutlich wurde, die erste Erfahrung mit einem Mikrofon war. Offenbar beschäftigten ihn die phonetischen und proxemischen Eindrücke - sie waren für ihn im Rahmen des Vorleseprozesses eine ästhetische Erfahrung. Was Fatih dann versucht auszudrücken, deute ich als die oben mehrfach erwähnte Verschmelzung im mimetischen Prozess - des war dann so wie arturs stimme meine is .. oder beide sind eine stimme. Er hört seine Stimme verbunden mit der seines Lesepartners. Am Ende fügt er hinzu, dass ihm das punktuell mögliche Aufmerksamwerden auf seine eigene Stimme im Laufe des Leseprozesses nicht mehr bewusst gewesen sei. Im Tandemlesen hat Fatih einen mimetischen Angleichungsprozess vollzogen, der ihn nicht nur psychisch unterstützt, sondern ihm deutlich gesteigerte Vorleseleistungen ermöglicht hat.

\section{Zusammenfassung und Schluss}

Konzeptionen von Deutschunterricht, die sich auf Lernende mit Deutsch als Erstsprache beschränken, werden der Realität nicht gerecht (vgl. Granzow-Emden 2008: 2). Für den Regelunterricht sollten sich Lernprinzipien etablieren, die auf Grundfähigkeiten von Lernenden rekurrieren und die sich für den gemeinsamen Unterricht von Schülerinnen und Schülern mit Deutsch als Erst- und Deutsch als Zweitsprache eignen. Mimetisch-ästhetisches Lernen kann als ein solches Lernprinzip gelten. In mimetischen Prozessen liegt eine Chance, Angleichungs- und gleichzeitig Alteritätserfahrungen zu ermöglichen und darüber hinaus unterstützend wirksam zu sein und Handlungsfähigkeit zu fördern. Das scaffolding-Prinzip, das hier als Form der Mimesis interpretiert wurde, ist wesentlicher Teil dieser Unterstützung und des mimetisch-ästhetischen Lernens. Es findet bisher vornehmlich in außerästhetischen Sprachlernkontexten Bedeutung. In diesem Beitrag wurde dafür plädiert, das Potential von scaffolding-Prozessen auch für ästhetisches Lernen zu erkennen. 
Die Etablierung mimetisch-ästhetischer Lernformen erfordert unter anderem,

- dass Sprache immer auch aus ästhetischer ${ }^{12}$, nicht nur aus pragmatischer oder funktionaler Perspektive betrachtet wird,

- dass interpersonellen Prozessen, auch zwischen Lehrenden und Schülerinnen und Schülern, Raum gegeben wird, und die Lehrenden scaffoldingProzesse angemessen begleiten,

- die Provokation von Irritation und Verfremdung,

- die Akzeptanz von Nicht-Verstehen (in Bezug auf interpretative Sinnzuschreibungen) in literarischen Gesprächskontexten und dessen Nutzung für weitere sprachliche Auseinandersetzungen mit dem Text und fremden Gesprächsbeiträgen,

- $\quad$ eine positive Neubewertung der Prinzipien Übung und Wiederholung und deren ästhetischen Werts,

- die Förderung rezeptions- und musterorientierten Handelns und

- die Ablehnung einer funktionalistischen Sicht auf die Schülerinnen und Schüler.

Wo mimetisch-ästhetisches Lernen sprachliches Lernen ermöglicht, da ermöglicht es gleichzeitig - und darin liegt seine zentrale Bedeutung für heterogene Lernergruppen - ein interpersonelles, sprachübergreifendes (und bisweilen auch sprachfreies!) Lernen in ästhetischen Erfahrungen. Unterschiedliche soziale, sprachliche oder kulturelle Lernvoraussetzungen können so für Unterrichtsprozesse bereichernd und nicht hinderlich sein. Darin liegt ihre große didaktische Chance.

\section{Literatur}

Abraham, Ulf (1996): StilGestalten: Geschichte und Systematik der Rede vom Stil in der Deutschdidaktik. Tübingen: Niemeyer.

Andresen, Helga (2002): Interaktion, Sprache und Spiel: Zur Funktion des Rollenspiels für die Sprachentwicklung im Vorschulalter. Tübingen: Narr.

Andresen, Helga (2007): Rollen, Regeln, Rätsel. In: Andresen, Helga; Januschek, Franz (Hrsg.): SpracheSpielen. Freiburg i.Br.: Fillibach, 27-44.

Belke, Gerlind (2012): Mehr Sprache (n) für alle. Sprachunterricht in einer vielsprachigen Gesellschaft. Baltmannsweiler: Schneider Verlag Hohengehren.

Birkle, Sonja (2012): Erwerb von Textmusterkenntnis durch Vorlesen. Eine empirische Studie in der Grundschule. Freiburg i.Br.: Fillibach.

Bourdieu, Pierre (1980): Le sens pratique. Paris: Editions de Minuit.

12 Vgl. dazu auch Haueis; Klotz 2009. 
Daucher, Hans (1979): Psychogenetische Erklärungsansätze zum Ästhetikbegriff. In: Daucher, Hans; Sprinkart, Karl-Peter (Hrsg.): Ästhetische Erịiehung als Wissenschaft. Probleme, Positionen, Perspektiven. Köln: Du Mont, 111-132.

Elley, Warwick B. (1989): Vocabulary acquisition from listening to stories. In: Reading Research Quarterly 24, 174-187.

Else, Gerald F. (1958): “Imitation" in the 5th Century. In: Classical Philology 53, 2, 73-90.

Erhart, Walter (2000): Mimesis. In: Fricke, Harald (Hrsg.): Reallexikon der deutschen Literaturwissenschaft. Bd. 2. 3., neubearb. Aufl.. Berlin u.a.: de Gruyter, 595-600.

Funke, Reinold (2005): Sprachliches im Blickefeld des Wissens. Grammatische Kenntnisse von Schülerinnen und Schülern. Tübingen: Niemeyer.

Gebauer, Gunter; Wulf, Christoph (1992): Mimesis. Kultur-Kunst-Gesellschaft. Reinbek bei Hamburg: rororo.

Gebauer, Gunter; Wulf, Christoph (2003): Mimetische Weltzugänge. Soziales Handeln Rituale und Spiele - ästhetische Produktionen. Stuttgart: Kohlhammer.

Gibbons, Pauline (2002): Scaffolding Language, Scaffolding Learning. Portsmouth: Heinemann.

Göhlich, Michael; Zirfas, Jörg (2007): Lernen - ein pädagogischer Grundbegriff. Stuttgart: Kohlhammer.

Granzow-Emden, Matthias (2008): Zeigen und Nennen. Sprachwissenschaftliche Impulse zur Revision der Schulgrammatik am Beispiel der „Nominalgruppe“. Tübingen: Stauffenburg.

Haueis, Eduard; Klotz, Peter (Hrsg.) (2009): Sprachästhetik. Duisburg: Universitätsverlag Rhein-Ruhr.

Härle, Gerhard; Steinbrenner, Marcus (Hrsg.) (2010): Kein endgültiges Wort. Die Wiederentdeckung des Gesprächs im Literaturunterricht. Baltmannsweiler: Schneider Verlag Hohengehren.

Hochstadt, Christiane (2014): Förderung der Musterverfügbarkeit im Sprachunterricht am Beispiel des Präteritums - ein rezeptionsorientierter Zugang über das Nacherzählen. In: Bredel, Ursula; Schmellentin, Claudia (Hrsg.): Welche Grammatik braucht der Grammatikunterricht? Baltmannsweiler: Schneider Verlag Hohengehren, 23-45.

Jakobson, Roman (1972): Linguistik und Poetik. In: Ihwe, Jens (Hrsg.): Literaturwissenschaft und Linguistik. Bd. 1. Frankfurt a.M.: Athenäum, 99-135.

Kleimann, Bernd (2002): Das ästhetische Weltverhältnis. Eine Untersuchung zu den grundlegenden Dimensionen des Ästhetischen. München: Fink. 
Kniffka, Gabriele; Siebert-Ott, Gesa (22009): Deutsch als Zweitsprache. Lebren und Lernen. Paderborn: Schöningh.

Kurtz, Gunde (2012): Bildungswortschatz trainieren - Robusten Wortschatz aufbauen. In: Merten, Stephan; Kuhs, Katharina (Hrsg.): Perspektiven empirischer Sprachdidaktik. Trier: WVT, 71-89.

Nix, Daniel (2007): Vorleseübung als Wortschatztraining. In: Willenberg, Heiner (Hrsg.): Kompetenzhandbuch für den Deutschunterricht. Auf der empirischen Basis des DESI-Projekts. Baltmannsweiler: Schneider Verlag Hohengehren, 157-158.

Nix, Daniel (2011): Förderung der Leseflüssigkeit. Theoretische Fundierung und empirische Überprüfung eines kooperativen Lautlese-Verfahrens im Deutschunterricht. Weinheim u.a.: Juventa.

Olsen, Ralph (2009): Von ästhetischen Theatererfahrungen sprechen - Haltungen von Schülerinnen und Schülern wahrnehmen. In: Krelle, Michael; Spiegel, Carmen (Hrsg.): Sprechen und Kommunizieren. Entwicklungsperspektiven, Diagnosemöglichkeiten und Lernszenarien in Deutschunterricht und Deutschdidaktik. Baltmannsweiler: Schneider Verlag Hohengehren, 243-259.

Olsen, Ralph (2010): Anschlusskommunikationen im Theater. In: Knapp, Werner; Rösch, Heidi (Hrsg.): Sprachliche Lernumgebungen gestalten. Freiburg i.Br.: Fillibach, 125-141.

Olsen, Ralph (2011): Mut zur Lenkung: neosokratische Impulse beim Reden über Kunst (nebst Anmerkungen zum Heidelberger Modell). In: Kirschenmann, Johannes; Richter, Christoph; Spinner, Kaspar H. (Hrsg.): Reden über Kunst. Fachdidaktisches Forschungssymposium in Literatur, Kunst und Musik. München: kopaed, 163-180.

Olsen, Ralph; Blöchle, Jana (2010): Die ästhetische Erfahrung (des Theaterzuschauers): ein didaktisches Stufen-Modell. In: Theaterrezeption. karlsruber pädagogische beiträge 75, 107-128.

Ortner, Hans-Peter (1996): Das Imitationslernen und der Erwerb der Schreibkompetenz. In: Feilke, Helmuth; Portmann, Paul R. (Hrsg.): Schreiben im Umbruch. Schreibforschung und schulisches Schreiben. Stuttgart: Klett, 86-95.

Peez, Georg (2005): Evaluation ästhetischer Erfahrungs- und Bildungsprozesse. Beispiele zu ihrer empirischen Erforschung. München: kopaed.

Pracht, Henrike (2010): Alphabetisierung in der Zweitsprache Deutsch als Schemabildungsprozess. Bedingungsfaktoren der Schemaetablierung und -verwendung auf der Grundlage der „usage-based theory“. Münster: Waxmann.

Rosebrock, Cornelia; Nix, Daniel (2012): Grundlagen der Lesedidaktik und der systematischen schulischen Leseförderung. Baltmannsweiler: Schneider Verlag Hohengehren. 
Seel, Martin (2004): Über die Reichweite ästhetischer Erfahrung - Fünf Thesen. In: Mattenklott, Gert (Hrsg.): Ästhetische Erfahrung im Zeichen der Entgrenzung der Künste. Epistemische, ästhetische und religiöse Formen von Erfahrung im Vergleich. Hamburg: Meiner, 73-81.

Staudte, Adelheid (1993): Im Spiel zwischen Sinnlichkeit und Vernunft. Die ästhetische Dimension des Lernens. In: Staudte, Adelheid (Hrsg.): Ästhetisches Lernen auf neuen Wegen. Weinheim u.a.: Beltz, 7-18.

Steinbrenner, Marcus (2009): Mimetische Annäherung an lyrische Texte im Sprach-Spiel des literarischen Gesprächs. In: Anz, Thomas; Kaulen, Heinrich (Hrsg.): Literatur als Spiel. Evolutionsbiologische, ästhetische und pädagogische Konzepte. Berlin: de Gruyter, 645-668.

Steinbrenner, Marcus (2010a): Mimesis in Literarischen Gesprächen und poetisches Verstehen. In: Winkler, Iris; Masanek, Nicole; Abraham, Ulf (Hrsg.): Poetisches Verstehen. Literaturdidaktische Positionen - empirische Forschung - Projekte aus dem Deutschunterricht. Baltmannsweiler: Schneider Verlag Hohengehren, 37-54.

Steinbrenner, Marcus (2010b): Mimetische Textbezüge in Literarischen Gesprächen. Literaturdidaktische Theoriebildung im Spannungsfeld von Empirie und Kulturwissenschaften. In: Baum, Michael; Bönnighausen, Marion (Hrsg.): Kulturtheoretische Kontexte für die Literaturdidaktik. Baltmannsweiler: Schneider Verlag Hohengehren, 25-46.

Steinbrenner, Marcus (2011): „... und wenn die zwei sich in die Augen geschaut haben, haben sie noch LICHT gesehen“. Literarische Erfahrungen in einem Gespräch mit einer 9. Realschulklasse. In: Steinbrenner, Marcus; Mayer, Johannes; Rank, Bernhard (Hrsg.) (2011), 263-285.

Steinbrenner, Marcus; Wiprächtiger-Geppert, Maja (2010): Verstehen und NichtVerstehen im Gespräch. Das Heidelberger Modell des Literarischen Unterrichtsgesprächs. Online: http://www.leseforum.ch/steinbrenner_wipraechtiger_10_3.cfm (Stand: 15.09.2013).

Steinbrenner, Marcus; Mayer, Johannes; Rank, Bernhard (Hrsg.) (2011): „Seit ein Gespräch wir sind und hören voneinander". Das Heidelberger Modell des Literarischen Unterrichtsgesprächs in Theorie und Praxis. Baltmannsweiler: Schneider Verlag Hohengehren.

Welsch, Wolfgang (2003): Ästhetisches Denken. 6., erw. Auflage. Stuttgart: Reclam.

Wood, David; Bruner, Jerome S.; Ross, Gail (1976): The Role of Tutoring in Problem Solving. In: Journal of Child Psychology and Psychiatry 17, 89-100.

Wulf, Christoph (2001): Mimesis und performatives Handeln. Gunter Gebauers und Christoph Wulfs Konzeption mimetischen Handelns in der sozialen Welt. 
In: Wulf, Christoph; Göhlich, Michael; Zirfas, Jörg (Hrsg.): Grundlagen des Performativen. Eine Einführung in die Zusammenhänge von Sprache, Macht und Handeln. Weinheim u.a.: Juventa, 253-272.

Wulf, Christoph (2007): Mimetisches Lernen. In: Göhlich, Michael; Wulf, Christoph; Zirfas, Jörg (Hrsg.): Pädagogische Theorien des Lernens. Weinheim u.a.: Beltz, 91-101.

Wygotski, Lew Semjonowitsch (1974/1934): Denken und Sprechen. Frankfurt a.M.:

Fischer. 


\section{Die Farbe Blau: Literatur und Kunst im DaF-Unterricht}

\section{Dietrich Rall}

Anhand des Beispiels Die Farbe Blau wird gezeigt, wie ein linguistisch, literarisch, künstlerisch, physikalisch und kulturell bedeutendes Motiv Ausgangspunkt sein kann für eine interdisziplinär und interkulturell ausgerichtete Unterrichtsreibe Literatur und Kunst im Fach DaF, und dass die Farbe Blau ein Thema ist, das ästhetisch, literaturhistorisch und komparatistisch betrachtet eine überraschend große Rolle spielt.

\section{Vorüberlegungen}

In diesem Beitrag wird von einer Zielgruppe ausgegangen, für welche die deutsche Sprache und Kultur die Grundlage ihres künftigen oder gegenwärtigen Berufs ist (Deutschlehrkräfte, Teilnehmende an einer Deutschlehrerausbildung oder Deutschlehrerfortbildung, Studierende der Germanistik). Es geht darum, dass sie ihre Lesekompetenz erweitern, besonders im Umgang mit landeskundlichen, literarischen und wissenschaftlichen Diskursen. Als Einführung mag z.B. Lesen als Verstehen von Swantje Ehlers nützlich sein. Für künftige Lehrkräfte kann es auch eine gute Übung sein, sich mit längeren literarischen Texten aus den letzten Jahren zu beschäftigen, zum Beispiel mit Das blaue Kleid von Doris Dörrie (2002), ein Roman der z.T. in Mexiko spielt. Anhand der Reise zur blauen Stadt von Uwe Tellkamp (2009) kann man sich interkulturell der Stadt Istanbul und der Blauen Moschee nähern und überhaupt dem Orient, wo die Farbe Blau eine eigene, spezifische Symbolik hat. Ausschnitte aus dem Roman Robinsons blaues Haus (2012) von Ernst Augustin können in einem komparatistisch ausgerichteten Germanistik-Seminar Ausgangspunkt sein für eine Unterrichtseinheit über die Aktualität des Robinson- 
Themas in Literatur und Film. Diese Aktualität wird immer wieder bestätigt, z.B. in dem von Ada Bieber und anderen 2009 herausgegebenen Band Angeschwemmt Fortgeschrieben. Robinsonaden im 20. und beginnenden 21. Jabrbundert. Nützlich und notwendig für die Zielgruppe ist auch die Erweiterung ihrer Kompetenzen im Hörverständnis und in der mündlichen Produktion: das Verstehen von Vorträgen und die aktive Teilnahme an akademischen Diskussionen in der Fremdsprache. Auch das Verfassen schriftlicher Texte über Themen ihres Faches sollte intensiv geübt werden: Zusammenfassungen, Referate, Essays, Seminararbeiten. Diese Fertigkeiten werden selten systematisch in den Unterricht einbezogen. Diese Zielgruppen sollten also mit Texten umgehen können, die sich nicht auf Alltagssituationen und auf den Vorrang des Mündlichen beschränken. Auf diesem Niveau, etwa von B2 bis C2 und in der Lehreraus- und -fortbildung sind auch solide Kenntnisse der deutschen Grammatik nötig, nicht nur in der Morphologie, in der Wortbildung und Phraseologie, sondern vor allem auch in der Syntax, der Textlinguistik und Pragmatik. Solche Kompetenzen erwirbt man im Umgang mit anspruchsvollen Texten und Themen, die landeskundliche, literarische oder andere kulturelle Inhalte und Traditionen behandeln. Es geht also nicht nur um die Frage, was bringt ein Thema für die alltägliche Unterrichts-Praxis, die um das Alltagsleben kreist, sondern es geht auch darum, kulturelles, ästhetisches, historisches und gesellschaftliches Wissen zu vermitteln.

Anspruchsvoll klingt elitär, aber so ist diese Argumentation nicht gemeint. Von Studierenden der Germanistik, von Personen, die den Deutschlehrerberuf wählen, kann man erwarten, dass ihr sprachliches und kulturelles Interesse weiter geht als bis Stufe B1. Man sollte sie fordern und ihnen etwas bieten, was sie weiterbringt. Man soll Studierende nicht überfordern, ist ein weitverbreitetes Credo. Aber: Warum soll die künftige Elite eines Landes nicht gefordert, ja manchmal überfordert werden?

Es ist ein wenig wie mit Fernsehprogrammen. Das Fernsehen interessiert sich heute vor allem fürs Rating, d.h., was wollen die Leute sehen, was macht Spaß, was bringt die größten Einschaltquoten? Im Januar 2013 sagte der frühere Fernsehredakteur Martin Wiebel in einem Interview mit dem Wochenblatt DIE ZEIT, man solle nicht dem Zuschauer hinterherlaufen und ihn abholen, wo er steht. Sondern man könne ihn dazu bringen, sich für etwas anderes zu interessieren.

Anspruch galt nicht als etwas Schreckliches. Sondern als etwas Richtiges. Man soll den Menschen ein Angebot machen. Sie müssen es nicht annehmen. Aber wenn sie es annehmen, haben sie etwas davon (Richter 2013: 3).

Dieser Beitrag ist ein Vorschlag, sich mit einem Thema zu befassen, das ästhetisch, künstlerisch, physikalisch, literaturhistorisch, linguistisch und unter komparatistischen Gesichtspunkten eine überraschend große Rolle spielt. Anhand des Beispiels Die Farbe Blau möchte ich zeigen, wie ein solches Thema Ausgangspunkt sein kann für eine interdisziplinär und interkulturell ausgerichtete Unterrichtsreihe Literatur und Kunst im Fach Deutsch als Fremdsprache. 
Es ist zu begrüßen, dass die Organisatorinnen und Organisatoren des internationalen Kongresses Ästhetisches Lernen im DaF-Unterricht. Musik - Kunst - Film - Theater - Literatur ein Thema gewählt haben, das sich mit kulturellen Bereichen im Sprachunterricht beschäftigt und zu dem sich Referentinnen und Referenten mit anregenden Vorträgen und Workshops angemeldet haben. Einige ästhetische Bereiche, wie z.B. die Literatur und das Theater, sind mehr vom Rückgang betroffen als z.B. der Film oder die Musik - es kommt nur darauf an, welche Art von Film (z.B. Bleu von Kieslowski aus der Trilogie Trois couleurs oder Der blaue Engel, Josef Sternbergs Verfilmung von Heinrich Manns Professor Unrat) und welche Art von Musik man meint. Sicher nicht in erster Linie die Oper und die klassische Musik. Und es kommt auch darauf an, von welcher Art von Kunst oder Literatur man spricht: von den Brüdern Grimm und/oder Walt Disney, von Thomas Mann oder von Agatha Christie (z.B. The Mystery of the Blue Train) oder von Asterix, von Das Leben der Anderen oder von La Tetona Mendoza y el Santos, von dem blauhäutigen Globi in seiner Schweizer Welt, die manchmal von Schiller inspiriert ist; oder von den blauen Schlümpfen in ihrer Zwergenwelt, an der sich trefflich deutsche Phonetik üben lässt: der Schlumpf, die Schlümpfe; der hundertste Schlumpf; Das Zauberei und die Schlümpfe. Will man von Dürer oder von Georg Baselitz sprechen, von einer Maria im blauen Mantel oder von René Magrittes Blauer Vogel (1962), von Paul Klees Blaue Blume (1939), von Franz Marcs Blaue Pferde (1911/1913) oder von Pablo Picassos Blauer Periode und Elvira Bachs blauem Frauenbildnis Obne Titel (1987)?

\section{Das Wort blau in der deutschen Sprache}

Die Farben gehören zum Grundwortschatz jeder Sprache. Da macht das Deutsche keine Ausnahme, und unter den Farben ist blau eine der beliebtesten. Blau die himmlische Farbe ist der Titel eines Bandes der Insel-Bücherei (2001), der u.a. Texte von Goethe, Mörike, Rilke, Trakl, Hesse, Benn, Bachmann und Celan enthält, sowie u.a. Bilder von Marc, Magritte, Klee, Picasso. Gabriele Pommerin-Götze gab ihrem Schreibprojekt „Poetisches Spiel mit der ,schönsten aller Farben““ (2006: 3) den Titel Neruda Blau (2006), angeregt von Nerudas Gedichtband Libro de las preguntas. Das Thema der Farbe Blau ist fast so unendlich wie der uns blau erscheinende Äther und das blaue Meer: In seinem PoeMar besingt Fernando del Paso das Blau des Meeres, „la azuleidad del mar“ (2004: 176). Heinrich von Ofterdingen macht sich in Novalis' gleichnamigem Roman auf die Suche nach der blauen Blume; Rubén Darío wurde berühmt mit seinem Band Azul (1888), ebenso wie Stéphane Mallarmé mit seiner Beschwörung des ewigen Blau: „Je suis hanté. L’Azur! L'Azur! L’Azur! L'Azur!“‘ (Mallarmé 1945: 39)

Wenn es um die Farbe Blau geht, kommen viele Dichter ins Schwärmen. Mallarmé fühlt sich „hanté“ (Mallarmé 1945: 39), also verzaubert, besessen von dieser Farbe, von diesem Seelenzustand. Der Schweizer Dichter des 19. Jahrhun- 
derts, Conrad Ferdinand Meyer, empfindet religiösen Schauer, wenn er in seinem Gedicht Heilige Bläne schreibt:

O du heil'ge Bläue,

Immer freut aufs neue

Mich der stille Glanz.

Abgrund ohne Ende!

Himmlisches Gelände,

Seele, tauche unter ganz!

Aber nicht nur die Poesie, auch die Alltagssprache kennt viele Wendungen, die schon für Deutschlernende in der Grundstufe interessant und nützlich sein können (für spanischsprachige Lernende vgl. Balzer u.a. 2010).

Sich ein Bier bestellen können, gehört zu den Grundfertigkeiten eines globalisierten Touristen. Aber es ist auch nützlich, ausdrücken zu können, wie man sich danach eventuell fühlt: ich bin blau, ich war mal wieder blau, oder gar kornblumenblau, vielleicht auch veilchenblau; blau wie ein Veilchen ist durch die Metapher schon wieder poetisch, wie so viele Wendungen der Umgangssprache. Aber blaue Jungs sind keine betrunkenen Jungs, sondern Seeleute, Matrosen; die können allerdings auch mal betrunken sein.

Sein blaues Wunder erleben kann auf die aus der deutschen Mythologie stammende Blaue Wunderblume zurückgehen, von der auch Novalis' blaue Blume inspiriert ist;

blauen Dunst machen, bedeutet, jemandem etwas vormachen, etwas vorlügen; wenn jemand blauängig ist, ist er oder sie naiv und harmlos; wenn sich jemand grün und blau ärgert, ist er fuchsteufelswild.

Wird jemand grün und blan geschlagen, hat er hinterher sicher blaue Flecken und womöglich auch ein blaues Auge und muss mit Blaulicht ins Krankenhaus gefahren werden - vielleicht war er ja zu vertrauensvoll, zu blauängig, als er sich in eine zwielichtige Gesellschaft begeben hat. Es kann aber noch wesentlich schlimmer kommen, wenn einem blaue Bohnen um die Ohren fliegen.

Eine Fahrt ins Blaue ist eine Fahrt ohne festes Ziel; blau machen bedeutet, sich einen Tag frei nehmen, nicht arbeiten; ein Blaustrumpf war bis ins 20. Jahrhundert hinein ein unerfahrenes Mädchen, sagte man aber auch von einer emanzipierten und etwas spröden Frau. Die blaue Stunde ist die Stunde zwischen Tag, Dämmerung und Traum.

Eine lexikalische Einheit über die Farbe Blau in der Sprache kann den lehrbuchfixierten Unterricht etwas auflockern und kann auch weiterführen in die Literatur und in die Kunstbetrachtung. Eine solche Unterrichtseinheit kann beispielsweise anhand des folgenden Textes aufbereitet werden.

In ihren Assoziationen in Blau schrieb Christa Wolf (2003), unter anderem:

Blau, blau, blau sind alle meine Kleider. Blau ist die Farbe der Treue [....] Rot und Blau schmückt die Sau und dem Kasper seine Frau. Er macht gerne mal 
blau. Heute blau und morgen blau, und übermorgen wieder. Blauer Montag (Wolf 2003: 25).

Christa Wolfs Text enthält an die 80 phraseologische Ausdrücke im semantischen Feld des Wortes blau und kann auszugsweise zur Erweiterung des Wortschatzes, des Gebrauchs von Redewendungen und zur Entdeckung von Zitaten und intertextuellen Bezügen innerhalb der literarischen Tradition der deutschsprachigen Länder dienen. So kann die Farbe Blau ein Ausgangspunkt sein zur Erweiterung des Wortschatzes und der Redewendungen im Deutschen. Das gilt natürlich auch für alle anderen Farben und für eine große Anzahl von Wörtern und Begriffen, von denen aus sich große lexikalische und semantische Felder erschließen lassen.

\section{Blau farbentheoretisch und farbenpsychologisch gesehen}

Schon in den wenigen zitierten Beispielen leuchtet auf, dass Blau nicht irgendeine Farbe ist, sondern dass sie stark mit Emotionen und Seelenzuständen in Verbindung gebracht wird. Das wussten schon die deutschen Romantiker und drückten diese Beobachtung in ihren poetischen Werken und in ihren synästhetischen Überlegungen aus. Mit der Berufung auf die Romantik und auf den Traum von der blauen Blume sollte man auch die Kritik an diesem Traumdiskurs mitdenken und sich bewusst sein, dass die sich um die Farbe Blau rankenden Assoziationen nicht festgeschrieben sind, sondern sich verändern können. Heinrich Heine kritisierte schon in seinem 1833 entstandenen und 1835 (mit dem Datum 1836) publizierten Werk Die Romantische Schule die den Werken der Autoren dieser Schule und damit auch der blauen Blume inhärente Ideologie; für ihn war die romantische Schule „nichts anders als die Wiedererweckung der Poesie des Mittelalters“ (Heine 1971: 361). Walter Benjamin beginnt seinen Textentwurf von 1925, Traumkitsch, (publiziert 1927 unter dem Titel Glosse zum Surrealismus) mit dem kritischen Statement: „Es träumt sich nicht mehr recht von der blauen Blume. Wer heut als Heinrich von Ofterdingen aufwacht, muss verschlafen haben" (Benjamin zit. nach Lindner 2012: 53).

Nach neuesten physikalischen Erkenntnissen war anscheinend selbst der Äther nicht immer blau. Eine der letzten Nummern von GEOkompakt ist unter dem Titel Warum ist der Himmel blau? der Physik gewidmet. Dass uns der Himmel blau erscheint

hängt mit der Erdatmosphäre zusammen. Und mit der Art, wie Lichtstrahlen und die Gasteilchen der Lufthülle miteinander reagieren. [...] Die uns vertraute Tönung des Himmels hat es allerdings nicht immer gegeben. Bis vor 2,5 Millarden Jahren enthielt die Atmosphäre der Erde vermutlich sehr viel Methan. Damals hätte die Frage daher lauten müssen: ,Warum ist der Himmel orangefarben?‘ (Blume 2013: 28). 
Aber kommen wir zurück in die Gegenwart.

In einem Aufsatz über die physikalischen Eigenschaften der Farbe Blau erwähnt der Ingenieur und Maler Harald Küppers, dass es drei theoretische Perspektiven, drei wissenschaftliche Lager gibt, um die Farbe Blau zu betrachten: „das physikalisch orientierte, das materialorientierte und das physiologisch orientierte Lager“ (Küppers 1990: 26). Dazu kommt als vierte Perspektive die

ästhetische Betrachtungsweise [die aber] mit Farbenlehre genaugenommen nichts zu tun hat. Es handelt sich bei ihr vielmehr um individuelles Ermessen und um Geschmacksfragen (ebd.: 26).

Physikalisch gesehen,

[entsteht] eine blaue Farbempfindung also grundsätzlich dann, wenn im Buntwert einer Farbnuance die Teilmenge einer der beiden blauen Grundfarben, also entweder die von Violettblau oder die von Cyanblau, dominiert. Durch diese Ausführungen wird deutlich, dass der Farbname Blau - wie alle anderen Farbnamen aus der Umgangssprache auch - keine bestimmte Farbe bezeichnen kann. Vielmehr ist damit eine riesige Anzahl von Farbnuancen gemeint, die etwa einen Drittelbereich des gesamten Farbenraums ausfüllen. Um in diesem großen Blau-Bereich durch sprachliche Differenzierung zu einer etwas genaueren Aussage zu gelangen, werden alle möglichen Wortverbindungen praktiziert: Himmel-, Wasser-, Preußisch-, Ultramarin-, Blass-, Cölin-, Kobalt-, Echt-, Türkis-, Marine- oder Orientblau oder Grünblau, um nur einige zu nennen (ebd.: 30).

Sogar auf den Ausdruck Bodensee-Blau kann man stoßen.

Harald Küppers hat versucht, die vielen Variationen von Blau in einem von ihm entworfenen Gemälde festzuhalten, dem er den Titel Nachbarschaft zu Blau gab (vgl. ebd.: 29). Das Bild kann im DaF-Unterricht ein Sprechanlass sein, um über die Farbbeobachtungen und Farbempfindungen der Teilnehmer zu diskutieren, durchaus auch mit interkultureller Perspektive. Denn was in einer Kultur als Blan erkannt wird, kann in einer anderen als Grün bezeichnet werden. Die alten Griechen sahen das Meer oder den Himmel noch weinrot oder schwarz.

Immer wieder wurden neue Namen für eine ganz bestimmte Blautönung entwickelt, wie z.B. im 18. Jahrhundert das Berliner Blau, dem man im Laufe der Jahrhunderte noch ingesamt 61 andere Namen gab (vgl. Becker 1990: 49). Mitte des 20. Jahrhunderts entwickelte der französische Maler Yves Klein sein Blau, inspiriert vom Himmel der Côte d'Azur, der Blauen Küste, und nannte es International-KleinBlue (IKB), mit dem er gegen Ende seines Lebens (1962) ausschließlich malte.

Das IKB, dieses unnachahmliche Blau, das sich wie keine andere Farbe mit einem bestimmten Künstler [des 20. Jahrhunderts] verbindet, steht für die vollkommene Symbiose zwischen Künstler und Medium (Schuth 1990: 426). 
Bei Kleins Fixierung auf sein Blau haben wir es mit einem Übergang zu tun von der physikalisch oder physiologisch orientierten Analyse von blau zur ästhetischen Betrachtungsweise der Farbe Blau. In einer Unterrichtseinheit über die Farben ließen sich mit dieser Zusammenstellung von Werken von Yves Klein interessante und auch kritische Kommentare von Kursteilnehmern über den Zusammenhang von Farben und Emotionen provozieren.

Pierre Restany schreibt,

Für mich, der ich Schritt für Schritt Yves Kleins Abenteuer der Monochromie verfolgt habe und Zeuge seiner entscheidenden Entwicklungsphase war, ist Blau in erster Linie ein einzigartiger Katalysator von Sensibilität, das sichtbare Zeichen des Unendlichen in seiner inneren Unermesslichkeit. Mit Blau verbinden wir Offenbarung: blau erscheint uns der Himmel (Restany 1990: 15).

Die Sehnsucht und die Obsession, das Unerreichbare zu finden, das Ideal, verbindet sich oft mit der Farbe Blau, wie bei Yves Klein, wie in Anna Seghers Erzählung Das wirkliche Blau, wie in der blauen Blume von Novalis.

Bei Künstlern und Dichtern wird man schnell fündig, wenn man nach den emotionalen Reaktionen auf die Farbe Blau sucht. Für Goethe ist Blau „eine Farbe der Energie“" (Goethe zit. nach Gercke 1990b: 20), und seine Farbenlebre ist voll von physiologischen und möglichen psychologischen Reaktionen auf die Farbe Blau:

Wie wir den hohen Himmel, die fernen Berge blau sehen, so scheint eine blaue Fläche auch vor uns zurückzuweichen. Wie wir einen angenehmen Gegenstand, der vor uns flieht, gern verfolgen, so sehen wir das Blau gerne an, nicht weil es auf uns dringt, sondern weil es uns nach sich zieht (ebd.).

Thomas Mann, der sich als geistiger Erbe von Goethe betrachtete, hat unter anderem in Der Zauberberg das Motiv der Bläue variiert. Rolf Renner hat dieses Thema ausführlich interpretiert in seinem Artikel Beschriebenes und erscbriebenes Blau. Die Farbe Blau in literarischen Texten. Hier sei nur kurz darauf verwiesen. Im Kapitel Schnee des Zauberberg wird geschildert, wie sich Hans Castorp auf einer Skitour verirrt, wie er vor Erschöpfung an einer Hütte zusammensinkt und in dieser Grenzsituation zwischen Leben und Tod im Halbschlaf zu träumen beginnt. Rolf Renner schreibt:

Die Phantasie der Entgrenzung, die in Castorps Schneetraum mit der Farbe Blau verbunden ist, findet sich noch an einer anderen Stelle des Romans, auch dort ist sie Teil einer synästhetischen Empfindung, die mit einer intensiven Wahrnehmung von Musik verknüpft ist [...] Die Farbe Blau ist in diesem Zusammenhang mehr als das Zeichen für eine Entgrenzung, eine bewusste Entfernung von der Welt. Sie erschließt einen Bereich, der sich der Vernunft und Selbstkontrolle entzieht (Renner 2000: 221). 
Aus der Zeit, in der Der Zauberberg entstand, stammt das Gemälde Mondnacht im Winter (1918/1919) von Ernst Ludwig Kirchner, der sich lange in Davos aufhielt und die blauen Berge in seiner Malerei festhielt.

Für den Maler Wassily Kandinsky, der mit seinem Gemälde Der blaue Reiter (1903) der gleichnamigen expressionistischen Malergruppe ihren Namen gab, wird das Blau ,zur Farbe des ,Geistigen in der Kunst', [es erinnere den Menschen an das] Unendliche, weckt in ihm die Sehnsucht nach Reinem und schließlich Übersinnlichem" (Gercke 1990b: 20). Seine Zeitgenossen Else Lasker-Schüler (Mein blaues Klavier), Oskar Loerke (Blauer Abend in Berlin), Gottfried Benn (Blaue Stunde) und Rainer Maria Rilke evozierten mehrfach in ihren Gedichten die Farbe Blau. In Rilkes Gedicht Blaue Hortensie heißt es:

Doch plötzlich scheint das Blau sich zu verneuen

In einer von den Dolden, und man sieht

Ein rührend Blaues sich vor Grün zu freuen

(Rilke zit. nach Linder 2001: 57).

Rilke wusste aber auch, dass das Thema so unendlich ist, wie der uns blau erscheinende Äther, als er schrieb: „Es ließe sich denken, dass jemand eine Monographie des Blaus schriebe“ (an Clara Rilke, 08.10.1907; zit. nach Linder 2001: 17). Eine einzige Monographie reicht sicher nicht aus. Das Gefühl des Unermesslichen und der Unendlichkeit, das immer wieder mit der Farbe Blau assoziiert wird, zieht sich wie ein Leitfaden durch die Literatur und Malerei, und das Thema Farbe Blau mit seinen vielen Motiven bietet in der Germanistik durchaus die Möglichkeit, auch einmal von hier aus sowohl Literatur- und Kulturwissenschaft als auch Komparatistik zu betreiben.

\section{Projektarbeit}

Im DaF-Unterricht, vor allem in den Kursen für Fortgeschrittene und in der Berufsausbildung für Deutschlehrkräfte und GermanistInnen kann man sich nicht mit Lehrbuchmaterialien begnügen. Lesekompetenz mit literarischen Texten erreicht man so nicht. Im Folgenden wird anhand einiger weniger Beispiele gezeigt, wie man, von einem Lehrbuch ausgehend, zusätzlich literarische Texte und Objekte der Kunst in den Unterricht einbringen kann.

In das Lehrbuch Sprachbrücke, interkulturell konzipiert, wurde das Thema der Farbensymbolik und der Farbassoziationen eingebracht und in mehreren Übungen der Lektion 6 erweitert (vgl. Mebus u.a. 1987: 83). Das Lehrbuch Blaue Blume enthält viele narrative Texte, Gedichte, Reime und Lieder, „um das Deutschlernen attraktiver zu machen“, wie es im Vorwort heißt. Dieses Lehrbuch Blaue Blume mit explizit ästhetischer Ausrichtung widmet dem Thema Farben die ganze Lektion 4 unter dem Titel Farben hören - Töne schmecken. Es handelt von den Synästhetikern, die bei bestimmten Vokalen, Tönen, Gerüchen entsprechende Farben assoziieren. Die 
Vokale mit Farben zu assoziieren, geht auf eine romantische Tradition zurück: August Wilhelm Schlegel assoziierte in seinem Werk über Sprache und Poetik z.B. beim Vokal ,I‘ das Blau des Himmels, für Baudelaire war dagegen in seinem Gedicht Voyelles das ,O` der Vokal der Bläue. Weiterführende Texte über Farbsymbolik in der deutschen Literatur des 18. bis zum 21. Jahrhundert zu finden, ist nicht schwer.

Im Jahr 2007 legte ich am Centro de Enseñanza de Lenguas Extranjeras (CELE) der $U N A M$ die Konzeption eines Literaturmoduls für die Mittelstufe vor mit dem Vorschlag, in diesem 7. Niveau (zwischen B2 und C1) die im Lehrbuch Auf neuen $W$ egen vorgegebenen Kursinhalte durch literarische Texte zu den jeweiligen Themen zu ergänzen. Der Themenbereich Emotionen, in dem u.a. die Arbeit mit Farben im Expressionismus thematisiert wird, kann mit Texten von Max Frisch und über die Maler des Blauen Reiter erweitert werden. Die Einstiegseite von Lektion 5, mit Portraits (Bildnisse) von expressionistischen Malerinnen und Malern wird dazu benutzt, Charakteristika des Expressionismus zu kommentieren, über diese Epoche der Malerei zu sprechen und etwas zu den Biographien, Werken und Maltechniken zu sagen.

Wir haben es in dieser Lektion mit einem Anfang von Bildbeschreibungen in kurzen Texten zu tun, mit einer elementaren Ekphrasis, die weiter geübt und studiert werden kann. Der Begriff Ekphrasis (von gr. Ek = aus; phrázein = sagen, erklären) bedeutet, Beschreibung und Erklärung, und er wurde seit der Antike angewandt auf die schriftliche, speziell literarische Darstellung von visuellen Kunstwerken (Gemälde, Statuen usw.). Murray Krieger definierte Ekphrasis 1967 als „die Immitation eines Kunstwerks mit literarischen Mitteln“ (González Aktories; Artigas Albarelli 2011: 12). Der Begriff wurde zunächst vor allem in der Kunstwissenschaft verwendet, hat dann aber in den Kulturwissenschaften eine Ausweitung erfahren in der Richtung, dass ,,jegliche verbale Äußerung über ein Kunstwerk als Ekphrasis betrachtet wird“ (Wagner 1998: 112). Heutzutage wird Ekphrasis als Ausdruck künstlerischer Intertextualität und Intermedialität noch weiter gefasst als „Beziehung zwischen Texten verschiedener Medien [und als] interdiskursive Phänomene“ (González Aktories; Artigas Albarelli 2011: 24). Ausgehend vom genannten Lehrbuch Auf neuen Wegen, Lektion 5 über Emotionen und expressionistische Maler, wurden den Kursteilnehmenden z.B. Bilder und Skizzen von Franz Marc gezeigt und mit ihnen kurze Texte über Marc und sein Werk gelesen. Franz Marc sagte einmal: „Blau ist die einzige Farbe, bei der ich mich wohlfühle“ (Marc zit. nach Bahnmüller 2012: 4). Über den Turm der blauen Pferde von Marc heißt es in dem Geleitwort von Klaus Lankeit zum Band Franz Marc. Tierstudien:

Franz Marc ist der Schöpfer der großen Tiersymbole. Beim Klang seines Namens denken wir zuerst an jene farbstarken Gemälde, in denen der Künstler mittels der Tiere Sinnbilder unseres eigenen Daseins gestaltet hat. Der ,Turm der blauen Pferde‘ leuchtet wie das Glasfenster einer gotischen Kathedrale, die traumhafte Farbigkeit der ,Tierschicksale' prägt sich dem 
Betrachter unvergesslich ein (Lankeit 1953: 3) (vgl. Franz Marc: Der Turm der blauen Pferde).

Anhand solcher Beispiele aus Kunst und Literatur war es Aufgabe für die Studierenden, in Partnerarbeit expressionistische Portraits oder Stadt- und Landschaftsbilder auszusuchen, mündlich zu kommentieren und dann ihre Beschreibung schriftlich zu formulieren, unter den Gesichtspunkten:

Warum haben Sie dieses Bild ausgesucht? Welche expressionistischen Merkmale enthält es? Was drücken die Farben aus? Welchen Zusammenhang sehen Sie zwischen Farben, Formen, Figuren, Motiven und Gefühlen?

Ähnliche Übungen lassen sich weiterführen anhand von anderen Beispielen und indem man das visuelle Kunstwerk mit einer literarischen Repräsentation desselben vergleicht und kommentiert. Ausgehend von einem Gemälde von Max Ackermann (1887-1975) aus dem Zyklus Überbrückte Kontinente (1954) (vgl. Kranz 1975: 80, 103) können die Kursteilnehmer nach einer Phase mündlicher und schriftlicher Kommentare ihre Assoziationen zu diesem interkontinentalen Thema vergleichen mit einem ekphratischen literarischen Text von dem Lyriker, Kunsthistoriker und Übersetzer Kurt Leonhard (1910-2004), um dann über die verschiedenen Interpretationen zu diskutieren.

Zu einem Bild von Max Ackermann:

Das Bildrechteck schneidet den Schauplatz

einer Überraschung aus der

Einsamkeit,

Unendlichkeit,

Unmenschlichkeit utopischer Topographien.

Man sieht:

Flächen und Grenzen, leere Flächen, scharfe Grenzen, Farbflächen und Grenzlinien, eintönige Farbflächen, großzügige Grenzlinien:

Kontinente, Einflussgebiete, kosmische Zonen, blaues Kältereich, violetten Kältestrom, braune Erdküste, grünes Hinterland.

Wo Blau und Braun sich fast berühren, überbrückt den Engpass ein zartes Gestell. Schwarze Drahtschleifen in freier Schwebe (Leonhard zit. nach Kranz 1975: 82.) 
Zum Schluss soll an dem Fragment von Friedrich Hölderlin In lieblicher Bläue... gezeigt werden, wie man mit dem Text eines Klassikers im Deutschunterricht arbeiten kann. Den Anstoß, sich mit diesem Text zu beschäftigen, kam von den Teilnehmenden an dem zweisemestrigen Lesekurs für Philosophen, den der Verfasser für Magisterstudierende und Promovierende an der Facultad de Filosofía y Letras der UNAM gegeben hat. Einige Teilnehmer waren bei der Lektüre Heideggers auf Hölderlin-Zitate gestoßen. In seinem Aufsatz Hölderlin und das Wesen der Dichtung (1951) spricht Heidegger von „dem großen und zugleich ungeheuren Gedicht, das beginnt: ,In lieblicher Bläue blüht mit dem metallnen Dache der Kirchturm“" (Heidegger 1951: 42) und zitiert mehrere Textstellen daraus. Der vollständige Hölderlin-Text war den Kursteilnehmenden nie in spanischer Übersetzung zugänglich gewesen, deshalb reizte sie die Herausforderung, In lieblicher Bläue... ins Spanische zu übertragen, sowohl sprachlich als auch syntaktisch sowie von der Deutung her gesehen ein schwieriger, dunkler und sperriger Text. Generell ist die Übersetzung für Kursteilnehmer aus den Geisteswissenschaften ein bewährtes didaktisches Mittel, bei schwierigen Texten das exakte Verständnis zu überprüfen.

Dieses Werk Hölderlins, in poetischer Prosa überliefert, war ursprünglich wohl eine in Hexametern geschriebene pindarische Ode Hölderlins. Der seit Jahren schon geisteskranke Hölderlin hat vermutlich im Jahr 1822 dem jungen Dichter Wilhelm Waiblinger, damals Student am Tübinger Stift, das Gedicht geschenkt. Schon 1822 fasste Waiblinger den Entschluss, einen Roman über einen in der Umnachtung endenden Künstler zu schreiben, inspiriert vom Schicksal Hölderlins. Der Künstlerroman Phäeton erschien 1823. 1831 erschien posthum die erste detaillierte Krankengeschichte Friedrich Hölderlins Leben, Dichtung und Wabnsinn, verfasst von Waiblinger, der 1830 im Alter von 26 Jahren in Rom gestorben war.

In lieblicher Bläue blühet mit dem metallenen Dache der Kirchturm. Den umschwebet Geschrei der Schwalben, den umgibt die rührendste Bläue. Die Sonne gehet hoch darüber und färbet das Blech, im Winde aber oben stille krähet die Fahne. Wenn einer unter der Glocke dann herabgeht, jene Treppen, ein stilles Leben ist es, weil, wenn abgesondert so sehr die Gestalt ist, die Bildsamkeit herauskommt dann des Menschen. Die Fenster, daraus die Glocken tönen, sind wie Tore an Schönheit. Nämlich, weil noch der Natur nach sind die Tore, haben diese Ähnlichkeit von Bäumen des Walds. Reinheit aber ist auch Schönheit. Innen aus Verschiedenem entsteht ein ernster Geist. So sehr einfältig aber die Bilder, so sehr heilig sind sie, dass man wirklich oft fürchtet, die zu beschreiben. Die Himmlischen aber, die immer gut sind, alles zumal, wie Reiche, haben diese, Tugend und Freude. Der Mensch darf das nachahmen (Hölderlin 1953, 2. Bd.: 372).

An nur einem Beispiel, nämlich am ersten Satz, möchte ich zeigen, welche Ansprüche der Text an die Übersetzer stellt: „In lieblicher Bläue blühet mit dem metallenen Dache der Kirchturm“ (ebd.). 
In der spanischsprachigen Tradition werden die ersten drei Wörter, die dem Text den Titel gegeben haben, zitiert als „En amable azul...“ oder „En azul amable...“. Man findet aber auch „En amoroso azul“ (Heidegger 2005: 46).

Hier zunächst die Übersetzung von Samuel Ramos aus Heideggers Aufsatz Hölderlin und das Wesen der Dichtung (Heidegger 1973: 38): „En azul amable florece el techo metálico del campanario“ (ebd.).

Von den Teilnehmern an dem Deutschkurs für Philosophen wurden auch andere Übersetzungsvorschläge gemacht:

En amable azul florece con su techo metálico el campanario; El campanario de la iglesia con el metálico techo florece en el amable azul; En primoroso azul florece con el metálico tejado el campanario.

Amable bedeutet mehr liebenswürdig als lieblich. Deshalb einigte sich die Übersetzungsgruppe der Philosophischen Fakultät, in Ermanglung einer genauen Entsprechung, auf den Übersetzungs-Vorschlag en primoroso azul - wobei primoroso soviel wie schön, liebreich, freundlich, entzückend bedeuten kann. Man hätte auch daran denken können, die Bläue mit einem Substantiv wiederzugeben, z.B. mit en el esplandor del azul. Apacible scheint ebenfalls ein guter Vorschlag zu sein; es entspricht im Deutschen etwa mild, anmutig, lieblich, freundlich, sanft (vgl. Rall 2007: 313f.).

\section{Schluss}

Mit diesem hölderlinschen Blick in die „liebliche“, in die „rührendste“ Bläue des Himmels schließe ich diesen Beitrag ab.

Während des Kongresses bekam man in den verschiedenen Sektionen und Workshops viele interessante Anregungen zum Ästhetischen Lernen im DaFUnterricht. Aber es ist zum Schluss noch auf eine Stelle im Text Hölderlins In lieblicher Bläue... hinzuweisen, die zu denken geben kann, wenn man sich mit Hermeneutik, Bildbeschreibungen und Ekphrasis beschäftigt: „So sehr einfältig aber [sind] die Bilder, so sehr heilig sind die, dass man wirklich oft fürchtet, die zu beschreiben“" (Hölderlin 1953, 2. Bd.: 372).

Jedes Kunstwerk steht auch für sich selbst. Man sollte es also mit der Interpretiererei ästhetischer Objekte nicht übertreiben, schon gar nicht im DaF-Unterricht. Wir wollen uns ja keinen blauen Dunst vormachen. 


\section{Literatur}

Albarrán, Jairo Calixto (2012): El ángel exterminador. La Tetona Mendoza y el Santo. In: Milenio 26.11.2012, 42.

Bahnmüller, Lisa; Bahnmüller, Wilfried (2012): „Mein Leben ist blau!“ Von Künstlern, Königen und Kuriositäten - Entdeckertouren per Rad oder zu Fuß im Fünfseenland und Pfaffenwinkel. München: J. Berg Verlag.

Balzer, Berit; Moreno, Consuelo; Piñel, Rosa; Raders, Margit; Schilling, María Luisa(2010): Kein Blatt vor den Mund nehmen. No tener pelos en la lengua. Diccionario fraseológico alemán-español. Phraseologisches Wörterbuch Deutsch-Spanisch. Ismaning: Hueber.

Becker, Hans (1990): Blau als Pigment oder blau ist nicht gleich blau. In: Gercke, Hans (Hrsg.) (1990a), 36-52.

Bieber, Ada; Greif, Stefan; Helmes, Günter (Hrsg.) (2009): Angeschwemmt - Fortgeschrieben. Robinsonaden im 20. und beginnenden 21. Jabrbundert. Würzburg: Königshausen \& Neumann.

Blume, Patrick; Engeln, Henning; Gilges, Susanne; Süssemilch, Bettina (2013): Warum ist der Himmel blau? In: GEOkompakt. Die Grundlagen des Wissens. Die Physik 35, 28-29.

Dörrie, Doris (2002): Das blaue Kleid. Zürich: Diogenes.

Ehlers, Swantje (1992): Lesen als Verstehen. Zum Verstehen fremdsprachlicher literarischer Texte und zu ibrer Didaktik. Fernstudieneinheit 2. Berlin u.a.: Langenscheidt.

Eichheim, Hubert; Bovermann, Monika; Tesařová, Lea; Hollerung, Marion (2002): Blaue Blume. Deutsch als Fremdsprache. Kursbuch. Spanische Ausgabe. Ismaning: Hueber.

Gercke, Hans (Hrsg.) (1990a): Blau. Farbe der Ferne. Heidelberg: Das Wunderhorn.

Gercke, Hans (1990b): Das Wunderbare und das Nichts. Eine Einführung. In: Gercke, Hans (Hrsg.) (1990a), 17-25.

González Aktories, Susana; Artigas Albarelli, Irene (Hrsg.) (2011): Entre Arte, entre Actos. Ecfrasis e intermedialidad. México: UNAM.

Heidegger, Martin (1951): Hölderlin und das Wesen der Dichtung. In: Erläuterungen zu Hölderlins Dichtung. 4. Aufl. Frankfurt a.M: Vittorio Klostermann, 33-48.

Heidegger, Martin (1973): Arte y poesía. Traducción y prólogo de Samuel Ramos. México: FCE.

Heidegger, Martin (2005): Aclaraciones a la poesía de Hölderlin. Versión castellana de Helena Cortés y Arturo Leyte. Madrid: Alianza Editorial. 
Heine, Heinrich (1971): Sämtliche Schriften. Dritter Band. München: Carl Hanser Verlag.

Hölderlin, Friedrich (1944-1962): Sämtliche Werke. Hrsg. von Friedrich Beissner, 6 Bände (Kleine Stuttgarter Hölderlin-Ausgabe).

Kranz, Gisbert (Hrsg.) (1975): Deutsche Bildwerke im deutschen Gedicht. München: Hueber.

Küppers, Harald (1990): Was ist Blau eigentlich farbentheoretisch gesehen? In: Gercke, Hans (Hrsg.) (1990a), 26-30.

Lankeit, Klaus (1953): Geleitwort. In: Marc, Franz (1953): Tierstudien. 36 Handzeichnungen und eine Vignette. Wiesbaden: Insel.

Linder, Gisela (2001): Blau die bimmlische Farbe. Texte und Bilder. Frankfurt a.M. u.a.: Insel.

Lindner, Burkhardt (2012): Versuch über Traumkitsch. Die blaue Blume im Land der Technik. In: Neue Rundschau 123, 4, 53-72.

Mallarmé, Stéphane (1945): Poésies complètes. Paris: Gallimard.

Mebus, Gudula; Pauldrach, Andreas; Rall, Marlene; Rösler, Dietmar (1987): Sprachbrücke 1. Deutsch als Fremdsprache. Stuttgart: Klett.

Pommerin-Götze, Gabriele (Hrsg.) (2003): Neruda blau. Ein poetisches Spiel mit der , schönsten aller Farben`. Bilder von Bómbolo N. Graubner. Ulm: Realis.

Rall, Dietrich (2007): ,Innen aus Verschiedenem entsteht ein ernster Geist'. Hölderlin-Fragmente als Herausforderung in einem Lesekurs für Philosophen. In: Jahrbuch Deutsch als Fremdsprache 33, 307-320.

Rall, Dietrich (2009): ,Innen aus Verschiedenem ensteht ein ernster Geist‘. Hölderlinfragmente für Philosophen in Mexiko. In: Hess-Lüttich, Ernest W. B.; Müller, Ulrich (Hrsg.): Kommunikation und Konflikt. Kulturkonzepte in der interkulturellen Germanistik. Frankfurt a.M.: Lang, 619-634.

Renner, Rolf G. (2000): Beschriebenes und erschriebenes Blau. Die Farbe Blau in literarischen Texten. In: Revista de Filologia Alemana 1, 14, 8, 217-230.

Restany, Pierre (1990): Blau oder die innere Unermesslichkeit. In: Gercke, Hans (Hrsg.) (1990a), 15-16.

Richter, Peter (2013): Gute Unterhaltung. Es gab eine Zeit, da waren ARD und ZDF das Paradies. [...] Der Redakteur Martin Wiebel kannte diese Zeit. Und ihr Ende. Ein Besuch. In: DIE ZEIT 26./27. Januar 2013, 3.

Schuth, Dietmar (1990): Yves Klein, geb. 1928 in Nizza, gest. 1962 in Paris. In: Gercke, Hans (Hrsg.) (1990a), 426-429. 
Tellkamp, Uwe (2009): Reise zur blauen Stadt. Frankfurt a.M. u.a.: Insel.

Wagner, Hans-Peter (1998): Ekphrasis. In: Nünning, Ansgar (Hrsg.): Metzller Lexikon Literatur- und Kulturtheorie. Ansätze - Personen - Grundbegriffe. Stuttgart u.a.: Metzler, 112.

Waiblinger, Friedrich Wilhelm (1823): Phaethon. Stuttgart: Franck.

Waiblinger, Wilhelm (1831/1981): Friedrich Hölderlins Leben, Dichtung und Wahnsinn. Tübingen: Schwäbische Verlagsanstalt.

Wolf, Christa (2003): Assoziationen in Blau. In: Pommerin-Götze (2003), 25-27. 



\title{
Literatur bewegt Grammatik. Ästhetisches Lernen im Grammatikunterricht des Deutschen als Fremdsprache
}

\author{
Angelike Weber \\ Immer wieder wird auf das besondere Poten₹ial von Literatur bingewiesen, Lernende emotional \\ zu berïbren und zu eigenen Produktionen anzuregen, auch im Fremdsprachenunterricht. Die \\ Arbeit mit Literatur braucht aber nicht auf den Literaturunterricht beschränkt zu werden, son- \\ dern auch Grammatikvermittlung kann anhand von literarischen Texten statfinden. Zu diesem \\ Zweck, wird ein Unterrichtsmodell entwickelt und es wird praktisch vorgeführt, wie Literatur im \\ Sprachunterricht integriert werden kann, um nicht nur Grammatik, sondern auch Literarizität \\ und kulturbezogenes Lernen zu vermitteln. Grundlage dieses Ansatzes stellt die Textgrammatik. \\ Harald Weinrichs dar, die als Basis für die bier vorgestellte Lernergrammatike dient.
}

\section{Literatur, Grammatik und (inter-)kulturelles Lernen im DaF-Unterricht}

Lange ist Literatur im Fremdsprachenunterricht zugunsten der Forderung nach alltagssprachlicher kommunikativer Kompetenz vernachlässigt worden. Seit Beginn der 1980er-Jahre findet eine „Wiederentdeckung“ (Neuner 1989: 67) von Literatur statt, und zwar nicht nur für Deutsch als Muttersprache, sondern auch für Deutsch als Fremdsprache. Den Vorzug der Literatur sieht Gerhard Neuner darin, dass der Einsatz literarischer Texte im Fremdsprachenunterricht die Begegnung mit der fremden Welt ermögliche, die in diesem Lernprozess auch der Persönlichkeitsentwicklung diene, und zwar werde die schöpferische Kraft entfaltet, die sich in Fantasie, Vorstellungskraft und Kreativität der Lernenden äußere. Sachtexte können 
zwar über ein fremdes Land informieren, so Neuner; dagegen regten fiktionale Texte die „interpretatorische Phantasie“ (ebd.) des Lernenden an, indem er seine eigene Lebens- und Welterfahrung zu Hilfe nehme, um Hypothesen über den „Sinn“ (ebd.) des Textes zu entwerfen.

Die Grammatik erfuhr im Laufe des vorigen Jahrhunderts ebenfalls unterschiedliche Schwerpunktsetzungen. Heute ist die Frage nicht mehr, ob Grammatik, sondern "wieviel, [...] und auf welche Weise“ (Rall 2001: 881). Dabei wird etwa von Thurmair (vgl. 1997: 38f.) ein kontextualisiertes und inhaltsorientiertes Grammatiklernen befürwortet, von Texten ausgehend, in denen die Lernenden aktiv einbezogen sind, Regeln zu entdecken und zu erkennen. Lern- und gedächtnispsychologische Gründe sprechen dafür, dass auf diese Weise erworbene Kenntnisse und Wissen besonders gut behalten werden, wie Schouten-van Parreren (1990: 12ff.) nachweist. Zugleich sollte das Konzept des lerner- und handlungsorientierten Unterrichts (vgl. Kast 1994: 8f.) mit berücksichtigt werden, dem ein kreativer Umgang mit literarischen Texten zugrunde liegt und der eigene Sprachproduktionen der Lernenden anregt.

Ein Grammatikunterricht, der Raum zur Beschäftigung mit literarischen Texten gibt, in denen induktiv Grammatikregeln entdeckt werden, die aber gleichzeitig die Fantasie und Kreativität der Lernenden herausfordert, scheint hier einen begehbaren Mittelweg anzubieten. Allerdings existiert meines Wissens eine solchermaßen didaktisierte Lernergrammatik noch nicht. Beide, sowohl die explizite Grammatik als auch die Literarizität der Texte, sollten einen gleichrangigen Stellenwert haben, und zwar in kommunikativer Einbettung, so dass ein kreatives Handeln mit der Fremdsprache praktiziert wird.

Der Begriff Literarizität wird bei Miall; Kuiken (1999) und Dobstadt (2009) näher ausgeführt und definiert. Unter Literarizität versteht Dobstadt (2009: 22) „die Vertrautheit mit Literatur und ihren Verfahren“. Literarizität sei ein Merkmal, das an eine bestimmte Einstellung des Rezipienten/der Rezipientin bzw. des Produzenten/der Produzentin eines Textes gebunden ist; sie sei kein textinhärentes Merkmal, sondern von der Rezeption abhängig. Literarizität manifestiere sich darin, dass sich die vertikale Struktur des sprachlichen Zeichens mit dem horizontal organisierten Geflecht (dem Text) in einer Weise decke, dass dadurch „vielschichtige, bisweilen widersprüchliche [...] Bedeutungen erzeugt werden“ (ebd.: 24). Nach Miall; Kuiken (1999) setzt sich Literarizität aus drei Komponenten der Reaktion auf einen literarischen Text zusammen:

- Stilmittel, die typisch für literarische Texte sind;

- ungewohnte Formulierungen, die den Lesenden emotional berühren, aufwühlen, beunruhigen oder verunsichern;

- konventionelle Konzepte oder Gefühle, die verfremdet, modifiziert oder transformiert werden. 
Wo diese drei Komponenten präsent sind und miteinander interagieren, kann Literarizität nach Miall; Kuiken (ebd.: 2) erzeugt werden. Sie argumentieren weiter, dass gerade die Literatur psychologische oder gefühlsmäßige Veränderungen bei Lesenden initiieren kann. Dadurch werde die Bedeutung der Literatur auch für eine Didaktik des Deutschen als Fremdsprache deutlich.

Weil aber in literarischen Texten auch kulturelle Aspekte einer Sprachgesellschaft zum Ausdruck kommen - ihr Leben, ihr Verhalten, ihre Weltbilder und Wertsysteme (vgl. Bischof; Kessling; Krechel 1999: 5) - bietet sich gleichzeitig auch die Möglichkeit des (inter-)kulturellen oder kulturbezogenen Lernens an. ${ }^{1}$ Literatur kann weit mehr bewegen als lediglich das Vermitteln landeskundlicher oder kultureller Information. Anstatt interkulturelle Vergleiche anzustellen, sollte differenziert mit und an kulturellen Deutungsmustern gearbeitet werden (vgl. Dobstadt; Riedner 2011: 7), d.h. mit dem kulturbezogenen Wissen, wodurch wir uns selbst, unserer Umwelt und unserem Handeln Sinn geben (vgl. Altmayer 2006: 184).

Diesen Anforderungen kann ein Fremdsprachenunterricht genügen, der vom literarischen Text ausgehend Grammatikphänomene explizit macht und gleichzeitig die Literarizität des Textes sowie (inter-)kulturelle Aspekte thematisiert.

\section{Die Textgrammatik Harald Weinrichs}

Weil Harald Weinrich in seiner Textgrammatik der deutschen Sprache (1993) sprachliche Erscheinungen bzw. Grammatik in Texten beschreibt, stellt sie die geeignete Grundlage für einen solchen Ansatz dar: „Die grammatischen Regeln werden nicht für einzelne Wörter oder zusammenhanglose Sätze formuliert, sondern auf größere Sinneinheiten bezogen", heißt es im Klappentext der oben genannten Textgrammatik. Der Text, nicht der Satz, wird in dieser Textgrammatik als oberste sprachliche Einheit angesehen, weil sich sprachliche Kommunikation immer in Texten, nicht in Sätzen und Wörtern vollzieht. Das Problem der herkömmlichen Grammatiken sei es, dass sie Texte auflösten, wodurch häufig die Textstrukturen verloren gingen (vgl. Weinrich 2001: 21).

\footnotetext{
1 Wo kulturelles Lernen eher die landeskundlichen Aspekte des Fremdsprachenunterrichts bezeichnet (vgl. Altmayer 2006: 181, Bauer 2009: 6), gehe es beim interkulturellen Lernen der 1980er-Jahre um die „Gegenüberstellung von eigener und fremder Kultur“; der interkulturelle Ansatz gehe von einer „eigen- und fremdkulturellen Perspektive“ aus (Dobstadt 2011: 7). Dieses interkulturell vergleichende Vorgehen werde in der neueren Forschung durch den Übergang zur „Didaktik eines umfassenden kulturbezogenen Lernens, das die kulturellen Gegensätzlichkeiten auflöst und überschreitet" (ebd.) abgelöst. Ein solches kulturbezogenes Lernen sei „auf das Einüben eines flexiblen, offenen Umgangs mit Fremdheit ausgerichtet“ (ebd.: 8). Nach Altmayer (2006: 184) sollten „landeskundliche bzw. kulturbezogene Lernprozesse [...] sich an dem Ziel orientieren, Lerner zum Verstehen deutschsprachiger Diskurse und zur Partizipation an ihnen zu befähigen, d.h. sie mit kulturbezogenem Wissen und kulturbezogenen Kompetenzen auszustatten, die sie in die Lage versetzen, deutschsprachige Diskurse zu verstehen und zu ihnen begründet (affirmativ oder kritisch) Stellung zu nehmen“".
} 
Mit der Didaktisierung der Textlinguistik für den Unterricht des Deutschen als Muttersprache und parallel dazu für den Fremdsprachenunterricht, wird der Text als die zentrale sprachlich-kommunikative und didaktische Einheit angesehen (vgl. Meier 2006: 193). Die Lernenden entnehmen dem Text Informationen, Sachverhalte oder Meinungen und erkennen dabei gleichzeitig deren sprachlich-situative Eingebundenheit in die fremde Sprache. Meier weist darauf hin, dass Texte als Ausgangspunkt und Ziel des Unterrichts verstanden und erarbeitet werden, damit die Lernenden zunehmend fähig sind, selbstständig neue und immer komplexere Texte zu rezipieren und zu produzieren.

Aus diesen einleitenden Beobachtungen zu der wechselnden Stellung von Literatur und Grammatik im Fremdsprachenunterricht entwickelte ich ein Unterrichtsmodell, welches die Rolle der Literatur bzw. Literarizität mit eben jenen Lernzielen der Grammatikvermittlung in Einklang bringt.

\section{Das Unterrichtsmodell}

Bevor die einzelnen Phasen nacheinander ausführlicher erklärt werden, um die Verfahrensweise des hier vorzustellenden Unterrichtsmodells deutlich zu machen, sollen zunächst zwei Begriffe erklärt werden. Der Begriff Inputtext für den literarischen Muster- oder Basistext und Outputtext für das Lernerergebnis wurden gewählt in Analogie zu den in der Psycholinguistik gängigen Begriffen des Inputs und Outputs beim Spracherwerb. Denn nach Wode (vgl. 1993: 22) findet der Sprachlernvorgang folgendermaßen statt: Die Sprache, der der Lernende ausgesetzt ist, ist der Input. Dieser wird verarbeitet und der Lernende erschließt sich daraus das System der Zielsprache. Seine sprachlichen Leistungen äußern sich im Output. Der Sprachlernvorgang ist also nicht nur ein bloßes Imitieren und Reproduzieren vorgegebener Äußerungen, sondern der Lernende muss sich die Zielsprache aus dem sprachlichen Input, den er registriert, „kreativ erschließen” (ebd.). Exakt nach diesem Muster soll der Lernende den literarischen Text als sprachlichen Input kreativ erschließen und in einem Outputtext eine sprachliche Leistung erbringen. Über den Lernvorgang zwischen Input und Output hat der Lehrende nur indirekte, bedingte Kenntnis, denn das Lernen produziert sich selbst, wie Spitzer in seinem Buch über das Lernen nachweist (vgl. Spitzer 2006: 417)2 ${ }^{2}$ Nur durch eine Interpretation des Outputs kann festgestellt werden, was wirklich gelernt wurde.

Es wurde ein Unterrichtsmodell mit den folgenden vier Phasen genutzt, die im Anschluss durch Erläuterung anhand von Beispielen näher erklärt werden:

\footnotetext{
${ }^{2}$ Der Begriff vermitteln sei falsch. Jeder lernt auf seiner Weise und genau das, was in das Gefüge seiner Synapsen am besten passt (ebd.).
} 


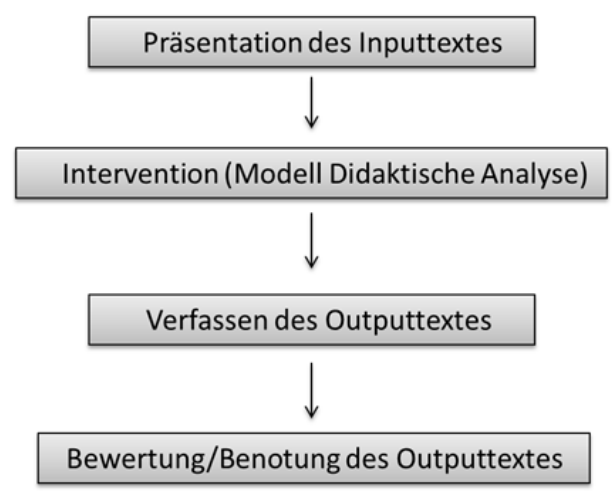

Abb. 1: Vierphasiges Ablaufmodell

\subsection{Die Inputtexte}

Ein literarischer Text dient als Grundlage für den Grammatikunterricht. Diese Inputtexte sind vor allem literarische Kurzformen wie Gedichte, sogenannte grammatische Gedichte, in denen die Grammatik mit der Lyrik gepaart wird (vgl. Wiemer 1974: 20)33, konkrete Poesie, Fabeln, Märchen und Auszüge aus Romanen. Einerseits sollten in dem literarischen Text genügend Beispiele für ein bestimmtes grammatisches Phänomen im Text vorhanden sein, um eine Regel erkennbar zu machen ${ }^{4}$. Andererseits sind aber in den Texten immer auch kulturelle, landeskundliche und ästhetische bzw. literarische Aspekte zu entdecken. Denn erst darin liegt das Potenzial der Literatur, kulturbezogene und sprachliche Kompetenzen zu vermitteln.

\subsection{Die Intervention: Modell Didaktische Analyse}

Im Die Intervention läuft nach dem Modell Didaktische Analyse ab. Dieses Modell wurde von dem Bildungstheoretiker und Erziehungswissenschaftler Wolfgang Klafki (1962) für Unterrichtsvorbereitung ganz allgemein geprägt und 1987 von Gerard Westhoff für den Fremdsprachenunterricht adaptiert (vgl. Bimmel; Kast; Neuner 2003: 29). Ich möchte darauf hinweisen, dass die didaktischen Leitfragen von Klafki nach Steinig; Huneke (2011: 263f.) bis heute als Richtlinie für die didaktische Analyse als zentralem Teil eines Unterrichtsentwurfs in der Lehrerausbildung dienen. Demnach wird der Unterricht in einzelne Phasen eingeteilt, in denen der Lernprozess abläuft. Nach der Einführung, Präsentation und Semantisierung

\footnotetext{
3 Nach Weinrich (1981: 180) unterscheiden sich diese Gedichte als grammatische Paradigmen von herkömmlichen Paradigmen als grammatische Übungen durch „de[n] kleine[n] Reiz einer genau kalkulierten Wortwahl“", die ,irritations-ästhetische Wirkungen“ auslösten.

${ }^{4}$ Butzkamm (1985: 119) weist darauf hin, dass oft schon ein einziges Beispiel im Kontext genüge, um ein grammatisches Phänomen zu verdeutlichen, beispielsweise die Verbendstellung in Nebensätzen.
} 
des Textes, der die neuen sprachlichen Mittel enthält, erfolgt die Entdeckung der Grammatikregel, ggf. durch eine gelenkte Übung.

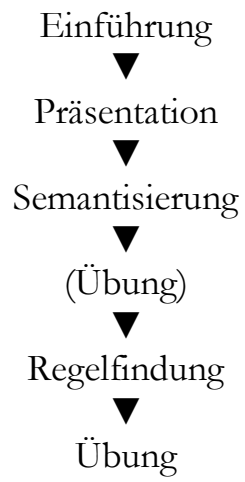

Abb. 2: Phasierungsmodell: Induktives Vorgehen bei Grammatikregeln (vgl. Bimmel u.a. 2003: 117).

Dieses Modell mit seinen Unterrichtsphasen eignet sich besonders gut für einen induktiven Grammatikunterricht, da in einem solchen Unterricht Texte als Grundlage und Ausgangspunkt für die „Entdeckung“ (Bimmel u.a. 2003: 116) der grammatischen Phänomene dienen. Nachdem der Text mit der zu lernenden Grammatikstruktur eingeführt, präsentiert und semantisiert wurde, „entdecken“ (ebd.) die Lernenden die Regel. Der Text hat weiterhin die Funktion, dem Lernenden für die eigene Textproduktion Anregung zu bieten, in der die neue Struktur frei, als offene Übung, angewendet wird. Denn letztlich ist die Grammatik nicht Ziel des Unterrichts, sondern Mittel zum Zweck: aktive, kreative, ästhetische und reflexive Verwendung der fremden Sprache durch die Lernenden.

\subsection{Die Outputtexte}

Als Hausaufgabe müssen die Lernenden nun selbst einen Text produzieren, in mehr oder weniger enger Anlehnung an den literarischen Inputtext. Letzterer soll ihnen als Anhaltspunkt, als Ausgangspunkt, als strukturelle Hilfe, als Modell dienen. Sie können sich eng an ihn halten, oder sich von ihm entfernen und ihrer Kreativität freien Lauf lassen. Enge bzw. keine Vorgaben hängen von der Aufgabenstellung und den Zielen des Lehrenden ab. Beispielsweise können sie zu einem Gedicht, das als Inputtext dient, ein Parallelgedicht schreiben, d.h. in Analogie zur formalen Textstruktur eines Gedichts ein eigenes Gedicht mit neuen Inhalten und Ideen füllen, oder aber sie können statt eines Parallelgedichts einen Prosatext schreiben. Auf diese Weise wird der kreative Umgang mit dem Text evoziert und der Lernende in die Lage versetzt, seinen eigenen Lernprozess „aktiv, in selbständiger, problemlösender, kreativ-konstruktiver Weise“" (Weirath 1995: 238) zu gestalten. Das Lernziel ist nicht die bloße Nachahmung des Inputtextes, sondern einerseits die grammatische Kompetenz, und andererseits die Umsetzung einer 
Erfahrung in ein Erlebnis, oder mit den Worten des Phänomenologen Bernhard Waldenfels, der „originäre Response“ (Waldenfels 2006: 56)5 auf den Inputtext.

\subsection{Bewertung und Benotung der Outputtexte}

Die letzte Phase des Unterrichtsmodells besteht aus der Bewertung bzw. Benotung der Outputtexte. Zunächst stellt sich die Frage, ob kreative Leistungen im Sprachunterricht überhaupt ermittelt und angemessen eingeschätzt werden können? Können Konzepte wie Originalität, Ästhetik, Erfindungsgabe, Sprachspiele und neue Ideen bewertet oder gar benotet werden? So schreibt etwa Ingrid Mummert (1989: 37), dass sie die literarischen Texte der Lernenden nicht zensieren würde, um sie vom Leistungsdruck auszuschließen. Kreativität und Originalität könnten sich nur „,in einem geschützten Raum frei von Kritik und Noten“ (Mummert; Pommerin 2000: 3) entfalten. Dagegen argumentiert Kern (2000: 298), dass Bewertung und Benotung dem Lernen an sich zuträglich seien. Auch aus meinem Ansatz heraus kann und soll dem Lernenden Feedback gegeben werden. Wenn das Lernziel auch Kreativität bzw. holistisches Engagement mit dem Text ist, so müssen wir das dem Lernenden rückmelden. Außerdem lebt die Ästhetik eines kreativen Textes gerade von der Grammatik und kann deshalb auch mit bewertet werden. Das Markieren von Fehlern und die Kommentierung der Outputtexte ermöglichen schriftliche Korrekturen - ein Prozess, der nach Kast (1999: 170) als „entwicklungsspezifische Notwendigkeit" verstanden werde. Fehler seien Zwischenetappen im Lehr- und Lernprozess, deren Korrekturen dazu beitragen, das Schreibvermögen der Lernenden kontinuierlich zu verbessern.

Da institutionelle Forderungen nicht nur die Bewertung, sondern auch die Notengebung verlangen, sollen folgende Leitfragen dazu dienen, eben diese Aspekte zu ermitteln und dabei Kriterien wie kommunikative Angemessenheit und grammatische Richtigkeit zu berücksichtigen. Die Leitfragen stützen sich auf Pommerin; Mummert (2001: 70), die, entgegen ihrer früheren Überzeugung, Leitfragen zur Ermittlung von Literarizität entwickelt haben:

- Positive Wahrnehmung: Was gefällt an dem Text, was ist originell oder kreativ, treffend beschrieben, witzig oder spannend?

- Welche Merkmale der Literarizität enthält der Text, z.B. Wiederholung, Kontraste und Widersprüche, Spannung, Bildhaftigkeit oder Doppeleffekt?

- Welche Emotionen evoziert der Text?

- Gibt es Leerstellen und Irritationen? Was ist unklar? Was irritiert?

- Kohärenz und Kohäsion: Gibt es logische Sprünge oder Ungereimtheiten?

\footnotetext{
5 Vgl. Waldenfels' Theorie der Responsivität (2006: 56f.): Indem Texte responsiv werden, binden sie den Leser in eine Leseerfahrung ein. Die „responsive Differenz“ (ebd.: 58) zwischen dem, was ich antworte und dem, worauf ich antworte, muss durch ein fragendes Wissen- und Verstehenwollen eingeebnet werden. Dadurch verliere das Fremde seine Fremdheit.
} 
- Welche (inter-)kulturellen Lernerbezüge weist der Text auf?

- Welche Fehler in Bezug auf das grammatische Thema wurden gemacht? Welche anderen Grammatikfehler gibt es? Welche Orthografie- und Interpunktionsfehler gibt es?

\section{Ergebnisse aus der Unterrichtspraxis}

Aus meiner Unterrichtspraxis an der Universität Pretoria möchte ich nun anhand eines Beispiels demonstrieren, wie dieses Modell praktisch einsetzbar und durchführbar ist. Die Studierenden befinden sich in etwa auf dem Niveau B1. Der Text von Ernst Eggimann, der uns hier als Beispiel dienen soll, stammt aus der Anthologie von R. O. Wiemer bundesdentsch. lyrik zur sache grammatik (1974):

der hof des bauern

der hut des bauern

der sonntagsanzug des bauern

der schweinestall des bauern

das vaterland des bauern

die milch des bauern

das vieh des bauern

der hund des bauern

die frau des bauern

Da der Text ausschließlich aus Genitivkonstruktionen besteht, eignet er sich zur Einführung oder Wiederholung des Genitivs, mit Berücksichtigung der n-Deklination des Substantivs. Im interkulturellen Sinne ist der Text deswegen interessant, weil sich der durchaus aktuelle Vergleich zwischen Bauern in Deutschland versus Farmern in Südafrika anbietet. Was südafrikanischen Lernenden durch die Darstellung des Eggimann-Textes fremd erscheint, soll dazu dienen, ,ihnen einen neuen Blick auf die Welt zu ermöglichen und ihre kulturellen Deutungsmuster zu reflektieren, zu bearbeiten und zu verändern“" (Dobstadt; Riedner 2011: 8). So kommen sie zu einem neuen, eigenen Ausdruck.

Auf den ersten Blick scheint es sich lediglich um eine willkürliche Auflistung typischer Dinge und Gegenstände zu handeln, die für einen Bauern von existenzieller Bedeutung sind. Das Gedicht hat eine monotone Struktur, die durch die Wiederholung stark an ein pattern drill erinnert. Doch enthalten die Zeilen einen Rhythmus: die Akzentuierung oder Hebung der jeweils ersten Silbe des Genitivattributs (der Hóf des Bauern, der Hút des Bauern usw.). Durch diesen Rhythmus prägt sich die Struktur leicht ein. Dadurch, dass es sich bei dem Text um ein zusammenhängendes Ganzes handelt, das dem Lesenden das Bild der Lebenswelt eines Bauern vor Augen malt, kann hier die Sprachtheorie des französischen Sprach- und Literaturwissenschaftlers Meschonnic angewandt werden, der die Sprache „als Sprachtätigkeit vom Rhythmus her denkt“, wie Lösener (2006: 67) das 
in seinem Buch Zwischen Wort und Wort beschreibt. Mit Rhythmus ist nicht unbedingt ein metrisches Muster gemeint, sondern die „Bewegung des Sprechens in der geschriebenen oder gesprochenen Rede“ (ebd.). Diese Sprechbewegung ist für Meschonnic immer auch eine Sinnbewegung, wobei es darum geht, diesen Sinn zu entdecken, ihn „herauszuhören“ (ebd.). Der Rhythmus gliedert die Rede, und ist gleichzeitig auch eine Sinngliederung (ebd.: 94). Nicht nur die Aussage eines Textes ist wichtig, sondern auch die Art und Weise, wie diese Aussage gemacht wird. Das Gedicht von Ernst Eggimann kann also durchaus wie ein pattern drill zur wiederholenden Einübung einer Struktur benutzt werden - ein Prozess, der nach Butzkamm (2002: 234) für das Lernen sehr wichtig ist, ${ }^{6}$ weil dadurch diese Struktur dem Lernenden verfügbar wird. Der Unterschied zu einem pattern drill im traditionellen Sinn liegt allerdings darin, dass eine solche Übung „durch interessante Austauschmöglichkeiten [den Lernenden] nahelegen kann, dass diese Satzstruktur auch für eigene Ausdrucksbedürfnisse taugt" (Butzkamm 2002: 219). Er kann also mit anderem Sinn gefüllt werden. Aus der Strukturübung muss dem Lernenden Gelegenheit gegeben werden, mit eigenen, neuen Ideen neue Texte zu „komponieren“ (ebd.: 239). Dieses sei ein wichtiger Schritt, der den Übergang vom Üben zum Kommunizieren ermögliche.

Der Eggimann-Text fällt aber auch durch die syntagmatische und paradigmatische Dimension der Sprache auf, wie sie in der Sprachwissenschaft dargestellt wird (vgl. Volmert 2005: 26f.): In der syntagmatischen Beziehung gehen die sprachlichen Zeichen in jeder Zeile in horizontaler Richtung in dem "Nebeneinander“ (ebd.) der Wörter Bindungen ein (Hof und Bauer; Hut und Bauer usw.). Die paradigmatischen Beziehungen werden dagegen vertikal in dem „Statteinander“ (ebd.) ausgedrückt (statt Hof - Hut; statt Hut - Sonntagsanzug usw.). Diese beiden Achsen bilden nach Dobstadt; Riedner (2011: 9f.) ein „semantisches Netz“, d.h. sie stehen in einem unmittelbaren Zusammenhang miteinander. ${ }^{7}$ Und hieraus lassen sich neue Zusammenhänge schaffen. Dieses soll in den folgenden Outputtexten gezeigt werden. Im ersten Beispiel wurde es den Lernenden überlassen, zu dem Eggimann-Text einen neuen, eigenen Text zu erstellen. Obwohl Ernst Eggimann die durchgehende Kleinschreibung und das Weglassen von Satzzeichen als literarisches Stilmittel benutzt, werden die Lernenden aufgefordert, sich an die Regeln der Orthografie zu halten.

${ }^{6}$ Butzkamm (2002: 234) nennt die Analogiebildung, die durch ein Muster, das in verschiedenen „Verkleidungen“" wiedererkannt wird, einen „Grundvorgang menschlichen Wissenserwerbs, ja des Lebens überhaupt.“

7 Roman Jakobson nennt diese Zusammenhänge der Sprache „sprachliche Äquivalenz“ (Weinrich 1981: 179; Dobstadt; Riedner 2011: 9f.). 


\section{Der Hund}

Mein Haus, das Haus des Hunds

Meine Stuhl, die Stuhl des Hunds

Meine Sofa, die Bett des Hunds

Meine Katze, das Freund des Hunds

Meine Schühen, die Essen des Hunds

Meine Toilette, die Wasser des Hunds

Meine Rasen, der Spielplatz des Hunds

Meine Bäumen, die Toiletten des Hunds

Der Hund, Mein Hund.

Dieser Outputtext ist eine sehr kreative, originelle Variante des Inputtextes. Statt lediglich typische Dinge des Hundes aufzuzeigen, beschreibt der Lerner, wie sich es sein Hund in seinem Haus zu Hause macht. Er benutzt die Möbel, als seien es seine eigenen; selbst die Freundschaft mit der Katze wird geteilt. Mit viel Humor beschreibt der Lerner in knappen Andeutungen, dass der Hund z.B. seine Schuhe zerkaut, aus der Kloschüssel säuft und im Garten die Bäume anpinkelt. In der letzten Zeile kommt die Liebe zu dem Tier durch die kurzen, treffenden Aussagen effektiv und kraftvoll zum Ausdruck.

Die Artikel werden zum großen Teil falsch verwendet, die Pluralformen in „meine Schühen“ und „meine Bäumen“ sind ebenfalls inkorrekt und durchgehend fehlt das „e" in der Genitivform von Hund, eine Tatsache, die insofern problematisch ist, als dass sich hier bei dem Lerner durch den fehlerhaften pattern drill eine fehlerhafte Struktur festgesetzt hat.

In einer weiteren Unterrichtseinheit wurde den Lernenden die Aufgabe gestellt, über einen Beruf ihrer Wahl einen Paralleltext zu dem Eggimann-Text zu schreiben.

\section{Ein stressiger Arzt}

Die Sprechstunde des Arztes

Das Leiden des Arztes

Der Stress des Arztes

Die Patienten des Arztes

Das Seizermesser des Arztes

Das Rezept des Arztes

Die Tablette des Arztes

Das Medikament des Arztes

Der gute Rat des Arztes

Der teuere Preis des Arztes

Der Outputtext gleicht dem Bauerntext in Struktur und Aufbau - und ist doch ein ganz anderer. Das Gedicht des Lerners entspricht genau den Anweisungen der Aufgabe, die aufgezählten Gegenstände sind nachvollziehbare Assoziationen zum Arztberuf. Direkt auf den Arzt selbst bezogen sind die beiden Begriffe „Leiden“ 
(gemeint ist wahrscheinlich das Mitleid mit den Patienten) und „Stress“ (wobei das Partizip „stressiger“ im Titel falsch benutzt wurde). Die letzte Zeile des Textes enthält eine überraschende Wendung, die den Tatsachen entspricht, aber auch witzig ist: Der Arzt kann helfen, er leidet mit und hat einen anstrengenden, stressvollen Beruf. Aber letztlich verlangt er vom Patienten dafür einen teuren Preis! Der Lerner hat die Pointe des Eggimann-Textes erkannt, und auf seinen eigenen Text übertragen. Auf diese Weise wird der Doppeleffekt sichtbar: Hier steht mehr als nur die einzelnen Sätze aussagen.

In einer weiteren Aufgabenstellung zu dem gleichen Inputtext wurden die Lernenden dazu aufgefordert, sich in einem Paralleltext zu politischen oder sozialen Umständen Südafrikas zu äußern und Kritik zu üben. Folgende Ergebnisse belegen die erfolgreiche Erfüllung dieser Aufgabe:

\author{
Der Präsident \\ die Villa des Präsidentes \\ die kleine Stadt des Präsidentes \\ das Schwimmbecken des Präsidentes \\ das Flugzeug des Präsidentes \\ die Reichheit des Präsidentes \\ die Frauen des Präsidentes \\ die Kinderin des Präsidentes \\ die Hochzeiten des Präsidentes \\ die Verantwortung des Präsidentes \\ Nein, die Steuern der Leute des Südafrikas!
}

In diesem Text wird offensichtlich der jetzige Präsident Südafrikas, Jacob Zuma, unter die Lupe genommen. Die Dinge, die hier im Zusammenhang mit dem Präsidenten genannt werden, sind überwiegend solche, für die er von der Öffentlichkeit kritisiert wird. ${ }^{8}$

Dass das Substantiv „Präsident“ ebenfalls nach der n-Deklination dekliniert wird, wurde hier nicht beachtet; hier ist die politische Emotionalität über das grammatische Lernziel hinausgeschossen. Auch hier hat sich wahrscheinlich durch den fehlerhaften pattern drill eine fehlerhafte Struktur beim Lernenden gefestigt. Die n-Deklination muss also erneut thematisiert werden.

\footnotetext{
8 Sein privates Anwesen in Nkandla (,die kleine Stadt“) wurde für über 200 Millionen erweitert, die zum großen Teil mit Steuergeldern bezahlt wurden. Er hat sechsmal geheiratet und hat 20 Kinder (abrufbar unter: http://de.wikipedia.org/wiki/Jacob_Zuma) (Stand: 6.2.2014).
} 


\section{Schlussfolgerung}

Anhand der Beispiele sollte gezeigt werden, wie ein literarischer Text zur induktiven Einführung eines grammatischen Themas dienen kann und wie Lernende dieses grammatische Phänomen in einem eigenen Text unter Anwendung ihrer eigenen, persönlichen, kulturellen und identitären Voraussetzungen zum Ausdruck bringen. Dabei aktualisieren sie ihre je eigenen kulturellen und auch literaturästhetischen Einstellungen. Die Arbeit am Genitiv wird zu einem ganzheitlichen, persönlichen Ausdruckserlebnis. Dass dieses möglich ist, sollen die vielfältigen Textbeispiele illustrieren und diese These belegen; dass jedoch die korrekte Anwendung der Grammatik dabei nicht immer gewährleistet werden kann, wird ebenfalls aus den Textbeispielen klar. Und doch wird, meine ich, in den Beispielen deutlich, dass durch das ästhetische Lernen ein Mehrwert gegeben ist, dass es um weit mehr geht als nur um kommunikative Angemessenheit und grammatische Richtigkeit. Kriterien der Literarizität, Originalität, Kreativität, affektive und emotionale Reaktionen und kulturbezogenes Lernen spielen gleichzeitig eine Rolle. Außerdem ermöglicht ein solcher Unterricht ein handlungs- und produktionsorientiertes Lernen. Und das lässt sich durchaus bewerten!

\section{Literatur}

Altmayer, Claus (2006): Landeskunde als Kulturwissenschaft. Ein Forschungsprogramm. In: Jahrbuch Deutsch als Fremdsprache 32, 181-199.

Bauer, Hans Ludwig (2009): Landeskunde und interkulturelles Lernen - Polemik und Praxis (1. Teil). In: Zielsprache Deutsch 36, 3, 3-21.

Bimmel, Peter; Kast, Bernd; Neuner, Gerd (2003): Deutschunterricht planen. Arbeit mit Lehrwerkslektionen. Berlin: Langenscheidt.

Bischof, Monika; Kessling, Viola; Krechel, Rüdiger (1999): Landeskunde und Literaturdidaktik. Berlin: Langenscheidt.

Butzkamm, Wolfgang (1985): Literarische Texte als Sprachlerntexte. In: Heid, Manfred (Hrsg.): New Yorker Werkstattgespräch 1984: Literarische Texte im Fremdsprachenunterricht. New York: Goethe House, 89-105.

Butzkamm, Wolfgang (2002): Psycholinguistik des Fremdsprachenunterrichts. Tübingen: Francke.

Dobstadt, Michael (2009): „Literarizität“ als Basiskategorie für die Arbeit mit Literatur in DaF-Kontexten. Zugleich ein Vorschlag zur Neuprofilierung des Arbeitsbereichs Literatur im Fach Deutsch als Fremdsprache. In: Deutsch als Fremdsprache 46, 1, 21-30. 
Dobstadt, Michael; Riedner, Renate (2011): Fremdsprache Literatur. Neue Konzepte zur Arbeit mit Literatur im Fremdsprachenunterricht. In: Fremdsprache Deutsch 4, 5-14.

Kast, Bernd (1994): Literatur im Anfängerunterricht. In: Fremdsprache Deutsch 11, 4-13.

Kast, Bernd (1999): Fertigkeit Schreiben. Berlin: Langenscheidt.

Kern, Richard (2000): Literacy and Language Teaching. Oxford: University Press.

Lösener, Hans (2006): Zwischen Wort und Wort. Interpretation und Textanalyse. München: Fink.

Meier, Jörg (2006): Angewandte Textlinguistik und DaF-Unterricht. In: Scherner, Maximilian; Ziegler, Arne (Hrsg.): Angewandte Textlinguistik. Perspektiven für den Deutsch- und Fremdsprachenunterricht. Tübingen: Narr, 193-203.

Miall, David S.; Kuiken, Don (1999): What is literariness? Three components of literary reading. In: Discourse Processes 28, 121-138.

Mummert, Ingrid (1989): Nachwuchspoeten. Jugendliche schreiben literarische Texte im Fremdsprachenunterricht Deutsch. München: Goethe-Institut/Klett.

Mummert, Ingrid; Pommerin, Gabriele (2000): Über die allmähliche Verfertigung von Texten (II). In: Deutsch als Fremdsprache 37, 1, 1-64.

Neuner, Gerhard (1989): Kinder- und Jugendliteratur im DaF-Unterricht - die Leser-/Lerner-Perspektive. In: Dilbilim VIII, Istanbul 8, 65-76.

Pommerin, Gabriela; Mummert, Ingrid (2001): Ansätze einer kreativitäts-orientierten Textanalyse und Textüberarbeitung (1). In: Deutsch als Fremdsprache 38, 2, 67-76.

Rall, Marlene (2001): Grammatikvermittlung. In: Helbig, Gerhard; Götze, Lutz; Henrici, Gert; Krumm, Hans-Jürgen u.a. (Hrsg.): Deutsch als Fremdsprache. Ein internationales Handbuch, 2. Halbband. Berlin: de Gruyter, 880-886.

Schouten-van Parreren, Caroline (1990): Wider das Vergessen. Lern- und gedächtnispsychologische Gesichtspunkte beim Wortschatzerwerb. In: Fremdsprache Deutsch 3, 12-16.

Spitzer, Manfred (2006): Lernen. Gehirnforschung und die Schule des Lebens. Heidelberg; Berlin: Spektrum.

Steinig, Wolfgang; Huneke, Hans-Werner (2011): Sprachdidaktik Deutsch. Eine Einfübrung. 4. Auflage. Berlin: Erich Schmidt.

Thurmaier, Maria (1997): Nicht ohne meine Grammatik! Vorschläge für eine Pädagogische Grammatik im Unterricht Deutsch als Fremdsprache. In: Jabrbuch Deutsch als Fremdsprache 23, 25-45. 
Volmert, Johannes (Hrsg.) (2005): Grundkurs Sprachwissenschaft. 5. Aufl. München: Fink.Waldenfels, Bernhard (2006): Grundmotive einer Phänomenologie des Fremden. Frankfurt a.M.: Suhrkamp.

Weinrich, Harald (1981): Von der Langeweile des Sprachunterrichts. In: Zeitschrift für Pädagogik 27, 169-185.

Weinrich, Harald (1993): Textgrammatik der deutschen Sprache. Unter Mitarbeit von Eva Breindl, Maria Thurmair, Eva-Maria Willkop. Mannheim: Dudenverlag.

Weinrich, Harald (2001): Tempus. Besprochene und erzählte Welt. München: Beck.

Weirath, Angela (1995): Kreative Übungen. In: Bausch, Karl-Richard; Christ, Herbert; Krumm, Hans-Jürgen (Hrsg.): Handbuch Fremdsprachenunterricht, 3. Aufl. Tübingen: Francke, 238.

Wiemer, Rudolf Otto (Hrsg.) (1974): bundesdeutsch. lyrik zur sache grammatik. Wuppertal: Hammer.

Wode, Henning (1993): Psycholinguistik. Eine Einführung in die Lehr- und Lernbarkeit von Sprachen. Theorien, Methoden, Ergebnisse. Ismaning: Hueber. 


\title{
Ästhetische Kommunikation im DaF-Unterricht Ich habe es eher als ein Arbeitswerkzeug betrachtet als ein richtiges Gedicht
}

\begin{abstract}
Anke Stöver-Blabak
Ästhetische Kommunikation, bier gesehen als Teil der Sprechwissenschaft/Sprecherziehung, wird im muttersprachlichen Unterricht Deutsch schon seit längerem diskutiert und eingeset:t. Im Fremdsprachunterricht gibt es dagegen kaum dokumentierte Beispiele oder Forschungsprojekte aus diesem Feld. In diesem Beitrag wird dargestellt, wie Methoden der Ästhetischen Kommunikation im DaF-Unterricht eingesetzt und dann im Rahmen eines Forschungsprojektes evaluiert wurden. Dabei geht es auch um eine Einführung dieses Konzeptes in die Fremdsprachendidaktik und seine Verortung im Kontext der Verwendung von künstlerischen Mitteln beim Lernen einer fremden Sprache.
\end{abstract}

\section{1 Ästhetische Kommunikation - Einführung}

Die wissenschaftliche Disziplin Sprechwissenschaft/Sprecherziehung unterteilt sich in die Bereiche Sprechbildung, Rhetorische Kommunikation, Therapeutische Kommunikation und Ästhetische Kommunikation.

Alltagssprachlich wird Ästhetische Kommunikation sehr allgemein als Kommunikation mit ästhetischen Mitteln verstanden. Innerhalb der Sprechwissenschaft/Sprecherziehung wird ihr Inhalt unterschiedlich ausgelegt: Gutenberg (2004: 246) z.B. hat ein sehr umfassendes Verständnis. Für ihn ist Ästhetische Kommunikation „das genussbereitende Moment menschlicher Produktivität“ (ebd.: 349). Damit ist prinzipiell jede Form menschlicher Kommunikation ästhe-

${ }^{1}$ Zitat Natalia, Skype-Interview, vgl. Stöver-Blahak 2012: 246 
tisch oder ästhetisierbar - nicht nur solche, die explizit als Kunst ausgewiesen ist (vgl. Gutenberg 1994: 349). Geißner dagegen versteht Ästhetische Kommunikation als „Interpretierendes Textsprechen“ (1981: 143) und auch Krech (1987) geht von einem sehr viel engeren Verständnis aus. Sie lehnt den Ausdruck Ästhetische Kommunikation ab, weil er ihr zu unpräzise erscheint:

So existiert das Ästhetische nicht nur im Zusammenhang mit dem Künstlerischen, sondern auch in anderen Bereichen des gesellschaftlichen Lebens; desgleichen lassen sich in bezug auf die Sprachverwendung ästhetische Komponenten in Sachtexten ebenso nachweisen wie in poetischen (ebd.: 13).

Sie definiert stattdessen: „Vortragskunst ist die Kunst der sprechgestaltenden Dichtungsinterpretation“ (ebd.: 13) und spricht von „sprechkünstlerischer Kommunikation“ (ebd.: 19) zwischen Sprecherin/Sprecher und Hörerin/Hörer. Diese eng gefasste Definition ist die Grundlage für die hier entwickelte Methode und sie wird trotz Krechs Vorbehalten unter das weite Dach der Ästhetischen Kommunikation gestellt, weil sie damit in der Sprechwissenschaft/Sprecherziehung besser zu verorten ist. Sie wurde aber, wie alle genannten Definitionen, für die Muttersprache Deutsch verfasst und noch nicht direkt auf unterrichtliche Kontexte oder, wie Krech formuliert, „pädagogische Situationen“ (ebd.: 147) bezogen. Eine solche, so Krech,

unterscheidet sich vor allem in der Zielsetzung und damit in der Ergebnisform. Zugleich unterscheidet sie sich dadurch, daß sich die verschiedenen Etappen der Aneignung (nicht nur der erarbeitete Vortrag) in steter Begegnung zwischen Sprecher und Hörer vollziehen. Sie umfaßt damit den gesamten Prozeß der (sprecherischen) Aneignung von Dichtungen von der Erstbegegnung bis zum erarbeiteten Vortrag (ebd.: 147).

Sprechen, Körperausdruck, Kommunikation und die Übermittlung von Sinn/Inhalt sind Aspekte, die für jeden Sprachunterricht bedeutsam sind. Allerdings werden diese performativen Kompetenzen vielfach im Kontext Dramapädagogik verortet, seltener im Bereich der Ästhetischen Kommunikation. Dabei beziehen sie sich dann auch eher auf den Bereich der Muttersprache Deutsch und nicht auf Deutsch als Fremdsprache.

Mit Methoden der Ästhetischen Kommunikation könnte wie im muttersprachlichen auch im Fremdsprachenunterricht eine, wie Bartsch formuliert, dritte Didaktik, eine „Sprech-Didaktik“ (vgl. Bartsch in Ertmer 1996: Nachwort, ohne Seitenzählung) neben der linguistischen und der literarischen entwickelt werden. Ertmer sieht

gestaltendes Sprechen“ als einen Prozeß der gezielten Anwendung von Sprechausdrucks- und Körperausdrucksmitteln in kommunikativer Absicht, in dem es dem Sprecher darum geht, dem Hörer den Sinngehalt des Ge- 
sprochenen über die Schallgestalt zu vermitteln, bzw. durch die Schallgestalt eine Vorstellung bezüglich des Sinngehalts im Hörer zu erwecken (Ertmer 1996: 29).

\section{2 Ästhetische Kommunikation als neues Feld zwischen Literaturunterricht und Dramapädagogik}

Der Titel des vorliegenden Sammelbandes zählt fünf Einsatzbereiche des Ästhetischen Lernens auf: Musik - Kunst - Film - Theater - Literatur. Der in diesem Beitrag vorgestellte Einsatz von Gedichten im DaF-Unterreicht scheint zunächst auf den fünften Bereich Literatur zu verweisen. Gedichte werden in dem hier vorgestellten Projekt nicht wie im traditionellen Literaturunterricht sitzend und überwiegend kognitiv analysiert, um sie danach möglicherweise vorzutragen, sondern sie werden ersprochen, d.h. sprechend erarbeitet. Dadurch rückt die vorgestellte Methode in den Bereich Theater. Die Beziehungen zu beiden Bereichen sind stark. Es gibt keine scharfen Trennlinien, sondern eher gemeinsame Felder. Wie Ästhetische Kommunikation als eigenständiger Bereich dazwischen zu sehen ist, soll im Folgenden gezeigt werden.

Der Einsatz von Methoden der Ästhetischen Kommunikation im Fremdsprachenunterricht stellt die Lernenden vor eine deutlich komplexere Aufgabe als Muttersprachlerinnen und Muttersprachler: Sie haben neben den für alle geltenden Differenzen zwischen der Entstehungszeit des Gedichtes und der Vortragszeit (vgl. Geißner 1981; Gutenberg 1994) noch weitere Aspekte zu bearbeiten: Sie sprechen ein Gedicht möglicherweise aus einer längst vergangenen Zeit und aus einer anderen Kultur und in einer anderen Sprache. Die Beziehung zwischen Sprecherinnen und Sprechern und ihren Gedichten ist dabei eine ganzheitliche. Indem sie einen Text aus einem fremdkulturellen Kontext sprechen, verleiben ${ }^{2}$ sie ihn sich quasi ein. Körper, Kognition und Emotionen sind beteiligt, Elemente von Fremdheit - lexikalische oder phonetische Hindernisse, aber auch das Wahrnehmen oder Nichtverstehen des kulturell und/oder historisch Anderen - treten beim sprecherischen Erarbeiten auf und werden in diesem Kontext behandelt und bestenfalls gelöst. Dabei, so die Ergebnisse der hier zugrundeliegenden Studie, konzentrieren sich Lernende zunächst auf Probleme der Lexik und Aussprache - zunehmend aber kommen suprasegmentale Elemente wie Intonation und Pausensetzung und in weiteren Schritten Mimik, Gestik, Haltung etc. hinzu. Da diese nicht ohne Bezug zum Inhalt bearbeitet werden können, entwickelt sich parallel die Interpretation. Ob und in welchem Umfang ggf. literaturwissenschaftliche Kenntnisse wie z.B. Wissen über Literaturgeschichte oder über die Biographie der Autorin/des Autors zur Erarbeitung der Sprechfassung hinzugezogen werden, ergibt sich ebenfalls während des Erarbeitungsprozesses. Wenn es für das Verständnis des Gedichtes

2 Zu dem Begriff der Einverleibung vgl. Schwerdtfeger 2000; 2002. 
notwendig oder auch einfach schon vorhanden ist, so kann und soll es eingesetzt werden. Wenn aber das Gedicht auch ohne weitere Information für die Sprechenden klar und verständlich ist, kann darauf verzichtet werden. Der Aneignungs- und Gestaltungsprozess ist hier in Abhängigkeit zu den Sprechenden und den Gedichten mit ihren jeweils spezifischen Besonderheiten zu sehen. Der Ausgangspunkt ist jedoch immer der Text. Konkret bedeutet dies, dass aktuellere Gedichte etwa von Erich Fried oder Hilde Domin zumeist auch ohne weitere Informationen erarbeitet werden können, ebenso Gedichte mit starken, sich selbst erklärenden Bildern wie z.B. Herbsttag von Rainer Maria Rilke. Das Lied von Lynkeus von Johann Wolfgang von Goethe dagegen erfordert eher eine Beschäftigung mit dem Kontext (Faust) und der mythischen Figur des Lynkeus (vgl. Stöver-Blahak 2013: 83ff.). Diese wird allerdings nicht von der Lehrperson angeordnet, sondern ergibt sich durch Hindernisse im Verstehens- und Erarbeitungsprozess. Wie diese Hindernisse überwunden werden, ist individuell zu betrachten. Aufgabe der Lehrkraft ist es, Hilfestellungen zu geben, wenn die Lernenden in ihrem Erarbeitungsprozess nicht weiterkommen. Solche Unterstützungen können direkte Erklärungen sein, aber auch Hinweise auf weiterführende Literatur oder aber das Problem wird in der Gruppe diskutiert und gelöst.

Sprech- und Vortragskompetenzen sind auch ein Teilbereich der performativen Kompetenz, die im fremdsprachendidaktischen Diskurs vor allem in der Dramapädagogik thematisiert wird (vgl. u.a. Hallet 2010, Haack; Surkamp 2011, Schewe 2011) und sie sind zumindest in akademischen Kontexten oft von großer Bedeutung. Methoden der Ästhetischen Kommunikation (hier: das gestaltende Sprechen eines Gedichtes bzw. die Erarbeitung einer Vortragsfassung eines Gedichtes) eignen sich sehr gut, genau diese Kompetenzen zu erweitern, zu entwickeln und zu üben. Beim Einsatz von Methoden der Ästhetischen Kommunikation im Fremdsprachenunterricht sollen keine Rezitatorinnen und Rezitatoren ausgebildet werden, sondern es werden - wie in der Dramapädagogik im Fremdsprachenunterricht - Methoden aus einem künstlerischen Bereich eingesetzt, um Ziele zu erreichen, die im pädagogischen Bereich liegen (vgl. Schewe 1993: 61ff.). Durch sie kann ganzheitlich und mit allen Sinnen z.B. an der Aussprache gearbeitet, der Einsatz von Mimik und Gestik geübt oder Sprechangst überwunden, eben die Sprech- und Vortragskompetenz trainiert werden.

Wie das Spielen in der Dramapädagogik ermöglicht auch das Vortragen eines Gedichtes den Lernenden, in einer Rolle zu sprechen, sich einer Maske zu bedienen, die ihnen Schutz bietet, aber gleichzeitig die Möglichkeit enthält, die Wirkung der eigenen Person zu testen. Lösener (2007) formuliert das für den muttersprachlichen Unterricht wie folgt:

So gesehen bietet die Situation des auswendig Sprechens einem Schüler die Möglichkeit, sich einerseits von der eigenen Person zu distanzieren (da er ja einen ,fremden` Text spricht, eine vorgegebene Maske trägt), gleichzeitig aber auch, unmittelbar die Wirkung der eigenen Person zu spüren und in- 
nerhalb einer Gruppe zu erproben (er hat sich diesen fremden Text ja zu eigen gemacht, die Maske zu seinem lebendigen Gesicht werden lassen) (ebd.: 139).

Für den Fremdsprachenunterricht gilt noch zusätzlich: Beim Erarbeiten einer Sprechfassung eines Gedichtes arbeiten die Lernenden mit einem gegebenen, fertigen Text. Sie sind deshalb entlastet vom Generieren eigenen Inhalts, sie müssen sich nicht auf Lexik oder den korrekten Gebrauch von Grammatik konzentrieren und haben dadurch die Möglichkeit, sich zunächst auf Aspekte der Aussprache zu konzentrieren und können je nach ihren Bedürfnissen langsam prosodische und sprechbegleitende Elemente hinzuziehen.

Elemente des Theaters wie Bewegungen im Raum, Requisiten u.Ä. sind möglich, wenn sie der Interpretation und ihrer Darstellung dienen. Über Einsatz und Form entscheidet allein der/die Vortragende.

Interaktion mit Mitspielerinnen oder Mitspielern gibt es in der Regel nicht und wenn, dann nur unter der Regie der Vortragenden. Im Mittelpunkt steht immer die/der Vortragende mit der ihr/ihm angemessenen Interpretation ihres/seines Gedichts in einer Kommunikationssituation mit dem Publikum. Die Vortragenden erhalten Zeit und Raum, von ihnen selbst bestimmte Phänomene des Sprechens und Vortragens in einer Gruppe ganzheitlich zu trainieren, mit der Möglichkeit zu kontrolliertem Feedback und zur Reflexion. Es geht um die individuell angemessene Form der Interpretation und Präsentation des Gedichts. Am Ende steht ein Produkt: die durchdachte, reflektierte, überprüfte, der Sprecherin/dem Sprecher, dem Gedicht und der Kommunikationssituation entsprechende Sprechfassung (vgl. Stöver-Blahak 2012: 98f.).

Es gibt keine klar definierte Grenze zum Literaturunterricht oder zur Dramapädagogik. Ästhetische Kommunikation im Fremdsprachenunterricht enthält Elemente aus beiden Bereichen und ist dennoch eigenständig. Der Unterricht ist sowohl handlungs- als auch prozess- als auch produktorientiert: Die Lernenden handeln, indem sie ihr Gedicht vortragen. Es geht um den Prozess der Erweiterung der Kompetenzen und am Ende steht ein Produkt, das sie einem Publikum vortragen. Der Prozess ist kreativ, denn es entsteht etwas Einzigartiges: eine im Moment des Vortragens stimmige Interpretation des Gedichts.

\section{Das Unterrichtsprojekt}

\subsection{Methodischer Ansatz}

Den Anstoß zu diesem Unterrichtsprojekt gab eine Beobachtung aus meiner Praxis als Deutsch als Fremdsprache-Dozentin am Fachsprachenzentrum der Leibniz Universität Hannover. Viele Studierende - auch, aber nicht nur mit langen DaFUnterrichtserfahrungen und guten Deutschkenntnissen - hatten Probleme, flüssig, 
gebunden, mit angemessener Intonation und Haltung zu sprechen. Bei den Recherchen nach einer adäquaten Methode, genau diesen Bereich zu trainieren, entdeckte ich eine Lücke zwischen Phonetikunterricht auf der einen und Präsentationstrainings auf der anderen Seite. Im Phonetikunterricht steht mehr die korrekte Verwendung von Einzellauten und Suprasegmentalia im Vordergrund, bei Präsentationstrainings geht es um das Erstellen und Halten von Präsentationen auf inhaltlicher und formaler Ebene - weniger auf der sprechtechnischen.

Beim Entwickeln einer Methode, die genau diese Lücke schließt, wurde berücksichtigt, dass Menschen zwar kognitiv aufnehmen können, welche Bereiche beim Vortragen zu bedenken sind (z.B. korrekte Aussprache, Intonation, Lautstärke, Sprechtempo, Haltung, Augenkontakt, Mimik, Gestik, u.a.) - dass sie aber im Moment des Vortragens, insbesondere in einer Fremdsprache, nicht in der Lage sind, alle diese Faktoren bewusst zu beachten. Das bedeutet, dass eine Reduktion vorgenommen werden muss.

Da es nur einen limitierten Vorrat an Aufmerksamkeit gibt und gleichzeitig auszuführende aufmerksamkeitsbeanspruchende Aktivitäten miteinander darum konkurrieren, muß die Aufmerksamkeit strategisch und möglichst effizient eingesetzt werden (Aguado 2003: 15).

Um den Vorrat an Aufmerksamkeit hier aber möglichst strategisch und effizient für den Vorgang des Vortragens nutzen zu können, soll der Bereich des Generierens von Inhalt dadurch entlastet werden, dass der Text schon vorgegeben ist. Der Weg zu den Gedichten ist (zunächst) also ein pragmatischer, sachorientierter. Aus ihm resultiert auch die hier zugrunde liegende Arbeitsdefinition: Gedichte sind relativ kurze Texte, die sich gut sprechen lassen.

Lange Balladen eigenen sich z.B. nicht, weil sie beim Vortragen zu viel Aufmerksamkeit auf das Erinnern des Textes fordern - Aufmerksamkeit, die dann für den Vorgang des Sprechens nicht zur Verfügung steht. Gründe für gute Sprechbarkeit können im Rhythmus, in der Melodie, im Metrum, in den Reimen oder in anderen Merkmalen der Lautung liegen. Der Inhalt muss für die Vortragenden eingängig und mitteilenswert sein - deshalb ist es bedeutsam, dass sie die Gedichte selbst auswählen. Nur dann kann eine Beziehung aufgebaut werden. Nonsensgedichte oder Gedichte mit sehr abstrakten, schwer zu entschlüsselnden Gedankengängen oder Metaphern oder mit einer besonders gestalteten äußeren Form sind ebenfalls - zumindest im ersten Schritt - nicht geeignet. Auch hier wird zu viel Aufmerksamkeit gebunden. Bewährt hat sich in der Praxis eine Auswahl von ca. 20 Gedichten, angefangen bei Goethe und Schiller über Heine, Hesse bis zu Fried und Domin (vgl. Stöver-Blahak 2012: Anhang A220). Aber sicher gibt es eine Vielzahl von Gedichten, die die Kriterien erfüllen und ebenfalls gut geeignet sind.

Der Unterricht wird nach konstruktivistischen Prinzipien durchgeführt (vgl. u.a. Wolff 2002a, Wolff 2002b) und basiert auf den Grundlagen der Lernerautonomie (vgl. u.a. Holec 1981, Wolff 2003, Wolff o.A.). Lernen, Fremdsprachenlernen und insbesondere das Lernen von Sprechen und Vortragen wird als ganzheitlicher Pro- 
zess gesehen, bei dem Kognition, Emotion, Körper und Sozialität untrennbar miteinander verbunden sind (vgl. Schwerdtfeger 1996, 1997, 2000, 2002).

\subsection{Rahmenbedingungen}

Der Kurs ist ein Teil des studienbegleitenden DaF-Angebots des Fachsprachenzentrums an der Leibniz Universität Hannover. Er wird ausgeschrieben als Kurs für Mündliche Kommunikation auf dem Niveau C1 - also für recht fortgeschrittene Lernende und Studierende aller Fakultäten der eher ingenieurwissenschaftlich geprägten Leibniz Universität. Die Praxis der vergangenen Jahre hat gezeigt, dass immer sehr heterogene Gruppen zusammenfinden: Herkunftsländer, Ausgangssprachen, Studienfächer, Semesterzahl und Lebensalter sind in der Regel bunt gemischt. Der Kurs läuft ein Semester (12-14 Wochen), er umfasst zwei Semesterwochenstunden, die Teilnehmerinnen und Teilnehmer erhalten drei ECTS ${ }^{3}$ Punkte. Als Semesterleistung gilt der Vortrag des ausgewählten Gedichts bei einer Abschlussveranstaltung vor einem öffentlichen Publikum (jede Teilnehmerin/jeder Teilnehmer lädt fünf Freundinnen und Freunde ein).

\subsection{Kursverlauf: Aufbau einer Sensibilisierung für performative Kompetenz}

Methodisch ist die erste Hälfte des Kurses geprägt von der schrittweisen Erarbeitung verschiedener Aspekte des Vortragens (vgl. Stöver-Blahak 2012: $141 \mathrm{ff}$.). Dabei werden bei jedem Termin in den ersten 15-20 Minuten Übungen zur Körperhaltung, zu Vokalen und Konsonanten, zur Lautstärke, zu Mimik, Gestik u.a. gemacht, häufig auch schon verbunden mit Aspekten zu gutem Vortragen, z.B. vor das Publikum treten, den Namen nennen und Augenkontakt halten. Wichtig ist hier, dass die einzelnen Übungen nicht isoliert für sich stehen, sondern gleich mit den Vorträgen der Gedichte verbunden werden. Die Teilnehmerinnen und Teilnehmer wählen nach ihren eigenen Kriterien ein Gedicht aus, für das sie dann im Lauf des Semesters eine Sprechfassung erarbeiten. Von der zweiten Stunde an sprechen sie ihr Gedicht vor der Gruppe. Danach berichten sie zunächst von ihren eigenen Eindrücken, dann geben die Zuhörerinnen und Zuhörer Feedback und am Ende können die Aussagen der einzelnen ggf. noch einmal an der Videoeinspielung verifiziert oder auch falsifiziert werden. Gemeinsam wird ein Kriterienkatalog für gutes Vortragen entwickelt ${ }^{4}$, der von der vierten Stunde an für alle zur Verfügung steht und nach dem jede/jeder einmal von allen beurteilt wird. Die ausgefüllten Kriterienkataloge bekommen die jeweils Vortragenden. Sie werten sie aus, entscheiden, welche Kritik sie annehmen möchten und sagen vor ihrem nächsten

\footnotetext{
${ }^{3}$ European Credit Transfer and Accumulation System, hier: Leistungspunkte, die von Hochschulen in Europa nach der durchschnittlichen Arbeitslast des Kurses (workload) vergeben werden.

4 Vgl. Stöver-Blahak 2012: 174 und Anlage 1 für den Kriterienkatalog des Sommersemesters 2014.
} 
Auftritt, worauf sie besonders achten wollen. Dabei sollen sie nur maximal zwei Aspekte nennen, weil, wie oben dargelegt, die Aufmerksamkeit in der Regel nicht für mehrere Phänomene reicht. Mit der Anwendung des Kriterienkatalogs wird das Wahrnehmungsvermögen der Teilnehmerinnen und Teilnehmer geschärft und die Kritik differenzierter und sachlicher. Gerade durch das geleitete Beurteilen schulen sie ihre performative Kompetenz, wie sie z.B. Hallet (2010) und Bonnet; Küppers (2011) in der Dramapädagogik verorten. Sie erleben und reflektieren individuell und in der Gruppe, wie sie und andere sich selbst und ihre Vorträge inszenieren, wie sie und andere Emotionen und Körper einsetzen, welche Wirkungen sie und andere erzielen wollen und können. Dabei ist ihnen durchaus bewusst, dass das Vortragen von Gedichten für sie nicht lebensweltlich relevant ist. Der Proband Ryan formuliert wie folgt: „Ich weiß nicht, wie viele deutsche Gedichte ich in der Zukunft vortragen werde, aber ich werde immer Konsonanten brauchen [...] jeden Tag“ (Stöver-Blahak 2012: 235). Darüber hinaus kennen die Kursteilnehmerinnen und Kursteilnehmer Vortragssituationen und erleben die Unterrichtssituation als authentisch. Die Gedichte mit ihrer verdichteten, schönen Sprache geben ihnen neben der Gelegenheit, Konsonanten u.Ä. zu üben, mehr Möglichkeiten zu experimentieren und neue Sprech-Varianten auszuprobieren, als sie es mit Sachtexten aus ihren Studienfächern könnten (vgl. Stöver-Blahak 2012: 119ff.).

Im Verlauf des Unterrichts verschiebt sich der Schwerpunkt ihrer Aufmerksamkeit immer mehr von dem Bewältigen von Aussprachehürden zu sprechbegleitenden und interpretatorischen Aspekten bis zu kompletten Inszenierungen. Der Werkzeugcharakter verschwindet, das Gedicht als vielfältig interpretierbares Kunstwerk rückt in den Aufmerksamkeitsfokus. Am Anfang beschreibt die schon in der Überschrift zitierte Probandin Natalia „Ich habe es [das Gedicht] eher als ein Arbeitswerkzeug betrachtet als ein richtiges Gedicht.“" (Stöver-Blahak 2012: 246), im Verlauf des Kurses ändern sich die Schwerpunkte: ,Je länger ich das Gedicht analysierte, desto besser konnte ich es aussprechen. Parallel war das Verständnis des Gedichts und das Aussprechen." (Stöver-Blahak 2012: 250). Bemerkenswert ist hierbei insbesondere die von ihr wahrgenommene Parallelität von zwei Entwicklungen, die miteinander verzahnt sind: Die Aussprache wird nicht an Einzellauten geübt, sondern immer im Kontext. Fragen der Interpretation ergeben sich im Prozess der sprecherischen Erarbeitung der Vortragsfassung. Pausensetzung, Intonation und Prosodie lassen sich nicht ohne eine intensive Auseinandersetzung mit dem Inhalt üben, wodurch der literarische Mehrwert des Textes Berücksichtigung findet.

In der zweiten Hälfte des Kurses beginnt die Vorbereitung der Abschlussveranstaltung, die komplett von den Teilnehmerinnen und Teilnehmern organisiert und durchgeführt wird. Sie müssen sich über Ankündigung, Werbung, Programmgestaltung, Moderation, Vortragsreihenfolge etc. Gedanken machen, Personen bestimmen, Rollen übernehmen. Auch dadurch schulen sie ihre performativen Kompetenzen. Sie verlassen mit dem kontrollierten, vorbereiteten Übergang in eine 
ihnen unbekannte Öffentlichkeit den geschützten Klassenraum und stellen sich einer realen Vortragssituation.

In einem ganzheitlichen Prozess entwickeln sich mit unterschiedlichen Akzentuierungen die Aussprachefähigkeiten, die Interpretationen und die Einsichten in die Möglichkeiten von Inszenierungen (vgl. Stöver-Blahak 2012: 232).

\subsection{Die Aufgaben der Lehrperson}

Die Lehrperson ist zunächst verantwortlich für den Kursablauf. Im Kontext der Studienbegleitung macht sie/er ein Angebot, das die Teilnehmerinnen und Teilnehmer annehmen. Da dieses Konzept in der Regel unbekannt ist, müssen am Anfang die Ziele und der Weg dorthin erläutert werden. Es hat sich bewährt, Videobeispiele aus vorhergehenden Kursen zu zeigen.

Im Kursverlauf hat die Lehrperson dann die Aufgabe, die Lernumgebung zu organisieren und so zu gestalten, dass das Lernen in der gewünschten Form stattfinden kann. Sie steht als Muttersprachlerin/Muttersprachler bzw. als kompetente Sprecherin/kompetenter Sprecher zur Verfügung, gibt als Pädagogin/Pädagoge dem Unterricht Struktur und Form, berät die Lernenden individuell, unterstützt und hält zu gemeinschaftlichem Lernen und Respekt vor den Leistungen und Schwierigkeiten einzelner an. Nach dem Prinzip der Lernerautonomie bestimmen die Kursteilnehmerinnen und -teilnehmer selbst ihre Ziele. Die Aufgabe der Lehrperson ist es, diese zu erkennen und geeignete Hilfestellungen zu geben (vgl. Stöver-Blahak 2012: 63ff., $141 \mathrm{ff}$.$) .$

\section{4 Ästhetische Kommunikation im DaF-Unterricht: Aus der Praxis in die Forschung und zurück}

Das hier vorgestellte Modell entstand aus der Praxis heraus. Es wurde in einer umfassenden Untersuchung evaluiert, deren Kernstück sieben Lernerinnen- und Lernerprofile sind, die durch eine große Datendichte sehr genaue Einblicke in die verschiedenen, höchst individuellen Lernprozesse der Probandinnen und Probanden während des Kurses geben (vgl. Stöver-Blahak 2012: 235ff.). Ersichtlich wird daraus, dass die Methoden der Ästhetischen Kommunikation von den Probandinnen und Probanden sehr unterschiedlich genutzt wurden. Dem Ansatz des konstruktivistischen Lehrens und Lernens folgend und auf der Basis des Konzepts vom autonomen Lernen hat jede Probandin/jeder Proband eigene Schwerpunkte gesetzt und sie im Rahmen des Unterrichts bearbeitet. Alle Probandinnen und Probanden konnten sowohl im eigenen Erleben als auch in der Diagnose von externen Gutachterinnen und Gutachtern Erfolge und Verbesserungen in den Bereichen Aussprache/Intonation, Authentizität, Werkangemessenheit, Hörerinnen-/ 
Hörerbezug und Situationsangemessenheit verzeichnen. ${ }^{5}$ Ästhetische Kommunikation ist demnach ein Weg, Sprechen und Vortragen sinnvoll und erfolgversprechend zu üben und die oben ausgemachte Lücke zwischen Phonetikunterricht und Präsentationstrainings zu füllen. Ein weiteres Forschungsergebnis ist, dass die im Rahmen dieser Arbeit entwickelten Deskriptoren zu den Feldern Authentizität, Bezug zum Publikum und inhaltliche und situative Angemessenheit zu einer Präzisierung des Gemeinsamen europäischen Referenzrahmens, der im Bereich der performativen Kompetenzen oberflächlich bleibt, beitragen könnten. Die Skalen zur Mündlichen Kommunikation umfassen überwiegend sprachlich-strukturelle Merkmale, die den inhaltlichen Aufbau eines mündlichen Beitrags betreffen (vgl. Trim u.a. 2001, 2000: 37f.). Die auch im Rahmen des Forschungsprojektes eingesetzte Skala zur Aussprache und Intonation (ebd.: 117) weist zum einen zwischen den Niveaustufen C1 und C2 keine Differenzierungen auf, zum anderen bleiben die angebotenen Deskriptoren sehr allgemein (z.B. „B2: Hat eine klare, natürliche Aussprache und Intonation erworben." (ebd.)) und lassen alle weiteren Einflussfaktoren außer Acht.

In der Fremdsprachendidaktik nutzt Ästhetische Kommunikation als Teil der Sprechwissenschaft/Sprecherziehung und verstanden als das gestaltende Erarbeiten einer Sprechfassung eines Gedichts einen künstlerischen Bereich ebenso wie Musik, Kunst, Film, Theater oder Literatur. Das Ziel ist eine Vortragsfassung, die der/dem Vortragenden, dem Gedicht und der Situation angemessen ist. Dabei geht es nicht um eine richtige Fassung oder gar darum, wie die Autorin/der Autor zu sprechen.

In der ,leibliche(n) Ko-Präsenz von Akteuren und Zuschauern' (FischerLichte 2004: 47) geht es nicht mehr um die Präsentation eines für sich bestehenden, unabhängig existierenden Kunstwerks, dem in der Aufführung Bedeutung repräsentativ verliehen wird, sondern um ein performatives Ereignis, in dem nicht Bedeutung beigelegt wird (Zeichencharakter), sondern das , selbstreferentiell und wirklichkeitskonstituierend' zugleich ist - so die Definition von ,performativ' (Kopfermann 2007: 67f., Hervorhebung im Original).

Kopfermann verfolgt in seinem Artikel keine fremdsprachendidaktischen Ziele. Dennoch meine ich, dass die hier gegebene Definition auch in diesem Rahmen Bestand hat. Die erarbeitete Präsentation eines Gedichtes in deutscher Sprache durch ausländische Studierende ist in dem Moment als performatives Ereignis ebenso selbstreferentiell und wirklichkeitskonstituierend wie die Präsentation des Gedichts durch eine muttersprachliche Rezitatorin/einen muttersprachlichen Rezitator (vgl. Stöver-Blahak 2012: 124).

Dieser Beitrag versteht sich als Plädoyer, Ästhetische Kommunikation, das gestaltende Sprechen eines Gedichts, als eigenständige Kunstform zu sehen, die der Fremdsprachendidaktik neue und eigene Möglichkeiten öffnet.

\footnotetext{
${ }^{5}$ Vgl. Auswertungen in Stöver-Blahak 2012: 308.
} 


\section{Literatur}

Aguado, Karin (2003): Kognitive Konstituenten der mündlichen Produktion in der Fremdsprache: Aufmerksamkeit, Monitoring und Automatisierung. In: Fremdsprachen Lehren und Lernen 32, 11-26.

Bartsch, Elmar (1996): Nachwort. In: Ertmer, Cornelia: Gestaltendes Sprechen in der Schule. Münster: Lit, o.S.

Bonnet, Andreas; Küppers, Almut (2011): Wozu taugen kooperatives Lernen und Dramapädagogik? Vergleich zweier populärer Inszenierungsformen. In: Küppers, Almut; Schmidt, Torben; Walter, Maik (Hrsg.): Inszenierungen im Fremdsprachenunterricht: Grundlagen, Formen, Perspektiven. Braunschweig: Bildungshaus Schulbuchverlage, Julius Klinkhardt Verlagsbuchhandlung, 32-52.

Ertmer, Cornelia (1996): Gestaltendes Sprechen in der Schule. Münster: Lit.

Fischer-Lichte, Erika (2004): Ästhetik des Performativen. Frankfurt a.M.: Suhrkamp.

Geißner, Hellmut K. (1981): Sprechwissenschaft - Theorie der mündlichen Kommunikation. Königstein: Scriptor.

Gutenberg, Norbert (1994): Grundlagen zu Sprechwissenschaft und Sprecherziehung. Göppingen: Kümmerle.

Gutenberg, Norbert (Hrsg.) (2004): Sprechwissenschaft und Schule. München u.a.: Reinhardt.

Haack, Adrian; Surkamp, Carola (2011): Gründe für eine Integration dramapädagogischer Methoden in der Lehrerausbildung. In: Küppers, Almut; Schmidt, Torben; Walter, Maik (Hrsg.) (2011), 53-66.

Hallet, Wolfgang (2010): Performative Kompetenz und Fremdsprachenunterricht. In: Scenario 2010, 15-18. Online: http://research.ucc.ie/scenario/2010/01/ hallet/02/de (Stand: 27.11.2013).

Holec, Henri (1981): Autonomy in Foreign Language Learning. Oxford: Pergamon Press.

Kopfermann, Thomas (2007): Wider die „Bauchrede des Autors“ - Sprech-Kunst nach der perfomativen Wende? In: Edith Slembek (Hrsg.): Transzensionen: angeregt - weiterdenken. Ehrenkolloquium zum 80. Geburtstag von Hellmuth K. Geißner. St. Ingbert: Röhrig Universitätsverlag, 61-71.

Krech, Eva-Maria (1987): Vortragskunst - Grundlagen der sprechkünstlerischen Gestaltung von Dichtung. Leipzig: VEB Bibliographisches Institut Leipzig.

Lösener, Annegret (2007): Gedichte sprechen - Ein didaktisches Konzept für alle Schulstufen. Baltmannsweiler: Schneider Verlag Hohengehren. 
Schewe, Manfred (1993): Fremdsprache inszenieren - Zur Fundierung einer dramapädagogischen Lehr- und Lermpraxis. Oldenburg: Zentrum für pädagogische Berufspraxis der Carl von Ossietzky Universität Oldenburg.

Schewe, Manfred (2011): Die Welt auch im fremdsprachlichen Unterricht immer wieder neu verzaubern - Plädoyer für eine performative Lehr- und Lernkultur! In: Küppers, Almuth; Schmidt, Thorben; Walter, Maik (Hrsg.) (2011), 20-31.

Schwerdtfeger, Inge Christine (1996): Ansätze für eine anthropologische Begründung der Didaktik des Unterrichts Deutsch als Fremdsprache. In: Info DaF 23, 4, 430-442.

Schwerdtfeger, Inge Christine (1997): Der Unterricht Deutsch als Fremdsprache: Auf der Suche nach den verlorenen Emotionen. In: Info DaF 24, 5, 587-606.

Schwerdtfeger, Inge Christine (2000): Leiblichkeit und Grammatik. In: Düwell, Henning; Gnutzmann, Claus; Königs, Frank G. (Hrsg.): Dimensionen der Didaktischen Grammatik, Festschrift für Günther Zimmermann zum 65. Geburtstag. Bochum: AKS-Verlag, 281-303.

Schwerdtfeger, Inge Christine (2002): Ganzheitliches Lernen und Leiblichkeit zwei Seiten einer Medaille? In: Wolff, Armin; Lange, Martin (Hrsg.): Europäisches Jahr der Sprachen: Mehrsprachigkeit in Europa. Regensburg: FaDaF, 247-263.

Stöver-Blahak, Anke (2012): Sprechen und Vortragen lernen im Fremdsprachenunterricht. Interpretativ, kreativ und ganzheitlich mit Gedichten. Frankfurt a.M.: Lang.

Stöver-Blahak, Anke (2013): Sprechen und Vortragen kreativ, ganzheitlich und effektiv lernen. Ästhetische Kommunikation im Fremdsprachenunterricht. In: Bredel, Ursula; Ezhova-Heer, Irina; Schlickau, Stephan (Hrsg.): Zur Sprache.kom. Deutsch als Fremd- und Zweitsprache. 39. Jahrestagung des Fachverbandes Deutsch als Fremdsprache an der Universität Hildesheim. Göttingen: Universitätsverlag, 212-226.

Trim, John; North, Brian; Coste, Daniel (2001): Gemeinsamer europäischer Referenzrahmen für Sprachen: lernen, lehren, beurteilen. Berlin: Langenscheidt.

Wolff, Dieter (2002a): Fremdsprachenlernen als Konstruktion: Grundlagen für eine konstruktivistische Fremdsprachendidaktik. Frankfurt a.M.: Lang.

Wolff, Dieter (2002b): Fremdsprachenlernen als Konstruktion - Einige Anmerkungen zu einem vieldiskutierten neuen Ansatz in der Fremdsprachendidaktik. In: Babylonia 4, 7-14. Online: http:/ / babylonia.ch/fileadmin/user_upload/ documents/2002-4/Baby4_02Wolff.pdf (Stand: 27.11.2013). 
Wolff, Dieter (2003): Lernerautonomie und selbst gesteuertes Lernen: Überblick. In: Bausch, Karl Richard; Christ, Herbert; Krumm, Hans-Jürgen (Hrsg.): Handbuch Fremdsprachenunterricht. Tübingen u.a.: Francke, 321-326.

Wolff, Dieter (o.A.): Lernstrategien: Ein Weg zu mehr Lernerautonomie, 11. Online: http://paedpsych.jk.uni-linz.ac.at:4711/LEHRTEXTE/Wolff98.html (Stand: 27.11.2013). 



\title{
Leseförderung mit literarischen Texten im DaZ-Unterricht
}

\author{
Antje Dobrn \\ Der folgende Beitrag zeigt, wie ästhetisches Lernen mit Literatur den Zweitspracherwerb fördern \\ und als eine wichtige Kompetenz und Mebrwert im DaZ-Unterricht auf- und ausgebaut werden \\ kann. Ein Leseförderungsmodell, das methodisch-didaktische Bausteine aus den fachdidaktischen \\ Teilgebieten Deutsch als Muttersprache (DaM), Deutsch als Zweitsprache (DaZ) und Deutsch \\ als Fremdsprache (DaF) einberieht, liefert die theoretische Grundlage, die durch eine Übungsty- \\ pologie ergänzt wird. Diese wurde im Rahmen einer Studie im Unterricht erprobt und veran- \\ schaulicht die Umsetzung in die Praxis. Der daraus resultierende sprachintegrative, literaturge- \\ stützte und DaZ-orientierte Regelklassenunterricht für die Sek I verstebt sich durch diese Synthe- \\ se bier ebenfalls als kultureller Begegnungsort.
}

\section{DaZ-Unterricht als Ort kultureller Begegnung}

Durch den regelmäßigen und gezielten Einsatz literarischer Texte im DaZUnterricht kann dieser als Ort kultureller Begegnung dienen und über die bloße Sprachvermittlung hinausgehen. Oftmals werden im DaZ-Unterricht literarische Texte als Vehikel und Unterlage für bestimmte sprachliche Phänomene, die es einzuüben gilt, eingesetzt oder Lesen wird auf rein funktionales Verstehen reduziert. Der didaktische Nutzen ist einsichtig, von ästhetischem Lernen kann so aber nicht die Rede sein.

Der Begriff Ästhetische Bildung hat seinen kulturphilosophischen Hintergrund in Friedrich Schillers Schrift Über die ästhetische Erziebung des Menschen (1795) und bezeichnet einen Ansatz in den Erziehungswissenschaften, bei dem der Mensch sich durch sinnliche Erfahrungen bildet und entwickelt. Es geht hier nicht allein um die 
Erfahrungen, die an künstlerischen Werken gemacht werden, sondern ästhetische Bildung zielt auf die Bildung der reflexiven Wahrnehmungs- und Empfindungsfähigkeit in allen Lebensbereichen ab. Bildung wird nicht in erster Linie als Wissensaneignung aufgefasst, bei der das Denken über der Wahrnehmung steht, sondern sie ist Weg und Ergebnis sinnlicher Erfahrungen - also auch sinnliche Erfahrungen mit anderen Kunst- und Medienformen, wie z.B. der Literatur und literarischen Texten. Diesen ästhetischen Zugang zur Bildung gilt es insbesondere angesichts der gegenwärtigen Effizienz- und Outputorientierung von DaZ im schulischen Unterricht und in der Lehrerfortbildung zu stärken. Didaktisch-methodische Möglichkeiten ästhetischen Gestaltens mit Literatur in der pädagogischen Praxis sind vielfältig, wie auch die Unterrichtsvorschläge in diesem Aufsatz zeigen werden. So können literarische Texte z.B. zur Vermittlung sprachlicher und landeskundlicher Inhalte verwendet werden. Die nicht nur rezeptive, sondern auch produktive und auf dem Hintergrund eines sprachintegrativen Vermittlungskonzeptes aufbauende Arbeit mit literarischen Texten impliziert Irritation, Imagination, Verfremdung, verweilende Aufmerksamkeit durch bestimmte Lesestrategien und Reflektion. Persönliche Teilnahme und Empathie, Vielperspektivität und Distanz zum Text gehen bei der ästhetischen Leseförderung eine Synthese ein und fördern das Lese- und Textverständnis. Die Spracharbeit mit literarischen Texten geht somit weit über die Vermittlung eines grammatischen Inventars zur Textcodierung hinaus.

\section{Die Förderung von Lesekompetenz im Bereich DaZ}

Ob ein Kind zum Leser oder zur Leserin wird, ist vor allem davon abhängig, ob es die Erfahrung machen kann, dass das Lesen seine Bedürfnisse nach Weltorientierung, sinnlich-ästhetischer Erfahrung und Selbstaufklärung betrifft und auch im sozialen Zusammenhang Sinn macht (Hurrelmann; Menzel 2002: 18).

Vor allem Migranten und Migrantinnen in der Sekundarstufe I (Sek I) sind die Verlierer und Verliererinnen im deutschen Bildungssystem. Viele Kinder und Jugendliche mit Migrationshintergrund, aber auch diejenigen deutscher Muttersprache aus bildungsfernen Familien, erleben die Sek I als eine schwer zu überwindende Hürde in ihrer Schullaufbahn. In den neunten und zehnten Klassen der deutschen Hauptschulen finden sich prozentual besonders viele DaZ- Schüler und Schülerinnen, was nicht erst seit den Ergebnissen von PISA bekannt ist. Da Lesekompetenz bei PISA in einem strikt funktionalistischen Sinne als Basis- oder Schlüsselkompetenz bewertet wird, ist sie grundlegend für den Erfolg in allen Schulfächern und maßgeblich am Schulabschluss beteiligt. Zur Entfaltung von Lesekompetenz bedarf es der Motivation zum Lesen und Nutzen von Texten, d.h. es muss Leseinteresse geweckt werden. Daneben muss die stetige Weiterentwicklung von Texterschließungsfähigkeiten betrieben werden. Beide Aspekte müssen in einer überzeugenden Verbindung unterrichtlich umgesetzt werden, damit sich der 
Aufbau von Lesekompetenz auf schulische wie persönliche Entwicklungsprozesse positiv auswirken kann. Gängige Formen der Lesemotivation orientieren sich an Schülern und Schülerinnen, denen die Lesemotivation fehlt, weil sie keine oder zu wenig Anreize bekommen. Vorgeschlagen werden die Einrichtung von Leseecken, die Inszenierung von Autorenlesungen, Lesenächte, literarische Spaziergänge, Theaterbesuche, das Erarbeiten und die Aufführung von Theaterstücken, Besuche bei Verlagen, in Buchhandlungen und Bibliotheken. Ein erheblicher Teil der Heranwachsenden (nicht nur unserer Zielgruppe) kann daran aber erst gar nicht teilnehmen, weil andere Teilbereiche der Lesekompetenz zu wenig ausgebildet sind, um die erhoffte Wirkung erzielen zu können. Die Schüler und Schülerinnen verstehen oftmals viele Wörter und Satzmuster nicht, ihre Verstehensvoraussetzungen werden zu wenig beachtet oder sie finden nicht genug Gelegenheit, im Unterricht an eigene Erfahrungen anknüpfen zu können und die verwendeten Begriffe mit Bedeutung zu füllen. Verstehensschwierigkeiten und die Ausgangsbedingungen dieser Schüler und Schülerinnen müssen viel stärker antizipiert und ins Zentrum gerückt werden, wobei sie nach und nach dazu geführt werden sollen, sich ihre Defizite auf diesem Gebiet selbst bewusst zu machen, nach unbekannten Wörtern zu fragen und zu lernen, diese auch selbstständig aus dem Kontext zu erschließen. Leseförderung bei Schülern und Schülerinnen nicht deutscher Herkunftssprache und/oder aus bildungsfernen sozialen Umgebungen ist also in jedem Fall weit mehr als vorrangige Motivierung zum Lesen; sie ist als kognitiver komplexer Prozess zu verstehen, in dem es um die Vermittlung basaler Lesefähigkeiten, um Texterschließungskompetenz und Vermittlung von Lese- und Textverstehensstrategien geht.

\section{Lesekompetenz und ästhetische Bildung im DaZ-Unterricht}

Hurrelmann geht von einem sehr weit gefassten Lesekompetenzbegriff aus und bezieht folgende Aspekte ein: die emotionale Dimension, die Fähigkeit, Texte bedürfnisbezogen auszuwählen, eigene Erfahrungen und Gefühlserlebnisse mit der Lektüre zu verbinden, das Vermögen, bei schwierigen Texten mit Unlust umzugehen, die Fähigkeit zum ästhetischen Wahrnehmen und Genießen (vgl. Spinner 2002: 54, Spinner 1998: 155-170). Als weitere Dimension wird dann die Fähigkeit zur Anschlusskommunikation einbezogen. Damit ist die Fähigkeit gemeint, sich über Gelesenes mit anderen auszutauschen, aber auch die Toleranz und Akzeptanz unterschiedlicher Interpretationen, das Aushandeln von Bedeutungskonsensen. Dieser Faktor erinnert sehr an das Unterrichtsgespräch, das Literaturgespräch im Unterricht, das ja nicht nur die Richtigkeit von Textrezeptionen überprüft, sondern als soziale Ko-Konstruktion von Bedeutungen in die Verständigung über Verstandenes einführt. Auch außerhalb der Schule wird erst über Anschlusskommunikation die Verbindung zwischen individueller Lektüre und Lesekultur sowie die Teilhabe der Lesenden am kulturellen und gesellschaftlichen Leben hergestellt. Hur- 
relmann bezeichnet dieses „kulturwissenschaftlich orientierte“ (Hurrelmann 2003: 18f.) Lesekompetenzmodell als didaktisch brauchbares Konzept zur Förderung der Lesekompetenz, da es sowohl motivationale, emotionale und interaktive Dimensionen des Textverstehens berücksichtigt. Eine andere Frage, die sich im Hinblick auf die Lesekompetenz der Lesenden im Sozialisationskontext stellt, ist die Verortung des lesenden Subjekts. Dabei stellt sich die Frage: Leistet die Lesekompetenz im Leben der jugendlichen Leser und Leserinnen heute noch einen unverzichtbaren Beitrag zu ihrer Subjektbildung - respektive sozialen und kulturellen Handlungsfähigkeit (vgl. Groeben; Hurrelmann 2002: 84)? Eventuell müssen auch die modernen Medien stärker miteinbezogen werden - nicht kompensatorisch, sondern vielmehr additiv. In ihrer Idealform sollte Lesekompetenz Informiertheit, Fähigkeit zur Weiterbildung, politisches Interesse, Kritikfähigkeit, kulturelles Gedächtnis (auf sozialer Seite), Fähigkeit zur Selbstreflexion, Artikulations- und Ausdrucksfähigkeit, Vorstellungsfähigkeit, ästhetische Genussfähigkeit (personale Seite) - soziokommunikative und personale Qualifikationen - umfassen. Wichtig in Bezug auf die DaZ-Lerner und -Lernerinnen scheint es jedoch, das Textverständnis durch systematische Spracharbeit an Texten und durch Herausbildung von Lesestrategien erst einmal so zu sichern, dass diese vorläufige Lesekompetenz als Grundlage für die weiteren Ziele dienen kann.

\section{Handlungs- und produktionsorientiertes Lesen und Textverstehen von literarischen Texten}

Aktive und produktive Momente konstituieren den Vorgang des Lesens. Dabei kommt der Definition von Lesen im Sinne von literarischem Lesen eine große Bedeutung zu. Waldmann versteht darunter nicht die kognitive Übernahme der in einem literarischen Text enthaltenen Aussagen nach dem Schema: Ein Sender/Autor bzw. eine Senderin/Autorin legt in ein Kommunikationsmittel/einen Text bestimmte Nachrichten, die der Empfänger/die Empfängerin dann entnimmt, indem er/sie die Nachricht kognitiv dekodiert/liest. Seiner Definition nach bedeutet der Lesevorgang etwas anderes: Lesen ist bei Waldmann immer sinnverstehendes Lesen; es muss als eine Synthese von rezeptivem und produktivem Prozess einerseits und kognitivem und imaginativem andererseits gelehrt werden. Diese Synthese sieht er im handlungs- und produktionsorientierten Unterricht verwirklicht. Wichtig im Kontext der Lernenden mit nicht deutschmuttersprachlichem Hintergrund ist seine These, dass die Voraussetzung für sinnverstehendes Lesen das Verständnis der Wörter ist. Hierbei handelt es sich um ein ästhetisches Textverständnis - der Leser/die Leserin wird zum Mitautor/zur Mitautorin (vgl. Waldmann 1989: 107). Im Folgenden schlägt Waldmann einen systematischen Katalog von Formen produktionsorientierten Umgangs mit literarischen Texten vor, an dem man sich orientieren kann, auch wenn er für die in Frage kommende 
Schülergruppe erweitert und modifiziert werden muss. Genannt werden Verfahren wie

- $\quad$ aktive und produktive Rezeption eines Textes

Methode: textgenaues Lesen, eigene Erfahrungen können auf den Text bezogen werden und umgekehrt

Ziel: Lesen führt zu aktivem und produktivem Umgehen mit dem Text

- aktives Hören von Texten

Ziele: Sensibilisierung für den Text über den auditiven Sinnkanal, Schulung des produktiven Hörens

Methode: Hören und Gespräche darüber, kritisches Hören von Texten, bei denen wichtige Stellen ausgelassen werden, neu dazugekommen sind, Aussagen falschen Personen zugeordnet wurden, Gespräche darüber, Vergleiche zwischen verschiedenen Fassungen und Original etc.

- aktives Lesen von Texten

Ziele: Weitgehendes Interesse am Text sowie kognitives und affektives Textverständnis

Methode: Erlesen mit verteilten Rollen, auch in Abschnitten etc.; Unterstreichen von wichtigen Textstellen, Herausschreiben wichtiger Textstellen, Plakaterstellung, Transportierung in andere Gattungsformen (z.B. Comic mit Sprechblasen o.ä.), Aushang, Gespräche über die Produktionen und Vergleich mit Original

- Darstellung gelesener Texte

Ziele: Nacherzählen, weitgehendes Textverständnis, kreative Textnäherung zwecks differenzierter Textwahrnehmung

Methode: perspektivische Umformungen, szenisches Darstellen, Rezitieren, Aufführen zwecks besseren Inhaltsverständnisses

- visuelle Darstellung gelesener Texte

Ziele: besseres affektives Textverständnis, Spiel mit dem Text, Anregung der Kreativität und Phantasie

Methode: Herstellung von Umschlagbildern, Werbeplakate, Illustrationen. Umsetzen eines Textabschnittes in eine Bildfrequenz oder einen Comic (vgl. ebd.: 114).

Waldmann betont die Vorteile einer produktiven Rezeption anhand mehrerer Beispiele für den Literaturunterricht, z.B. indem er die Möglichkeiten aufzeigt, mit einem modifizierten Text umzugehen:

- $\quad$ aktive Rezeption des Textes

- Rekonstruktion des modifizierten Textes

- Rekonstruktion vermischter Texte

- Ergänzung ausgelassener Textteile

- Konkretisierung der Umwelt eines Textes

- Konkretisierung der Figuren eines Textes 
- Konkretisierung der Handlungen und Handlungsverläufe eines Textes

- identifizierende Konkretisierung eines Textes

- $\quad$ konkretisierende Diskussion inhaltlicher Probleme eines Textes (vgl. ebd.: 121).

Wichtig sind die Vorüberlegungen, die zu dieser Herangehensweise führen: Durch Modifikationen des Textes soll seine Rezeption gehemmt und so wichtige Aspekte des Textes, die im üblichen, oft flüchtigen, automatisierten oder massenmedial deformierten Lesen nicht wahrgenommen werden, auffällig und erkennbar gemacht werden. Veränderungen am Text sind nie Selbstzweck, sondern haben die Funktion, zu einer intensiveren Textaufnahme zu führen. Durch die produktive Texterfahrung mit dem modifizierten Text sind Vorstellungsvorgänge und Phantasie gefordert und die eigene Erlebniswelt des Lesers wird aktiviert, an die der Text angeschlossen werden kann. Diese Eigentätigkeiten bilden in diesem Stadium bereits eine, wenn auch unausdrückliche, Analyse des Textes (vgl. ebd.: 119). Waldmanns Vorschläge zu einer angeleiteten und freien Produktion eines Textes umfassen ein breites Spektrum von starker Anleitung hin zu ganz freien Produktionen, was sowohl von den sprachlichen als auch inhaltlichen und entwicklungsspezifisch bedingten Voraussetzungen der Lernendengruppe abhängig ist. Es gilt nun, die didaktisch-methodischen Überlegungen Waldmanns in Bezug auf den Umgang mit der ausgewählten Literatur in die Ergebnisse der Leseforschung, wie sie in diesem Aufsatz unter der vorliegenden Fragestellung zusammengefasst wurden, in Einklang zu bringen und für den Unterricht in den in Frage kommenden Zielgruppen nutzbar zu machen. Dies soll folgendes Leseförderungsmodell leisten. 


\section{Leseförderungsmodell auf der Grundlage literarischer Texte für Regelklassen der Sek I mit hohem Anteil von Lernenden nicht deutscher Herkunftssprache}

Dohrn (2007) erstellte folgendes Leseförderungsmodell:

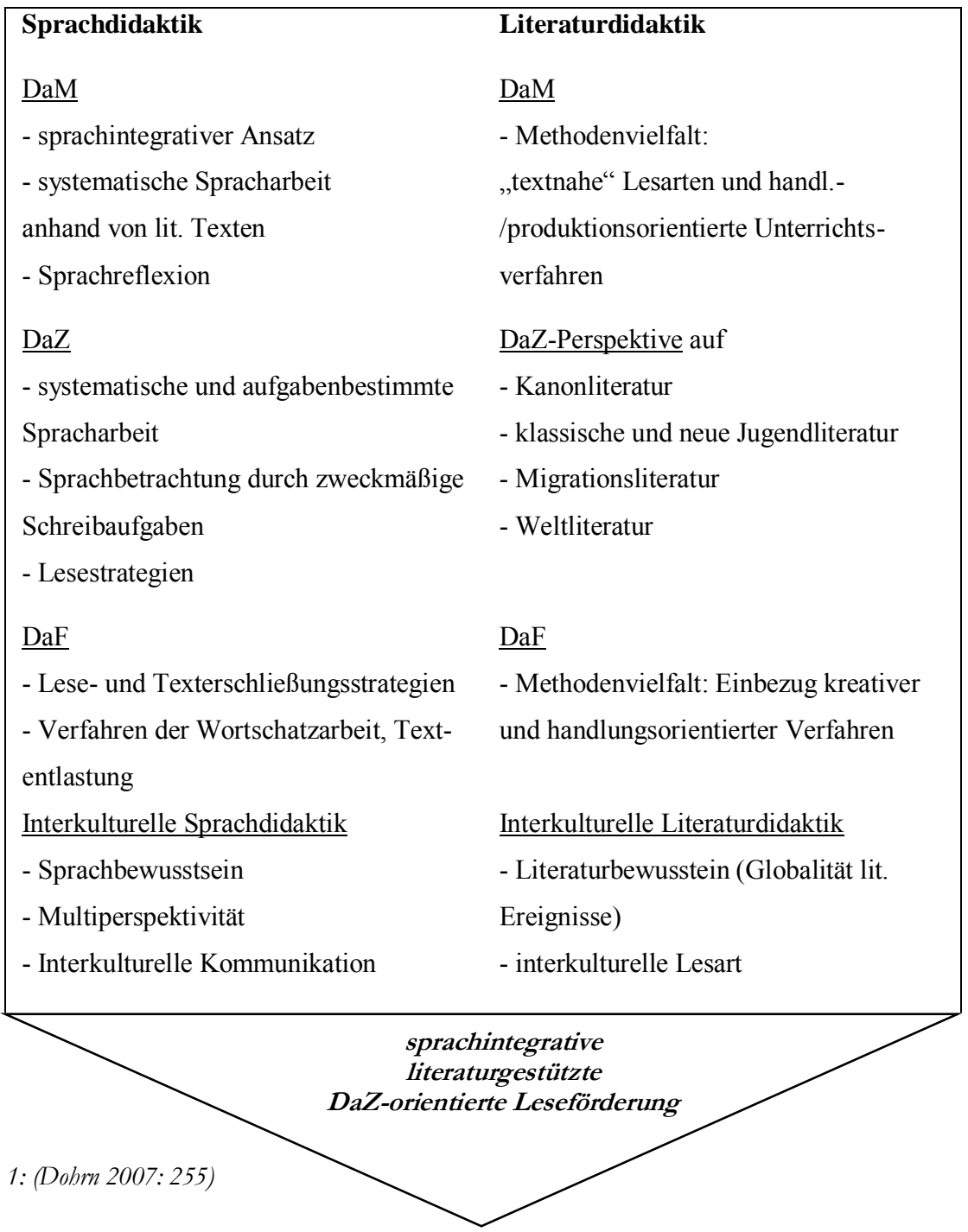


Die verstärkte Betonung der sprachlichen Anteile bei der Erschließung von literarischen Texten unter Einbeziehung von Verfahren aus der DaF-, Sprach- und Literaturdidaktik führen zu einem DaZ-orientierten Deutschunterricht für eine heterogene Regelklasse der Sek I. Das sprachintegrative Prinzip verbindet die Teilbereiche Sprach- und Literaturdidaktik. Hier fließen die auch im DaM-Unterricht systematisch zu verfolgende Spracharbeit und Sprachreflexion vor dem Hintergrund der Lernenden aus dem DaZ-Bereich mit ein. Elementar in diesem Zusammenhang ist eine stets parallel $\mathrm{zu}$ jedem Unterricht $\mathrm{zu}$ verfolgende Ausbildung und Erweiterung von Lese- und Texterschließungsstrategien, die den fachdidaktischen Teilbereichen der Fremdsprachen- und Muttersprachendidaktik entnommen wurden. Die erweiterte Palette an literarischen Texten, auf deren Grundlage Textverständnis erzielt werden soll und die sich für diesen literaturgestützten Ansatz eignet, dient der Erweiterung der Schüler-/Schülerinnen und Lehrer-/Lehrerinnenperspektive: Es erfolgt die Betrachtung der Texte aus Sicht von Lehrern/Lehrerinnen, muttersprachlichen Schülern/Schülerinnen und Schülern/Schülerinnen mit Migrationshintergrund. Ziel ist darüber hinaus ein Perspektivwechsel im Sinne interkulturellen Lernens. Texte aus der Kanonliteratur bieten sich hierfür ebenso an wie ausgewählte Werke der Jugend-, internationalen Welt- und Migrationsliteratur. In den Unterricht der Regelklassen müssen verstärkt Themen einbezogen werden, die die Lernbedürfnisse und -hintergründe der DaZ-Lernenden stärker berücksichtigen. Gerade die Situation in einer Regelklasse verlangt aber ebenfalls neue methodisch-didaktische Wege, da leicht die Gefahr besteht, mit den deutschen Kindern Gastarbeiterprobleme zu behandeln, ohne dass ausländische Kinder wegen ihrer sprachlichen Defizite - gleichberechtigt beteiligt wären (vgl. Luchtenberg 1989: 121). Neben der Textauswahl und der Didaktisierung unter Sprachlernschwerpunkten trägt das methodische Vorgehen entscheidend zum Ziel der Leseförderung bei. Durch die sinnvoll auf die Lernendengruppe abgestimmte Progression und abwechslungsreiche Auswahl an Texterschließungsverfahren und -strategien entsteht eine Synthese aus DaF- und DaM-Literaturdidaktik, die der sich entwickelnden DaZ-Literaturdidaktik den Weg ebnet. Verfahren aus der DaFSprachdidaktik wie z.B. aus dem Bereich der Wortschatzarbeit oder Textentlastung können den Schülern und Schülerinnen bei der ersten Textbegegnung und in weiteren Phasen einer tiefer gehenden Texterschließung Hilfen geben, ihre sprachliche Kompetenz und ihr Wissen erweitern und nicht zuletzt ihre Motivation bzw. den Leseatem aufrechterhalten. Emotionale und motivationale Anforderungen an ein Leseförderungsmodell werden somit ebenfalls berücksichtigt. Angestrebt werden sollte immer ein gemeinsames Lernen von DaM- und DaZ-Schülern und Schülerinnen, also ein erweitertes Konzept. 


\section{DaZ-didaktisch gestützte Möglichkeiten von Leseförderung am Beispiel von Fabeln}

Die folgenden Text- und Aufgabenbeispiele sollen exemplarisch aufzeigen, in welcher Art und Weise der zuvor in dieser Arbeit aufgezeigte Weg für den Bereich der Förderung von Lesekompetenz in den betreffenden Klassen möglich ist. Sie basieren auf den theoretischen Ausführungen dieses Aufsatzes, der inhaltlich einige relevante Aspekte zum Thema Leseförderung mit dem Schwerpunkt ästhetische Bildung im DaZ-Unterricht verbindet (vgl. Dohrn 2006: $187 \mathrm{ff}$.$) . Die einzelnen$ Bausteine, die sich aus der Muttersprachen-, Fremdsprachen- und Zweitsprachen(Literatur)didaktik in Hinblick auf das Ziel der Förderung von Lesekompetenz in Klassen mit hohem Anteil von Schülern und Schülerinnen nicht-deutscher Herkunftssprache als brauchbar erwiesen haben, lassen sich wie folgt konkretisieren sicherlich auch mit der Option, nach weiteren Erprobungsphasen und Modifikationen als Modell für einen Unterricht in diesen Lernergruppen zu fungieren. Dabei sind die exemplarisch ausgewählten Texte/Genres und Aufgaben keinesfalls verbindlich, sondern können durch entsprechende andere geeignete Texte/Genres und Aufgaben ausgetauscht bzw. erweitert und der jeweiligen Gruppe von Lernenden angepasst werden. Die Umsetzung der theoretischen Teile dieser Arbeit und ihrer Synthese unter dem Blickwinkel der Förderung von Lesekompetenz für die betroffene Gruppe von Lernenden soll anhand einer im Rahmenplan Deutsch für die siebten Klasse vorgesehenen Einheit zu epischen Kleinformen exemplarisch aufgezeigt werden (vgl. Senatsverwaltung für Schule, Jugend und Sport 2014: 28). Als konkretes Beispiel wurde das Thema Fabeln gewählt. In fast allen aktuellen Schulbüchern aller Schulformen findet sich gemäß den Richtlinien des Rahmenplanes eine Einheit zum Thema Fabeln. Analytische (Inhaltsfragen, oftmals in Form von W-Fragen) und handlungs- und produktionsorientierte Verfahrensvorschläge (Überschriften suchen, Leerstellen im Text füllen, Ende umschreiben o.̈.) wechseln und sind mehr oder weniger dominierend - abhängig von der didaktischen Ausrichtung des jeweiligen Lehrwerks. Dabei gibt es auch Übungen zur Optimierung der Lesekompetenz, die sich allerdings nur auf Teilaspekte beziehen (vgl. Menzel 2002: 33). DaZ-spezifische Aspekte, die den Zugang zum Text erleichtern oder sogar erst möglich machen, und Übungen, die das Textverständnis schrittweise erleichtern, sprachliches Wissen (re)aktivieren und zur Anwendung bringen, fehlen jedoch. Den theoretischen Erkenntnissen der Leseforschung/Sprach- und Literaturdidaktik aller einbezogenen Bereiche folgend könnte eine Leseförderung unter DaZ-spezifischen Aspekten durch folgende Vorgehensweise erreicht werden:

1. erste Textbegegnung

2. sukzessive Texterschließung

3. vertiefendes und selektives Textverstehen

4. textanalytisches Lesen und weiterführendes Textverstehen

5. handlungs- und produktionsorientierte Textproduktion 
Inhaltlich und thematisch sind folgende Schwerpunkte denkbar:

Fabeln aus verschiedenen Epochen: Motive im Vergleich

Hierbei bieten sich beispielhaft folgende Fabeln an:

- Jean de La Fontaine: Der Fuchs und der Rabe

- G. E. Lessing: Der Rabe und der Fuchs

- James Thurber: Der Fuchs und der Rabe

- James Thurber: Variationen über das Thema Rabe und Fuchs

\section{$7 \quad$ Texte und Aufgaben}

Wie Leseförderung auf der Grundlage des vorgestellten Leseförderungsmodells aussehen könnte, wird in diesem Kapitel exemplarisch verdeutlicht. Dabei kann nach dem Baukastenprinzip vorgegangen werden, d.h. je nach Leistungsstand der Zielgruppe, den Zielen des Unterrichts und der Zeit, die zur Verfügung steht, können Aufgaben aus den fünf Phasen der Lese- und Textverstehensförderung ausgewählt werden. Eine Progression lässt sich so individuell entwickeln. In einigen Aufgaben überschneiden sich Phasen (z.B. in Aufgabe 3, die mehrere Teilaufgaben enthält). Phasen einer handlungs- und produktionsorientierten Vorangehensweise können wiederum den Zielen selektiven Textverständnisses und/oder weiterführenden Textverstehens dienen. Die Verzahnung der Bereiche anstelle einer Abgrenzung voneinander ist im Sinne eines holistischen Ansatzes und dem Ziel des ästhetischen Lernens mit literarischen Texten erwünscht.

Der Fuchs und der Rabe (Jean de La Fontaine)

(Müller; Wolff 1982: 10)

Auf einem Baume Meister Rabe hockt, im Schnabel hält er einen Happen Käse.

Vom Käseduft herbeigelockt, spricht Meister Fuchs so fein, als ob er läse:

Ei, guten Morgen, Herr von Rabe,

was seid ihr hübsch, welch stattliches Gehabe!

Nein, ohne Lüge, Eurer Stimme Pracht, wär sie so schön wie Dero Federtracht, des Waldes König wäret, ohne Zweifel, Ihr!

Der Rabe schnappt fast über vor Begier; gleich soll der Wohllaut seiner Stimme schallen:

Er reißt den Schnabel auf und lässt den Käse fallen;

Den schluckt der Fuchs, es schmunzelte der Heuchler

Und sprach: Mein Herr, ein jeder Schmeichler

Lebt gut und gern von dem, der auf ihn hört:

Die Lehre ist doch wohl ein Stückchen Käse wert! 
Der Rabe, wütend und verdrossen, schwor $\mathrm{ab}$, jedoch zu spät, für immer solchen Possen.

Aufgabenbeispiele zum ersten Text: Der Fuchs und der Rabe (Jean de La Fontaine) Zum Umgang mit dem Text wäre folgende Vorgangsweise möglich:

\section{Erste Textbegegnung}

Aufgaben:

1) Schreibe in zwei Spalten einer Tabelle Adjektive, die die Tiere Fuchs und Rabe charakterisieren.

2) Welche Adjektive sind für die Tiere Fuchs und Rabe passend? Begründe deine Wahl!

3) mutig, dumm, eingebildet, leichtgläubig, unschuldig, schnell, listig, stoly, intelligent, schön, prächtig, begabt, eingebildet, unsicher, hinterlistig, naiv, unerfahren, gemein, betrügerisch, oberflächlich, berechnend, eitel

4) Finde für jedes der übrig gebliebenen Adjektive ein anderes passendes Tier, das mit diesem Adjektiv deiner Meinung nach gut charakterisiert ist (z.B. Löwe $=$ stolz).

5) In welchen Kulturen werden diese Eigenschaften diesen Tieren zugeschrieben? Wo nicht?

6) Schreibe fünf Schlüsselwörter auf, die dir zum Titel Der Fuchs und der Rabe einfallen.

7) Was könnten ein Fuchs und ein Rabe miteinander zu tun haben? Überlege dir eine Handlung in vier-fünf Stichpunkten.

8) Was unterscheidet Raben und Füchse deiner Meinung nach am meisten? Denk dir aus diesen Unterschieden einen Konflikt zwischen beiden aus, den du in vier-fünf Stichpunkten aufschreibst (mögliche Sozialformen: Einzelarbeit (EA), Partnerarbeit (PA), Gruppenarbeit (GA)).

\section{2. sukzessive Texterschließung}

a) Wortschatz

schwierige Wörter (Auswahl)

- bocken - in der Hocke sitzen (Körperbaltung andeuten)

- anlocken -jemanden zu sich bringen (Handbewegung)

- stattlich - prächtig, stolz.

- das Gehabe - eine unnatürliche Art sich zu benehmen (,Theater")

1) Die Wörter in der linken Spalte und ihre Erklärungen in der rechten Spalte werden durcheinander gewürfelt und müssen dann neu zusammengebracht werden (Pfeile, Verbindungslinien...).

Sozialform: PA oder Wettspiel in zwei Gruppen an der Tafel 
2) Text vortragen oder von einem Tonträger abspielen:

- Hörauftrag: Was passiert zwischen dem Fuchs und dem Raben?

- (Zuhören und dann in einem Satz aufschreiben!)

- In drei Bildern/Zeichnungen/Skizzen (mit Zeitvorgabe!) Inhalt wiedergeben: Auswertung im schülerzentrierten Unterrichtsgespräch.

- Schülerpräsentationen auf Folie, Austausch und gemeinsame Korrektur: Überprüfung der mündlichen Sprachkompetenz/des globalen Textverstehens.

- Mit drei Farben alle Sprecherrollen im Text markieren und jeweils angeben, wer spricht.

3) Stilles Lesen der Fabel, unbekannte Wörter und unklare Textstellen unterstreichen mit einer Farbe, mit anderer Farbe die jeweiligen Sprecher (Fuchs, Rabe, Erzähler) markieren.

4) Von welchem Infinitiv stammt die Verbform läse in Vers vier?

\section{3. vertiefendes und selektives Textverstehen}

1) Wortreihen laut lesen:

a) Posse/Flosse/Bosse/große/Füße/Regengüsse

b) Schmeichler/Heuchler/Rächer/Fleischer/Wäscher

c) schallen/krallen/wallen/zahlen/malen

d) Flocken/zocken/locken/kokeln/mogeln

e) Gatte/Ratte/Stadt/Staat/Rad/Rat

f) Lehre/Leere/Lerche/Kirsche/Birke

2) Text vortragen oder von einem Tonträger abspielen:

- Hörauftrag: Was passiert zwischen dem Fuchs und dem Raben?

- (Zuhören und dann in einem Satz aufschreiben!)

- In drei Bildern/Zeichnungen/Skizzen (mit Zeitvorgabe!) Inhalt wiedergeben: Auswertung im schülerzentrierten Unterrichtsgespräch.

- Schülerpräsentationen auf Folie, Austausch und gemeinsame Korrektur: Überprüfung der mündlichen Sprachkompetenz/des globalen Textverstehens).

- Mit drei Farben alle Sprecherrollen im Text markieren und jeweils angeben, wer spricht.

3) Beantwortung folgender Fragen zum Text/Multiple-Choice(MC)-Aufgabe:

a) Der Rabe lässt den Käse fallen, weil

- er Angst vor dem Fuchs hat.

- der Fuchs seinen Gesang gelobt hat und er ihm etwas vorsingen möchte.

- $\quad$ er zu gierig auf den Käse war und ihn verlor. 
b) Der Fuchs schmeichelt dem Raben, weil

- er ihn fressen will.

- $\quad$ er den Käse des Raben stehlen will.

- er den Gesang des Raben bewundert.

4) Warum ist der Fuchs ein Heuchler? (Ein bis zwei Sätze)

5) MC-Fragen beantworten:

- Welche Moral passt zu dieser Geschichte? Begründen Sie!

a) Ehrlich währt am längsten.

b) Wer anderen eine Grube gräbt, fällt selbst hinein.

c) Eitelkeit kommt vor dem Fall.

d) ?

- Wie nennt man eine Geschichte, in der Tiere menschliche Eigenschaften haben und einen Streit oder ein Problem/einen Konflikt miteinander austragen, an dessen Ende oftmals eine Lehre/Moral steht? Die anderen Gattungen kurz schriftlich erklären lassen, soweit bekannt.
a) Kurzgeschichte
b) Fabel
c) Anekdote
d) Sage

\section{4. textanalytisches Lesen und weiterführendes Textverstehen}

1) Überprüfung der ersten Textbeobachtungen und -ergebnisse/Überprüfung der Zuordnung der Adjektive zu den beiden Tieren, Korrektur, Erweiterung des Wortschatzes (gierig, schmeichlerisch, heuchlerisch...).

2) Beantwortung folgender Fragen zur Text/Multiple-Choice(MC)-Aufgabe:

a) Der Rabe lässt den Käse fallen, weil

- er Angst vor dem Fuchs hat.

- der Fuchs seinen Gesang gelobt hat und er ihm etwas vorsingen möchte.

- $\quad$ er zu gierig auf den Käse war und ihn verlor.

b) Der Fuchs schmeichelt dem Raben, weil

- er ihn fressen will.

- $\quad$ er den Käse des Raben stehlen will.

- $\quad$ er den Gesang des Raben bewundert.

3) Die Fabel im heute gültigen Satzbau aufschreiben.

4) Eine passende Moral oder Lehre am Schluss dieser Geschichte formulieren und am Text begründen.

5) Die Moral der Geschichte in eigenen Worten wiedergeben. 


\section{5. handlungs- und produktionsorientierte Textproduktion}

1) Text vortragen oder von einem Tonträger abspielen:

- Hörauftrag: Was passiert zwischen dem Fuchs und dem Raben?

- (Zuhören und dann in einem Satz aufschreiben!)

- In drei Bildern/Zeichnungen/Skizzen (mit Zeitvorgabe!) Inhalt wiedergeben: Auswertung im schülerzentrierten Unterrichtsgespräch

- Einstudieren des Textes in Partnerarbeit (flüssiges, betontes Rollenlesen mit Rollenwechsel).

- Schülerpräsentationen auf Folie, Austausch und gemeinsame Korrektur: Überprüfung der mündlichen Sprachkompetenz/des globalen Textverstehens).

- Mit drei Farben alle Sprecherrollen im Text markieren und jeweils angeben, wer spricht.

2) Einstudieren des Textes in Partnerarbeit (flüssiges, betontes Rollenlesen mit Rollenwechsel).

3) Die Fabel im heute gültigen Satzbau aufschreiben.

4) Die Fabel nur in Dialogform und in heutigem Deutsch zwischen den beiden Tieren (Gesagtes und Gedachtes) aufschreiben lassen.

5) Die Fabel in Umgangssprache umschreiben (PA oder EA).

6) Die beiden Tiere durch bestimmte Menschentypen, denen sie entsprechen (keine persönlich bekannten Personen!), ersetzen und die Fabel neu schreiben.

7) Den Käse durch ein anderes passendes Streitobjekt ersetzen und zwei bis drei andere Dinge an der Fabel unter Beibehaltung der Moral verändern.

8) Die Rollen von Fuchs und Rabe umdrehen und eine passende Fabel dazu schreiben.

9) Nach dem 12. Vers ein anderes Ende ausdenken und die Geschichte zu Ende schreiben.

10) Fabeln aus anderen Kulturkreisen erzählen lassen.

Diese Vorgehensweise ist systematisch übertragbar auf andere Texte und Textsorten. Zur weiteren Förderung der Sprachkompetenz oder zur Vertiefung bestimmter sprachlicher Problem- bzw. Übungsfelder bei lernschwachen Gruppen bieten sich eine Vielzahl weiterer Übungen und Aufgaben an, die sich aus den vorliegenden Texten ergeben und zudem prinzipiell auf andere literarische Texte und Textsorten übertragbar sind. Eine ähnliche Vorgehensweise kann auch auf eine kleinere Unterrichtseinheit oder -phase zugeschnitten werden oder kurze Fabeltexte können für einen Test verwendet werden. Die DaZ-orientierte Aufgabenauswahl sollte aus einer Synthese zwischen literarischem Lesen, Methoden aus dem handlungs- und produktionsorientieren Unterricht sowie der DaF-Literaturdidaktik und der DaZ-Didaktik entstehen. Das vorgeschlagene Verfahren eignet sich nicht nur zur DaZ-orientierten Förderung der Lesekompetenz anhand von literarischen Texten, sondern es kann auch für eine Sprachstandsdiagnose mit dieser Zielsetzung eingesetzt werden. Anhand einer Fabel und der dargestellten Aufgaben kön- 
nen so vor Beginn der sprachintegrativen Unterrichtseinheit im Bereich der Literaturerschließung der Leistungsstand der Lernergruppe erfasst und entsprechende Förderungsaufgaben aus dem Gesamtrepertoire sinnvoll ausgewählt werden. Stärken und Schwächen der Schüler und Schülerinnen im Bereich der Textverstehenskompetenz werden sowohl im rezeptiven als auch im produktiven Bereich erfasst und können als Grundlage einer weiteren Förderung und Zielbestimmung dienen. Anschließend sind konkrete Förderungsschwerpunkte (z.B. Adjektivflexion, Artikel) zu bestimmen, die in individueller Abstimmung auf die zuvor festgestellten Stärken und Schwächen der Lernergruppe mittels geeigneter Aufgabentypen und in methodisch vielfältiger sowie systematischer Weise im literaturorientierten Unterricht verfolgt werden.

Die Auswertung der Schüler- und Schülerinnenantworten kann darüber hinaus wiederum als Sprachförderung genutzt und/oder erweitert werden. Weitere Teilaufgaben zu unterschiedlichen Bereichen des Spracherwerbs (Grammatik, Rechtschreibung, Wortfeldarbeit im Bereich der Lexik o.̈.) können im Verlauf des Unterrichts und unter der eingenommenen Zielsetzung des rezeptiven und produktiven sprachlich angemessenen Textverstehens genutzt werden.

\section{Fazit}

Wie dieser Beitrag zeigt, gibt es eine große Anzahl von Möglichkeiten, durch ein sprachintegratives Unterrichtsprinzip ästhetisches Lernen und ästhetische Bildung im DaZ-Unterricht anhand des Einsatzes literarischer Texte auf- und auszubauen. Dabei konnten die ausgewählten didaktisch-methodischen Überlegungen aus der Lese- und Fremdsprachenliteraturforschung sowie bildungspolitische Hintergründe der DaZ-Sprach- und Literaturdidaktik zeigen, dass ästhetisches Lernen auch im DaZ-Unterricht einen Mehrwert hat und nicht im Gegensatz zur zunehmenden Kompetenzorientierung, sondern als ihre notwendige Ergänzung im Zeitalter von Globalisierung, zunehmender Mehrsprachigkeit, Interkulturalität und Informationsüberschwemmung zu sehen ist.

\section{Literatur}

Dohrn, Antje (2005): Mehr Lesekompetenz für mein Kind. Stuttgart: Urania.

Dohrn, Antje (2007): Leseförderung mit literarischen Texten im DaZ-Unterricht. Frankfurt a.M.: Lang.

Groeben, Norbert; Hurrelmann, Bettina (2002): Lesekompetenz: Bedingungen, Dimensionen, Funktionen. Weinheim u.a.: Juventa.

Hurrelmann, Bettina (2002b): Sozialhistorische Rahmenbedingungen sowie soziale und personale Einflussfaktoren. In: Groeben, Norbert; Hurrelmann, Bettina 
(Hrsg.): Lesekompeten₹. Bedingungen, Dimensionen, Funktionen. Weinheim u.a.: Juventa.

Hurrelmann, Bettina (2003): Leseleistung - Lesekompetenz. In: Menzel, Wolfgang (Hrsg.): Praxis Deutsch: Texte lesen - Texte verstehen. Sonderheft. Seelze: friedrich, 10-21.

Menzel, Wolfgang (2002): Lesen lernen dauert ein Leben lang. In: Praxis Deutsch 29, 176. Seelze: friedrich, 20-24.

Müller, Hans Georg; Wolff, Jürgen (Hrsg.) (1982): Fabel und Parabel. Stuttgart u.a.: Klett.

Senatsverwaltung für Schule, Jugend und Sport (Hrsg.): Rahmenplan für Unterricht und Erziehung in der Berliner Schule; Deutsch Sek I. Online: https://www.berlin.de/ imperia/md/content/sen-bildung/schulorganisation/lehrplaene/sek1_deutsch .pdf?start\&ts $=1150100794 \&$ file $=$ sek1_deutsch.pdf (Stand: 19.02.2014).

Spinner, Kaspar Helmut (1998): Vorschläge für einen kreativen Literaturunterricht. Frankfurt a.M.: Diesterweg.

Spinner, Kaspar Helmut (2002): Kreativer Deutschunterricht. Identität. Imagination. Kognition. Seelze: Klett/Kahlmeyer.

Waldmann, Günther (1989): Produktiver Umgang mit Literatur im Unterricht: Grundriss einer produktiven Hermeneutik. Baltmannsweiler: Schneider Verlag Hohengehren. 


\title{
Übersetzen von Liedern im DaF-Unterricht
}

\author{
Ulrike Pleß \\ In dem Artikel Übersetzen von Liedern im DaF-Unterricht wird diskutiert, inwiefern \\ das Übersetzen von Liedern für den Deutsch als Fremdsprache (DaF)-Unterricht relevant ist. In \\ diesem Zusammenhang wird ein Didaktisierungsvorscblag für verschiedene Sprachniveaus ge- \\ macht. Das Ziel ist, dass die Kursteilnehmenden einen Einblick in die fremde Welt und deren \\ Kultur erfabren. Sie sollen dabei sowobl von der emotionalen Wirkung, die durch die Musik \\ hervorgerufen wird, als auch von den spracblichen Elementen des Liedes lernen, indem sie sich \\ beim Übersetzen des Liedtextes intensiv mit der Sprache auseinandersetzen.
}

\section{Einführung}

Translation und Fremdsprachenunterricht pflegen schon seit jeher eine schwierige Beziehung. Das eine geht nicht ohne das andere und dennoch wurde das Übersetzen nach der Grammatik-Übersetzungsmethode jahrelang aus dem DaF-Unterricht verbannt (vgl. Haß 2010: 151ff.). Seit einiger Zeit gibt es bereits verschiedene erfolgreiche Ansätze, die Translation wieder in den DaF-Unterricht zu integrieren. Als Sprachmittlung hat sie Einzug in den Gemeinsamen Europäischen Referenzrahmen (GeR) erhalten (vgl. Trim u.a. 2001: 89ff.).

Dass die Vermittlung einer Fremdsprache losgelöst von der zugehörigen Kultur nur schwer möglich ist, ist ebenfalls kein Geheimnis (vgl. Hallet 2010: 129ff.). Aus diesem Grund wird die Wichtigkeit der Inbezugnahme verschiedener Kunstformen in den Fremdsprachenunterricht zur Kulturvermittlung immer stärker betont. Ästhetik als kultureller Begegnungsort im Klassenzimmer spricht die Emotionalität der Kursteilnehmenden an. Das ästhetische Lernen aktiviert verschiedene Sinne gleichzeitig und kann bei den Kursteilnehmenden eine emotionale Wirkung entfalten mit einer ganzheitlicheren Wahrnehmung als bei nur verkopftem Lernen. Ästhe- 
tik bietet den Kursteilnehmenden in der Regel die Möglichkeit, einen emotionalen Bezug zu ihrer eigenen Realität zu erstellen und diese in Beziehung zur Realität der Welt zu setzen. Auf diese Weise erleben sie das Klassenzimmer als kulturellen Begegnungsort ganz neu und reflektieren die Erfahrung emotional und mit ihrem eigenen Wissenshintergrund. Das heißt, es werden ganz neue Verbindungen für die Kursteilnehmenden hergestellt. Musik ist ein Beispiel für Ästhetik im Lernen, die einen authentischen Kulturträger darstellt. Sie lässt sich auf verschiedene Weisen im Deutschunterricht verwenden und spricht, je nach Aufgabenstellung, mehrere oder sogar alle vier Fertigkeiten an (vgl. Wicke, Rottmann, 2013: 4ff.).

In dem vorliegenden Artikel soll die Möglichkeit und Unmöglichkeit des Übersetzens von Liedtexten im DaF-Unterricht (vgl. Keim 2003: 388) analysiert werden. Im Besonderen soll dies am Unterricht mit spanischsprachigen Kursteilnehmenden untersucht werden, die am CUCSH (Centro Universitario de Ciencias Sociales y Humanidades) der Universität Guadalajara, Mexiko, Deutsch lernen. Dabei soll sowohl auf die Vorteile als auch Schwierigkeiten dieser Aufgabenform hingewiesen werden. Die Aufgabenstellung wird an unterschiedlichen Beispielen vorgestellt. Es werden konkrete Lieder vorgestellt, die sich gut für die untersuchten Sprachniveaus eignen, ebenso wie einige Negativbeispiele.

\section{Musik im DaF-Unterricht}

Musik spielt in allen Kulturen eine wichtige Rolle. Sie ist ein gesellschaftliches Phänomen und beide, Gesellschaft und Musik, stehen in wechselseitiger Beziehung zueinander. Für Musik ist im Grunde jedes Individuum zu begeistern.

Bei Liedern handelt es sich in der Regel um eine sangbare lyrische oder epische Kurzform, die den ursprünglichsten Ausdruck von Gefühlen und Stimmungen darstellt. Lieder sind in der Gesellschaft verankert und können zur Identifizierung verschiedener soziokultureller Gruppen dienen. Sie stellen einen wichtigen und authentischen Kulturträger dar, der über aktuelle gesellschaftliche Bewegungen und Stimmungen informiert.

Laut dem Neurophysiologen Eckart Altenmüller ist „Musik der stärkste Reiz für neuronale Umstrukturierung, den wir kennen“" (Altenmüller 2003: 68). Von dieser Erkenntnis sollte die Lehrkraft im Unterricht Gebrauch machen. Lieder sind emotional geprägt und können auf den Hörenden eine entspannende und stimulierende Wirkung haben; sie sind ein ausgezeichnetes Mittel, um die Unterrichtsroutine aufzubrechen. Musik im Unterricht kann zur Steigerung der Motivation und zur Vermittlung landeskundlicher Themen dienen. Mit Liedern kann man alle vier Fertigkeiten schulen, Wortschatz einführen bzw. festigen und grammatische Strukturen einüben (vgl. Goethe-Institut Brüssel o.A.: 1). Musik hat, wie wir sehen, verschiedene Vorzüge; bei solch einer Vielfalt an Verwendungsmöglichkeiten, muss die Lehrkraft den Schwerpunkt gezielt auf ein Thema setzen. 


\section{3 Übersetzen im DaF-Unterricht}

Wenn auch das Übersetzen aus dem Fremdsprachenunterricht für lange Zeit ausgeschlossen wurde, gibt es doch verschiedene Argumente, die für das Übersetzen im DaF-Unterricht sprechen. So ist beispielsweise nachgewiesen, dass Einsprachigkeit im Klassenraum nicht möglich ist, da die Muttersprache ständig im Kopf der Kursteilnehmenden präsent ist:

[D]er Lerner [bringt] nicht nur seine Muttersprache mit in den Unterricht, auch andere, bereits erlernte Fremdsprachen sind zugleich in seinem Kopf präsent und machen beim Lernen der neuen Fremdsprache ein großes Pontenzial an Informations- und Unterstützungsmaterial aus, das im Unterricht nicht ungenutzt bleiben sollte (de Carvalho Neto 2005: 34).

Sie vergleichen die erlernten Phänomene automatisch mit der Muttersprache sowie auch mit anderen bereits erlernten Sprachen. Des Weiteren ist das Übersetzen ein bewährtes Mittel zur Bewusstmachung von Fehlern. Worauf die Lehrkraft bei Übersetzungsübungen jedoch stets zu achten hat, ist, dass sie hauptsächlich zur Schulung des Textverstehens dienen, den allgemeinen Zielen des Unterrichts untergeordnet sein müssen und Schwierigkeitsgrad und Übungsform auf die Kursteilnehmenden zugeschnitten sein sollten (vgl. Königs 2010: 98).

Ulrike Draesner bestätigt: Das „Übersetzen ist die intensivste Weise, die ich kenne, einen Text zu lesen“ (Draesner 2008). Diese intensive Auseinandersetzung mit dem Text hilft den Kursteilnehmenden ihn zu verstehen und in vielen Fällen festzustellen, dass sie doch viel mehr verstehen, als sie eigentlich dachten, wenn sie den Text nur ausführlich genug lesen.

Das Übersetzen - wie auch das Dolmetschen - haben unter dem Überbegriff der Sprachmittlung schon vor einiger Zeit Einzug in den GeR erhalten. Es wird von sogenannten sprachmittelnden Aktivitäten gesprochen, bei denen es

den Sprachverwendenden nicht darum [geht], seine/ihre eigenen Absichten zum Ausdruck zu bringen, sondern darum, Mittler zwischen Gesprächspartnern zu sein, die einander nicht direkt verstehen können, weil sie Sprecher verschiedener Sprachen sind (was der häufigste, aber nicht der einzige Fall ist). Zu den sprachmittelnden Aktivitäten gehören Dolmetschen und Übersetzen sowie das Zusammenfassen und Paraphrasieren von Texten in der selben Sprache, wenn derjenige, für den der Text gedacht ist, den Originaltext nicht versteht (Trim u.a. 2001: 89f.).

Der GeR unterscheidet zwischen mündlicher und schriftlicher Sprachmittlung; für beide liegen jedoch noch keine Bewertungsskalen vor. In der schriftlichen Sprachmittlung nennt der GeR unter anderem das literarische Übersetzen, unter welches das Übersetzen von Liedern als literarische Textgattung fällt.

Man kann die unterschiedlichsten Übersetzungsaufgaben im DaF-Unterricht stellen. So kann man einzelne Sätze übersetzen lassen, beispielsweise um die Kurs- 
teilnehmenden auf eigene Fehler aufmerksam zu machen. Man kann allgemeinsprachliche Texte zur Einführung in verschiedene Thematiken übersetzen. Es können Texte mit Lokalkolorit zur Vermittlung landeskundlicher Themen übersetzt werden und auch Fachtexte, z.B. bei der Thematik Erfindungen, um nur einige Beispiele zu nennen.

\section{4 Übersetzen von Liedern}

Eine weitere Variante ist das Übersetzen von Liedern. Der Lehrkraft sollen hier zwei Möglichkeiten vorgestellt werden: Sie hat einerseits die Möglichkeit, das Lied selbst auszuwählen, passend zu dem Thema der behandelten Lektion; diese Variante bietet sich vor allem bei niedrigen Niveaus an (beispielsweise A1), um die Anpassung an das Niveau der Kursteilnehmenden zu garantieren. Oder sie bittet die Kursteilnehmenden, sich ein Lied auszusuchen. Dieses wird dann mit Name der Musikgruppe, Titel des Liedes, Thematik des Liedes sowie Begründung, warum das Lied ausgewählt wurde, von den Kursteilnehmenden vorgestellt. Dabei sollte die Lehrkraft gegebenenfalls einschreiten, um sicherzugehen, dass sich der Liedtext für eine anschließende Übersetzung eignet. Die Kursteilnehmenden bekommen daraufhin folgenden Übersetzungsauftrag: Ein mexikanischer Freund hat ein deutsches Lied gehört, das ihm sehr gefallen hat. Er versteht jedoch kein Deutsch und weiß, dass du die Sprache lernst. Er bittet dich daher, ihm mit der Übersetzung des Liedtextes zu helfen. Übersetze den Liedtext so, dass dein Freund keine Probleme hat, ihn zu verstehen. Füge, wenn nötig, Erklärungen hinzu. Die Kursteilnehmenden übersetzen den Liedtext ihres Liedes als Hausaufgabe oder aber im Kurs; in diesem Fall sollte für Internetzugang gesorgt sein. Es ist wichtig, dass den Kursteilnehmenden ausreichend Zeit eingeräumt wird, um gegebenenfalls tief gehende Recherche betreiben zu können. Die Aufgabe dient „der Simulation von authentischen Sprachmittlungssituationen“ (Königs 2010: 98), sie ist sehr realitätsnah formuliert und sollte von den Kursteilnehmenden dementsprechend gelöst werden können, das heißt mit Zugang zu allen Hilfsmitteln: Internet, Wörterbücher, Komilitonen/Komilitoninnen oder Freunde/Freundinnen, Muttersprachler/Muttersprachlerinnen etc. Es sollte den Kursteilnehmenden außerdem nahegelegt werden, nicht oder mit großer Vorsicht Google Translate zu verwenden, da es sich bei diesem Werkzeug um eine Maschinenübersetzung handelt, nicht um einen professionellen Übersetzungsdienst, weshalb die auf diesem Wege generierten Übersetzungen in der Regel sehr fehlerbehaftet sind. ${ }^{1}$

Meine Erfahrungen mit dieser Aufgabenstellung beziehen sich vor allem auf den Anfängerbereich und zwar auf die Niveaustufen A1 bis A2. Nachfolgend werden verschiedene Beispiele mit Liedern angeführt, die von den Kursteilnehmenden übersetzt wurden. Die Übersetzungen rangieren von sehr guten Ergebnissen, über

\footnotetext{
${ }^{1} \mathrm{Zu}$ empfehlen sind Online-Wörterbücher wie Pons oder Langenscheidt, der Duden wie auch die Nutzung von Enzyklopädien wie Wikipedia etc.
} 
fehlerbehaftete bis hin zu Negativbeispielen von Liedern, die sich für eine solche Aufgabe bzw. für das Niveau nicht eignen.

Das erste Lied, das hier vorgestellt werden soll, ist Mach die Augen $z u^{2}$ von den Ärzten. Dieses Lied wurde von der Kursleiterin vorgegeben und zur Einführung in den Imperativ in einem fortgeschrittenen A1-Kurs verwendet. Anhand eines Auszugs aus dem Liedtext wird auf einige Problemstellen hingewiesen: „Mach die Augen zu und küss mich/und dann sag, dass du mich liebst/ich weiß genau, es ist nicht wahr/doch ich spüre keinen Unterschied - wenn du dich mir hingibst...". Problematisch für die Kursteilnehmenden ist in diesem Ausschnitt das trennbare Verb „zumachen“, das ihnen noch nicht bekannt ist, wie auch die Wendung „sich jmdm. hingeben“. Diese Schwierigkeiten wurden bei der Übersetzung jedoch problemlos überwunden, die Aufgabe wurde also erfolgreich gelöst. Die Kursteilnehmenden verstanden den Imperativ auf Anhieb und fanden Gefallen sowohl an der Musik als auch am Liedtext. Die Musik trifft den Geschmack vieler Kursteilnehmender und regt sie an, weitere Lieder dieser Musikgruppe zu hören. Hinzu kommt, dass der Text ziemlich klar gesungen und daher gut zu verstehen ist.

Ein weiteres Lied, das nach Vorgabe auf diesem Niveau übersetzt wurde, ist $D u$ hast ${ }^{3}$ von Rammstein. Dieses Lied wurde von der Kursleiterin ausgewählt, da die Musikgruppe einerseits in Mexiko sehr bekannt und unter den Kursteilnehmenden beliebt ist und andererseits, um Bedeutungsänderungen durch schon geringfügige Wortänderungen zu verdeutlichen. „Du - du hast - du hasst mich - du hasst mich - du hast mich gefragt - du hast mich gefragt - du hast mich gefragt und ich hab nichts gesagt! - Willst du bis der Tod euch scheidet - treu ihr sein für alle Tage Nein, nein" (Rammstein: 2013). Bei diesem Lied liegt die Hauptschwierigkeit in der artikolatorischen Gleichheit von „du hast" und „du hasst" sowie darin, den Satz „Willst du bis der Tod euch scheidet, treu ihr sein für alle Tage?“ zu verstehen. Dennoch haben die Kursteilnehmenden die Hürden eigenständig und problemlos überwunden. Die einzelnen Wörter sind zwar relativ klar zu verstehen, der Refrain hingegen weniger.

Auf A2-Niveaus wurde die andere Variante dieser Aufgabe gestellt, in der sich die Kursteilnehmenden selbst Lieder aussuchen konnten.

Als erstes Beispiel dient das Lied Das Zelt von Jeans Team, das eine Kursteilnehmerin ausgewählt und übersetzt hat. Wie man an den Korrekturen - kursiv gesetzt - der eingereichten Hausaufgabe sehen kann, bereitete die Übersetzung so gut wie keine Probleme (s.u.). Wenn auch der Liedtext die eine oder andere Herausforderung an den Übersetzer/die Übersetzerin stellt, ist dies ein Beispiel, das sich ideal auf einem A2-Niveau verwenden lässt. Es gibt im Großen und Ganzen keine Verständnisschwierigkeiten für die Kursteilnehmenden. Des Weiteren ist das Lied so gesungen, dass bereits beim Hören ein Großteil verstanden wird.

\footnotetext{
2 Die Ärzte: Die Bestie in Menschengestalt. Hot Action Records 1993.

${ }^{3}$ Rammstein: Sebnsucht. Temple Studios 1997.
} 
Liedübersetzung Das Zelt ${ }^{4}$ von Jeans Team:

Das Zelt - Jeans Team

Mach dich auf (aufmachen nach= abrirse camino a, ponerse en camino hacia)

In die Welt

In ein anderes Land

Wo es dir gefällt

Bis zum Rand(borde)

und übers Meer

Dich hält (hälten= retener)

hier nichts mehr

Kein Gott

Kein Staat

Keine Arbeit

Kein Geld (x2)

Aus dem Haufen (montón)

Dieser Stadt

Musst du raus(fuera)

Und du wirst sehen

Du wirst dich verändern (cambiar)

In all diesen Ländern

Kein Gott

Kein Staat

Keine Arbeit

Kein Geld

Mein Zuhause (hogar)

Ist die Welt

Mein Zuhause

Ist die Welt

Das Himmelszelt(firmamento, cielo)

Ist dein Dach

Mit all den Lichtern(luces)

Die dich leiten(guiar)

Von den Sternen $($ Stern $=$ estrella)

Die dich begleiten(acompañar)

Kannst du lernen

Klar zusehen (a ver)

Kein Gott
La carpa - Jeans Team

Ponte en camino

En el mundo

En otro país

En donde te guste

Hasta el borde

Y sobre el mar

Te detiene

Aquí ya nada

$\operatorname{Sin}^{5}$ dios

Sin estado

Sin trabajo

Sin dinero (x2)

Del montón

De esta ciudad

Debes tú salir

Y tú verás

Tú cambiaras

En todas estos países

Sin dios

Sin estado

Sin trabajo

Sin dinero

Mi casa

Es el mundo

Mi casa

Es el mundo

El firmamento

Es tu techo

Con todas las luces

Que te guiarán

De las estrellas

Que te acompañara

Puedes tú aprender

A ver claramente

Sin dios

\footnotetext{
${ }^{4}$ Jeans Team: Das Zelt. Louisville Records 2006.

5 Die Übersetzungsfehler sind immer kursiv markiert.
} 
Kein Staat

Keine Arbeit

Kein Geld

Mein Zuhause

Ist die Welt

Mein Zuhause

Ist die Welt (x3)
Sin estado

Sin trabajo

Sin dinero

Mi casa

Es el mundo

Mi casa

Es el mundo (x3)

Die Liedwahl der Kursteilnehmenden fällt wieder und wieder auf 99 Luftballons von Nena. Dies ist auf den relativ starken Wiedererkennungswert des Liedes weltweit zurückzuführen. Es handelt sich bei dem Liedtext um einen anspruchsvollen Text, der bei der Übersetzung verschiedene Schwierigkeiten mit sich bringt.

Liedübersetzung 99 Luftballons $^{6}$ von Nena:

Hast du etwas Zeit für mich?

Dann singe ich ein Lied für dich

Von 99 Luftballons

Auf ihrem Weg zum Horizont

Denkst du vielleicht g'rad an mich

Dann singe ich ein Lied für dich

Von 99 Luftballons

Und dass so was von so was kommt

99 Luftballons

Auf ihrem Weg zum Horizont

Hielt man für Ufos aus dem All

Darum schickte ein General

'ne Fliegerstaffel hinterher

Alarm zu geben, wenn es so wär

Dabei war'n da am Horizont

Nur 99 Luftballons

99 Düsenjäger

Jeder war ein großer Krieger

Hielten sich für Captain Kirk

Das gab ein großes Feuerwerk

Die Nachbarn haben nichts gerafft

Und fühlten sich gleich angemacht

Dabei schoss man am Horizont
Tienes algo de tiempo para mí?

Entonces canto una canción para ti acerca de 99 globos

En su camino al horizonte

Piensas tú tal vez en mí?

Entonces canto una canción para ti

Acerca de 99 globos

$\mathrm{Y}$ ese algo viene de algo

(Ella soltó los globos dedicados para ét)

99 globos

En su camino al horizonte

Los considera uno OVNIs del espacio

Por tanto un general mandó

Un escuadrón tras ellos

Para sonar la alarma si realmente lo fueran

Pero ahí en el horizonte había

solo 99 globos

(El general los consideró una amenaza

ya que pensó que era una invasión espacial)

99 Jets de pelea

Cada uno un gran guerrero

Considerándose ellos mismo el capitán

Kirk

Había unos grandes fuegos artificiales

Los vecinos no entendían nada

Y se sentían molestos

\footnotetext{
${ }^{6}$ Nena: 99 Luftballons. Epic Records 1984.
} 
Auf 99 Luftballons

99 Kriegsminister -

Streichholz und Benzinkanister -

Hielten sich für schlaue Leute

Witterten schon fette Beute

Riefen Krieg und wollten Macht

Mann, wer hätte das gedacht

Dass es einmal soweit kommt

Wegen 99 Luftballons

99 Jahre Krieg

Ließen keinen Platz für Sieger

Kriegsminister gibt's nicht mehr

Und auch keine Düsenflieger

Heute zieh' ich meine Runden

Seh' die Welt in Trümmern liegen

Hab' 'nen Luftballon gefunden

Denk' an dich und lass' ihn fliegen
Así que dispararon al horizonte

A los 99 globos

(Los vecinos pensaron lo mismo y comenzaron a dispararles pero eran solamente globos)

99 ministros de guerra

Cerillos y botes de gasolina

Se creían gente inteligente

Oliendo una buena generosidad*

Gritando por la guerra y queriendo el poder

Hombre, quién hubiera pensado

Que las cosas tan lejos llegarían

Tan sólo por 99 globos

Nadie podía creer que unos globos comenzarían una guerra)

99 años de guerra

No dejaron lugar para ganadores

No hay más ministros de guerra

Ni tampoco jets de guerra

Hoy hago yo mis rondas

Veo al mundo estar en ruinas

He encontrado un globo

Pienso en ti y lo dejo volar.

(Después de la guerra ahora todo está en ruinas, sin embargo aún queda un globo rojo, el cual ella sigue dedicando a su amado)

Dennoch wurde der Inhalt im Ganzen korrekt wiedergegeben, grobe Verständnisschwierigkeiten gab es nicht. Der Text ist auch gesungen gut zu verstehen und die meisten der Kursteilnehmenden haben es bereits mehrmals sowohl auf Deutsch als auch auf Englisch gehört. Aus diesem Grund kann bereits ab höheren A2-Niveaus mit diesem Lied gearbeitet werden.

Ein weiteres Lied, das in einem fortgeschrittenen A2-Niveau gewählt wurde, ist Dieser $W_{e g}^{7}$ von Xavier Naidoo. Obwohl der Text etwas komplizierter ist, wurde die Übersetzung mit nur wenigen Fehlern angefertigt, die zeigen, dass der Text im Groben verstanden wurde. Auch dieser Text ist relativ deutlich gesungen und dementsprechend von den Kursteilnehmenden gut zu verstehen. Aus diesem Grund ist die Arbeit mit diesem Lied auf A2-Niveau gut begründbar.

${ }^{7}$ Xavier Naidoo: Telegramm X. 3p 2005. 
Liedübersetzung Dieser Weg von Xavier Naidoo (Naidoo 2005):

Dieser Weg

Also ging ich diese Straße lang

und die Straße führte zu mir

Das Lied, das du am letzten Abend sangst

Spielte nun in mir

Noch ein paar Schritte

Und dann war ich da mit dem Schlüssel

zu dieser Tür

Dieser Weg wird kein leichter sein

Dieser Weg wird steinig und schwer

Nicht mit vielen wirst du dir einig sein

Doch dieses Leben bietet so viel mehr

Es war nur ein kleiner Augenblick

Einen Moment war ich nicht da

Danach ging ich einen kleinen Schritt

Und dann wurde es mir klar

Dieser Weg wird kein leichter sein

Dieser Weg wird steinig und schwer

Nicht mit vielen wirst du dir einig sein

Doch dieses Leben bietet so viel mehr

Manche treten dich

Manche lieben dich

Manche geben sich für dich auf

Manche segnen dich

Setz dein Segel nicht,

Wenn der Wind das Meer aufbraust
Este camino

Iba caminando por esta calle larga

y la calle se dirige al mar

la canción que cantaste la última tarde suena ahora en $\mathrm{mi}$

Solo un par de pasos y estaba allí con la llave de esta puerta.

Este camino no será fácil

Este camino será pedregoso y difícil

No con todos estarás de acuerdo

Pero esta vida ofrece mucho más.

Era solo un pequeño momento

un momento no estaba allí

Entonces di un pequeño paso

y así todo me fue claro.

Este camino no será fácil

Este camino será pedregoso y difícil

No con todos estarás de acuerdo

Pero esta vida ofrece mucho más.

Algunos te pisan, algunos te aman

Algunos dan todo por ti, algunos te bendicen

No hices tu vela, cuando el viento esté en tu contra.

Ich werd die Welt verändern von Revolverheld wurde ebenfalls in einem fortgeschrittenen A2-Niveau vorgestellt und übersetzt. Es gibt an der eingereichten Übersetzung nichts auszusetzen; anzumerken ist jedoch an dieser Stelle, dass die Lernerin für dieses Niveau bereits sehr fortgeschritten war. Der Text ist auch gesungen nicht ganz leicht zu verstehen, da im Text viele umgangssprachliche Formen verwendet werden. Aus diesem Grund wird empfohlen, das Lied ab dem Niveau B1 einzusetzen. 
Liedübersetzung Ich werd die Welt verändern ${ }^{8}$ von Revolverheld:

Ich werd die Welt verändern

Ich kenne diese Tage jetzt seit Jahren schon zur genüge

Und es ist schon fast als ob ich mich selber gern bekriege

Ich kann nicht gut allein sein

Und unter Menschen fang ich an durchzudrehen

Ich kann mir viel zu viele Fragen stellen Doch kann ich niemals klare Lösungen sehen

Doch irgendwann wird alles das zu Ende sein

Und ich werd' anfangen mein Leben zu feiern

Ich werd' die Welt verändern Werd' endlich alles besser machen Werd' anfangen wieder klar zu kommen

Und mal über mich selber lachen

Und ich weiß dass irgendwann aus Böse auch mal Gut werden kann Und wenn gar nichts mehr geht, fang ich einfach wieder von vorne an Vielleicht muss ich nur die Tage zählen Mich durch nervig lange Stunden quälen es ist ganz egal wie lang das noch geht weil ich weiß wer am Ende noch steht
Conozco esos días, desde hace años ha sido suficiente Y parece como si me gustara pelear conmigo mismo No puedo estar bien solo Alrededor de personas me empiezo a marear

Me puedo plantear muchas preguntas Pero casi nunca puedo ver soluciones claras

Pero algún día todo va a terminar

Y voy a empezar a festejar mi vida.

voy a cambiar el mundo

Finalmente voy a hacer todo mejor

Voy a volver a estar bien

de vez en cuando reírme de mi mismo

Y yo sé que algún día

De lo malo a veces pueden ser salir cosas buenas

Y si nada funciona (y si ya no puedo más)

Vuelvo a empezar simplemente desde el principio

Tal vez sólo tenga que contar los días

Torturarme aguantando largas horas irritantes

No importa que tanto dure eso

Porque sé quién queda de pie al final

Ich werde aufhören immer zu verlieren, Voy a dejar de perder siempre werde alles Alte ausrangieren
Voy a tirar todo lo viejo

\footnotetext{
${ }^{8}$ Revolverheld: Chaostheorie. Sony BMG Music Entertainment 2007.
} 
Ich werd' mich nur noch selber kopie- $\quad$ Y voy a copiarme sólo a mí mismo ren

Als Negativbeispiel für dieses Niveau soll das Lied Eisbär von Grauzone angeführt werden, das eine Lernerin in einem fortgeschrittenen Niveau A2 ausgewählt hat.

Liedübersetzung Eisbär von Grauzone:

Eisbär

Eisbär, Eisbär,

kaltes Eis, kaltes Eis,

Oso polar, oso polar,

Eisbär, Eisbär,

kaltes Eis, kaltes Eis.

Hielo frío, hielo frío.

Oso polar, oso polar,

Hielo frío, hielo frío.

Ich möchte ein Eisbär sein

im kalten Polar,

Quisiera ser un oso polar

dann müsste ich nicht mehr schreien, alles wär so klar.

Ich möchte ein Eisbär sein

im kalten Polar,

dann müsste ich nicht mehr schreien,

en el frío polar,

entonces no tendría que gritar más, todo estaba muy claro.

Quisiera ser un oso polar

en el frío polar,

alles wär so klar.

Ich möchte ein Eisbär sein

im kalten Polar,

dann müsste ich nicht mehr schreien,

entonces no tendría que gritar más,

todo estaba muy claro.

Quisiera ser un oso polar

en el frío polar,

alles wär so klar.

Ich möchte ein Eisbär sein

im kalten Polar,

entonces no tendría que gritar más, todo estaba muy claro.

Quisiera ser un oso polar

en el frío polar,

dann müsste ich nicht mehr schreien, alles wär so klar.

entonces no tendría que gritar más, todo estaba muy claro.

Eisbären müssen nie weinen.

Los osos polares no deben lloran.

Eisbären müssen nie weinen.

Los osos polares no deben lloran.

Eisbären müssen nie weinen.

Los osos polares no deben lloran.

Eisbären müssen nie weinen.

Los osos polares no deben lloran.

In dem Text wird mit viel Wiederholung gearbeitet, wodurch der Schwierigkeitsgrad für ein A2-Niveau zu niedrig wäre. Für ein Anfängerniveau könnte jedoch genau davon Nutzen gemacht werden. Es könnte eine zusätzliche Aufgabe gestellt werden, in der die Kursteilnehmenden Informationen über die Musikgruppe recherchieren sollen und die Bedeutung des Liedtextes interpretiert werden soll.

${ }^{9}$ Grauzone: Eisbär. mital-U 1981. 


\section{$5 \quad$ Kriterien für die Bewertung}

Bei der Bewertung der Übersetzung sollte die Lehrkraft vor allem darauf achten, dass die wiedergegebene Information vollständig ist:

Wird die Frage nach der Qualität einer Übersetzung damit beantwortet, dass sie ,richtig' sein muss, so lässt dies auf eine eher akademische Betrachtungsweise schließen. Kriterien dabei sind Vollständigkeit und Genauigkeit einer Übersetzung, wie sie besonders bei Übersetzungsübungen im Fremdsprachenunterricht angelegt werden, wenn es noch im Wesentlichen um die Vermittlung von Grundlagenkenntnissen geht (Schippel 2006: 31).

Ein weiteres Kriterium, das bei der Bewertung zu beachten ist, ist die Verständlichkeit der Übersetzung (vgl. Schippel 2006: 31). Weiterhin sollte berücksichtigt werden, dass inhaltlich angemessen übersetzt wurde; Grammatik- und Rechtschreibefehler werden nur bei Sinnveränderungen negativ bewertet: „Die Evaluation soll sich dabei auf die inhaltliche [... Ebene beziehen“ (De Florio-Hansen; Inez 2008: 5). An dieser Stelle soll in den Vordergrund gerückt werden, dass es sich bei den Kursteilnehmenden nicht um professionelle Übersetzer/Übersetzerinnen handelt. Aus diesem Grund wird auch keine professionelle Übersetzung erwartet. Ziel der Übung ist viel mehr, dass sich die Kursteilnehmenden intensiv mit dem Text auseinandersetzen und Lernerfolge verzeichnen. So muss auch an erster Stelle der Bewertung liegen, dass die Aufgabe (und damit der oben gestellte Übersetzungsauftrag) erfüllt wurde, sprich, dass die Kursteilnehmenden einem Freund/einer Freundin den Liedtext so übersetzen konnten, dass dieser/diese das Lied (hypothetisch) problemlos versteht.

\section{Schlussfolgerung}

Da die Kursteilnehmenden mit Musik arbeiten und Lieder nach ihrem eigenen Geschmack auswählen können, die so eine emotionale Wirkung bei ihnen hervorrufen, und sich im Anschluss intensiv mit diesen beschäftigen, ist das Interesse der Kursteilnehmenden automatisch geweckt. Des Weiteren handelt es sich hier um eine realitätsnahe Aufgabenstellung, die den Kursteilnehmenden tatsächlich widerfahren könnte oder bereits widerfahren ist. Diese Aufgabenstellung bietet die Möglichkeit, intensive Text- und Wortschatzarbeit zu leisten und grammatikalische Strukturen einzuüben. Durch das Anhören der Lieder wird gleichzeitig die Hörfertigkeit geschult. Die Kursteilnehmenden können ihre eigenen Präferenzen in den Unterricht einbringen und können sich, wie auch die Lehrkraft, in Bezug auf die verschiedenen Musikgenres gegenseitig bereichern. Diese Aufgabenstellung kann außerdem die Kursteilnehmenden dazu anregen, sich auch außerhalb des Unterrichts mit deutschsprachiger Musik zu befassen und diese als Mittel zum Lernen zu nutzen. 
Es soll an dieser Stelle nochmals betont werden, dass das Übersetzen von Liedern für den DaF-Unterricht eine gute Alternative zu den üblichen Unterrichtsstrukturen darstellt und daher auch als solche genutzt werden soll. Es liegt dem Sinn dieses Artikels fern, dafür zu werben, regelmäßig Liedübersetzungen anzufertigen; diese sollen noch immer die Ausnahme im Unterricht darstellen. Es ist empfehlenswert, den Unterricht möglichst abwechslungsreich zu gestalten und von der Methodenvielfalt Gebrauch zu machen, um der Heterogenität der Kursteilnehmenden zu begegnen. Es ist von äußerster Wichtigkeit, dass die Übersetzungsaufgaben den allgemeinen Zielen, wie Thematik der Lektion, grammatikalische Einheit etc. des Unterrichts untergeordnet und angepasst werden (vgl. Keim 2003: 387).

\section{Literatur}

Altenmüller, Eckart (2003): Macht Musik den Menschen besser?. In: GEO, 11, 68.

De Carvalho Neto, Geraldo Luiz (2005): Übersetzungsübungen im DaF-Unterricht: Mittel zur Überbrückung sprachlicher Schwierigkeiten. In: DaF Brücke 7, 34-35.

De Florio-Hansen, Inez (2008): Sprachmitteln. Überlegungen zur Mediation im Fremdsprachenunterricht. In: PRAXIS Fremdsprachenunterricht 5, 3-8.

Draesner, Ulrike (2008): „Fremdheit erscheinen zu lassen ist eine Chance und die Kunst von Übersetzungen". Online: http://www.goethe.de/ins/cz/prj/lit/buc/ueb/de 3566470.htm (Stand: 13.10.2013).

Goethe-Institut Brüssel (o.A.): (Pop-)Musike im DaF-Unterricht. Online: http://www.goethe.de/mmo/priv/4361501-STANDARD.pdf (Stand: 12.10.2013).

Hallet, Wolfgang (2010): Kulturelles Lernen. In: Hallet, Wolfgang; Königs, Frank G. (Hrsg.): Handbuch Fremdsprachendidaktik. Berlin: Klett; Kallmeyer, 129-132.

Haß, Frank (2010): Methoden im Fremdsprachenunterricht. In: Hallet, Wolfgang; Königs, Frank G. (Hrsg.): Handbuch Fremdsprachendidaktik. Berlin: Klett; Kallmeyer, 151-156.

Keim, Lucrecia (2003): Übersetzen im DaF-Unterricht. In: Info DaF 30, 4, 383-394.

Königs, Frank G. (2010): Sprachmittlung. In: Hallet, Wolfgang; Königs, Frank G. (Hrsg.): Handbuch Fremdsprachendidaktik. Berlin: Klett; Kallmeyer, 96-100.

Nord, Christiane (2011): Funktionsgerechtigkeit und Loyalität. Theorie, Methode und Didaktik des funktionalen Übersetzens. Berlin: Frank \& Timme. 
Reiß, Katharina; Vermeer, Hans J. (1984): Grundlegung einer allgemeinen Translationstheorie. Tübingen: Niemeyer.

Schippel, Larisa (2006). Übersetzungsqualität: Kritik - Kriterien - Bewertungshandeln. Berlin: Frank \& Timme.

Trim, John; North, Brian; Coste, Daniel (2001): Gemeinsamer europäischer Referen₹rahmen für Sprachen: lernen, lehren, beurteilen. Berlin: Langenscheidt.

Wicke, Rainer E.; Rottmann, Karin (2013): Musik und Kunst im Unterricht Deutsch als Fremdsprache. Berlin: Cornelsen. 


\section{Theater}





\title{
Für das Ästhetische einen Ort schaffen. DaF als Bauhaus - ein Vorentwurf
}

\begin{abstract}
Manfred Schewe
Dieser Beitrag versteht sich als erste Annäherung an eine ästhetisch orientierte Konzeption von Deutsch als Fremdsprache, in der die Grundidee vom Baubaus zu einem zentralen Bezugspunkt wird. Anfangs wird problematisiert, dass die modernen Fremdsprachen zu einseitig auf Wissenschaftlichkeit fixiert sind und den Künsten nicht genug Raum geben. Es folgen Überlegungen zu künstlerischer Orientierung in der Pädagogik, und exemplarisch wird auf Studien verviesen, an die weitere Arbeiten zum Stellenwert des Ästhetischen im Bereich Fremdsprachen anknüpfen könnten. Der Beitrag endet mit einem Bezug zum Theater, das als vermittelnde Kunstform den Kern einer performativen Fremdsprachendidaktik bildet, in der die ästhetische Bildung der Lernenden einen bohen Stellenwert einnimmt.
\end{abstract}

\section{Archaischer Torso Apollos}

Wir kannten nicht sein unerhörtes Haupt, darin die Augenäpfel reiften. Aber sein Torso glüht noch wie ein Kandelaber, in dem sein Schauen, nur zurückgeschraubt,

sich hält und glänzt. Sonst könnte nicht der Bug der Brust dich blenden, und im leisen Drehen der Lenden könnte nicht ein Lächeln gehen zu jener Mitte, die die Zeugung trug.

Sonst stünde dieser Stein entstellt und kurz unter der Schultern durchsichtigem Sturz 
und flimmerte nicht so wie Raubtierfelle;

und bräche nicht aus allen seinen Rändern

aus wie ein Stern: denn da ist keine Stelle,

die dich nicht sieht. Du musst dein Leben ändern.

(Rilke 1955: 557)

Vermutlich werden heutige Leser/innen sich in den meisten Fällen schwer damit tun, sich auf dieses Gedicht einzulassen und nicht lange davor verharren. Aber wer es zu Ende liest, wird voraussichtlich dem letzten Satz besondere Aufmerksamkeit schenken: Du musst dein Leben ändern. Und vielleicht dann darüber nachrätseln, warum von dieser Skulptur auf das lyrische Ich eine so starke Wirkung ausgeht.

Kunst ermöglicht ästhetische Erfahrung, kann uns stark bewegen und besonders auch das Lehren und Lernen auf vielfältige Weise bereichern. Aber warum führt sie immer noch so ein Schattendasein in den modernen Fremdsprachen? Sowohl in der Satzung der Deutschen Gesellschaft für Fremdsprachenforschung ${ }^{1}$ als auch des Fachverbandes Deutsch als Fremdsprache 2 ist an etlichen Stellen von »Wissenschaftler/inne/n«, »wissenschaftlich« und »Wissenschaft« die Rede, aber vergeblich sucht man nach Spuren von »Kunst«, »Künstler/inne/n«, »künstlerisch«.

Dabei ist das Lehren einer Fremdsprache natürlich nicht ausschließlich Wissenschaft, sondern ebenso eine Kunst. ${ }^{3}$

Was in Satzungen steht, reflektiert allerdings nicht die bunte Vielfalt lebendiger Praxis. Das allgemeine Interesse an künstlerischer Orientierung scheint im Bereich Deutsch als Fremdsprache deutlich zuzunehmen. Indiz dafür sind z.B. Konferenzen zu Themen wie Kunst des Unterrichtens - Unterrichten mit Kunst (Goethe Institut Bangalore, 2012), Ästhetisches Lernen im DaF-Unterricht: Musik - Kunst - Film - Theater - Literatur (Universidad Nacional Autónoma de México, 2013) oder auch Sprachen lernen - keativ, aktiv, handlungsorientiert (Universität Kassel, 2015).

Bei solchen Zusammenkünften treffen sich DaF-Forschende und -Lehrende, für die Bildung mehr bedeutet als stets messbare Leistung und die sich über eine Vision des Faches austauschen, die Alternativen zu einer einseitig-wissenschaftlichen Ausrichtung bietet.

Kunst setzt auf die Aktivierung von Vorstellungskraft. Nur indem wir uns Bilder vom Möglichen schaffen, können wir frisch auf die gegenwärtige Bildungswirklichkeit blicken und erschaffen, was über diese hinausweist.

Warum also nicht, als pädagogische Alternative zum gegenwärtigen Standardisierungstrend im Bildungssektor, sich Deutsch als Fremdsprache als eine Disziplin vorstellen, in der die Künste einen wichtigen Stellenwert haben und die Grundidee vom Bauhaus umgesetzt werden könnte?

\footnotetext{
1 Vgl. online: http://www.dgff.de/uploads/media/Satzung_DGFF_01.pdf (Stand: 23.06.2014).

2 Vgl. online: http://www.fadaf.de/de/wir_ber_uns/der_fadaf/satzung_neu_22.03.2013.pdf (Stand: 23.06.2014).

${ }^{3}$ Vgl. zur weiterführenden Lektüre zum Thema: Schewe, Manfred 1997.
} 
Das Bauhaus wurde 1919 gegründet, war eine Kunstschule neuen Typs, an der Grundlagen für den neuen Bereich Design erarbeitet wurden. Im damaligen reformpädagogischen Klima entstanden dort theoretische Konzepte und praktische Ansätze, die in ihrer politischen Ausrichtung den Nationalsozialisten suspekt waren, so dass das Bauhaus 1933 wieder geschlossen wurde. Auf die ideen- und sozialgeschichtlichen Hintergründe und verschiedenen pädagogischen Konzeptionen des Bauhauses kann hier nicht weiter eingegangen werden. Ausführungen dazu finden sich z.B. bei Wick (1982), der feststellt, dass das Baubaus, in seiner Zeit einen der bedeutendsten Beiträge zur ästhetischen Erziehung geleistet hat" (Wick 1982: 14). Im Kontext der Argumentation in diesem Beitrag soll aber speziell hervorgehoben werden, dass es dem Bauhaus um die Grundidee einer ,ästhetischen Synthese" ging, d.h. die Integration aller Kunstformen. Für dort tätige Lehrer, etwa den Maler Paul Klee, war es selbstverständlich, sich zwischen verschiedenen Künsten hin- und her zu bewegen. ${ }^{4}$

Die Disziplin DaF ist natürlich keine Kunstschule, aber trotzdem ließe sie sich als ein interdisziplinäres Experimentierfeld vorstellen, in dem sich verschiedene Kunstformen begegnen. Der Kongress an der Universität Mexiko, aus dem dieser Sammelband hervorgeht, hat in dieser Hinsicht Pionierarbeit geleistet. Er ist ein gutes Beispiel dafür, wie fruchtbar es ist, den Dialog zwischen verschiedenen Kunstformen zu fördern und fachliche Aspekte aus der Perspektive verschiedener Kunstformen zu betrachten, um dem Ästhetischen in der Disziplin angemessenen Raum zu verschaffen.

\section{Künstlerische Orientierung in der Pädagogik}

In den Vereinigten Staaten hat Elliot W. Eisner über viele Jahrzehnte Kritik an einem straff zweckrational ausgerichteten Erziehungssystem geübt und immer wieder den wichtigen Stellenwert betont, den die Künste in der Erziehung einnehmen sollten. Er hält die Tendenz zu Verwissenschaftlichung und Durchökonomisierung im Bereich Erziehung für sehr problematisch und plädiert dafür, sich stattdessen am Modell der Künste zu orientieren: ${ }^{5}$

The arts, I argue, can serve as models of what educational aspiration and practice might be at its very best. To be able to think about teaching as an artful undertaking, to conceive of learning as having aesthetic features, to regard the design of an educational environment as an artistic task - these ways of thinking about some of the commonplaces of education could have

\footnotetext{
${ }^{4}$ Vgl. in diesem Kontext: Düchting, Hajo 2004.

${ }^{5}$ Eisners ausführliche Begründungen dafür, warum die Künste sich besonders als Modell für die Pädagogik eignen, können hier nicht im Detail wiedergegeben werden, verwiesen sei aber insbesondere auf Kapitel 8 (What Education can learn from the Arts) in seiner Veröffentlichung The Arts and the Creation of Mind 2002.
} 
profound consequences for redesigning the practice of teaching and reconceiving the context in which teaching occurs (Eisner 2002: xiif.).

Übertragen auf den Bereich DaF hieße das: Inwieweit verstehen Lehrpersonen sich als künstlerisch tätig? Welche Aufmerksamkeit wird der ästhetischen Dimension von Lernen bzw. einer künstlerisch inspirierten Gestaltung der Lehr- und Lernumgebung geschenkt? Offene Fragen.

Wenn auch vielleicht nicht so konsistent wie bei Eisner, so ist auch in deutschsprachigen Ländern der Zusammenhang zwischen Pädagogik und Ästhetik durchaus beleuchtet worden, etwa von Koch; Marotzki; Peukert (1994). Hier sei aber speziell an die Überlegungen von Lothar Klingberg (1982) angeknüpft, einem führenden Experten im Bereich Allgemeindidaktik in der ehemaligen Deutschen Demokratischen Republik. Diese sind zwar deutlich von der damaligen Diskussion um eine humanistisch-sozialistische Erziehung gefärbt, aber seine Grundüberlegungen zur Thematik Ästhetik und Unterricht sind nach wie vor höchst relevant, etwa wo er schreibt:

Die pädagogische Effektivität des Unterrichtsprozesses hängt wesentlich von der Ausprägung seiner ästhetischen Komponente ab. Die ästhetische Komponente des Unterrichts ist deshalb etwas so Naheliegendes, weil der Unterricht als Prozeß gestaltet werden muß. Er ist ein Prozeß der schöpferischen Begegnung zwischen Lehrer und Schüler, der Elemente eines künstlerischen Gestaltungsprozesses aufweist. [...] Jede Unterrichtsstunde ist eine didaktische Einheit im Unterrichtsprozeß, etwas relativ Geschlossenes, Ganzes, Gestaltetes. Auch im Aufbau der Unterrichtsstunde gibt es schöne und weniger schöne Lösungen. Die didaktische Gestaltung der Unterrichtsstunde setzt deshalb nicht nur wissenschaftliche Einsicht und didaktisches Können voraus, sondern auch ein Organ für ihre Ausgewogenheit und Harmonie, für ihren Rhythmus und ihre Spannung, für ihre Intonation und Musikalität, mit einem Wort: für ihre Ästhetik.

Eine gute Unterrichtsstunde entspricht sowohl den Grundsätzen der Wissenschaftlichkeit (der Pädagogik, Didaktik, Psychologie) als auch denen der Ästhetik. In diesem Sinne sollte Didaktik Theorie und ,Kunstlehre“ des Unterrichts zugleich sein (Klingberg 1982: 158f.).

Klingberg betont die wünschenswerte Balance zwischen Wissenschaft und Kunst und bezieht sich auf verschiedene Kunstformen (Musik, Architektur, Theater) als Inspirations- und Bezugsquellen für eine künstlerisch orientierte Unterrichtsgestaltung. Auf die Frage, ob es im Unterrichtsprozess Elemente künstlerischer Tätigkeit bzw. im didaktischen Prozess gewisse Analogien zum künstlerischen Schaffen gebe, liefert er keine glatte Antwort, erwähnt aber beispielhaft: 
- künstlerische Elemente in der Unterrichtssprache (die Lehrerzählung, der didaktische Dialog, andere künstlerisch-sprachliche Gestaltungsmittel);

- der dramaturgische Aspekt im didaktischen Prozess (Unterricht als ,Schauspiel', ,Rollenverteilung' der ,Akteure', Entwicklung der didaktischen Szene, dramaturgische Momente im problemhaften Unterricht, Momente der Spannung und Entspannung);

- die architektonische Komponente in der Gestaltung des Unterrichtsprozesses (Unterrichtsstunden als ,Gebäude', Stoffeinheit als ,gestaltete Stoffmasse', Struktur der Unterrichtsstunde);

- die musikalische Komponente der Prozeßgestaltung des Unterrichts (Intonation, Harmonie, Dissonanzen, Rhythmik des Unterrichts; Dialektik als ,Kompositionslehre' des Unterrichts) (ebd.: 161).

Vor dem Hintergrund der in diesem Sammelband behandelten Thematik scheint mir besonders relevant, dass für ihn das Ästhetische nicht die alleinige Domäne künstlerischer Fächer ist, sondern essentiell auch in anderen Fächern, etwa dem fremdsprachlichen Deutschunterricht, verortet ist:

Unterstrichen werden muß die Legitimität und pädagogische Bedeutung des ästhetischen Blickpunktes, des ästhetischen Wertens und Erlebens in allen Unterrichtsdisziplinen, also auch in denen, die nicht primär an ästhetischen Inhalten und Methoden, sondern am wissenschaftlichen Erkenntnisprozeß orientiert sind (ebd.: 154).

\title{
2 Schlaglichter auf das Ästhetische im Bereich Fremdsprachen
}

\author{
Was war wirklich? \\ Jedenfalls war nichts wirklich ohne eine Form. \\ Ohne eine Form hatte es das Erlebnis gar nicht gegeben. \\ Peter Handke: Die Geschichte des Bleistifts
}

In der Waldorfpädagogik wird künstlerischer Orientierung ein hoher Stellenwert beigemessen. Von ihr könnten wichtige Impulse für die Praxis im Fach Deutsch als Fremdsprache ausgehen. Diesbezüglich empfiehlt sich die Lektüre von Peter Lutzkers (2007) The Art of Foreign Language Teaching. Im ersten Teil seiner umfangreichen Studie trifft er die grundsätzliche Unterscheidung zwischen - einerseits pädagogischen Konzepten, die sich an Modellen von Science und Business orientieren, und - andererseits - einem übergreifenden Verständnis von Lehren als Kunst. Auf diesem theoretischen Hintergrund aufbauend beschreibt er im zweiten Teil ästhetisch akzentuierte Unterrichtsprojekte, die im Rahmen der Fremdsprachenvermittlung an Waldorfschulen durchgeführt wurden und beleuchtet dabei die vielfältigen Lernprozesse, die sich beispielsweise bei der Probe und Aufführung 
eines Theaterstücks vollziehen. Lutzker analysiert beispielsweise im folgenden Auszug, inwiefern die Waldorfschüler von der Mitwirkung an einem Theaterprojekt profitiert haben:

A strong sense of personal involvement was present in almost all of the pupils' final responses. This is viewed as being connected to the act of fully entering into the feelings and life of another while letting go of one's own ego. [...] The possibilities which artistic activity offers in regard to the development and discipline of emotional life have been discussed. The particular challenges for the actor in learning to fully embody and affirm his role while acting, and being able in the next moment to step back and yield to suggestions and criticisms, has been considered as the prevalent and dynamic mode of learning in the rehearsals. In this regard, pupils were regularly confronted with fundamental emotional challenges and were thereby able to learn, both individually and collectively, forms of emotional self-discipline based on a common artistic goal of trying to achieve the best possible results. This type of learning is intrinsic to artistic work and presents a contrast to most forms of school learning. Artistic experience is thus viewed as an education of feelings through which pupils matured in significant respects (Lutzker 2007: 407, Hervorhebung MS).

Laut Lutzker wurden die Schüler in den künstlerisch orientierten Aktivitäten, wenn man einen Vergleich zu herkömmlichen Unterrichtsabläufen anstellt, emotional deutlich stärker gefordert und gefördert. Der Autor bewegt sich hier im Bereich des ästhetischen Lernens, bei dem die Emotionen von Schülerinnen und Schülern, aber damit verbunden auch ihre Sinne, ihre Vorstellungskraft sowie ihre Rationalität aktiviert werden. ${ }^{6}$

Ruth Huber, die in ihrer Studie theaterbezogene Projekte auswertet, die sie mit DaF-Studierenden an der Universität Lissabon durchführte, spricht explizit von einem aisthetisch-ästhetisch orientierten Fremdsprachenunterricht, den sie anfangs wie folgt erläutert:

Aisthesis, die Sensibilisierung der Wahrnehmung, und Ästhetik, die ästhetische Darstellung subjektiver Sprach- und Weltwissenskonstruktionen, bringen eine Dialektik zwischen den lernersprachlichen Konstruktionen ,im $\mathrm{Kopf}^{\varsigma}$ und den kunstförmigen Konstrukten ,in der Welt ${ }^{\varsigma}[\ldots]$ ins Spiel: Das gestaltete Produkt lässt die Konstruktionen im Kopf besser (be)greifbar und zugänglich werden, es macht Schönheit und Sinn erfahrbar [...] So wird die Kreativität des Fremdsprachlers zu einer Ressource, die nicht nur seinem eigenen Lernen zugute kommt, sondern der kulturerzeugenden Dynamik insgesamt. Es entsteht eine Kommunikationskultur sui generis, die erst die Be-

\footnotetext{
${ }^{6}$ Vgl. in diesem Kontext die an ein Praxisbeispiel aus dem DaF-Unterricht gekoppelten Ausführungen zu ästhetischem Lernen in Beug; Schewe 1999.
} 
dingungen für Kommunikation schafft: Nähe, Kooperation, Solidarität (Huber 2003: 3).

Hubers Studie kann hier nicht detaillierter dargestellt werden, bleibt aber im fremdsprachenpädagogischen Kontext ein wichtiger Bezugspunkt, um das Ästhetische im Fremdsprachenunterricht weiter auszuleuchten.

Dazu gehört auch eine Klärung der Frage: Wie können DaF-Lehrkräfte durch Aus- und Fortbildung angemessen darauf vorbereitet werden, Lernenden ästhetische Erfahrung zu ermöglichen? ${ }^{7}$ Ganz allgemein gilt sicherlich, dass Lehrpersonen im Laufe ihrer Aus- und/oder Fortbildung Erfahrungen im Bereich Sprachgestaltung machen sollten:

Wer als Lehrperson der ästhetischen Seite von Sprache im Fremdsprachenunterricht mehr Raum geben möchte, der muss selber einen Sinn für Sprache haben, von ihrem Klang und Rhythmus fasziniert sein und es genießen, die abzuschmecken und auf der Zunge zergehen zu lassen. Natürlich lässt er sich anstecken von Texten, die besondere ästhetische Qualitäten aufweisen. Erst wenn er diese erspürt und in ihrer Besonderheit erfasst hat, reifen Ideen dafür, wie solche Texte im Fremdsprachenunterricht eingesetzt werden können, um Lernenden im spielerischen Umgang mit Sprache ästhetische Erfahrungen zu ermöglichen (Schewe 2012: 86).

Mit Blick auf einen ästhetisch orientierten Fremdsprachenunterricht muss es für Sprachlehrkräfte darum gehen, über Form im Sinne von grammatischer Kategorie (Adjektiv, Adverb etc.) hinauszudenken. ${ }^{8}$ Sie sollten sich stets bewusst bleiben, dass die Form, in der jemand sich sprachlich und nichtsprachlich ausdrückt bzw. die Form, in der sich Fremdsprachenunterricht jeweils vollzieht, aufs Engste an den Inhalt gekoppelt ist bzw. diesen erst entstehen lässt. In diesem Zusammenhang sei nochmals auf Eisners Überlegungen verwiesen:

Another lesson that education can learn from the arts is that the way something is formed matters. We tend in our culture to differentiate between content and form. What is said, for example, is believed to constitute content. How it is said is believed to constitute form. It's all very tidy. However, what is said cannot be neatly separated from how something is said. Form and content interpenetrate. The way in which something is spoken shapes its meaning; form becomes content. Actors have learned this lesson well. So, too, have poets, painters and musicians (Eisner 2002: 197).

1995 habe ich auf dem 16. Kongress für Fremdsprachendidaktik in einer Arbeitsgruppe zum Thema Eriziehender Fremdsprachenunterricht - out of date? an der Martin-

\footnotetext{
${ }^{7}$ Vgl. hierzu besonders den Beitrag von Fleiner in diesem Sammelband.

8 Dass dies nicht selbstverständlich ist, zeigt ein neuerer Artikel von Pouresmaiel, Amin; Gholami, Javad 2014. Für die Autoren ist anscheinend Form und Bedeutung ein Gegensatzpaar und Form eine ausschließlich linguistische und nicht etwa auch ästhetische Kategorie.
} 
Luther-Universität Halle einen (unveröffentlichten) Vortrag zum Thema Das Spannende am Inhalt ist die Form: Fremdsprachenunterricht im Blickwinkel ästhetischer Erziehung gehalten. Auf meinem Handout hatte ich acht Thesen formuliert, darunter:

- Die Fremdsprachendidaktik ist zu inhaltsfixiert. In der ästhetischen Praxis hingegen ist die FORM zentral: Aus dem ,Spiel mit der Form` erwächst der Inhalt. Fremdsprachenunterricht braucht (mehr) Risiko zum Experiment.

- Voraussetzung für die Gestaltung von ästhetisch orientiertem Fremdsprachenunterricht ist eine besondere Sensibilität für die FORM, in der sich Unterricht als Prozess vollziehen kann. Die Lehrperson braucht ,künstlerisches Gespür‘ und nicht zuletzt: eine ,künstlerische Grammatik‘.

Im abschließenden Teil soll noch kurz auf das Konzept einer Performativen Fremdsprachendidaktik eingegangen werden. In dieser Bezeichnung ist der Aspekt Form und damit auch eine explizit ästhetische Ausrichtung akzentuiert. ${ }^{9}$

\section{Performatives Lehren und Lernen}

Seit den 90er-Jahren ist in der deutschen fremdsprachendidaktischen Fachdiskussion in Anlehnung an das englische Drama in Education (vgl. z.B. Bolton 1979) zunehmend der Begriff Dramapädagogik verwendet worden. Er bezieht sich auf die Theorie und Praxis eines ästhetisch-ganzheitlich orientierten Fremdsprachenunterrichts, in dem die dramatische Kunst (insbesondere als Theaterkunst, aber durchaus im Zusammenspiel mit anderen Kunstformen wie z.B. Film, Performance Art, Storytelling, Tanz) zur Inspirationsquelle und zur Orientierung für das pädagogische Handeln wird. ${ }^{10}$

Weil daneben in der Fachdiskussion zunehmend auch der Begriff Theaterpädagogik Verwendung findet und die Grenzen zwischen Drama- und Theaterpädagogik eher fließend sind, bietet es sich an, als Oberbegriff für drama- und theaterbezogene Unterrichtsgestaltung die Bezeichnung performatives Lehren und Lernen zu verwenden. ${ }^{11}$ Dieser Begriff hat den Vorteil, dass er nicht nur die ursprünglich in Großbritannien entwickelte Dramapädagogik sowie die Theorie und Praxis der deutschen

\footnotetext{
9 Überlegungen zum Verständnis des Wortteils form im Wort performativ hatte ich in dem mit Susanne Even gemeinsam gehaltenen Vortrag auf der Konferenz Performative Teacbing, Learning and Research (Universität Cork, 29. Mai - 1. Juni 2014) angestellt. Der Vortrag wurde gefilmt und kann unter folgendem Link angesehen werden. Online: http://youtu.be/_hJbhJOslZI (Stand: 30.06.2014).

10 Vgl. den Beitrag von Schewe 2010 im Lexikon Fremdsprachendidaktik.

11 In diesem Kontext sei auf das Symposium Performative Teaching and Learning 2013 sowie auf die Konferenz Performative Teaching, Learning and Research 2014 verwiesen. Beide Tagungen fanden an der Universität statt, wo ein SCENARIO FORUM - Performative Teaching, Learning and Research eingerichtet wurde. Nähere Informationen zum Forum, der Konferenz und aus dieser hervorgehenden Publikationen können unter folgendem Link heruntergeladen werden: Online: http://www.ucc.ie/en/scenario /scenarioforum/ (Stand: 30.06.2014).
} 
Theaterpädagogik abdeckt, sondern darüber hinaus auch entsprechende pädagogische Konzepte, die in anderen Kulturen entwickelt worden sind, integrieren kann. Mit dem Begriff performativ wird deutlich eine enge Anbindung an Kunstform Theater markiert, aber er umfasst auch die performativen Praktiken in anderen Kunstformen, etwa Musik, Tanz und Performance Art.

In Bezug auf das Performative in der Kunstform Theater sei besonders auf Erika Fischer-Lichtes (2004) Veröffentlichung Ästhetik des Performativen verwiesen. Das konzeptuelle Grundgerüst einer Ästhetik des Performativen, das hier nicht weiter ausgeführt werden kann, bildet nach Fischer-Lichte die Trias der Begriffe Ereignis - Insæenierung - ästhetische Erfahrung. Inwiefern ihre Überlegungen zu Grundelementen einer Ästhetik des Performativen (z.B. Körper, Stimme, Präsenz, Raum) auf den Fremdsprachenunterricht beziehen lassen, wird in Schewes (2011) Beitrag Die Welt auch im fremdsprachlichen Unterricht immer wieder neu verzaubern - Plädoyer für eine performative Lehr- und Lernkultur! thematisiert.

Das Theater und die mit ihr verbundenen pädagogischen Disziplinen (Dramapädagogik und Theaterpädagogik) können eine zentrale Rolle dabei spielen, im Bereich Deutsch als Fremdsprache ein didaktisches Gebäude zu errichten, in dem das Ästhetische einen angemessenen Ort hat. Erinnert sei hier an das Bauhaus, wo das Theater eine wichtige Brückenfunktion hatte:

Wer aber das Bauhaus in Dessau besucht, kann schon aufgrund der architektonischen Gegebenheiten feststellen, welch einen zentralen Stellenwert die Theaterkunst im Denken und Leben der ,Bauhäusler' innehatte: Die Bauhausbühne ist genau in der Mitte zwischen den Werkstätten und dem Wohnbereich der Studierenden angesiedelt. Sie kann nach zwei Seiten hin bespielt werden: in Richtung der Aula, aber auch zur Mensa hin. Sie befindet sich damit auf der Schnittstelle von intimem und öffentlichem Bereich und ist zugleich inmitten des gesellschaftlichen Lebens angesiedelt. Wäre es nicht denkbar, allein aus dieser Ansiedelung heraus eine Funktionsbestimmung für die Kunstform Theater in pädagogischen Kontexten zu entwickeln? (Hilliger 2010: 73f.)

Das Theater ist eine vermittelnde Kunstform. Sie kann Elemente aus anderen Künsten leicht integrieren, man denke etwa an die literarische Stückvorlage, das Bühnenbild bzw. musikalische und tänzerische Elemente in Aufführungen. Als solche bildet sie den Kern einer performativen Fremdsprachendidaktik, in der die ästhetische Bildung der Lernenden einen hohen Stellenwert einnimmt. ${ }^{12}$

\footnotetext{
12 Vgl. Schewes 2013 Überlegungen zu einer Performativen Fremdsprachendidaktik. In Bezug auf den Zusammenhang von Theaterspielen und ästhetische Bildung siehe z.B. Hentschel 2010.
} 


\section{Literatur}

Beug, Joachim; Schewe, Manfred (1999): Learning and teaching culture from an aesthetic perspective: some theoretical reflections and practical examples. In: Chambers, Angela; Ó Baoill, Dónall (Hrsg.): Intercultural Communication and Language Learning. Dublin: The Irish Association for Applied Linguistics (IRAAL) in association with the Royal Irish Academy, 119-134.

Bolton, Gavin (1979): Towards a Theory of Drama in Education. Harlow: Longman.

Düchting, Hajo (2004): Painting Music. München u.a.: Prestel.

Eisner, Elliot W. (2002): The Arts and the Creation of Mind. New Haven u.a.: Yale University Press.

Hentschel, Ulrike (2010): Theaterspielen als ästhetische Bildung. Über einen Beitrag produktiven künstlerischen Gestaltens zur Selbstbildung. Berlin: Schibri.

Hilliger, Dorothea (2010): ,Die Kunst zu erben‘: Das Bauhaus als Modell für die Theaterpädagogik? In: Vaßen, Florian (Hrsg.): Korrespondenzen: Theater- Ästhetik - Pädagogik. Berlin: Schibri, 73-86.

Klingberg, Lothar (1982): Unterrichtsprozeß und didaktische Fragestellung. Berlin: Volk und Wissen.

Koch, Lutz; Marotzki, Winfried; Peukert, Helmut (Hrsg.) (1994): Pädagogik und Ästhetik. Weinheim: Deutscher Studien Verlag.

Lutzker, Peter (2007): The Art of Foreign Language Teaching. Improvisation and Drama in Teacher Training. Tübingen: Francke.

Pouresmaiel, Amin; Gholami, Javad (2014): What comes first in your classes? Form or meaning! In: Humanising Language Teaching 16, 3. Online: http://www.hltmag.co.uk/jun14/mart06.htm (Stand: 25.06.2014).

Rilke, Rainer Maria (1955): Archaïscher Torso Apollos. In: Sämtliche Werke. Erster Band. Frankfurt a.M.: Insel.

Schewe, Manfred (1997): DaF-Lehrer/innen-Ausbildung: Nicht nur als Wissenschaft, sondern ebenso als Kunst! In: Wolff, Armin; Tütken, Gisela; Liedtke, Horst (Hrsg.): Gedächtnis und Sprachlernen - Prozeßorientiertes Fremdsprachenlernen Deutschlehrerausbildung in West- und Osteuropa - Eine deutsche Literatur: AutorInnen nichtdeutscher Muttersprache. Beiträge der 24. Jahrestagung 1996. Regensburg: FaDaF, 245-254.

Schewe, Manfred (2010): Dramapädagogik. In: Surkamp, Carola (Hrsg.): Metzler Lexikon Fremdsprachendidaktik. Stuttgart: Metzler, 28-41.

Schewe, Manfred (2011): Die Welt auch im fremdsprachlichen Unterricht immer wieder neu verzaubern - Plädoyer für eine performative Lehr- und Lernkultur! 
In: Küppers, Almut; Schmidt, Torben; Walter, Maik (Hrsg.): Inszenierungen im Fremdsprachenunterricht. Grundlagen, Formen, Perspektiven. Braunschweig:

Diesterweg.

Schewe, Manfred (2012): Auf dem Wege zu einer Performativen Fremd- und Zweitsprachendidaktik. In: Dirim, Inci; Krumm, Hans-Jürgen; PortmannTselikas, Paul R.; Schmölzer-Eibinger, Sabine (Hrsg.): Theorie und Praxis. Jahrbuch Deutsch als Fremd- und Zweitsprache. Band 1. Schwerpunkt: Körper, Klang, Rhythmus. Wien: Praesens, 77-94.

Schewe, Manfred (2013): Taking Stock and Looking Ahead: Drama Pedagogy as a Gateway to a Performative Teaching and Learning Culture. In: SCENARIO VII, 1, 5-27. Online: http://research.ucc.ie/scenario/2013/01/Schewe/02/en (Stand: 25.6.2014).

Wick, Rainer (1982): Bauhaus-Pädagogik. Köln: Du Mont. 



\title{
Zur Notwendigkeit einer performativ-ästhetischen Fremdsprachenlehrerausbildung im deutschsprachigen Hochschulraum: Zusammenfassende Einblicke in Theorie und Praxis
}

\author{
Micha Fleiner \\ Der Beitrag stellt die zusammenfassende Beschreibung eines Forschungsprojektes dar, das einen \\ curricular verankerten Brückenschlag zwischen der Fremdsprachendidaktik und den performati- \\ ven Künsten (Theater, Literatur, Filmkunst, Bildende Kunst, Musik, Tanz) anstrebt. Ein \\ kontrastierender Blick in die dramapädagogische Lehrpraxis soll zudem verdeutlichen, auf welche \\ Weise performativ-ästhetische Zieldimensionen im konkereten Kontext der Hochschule Gestalt \\ anzunehmen vermögen.
}

\section{Projektbeschreibung}

Die nachfolgenden Ausführungen widmen sich zunächst einer Darstellung des Forschungskontextes, der eine Beleuchtung zentraler Zieldimensionen des gegenwärtig durchgeführten Dissertationsprojektes folgt. Hieran knüpft eine Beschreibung der zugrunde liegenden Forschungsmethodik an, in deren Rahmen Aufgaben-, Anwendungs- und Ergebnisbereiche des vorliegenden Arbeitsvorhabens nachgezeichnet werden. 


\subsection{Kunstaffiner Forschungskontext}

Die Durchführung des Projektes in einem kontextübergreifenden Forschungsfeld eröffnet die Möglichkeit, wesentliche Impulse der ästhetischen Einzeldisziplinen Theater, Literatur, Filmkunst, Bildende Kunst, Musik, Tanz - aufzugreifen und zielorientiert in einer fremdsprachendidaktischen Gesamtperspektive zu bündeln. Der Kunstform Theater wird im vorliegenden Forschungsvorhaben besondere Relevanz beigemessen, weist sie doch ob ihres gleichermaßen performativen und polyästhetischen Grundcharakters eine besondere Nähe zu künstlerischen Nachbardisziplinen auf (vgl. Schewe 2010a: 38). Ein solcherart synästhetisches Überschneidungsfeld ermöglicht zahlreiche Vernetzungen zwischen rationalen und intuitiven beziehungsweise zwischen verbalen und nonverbalen Kommunikationsprozessen, denen nicht zuletzt das besondere Potenzial innewohnt, kreativhandlungsorientierte Situationen für das Lehren und Lernen einer Fremd- und Zweitsprache zu generieren (vgl. u.a. Schewe 1993: 61-119, Tselikas 1999: 21-37, Even 2003: 145-191, Kessler 2008: 37-92).

Akzentuiert wird sonach ein fremdsprachendidaktisches Grundverständnis, das „auf einem weiten Kommunikationsbegriff basiert“ (Schewe 1993: 74) und „den Einsatz aller zur Verfügung stehenden Ausdrucksmittel“" (ebd.) einbegreift. Denn „[1]anguage opens itself up in gesture: dancing, singing, shouting, the expressions of the face, the gestures of the body [...] have their own modes of significance" (Erlenwein 1993: 193). Mitnichten sollte eine solcherart holistische Betrachtungsweise dem Missverständnis unterliegen, „sinnlich-präsentative Unterrichtsformen lediglich als Kompensationsformen für fehlendes Sprechvermögen zu legitimieren“ (Schewe 1993: 74). Im hier dargestellten Forschungskontext werden performativ ausgerichtete Arbeitsformen als eine dynamische „Verbindung von kognitiven und emotionalen Lernprozessen“ (Müller 2010: 61) betrachtet, die „[d]as narrative Potenzial von Bild-, Film- und Textmaterial und auch deren Leerstellen“ (ebd.) zur Verdichtung fremdsprachlicher Aneignungsvorgänge nutzen. Ein drama- und theaterbezogener Ansatz ,teaches more than language structures and vocabulary“ (Fitzgibbon 1993: 281), er richtet seinen Fokus auf ein beziehungsreiches „continuum between reception and activity“ (ebd.: 269) im weiten Feld der künstlerischen Ausdrucks- und Gestaltungsmöglichkeiten.

Ein Forschungsprojekt, das den Leitgedanken einer dramapädagogischen Theorie und Praxis des Lehrens und Lernens - Ästhetik, Ganzheitlichkeit, Fiktion, Transformation (vgl. Schewe 2010a: 38) - Rechnung trägt, bewegt sich denn auch konsequentermaßen in einem Forschungskontext, der das Prinzip der Monodisziplinarität nicht lediglich vereinzelt zu erweitern, sondern letzten Endes - im Sinne eines nachdrücklichen Öffnungsimpulses hin zu den Künsten - gleichermaßen zu durchbrechen und zu überwinden sucht. 


\subsection{Zieldimensionen des Forschungsvorhabens}

Ausgehend von einem disziplinübergreifenden Forschungskontext, der im Schnittbereich von Fremdsprache, Ästhetik, Hochschuldidaktik und Bildungsforschung liegt, widmet sich das vorliegende Arbeitsvorhaben der Leitfrage, auf welche Weise die gegenwärtige universitäre Fremdsprachenlehrerausbildung um performativästhetische Kompetenzdimensionen erweitert werden kann. Da die Kunstform Theater in Gestalt der Dramapädagogik ${ }^{1}$ eine beziehungsreiche Nahtstelle zwischen ästhetischen und fremdsprachendidaktischen Handlungsfeldern bildet ${ }^{2}$, konzentriert sich das Forschungsinteresse auf die Entwicklung eines Konzeptes zum Erwerb dramapädagogischer Lehrkompetenz für angehende Fremdsprachenlehrkräfte. Denn Lehrkräfte waren gewissermaßen ,schon immer Akteure, die den Schülern etwas so ,vorzuspielen' versuchten, dass die Aufmerksamkeit des Lernerpublikums gebannt blieb“" (Schewe 2008: 127). Sonach besteht seit Anbeginn eine natürliche innere Beziehung zwischen präsentativen Inszenierungsmustern und fremdsprachlichen Kommunikationshandlungen, da

Lehrer und Schüler [...] im fremdsprachlichen Unterricht immer schon ,Theater gespielt ${ }^{c}$ [haben], indem sie so taten, als ob die Unterhaltung in der fremden Sprache für sie natürlich sei (ebd.).

Dies impliziert zudem, dass der individuelle

Sprachaneignungsprozess [...] nicht nur das Erlernen von Vokabular, Sprachstruktur etc. [beinhaltet], sondern auch das Wissen über [...] Konventionen, die dem Ausdruck durch nonverbale Zeichen zugrunde liegen und die die Sprache begleiten (Tselikas 1999: 28).

Augenfällige Parallelen zwischen Fremdsprachenunterricht und Schauspielkunst existieren hierbei etwa insoweit, als ,jede Sprache [...] ihren eigenen gestischen Ausdruck, Rhythmus, ihre Mimik und ihr Verständnis von räumlicher Nähe und Distanz" (ebd.) besitzt. Konstitutiv für solcherart körperbezogene Kommunikationshandlungen ist ein differenziertes Wahrnehmungsvermögen: Dabei geht es zugespitzt formuliert - um „die Gesamtheit der Prozesse, wie mit den Sinnesorganen aufgenommene Information verstanden und interpretiert" (Biechele 2010: 355) beziehungsweise auf welche Weise „unsere Umgebung in bedeutungsvolle Gestalten und Geschehnisse gegliedert“ (ebd.) werden kann. Damit ,[d]ie Situation des Als-ob und die theatralische Distanzierung" (Tselikas 1999: 33) in zielsprachlichen Lehr-Lern-Situationen eine angemessene Umsetzung erfahren können, damit

\footnotetext{
1 Die Bezeichnung Dramapädagogik „bezieht sich auf die Theorie und Praxis eines ästhetischganzheitlich orientierten [Fremdsprachenunterrichts] [...], in dem die dramatische Kunst [...] zur Inspirationsquelle und zur Orientierung für das pädagogische Handeln wird" (Schewe 2010a: 38).

2 ,Abgesehen von den intensiven, oftmals zugleich emotional, ästhetisch und kognitiv stimulierenden Erfahrungen mit Dramatisierungen“" (Sambanis 2013: 137), bestehen positive Effekte auf lern-, neuro- und sozialpsychologischer sowie auf sprachlerntheoretischer und psycholinguistischer Ebene (vgl. Schewe 1993: 207ff.).
} 
Lernende unter professioneller Anleitung ermutigend unterstützt und begleitet werden, „ihre Erfahrungen [...] mit der fremden Sprache zu verarbeiten und mit neuem Sinn zu belegen“ (ebd.), bedarf es zuvörderst einer Lehrkraft, die über ein fundiertes performativ-ästhetisches Kompetenzprofil verfügt. Aus diesen Gründen soll zukünftigen Lehrkräften im Verlauf ihres Fremdsprachenstudiums in curricular strukturierter Form Gelegenheit geboten werden, mit drama-, theater- und darstellungsbezogenen ebenso wie mit literarischen, gestalterischen sowie film-, tonund tanzkünstlerischen Elementen in Berührung zu gelangen. Ein ästhetischfachübergreifender Impuls in diesem Sinne besitzt auch insofern erhöhte Relevanz, als ,sowohl an den Schulen als auch in der Lehrerausbildung bis dato isoliertes Fachdenken vorherrscht" (Mentz 2010: 39). Dies ist umso weniger verständlich, als „seit vielen Jahren in den meisten Bundesländern fachübergreifendes bzw. -verbindendes Arbeiten von den Kultusverwaltungen eingefordert wird“ (ebd.).

Im Hinblick auf die Durchführung des Forschungsvorhabens impliziert dies einerseits, die mit dem Erwerb einer performativ-ästhetischen Lehrkompetenz intendierten Bildungsziele - etwa in fachwissenschaftlicher, fachdidaktischer und unterrichtspraktischer Hinsicht - für den Bereich der hochschulischen Lehramtsausbildung zu definieren. Andererseits gilt es, Lösungsansätze für eine curriculare Umsetzung der einzelnen Zielbereiche aufzuzeigen, welche die studiengangsspezifischen Rahmenfaktoren - angestrebte Schulform, Kombination der Studienfächer, Gewichtung der Fremdsprache, Formen der Leistungsbewertung und anderes mehr - in gebührender Form einbeziehen.

Ohne den Blick in die hochschulische Lehr- und Lernpraxis wäre die Entwicklung eines theoriebasierten Konzeptes zum Erwerb dramapädagogischer Fremdsprachenlehrkompetenz jedoch nur in unzureichendem Maße durchführbar. Aus diesem Grund erscheint es von der Sache selbst gefordert, einen umfassenden Einblick in die gegenwärtige Situation der Dramapädagogik im deutschsprachigen Hochschulraum zu gewinnen. Neben einer statistischen Ermittlung des Status quo richtet sich das Erkenntnisinteresse sowohl auf aussagekräftige dramapädagogische Akteursgruppen als auch auf deren Handlungskontexte: Hierfür wird beispielsweise untersucht, in welchen Zusammenhängen performativ-ästhetische Elemente im Rahmen der hochschulischen Ausbildungsphase eingesetzt werden und welche Bedingungen, Zielsetzungen und Konsequenzen mit der Implementierung ästhetisch akzentuierter Sprachlehr- und -lernformen verbunden sind. Neben der Analyse fremd- und körpersprachlicher Interaktionsprozesse zwischen Dozierenden und Studierenden wird zudem der Frage nach möglichen Problem-, Grenz- und Risikobereichen nachgegangen, die mit dem Einsatz kreativ-künstlerischer Arbeitsformen im Rahmen der hochschulischen Fremdsprachenlehre in Verbindung stehen. Welche Forschungsmethoden und konkreten Arbeitsschritte den einzelnen Arbeitszielen hierbei zugrunde liegen, soll im nachfolgenden Abschnitt aufgezeigt werden. 


\subsection{Forschungsmethodik}

Die übergreifenden Rahmenfaktoren des hier beschriebenen Dissertationsprojektes - etwa die Mehrdimensionalität des Forschungsgegenstandes, die Offenheit und Interdisziplinarität des Forschungsfeldes sowie die Notwendigkeit „,eines iterativ-zyklischen, theoriegenerierenden Verfahrens auf Basis (vorwiegend) qualitativer Daten“ (Strübing 2008: 85) - legten es nahe, die Forschungsmethodik auf Grundlage der Grounded Theory zu entwickeln. Der Grounded Theory-basierte Forschungsansatz, ,der die Generierung von Hypothesen und Theorien explizit in den Mittelpunkt stellt und in einem mehrstufigen Prozess Kategorien am Material entwickeln will“" (Kuckartz 2012: 67), bildete den Ausgangspunkt für die Entwicklung eines mehrdimensionalen Forschungsdesigns. Dieses war insbesondere durch das Prinzip der Methodentriangulation gekennzeichnet und umfasste folgende zentrale Arbeitsziele: Im Zusammenhang mit einer Vollerhebung an über sechzig Hochschulen in Deutschland, Österreich und der Schweiz wurde in einem ersten Schritt analysiert, welche universitären Standorte in den Jahren von 2010 bis 2012 performativ-ästhetische Lehr-Lern-Elemente im Rahmen der Fremdsprachenlehrerausbildung anboten. Eine Dokumentenanalyse aktueller Studien- und Prüfungsordnungen sowie des Lehrangebotes über einen Zeitraum von drei Semestern sollte Aufschluss darüber geben, ob - beziehungsweise in welchem Maße - die Bereiche Theater, Literatur, Filmkunst, Bildende Kunst, Musik und Tanz im Rahmen des lehramtsbezogenen Fremdsprachenstudiums Berücksichtigung fanden. Mit dem Ziel, vertiefte Einblicke in die Umsetzung performativ-ästhetischer Formen des Lehrens und Lernens in fremdsprachlichen Hochschulkontexten $\mathrm{zu}$ gewinnen, wurden in einem zweiten Schritt leitfadengestützte Einzelinterviews mit dreißig ausgewählten Dozierenden und Studierenden durchgeführt. Im Rahmen dieser interviewbasierten Perspektivenanalyse wurden in erster Linie Ursachen, Kontexte, Konsequenzen und persönliche Erfahrungen erforscht, die mit kreativkünstlerischen Lern- und Vermittlungsvorgängen in der Zielsprache verbunden waren. Im Sinne einer externen Perspektivenergänzung und Verdichtung der Daten stand im dritten Schritt die Durchführung zweier teilnehmender Seminarbeobachtungen im Mittelpunkt des Forschungsinteresses. Mit der persönlichen Teilnahme an zwei Lehrveranstaltungen, in denen darstellende Kunstformen zum Erlernen der Zielsprache und Zielkultur integriert wurden, war das Interesse verbunden, praxisbasierte Informationen zu erhalten: Dies insbesondere im Hinblick auf die Seminargestaltung, auf den methodisch-didaktischen Umgang mit performativen und ästhetischen Lernelementen, auf die Motivation der Teilnehmenden, auf Interaktionsprozesse zwischen Dozierenden und Studierenden sowie auf die seminarspezifischen Rahmenbedingungen wie Räumlichkeiten, Equipment und Formen der Zusammenarbeit. In einem noch ausstehenden abschließenden Schritt wird das im Rahmen der Dokumentenanalyse, der Experteninterviews und der Seminarbeobachtungen erhobene Datenmaterial anhand eines mehrphasigen Auswertungsprozesses zusammengeführt: Da Grounded Theory „die praktische Rele- 
vanz der Ergebnisse“ (Strübing 2008: 85) im Sinne „einer verbesserten Handlungsfähigkeit der Akteure im Untersuchungsbereich“ (ebd.) anstrebt, soll - im Zielhorizont einer systematischen Datensynthese und empirisch begründeten Theoriebildung - die Entwicklung eines Konzeptes zum Aufbau dramapädagogischer Lehrkompetenz für angehende Fremdsprachenlehrkräfte den Abschluss des Forschungsvorhabens bilden.

\section{Praxiseinblicke}

Mannigfaltig sind die Formen, Akteursgruppen und Rahmenstrukturen, die mit einem potenziellen Einsatz kreativer Lehr-Lern-Elemente an der Hochschule in Verbindung gebracht werden. Nicht selten haben hierbei curriculare Zieldefinitionen bestimmende Wirkung auf den konkreten Implementierungsprozess einer Lehrveranstaltung, die performativ-ästhetische Kompetenzfelder im Bereich der Sprach-, Literatur- oder Kulturdidaktik zu integrieren beabsichtigt. In exemplarischer Weise werden im Folgenden zwei hochschulische Lehrsettings abgebildet, die - obschon beiden gemein ist, den Erwerb einer Fremdsprache durch Betonung performativer Gestaltungsfelder wie Theater, Literatur, Filmkunst, Bildende Kunst, Musik und Tanz zu unterstützen - in curricularer, organisatorischer sowie methodisch-didaktischer Hinsicht unterschiedliche Grundtendenzen aufweisen.

\subsection{Seminarkontext A: aufführungsbezogen, fachübergreifend, curricular verankert}

An erster Stelle soll eine theaterprojektbasierte Lehrveranstaltung Erwähnung finden, die ich über einen Zeitraum von zwei Semestern (2012-2013) in sprach- und fachübergreifender Form - beteiligt waren das Institut für Romanistik sowie das Institut für deutsche Literatur und Sprache - an der Pädagogischen Hochschule Freiburg in Deutschland durchführte. Das fünfzigjährige Jubiläum des deutschfranzösischen Elysée-Vertrages diente als Anlass, den wechselvollen Beziehungen zwischen Frankreich und Deutschland auf inszenatorischem Wege - das heißt „mit Kopf, Herz, Hand und Fuß“ (Schewe 1993: 8) - nachzuspüren. Im Rahmen eines aufführungsbezogenen Arbeitsprozesses entwickelten Lehramtsstudierende aus Deutschland und Frankreich eine mehrdimensionale Szenencollage, die Schauspiel, Lyrik, Chanson, Tanzeinlagen, Slapstick, selbstkomponierte Instrumentalmusik sowie Licht- und Bühnendesign in gleichem Maße zu vereinen vermochte. Den Abschluss dieses interdisziplinären ästhetischen Projektes bildeten vier abendfüllende Theateraufführungen vor externem Publikum. Unter curricularem Blickwinkel war für die Teilnehmenden von Belang, dass die Studienordnung eine erfolgreiche Projektteilnahme und -präsentation als verpflichtenden Bestandteil des Grundstudiums vorsah. Die hiermit einhergehende Notwendigkeit einer abschließenden Leistungsdiagnose stellte eine zusätzliche Einflussvariable dar, deren Dynamik - 
positiv wie negativ besehen - gerade im Rahmen präsentativ-schöpferischer Arbeitsprozesse zu keinem Zeitpunkt unterschätzt werden sollte. Die fachübergreifende Grundstruktur ermöglichte es, das Theaterprojekt in Gestalt des TeamTeachings zu realisieren: Frühzeitige Planungs- und Zielabsprachen, eine konsequente Dialogorientierung sowie eine klare Aufteilung der künstlerischen, fachwissenschaftlichen und organisatorischen Tätigkeitsfelder erleichterten den zweisemestrigen Arbeitsprozess hierbei in beträchtlichem Maße. Ein weiteres Spezifikum dieses bilingualen Hochschulprojektes stellte der ausgeprägte Heterogenitätsgrad der Lerngruppe dar: Da fremdsprachliche Kompetenzen, künstlerisch-praktische Vorerfahrungen im Allgemeinen - etwa in schauspielerischer, musikalischer oder tänzerischer Hinsicht - sowie theaterbezogene Kenntnisse im Besonderen - etwa in den Bereichen Regie, Dramaturgie, Szenografie - bisweilen in hohem Maße voneinander abwichen, bildete der verstärkte Einsatz binnendifferenzierter Arbeitsformen im Theaterprojekt ein gleichermaßen motivierendes wie effektives Methodenelement. Denn gerade die projektzentrierte Theaterarbeit in der Fremdsprache bot den deutschen und französischen Lehramtsstudierenden zahlreiche Möglichkeiten, individuelle Fähigkeiten und Fertigkeiten über einen längeren Zeitraum zielgerichtet zu integrieren und auf diesem Wege bleibende Erfolgserlebnisse im Kontext der Zielsprache zu generieren (vgl. Schewe 2010b: 199). Es ist gleichwohl hervorzuheben, dass „eine szenisch-dramatische Großform“ (ebd.) wie im beschriebenen Fall ,sehr zeitaufwendig ist, [...] von den Beteiligten hohe Motivation und enormen Einsatz verlangt und zumeist nur extracurricular zu realisieren ist" (ebd.).

\subsection{Seminarkontext B: prozessorientiert, fachimmanent, fakultativ}

An zweiter Stelle soll das Bild eines prozessorientierten Dramapädagogikseminares vermittelt werden, das ich im Herbst/Winter 2013 am Department of German des University College Cork in Irland anbot. Teilnehmende waren in diesem Falle irische Lehramtsstudierende der Germanistik, die sich im Abschlussjahr befanden und die die Veranstaltung auf freiwilliger Basis belegen konnten. Der fakultative Grundcharakter des Seminares schloss eine offizielle Form der Leistungsbewertung aus und eröffnete den Studierenden auf diese Weise von Anbeginn ein sanktionsfreies Lern- und Experimentierfeld in der Fremdsprache. Da „Sprachunterricht [...] eine ermutigende Atmosphäre [braucht]" (Huneke; Steinig 2013: 166), war es in diesem Kontext von besonderem Interesse, ,immer wieder Anlässe und Situationen zu schaffen, in denen die Lerner als möglichst autonom kommunizierende, ganze Personen handeln können“ (ebd.). Die grundlegende Zieldimension lag darin, den Lernerinnen und Lernern Gelegenheit zu bieten, der deutschen Sprache auf performativem - das heißt auf verbalem ebenso wie auf para- und nonverbalem - Wege gewahr zu werden. So konzentrierte sich jeder Veranstaltungstermin auf ein vorab definiertes ästhetisches Schwerpunktthema, das Elemente der darstellenden und der bildenden Kunstformen gleichermaßen zu berücksich- 
tigen suchte. Den irischen Studierenden wurden - um einzelne Beispiele solch polyästhetischer Lernkontexte anzuführen - Möglichkeiten eröffnet, fremdsprachliche Wort- und Bedeutungsfelder auf musikalisch-assoziativem Wege zu visualisieren, Höhepunkte in der deutschen Film- und Musikgeschichte inszenatorisch darzustellen, charakteristische Formelemente deutschsprachiger Lyrik in die Gestalt von Tanz und Bewegung zu überführen, Storyboards auf der Grundlage zielsprachlicher Literaturverfilmungen zu entwickeln, einflussreiche Kunstwerke der deutschen Malerei gruppenimprovisatorisch zu verkörpern und anderes mehr. Im Rahmen solch „szenisch-dramatische[r] Kleinformen“ (Schewe 2010b: 201) wird „Fremdsprachenunterricht [...] meist [...] als ein (Improvisations-)Prozess [verstanden]" (ebd.), innerhalb dessen ,(körper-)sprachlich intensiv gehandelt" (ebd.) wird. Grundsätzlich ist davon auszugehen, dass der theaterpraktische und -theoretische Kompetenzgrad der beteiligten Akteure maßgeblichen Einfluss auf „die ästhetische Qualität und damit auch [auf die] Bedeutungsdichte der im Unterricht jeweils geschaffenen Kleinform“ (ebd.) ausübt. Die prozessbasierte Ausrichtung des Seminares bot in diesem Fall nicht nur die Chance, persönliche Lernerfahrungen und -strategien der irischen Studierenden in angemessenem Umfang zu berücksichtigen, sondern auch - und gerade bei Erstbegegnungen mit Dramapädagogik an der Hochschule ist dies von besonderer Relevanz -, die Akteurinnen und Akteure sorgsam, das heißt ohne Zeit- und Leistungsmessung, an performative Lernformen in der Zielsprache Deutsch heranzuführen.

\subsection{Weiterführende Überlegungen}

Anhand des vorstehenden Exkurses in die dramapädagogische Hochschulpraxis sollte resümierend verdeutlicht werden, dass performativ-ästhetische Interaktionssituationen in der Fremdsprache nicht allein von einer Vielzahl äußerer Rahmenbedingungen abhängen, sondern dass Dramapädagogik selbst in hohem Grade durch das Moment der Mehrdimensionalität gekennzeichnet ist. Dieser mehrdimensionale Charakter stellt - positiv besehen - ein beachtliches Potenzial für die ästhetische Gestaltung fremd- und zweitsprachlicher Kommunikationsprozesse dar, eröffnet er doch ein nahezu unbegrenztes Spektrum an methodischen, didaktischen und curricularen Einsatzmöglichkeiten (vgl. Schewe 2010a: 39f.). ${ }^{3}$ Um dieses Potenzial für Sprachlehr- und -lernprozesse fruchtbar zu machen, bedarf es jedoch eines systematischen Aufbaus dramapädagogischer Lehrkompetenzen, da ein Mangel an darstellungsbezogenen theoretischen Kenntnissen und theaterpraktischen Grunderfahrungen bei Lehrenden mitunter Orientierungslosigkeit oder - schwerwiegender noch - Widerstand auslösen kann:

The reason that new working methods have not achieved wider acceptance in the practice of foreign-language instruction lies [...] primarily in the fact

${ }^{3}$ Vgl. hierzu auch Schewe 2011: 20-31. 
that these methods represent uncharted territory to most teachers. They were not trained in or for these methods. Their resistance, based on a lack of personal experience and information, leads many of them to avoid this subject altogether (Feldhendler 1993: 191).

Obgleich dieser Zusammenhang im deutschsprachigen Hochschulraum seit Längerem bekannt ist, und obgleich ,,[d]ie mit der Dramapädagogik assoziierte neue [...] Lehr-/Lernkultur [...] auf stetig zunehmendes Interesse [stößt]“ (Schewe 2010b: 201), ist nicht ohne Verwunderung festzustellen, dass performativ-ästhetische Arbeitsformen im Bereich der universitären Ausbildung sowie der Fort- und Weiterbildung fremdsprachlicher Lehrpersonen nach wie vor nur in unzureichendem Maße integriert werden. Ein Hauptproblem hierbei ist, dass es auch zum gegenwärtigen Zeitpunkt ,noch an einer adäquaten Infrastruktur in den fremdsprachlichen Fächern bzw. in der Allgemeinen Pädagogik [fehlt]“ (Schewe 2010a: 38). Mit der Entwicklung eines Konzeptes zum Erwerb dramapädagogischer Lehrkompetenz für angehende Fremdsprachenlehrkräfte möchte das hier beschriebene Forschungsprojekt einen Beitrag zur stärkeren Verschränkung von Wissenschaft und performativen Kunstformen im Bereich der universitären Ausbildungsphase leisten.

\section{Impulse für eine performative Lehr-, Lern- und Forschungskultur}

Eine performativ-ästhetischen Leitgedanken verpflichtete Lehr-, Lern- und Forschungskultur bedarf, will sie den Anforderungen der Zukunft entsprechen, eines deutlich stärkeren Vernetzungsgrades auch über Sprach- und Ländergrenzen hinweg, um die unterschiedlichen Akteursgruppen - Lehrende, Forschende, Praktizierende - und Institutionen - schulische, hochschulische, außerschulische - in einen impulsstarken Dialog zu bringen. ${ }^{4}$ Als Inspirationsquelle für die Unterrichtspraxis diene hierbei im Besonderen die von Schewe (2013: 14) entwickelte Zusammenschau unterschiedlicher darstellungsbasierter Projektformate. Für eine mittel- und langfristig erfolgreiche Umsetzung sogenannter „Large-scale forms“ (ebd.) wird es in besonderer Weise erforderlich sein, die einzelnen Akteure - seien es Lehrkräfte, Fortbildende, Dozierende, Kunst- und Kulturschaffende, wissenschaftliche Nachwuchskräfte, Studierende oder Schülerinnen und Schüler - auf bestmöglichem Wege im konkreten Projektprozess zu unterstützen. Solcherart flankierende Maßnahmen - etwa institutionsübergreifende Kooperationsformate, curriculare Flexibilität, bildungspolitische Fördermodelle und Ähnliches - böten letztlich das Potenzial zu einer konsequenteren Verflechtung des Bildungssektors mit dem Kunst-

\footnotetext{
${ }^{4}$ An dieser Stelle sei namentlich auf die bilinguale Internet-Zeitschrift Scenario verwiesen, die aufgrund ihrer internationalen Ausrichtung ein wichtiges Publikations- und Kommunikationsorgan auf dem Gebiet der performativen Fremdsprachen-, Literatur- und Kulturdidaktik darstellt. Die Fachzeitschrift ist online verfügbar unter: http:// scenario.ucc.ie (Stand: 10.03.2014).
} 
und Kultursektor. Es bleibt abzuwarten, ob beziehungsweise in welchem Grade dies im Alltag einer performativen Lehr- und Lernpraxis konkrete Umsetzung erfahren wird. Ebenfalls bleibt abzuwarten, in welcher Form intensivere dramapädagogische Akzente im Bereich der Fort- und Weiterbildung von fremdsprachlichen Lehrkräften gesetzt werden können: Nimmt man die übergreifende Herausforderung ernst,

durch [...] Einbeziehen des Praxiswissens der Lehrenden die Praxis des Fremdsprachenunterrichts (und nicht die Systemlogik seiner Bezugswissenschaften) konsequent [...] zur Zielebene von Fortbildung zu machen (Duxa 2010: 355),

müssten präsentative, szenisch-reflexive Themen und Inhaltsbereiche in Lehrerfortbildungsplänen in deutlich stärkerem Grade repräsentiert sein. Dies ist bislang jedoch nicht der Fall.

Fernerhin wird es - um der wachsenden kulturellen Vielschichtigkeit gerecht zu werden - zukünftig in noch stärkerem Maße vonnöten sein, angemessene Implementierungskonzepte für den Einsatz performativer Arbeitsformen in unterschiedlichen Sprach- und Kulturräumen zu entwickeln. Kesslers (2008: 37-92) Überlegungen zur Fundierung einer interkulturell ausgerichteten Dramapädagogik bilden hierbei einen interessanten ersten Ausgangspunkt. Mit Blick auf die dramapädagogische Lehrperson bedeutet dies zudem, ein schärfer konturiertes Anforderungsprofil der performativ-ästhetischen Fähigkeiten und Fertigkeiten für den fremdsprachlichen Unterrichtsalltag zu erarbeiten: „A Performative Foreign Languages Didactics would need to further define what is meant by ,teacher artistry and how exactly this could be further developed“" (Schewe 2013: 18). Auch die Frage nach transparenten Leistungsstandards und angemessenen Möglichkeiten der Leistungsdiagnose - insbesondere vor dem Horizont eines generell steigenden Interesses an künstlerisch-ästhetischen Lehr- und Lernfeldern in der Fremdsprache (vgl. ebd.: 15-19) - wird zukünftig mit Vorrang zu behandeln sein. ${ }^{5}$ So existieren beispielsweise bis zum gegenwärtigen Zeitpunkt keine überzeugenden - das heißt theoretisch fundierten und hochschulpraktisch systematisch erprobten - Modelle zur Leistungsbewertung für dramapädagogische Akteure in hochschulischen Handlungsfeldern.

Mit Blick auf die im Vorstehenden genannte Forderung nach einer stärkeren Dynamisierung und Internationalisierung des Forschungsfeldes soll abschließend auf die First International Conference: Performative Teaching, Learning and Research aufmerksam gemacht werden, die im Mai 2014 am University College Cork durchgeführt wurde: Eine Veranstaltung - gewissermaßen als Bannerträgerin einer disziplin- und länderübergreifenden Lehr-, Lern- und Forschungskultur des ÄsthetischPerformativen agierend -, der - so ist zu hoffen - möglichst entwicklungsstarke

\footnotetext{
${ }^{5}$ Eine aufschlussreiche Darstellung über grundsätzliche Problemfelder der Leistungsbeurteilung in performativ-ästhetischen Lehr-Lern-Kontexten bietet Fleming 2011: 140-156; 2012: 86-95.
} 
Impulse folgen werden, um die Fremd- und Zweitsprachenlehre in noch stärkerem Maße mit theatralen, literarischen, gestalterischen sowie medien-, film-, tanz- und tonkünstlerischen Momenten zu verschränken.

\section{Literatur}

Biechele, Barbara (2010): Wahrnehmung. In: Barkowski, Hans; Krumm, HansJürgen (Hrsg.): Fachlexikon Deutsch als Fremd- und Zweitsprache. Tübingen u.a.: Francke, 355.

Duxa, Susanne (2010): Fort- und Weiterbildung von Fremdsprachenlehrern. In: Hallet, Wolfgang; Königs, Frank G. (Hrsg.): Handbuch Fremdsprachendidaktik. Seelze: Kallmeyer, 354-358.

Erlenwein, Peter (1993): From Movement to the Word. Experiences of and Reflections upon the Holistic Learning Process. In: Schewe, Manfred; Shaw, Peter (Hrsg.): Towards Drama as a Method in the Foreign Language Classroom. Frankfurt a.M. u.a.: Lang, 193-200.

Even, Susanne (2003): Drama Grammatik. Dramapädagogische Ansätze für den Grammatikunterricht Deutsch als Fremdsprache. München: iudicium.

Feldhendler, Daniel (1993): Enacting Life! Proposals for a Relational Dramaturgy for Teaching and Learning a Foreign Language. In: Schewe, Manfred; Shaw, Peter (Hrsg.) (1993), 171-191.

Fitzgibbon, Emelie (1993): Language at Play. Drama and Theatre in Education as Stimuli in Language Learning. In: Schewe, Manfred; Shaw, Peter (Hrsg.) (1993), 269-281.

Fleming, Mike (2011): Starting Drama Teaching. 3., überarb. und erw. Aufl. London u.a.: Routledge.

Fleming, Mike (2012): The Arts in Education. An Introduction to Aesthetics, Theory and Pedagogy. London u.a.: Routledge.

Huneke, Hans-Werner; Steinig, Wolfgang (2013): Deutsch als Fremdsprache. Eine Einfübrung. 6., neu bearb. und erw. Aufl. Berlin: Erich Schmidt.

Kessler, Benedikt (2008): Interkulturelle Dramapädagogik. Dramatische Arbeit als Vehikel des interkulturellen Lernens im Fremdsprachenunterricht. Frankfurt a.M. u.a.: Lang.

Kuckartz, Udo (2012): Qualitative Inhaltsanalyse. Methoden, Praxis, Computerunterstützung. Weinheim u.a.: Juventa.

Mentz, Olivier (2010): Alle Fächer eignen sich - oder doch nicht? Überlegungen zu einem bilingualen Fächerkanon. In: Doff, Sabine (Hrsg.): Bilingualer Sachfachunterricht in der Sekundarstufe. Eine Einführung. Tübingen: Narr, 29-43. 
Müller, Thomas (2010): Drama-Pädagogik. In: Barkowski, Hans; Krumm, HansJürgen (Hrsg.) (2010), 61.

Sambanis, Michaela (2013): Fremdsprachenunterricht und Neurowissenschaften. Tübingen: Narr.

Scenario: Language, Culture, Literature. Journal for Drama and Theatre in Foreign and Second Language Education. Online: http://scenario.ucc.ie (Stand: 10.03.2014).

Schewe, Manfred (1993): Fremdsprache inszenieren. Zur Fundierung einer dramapädagogischen Lehr- und Lernpraxis. Oldenburg: Universität Oldenburg, Zentrum für pädagogische Berufspraxis.

Schewe, Manfred (2008): Drama und Theater in der Fremd- und Zweitsprachenlehre - Blicke zurück nach vorn. In: Hentschel, Ingrid; Wildt, Beatrix; Wildt, Johannes (Hrsg.): Theater in der Lehre. Verfahren - Konzepte - Vorschläge. Münster u.a.: Lit, 127-137.

Schewe, Manfred (2010a): Dramapädagogik. In: Surkamp, Carola (Hrsg.): Metzler Lexikon Fremdsprachendidaktik. Ansätze - Methoden - Grundbegriffe. Stuttgart u.a.: Metzler, 38-41.

Schewe, Manfred (2010b): Szenisch-dramatische Formen. In: Hallet, Wolfgang; Königs, Frank G. (Hrsg.) (2010), 199-203.

Schewe, Manfred (2011): Die Welt auch im fremdsprachlichen Unterricht immer wieder neu verzaubern - Plädoyer für eine performative Lehr- und Lernkultur! In: Küppers, Almut; Schmidt, Torben; Walter, Maik (Hrsg.): Inszenierungen im Fremdsprachenunterricht. Grundlagen, Formen, Perspektiven. Bad Heilbrunn: Klinkhardt, 20-31.

Schewe, Manfred (2013): Taking Stock and Looking Ahead. Drama Pedagogy as a Gateway to a Performative Teaching and Learning Culture. In: Scenario 2013, 1, 5-27. Online: http://research.ucc.ie/scenario/2013/01/Schewe/02/en (Stand: 10.03.2014).

Strübing, Jörg (2008): Grounded Theory. Zur sozialtheoretischen und epistemologischen Fundierung des Verfahrens der empirisch begründeten Theoriebildung. 2., überarb. und erw. Aufl. Wiesbaden: VS.

Tselikas, Elektra I. (1999): Dramapädagogik im Sprachunterricht. Zürich: Orell Füssli. 


\title{
Dramapädagogik und Ästhetisches Lernen im Fremdsprachenunterricht
}

\begin{abstract}
Susanne Even
In diesem Beitrag wird Dramapädagogik als ein ästhetisierender Lehr- und Lernansatz, vorgestellt und argumentiert, dass eine dramapädagogische Herangehensweise Kontexte für die Konstruktion individueller Wahrnebmung schafft, was zur Ästhetisierung des Lernstoffs und damit zu nachbaltigen Lernerfahrungen fübrt. Das Unterrichtsmodul Die Füße im Feuer, basierend auf der Ballade von Conrad Ferdinand Meyer, veranschaulicht eine solch ästhetisierende Herangehensweise.
\end{abstract}

\section{Grundüberlegungen: Ästhetisches Lernen}

Die Notwendigkeit ästhetischen Lernens wird zunehmend Gegenstand der Fachdebatte um Bildungsinhalte, -formen und -prozesse.

Der Diskurs über die Besonderheit des ästhetischen Lernens ist Bestandteil und Voraussetzung jeder Qualitätsdebatte, die nicht nur die Qualität von Strukturen und Methoden der Kulturellen Bildung im Blick hat, sondern auch die Qualität der Bildungsprozesse des Individuums (Bundesvereinigung Kulturelle Kinder- und Jugendbildung 2012),

heißt es beispielsweise in den einleitenden Worten von Gerd Taube, dem Vorsitzenden der Bundesvereinigung Kulturelle Kinder- und Jugendbildung (BKJ) zur BKJ-Fachtagung 2012: Wie gelingt ästhetisches Lernen? Angesichts verschärfter Rahmenbedingungen durch Modularisierung und einseitiger Konzentration auf überprüfbare Learning Outcomes an Schulen und Hochschulen ist und bleibt die Frage nach Stellenwert und Realisierung ästhetischen Lernens von hoher Aktualität. 
Im alltagssprachlichen Verständnis gilt Ästhetik als allgemeine Theorie des Schö-

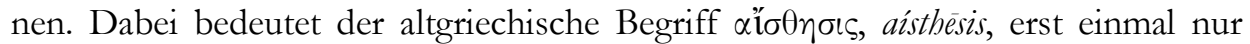
ganz wertfrei Wahrnebmung. Nach Alexander Gottlieb Baumgartens (1714-1762) Definition von Ästhetik als Theorie der sinnlichen Erkenntnis hängen ästhetische Erfahrungen davon ab, wie etwas in bestimmten Kontexten sinnlich wahrgenommen wird (vgl. Baumgarten 1983). Ästhetisches Lernen verfolgt damit die Ausbildung der selbstreflexiven Wahrnehmungsfähigkeit, die dem Individuum Lernwelten eröffnet, die über die reine Wissensaneignung hinausgehen. Es gilt daher, Lernstoff und Lernprozesse zu ästhetisieren.

„Ästhetisieren heißt, ein Etwas - Ding, Vorstellung, Lebenswelt - aus übergreifenden Einbeziehungen, die es funktionalisieren, herauszulösen", argumentiert Peper (2002: 1), „den Gegenstand aus übergreifenden Funktionen und Sinnrastern lösen, positiv gesagt: den Gegenstand vereigentlichen, individualisieren, ihn emanzipieren." In diesem Prozess werden kulturelle Gegebenheiten, Objekte und Zusammenhänge „zu einem Angebot für die Phantasie des emanzipierten Einzelnen“ (ebd.).

In The Turk Who Loved Apples (2013) beschreibt der US-Amerikaner Matt Gross eine solche ästhetische Erfahrung. Mit einem Freund koreanisch-amerikanischer Abkunft verbringt er 2005 ein Wochenende an einem gottverlassenen Grenzort von Myamar, wo sie Slim, einem Birmanen mit indischem Hintergrund begegnen und sich zusammen mit großem Vergnügen über Eminem, Pink Floyd und die Scorpions austauschen:

That weekend in Burma marked a turning point for me [...]. It was so short, so sweet, so weird, and so perfect - and it had all taken place so far from any location of significance. Tachileik was in the middle of nowhere, a town overlooked by everyone but those required to spend the night (or their lives), and yet there was Slim, and there we were. The connection, the moment, could happen, even there. Until then, my travels had shrunk the world. I had crossed continents by every conveyance imaginable and was developing [...] some mastery in the practicalities of travel [...]. Now, though, the world was starting to appear bigger than ever, a massively expanding network of tiny points where anything at all could happen, and within each point another infinite web of possibilities (Gross 2013: 5).

In diesem Sinne besteht eine Aufgabe des Fremdsprachenunterrichts darin, die Welt durch das Schaffen von Kontexten für die Konstruktion individueller Wahrnehmung zu vergrößern. Damit wird der Schwerpunkt von Lerninhalt zu Lernmodus verschoben; nicht mehr das Wissen über Fakten, Zusammenhänge, Vorgehensweisen usw. steht im Zentrum, sondern vielmehr, wie dieses Wissen erlebt und ausgestaltet wird. 


\section{Dramapädagogik als ästhetisierender Ansatz}

Dramapädagogik ist ein Lehr- und Lernansatz, der durch die bewusste Einbeziehung kinästhetischer Lernmomente bereits einen performativen Charakter in sich trägt. Mit Hilfe von Techniken der Schauspielausbildung werden Lerninhalte und Lernprozesse ästhetisiert und performative Erfahrungsräume bereitgestellt, die Möglichkeiten für individuelle Wahrnehmungen schaffen. Dabei bleiben die individuellen ästhetischen Erfahrungen nicht willkürlich, sondern finden in sozialen Zusammenhängen statt, wo sich die jeweiligen Wahrnehmungen überlagern und „das bislang funktional Einbezogene und somit Verborgene zu seinem Selbst- und Vielbezug" (Peper 2002: 7) kommt.

Anders gesagt: Bei der Lehrkunstform Dramapädagogik werden Lehre (Wissenschaft) und Kunst (Ästhetik) vereint; der Fokus liegt nicht mehr nur auf dem Lernprodukt, sondern insbesondere auch auf dem Lernprozess. Wenn Lernende unterschiedliche Rollen annehmen und im dramatischen Prozess miteinander weiterentwickeln, benutzen sie die Fremdsprache in personalisierten und lernerzentrierten Kontexten und werden $\mathrm{zu}$ authentisch Agierenden in dramatischen Handlungsräumen. Auf Papier gebundener Lernstoff wird individuell-sinnlich wahrgenommen, da das dramatische Medium die Kombination von kinästhetischen Dimensionen mit kognitivem, emotionalen und praktischen Lernmomenten verfolgt. Dinge, Äußerungen, Gegebenheiten und Situationen werden durch unterschiedliche Techniken (s.u.) aus ihren ursprünglichen Kontexten herausgelöst und damit ästhetisiert. Solche Ästhetisierungen machen multiple Bedeutungsschichten, deren Kontextgebundenheit und auch deren Wandelbarkeit erfahrbar, so dass der Lernstoff für die Lernenden individuelle Bedeutsamkeit annimmt.

\section{Herauslösen einer Textstelle}

Diese Technik wird oft als Einführung in einen Text benutzt. Ein Satz oder eine Passage aus dem (bisher unbekannten) Text wird ohne Zusatzinformationen gelesen. Die Aufgabe der Lernenden ist es dann, diese Textstelle zu diskutieren und in Standbildern oder kurzen dramatischen Szenarios zu rekontextualisieren. Ein Beispiel für eine solche Textstelle ist der Satz „Bald wird es keine Orte mehr geben, an denen sich Menschen treffen können“" aus Sansibar oder der letzte Grund (vgl. Schewe; Wilms 1995: 23). Authentische Rekontextualisierungen dieses Satzes, der sich in Alfred Andersch' Roman auf das Leben in Nazi-Deutschland bezieht, waren (in meinem eigenen Unterricht) u.a. Zukunftsvisionen über die zunehmende Verseuchung der Erde, die die Menschen daran hindert, sich gefahrlos an der Oberfläche zu bewegen, oder die Virtualisierung menschlicher Kontakte durch das Internet, die dazu führt, dass die Menschen in Zukunft immer weniger das Haus verlassen und sich in Cafés oder Kneipen treffen, weil es diese Orte kaum noch gibt. Solche Rekonstruktionen erweitern die Wahrnehmung von Sprache als multipler Bedeutungsträgerin und führen zu ausdifferenzierteren Erwartungshaltungen. 


\section{Herauslösen von Bedeutungen ${ }^{1}$}

Eine fiktive Figur aus dem Text wird von den Lernenden mit Attributen, Meinungen, Lebenskonzepten ausgestattet. Das kann in Form von Einfühlungsfragen oder von Hotseating stattfinden. Bei Einfühlungsfragen nehmen die Lernenden die Position dieser Figur an (oft mit Bildvorlage) und beantworten Fragen, die von der Lehrperson langsam vorgelesen werden, still für sich selbst. In einem zweiten Schritt erzählen sich die Lernenden in Kleingruppen gegenseitig von ihren Ideen. Beim Hotseating sitzt eine Person ${ }^{2}$ in der Mitte des Zimmers als diese fiktive Figur und beantwortet spontan Fragen zu ihrer Person, die von den anderen Lernenden gestellt werden. Die Fragen sind in beiden Fällen keine Abfrage-Fragen, die auf der Textgrundlage als richtig oder falsch beantwortet werden können, sondern beziehen sich auf Sachverhalte, Gedanken, Erinnerungen, Träume usw., die nicht im Text stehen. Bei beiden Techniken geht es um die kreative Ausgestaltung eines Charakters. Wenn die Lernenden die Körperhaltung einer Person einnehmen und aus dieser Perspektive Fragen beantworten (Einfühlungsfragen) oder als ein bestimmter Charakter in Kontakt mit den Fragenden treten (Hotseating), schafft die Kombination von äußerer und innerer Haltung neue Wahrnehmungskontexte; die Charaktere werden ästhetisiert.

\section{Herauslösen von Bedeutungen}

Ein Standbild (auch: Tableau, Freeze-Frame) ist ein eingefrorener Moment in Raum und Zeit, einem Foto vergleichbar oder einem durch die Pause-Taste eines DVDSpielers angehaltenen Film. Standbilder veranschaulichen Textmomente, sind aber nicht nur Abbildung des Gelesenen. Die Übersetzung von Geschriebenem in konkrete, anfassbare Bilder ist an sich schon eine ästhetisierende Handlung. Weiterhin können Standbilder auch zu performativen Metaphern werden, die die zu Grunde liegende Atmosphäre, Dynamik oder Problematik eines Moments ausgestalten und damit kontextuell erweitern.

Die Versprachlichung von Standbildern kann durch Thought-Tapping und Doppeln eingeleitet werden. Bei Thought-Tapping wird die Person bzw. werden die Personen im Standbild leicht angetippt, woraufhin sie das Erste sagen, was ihnen als die Figur, die sie verkörpern, in dieser Situation durch den Kopf geht. Beim Doppeln stellen sich Freiwillige hinter die Figur(en), nehmen ihre Körperhaltung(en) ein und verbalisieren ebenfalls, was diese Figure(en) innerlich beschäftigt. Aus solchen Äußerungsfragmenten können Dialoge entstehen, die mögliche Bedeutungen des jeweiligen Moments herausschälen.

\footnotetext{
1 Diese und die folgenden Techniken sind genauer nachzulesen in Even 2008; 2010.

2 Eine Variante dieser Technik ist das Multiple Hotseating, wo zwei oder drei Personen in der Mitte sitzen und die Fragen als eine Person beantworten vgl. Even 2011.
} 


\section{Herauslösen eines Dilemmas}

Das Spalier macht ein Dilemma begreifbar und nachfühlbar. Ausgehend von einer verwirrenden oder quälenden Situation im Text, die eine Entscheidungsfindung erfordert, sammelt eine Lernergruppe Argumente für ein bestimmtes Vorgehen, die zweite Argumente dagegen. Die zunächst sprachlich-kognitive Übung wird dann zu einer Performance: Die Pro- und Kontra- Gruppen stehen sich in zwei langen Reihen gegenüber und bilden so eine Gasse. Eine Person geht langsam durch diese Gasse, und die Argumente auf jeder Seite versuchen sie von ihrer Meinung zu überzeugen, wenn sie an ihnen vorbeikommt. Dabei sprechen immer mehrere gleichzeitig, weil die schreitende Person ja nicht stehen bleibt. Diese Technik vereindringlicht das Dilemma durch die verschiedenen Stimmen, die sich gleichzeitig Gehör verschaffen, und durch die physische Nähe der Argumente. Der Konflikt gewinnt durch die körperliche Positionierung, das (kin)ästhetische Erleben, schärfere Konturen und macht auf unterschiedliche Perspektiven aufmerksam: es geht nicht nur mehr um das Für und Wider, sondern gerade auch um das Dazwischen, um das Schwanken, die Unsicherheit, die Unentschlossenheit.

\section{Ästhetisierung von Poesie}

Gedichte und Balladen sind nicht jedermanns Sache. Obwohl ihre Form bereits Ästhetisches birgt, bleiben vielen Lernenden ihre ästhetischen Komponenten verschlossen, gerade wenn sich im Unterricht ausschließlich an formalen Elementen (Reimschema, Versmaß etc.) abgearbeitet oder der Inhalt lediglich mühevoll zusammengefasst wird. Das führt dann oft zu voreiliger Ablehnung (Gedichte mag ich nicht, verstehe ich nicht, sind doof), die letztendlich Bewertungen ohne Wahrnehmung sind. Anders gesagt: der Zugang zu Poesie wird nicht automatisch durch ihre ästhetische Form garantiert. Erst eine ästhetisierende Herangehensweise kann Türen öffnen zu individueller Wahrnehmung des Zusammenspiels von Form und Inhalt, durch das sich vielfältige Bedeutungsebenen erschließen können.

Als Beispiel einer solchen Ästhetisierung soll eine an der Indiana University (Bloomington, USA) im Rahmen eines Literaturdidaktikseminars konzipierte dramapädagogische Unterrichtseinheit dargestellt werden, die auf der Ballade Die Füße im Feuer von Conrad Ferdinand Meyer (1825-1898) basiert und die weit über die übliche didaktische Herangehensweise von Lesen - Zusammenfassen - Interpretieren hinausgeht. Mögliche Handlungsräume umfassen dabei die Ausgestaltung der gegebenen und erinnerten Orte, der Spannungskurve und des Traums, sowie des Konflikts zwischen ungefilterten Gefühlen und ethischen Grundsätzen. 


\section{Die Füße im Feuer}

Die Ballade Die Füße im Feuer (vgl. Reiners 1959: 154; Gesamttext im Anhang) schildert einen Abend, eine Nacht und einen Morgen im 16. oder 17. Jahrhundert. Ein Kurier des Königs von Frankreich sucht während eines Unwetters auf einem Schloss Zuflucht. Nach und nach geht ihm zu seinem Entsetzen auf, dass er schon einmal auf diesem Schloss gewesen ist: Mehrere Jahre zuvor hat er dort auf einer Hugenottenjagd die Frau des Schlossherren zu Tode gefoltert, weil sie den Aufenthaltsort ihres Mannes nicht preisgeben wollte. Die Kinder erkennen ihn sofort wieder. Als der Kurier sich erschrocken zur Nacht zurückzieht, sieht er, wie der Sohn dem Vater etwas zuflüstert. Er verbarrikadiert sich in seinem Schlafgemach und verbringt eine von Angstträumen gequälte Nacht. Am Morgen steht der Schlossherr an seinem Bett, der durch eine geheime Tür in den Raum gekommen ist. Schweigend begleitet er den Kurier ein Stück auf seinem Weg. Dieser lässt zum Abschied durchblicken, dass der Schlossherr weise gehandelt habe, einen Kurier des Königs unangetastet gelassen zu haben. Zunächst scheint der Schlossherr zuzustimmen, aber seine Abschiedsworte versprechen Unheil: Gott als der größte König wird die Tat sühnen.

Das folgende Unterrichtsmodul ist für fortgeschrittene Lernende (B2Kompetenz) konzipiert. Vorentlastungen wie Vokabellisten oder Grammatikerklärungen sind hierin nicht enthalten, da solche Entscheidungen auf Grundlage der jeweiligen Lerngruppe getroffen werden müssen.

\section{Ahnengalerie: Standbilder und Hotseating}

Als Einführung in die Ballade werden die Teilnehmenden (TN) aufgefordert eine Ahnengalerie zu entwerfen. Die verschiedenen Ahnenbilder sollen alle etwas miteinander zu tun haben (z.B. könnten sie zur gleichen Familie gehören). Dazu müssen die TN sich einigen

- $\quad$ auf einen Kontext (z.B. Familienporträts, Kunstsammlung)

- $\quad$ auf einen Ort (z.B. Museum, Privatbesitz)

- $\quad$ auf die dargestellten Personen (wer sie sind, wann und wie sie gelebt haben, wann und woran sie gestorben sind, usw.)

Danach überlegt sich jede/r TN Details zu seiner/ihrer Person und entwirft ein Wappen, mit dem diese Person auf dem Ahnenbild dargestellt ist. Diese Wappen werden auf große Pappbögen aufgemalt und dekoriert.

Die TN gehen zusammen mit ihren Wappen in ein Gruppenstandbild, als würden sie als Porträts nebeneinander an der Wand hängen. Auf ein Signal hin bleibt die erste Person in Position, und die anderen verlassen das Standbild, lassen aber ihre Wappen als Platzhalter zurück. Die erste Person sagt einen Satz, der gewissermaßen ihr Lebensmotto ist. Die anderen TN können dieser Person Fragen stel- 
len, die in Rolle beantwortet werden (dem Hotseating vergleichbar). ${ }^{3}$ Danach verlässt die erste Person das Bild, die zweite geht zurück in Position und beantwortet Fragen der Zuschauenden usw.

Diese konkrete Gruppe 4 entschied sich dafür, die Degeneration einer Dynastie darzustellen von dem Urahnen König Erich dem Ehrlichen, dem seine Aufrichtigkeit zum Ruin wird bis zu der modernen Prinzessin Paula und ihrem Zwillingsbruder Prinz Paul dem Faulen, die die Ehre und das Geld der Familie durch Partys, Reisen, Kleider, Drogen und Sex verspielen.

Diese Aktivität macht mit dem Wort Ahnengalerie vertraut und bereitet damit im weitesten Sinne den Ort des Geschehens vor:

Der Reiter tritt in einen dunklen Ahnensaal, / von eines weiten Herdes Feuer schwach erhellt, / und dort, bei seines Flackerns launenhaften Licht / droht hier ein Hugenott' im Harnisch, dort ein Weib, / ein stolzes Edelweib aus braunem Ahnenbild ... (vgl. Anhang, V. 11-15).

\section{Vortrag Ballade Teil I}

Als Vorentlastung für die Rezeption des ersten Teils der Ballade (Vers 1-35) wird der Begriff Hugenotten eingeführt und die Geschichte der Hugenotten in Frankreich kurz umrissen. Weiterhin bekommen die Teilnehmenden Vokabelhilfen zu dem nun folgenden Textausschnitt.

Die Teilnehmenden und die Lehrperson sitzen zusammen auf dem Boden. Der Raum ist abgedunkelt, eine Kerze brennt. Die Lehrperson trägt den ersten Teil der Ballade laut vor, die TN hören zu. Das besondere Setting hat hier mehrere Funktionen. Der abgedunkelte Raum mit Kerze ist eine Anspielung auf den dunklen Ahnensaal, und die mündliche Vortragsform erweckt die performativen Elemente der Ballade eindrücklich zum Leben.

\section{Der bekannte Raum: Erinnerungsreise}

Die TN sollen sich einen ihnen bekannten Raum ins Gedächtnis rufen, der in ihrem Leben von Bedeutung ist. Dazu schließen sie die Augen und hören getragene Musik (z.B. Chopins Walzer für Klavier in a-Moll, Opus 34). Die Lehrperson führt die TN langsam und mit ruhiger Stimme durch ihre Räume:

Stell dir vor, du gehst in ein Zimmer. Du kennst das Zimmer gut, aber du bist schon länger nicht hier gewesen. Was siehst du, wenn du geradeaus schaust? Was siebst du, wenn du nach links schaust? Was siehst du, wenn du nach rechts schaust? Welche Gegenstände sind im Zimmer? Welche Farbe haben die Wände? Welche Bilder hängen an den Wänden? Jetrt gehst du zum Fenster. Was siehst du, wenn du aus dem Fenster schaust? Jetat drehst du dich um und

\footnotetext{
${ }^{3}$ Bei einer großen Lernergruppe bleibt das Gesamtbild so stehen. Die konkrete Lerngruppe bestand aus nur sechs Teilnehmenden.

${ }^{4}$ Mein Dank gilt an dieser Stelle den Teilnehmenden an meinem Literaturdidaktikseminar 2011.
} 
betrachtest das Zimmer vom Fenster aus. Geh langsam zurück zur Tür und schau noch einmal zurück. Dann verlässt du das Zimmer.

Die TN tun sich zu zweit zusammen und setzen sich Rücken an Rücken. Jede Person bekommt ein Blatt Papier und einen Stift. Gegenseitig sollen sie sich ihre Räume beschreiben und den Raum der Partnerin oder des Partners nach der Beschreibung zeichnen. Nach Fertigstellung zeigen sich die TN ihre Zeichnungen, machen gegebenenfalls Korrekturen und erzählen einander, warum sie diesen Raum gewählt haben bzw. welche Bedeutung er für sie hat.

Diese Aktivität sensibilisiert die TN für räumliche Erinnerungen und damit zusammenhängende Assoziationen. Im Plenum wird im Anschluss daran diskutiert, woran der Kurier in der Ballade den Raum wiedererkennt, in dem er sich befindet und welche Erinnerungsfetzen ihm in den Kopf kommen. Die TN bekommen nun den ersten Teil der Ballade schriftlich zu sehen. Es folgt eine Verständnissicherung und erste Hypothesen werden formuliert: Was ist damals passiert? Und warum? Wie könnte es weiter gehen?

\section{Vortrag Ballade Teil I und II}

Das Klassenzimmer wird wieder verdunkelt und die Lehrperson trägt nun den ersten und den zweiten Teil der Ballade laut vor (Vers 1-53). Die TN haben den ersten Teil der Ballade inzwischen einmal gelesen, der zweite Teil ist jedoch neu (wieder mit Vokabeln als Vorentlastung).

\section{Der Abendtisch: Standbild und Thought-Tapping}

In Gruppen sollen die TN eine Sequenz von drei Standbildern entwerfen, die die Atmosphäre und Dynamik am Abendbrottisch darstellen. Die Wahl der Momente bleibt den Lernenden überlassen. Arbeitsgruppen, die noch nicht oft mit der Standbildtechnik gearbeitet haben, tendieren dazu das Geschehen lediglich abzubilden. Daher sollten die TN dazu angehalten werden, Momente darzustellen, die nicht im Text stehen oder in ihrer Standbildsequenz eine Kombination von äußeren und inneren Momenten zu verfolgen.

Mögliche Standbilder wären beispielweise:

- Der Schlossherr betritt mit dem Kurier den Raum und der Sohn lässt den Krug mit Wein vor Schreck fallen.

- Die kleine Tochter will nicht zu Tisch kommen und verbirgt sich hinter ihrem Bruder.

- Der Kurier kann seinen Blick nicht vom Kamin abwenden und der Schlossherr betrachtet ihn verwundert.

- Alle falten die Hände zum Tischgebet, nur die Kinder blicken den Kurier unverhohlen an. Der Schlossherr macht eine ungeduldige Geste; er ist von dem Benehmen seiner Kinder verärgert. 
- Die Bedienstete steht hinter der angelehnten Tür und lauscht.

- Der Schlossherr steht wie erstarrt, nachdem der Gast den Raum verlassen hat und ihm sein Sohn erzählt hat, um wen es sich handelt.

Jede Gruppe stellt ihre Standbildsequenz den anderen vor. Durch ThoughtTapping werden die Sequenzen ansatzweise versprachlicht. Im Anschluss daran sollen die TN von allen gezeigten Standbildern fünf oder sechs auswählen und damit eine neue Sequenz bilden. Die ausgewählten Standbilder werden neu zusammengestellt und ein weiteres Mal vorgeführt.

Diese Aktivität gestaltet die Spannungskurve aus und bereitet auf den Höhepunkt der Ballade vor. Die Kleingruppen entwerfen auf Grundlage individueller, gemeinsam ausgehandelter Ideen ihre eigenen Standbilder. In der Großgruppe werden dann kollaborative Entscheidungen getroffen, die die Ideen aller Kleingruppen in Betracht ziehen und auf eine Performance hinsteuern, an deren Genese alle TN beteiligt waren.

\section{Der Albtraum: Szenische Improvisation}

Albträume beinhalten oft Dinge, die man als Träumende/r aus unerklärlichen Gründen nicht ausführen kann; man erlebt sich in unlösbaren Zwangssituationen. Eine solche Situation soll in Anlehnung an die Ballade in der Gruppe improvisiert werden; die TN sollen eine Vorstellung von den Todesängsten des Kuriers bekommen.

An diesem Punkt bekommen die TN auch den zweiten Teil der Ballade zu lesen, der mit dem Albtraum des Kuriers endet (,aufsprüht und zischt ein Feuermeer, das ihn verschlingt", vgl. Anhang, V. 53).

Als Vorübungen eignen sich die folgenden Aktivitäten (nach Schewe; Wilms 1995: 17):

- Die TN tun sich zu zweit zusammen und schauen sich so lange wie möglich in die Augen ohne zu reden oder zu lachen.

- Gruppen von fünf-sechs TN stehen im Kreis und lassen ihre Blicke herumwandern. Schließlich bleiben alle Blicke - ohne Absprache - auf einer bestimmten Person im Kreis haften.

- Ein Verhör wird simuliert, ohne dass inhaltliche Details vorgegeben werden. Ein/e freiwillige/r TN wird von den anderen TN ausgefragt, ohne zu wissen, worin die Anklage besteht.

Nach jeder Aktivität gibt es ein kurzes Feedback, wie sich die TN gefühlt haben.

Ein großes Blatt Papier hängt an der Wand mit den Imperativen aus der Ballade, die den Kurier in seinem Traum heimsuchen: „Gesteh!“ (V. 51), „Bekenn!“, „Gib ihn heraus!“ (V. 28), „Sprich!“ (V. 27) Die TN schreiben weitere Äußerungen dazu, die der Kurier während seines Albtraums noch hören könnte, z.B. Sei still!, Wo ist er?, Komm her!, Sag endlich etwas! usw. 
Die TN wählen danach ein oder zwei Äußerungen aus und experimentieren mit ihnen, während sie im Raum umhergehen und die Äußerungen an die ihnen Begegnenden richten. Dabei sollen sie mit Intonation, Lautstärke, Tonlage experimentieren.

Die Lehrperson legt eine Decke auf den Boden und fordert die TN auf, den Albtraum zu inszenieren. Ein/e TN aus der Gruppe übernimmt die Rolle des Kuriers, der auf seinem Lager liegt. Die übrigen TN werden zu Sprachphantomen, die dem Träumer Erinnerungsfetzen zurückbringen. Sie verbinden sich Mund und Nase mit Tüchern. ${ }^{5}$ Die Lehrperson lenkt als Regisseur/in den Ablauf dieser szenischen Improvisation, indem sie Möglichkeiten der dramatischen Ausgestaltung vorher anspricht: Wie träumt der Kurier die Stimmen? Bewegen sie sich langsam um das Lager herum? Flüstern sie erst und lassen sie ihre Stimmen langsam lauter werden? Oder beginnt der Traum abrupt? Wie reagiert der Träumer? Liegt er ruhig da oder wirft er sich von einer Seite auf die andere, schreckt er aus dem Schlaf auf, usw.?

Die Improvisation kann durch Musik begleitet werden (z.B. Ry Cooder's Paris, Texas), die die Lehrperson zunehmend lauter dreht. Zum Ende der Improvisation wird die Musik langsam leiser. ${ }^{6}$

Im Nachgespräch erzählen die TN von ihren Erlebnissen: Wie hat sich der Träumende gefühlt? Wie war es für die anderen TN als Sprachphantome?

In meiner konkreten Gruppe entwickelte sich eine spontane Variante: Die Sprachphantome nahmen den Teppich hoch, auf dem der Träumende lag, und schaukelten ihn hin und her, während sie die Stimmen an- und abschwellen ließen. In der Feedbackrunde stellte sich heraus, dass diese Aktivität als sehr intensiv empfunden wurde, und zwar nicht nur von dem Träumenden, sondern genauso auch von den Sprachphantomen.

\section{Der Schlossherr: Spalier}

Die TN sollen sich nun Gedanken über den Schlossherren machen, der gerade von seinem Sohn erfahren hat, dass sein Gast, mit dem er gerade noch am Tisch gesessen hat, vor drei Jahren seine geliebte Frau getötet hat. Wie reagiert der Schlossherr auf diese Information? Der Mörder ist unter seinem Dach und damit auch in seiner Gewalt. Soll er Rache üben? Die TN stellen sich vor, wie der Schlossherr in der Nacht vor dem Kaminfeuer sitzt und von Trauer, Wut und Rachefantasien geplagt wird. Er könnte den Gast umbringen. Niemand würde es erfahren. Was soll er tun?

Die TN gehen in zwei Großgruppen zusammen. Eine Gruppe überlegt sich Argumente für Rache und die andere Argumente gegen Rache bzw. für den Ver-

\footnotetext{
${ }^{5}$ Für eine Variante der Traumimprovisation mit Masken siehe Schewe; Wilms 1995: $17 \mathrm{ff}$.

${ }^{6}$ Das gibt der Lehrperson die Gelegenheit, den Abschluss des Traums zu steuern, wenn die Gruppe die Aktivität nicht selbstständig abschließt.
} 
zicht auf Rache. Die beiden Gruppen stehen sich in zwei Reihen gegenüber. Eine Person geht als Schlossherr langsam durch die Gasse und wird dabei von beiden Seiten von Argumenten bedrängt.

Diese Aktivität leitet einen Perspektivwechsel ein. Während die vorigen Techniken ihren Ausgangspunkt tendenziell in den Empfindungen des Kuriers hatten (Erinnerung, Erschrecken, Angst), rückt nun der Schlossherr in den Mittelpunkt und damit der Konflikt zwischen möglichen Affekthandlungen und ethischen Prinzipien.

\section{Vortrag der ganzen Ballade}

Als Vorbereitung auf den Gesamtvortrag bekommen die TN wieder Vokabelhilfen für den letzten, ihnen noch unbekannten Teil der Ballade. Wieder wird die Ballade im abgedunkelten Raum vorgetragen, aber zu Beginn des dritten Teils („Erwach! Du solltest längst von hinnen sein! Es tagt!“, vgl. Anhang, V. 54) werden die Jalousien geöffnet bzw. das Licht angeschaltet. Im Anschluss an den Vortrag lesen die TN den letzten Teil durch und diskutieren, inwieweit das Ende für sie stimmig ist, ob sie davon überrascht sind und warum (nicht).

\section{Schlussbetrachtung}

$[\mathrm{D}]$ as Ästhetische besteht gerade darin, das Entscheidende nicht nur in einer Art imaginärer Mimesis mitzuvollziehen, sondern auch zu entziffern. Das Ästhetische und das Hermeneutische gehören zusammen, ja konvergieren. In einer Vielzahl, ja, vielleicht in allen Situationen emergiert der soziale Sinn im ästhetischen Schein wie dieser umgekehrt jenen erst codiert. Man kann den sozialen Sinn vom Ästhetischen nur ablösen um den Preis, ihn zu bloBer Information zu mortifizieren (Böhme 1995: 243).

Das hier dargestellte Unterrichtsmodul zu C.F. Meyers Die Füße im Feuer soll einen Eindruck des ästhetisierenden Potenzials von Dramapädagogik vermitteln. Dabei erheben die hier vorgestellten Aktivitäten keinen Anspruch auf Vollständigkeit; Literaturtheoretikerinnen und -theoretiker mögen eine umfassende Interpretation der Ballade vermissen und Fremdsprachenlehrenden fehlen u.U. genauere sprachdidaktische Anweisungen. Doch es geht hier weder um eine oder mehrere bestimmte Interpretationen einer deutschen Ballade noch um eine detaillierte sprachliche Analyse oder einen verbindlichen Unterrichtsplan. Vielmehr werden Aktivitäten zur Ästhetisierung der Ballade angeboten, die Kontexte für die Entfaltung individueller Wahrnehmung bereitstellen. Es handelt sich hierbei um die Herauslösung bzw. Vereigentlichung von Orten und Räumen, der Prozesse des Erinnerns und des Wiedererkennens, sowie der Emotionen von Angst und Rache. Weiterhin wird die Auseinandersetzung von Affekten/Impulsen mit ethischen Prinzipien herausgearbeitet. Durch eine dramapädagogische Herangehensweise wird die indi- 
viduelle Fantasie der Lernenden angeregt, die durch die sinnliche Wahrnehmung des Lernstoffs ihre eigenen Welten vergrößern. Dies geschieht in der Kombination von Individualisierung und kollaborativer Konstruktion und der hieraus entspringenden Dynamik im Sinne kreativer Unvorhersehbarkeit. Die Lernenden erleben sich als Handelnde, die, von Textvorlage und ihren eigenen Ideen geleitet, performative Erfahrungsräume betreten und miteinander ausgestalten. Die Ästhetisierung von Lernstoff, die erst einmal nicht ausschließlich auf das reine Verstehen des Inhalts oder gar Identifikation mit den Charakteren gerichtet ist, sondern eine Auffächerung der Wahrnehmung verfolgt, birgt das Potenzial multiple Bedeutungsschichten nicht allein zu generieren, sondern darüber hinaus zu dynamisieren und - letzten Endes - zu dechiffrieren.

Und das Ästhetische realisiert Bedeutungen, die nicht an Rede und intentional hervorgebrachte Zeichen gebunden sind, sondern jedem und allem zukommen können (ebd.: 247).

\section{Literatur}

Andersch, Alfred (1970): Sansibar oder der letzte Grund. Zürich: Diogenes.

Baumgarten, Alexander Gottlieb (1983): Texte zur Grundlegung der Ästhetik. Lateinisch-deutsch. Hamburg: Meiner.

Böhme, Hartmut (1995): Einführung in die Ästhetik. In: Paragrana 32, 4, 240-254.

Bundesvereinigung Kulturelle Kinder- und Jugendbildung (2011): Künste - Sinne Bildung. Wie gelingt ästhetisches Lernen? Online: http:/ / fachtagung2012.bkj.de/ (Stand: 30.07.2014).

Even, Susanne (2011): Multiple Hotseating. In: SCEN ARIO V, 2, 112-113.

Even, Susanne (2010): Dramagrammatischer Unterricht in der Fremdsprache: Denken und Handeln. In: Informationen zur Deutschdidaktik. 2, 104-112.

Even, Susanne (2008): Moving in(to) Imaginary Worlds: Drama Pedagogy for Foreign Language Teaching and Learning. In: Unterrichtspraxis Deutsch 41, 2, 161-170.

Peper, Jürgen (2002): Ästhetisierung als Aufklärung. Eine erste Annäherung. In: Peper, Jürgen (Hrsg.): Ästhetisierung als Aufklärung. Unterwegs zur demokratischen Privatkultur. Eine literarästhetisch abgeleitete Kulturtheorie. Berliner Beiträge zur Amerikanistik, Band 11. Berlin: John-F.-Kennedy-Institut für Nordamerikastudien, 1-13. Online: http:/ / www.uni-graz.at/ peper/Interpep.pdf (Stand: 30.07.2014). 
Reiners, Ludwig (1959): Der ewige Brunnen. Ein Hausbuch deutscher Dichtung. München: Beck.

Schewe, Manfred; Wilms, Heinz (1995): Texte lesen und inszenieren. Alfred Andersch: Sansibar oder der letə̧te Grund. München: Klett. 


\section{Anhang}

Die Füße im Feuer (Conrad Ferdinand Meyer)

Wild zuckt der Blitz. In fahlem Lichte steht ein Turm.

Der Donner rollt. Ein Reiter kämpft mit seinem Roß, springt ab und pocht ans Tor und lärmt. Sein Mantel saust im Wind. Er hält den scheuen Fuchs am Zügel fest. Ein schmales Gitterfenster schimmert goldenhell, und knarrend öffnet jetzt das Tor ein Edelmann ...

„Ich bin ein Knecht des Königs, als Kurier geschickt nach Nîmes. Herbergt mich! Ihr kennt des Königs Rock!“ „Es stürmt. Mein Gast bist du. Dein Kleid, was kümmert's mich? Tritt ein und wärme dich! Ich sorge für dein Tier!“

Der Reiter tritt in einen dunklen Ahnensaal, von eines weiten Herdes Feuer schwach erhellt, und je nach seines Flackerns launenhaftem Licht droht hier ein Hugenott im Harnisch, dort ein Weib, ein stolzes Edelweib aus braunem Ahnenbild ... Der Reiter wirft sich in den Sessel vor dem Herd und starrt in den lebend'gen Brand. Er brütet, gafft ... Leis sträubt sich ihm das Haar. Er kennt den Herd, den Saal. Die Flamme zischt. Zwei Füße zucken in der Glut.

Den Abendtisch bestellt die greise Schaffnerin mit Linnen blendend weiß. Das Edelmägdlein hilft. Ein Knabe trug den Krug mit Wein. Der Kinder Blick hangt schreckensstarr am Gast und hangt am Herd entsetzt ...

Die Flamme zischt. Zwei Füße zucken in der Glut. „Verdammt! Dasselbe Wappen! Dieser selbe Saal! Drei Jahre sind's ... Auf einer Hugenottenjagd ... Ein fein, halsstarrig Weib ..., Wo steckt der Junker? Sprich!

Sie schweigt. ,Bekenn!‘ Sie schweigt. ,Gib ihn heraus!‘ Sie schweigt. Ich werde wild. Der Stolz! Ich zerre das Geschöpf ...

Die nackten Füße pack ich ihr und stecke sie tief mitten in die Glut ... ,Gib ihn heraus!' ... Sie schweigt ... Sie windet sich ... Sahst du das Wappen nicht am Tor? Wer hieß dich hier zu Gaste gehen, dummer Narr? Hat er nur einen Tropfen Bluts, erwürgt er dich. " Eintritt der Edelmann. „Du träumst! Zu Tische, Gast ...“

Da sitzen sie. Die Drei in ihrer schwarzen Tracht und er. Doch keins der Kinder spricht das Tischgebet; ihn starren sie mit aufgerißnen Augen an. 
Den Becher füllt und übergießt er, stürzt den Trunk, Springt auf: „Herr, gebet jetzt mir meine Lagerstatt! Müd bin ich wie ein Hund!“‘ Ein Diener leuchtet ihm, doch auf der Schwelle wirft er einen Blick zurück und sieht den Knaben flüstern in des Vaters Ohr ... Dem Diener folgt er taumelnd in das Turmgemach. Fest riegelt er die Tür. Er prüft Pistol und Schwert. Gell pfeift der Sturm. Die Diele bebt. Die Decke stöhnt. Die Treppe kracht ... Dröhnt hier ein Tritt? Schleicht dort ein Schritt? ...

Ihn täuscht das Ohr. Vorüberwandelt Mitternacht.

Auf seinen Lidern lastet Blei, und schlummernd sinkt er auf das Lager. Draußen plätschert Regenflut.

Er träumt. „Gesteh!“ Sie schweigt. „Gib ihn heraus!“ Sie schweigt.

Er zerrt das Weib. Zwei Füße zucken in der Glut.

Aufsprüht und zischt ein Feuermeer, das ihn verschlingt ...

„Erwach! Du solltest längst von hinnen sein! Es tagt!“

Durch die Tapetentür in das Gemach gelangt, vor seinem Lager steht des Schlosses Herr - ergraut, dem gestern dunkelbraun sich noch gekraust das Haar.

Sie reiten durch den Wald. Kein Lüftchen regt sich heut. Zersplittert liegen Ästetrümmer quer im Pfad.

Die frühsten Vöglein zwitschern, halb im Traume noch. Friedsel'ge Wolken schimmern durch die klare Luft, als kehrten Engel heim von einer nächt'gen Wacht. Die dunklen Schollen atmen kräft'gen Erdgeruch. Die Ebne öffnet sich. Im Felde geht ein Pflug. Der Reiter lauert aus den Augenwinkeln: „Herr, ihr seid ein kluger Mann und voll Besonnenheit und wißt, daß ich dem größten König eigen bin. Lebt wohl! Auf Nimmerwiedersehn!“ Der andre spricht: „Du sagst's! Dem größten König eigen! Heute ward sein Dienst mir schwer ... Gemordet hast Du teuflisch mir mein Weib! Und lebst ... Mein ist die Rache, redet Gott." 



\title{
Bühne frei für Deutsch! - Rückbesinnung auf das Wesen des Theaters
}

\author{
Birgit Oelschläger \\ Ausgehend von drei grundlegenden Wesensmerkmalen des Theaters (Theater als ästhetische Ge- \\ staltung, als Kommunikation und als Präsentationsform) untersucht der Beitrag, welche Auswir- \\ kungen es auf den fremdsprachigen Deutschunterricht hat, die Sperifika von Theater als Kunst- \\ form ernst zu nebmen. Er nimmt Bezug auf die DaF-Unterrichtspraxis, um zu zeigen, wie man \\ an Hand von Basisregeln der Gestaltung sowie theaterberogenen Aufgabenstellungen zu ästhe- \\ tisch interessanten Ergebnissen kommt.
}

\section{Einführung}

Ich kann jeden leeren Raum nehmen und ihn eine Bühne nennen. Ein Mann geht durch den Raum, während ihm ein anderer zusieht; das ist alles, was zur Theaterhandlung notwendig ist (Brook 1983: 9).

So beginnt Peter Brooks Essay Der leere Raum. Theater kann fast überall stattfinden, aber es gibt einen Grundzug seines Wesens: Zum Theater gehört immer ein Mensch, der agiert und ein anderer, der ihm dabei zuschaut. Wenn hier im Folgenden von Theater als Kunstform im Unterricht die Rede sein wird, meine ich damit ausschließlich eine publikumsbezogene szenische Darbietung, die auf Wirkung zielt und erst in diesem Moment ihr künstlerisches Produkt sichtbar macht.

Im Zentrum theaterpädagogischer Praxis steht seit den 90er-Jahren weniger der pädagogische Nutzen von Theater in unterschiedlichen Zusammenhängen, sondern Theater als Kunstform mit der Frage nach seinem ästhetischen Bildungspotential. Theater wird dabei verstanden als Prozess, ,zwischen dem wahrnehmenden und gestaltenden Subjekt und den künstlerischen Objekten/Ereignissen, mit denen 
er sich auseinandersetzt" (Koch; Streisand 2010: 10). Die Theaterpädagogik hat sich damit von einer reinen Verwertung von Theater in pädagogisch-sozialen Feldern losgesagt und setzt sich heute mit der Kunstform Theater als Bildungsgegenstand auseinander (vgl. Hentschel 2010). Im Gegensatz dazu steht bei vielen DaFund DaZ-Konzepten im Rahmen einer Verbindung von Theater und Unterricht die Frage nach dem konkreten sprachlichen Kompetenzzuwachs, meist im Bereich mündliche Kommunikationsfähigkeit, im Mittelpunkt didaktischer Überlegungen (vgl. Oelschläger 2004: 1). Dabei wird oft das wahre Wesen von Theater vernachlässigt. Ziel dieses Artikels ist es, abseits der Instrumentalisierung von theaterpädagogischen Methoden zu schauen, wie Theater durch seine spezifischen ästhetischen Eigenschaften den Fremdsprachenunterricht bereichern kann.

\section{Theater ist Gestaltung}

Theater liegt ein künstlerisch gestalteter Kommunikationsprozess zu Grunde, der wie alle Kunstformen eine bestimmte Wirkungsabsicht verfolgt. Bezogen auf den Unterricht Deutsch als Fremdsprache gilt es von daher, Theater deutlich von Rollenspielen und anderen Formen der Simulation zu unterscheiden:

Im Rollenspiel wird - wie der Name sagt - eine mehr oder weniger präzis definierte Rolle zur Richtschnur des Handelns in einer vorgestellten Situation genommen (Meyer 1989: 357).

Im Unterschied zu einer Theaterszene wird beim Rollenspiel eine Rolle nicht klar definiert. Oft gibt es nur Angaben zur sozialen Einbettung der Rolle wie etwa Sie sind Verkäufer. Auch die Umstände ${ }^{1}$ der Situation werden in der Aufgabenstellung meist nicht weiter ausgeführt. Der größte Unterschied liegt jedoch in der Zielsetzung: Beim Rollenspiel geht es um eine Innensicht, nämlich die Spielerfahrung der Akteure/innen, während beim Theater die Außensicht für das Publikum entscheidend ist, also die Wirkung und damit die ästhetische Gestaltung.

Für die Gestaltung eines Auftritts ist die Erkenntnis am wichtigsten, dass alles Wirkung zeigt: Körper und Bewegung, Sprache und Stimme sowie die Nutzung des Raums sind dabei die wichtigsten Bedeutungsträger, die bewusst eingesetzt werden wollen. Körper und Bewegung können den sprachlichen Einsatz unterstützen, begleiten oder ersetzen und so je nach Theaterform mehr oder weniger Bedeutung im Vergleich zu den anderen Gestaltungsmitteln erlangen (vgl. Herrig; Hörner 2012: 18f.).

Für Fremdsprachenanfänger/innen kann der Einsatz von Körperausdruck zugleich eine große Hilfe sein: Sie beherrschen vielleicht nur einen einfachen Satz, um sich zu verständigen und müssen sich anderer Mittel bedienen, um die umfassendere Botschaft deutlich zu machen. Diese verbale Reduktion ist theatral gese-

\footnotetext{
${ }^{1}$ Siehe dazu weiter unten die Ausführungen zur Situation.
} 
hen meist von stärkerer Wirkung, denn Theater ist nicht nur Verbalsprache, sondern das, was dahinter bzw. dazwischen steht, der so genannte Subtext. Theater vermittelt sich durch das Nonverbale, insbesondere die Körpersprache, die Emotion, den Partnerbezug und die Raumnutzung. Ein großer Irrtum vieler Lerner/innen und Lehrkräfte beruht darauf, zu denken, dass Theater gesprochener Text auf einer Bühne ist und deshalb erst auf höherem Sprachniveau im Fremdsprachenunterricht eingesetzt werden kann. Aber schon mit zwei einfachen Sätzen lässt sich eine Theatersituation herstellen. Eine bekannte Theaterübung lässt zwei Spieler/innen mit nur zwei Sätzen improvisieren: Ich liebe dich und für den/die Partner/in Ich weiß (vgl. Hippe 2011: 135). Aus der Aktion im Raum und mit dem/der Partner/in und der Reaktion darauf kann hier mit wenig Sprache sehr viel spannendes Theater entstehen. Für den Fremdsprachenunterricht bedeutet dies, dass man nicht unbedingt über ein hohes Sprachniveau verfügen muss, um Theater zu spielen. Aber man muss verstehen, auf welche Weise Theater funktioniert und wie man es bewusst gestaltet. Die genannte Übung lässt sich auch gut für den Fremdsprachenunterricht abwandeln, indem man den Lerner/innen einen Minidia$\log$ aus einem Lehrbuch vorgibt, mit dem sie improvisieren sollen. ${ }^{2}$

Das Wissen darum, dass alles Wirkung zeigt, kann aber auch negative Konsequenzen haben und macht deutlich, dass der Einsatz einer Fremdsprache beim Theaterspielen viel verlangt: Einerseits das Bewusstsein über die sprachliche Bedeutung, andererseits impliziert dies auch die dauernde Überwindung der Angst vor Fehlern, wenn die Sprache noch nicht hundertprozentig verfügbar ist. So geht es darum, diesen hohen Anspruch, den Theater an die Lerner/innen stellt, zu einem befreienden Effekt werden zu lassen: Das Eigentliche beim Theaterspielen ist die Kommunikation mit den Mitspielern/innen und mit dem Publikum. So kann man begreifen, dass sowohl beim Theaterspielen als auch beim Fremdsprachenlernen Fehler unabdingbarer Teil des Prozesses sind. Nur wer keine Angst vor Fehlern hat, kann ein guter Spieler/eine gute Spielerin und Sprecher/in werden. Keith Johnstone, Begründer des modernen Improvisationstheaters, hat dazu gesagt: „Es geht beim Spielen letztlich nur darum, seine eigene Angst zu überwinden. " ${ }^{3}$ Beim Sprechen in der Fremdsprache ist es nicht anders.

Um bei den Lerner/innen ein Bewusstsein für szenische Gestaltung zu schaffen, kann man mit ihnen gemeinsam Regeln sammeln. Dabei habe ich oft festgestellt, dass Vieles bereits bekannt ist, selbst wenn die Teilnehmer/innen nicht über eine tiefer gehende Theatererfahrung verfügen. Meistens erarbeite ich einen Regelkatalog mit sieben bis zehn Regeln, aber man kann auch die folgenden drei Theaterregeln aufstellen, die alles zusammenfassen:

1. Der Mitteilungscharakter: Sich dem Publikum beim Spielen körperlich zuwenden (publikumsoffen spielen), das Publikum bewusst/unbewusst einbe-

\footnotetext{
${ }^{2}$ Siehe dazu die abgewandelte Übungsbeschreibung weiter unten in diesem Beitrag.

${ }^{3}$ Mündliche Mitteilung von Keith Johnstone am 02.10.2010 beim Workshop an der Bundesakademie für kulturelle Bildung in Wolfenbüttel.
} 
ziehen, sich dem Publikum verständlich machen (laut und deutlich sprechen).

2. Die bewusste Gestaltung: Die Mittel Körper, Bewegung, Stimme, Sprache, Nutzung des Raums werden bewusst, deutlich und je nach anvisierter Wirkung, Rolle oder Theaterform mit unterschiedlicher Gewichtung und Intensität eingesetzt. Zur Verdeutlichung: Wenn es um ein psychologischrealistisches Kammerspiel geht, werden körpersprachliche Mittel eher in reduzierter Form eingesetzt, während man bei einer Commedia dell'Arte die Mittel überdeutlich und vergrößert einsetzt.

3. Die Etablierung und Aufrechterhaltung des Als ob: Die Scheinrealität wird den ganzen Auftritt über aufrechterhalten, indem es einen deutlichen Anfangsund Endpunkt gibt und die Spieler/innen nicht aussteigen, d.h. nicht lachen oder einen anderen privaten Ausdruck zeigen. Das Motto lautet sozusagen: The show must go on.

Auch was die Arbeit mit Texten betrifft, kann man das Prinzip ästhetischer Gestaltung anwenden, um die Texte theatertauglich zu machen. Natürlich lassen sich auch Auszüge aus Dramen einsetzen, die schon ein hohes szenisches Potential enthalten, was den Gehalt an verdichteter Sprache, Spannung und Konflikt betrifft. Man kann aber auch versuchen, den vorhandenen Texten aus Lehrbüchern dramatische Zutaten hinzuzufügen, so dass sie ähnliche Wirkung wie ein Theatertext erzeugen. Meine drei Zutaten sind: 1. Emotionen, 2. Status und 3. Situation. Nachfolgend beschreibe ich nun einen Ablauf zur Arbeit mit Emotionen: Nach Vorübungen zum emotionalen Ausdruck, der in Körperausdruck umgesetzt wird, erhalten die Lerner/innen jeweils einen Satz oder verfassen ihn selbst, der nun zunächst von Allen simultan gesprochen wird, während sie sich jeder für sich durch den Raum bewegen. Die Emotionen wie auch die Sätze werden dabei immer wieder gewechselt, indem die Lehrkraft die Übung kurz stoppt und dazu auffordert. Schließlich kommt es zur Szene: Jeweils zwei Spieler/innen erhalten je einen Satz und eine Emotion, ohne dass das Publikum oder die Mitspieler/innen darüber informiert sind. Sie präsentieren dann mit ihrem Satz und der Emotion im Körperausdruck eine Begegnung, bei der sie miteinander kommunizieren. Dabei dürfen sie nur den einen Satz benutzen, den sie im weiteren Verlauf drei Mal wiederholen, indem sie auf ihre/n Partner/in reagieren und die Intensität steigern. Außerdem sollen sie gemeinsam ein sinnvolles Szenenende finden. Diese einfache Theaterübung beinhaltet viele der genannten grundlegenden Aspekte von Theater, so dass später gut auf sie aufgebaut werden kann. Eine weitere Möglichkeit, um einfache Dialoge aus Lehrbüchern aufzupeppen, ist die Arbeit am Status, die auf dem Improvisationstheaterkonzept von Keith Johnstone beruht. Dabei unterscheidet man Hoch- und Tiefstatus als ein Mittel zur Rollengestaltung. Eine Figur im Hochstatus zeigt dies, indem sie direkten Augenkontakt mit dem Gegenüber aufnimmt, den Gesprächspartner gerne berührt und insgesamt eine aufrechte ruhige 
Körperhaltung inne hat. Die Figur im Tiefstatus hat wenig Körperspannung, vorgezogene Schultern, meidet Blickkontakt und berührt sich gern selbst. Durch diese Zutat entstehen beispielsweise aus Verkaufs- und Kennenlerndialogen auf Anfängerniveau interessante Szenen. Die Technik kann noch erweitert werden, indem ein Statuswechsel eingebaut wird oder beide Spieler/innen um den jeweils höheren Status kämpfen.

Eine dritte dramatische Zutat besteht in der Vorgabe einer Situation. Die Situationsvorgabe geht zurück auf den russischen Theaterleiter, Regisseur und Schauspieltheoretiker Konstantin Stanislawski (1863-1938) und stellt eine unerlässliche Hilfe für die Entwicklung einer Szene und einer Figur dar. Um die Umstände einer Situation konkret festzulegen sind folgende W-Fragen hilfreich (vgl. Hentschel 2005: 165):

Wer bin ich? Name, Alter, Beruf, Charakter, Beziehungen zu anderen Figuren

Was tue ich? Körperliche Aktion, die in der Szene passiert

Wo bin ich? Ort des Geschehens, Raum, wie sieht es dort konkret aus?

Wann spielt die Szene? Tageszeit, Ubrzeit

Warum tue ich das? Motiv des Handelns

Da die Fragen schon auf niedrigem Sprachniveau verständlich sind, sich also für den Anfängerunterricht eignen, kann man einfachen Dialogen schon interessante Situationen zu Grunde legen. Hier ein Beispiel für einen einfachen Dialog, der durch das Zugrundelegen einer Situation an Authentizität gewinnt:

\section{A: Liebst du mich? \\ B: Ich verstehe nicht. \\ A: Liebst du mich! \\ B: Donnerstag ist gut.}

Durch die Vorgabe präziserer Umstände wird dann im Spiel ein höherer Identifikationsgrad erreicht und sowohl Spieler/innen als auch die Zuschauer/innen werden stärker ins Spiel und damit im Unterricht auch in den Lernprozess involviert.

\section{Theater ist Kommunikation}

In ihr (= der Aufführung) ereignet sich die künstlerische Kommunikation zwischen den Spielenden und einer Mehrheit von Zuschauenden. Diese theatrale Kommunikation kann als direkt bezeichnet werden, befinden sich doch Sender und Empfänger zur selben Zeit am selben Ort. Das theatrale Kunstwerk realisiert sich erst in der Aufführung und in Anwesenheit des Publikums, das rezipierend das ästhetische Objekt konstituiert (Hentschel 2005: 134f.).

Die Wirkungsabsicht von Kunst impliziert also eine Kommunikation zwischen Produzenten/innen und Rezipienten/innen, die einen anschließenden Austausch 
darüber interessant werden lässt. Wenn Theater im Unterricht rein als Methode eingesetzt wird, passiert es oft, dass Szenen im Unterricht zwar präsentiert werden, aber nur eine einseitige Kommunikation von den Spieler/innen zu den Zuschauer/innen entsteht, da die Präsentation der Szene keine erkennbare Gestaltung aufweist oder keine Aussage transportiert, über die sich der mündliche Austausch lohnen würde. Nutzen wir im Unterricht jedoch den bewussten Einsatz von Gestaltungsmitteln, entsteht eine Verdichtung, die oftmals sogar automatisch eine Reaktion des Publikums hervorruft. Diese wechselseitige Kommunikationssituation, der anschließende Austausch über das erlebte szenische Produkt aus beiden Perspektiven, von den Zuschauer/innen und Spieler/innen, bereichert den Unterricht durch eine der wenigen wirklich authentischen Kommunikationssituationen, die Unterricht überhaupt ermöglicht. Die Gruppe hat hier gemeinsam etwas im Augenblick erlebt und kann sich darüber unmittelbar mit ihren Gefühlen und Meinungen austauschen. Die Möglichkeiten, die die Auswertung szenischer Präsentationen auch unter dem Aspekt Hörsehverständnis bieten, sind vielfältig. Auf Anfängerniveau, in Bezug sowohl auf die Spiel- als auch auf die Fremdsprachenkompetenz, geht es zunächst um eine einfache Rückmeldung auf der Ebene der Beschreibung: Was hat das Publikum gesehen? Was ist passiert? Wie verhalten sich die Charaktere? Auf höherem Niveau kann die Szenenauswertung mit verschiedenen spezifischen Redemitteln verbunden werden und sich beispielsweise auf die Interpretation einer Textvorlage beziehen, indem sie Text und Inszenierung vergleicht: Welche Aspekte des Textes wurden besonders gut umgesetzt? Welche Aspekte fehlten ganz oder wurden verändert? Auch der Einsatz der Gestaltungsmittel lässt sich auswerten, indem besonders gelungene Momente und ihre Gestaltungsmittel genannt werden sowie Verbesserungsvorschläge gemacht werden: Welche szenischen Ideen waren besonders gelungen? Was hat besonders Wirkung gezeigt und wodurch? Woran sollte noch gearbeitet werden? So lernen die Teilnehmer/innen, ein differenziertes Feedback mit Begründungen zu geben und nicht nur zu sagen ibr habt richtig gut gespielt. Eine gute Beobachtungsfähigkeit ist nämlich die beste Voraussetzung für die Entwicklung eigener Spielkompetenzen.

\section{Theater ist Präsentation}

Der Begriff der Präsentation ist mittlerweile fester Bestandteil der DaF-Didaktik geworden. Präsentation kann ,jedwede Darbietung von Inhalten vor einem Publikum“" (Schmitz 2012: 5) bezeichnen und bezieht sich meist auf ein abschließendes Produkt, das vorher inhaltlich und gestalterisch vorbereitet wurde. Theater ist dabei nur eine mögliche Form der Präsentation, aber was sind seine Besonderheiten? An Inhalten kann theoretisch fast alles in Theater verwandelt werden: Ein literarischer oder auch nicht-literarischer Text wie etwa ein Zeitungsartikel oder ein Lehrbuchtext, eine landeskundliche Recherche, ein Foto, ein Comic usw. Aber auch hier gilt es, sich das Spezifische des Theaters zu vergegenwärtigen, bevor man 
die genannten Inhalte sozusagen theatralisiert. Durch seinen künstlerischen Charakter steht beim Theater immer eine subjektive Sichtweise im Vordergrund. Theater bleibt als künstlerische Form dem Inhalt nicht unbedingt treu, sondern fügt etwas hinzu, verformt und lässt die Spieler/innen eindeutige Positionen beziehen. Um reines Wissen zu vermitteln, ist Theater von daher kaum geeignet. Szenische Präsentationen bieten aber auf der anderen Seite den Vorteil, über Mittel zu verfügen, die die Aufmerksamkeit des Publikums stärker auf sich ziehen können, sie durch das Spiel zu bannen. Theater kann so den Unterricht in ein Ereignis verwandeln. Als flüchtigste Kunstform, die nur im Moment der Aufführung entsteht, kann Theater den Unterricht zu einem gemeinsamen authentischen Erlebnis werden lassen. Authentizität ist ein hehres Ziel, aber meist Mangelware im Fremdsprachenunterricht. Ein authentisches und intensives Erlebnis wird erreicht, wenn die entsprechenden Gestaltungsmittel und Gesetzmäßigkeiten dafür auch mit entsprechendem Einsatz der Spieler/innen genutzt werden. Im Fremdsprachenunterricht wird dagegen oft nur simuliert und halbher:ig präsentiert. Die oberflächliche Nachahmung oder Verstellung wird dann nicht den erwünschten Effekt beim Publikum erreichen (vgl. Hentschel 2010: 137).

In der Intensivierung der Darstellung durch bewusste Gestaltung liegt aber auch die größte Schwierigkeit von Theater im Unterricht: Es verlangt von seinen Lerner/innen etwas, was sie zunächst überfordert. Sie sollen als Spieler/innen im Spiel 100 Prozent geben, körpersprachliche Mittel einsetzen und ihr Publikum in den Bann ziehen, nachdem sie gerade noch auf ihren Stühlen saßen und einen Text gelesen haben. Damit dies gelingt, ist die wichtigste Voraussetzung eine kommunikative, angstfreie und entspannte Unterrichtsatmosphäre. Nur so können sich die Darsteller/innen öffnen und sich in ihrem Ausdruck frei fühlen. Da selbst ProfiSchauspieler/innen in eine Grundstimmung kommen müssen, um spielen zu können, gibt es eine Reihe von Aufwärmspielen, die sich gut im Fremdsprachenunterricht einsetzen lassen ${ }^{4}$ und die die verschiedenen Voraussetzungen für ein intensiveres Spiel ermöglichen. Dazu gehören Spiele zur Förderung von Energie, Konzentration, Präsenz, Reaktions- und Kooperationsfähigkeit, Kommunikation und Partnerbezug, zur Verbindung von Bewegung und Sprache sowie zum Sprechtraining (Atem, Stimme, Artikulation). Theaterspielen ist ein komplexer Vorgang, der viele verschiedene Kompetenzen erfordert - aber oft genügt schon ein einziges Spiel, um mit den Konventionen des traditionellen Deutschunterrichts zu brechen, die Lerner/innen für Körpereinsatz, Bewegung und für das Spiel zu öffnen und dabei den Fokus auf das Spiel zu lenken und weniger auf die Fehler, die sie beim mündlichen Ausdruck machen, so dass sie in und mit der Sprache frei werden.

\footnotetext{
${ }^{4} \mathrm{Da}$ es mehrere hundert Spiele gibt, möchte ich an dieser Stelle nur auf eine beispielhafte Sammlung im Internet verweisen: http://de.improwiki.com/improtheater/Aufwärmspiele (Stand: 9.1.2014).
} 


\section{$5 \quad$ Fazit}

Theater stellt nicht nur als Methode eine Bereicherung für den Fremdsprachenunterricht dar. Vielmehr steckt in seinen künstlerischen Eigenheiten ein Potential, das den Fremdsprachenunterricht zu einem intensiven Erlebnis werden lässt, das sowohl Spieler/innen als auch Zuschauer/innen betrifft. Durch einfache Theatertricks und ein Bewusstsein für Gestaltung kann so auch ein Spielniveau erreicht werden, das Theater mit seinen ästhetischen Maßstäben gerecht wird und Lerner/innen nicht nur die Fremdsprache anwenden lässt, sondern sie gleichzeitig einen Sinn für künstlerische Gestaltung und Intention entwickeln lässt. Hierfür gilt es, zunächst einige Grundregeln gemeinsam aufzustellen und mit Hilfe von Aufwärmspielen eine lockere, angstfreie Atmosphäre zu schaffen, in der die Lerner/innen auf das gemeinsame Spiel vorbereitet werden. Wenn das gelingt, können im Grunde die unterschiedlichsten sprachlichen Inhalte szenisch präsentiert werden. Alle Arten von Bild- und Textmaterial können zum Ausgangspunkt einer Szene werden, die so interessant gestaltet ist, dass sie im Anschluss einen Austausch darüber anstößt, bei dem die Lerner/innen einen authentischen Gesprächsgegenstand haben. Dabei ist die sprachliche Reduktion ein wesentliches Element von gutem Theater. Ein guter Theatertext beruht auf verdichteten Dialogen, die durch Bewegung und zugrundeliegende Situationen dem Theater seine ästhetische Wirkung verleihen. Dieser Aspekt von Theater kann im Fremdsprachenunterricht genutzt werden, denn so können schon Dialoge auf Anfängerniveau eine szenische Wirkung erzielen.

Natürlich ist Theater im DaF-Unterricht immer ein Mittel, um die Fremdsprache zu erlernen, und unterscheidet sich darin stark von theaterpädagogischer Arbeit, bei der über längere Zeit auf eine Aufführung hingearbeitet wird. Dennoch sollten auch hier die ästhetischen Eigenheiten von Theater beachtet werden, um im Unterricht einen intensiven Lernprozess zu erreichen, der die Lerner/innen in besonderem Maße mit der Fremdsprache verbindet.

\section{Literatur}

Brook, Peter (1985): Der leere Raum. Aus dem Englischen von Walter Hasenclever. Berlin: Alexander.

Hentschel, Ulrike (2010): Theaterspielen als ästhetische Bildung. Über einen Beitrag produktiven künstlerischen Gestaltens zur Selbstbildung. Uckerland/OT Milow: Schibri.

Herrig, Thomas A.; Hörner, Siegfried (2012): Darstellendes Spiel und Theater. Braunschweig u.a.: Bildungshaus Schulbuchverlage.

Hippe, Lorenz (2011): Und was kommt jetzt? Szenisches Schreiben in der theater-pädagogischen Praxis. Weinheim: Deutscher Theaterverlag.

Koch, Gerd; Streisand, Marianne (2005): Wörterbuch der Theaterpädagogik. Uckerland/OT Milow: Schibri. 
Meyer, Hilbert (1989): UnterrichtsMethoden II: Praxisband. Frankfurt a.M.: Scriptor.

Oelschläger, Birgit (2004): Szenisches Spiel im Unterricht Deutsch als Fremdsprache. In: gfl-journal 1, 24-34. Online: http://www.gfl-journal.de/1-2004/ oelschlaeger.pdf (Stand: 9.1.2014)

Oelschläger, Birgit (2011): Wenn man sieht, dass die Jugendlichen wirklich dabei sind. Das Schülertheaterprojekt der Partnerschulinitiative in Mittelosteuropa. In: Scenario 1/V. Online: http://publish.ucc.ie/scenario/2011/01/oelschlaeger /05/de (Stand: 9.1.2014)

Schmitz, Werner (2012): Editorial. In: Fremdsprache Deutsch 47, 5. 



\title{
Ich hab gar nicht gemerkt, dass ich Deutsch spreche-Wie die theatrale Erfahrung des Improvisationstheaters freies und authentisches Sprechen erlebbar macht und die kommunikative Kompetenz fördert
}

\author{
Magdalena Haftner \& Anne-Marie Kubfuß \\ Der Artikel geht der Frage nach, inwieweit Improvisationstheater freies und authentisches Spre- \\ chen in einer Fremdsprache ermöglicht. Dabei wird das Workshopkonzept spielendDeutsch vorge- \\ stellt, das grundlegende Regeln und Techniken des Improvisationstheaters nach Johnstone mit \\ Aspekten der Sprachlehrforschung verbindet, um einen angstfreien und experimentierfreudigen \\ Umgang mit der (Fremd-)Sprache zu ermöglichen. Der Fokus liegt dabei nicht auf der Sprach- \\ richtigkeit, sondern auf dem gemeinsamen szenischen Entwickeln von Geschichten und dadurch \\ zugleich auf der Förderung der kommunikativen Kompetenz. Der pädagogische Ansatz von \\ Johnstone und der Fokus auf die theatrale Erfahrung des Improvisationstheaters stellen eine neue \\ Perspektive im dramapädagogischen DaF-Kontext dar.
}

\section{Einleitung}

Kreativität, Spontaneität und Sprachkompetenz fördern? Sprechen und Geschichten erzählen, ohne Angst vor Fehlern, ohne stundenlanges Formulieren, einfach drauf los? Das alles kann passieren, wenn man improvisiert!

Improvisieren und eine Fremdsprache sprechen haben viel gemeinsam: In beiden Situationen geht es um spontane Ausdrucksfähigkeit. Improvisationstheater ermöglicht das Sich-Einlassen auf den Moment, befreit von mühsamen gedanklichen Antizipationen von Situationen und Verhaltensweisen bzw. Vorformulierun- 
gen von Sprechhandlungen. Sein Fokus liegt im aufmerksamen Zuhören und Beobachten der Spielpartner/innen ${ }^{1}$ und der kontextgebundenen Reaktion darauf. Daher birgt der Einsatz von Improvisationstheater besonderes Potential für einen kommunikativen Fremdsprachenunterricht. Eine der ersten Rückmeldungen einer Teilnehmerin des spielendDeutsch Workshops Ich hab gar nicht gemerk.t, dass ich Deutsch spreche wurde zum Leitsatz der weiteren Arbeit von artig, die Sprachförderung auf spielerischem Weg mit Einbezug des gesamten Körpers und aller Emotionen ermöglicht und ihren Fokus vor allem auf das kindliche Entdecken einer Sprache, und damit auf implizites Fremdsprachenlernen, legt.

Im folgenden Artikel wird dargestellt, wie der Einsatz von Improvisationstheater nach dem Konzept von spielendDeutsch einen angstfreien und experimentierfreudigen Umgang mit der (Fremd-)Sprache ermöglicht und dadurch die kommunikative Kompetenz fördert. Dazu wird zunächst die Bedeutung von Theater im DaFUnterricht erörtert, um in Folge auf das spezielle Potential des Improvisationstheaters unter Berücksichtigung des pädagogischen Ansatzes von Keith Johnstone einzugehen. Im zweiten Teil wird in Bezugnahme auf die theoretischen Erkenntnisse die Umsetzung von spielendDeutsch skizziert. Zum Abschluss werden die Erkenntnisse zusammengefasst.

\section{Theater im kommunikativen DaF-Unterricht}

Bereits in den 1970er-Jahren fand mit dem kommunikativen Ansatz eine Hinwendung zu Methoden und Lerntheorien statt, die davon ausgehen, dass Sprache so vermittelt werden müsse, dass ihre Verwendung durch die Lernenden im Vordergrund steht. Laut Schewe stellt das zentrale Anliegen kommunikativer Methoden die Entwicklung kommunikativer Kompetenz dar und damit die Anwendung von Sprache in ihrer instrumentellen, regulierenden, interaktiven, personalen, heuristischen, imaginativen und repräsentativen Funktion. Gleichermaßen spielt die soziolinguistische Kompetenz eine große Rolle, d.h. das Vermögen, die Fremdsprache entsprechend den sozialen Kontexten, wechselseitigen Beziehungen und kommunikativen Intentionen der Kommunikationsträger/innen passend zu verwenden (vgl. Schewe 1993: 287f.).

Die Ausrichtung des Unterrichts auf das Ziel kommunikativer Kompetenz fordert unter anderem folgende Veränderungen fremdsprachlicher Unterrichtspraxis: Handlungsorientierung im Fremdsprachenunterricht, Wertschätzung der Lerner/innensprache und damit ein Neuverständnis von Fehlern durch deren Integration in den Lernprozess, die Rolle der Lernenden als Vermittelnde zwischen dem eigenen Standpunkt und dem fremden und die Rolle der Lehrenden als Teilnehmende, Beratende und Moderierende (vgl. ebd.: 292f.). Huber kritisiert an der bis-

\footnotetext{
${ }^{1}$ Die Verwendung des Begriffs Spielpartner/innen weist darauf hin, dass sich die Fremdsprachenlernenden in einer impliziten Sprachlernsituation befinden. Der spielerische Aspekt der Lernsituation soll hierdurch hervorgehoben werden.
} 
herigen Kommunikation im Fremdsprachenunterricht, dass diese künstlich segmentiert wird und damit einseitig stattfindet. Es wird dabei nicht berücksichtigt, dass Kommunikation

stets musikalisch gestaltet in einem körpersprachlichen Ausdruckskontinuum eingebettet ist, dass ihr Sinn nicht einfach gegeben, sondern mittels interaktiver Verfahren gemeinsam konstruiert wird (Huber 2003: 202ff.).

So postuliert Huber, dass kommunikative Kompetenz erst dann voll zur Entfaltung gelangt, wenn es beim Sprechen um das sinnhafte Bezugnehmen aufeinander, um das Gestalten von Beziehungen geht.

Einhergehend mit dieser veränderten Ausrichtung des Unterrichts wächst das Interesse an alternativen Lehr- und Lernformen. Laut Schewe stellen diese Entwicklungen das theoretische Fundament eines dramabasierten Fremdsprachenunterrichts dar (vgl. Schewe 1993: 286). Auch Huber weist auf das Potential von Theater im Fremdsprachenunterricht hin, es ermögliche ein Kommunikationssetting, in dem eine fließende Verbindung von Sprache und Körpersprache stattfinde (vgl. Huber 2003: 324).

[Ü]berdies wird ein ganzer Katalog von Forderungen und Entwicklungstendenzen wie ,Handlungsorientierter Unterricht', ,Learning by doing' (Dewey), ,Ganzheitliches Lernen' (mit allen Sinnen), ,Interaktivität', ,Prozessorientierung', ,Lernerzentriertheit", ,Verbindung von Kognition und Emoti${ }^{o n}$ ' im Theater wie ,auf einem Streich' in einer kreativen Synthese integriert (ebd.).

Schewe konstatiert, dass der Stellenwert und die Akzeptanz dramapädagogischer Methodik ${ }^{2}$ für den Einsatz im Fremdsprachenunterricht in den letzten Jahren stark gestiegen ist. So hätten sowohl extracurriculare wie auch intracurriculare Inszenierungsformen zugenommen (vgl. Schewe 2010: 1584ff.). Allerdings steht zumeist die Lernzielorientierung des jeweiligen Fachs im Vordergrund (vgl. Schewe 1993: 284). Dadurch kann jedoch kein Fokus auf theatrales Lernen gesetzt werden, denn es bedarf eines Settings, bei dem die ästhetische Erfahrung des performativen Ausdrucks im Zentrum steht. Dies setzt eine Wahrnehmungssensibilisierung voraus, in der ein imaginativer, offener Blick und verstärkte Selbst- und Fremdwahrnehmung ermöglicht werden (vgl. Huber 2003: 202ff.). Dies bestätigen auch Liebau, Klepacki, Zirfas und stellen wie folgt die Besonderheit der mannigfaltigen Wahrnehmungsmöglichkeiten ästhetischer Erfahrung in den Vordergrund:

Im Gegensatz zum pragmatischen Lebensalltag mit seiner theoretischen oder utilitaristischen Haltung gewährt die ästhetische Erfahrung einen Freiheitsspielraum von Wahrnehmungsmöglichkeiten. Die ästhetische Erfah-

2 Unter dem aus dem britischen Kontext kommenden Begriff dramapädagogisch (Drama in Education) wird der Einsatz von Mitteln des Theaters verstanden, ,,um allgemeinpädagogische und bestimmte fachbezogene Ziele zu erreichen" (Schewe 2010: 1590). 
rung ist eine spezifische Form der Wahrnehmung von symbolischen Raumund Zeitstrukturen, ein synästhetisches Vernehmen der Erscheinungsqualitäten von Gegenständen, das sich durch die Momente der Offenheit und Pluralität, der Unmittelbarkeit und Gegenwärtigkeit auszeichnet (Liebau u.a. 2009: 98f.).

Wiese, Günther und Ruping weisen darauf hin, dass diese Form theatralen Lernens die Dramapädagogik in eine ambivalente Beziehung zu schulischem Regellernen setzt (vgl. Wiese u.a. 2006: 54f.). Diese Herausforderung kennen wir als Theaterlehrende allzu gut. Die Frage nach dem Sinn und Zweck einer Übung für den schulischen Lernzusammenhang steht oftmals im Vordergrund. Als Theaterlehrende versuchen wir zwischen diesen zwei Welten zu vermitteln. Die Herausforderung besteht darin, das Theaterspiel nicht als didaktisches Sprachspiel zu instrumentalisieren. Den Lernenden muss vielmehr ein Raum gegeben werden, in dem ohne schulischen Beurteilungszwang experimentiert werden kann und in dem ihnen ein spielerischer Zugang zu neuen Wahrnehmungsmöglichkeiten eröffnet wird.

\subsection{Zur Klärung des Begriffes und zum Potential von Improvisationstheater im DaF-Unterricht}

Der Begriff des Improvisationstheaters ist in der methodisch didaktischen Auseinandersetzung mit fremdsprachlichem Unterricht bisher begrifflich nicht klar eingegrenzt worden (vgl. Matthias 2007). Häufig werden darunter vorgefertigtes Textrollenspiel oder Lehrbuchdialoge subsumiert, bei dem die Absicht und der Verlauf der Kommunikation durch Vorentlastungen weitestgehend bekannt sind, wodurch keine spontanen Sprechhandlungen stattfinden können. So meint auch Kurtz in seiner Untersuchung zur Entwicklung spontansprachlicher Handlungskompetenz in der Zielsprache, dass dadurch der Zauber der Unmittelbarkeit und Unvorhersehbarkeit sprachlicher Interaktion vollkommen fehle (vgl. Kurtz 2001: 129). Improvisationstheater erfordert jedoch genau das, was gleichfalls authentische Kommunikation von seinen Gesprächspartner/innen abverlangt,

ein genaues Zuhören, Beobachten, Mitdenken und Eingehen auf die jeweiligen Improvisationspartner. Es ist zudem notwendig, die individuell oder kollektiv vorhandenen fremdsprachlichen Ressourcen im spontanen Treiben-Lassen der Gedanken unmittelbar verfügbar zu machen und aus dem Augenblick heraus flexibel einzusetzen (ebd.: 128f.). 
Dalziel und Pennacchi unterstreichen zudem den soziolinguistischen Aspekt authentischer Kommunikation in Bezug auf das Status-Konzept ${ }^{3}$ von Keith Johnstone (vgl. Dalziel; Pennacchi 2012). Dieses besagt, dass auch im Alltag ,jede Handlung, jeder Laut, jede Bewegung von Zwecken geleitet ist“" (Johnstone 2006a: 66), welche entweder den eigenen Status heben oder senken sollen. Die Sensibilisierung dieser Mechanismen ermöglicht zum einen authentisches theatrales Spiel und zum anderen gewährleistet es einen Raum, indem der soziolinguistische Aspekt von (Körper-)Sprache bewusst erlebbar wird.

Die bereits veröffentlichte Literatur zum Thema Improvisationstheater im DaF-Unterricht zeigt, dass das Potential von Improvisationstheater laut Kurtz sowie Dalziel und Pennacchi in der Förderung der fremdsprachlichen Sprechhandlungsfähigkeit, im Finden von Strategien beim Fehlen verbaler Ausdrucksmittel, im Mut zur Kommunikation, im Erleben der Grenze der eigenen Sprachfähigkeit in einem sicheren, sanktionsfreien Umfeld und im Aufbrechen der Grenze von Realität mithilfe von Fiktion liegt (vgl. Kurtz 2001: 126, Dalziel; Pennacchi 2012).

Der entscheidende Unterschied zwischen den bisherigen Ausführungen zum Improvisationstheater und dem Konzept von spielendDeutsch liegt im dramapädagogischen Verständnis und im konzeptionellen Aufbau.

\subsection{Der pädagogische Ansatz von Keith Johnstone als Basis für spielendDeutsch}

Bei der Theaterform des Improvisationstheaters existiert kein vorgeschriebener Text oder Szenenablauf, viel mehr gehen die Schauspieler/innen in vollem Vertrauen auf ihre Phantasie auf die Bühne und entwickeln szenisch Geschichten. Das Improvisationstheater, das die Grundlage des Workshops spielendDeutsch ist, wurde maßgeblich von Keith Johnstone geprägt. Sein Anliegen als Lehrer und auch später als Theaterregisseur, Dramaturg und Autor war es, die Phantasie und Spontaneität bei seinen Schüler/innen und Kolleg/innen zu wecken, indem er Übungen und Strategien entwickelte, die ihnen die Furcht vor dem Scheitern und Fehlermachen nehmen sollten.

Seine Aufgabe als Lehrender sieht er darin, den Lernenden die Angst zu nehmen, damit sie sich aufs phantasievolle Spiel einlassen und Lernprozesse freisetzen können (vgl. Johnstone 2006a: 46). Laut Johnstone schaffe es ein guter Lehrender, den Lernenden die Erfahrung des enttäuschenden, demotivierenden Scheiterns zu ersparen (vgl. ebd.: 26). Das Fehlermachen ist notwendiger Teil des Lernprozesses, der positive Resultate erst ermöglicht, aber ohne zum Scheitern zu führen: „You can't learn without failing so we should welcome failure and laugh because we are on the right track" (Johnstone 2008).

\footnotetext{
${ }^{3}$ Zur Erklärung des Begriffs Status: Er steht hier für etwas, das man tut, nicht für das, was man ist. So könne man laut Johnstone einen niedrigen sozialen Status haben, aber einen hohen Status durch Sprache und Aktionen vermitteln, was unter anderem die Komik im Theater ausmache (vgl. Johnstone 2006a: 57f.).
} 
Hier lässt sich die erste Parallele zum fremdsprachlichen Lernprozess finden: „Im Mut zur Blamage liegt eine wesentliche Eigenschaft guter Fremdsprachenlerner“ (Huber 2003: 63). Nicht nur der Lernprozess wird durch Angst aufgehalten, sondern auch die Entwicklung der Szene, denn ohne Veränderung kann eine Geschichte nicht voranschreiten. Angst blockiert den Lernprozess, nur möglichst angstfrei kann man spontan und kreativ handeln. Deshalb entwickelt Johnstone Übungen und Spiele, bei denen sich die Lernenden auf der Bühne sicher fühlen. Indem sie nicht dem Druck erliegen, schon vorplanen zu müssen wie die Szene endet, können sie sich auf den Moment einlassen und aus dem Moment heraus frei agieren. Ebenso ist Positivität, d.h. das Aufnehmen von Äußerungen anderer ohne diese negativ zu bewerten, und das Anbieten und Annehmen von Spielangeboten der Schlüsselpunkt für das Voranschreiten von Szenen. Spielangebote sind laut Johnstone Ideen, die die Geschichte weiterbringen und die abwechselnd von den Schauspieler/innen gebracht werden, damit eine Geschichte gemeinsam entsteht (vgl. Johnstone 2006b: 174). Damit das gemeinsame szenische Spiel gelingt, ist die Bereitschaft notwendig, seine eigenen Ideen und Vorstellungen von seinem/seiner Spielpartner/in verändern zu lassen und $\mathrm{ihm} / \mathrm{ihr}$ damit entgegenzukommen. Johnstone beschreibt den Prozess auf der Bühne metaphorisch als gemeinsames Schwimmen und gemeinsames Untergehen (vgl. ebd.: 89). Dieser Ansatz ist besonders spannend für den Lehrenden, der wie die Lernenden in diesem Prozess als Schwimmende beteiligt ist und sich damit mit ihnen auf gleicher Ebene befindet.

\subsection{Theatrale Erfahrung im Improvisationstheater}

Wie kann also das Potential von Improvisationstheater durch die Fokussierung auf eine theatrale und damit auch auf eine ästhetische Erfahrung potenziert und nachhaltig für den Lernenden greifbar gemacht werden?

Die Voraussetzung für eine theatrale Erfahrung liegt in der Etablierung einer theatralen Wirklichkeit, die wie jede Form von Fiktionalität eine Übereinkunft zwischen Zuschauer/in und Produzent/in darstellt. Beim Theaterspiel wird das so tun, als ob in der verbalen Sprache und in der Körpersprache der Schauspieler/innen auf der Bühne manifestiert. Die Grenze der zwei Realitätsbereiche des als und des als ob ermöglicht bei den Schauspieler/innen und Zuseher/innen verschiedene Handlungs-, Verhaltens-, Einstellungs-, Wahrnehmungs- und Ausdrucksmöglichkeiten (vgl. Hoppe 2011: 34f.). So schreibt Göhmann, dass sich der/die Schauspieler/in mit der theatralen Rolle eine sekundäre, theatrale Wirklichkeit schafft, mithilfe derer er/sie sich zwischen den Wirklichkeiten bewegt und eine Verbindung zwischen der Scheinwelt des Theaters und seinem/ihrem Alltag schaffen und darin experimentieren kann (vgl. Göhmann 2004: 100). Soziologisch betrachtet, stellt Theater laut Liebau; Klepacki; Zirfas (Liebau u.a. 2009: 55ff.) eine spezifische Form sozialer Interaktion dar, theatrales Lernen beinhaltet demnach immer auch soziale, interaktive und ästhetische Lernprozesse. 
In der szenischen Darstellung des Improvisationstheaters ist alles frei wählbar, unter anderem auch die gespielten Charaktere, welche im theatralen Prozess handeln. Deren Eigenschaften und Verhalten sind vollkommen fiktiv, was eine Distanz zur eigenen Person ermöglicht. Dies bedeutet den Ausstieg der Lernenden aus der Wirklichkeit und einen Einstieg als Schauspielende in die fiktive Realität. Mithilfe dieser theatralen Wirklichkeit können sich die Lernenden mit ihren sprachlichen Fähigkeiten zunächst erstmals in der Fiktion verstecken, sich jedoch darauf in einem Charakter zeigen. Huber bezeichnet die Fremdsprache in diesem Zusammenhang als eine sogenannte „Sprachmaske“:

Die fremde Sprache ist als Sprachmaske zusammen mit der Rolle ein wesentlicher Teil jener Verkleidung, die es dem Fremdsprachler als Schauspieler/in erlaubt, im Spiel, ich verstecke mich, um mich besser zu zeigen' mit größtmöglicher Sicherheit und Freiheit zu agieren (Huber 2003: 330).

Im fremdsprachlichen Improvisationstheaterunterricht haben die Lernenden völlige Entscheidungsfreiheit bei der Wahl ihrer Rolle und können somit eine Vielzahl an Rollen erproben. Es eröffnet sich ein experimenteller Spielraum, der ihnen eine Distanz zur eigenen Person und zur subjektiv wahrgenommenen Sprachkompetenz ermöglicht. So meint Huber: „Wer Masken trägt, braucht kein Gesicht zu wahren!““ (ebd.: 332) Die theatrale Erfahrung ermöglicht somit das „Ausloten und Ausleben des anderen in sich selbst“" (ebd.: 333).

Ein weiterer Aspekt, der sich mit dem Improvisationstheater realisieren lässt, ist die Forderung nach Authentizität, Handlungsorientierung und Lerner/innenzentriertheit. Die sekundäre Wirklichkeit für kurze Zeit zur wahrgenommenen Realität zu machen, ist der Schlüssel für eine Handlungs- und Lerner/innenorientierung im fremdsprachlichen Unterricht. Handlungsorientierung soll

den Schülerinnen und Schülern [ermöglichen], im Rahmen authentischer, d.h. unmittelbar-realer oder als lebensecht akzeptierbarer Situationen inhaltlich engagiert sowie ziel- und partnerorientiert zu kommunizieren, um auf diese Weise fremdsprachliche Handlungskompetenz(en) zu entwickeln (Bach; Timm 2003: 11f.).

Die Sprache ist beim Improvisationstheater Folge performativer Handlungen, sie wird nicht forciert, sondern kommt von ganz alleine. Die Performanz ermöglicht die Sprache, nicht die Sprache die Performanz. Indem die Lernenden selbst über den Inhalt und das Gesprochene im Spiel entscheiden, kommt die Sprechabsicht aus der Lebenswelt der Lernenden und entspricht nach Huber demnach dem Konzept von Lerner/innenorientierung (vgl. Huber 2003: 61). Die theatrale Wirklichkeit bzw. Fiktionalität im Improvisationstheater ermöglichen daher einen handlungsund lerner/innenorientierten Fremdsprachenunterricht. Genau aus diesem Grund ist es für uns fundamental wichtig, dass spielendDeutsch den Fokus auf das Erlernen der Improvisationstheatertechniken legt, denn in deren Anwendung beim szenischen Spiel kann theatrale Erfahrung erlebbar werden. Der Fokus im Unterricht 
liegt nicht auf der korrekten Verwendung der Fremdsprache, sondern auf der performativen Kompetenz, das heißt auf dem lustvollen und erfolgreichen Improvisieren von Szenen alleine und in der Gruppe, wodurch informell Sprachunterricht mit dem Fokus auf gelungene Kommunikation stattfindet. So verstehen wir, wie auch Bach und Timm, Sprache in ihrer Ganzheitlichkeit:

Aus der Fremdsprache werden nicht ,kognitive', ,affektive' und ,psychomotorische' Lernziele und -inhalte herauspräpariert. Sie wird vielmehr in erster Linie, wie die Muttersprache, als ein spontan und unreflektiert, aus dem Sprachgefühl heraus zu gebrauchendes Instrument sprachlichen Handelns angesehen, dessen Ziel in erster Linie im kommunikativen Erfolg (Verstehen und Reagieren, Mitteilen und Bewirken) und der daraus resultierenden Befriedigung liegt (Bach; Timm 2003: 16).

Prämisse für diese Art des theatralen Lernens mit Hinblick auf die Stärkung kommunikativer Kompetenz ist, dass spielendDeutsch nur in der Zielsprache abgehalten wird. Spielerklärungen und Regieanweisungen finden immer auf Deutsch statt, wodurch die Fremdsprache „- im Sinne der modernen Spracherwerbstheorien nicht linear und eher nebenbei im Handlungszusammenhang des sachfachlichen Lernkontextes erworben [wird]" (Bonnet u.a. 2006: 175). Demnach entspricht unser Workshop der bilingualen Konzeptionen des Sachfachunterrichts, in der die Zielsprache auch als Arbeitssprache verwendet wird. Ein wichtiges Thema im Rahmen des Konzepts von spielendDeutsch ist die sprachliche Fehlerkorrektur beim Improvisationstheater. Generell gilt für unser Konzept, dass wir uns an der von Kleppin vorgeschlagenen indirekten Fehlerkorrektur orientieren, indem der Satz beiläufig mit der richtigen Form wiederholt wird (vgl. Kleppin 2010: 1067). Diese stellt für uns eine angemessene Form der mündlichen Fehlerkorrektur dar, da sie keine Hierarchie zwischen Lehrenden und Lernenden als Wissende und Unwissende etabliert. Der Fehler wird dementsprechend als kollektiver Lernansatz verstanden (vgl. Kurtz 2001: 125ff.). Während des szenischen Spiels werden keine sprachlichen Fehler korrigiert, die Lernenden sollen selber eine Grenzerfahrung ihrer sprachlichen Möglichkeiten erleben bzw. Strategien finden, um im kooperativen Lernprozess in gemeinsamer Interaktion mangelndes Vokabular zu überbrücken. Gleiches gilt für Verständigungsschwierigkeiten innerhalb einer Szene. Nach eigenem Ermessen sollen die Lehrenden entscheiden, inwieweit häufig aufkommende Fehler in einer vom Improvisationstheaterunterricht getrennten Unterrichtsphase behandelt werden. Wichtig ist, dass die Korrektur ermutigend und nicht sanktionierend oder bloßstellend stattfindet (vgl. Kleppin 2010: 1067). 


\section{Aus der Praxis des Improvisationstheaters im DaF-Unterricht: spielendDeutsch}

Die spielendDeutsch-Workshops können als auflockernde Unterrichtsphasen oder als ein vom Regelunterricht abgekoppelter Projektunterricht innerhalb eines längerfristigen Zeitraums stattfinden, bei denen der Fokus auf einer vertieften theatralen Erfahrung liegt. Somit ist das Arbeiten in homo- wie auch heterogenen Sprachlerner/innengruppen möglich. Der Vorteil von heterogenen Gruppen ist, dass sich die Lerner/innen mit niedrigerem Sprachniveau mithilfe theatraler Ausdruckstechniken ihren Spielpartner/innen verständlich machen können und von ihnen neues Vokabular lernen. Gleichzeitig stellt diese sprachliche Heterogenität eine Herausforderung für Lerner/innen mit höherem Sprachniveau dar, die im gemeinsamen Spiel angeregt werden, Strategien zu finden, ihre Partner/innen bei Sprachschwierigkeiten zu unterstützen. Dadurch werden sie sich ihrer eigenen Sprachfähigkeiten bewusster und eine erfolgreiche Kommunikation in der Fremdsprache wird trotz unterschiedlicher Sprachniveaus erlebbar.

Der Projektunterricht spielendDeutsch gliedert sich in vier Phasen. Die erste Phase widmet sich gruppendynamischer Prozesse und fokussiert Entkopplungsübungen sowie Assoziationsübungen, die Körper und Geist aufwärmen sollen. In der zweiten Phase finden Spiele statt, die die Techniken des Improvisierens veranschaulichen und auf die freie Improvisation vorbereiten. In der dritten Phase werden improvisierte Szenen gespielt, die zwar ebenfalls einer Spielstruktur folgen, jedoch als szenisches freies Arbeiten verstanden werden. In der vierten Phase findet eine Reflexion der Unterrichtseinheiten statt und es können weiterführende Aufgaben gestellt werden. Im Folgenden wird aufgrund des begrenzten Rahmens des Artikels nur die dritte Phase mit einem konkreten Beispiel veranschaulicht.

Phase 1: Gruppendynamik und freies Assoziieren

Die erste Phase des gemeinsamen Arbeitens dient dem Kennenlernen sowie Körperaufwärm- und Assoziationsspielen. In dieser Phase wird die grundlegende Basis für ein angstfreies Umfeld etabliert. Es wird eine gemeinsame Zielorientierung geschaffen, die dafür notwendigen Normen und Regeln innerhalb der Gruppe ausgehandelt und ein Gefühl von Gruppenzugehörigkeit entwickelt (vgl. Wedel 2008: 478ff.). Dies ist für die Praxis des Improvisationstheaters besonders wichtig, da erst in einer Gruppe frei improvisiert werden kann, in der Experimentieren erwünscht und Fehler erlaubt sind (siehe 2.3). Durch Entkopplungsübungen wird das gemeinsame Scheitern geradezu provoziert und es wird deutlich, dass beim Kennenlernen von Neuem die Erfahrung des Scheiterns ganz normal und Teil des Lernprozesses ist. Der Vorgang des Fehlermachens wird spielerisch kollektiv durchlebt und der Erfolgsdruck gesenkt. Gleichzeitig werden Körper und Geist aktiviert und die Wahrnehmungsfähigkeit auf allen Sinnesebenen gefördert. Darauf aufbauend können nun die Regeln des Improvisierens spielerisch erprobt werden (siehe 2.2). 
Phase 2: Die Techniken des Improvisierens

In dieser Phase werden die grundlegenden Schauspieltechniken und Regeln der Improvisation durch Spiele und Regeln erprobt. Die wichtigsten Spielregeln der Improvisation (Sei positiv, nimm Angebote an und entwickle sie weiter, lass deine/n Partner/in gut aussehen!) sowie Schauspieltechniken (Charakter-/Figurenentwicklung, der Umgang mit imaginären Objekten und Räumen) konstituieren die Basis für jede Szene. Ebenso notwendig für das szenische improvisierte Geschichtenerzählen ist die Klärung der fünf W-Fragen (Wer bin ich? Wer bist du? Wie stehen wir zueinander? Wo sind wir? Und was machen wir hier?), die Charaktere, Beziehungen zueinander, Ort und Handlung einer Szene definieren. Den Spieler/innen werden diese, wenn nötig, in den Szenen als Regieanweisungen in Erinnerung gerufen.

Phase 3: Szenisches Spiel (Das Berufs-Chamäleon)

Bei diesem Spiel handelt es sich um ein konkretes Beispiel zur Veranschaulichung der Rolle der Spielleitung ${ }^{4}$. Es werden das Annehmen von Rollen und die Definition von Rollenbeziehungen in einem imaginären Raum und mittels imaginärer Objekte trainiert. Eine/r der Spieler/innen definiert den Beruf des/der anderen, sodass er/sie automatisch seine/ihre eigene Rolle und die Beziehung zwischen den beiden Rollen etabliert. Aufgabe der Spielleitung 5 ist es, durch Regieanweisungen sicherzustellen, dass die zuvor gelernten Improvisationsregeln eingehalten werden. Erst die Befolgung dieser Regeln in Verbindung mit dem dafür notwendigen Einfühlungsvermögen ermöglicht eine erfolgreiche Inszenierung. Die Spielleitung fungiert als side coach und hilft bei der Gestaltung der Szene. Im Folgenden wird die Spielanleitung während einer improvisierten Szene anhand eines Beispiels verdeutlicht. Der nun beschriebene Ablauf orientiert sich an einer Unterrichtseinheit für eine heterogene Gruppe (A1 bis B2) mit Lernenden unterschiedlichen Alters.

Es wird eine Bühne im Raum bestimmt, auf der die Szene gespielt wird. Die Gruppe setzt sich im Halbkreis davor und spielt nacheinander Szenen. Eine Person beginnt und stellt sich der Gruppe als Chamäleon (d.h. in einer neutralen Haltung) gegenüber. Der darauffolgenden Person wird von ihrem Nachbarn/ihrer Nachbarin ein Beruf ins Ohr geflüstert. Diesen Beruf wird das Chamäleon in der Szene darstellen. Nun geht die erste Person auf das Chamäleon zu und versucht ihm/ihr mithilfe von Mimik, Gestik und Sprache den eingeflüsterten Beruf im gemeinsamen Theaterspiel verständlich zu machen. Hierbei geht es nicht um das Erraten des Berufes, sondern darum mithilfe der Regeln des Improvisationstheaters, im speziellen durch aufmerksames Zuhören und Reagieren auf das improvisatorische Spiel des Partners/der Partnerin, eine Szene entstehen zu lassen. Die Spielleitung hat hierbei eine wichtige Rolle, denn dank ihrer Anweisungen kann

\footnotetext{
${ }^{4}$ Mögliche Spiele für die anderen hier erwähnten Phasen finden sich bei Johnstone, Keith 2006b.

${ }_{5}^{5}$ Die Verwendung des Begriffs Spielleitung weist darauf hin, dass sich die Fremdsprachenlehrenden in einer impliziten Sprachlehrsituation befinden. Der spielerische Aspekt der Lehrsituation soll hierdurch hervorgehoben werden (vgl. auch Fußnote 1).
} 
gerade zu Beginn durch die Einhaltung der Regeln des Improvisationstheaters leichter eine gelungene Szene und damit kommunikativer Erfolg gewährleistet werden. Im Folgenden beschreiben wir eine mögliche Situation, um die Rolle der Spielleitung und ihre Anweisungen genauer darzustellen und den pädagogischen Ansatz zu verdeutlichen.

Beruf „Tierärztin“:

A steht neutral der Gruppe gegenüber.

Die erste Person im Halbkreis, die von ihrer Nachbarin Tierärztin zugeflüstert bekommen hat, geht auf die Bühne und mimt ein kleines Tier auf dem Arm zu haben. Sie öffnet eine imaginäre Tür und betritt einen Raum.

B: Guten Tag! Können Sie meinem Hasen belfen?

A: Nein. Ich weiß nicht.

Spielleitung: Doch, du willst ihm helfen! Sag ja! Du bist die Expertin! ${ }^{6}$

A: Ah, ja! Guten Tag, Herr Mayer! Was ist denn passiert? (Sie stellt sich aufrecht hin, mimt sich die Brille auf der Nase zurechtzurücken und blickt auf ihn von oben herab. $)^{7}$

B: Ich weiß nicht, was mein Hoppel hat. Seit zwei Wochen frisst er nichts und ist schon ganz. dünn.

A: Dann sehen wir mal. (Nimmt das imaginäre Tier in die Hand, setzt es auf den Untersuchungstisch, drückt auf den Bauch.)

Spielleitung: Frag Herrn Mayer, wie es seiner Frau gebt? Und untersuch dabei den Hasen!'

A: Gut. Äh, wie geht es ihrer Frau? (Untersucht den Hasen.)

$\mathrm{B}:$ Ähm, nicht gut. Sie hat mich verlassen.

Spielleitung: Schaut euch in die Augen!?

(A und B stehen sich gegenüber und schauen sich in die Augen. A sieht B mitfühlend und legt ihre Hand auf seine Schulter.)

A: Oh, das tut mir leid...

B: Ja, das ist traurig. Ich bin allein mit meinem Hasen. Bitte helfen Sie!

A: Ich glaube, der Hase hat ein Problem mit dem Magen. Halten Sie! Ich gebe ihm ... (Schaut in das Publikum und fragt: Wie heißt das?)

\footnotetext{
${ }^{6}$ Hier wird auf die Regeln des Improvisationstheaters (Sei positiv und nimm die Spielangebote deines Partners an!) hingewiesen, damit gemeinsames kooperatives Geschichtenerzählen stattfinden kann (siehe 2.3).

${ }^{7}$ Die Spielerin reagiert auf das Spielangebot ihres Partners, verändert ihre körperliche Haltung und erhöht ihren Status, worin sich der soziolinguistische Aspekt der Sprache widerspiegelt (siehe 2.1).

${ }^{8}$ Hier bietet die Spielleitung eine Vertiefung der Szene an, indem sie eine nähere Beschreibung der Lebenssituation der Charaktere und dessen Beziehungen zueinander fordert (Fragen: Wer bin ich? Wer bist du?).

${ }^{9}$ Hier gibt die Spielleitung die Möglichkeit die Beziehung der Charaktere zueinander zu definieren (Frage: Wie stehen wir zueinander?). Die Spieler/innen entscheiden selbst, wie sie einander ansehen und damit emotional zueinander stehen.
} 
Spielleitung: Frag nicht uns, mach es einfach, wenn du das Wort nicht weißt! 10

(A öffnet einen imaginären Schrank, holt etwas hervor, mimt eine Spritze aufzuziehen, und injiziert sie dem Hasen.)

B: Oh, eine Spritze. Sehr gut, das hilft.

A: Ja, genau! Eine Spritze!

B: Danke, Frau Doktor. Ich komme nächste Woche wieder.

An dieser Stelle kann aufbauend auf dieser Szene die Geschichte weitergespielt werden. Je nach Spielerfahrung der Gruppe kommt entweder von der Spielleitung eine Anweisung, um den Fokus auf die Lebenssituation eines/einer Protagonisten/Protagonistin zu lenken oder die Spielpartner/innen spielen selbständig die Geschichte weiter. So könnte z.B. die nächste Szene eine Woche später in der Praxis spielen, wo die Ärztin ihn zum Essen einlädt.

Phase 4: Reflexion

Nach jeder Improvisationstheatereinheit wird in der vierten Phase eine Reflexion über positive Erlebnisse beim Improvisieren und Zusehen angeschlossen. Typische Fragen, die beantwortet werden sollen, sind etwa: Welche Szene hat euch besonders gut gefallen? Welche imaginären Objekte oder Räume? W as können wir schon? Welche szenischen Momente haben euch gefallen? Welche Wörter habt ihr gehört, die euch besonders aufgefallen sind oder neu für euch waren? Durch die Rückmeldungen bekommen die Spieler/innen ein positives Feedback über ihr Mitwirken und zusätzlich erfolgt noch einmal eine Zusammenfassung des Erlebten. Für das Lernen einer Fremdsprache bedeutend ist dabei den Fokus auf die gelungene Kommunikation und das Sammeln von Vokabular zu setzen, das den Teilnehmenden besonders gut gefallen hat oder neu für sie war.

Nach einer Pause können die entstandenen Geschichten verschriftlicht werden und in einer anderen Unterrichtsphase im gemeinsamen Arbeiten korrigiert und anschließend für alle abgetippt werden. Der Phantasie der Lehrperson zur Festigung des Vokabulars sind keine Grenzen gesetzt.

\section{Zusammenfassung und Ausblick}

Beim Improvisieren werden die Sensibilität für den Augenblick, eine Haltung der Offenheit und schnelle Reaktion eingeübt. In einer Atmosphäre der Akzeptanz und des positiven gegenseitigen Aufeinander-Bezugnehmens werden in der Unmittelbarkeit und Gegenwärtigkeit der jeweiligen Situation spielerisch spontane Sprachhandlungen evoziert. In der theatralen Erfahrung befreit das Improvisati-

\footnotetext{
${ }^{10}$ Hier erinnert die Spielleitung an Möglichkeiten der theatralen Ausdrucksformen, die nicht immer auf Sprache angewiesen sind, wie imaginäre Räume und Objekte. Diese stellen Strategien dar, trotz fehlenden Vokabulars eine erfolgreiche Kommunikation zu ermöglichen (siehe 2.1 und 3).
} 
onstheater und ermöglicht angstfreies Sprechen und Spielen in einer fremden Sprache.

Die Ungezwungenheit, Figuren entstehen zu lassen, Emotionen Raum zu geben, Situationen immer wieder neu zu definieren, vielseitig und mehrdeutig zu bleiben, ermöglicht durch spontane Einfälle Überraschungsmomente, die den Lernenden nachhaltig in Erinnerung bleiben. Wie gezeigt wurde ermöglicht Improvisationstheater das Erlebnis einer besonders persönlichen und kreativen, performativen Handlung, d.h. auch die Fähigkeit, Situationen und Beziehungen in einer fremden Sprache gestalten zu können. Diese Art theatraler Erfahrung wird durch die akzeptierende Haltung der Spielleitung sowie der Teilnehmenden möglich. Wie in diesem Artikel dargestellt, werden Fehler als natürliche Begebenheit des mündlichen Sprachausdrucks wahrgenommen und stellen einen wesentlichen Teil des Lernprozesses dar. Es geht also nicht um richtiges oder falsches Sprechen, vielmehr steht im Zentrum der gemeinsame Spaß am imaginativen Spiel, am Gebrauch der Sprache und der gelungenen Kommunikation. Es wurde gezeigt, inwieweit Improvisationstheater die Voraussetzungen schafft, freies und authentisches Sprechen im Fremdsprachenunterricht zu erleben und somit die kommunikative Kompetenz zu fördern. Wie ausgeführt, finden sich bereits bei Kurtz Ansätze zu Untersuchungen, die versuchen den Einsatz des Improvisationstheaters im Unterrichtsalltag zu rechtfertigen. Es fehlen jedoch weitere empirische Studien zu verschiedenen Fragestellungen wie zur genauen Wirkungsweise des Improvisationstheaters im Fremdsprachenunterricht oder zur Rolle der Lehrkraft Wünschenswert wäre es zudem Improvisationstheater verstärkt im (Sprach-)Unterricht anzuwenden. Dafür ist eine Erweiterung des Fortbildungsangebots für Lehrende notwendig, da - wie in unserem Artikel gezeigt - der pädagogische Ansatz der Spielleitung wesentlich für die Ausführung des Improvisationstheaters ist.

\section{Literatur}

Bach, Gerhard; Timm, Johannes-Peter (2003): Handlungsorientierung als Ziel und Methode. In: Bach, Gerhard; Timm, Johannes-Peter (Hrsg.): Englischunterricht. Grundlagen und Methoden einer handlungsorientierten Unterrichtspraxis. Tübingen u.a.: Francke, 1-21.

Berk, Ronald; Trieber, Rosalind (2009): Whose classroom is it, anyway? Improvisation as a teaching tool. In: Journal on Excellence in College Teaching 20, 3, 29-60. Online: http://www.celt.muohio.edu/ject/fetch.php?id=452 (Stand: 09.10.13)

Bonnet, Andreas; Breidbach, Stephan; Hallet, Wolfgang (2003): Fremdsprachlich handeln im Sachfach. Bilinguale Lernkontexte. In: Bach, Gerhard; Timm, Johannes-Peter (Hrsg.) (2003), 172-196. 
Dalziel, Fiona; Pennacchi, Andrea (2012): Looking for Henry: Improvisation and Storytelling in Foreign-Language Theatre. In: Scenario 5, 2. Online: http://research.ucc.ie/scenario/2012/02/Dalziel/03/en (Stand: 10.10.13)

Göhmann, Lars (2004): Theatrale Wirklichkeiten. Möglichkeiten und Grenzen einer systemisch-konstruktivistischen Theaterpädagogik im Kontext ästhetischer Bildung. Aachen: Mainz.

Hoppe, Hans (2011): Theater und Pädagogik. Grundlagen, Kriterien, Modelle pädagogischer Theaterarbeit. Berlin: Lit.

Huber, Ruth (2003): Im Haus der Sprache wohnen. Wabrnehmung und Theater im Fremdsprachenunterricht. Tübingen: Niemeyer.

Johnstone, Keith (1999): Impro for Storytellers. Theatresports and the art of making things bappen. London: Faber \& Faber.

Johnstone, Keith (2006a): Improvisation und Theater. Berlin: Alexander.

Johnstone, Keith (2006b): Theaterspiele. Spontaneität, Improvisation und Theatersport. Berlin: Alexander.

Johnstone, Keith (2008): Volume 2: Impro-Transformations. Online: http://www.keithjohnstone.com/main.aspx?id=76 (Stand: 15.10.13)

Kleppin, Karin (2010): Fehleranalyse und Fehlerkorrektur. In: Krumm, Hans-Jürgen; Fandrych, Christian, Hufeisen, Britta; Riemer, Claudia (Hrsg.): Deutsch als Fremd- und Zweitsprache. Ein internationales Handbuch. 2. Halbband. Berlin u.a.: de Gruyter, 1060-1072.

Kurtz, Jürgen (2001): Improvisierendes Sprechen im Fremdsprachenunterricht. Eine Untersuchung zur Entwicklung spontansprachlicher Handlungskompetenz in der Zielsprache. Tübingen: Narr.

Kurtz, Jürgen (2008): Szenische Improvisationen - Theoretische Grundlagen und unterrichtliche Realisierungsmöglichkeiten. In: Ahrens, Rüdiger; Eisenmann, Maria; Merkl, Matthias (Hrsg.): Moderne Dramendidaktik für den Englischunterricht. Heidelberg: Winter, 409-424.

Liebau, Eckart; Klepacki, Leobold; Zirfas, Jörg (2009): Theatrale Bildung. Theaterpädagogische Grundlagen und kulturpädagogische Perspektiven für die Schule. München: Juventa.

Matthias, Bettina (2007): Show don't tell! Improvisational Theatre and the Beginning Foreign Language Curriculum. In: Scenario 1, 1. Online: http://publish. ucc.ie/scenario/2007/01/matthias/03/en (Stand: 09.10.13).

Schewe, Manfred (1993): The theoretical Architecture of a Drama-based Foreignlanguage Class: a structure founded on communication and supported by 
action, interaction, real experience and alternative methods. In: Schewe, Manfred (Hrsg.): Towards drama as a method in the foreign language classroom. Frankfurt a.M. u.a.: Lang, 283-313.

Schewe, Manfred (2010): Drama- und Theaterpädagogik im Deutsch als Fremdund Zweitsprache-Unterricht. In: Krumm, Hans-Jürgen; Fandrych, Christian, Hufeisen, Britta; Riemer, Claudia (Hrsg.) (2010), 1589-1595.

Wedel, Heike (2008): Warming up und cooling down. Zu einer vernachlässigten Dimension bei der Arbeit mit dramatischen Formen In: Ahrens, Rüdiger; Eisenmann, Maria; Merkl, Matthias (Hrsg.) (2008), 471-493.

Wiese, Hans-Joachim; Günter, Michaela; Ruping, Bernd (2006): Theatrales Lernen als philosophische Praxis in Schule und Freizeit. Uckerland: Schibri. 



\title{
Mit Worten Räume bauen: Improvisationstheater und szenische Wortschatzvermittlung
}

\begin{abstract}
Maik Walter
Im Mittelpunkt des Beitrags steht das Improvisationstheater. Es wird erläutert, worin das Potenzial dieser Kunstform für den Fremdsprachenunterricht besteht. Dazu werden Möglichkeiten und Grenzen einer szenischen Wortschatzvermittlung mit den dort etablierten Techniken am Beispiel des "gesprochenen Bühnenbilds" ausgeleuchtet. Nach einer kurzen Einleitung in die Improvisation werden Techniken der Semantisierung und des Einübens lexikalischer Strukturen vorgestellt, bevor eine Schnittmenge der beiden Bereiche Wortschatzvermittlung und Improvisationstheater präsentiert wird. Abschließend werden die Grenzen einer szenischen Wortschatzvermittlung ausgelotet.
\end{abstract}

Die Befähigung eines Lehrers liegt darin, Kenntnisse so darzubieten, dass der Schüler erfolgreich sein muss. Johnstone (1993: 26)

\section{Angebot, Risiko und Scheitern: Fundamente der Improvisation}

Eine Ärztin und ein Patient führen ein Gespräch. Die Ärztin untersucht den Patienten und aus der bekannten Situation entspinnt sich eine Geschichte, von der man nicht weiß, wie sie endet. Wird es eine Liebesgeschichte, entpuppt sich die Ärztin als Vampir oder hinterzieht eine bestechliche Ärztin hier Steuern und untersucht einen Finanzbeamten, der inkognito ermittelt? All diese Geschichten könnten auf der Bühne passieren, und zwar in der Vorstellung eines Improvisationstheaters. Das Publikum entscheidet über die Figuren, das Genre, über bestimmte 
Ingredienzen und damit auch über den Fortgang der Geschichte. Es könnte sich aber genauso auch um eine szenische Aufgabe im Anfangsunterricht handeln, bei der ein Lehrwerksdialog mit den Mitteln der Improvisation bearbeitet wird. Hier würden die Lerner/innen Entscheidungen des Spielverlaufs treffen. Im folgenden Beitrag werden einige derart strukturierte Unterrichtsszenarien vorgestellt, wobei der Fokus auf der Vermittlung unbekannter Wörter liegt. Hierzu wird zunächst die Improvisation als eine ästhetische Form präsentiert, bevor die szenische Wortschatzvermittlung mit ihren Möglichkeiten und Grenzen thematisiert wird.

Neben der Performance gilt das Improvisationstheater als eine der populärsten Varianten der aktuellen deutschsprachigen Theaterszene: Gab es Anfang der 90erJahre des 20. Jahrhunderts nur wenige Gruppen, die sich dieser künstlerischen Form verschrieben, hat heute jede Volkshochschule, die in Segmenten der Kulturellen Bildung aktiv ist, ein entsprechendes Kursprogramm im Angebot. Jede kleinere Stadt in Deutschland hat ihre eigene Improvisationstheatergruppe. In Metropolen wie Berlin existieren sogar mehrere professionelle Gruppen, eine ganze Hand voll semiprofessioneller Gruppen und darüber hinaus eine blühende, zuweilen schon als ausufernd zu bezeichnende Amateurszene, die vom Schultheater über die Arbeit mit Tumorbetroffenen bis hin zum Seniorentheater reicht. Die Improvisation gedeiht ganz prächtig in diesen Nischen der Anwendung und natürlich hat auch der Fremdsprachenunterricht ${ }^{1}$ bereits eine dieser Nischen besetzt. Mit anderen Worten: Das Improvisationstheater ist sowohl als Raum der Selbsterfahrung als auch bei den Zuschauern/innen beliebt und erfolgreich. Die Theaterwissenschaftlerin und Theaterpädagogin Marianne Streisand sieht den Grund für diesen Erfolg im Umgang mit dem Scheitern der Spieler/innen auf der Bühne (vgl. Streisand 2006: 95). Das Publikum will sehen, wie ein/e Improspieler/in arbeitet, wie er/sie ein schwieriges Problem auf der Bühne löst. Sei es nun, eine Szene zu spielen, in der nur drei Worte fallen dürfen oder aber einen zu erratenen Gegenstand zu reklamieren. Das Scheitern ist hier Teil des Spiels und ein/e Improspieler/in muss lernen, ein Risiko einzugehen, unter Umständen auch erfolgreich zu scheitern und anschließend mit Spielfreude in die nächste Szene zu gehen.

Was genau versteht man nun unter Improvisation? Der Begriff ist auch aus der Musik und dem Alltagsleben bekannt (vgl. die Beiträge in Bormann u.a. 2010, Lösel 2013). Im Kontext des Theaters geht es bei der Improvisation im Kern um die Entwicklung von Szenen, die ohne zuvor abgesprochenen Text im Moment entstehen. Das Publikum kann Vorgaben liefern, die in die Szene eingebaut werden müssen und die Spieler/innen inspirieren (sollen). Die Spieler/innen kreieren also den Text und versetzen ihn synchron ohne eine/n Regisseur/in in einen theatralen Raum. Bei diesem Prozess handelt es sich um ein durchaus anspruchsvolles ästhetisches Verfahren, sofern er nicht in der bloßen Reproduktion von Stereotypen verharrt. Diese Gefahr ist groß, wenn beispielsweise die Figur einer Kranken-

${ }^{1}$ Einen aktuellen Überblick zum Theater in der Fremdsprachenvermittlung bietet Walter 2012a, für das Englische als Fremdsprache wird die Improvisation erstmals in Kurtz 2001 umfassend aufbereitet. 
schwester auf der Bühne nur in den ihr zugeschriebenen bekannten Stereotypen agiert und keine individuellen Züge entwickelt. Ein bewusstes künstlerisches Gestalten des entworfenen $A l s O b$ kann diesem Verharren im Klischee begegnen.

Das Fundament der Improvisation besteht darin, sich auf die Ideen der anderen Mitspieler/innen einzulassen, sie zu akzeptieren und sie nicht zu blockieren (vgl. Lösel 2013: 122ff.). Kommt beispielsweise in einer Szene ein/e Spieler/in mit dem Worten Hände hoch! auf die Bühne und der/die Mitspieler/in erwidert: „Sämtliche Seitenangaben sind erfunden!“, so wird das unterbreitete Angebot blockiert. Die kooperativ zu entwickelnde Geschichte gerät unweigerlich ins Stocken. Das Blockieren kann verschiedene Gründe haben: Sei es der durchaus verständliche Wunsch eines Menschen, kreativ zu sein, sei es die Überforderung in der Spielsituation oder aber in der Fremdsprache, die Worte der Mitspieler/innen wahrzunehmen und zu verstehen. Der Schauspiellehrer und Theaterpädagoge Keith Johnstone hat eine Reihe von Techniken entwickelt, um dieses Akzeptieren im Spiel zu lernen (vgl. u.a. Johnstone 2002: 174ff.). Eine der bekanntesten Übungen besteht darin, zu zweit eine Geschichte zu erzählen, Satz für Satz. Die Spielpartner/innen wechseln sich nach einem Satz ab und beginnen jeden Satz mit den Worten Ja genau! Und dann. Der folgende Satz muss sich mit diesem kleinen Trick auf den vorangegangen beziehen und dadurch entsteht eine kohärente Geschichte. Voraussetzung einer auf diese Weise kooperativ erzählten Geschichte ist, dass man genau zuhört und die in der Geschichte etablierten Personen aufbaut, sie in klare Beziehungen zueinander stellt und ihre Handlungen als logische Abfolge schrittweise entwickelt. Wenn man sich auf ein solches Unterfangen einlässt, Angebote zu akzeptieren und nicht abzulehnen, wird man leicht die Parallelen zum Fremdsprachenunterricht entdecken: Auch in der Fremdsprache geht es darum, sich auf Neues, Ungewohntes, auch Unerwartetes einzulassen. Sei dies nun der sprachliche Input in Form von Lauten, Tönen, Wörtern und größeren sprachlichen Strukturen wie komplexen Sätzen oder sei es die kulturell geprägte Sichtweise auf gesellschaftliche Konstrukte. Durch das Improvisieren kann man vor allem lernen, sich auf Angebote anderer Spieler/innen einzulassen, und das bedeutet zunächst einmal, ganz genau zuzuhören. Für den Fremdsprachenunterricht versteckt sich hier noch ein großteils unausgeschöpftes Potential, wie im Folgenden zu zeigen sein wird. Doch beleuchten wir zunächst die ästhetische Form der Improvisation.

\section{Spontane Ästhetik: Improvisation als ästhetische Form}

Das Improvisationstheater hat seinen Ursprung nicht erst in dem Auftritt des bereits zitierten Keith Johnstone. Karl Meyer geht in seiner umfangreichen Untersuchung zur Improvisation davon aus, dass sich die Anfänge aufgrund der Flüchtigkeit dieser ästhetischen Form zwar nicht präzise bestimmen lassen, aber weit in die Geschichte der Künste zurückverweisen. Meyer geht in seinen Ausführungen auf den antiken Mimus ein (vgl. Meyer 2008: 47), behandelt ausführlich das historisch 
belegte mittelalterliche Stegreifspiel und natürlich die Commedia dell'Arte. Dort agierten die laz: $i$ frei im Bühnengeschehen als Figuren und replizierten wiederkehrende Muster wie Kampfszenen, die als Einlagen im Theaterstück fungierten. Was konkret auf der Bühne in diesen Freiräumen passierte, blieb den Akteur/innen vorbehalten. Vermutlich wurden gerade diese Momente der Freiheit vom Publikum besonders geliebt. Vom ausgehenden Mittelalter ziehen sich die Bahnen des Unvorhergesehenen bis zu heute beliebten Kurzformaten wie dem Theatersport sowie Langformaten wie dem Kriminalstück oder der Heldengeschichte. Diese moderneren Theaterformate wiederum sind nun mit Keith Johnstone verbunden, der mit seiner Arbeitsweise in den späten 60er-Jahren des 20. Jahrhunderts eine Renaissance dieser ästhetischen Form ${ }^{2}$ begründete. Er etablierte in den USA und Kanada Spielgruppen, die nach von ihm entwickelten Grundregeln der Improvisation kleine Szenen im Moment, das heißt ohne vorherige Absprache, erspielten. Diese Bewegung breitete sich nach Frankreich, Dänemark, in die Niederlande und auch nach Deutschland aus, wo sich in den 1990er-Jahren eine ausgesprochen lebendige und kreative Improvisationstheaterszene mit eigenen Spielorten, Festivals und Workshops herausbildete. Neben der ästhetisch dominierten Improvisation gibt es zudem Zugänge, die sich stärker auf die Selbsterfahrung der Spieler/innen fokussierten und nicht auf eine Aufführung vor einem Publikum. Exemplarisch seien hier die Ansätze von Viola Spolin und das Theater der Unterdrückten von Augusto Boal angeführt (vgl. z.B. Spolin 1997, Boal 1976).

\section{Wörter, Wörter nichts als Wörter: Wortschatzvermittlung}

In der Fremdsprachdidaktik wurden bereits eine Vielzahl von Ansätzen und Techniken für die effiziente Vermittlung von lexikalischen Strukturen diskutiert und zusammengetragen. ${ }^{3}$ Nachdem in den 80er-Jahren vorrangig grammatische Strukturen und Muster im fremdsprachendidaktischen Fokus standen, rückten in den 90er-Jahren des 20. Jahrhunderts die lexikalischen Einheiten ins Zentrum der Sprachvermittlung. Grammatische Phänomene wie die Valenz der Verben werden in solch lexikdominierten Ansätzen von den lexikalischen Einheiten ausgehend behandelt. ${ }^{4}$ Aber auch in Ansätzen, die nicht die Lexik in den Mittelpunkt stellen, kann als gesichert gelten, dass Wörter vernetzt erworben werden und damit auch

\footnotetext{
$2 \mathrm{Ob}$ es sich bei der Improvisation um eine ästhetische Form handelt, wurde im Laufe der Theatergeschichte durchaus kontrovers diskutiert (vgl. Bormann et al. 2010: 7). Frost; Yarrow (2007: 19ff.) sehen heutzutage drei Einsatzbereiche der Improvisation im Theater: die Vorbereitung, die Probenmethode und die Aufführungstechnik/die Theaterform (vgl. hierzu auch die Ausführungen in Lösel 2013). Insbesondere für den letztgenannten Bereich dürfte der ästhetische Status allgemein akzeptiert sein. Eine Aufbereitung und Vertiefung dieser Grundsatzdebatte soll an dieser Stelle nicht weitergeführt werden, denn die Frage führt im fokussierten Fremdsprachenkontext zu weit.

3 Vgl. die Überblicksartikel Köster 2010 sowie Stork 2010.

${ }^{4}$ Vgl. den lexikalischen Ansatz von Michael Lewis 1993.
} 
möglichst in Netzen vermittelt werden sollten. ${ }^{5}$ So sollte ein Adjektiv mit seinen Synonymen, seinen Antonymen und auch seinen Kollokationen möglichst in natürlichen Kontexten vermittelt werden. Auch wenn sich im fremdsprachendidaktischen Diskurs noch keine allgemein verbindliche Ordnung in der entsprechenden Begriffsbildung abzeichnet (vgl. Stork 2003: 14ff.), so findet sich die von Rainer Bohn vorgeschlagene Systematik der Verfahren sowohl in vielen Forschungsarbeiten als auch in praktischen Unterrichtshilfen.

\begin{tabular}{|c|c|c|c|}
\hline $\begin{array}{l}\text { nichtsprachliche } \\
\text { Erklärungstechniken }\end{array}$ & $\begin{array}{l}\text { teilweise nichtsprachliche } \\
\text { Erklärungstechniken }\end{array}$ & einsprachige Verfahren & zweisprachige Verfahren \\
\hline $\begin{array}{l}\text { - Piktogramme } \\
\text { - Verkehrszeichen } \\
\text { - Zahlen } \\
\text { - Zeichen }\end{array}$ & $\begin{array}{l}\text { - Gegenständliche } \\
\text { Veranschaulichung } \\
\text { - Bildliche Veranschaulichung } \\
\text { - Gestik/Mimik/Pantomime } \\
\text { - Klangbilder }\end{array}$ & $\begin{array}{l}\text { - Erklärungen durch den Kontext } \\
\text { Bedeutungserklärungen, die } \\
\text { paradigmatische Beziehungen } \\
\text { nutzen (Synonyme, Antonyme, } \\
\text { Wortbildungskenntnisse, Reihen) } \\
\text { - Bedeutungserklärungen, die } \\
\text { verstärkt logisch-begriffliche } \\
\text { Beziehungen nutzen } \\
\text { (Analogieschlüsse, Gleichungen) } \\
\text { - Umschreibende } \\
\text { Bedeutungserklärungen } \\
\text { (Definitionen, Beispielsătze, } \\
\text { Paraphrasen) }\end{array}$ & $\begin{array}{l}\text { - Übersetzung } \\
\text { - Wortăhnlichkeiten } \\
\text { zwischen Mutter- } \\
\text { und Fremdsprache } \\
\text { - Wortähnlichkeiten } \\
\text { zwischen erster und } \\
\text { zweiter } \\
\text { - Intemdsprache } \\
\text { - Internationalismen }\end{array}$ \\
\hline
\end{tabular}

Abb. 1: Semantisierungsverfahren nach Bobn (2000: 63ff.)

Es soll deshalb auch an dieser Stelle als bewährtes, Orientierung gebendes Raster herangezogen werden, wenn es darum geht, die Bedeutung der Wörter zu vermitteln und hierzu eine fremdsprachendidaktische Kartografie für die entsprechenden Techniken einzusetzen. Bohn (2000: 59ff.) unterscheidet bei der so genannten Semantisierung zwischen nichtsprachlichen und sprachlichen Verfahren (vgl. Abb. 1). Die Semantisierung ist ein wesentlicher Teil der Wortschatzarbeit, die auch andere Bereiche wie das Einüben von lexikalischen Strukturen umfasst. ${ }^{6}$ Unter szenischer Wortschatzarbeit verstehe ich eine ästhetisch akzentuierte Wortschatzarbeit, die auf theatrale Techniken zurückgreift. Das bedeutet, es kommen Techniken zum Einsatz, mit denen bewusst fiktionale Räume des $A l s O b$ gestaltet werden. In diesem Prozess kann eine ästhetische Qualität entstehen. Begünstigt wird dies vor allem, wenn die konkrete Gestaltung auch reflektiert wird. Im Anfangsunterricht wird aufgrund fehlender sprachlicher Mittel die Reflexionsphase in der Muttersprache durchgeführt. Im fortgeschrittenen Fremdspracherwerb hingegen sollte diese Reflexion selbst als ein Sprechanlass in der Fremdsprache genutzt werden. Auf dem Sprachniveau B2 des GER können beispielsweise bereits der Unterschied zwischen dem Beschreiben und dem Interpretieren eines Standbilds vermittelt

\footnotetext{
5 Vgl. zu einer umfassenden Diskussion zum Aspekt der Vernetztheit die Arbeit von Christiane Neveling 2004 zum Französischen als Fremdsprache.

${ }^{6}$ Zum Überblick vgl. Nation 2001.
} 
sowie die entsprechenden sprachlichen Mittel wie z.B. lokale Präpositionen oder Modalausdrücke geübt werden (vgl. Walter 2011). Blenden wir die zu übenden sprachlichen Strukturen einmal aus, ist der hier thematisierte Unterschied einer der wesentlichen Herangehensweisen im ästhetischen Lernen. Im ästhetischen Lernen geht es vereinfacht gesagt darum, mit der Kunst Lernprozesse in Gang zu setzen und hierbei auch die Kunst zu verstehen, ob nun ein gemaltes Bild, eine Sinfonie oder eine Theateraufführung. Das Verstehen der Kunst baut auf einer intensiven Wahrnehmung des Kunstwerks auf. Das bedeutet, dass die ästhetischen Mittel im Lernprozess bewusst gemacht werden. ${ }^{7}$ Dieser kognitive Vorgang kann intensiviert werden, wenn eigene ästhetische Lernerlebnisse angeregt werden. Dadurch können ästhetische Erfahrungen gemacht werden. Für szenische Verfahren heißt das, die Lerner/innen lernen theatrale Mittel wie die Modulierung der Stimme oder die Zielgerichtetheit von Bewegungen kennen, probieren diese Mittel aus und reflektieren ihre Wirksamkeit. Damit ist die szenische Wortschatzarbeit auch unter dem Dach eines ästhetischen Lernens anzusiedeln.

Meiner Ansicht nach findet sich in den Bohnschen Hybridverfahren, die sprachliche und nichtsprachliche Informationen koppeln, das größte Potenzial für die szenische Wortschatzvermittlung. Warum? Durch die Verknüpfung der beiden Informationstypen können die entsprechenden blinden Flecken schnell zum Verschwinden gebracht werden. Im Fremdsprachenkontext wird dies im Normalfall die fehlende sprachliche Information sein. Nehmen wir beispielsweise die Wörter für die Gegenstände, die sich in einem Wartezimmer befinden können: der Tresen, der Wartebereich, die Stühle, das Bild, die Spritzen, das Blutdruckmessgerät, der Schrank mit den Medikamenten, das Aquarium, der Kugelschreiber, die zerlesenen Zeitschriften usw. All diese Realien werden als solche in der Regel bekannt sein, im Fremdsprachenerwerb müssen die entsprechenden Benennungen zunächst im Deutschen herausgefunden und anschließend memoriert werden. In der Regel wird man die entsprechenden Gegenstände nicht im Klassenraum zur Verfügung haben. Aber wozu gibt es die ästhetischen Konstruktionen im Als Ob? Im Improvisationstheater findet man in der Regel keine pantomimisch dargestellten Gegenstände, stattdessen werden die Objekte gestisch angedeutet (z.B. ein Messer). Es wird mit ihnen gehandelt, beispielsweise wird mit dem Messer etwas geschnitten oder es wird geschärft. Dieses Handeln vollzieht sich deutlicher, als man es gewöhnlich tun würde, wenn man mit einem realen Gegenstand agieren würde. Es sollte für Mitspieler/innen und auch das Publikum erkennbar sein. Ein gutes Beispiel für diesen gestischen Ausdruck liefert der Improspieler und Schauspiellehrer Stephen Sim von der kanadischen Improvisationstheatergruppe Crumbs in den ersten Minuten

\footnotetext{
${ }^{7}$ Vgl. hierzu das Konzept des „Sehen Lernen im Theater“, das in Walter 2012b vorgestellt wird.
} 
seiner Präsentation zu den Grundprinzipien des Improvisationstheaters auf der TED-Konferenz 2013. ${ }^{8}$

Im nächsten Abschnitt wird exemplarisch eine der Techniken aus dem Improvisationstheater vorgestellt, die für die Semantisierung herangezogen werden kann.

\section{Das gesprochene Bühnenbild: Eine Technik (auch) für die Wortschatzarbeit}

Stellen wir uns dazu vor, dass eine Spielerin auf die Bühne kommt. Wenn sie die Technik des gesprochenen Bühnenbilds (scene painting) anwendet, zeichnet sie die Bühne mit ihrem Körper und ihrer Sprache. Der Raum wird hierdurch sprachlich und gestisch gemalt und im Kopf des Publikums konstruiert. Beispielsweise kann das bereits als Beispiel herangezogene Wartezimmer auf einer Bühne etabliert werden, indem die Spielerin diese betritt, vier reale Stühle aufstellt und dabei jeden Stuhl mit einfachen Worten beschreibt: Ein weißer Stubl obne Armlehnen, aus Holz mit einem gelben Kissen. Drei grüne Stühle auch obne Armlehnen und mit einem Polster. Dabei wird auf die fiktiven Kissen mit den Händen gedeutet. Hierbei können auch Formen und sogar Materialeigenschaften wie die Festigkeit der Kissen angedeutet werden. Hinter den Stüblen gibt es eine weiße $W$ and mit einem Bild des Berliner Reichstagsgebäudes. Auch hier deutet man wieder auf die Wand und ggf. auch auf die Umrisse, um die Größe zu definieren. Vor den Stühlen steht ein Glastisch mit den Zeitungen der letzten Monate. Die Spielerin geht an den linken Bühnenrand und sagt: Hier steht ein Tresen, hinter dem die Arzthelferin sitzt. Ein Medikament liegt auf dem Tresen. Die Tür des Schrankes mit den Medikamenten ist geöffnet. Diese Technik zeigt zumindest zwei ästhetische Rahmenbedingungen: Erstens der leere Brooksche Raum, der den Motor der Phantasie im Spiel anwirft (vgl. Brook 2009) und zweitens die Reduktion auf wesentliche nachvollziehbare Gegenstände, die in entsprechenden Räumen erwartbar sind. Mit einem solchen gesprochenen Bühnenbild kann gerade in improvisierten Langformen ein Szenenanfang gestaltet werden.

In der Fremdsprachenvermittlung kann diese Technik von der Lehrperson für die Semantisierung eingesetzt werden. Es eignet sich beispielsweise hervorragend dafür, einen Lehrwerksdialog einzubetten. Gehen wir zum oben bereits eingeführten Wartezimmer. Dieses von der Lehrperson präsentierte Bühnenbild bietet einen kognitiven Zugang: Der/die Lerner/in konstruiert schrittweise einen fiktiven Raum im Kopf durch das von Sprache begleitete Handeln der Lehrperson. Zugleich handelt es sich um ein emotional aufgeladenes Konstrukt, da die Gegenstände in bestimmten Stimmungen präsentiert werden. Was bedeutet das? Mit der Technik werden Objekte gestisch dargestellt, indem mit den fiktiven Gegenständen

\footnotetext{
8 Vgl. Sim 2013. Seit 1984 tauschen sich auf der Konferenz TED (Teaching, Entertainment, Design) im kalifornischen Monterey Experten aus verschiedenen Gebieten über ihr Fachwissen aus (http://www.ted.com). Besonders bekannt wurde die TED durch die kostenfrei im Internet zur Verfügung gestellten Videos der Präsentationen.
} 
gehandelt bzw. auf sie gedeutet wird. Diese Objekte werden dabei synchron mit der sprachlichen Form verbunden. Eine solche körperliche Ausgestaltung eines Raums erinnert sehr stark an die im Fremdsprachenunterricht häufig eingesetzten illustrierten Wortfelder (vgl. Dudenredaktion 2005: 64). Man könnte sich die entsprechenden gesprochenen Bühnenbilder auch als theatralisierte Wortfelder vorstellen, die mit einem großen Körper- (und auch Stimm-)Einsatz der Lehrperson beschrieben werden. Wie könnte es nun in die alltägliche Unterrichtspraxis einbezogen werden? Bleiben wir bei unserem Beispiel des Wartezimmers und sehen uns einen typischen Dialog auf dem A-Niveau des GER an.

A: Guten Tag, Herr Aigner. Was fehlt Ihnen denn?

B: Ich habe seit drei Tagen Fieber, mein Hals tut weh und ich habe Kopfschmerzen.

A: Sagen Sie mal „Aaaah“! Husten Sie mal! Alles rot. Sie haben eine Angina.

B: Wie bitte?

A: Eine schwere Halsentzündung. Sie sind stark erkältet. Ich verschreibe Ihnen Tabletten und Hustensaft. Bitte nehmen Sie die am Morgen, Mittag und Abend. Rauchen Sie?

B: Ja, aber nicht so viel. So 20 Zigaretten am Tag.

A: Aha, ich schreibe Sie eine Woche krank. Sie müssen viel trinken und dürfen natürlich nicht rauchen. Bitte machen Sie einen Termin für nächste Woche. Gute Besserung!

B: Dann bis nächste Woche. Auf Wiedersehen, Frau Doktor.

Dialog Im Sprechzimmer aus dem Lehrwerk studio (21). Das Deutschbuch A1 (vgl. Funk; Kuhn 2013: 221)

Wie kann man konkret vorgehen? Nachdem die Lehrperson das gesprochene Bühnenbild eines Wartezimmers in der oben beschriebenen Weise entworfen hat, sollen drei Lerner/innen als Patienten/innen dieses Wartezimmer betreten und dürfen in der Szene lediglich einen Satz sagen. Die Lehrperson skizziert somit ein Bühnenbild als ein Muster, an denen sich die Lerner/innen im zweiten Schritt orientieren können. Anschließend finden alle drei Spieler/innen einen Grund, das Wartezimmer zu verlassen. Bevor die Spielszene im ersten Schritt beginnt, werden die Personen durch die Zuschauer/innen mit bestimmten Details ausgestattet. Hierzu stellt die Lehrperson gezielte Fragen nach dem Alter der jeweiligen Figur, dem Beruf, dem Hobby etc. Im Anschluss bereiten die Lerner/innen zu dritt den Sprechstunden-Dialog vor. Hierzu skizziert zunächst ein/e Lerner/in den Behandlungsraum mit Worten, wendet also die Technik des gesprochenen Bühnenbilds in einem vergleichbaren Szenario an. Die beiden anderen agieren als Ärztin und Patient, wobei die Sätze des Lehrwerksdialogs gesprochen werden. Die Szene kann im Anschluss noch einmal in einem anderen Genre wie einem Western wiederholt werden. Auch hier wird die Szene wieder mit einem gesprochenen Bühnenbild etabliert. Auch wenn die Sätze des daran anschließenden Dialogs lediglich wieder- 
holt werden, langweilen sich die Lerner/innen an dieser Stelle keineswegs, ob sie nun sprechen oder ob sie zuschauen, denn der Fokus der Lerner/innen liegt gewöhnlich auf der Art und Weise der Präsentation, auf ihrer Performativität.

Warum aber sollte eine Lehrperson diesen Aufwand treiben, wenn es doch diese Wortfelder bereits gibt? Zunächst einmal existieren nicht für alle Wortfelder ansprechende Abbildungen. Zudem ist die Verbindung von Körperlichkeit und Sprache, wie sie gerade in der performativen Didaktik (vgl. Hallet 2010) postuliert und als Mehrwert beschrieben wird, zumindest nicht abträglich für den Fremdsprachenerwerb (vgl. Sambanis 2013), sofern die Lehrperson die Techniken beherrscht. Fortbildungen können hier einen geschützten Rahmen schaffen, indem entsprechende Techniken ausprobiert, geübt und mit einem kollegialen Feedback versehen werden, bevor sie dann im Kursraum eingesetzt werden.

Scheinbar abwegig, aber durchaus interessant, ist ein kleines Detail der Theatergeschichte, das Improvisation und Unterricht verbindet. Das moderne Improvisationstheater hat nämlich grundlegende Inspirationen durch die reflektierte Tätigkeit des Lehrens erfahren. Keith Johnstone selbst war als junger Lehrer in einer Schule tätig und entwickelte in der Auseinandersetzung mit seinen Schulversuchen grundlegende Ideen seines Theaterkonzepts (vgl. Johnstone 2002: 13-50). Auch wenn man im pädagogischen Diskurs der 1950er-Jahre noch nicht von Aktionsforschung sprach, lohnt es sich, seine reflektierende Arbeitsweise in seinen Erinnerungen (ebd.) einmal genauer unter diesem Aspekt zu beleuchten und den methodischen Spuren zu folgen. Die Übungen und Spiele des modernen Improvisationstheaters wurden später sehr erfolgreich für den Unterricht adaptiert und in gewisser Weise damit dem Unterricht zurückgegeben. ${ }^{9}$ Im nächsten Abschnitt werde ich weitere Beispiele aus dem Unterricht diskutieren und dabei die möglichen Stolpersteine thematisieren.

\section{Vorsicht Fallgefahr! Grenzen der szenischen Wortschatzarbeit}

Die Arbeit mit Improvisationen birgt auch Fallstricke ${ }^{10}$. Und die Fallhöhe ist nicht unbeträchtlich, wenn man bedenkt, dass die Lehrperson sich auf ungewisses Terrain begibt. Ein Scheitern kann hier schnell zu Unmut und Frustration sowohl bei engagierten Lehrern/innen als auch motivierten Lernern/innen führen. Beginnt man zu früh mit allzu komplexem Wortschatz, wird das Zuviel an sprachlichem Unverständnis die Lerner/innen irritieren, wenn nicht gar völlig überfordern. Permanente Überforderung ist jedoch fast immer ein Garant für Demotivation. Das eingangs erwähnte freudvolle Scheitern bleibt hier reine Rhetorik. Ein guter An-

\footnotetext{
9 Vgl. zum Überblick allgemein: Vlcek 2003 und Masemann; Messer 2009, für den Bereich Darstellendes Spiel: List 2012, für den Fremdsprachenunterricht: Wilson 2008.

10 Stolpersteine genereller Art, die bei der Improvisation in Gruppen auftreten, beschreibt Wolfgang Wendlandt 2013.
} 
haltspunkt ist die Orientierung am Vokabular, das in den Lektionen benötigt wird. Es kann in der Regel dann auch mit dem Lehrwerk die zu vermittelnden lexikalischen Strukturen stützen. Im nächsten Abschnitt soll ein Blick über den Tellerrand der Wortschatzvermittlung im Deutschen als Fremdsprache eine Möglichkeit aufzeigen, die Überforderungshürde im Bereich der fremdsprachlichen Improvisation zu meistern.

Jürgen Kurtz, der in seiner Habilitation das improvisierte Sprechen im schulischen Englischunterricht untersucht hat, entwickelte Unterrichtsszenarien, in denen improvisiert und dadurch das freie Sprechen in der Fremdsprache trainiert wird. Das bekannteste dieser sieben Szenarien (vgl. Kurtz 2001: 143ff.) ist das der Bushaltestelle. Es ist an den amerikanischen Spielfilm „Forrest Gump“ angelehnt. Die Hauptfigur Forrest Gump erzählt an einer Bushaltestelle verschiedenen Menschen, die ebenfalls auf den Bus warten, die Geschichte seines Lebens. Er bietet ihnen Süßigkeiten mit der Lebensweisheit seiner Mutter an: „My Momma always said life was like a box of chocolates [...] you never know what you're going to get" (Kurtz 2001: 141). Das Unterrichtsszenario besteht nun darin, dass die Schüler/innen zunächst einen Namen zugewiesen bekommen und im Spielverlauf an einer Bushaltestelle über ein Thema wie das Wetter frei sprechen. Hierzu gibt es einen kurzen Anfangs- und einen Enddialog, der hier wiedergegeben ist.
A: Hallo.
B: Hallo, ich heiße
A: Schön Sie kennenzulernen. Mein Name ist
B: Warten Sie auf den Bus?
A: Ja. Wie wäre es mit etwas Süßem?
B: Oh, vielen Dank.

Anfangsdialog für die Improvisation Bushaltestelle, (vgl. Kurtz 2001: 140, Übersetzung M.W.)

Es folgt das improvisierte Sprechen über ein Thema, das als Praline aus einer Pralinenschachtel, gefüllt mit von der Lehrperson erstellten Themenzetteln, per Zufall gezogen wird. Der für die Praxis ausgesprochen hilfreiche Abschluss der Improvisation wird mit der kurzen Sequenz (vgl. folgenden Dialog), die Jürgen Kurtz den „kommunikativen Notausgang“" (Kurtz 2001: 142) genannt hat, beendet:

A/B: Oh, da kommt mein Bus. Ich muss gehen. Es war schön, mit Ihnen zu sprechen. Auf Wiedersehen!

B/A: Auf Wiedersehen!

Enddialog für die Improvisation Bushaltestelle (vgl. Kurtz 2001: 140, Übersetzung M.W.)

Mit diesem Notausgang, der für beide Spielpartner/innen offen gehalten wird, gelingt es, ein differenziertes Angebot mit der Möglichkeit einer positiven Lernerfahrung zu koppeln. Auch Schüler/innen auf einem niedrigeren Sprachniveau 
können einen Satz zu einem Thema wie (Taschen-)Geld oder Fußball beisteuern und dann elegant mit dem finalen Satz die Szene verlassen. Eloquentere Schüler/innen können sich in der Improvisation breiter entfalten. Das ist wie fast alle didaktischen Meisterleistungen im Grunde sehr einfach. Es erlaubt, die Szene zu beenden, ob nun nach zwei Sätzen, nach einem Satz und langen Schweigesentenzen oder aber nach einer wortgewaltigen Satzschlacht.

Jürgen Kurtz zeigt sehr überzeugend, dass es nicht ausreicht, nur Improvisationstechniken anzuwenden, sondern dass diese Techniken von der Lehrperson mit einem sprachdidaktischen Filter versehen werden müssen, damit ein sprachliches Lernen stattfindet. Dieser Filter speist sich zunächst aus einem Hintergrundwissen zu den sprachlichen Gegenständen (vgl. Walter 2004). Beispielsweise werden Lehrende ihr Wissen um die Bildung und Verwendung der verschiedenen Pluralformen im Deutschen für die Auswahl von zu vermittelnden Strukturen und deren Erklärung heranziehen. Arbeitet man lediglich mit Lehrwerken, nehmen die Autoren/innen die entsprechenden Entscheidungen ab, nutzt man stärker eigene Materialien, bedarf es eines solchen Hintergrundwissen über die zu vermittelnde Sprache, um nicht nur freud-, sondern auch sinnvollen Unterricht durchzuführen. Darüber hinaus wird der sprachdidaktische Filter von den immensen Erfahrungen, die Lehrer/innen im Laufe ihrer Unterrichtspraxis angehäuft haben, angereichert. Das in Kurtz (2001: 140ff.) ausführlich beschriebene Szenario der Bushaltestelle wurde für den Unterricht in der Sekundarstufe im Fach Englisch als Fremdsprache mit den entsprechenden Zielen, differenzierten Aufgabenstellungen, Arbeitsblättern sowie einem Videomitschnitt einer Unterrichtssequenz für die Ausbildung von Fremdsprachenlehrer/innen in Siebold (2004: 114ff.) aufbereitet. ${ }^{11}$

Im Fremdsprachenkontext wurden bereits weitere Szenarien dafür entwickelt, mit Improvisationen zu arbeiten. So beschreibt Anja Jäger beispielsweise ihre Arbeit mit der Improvisation auf der Basis von englischsprachiger Jugendliteratur, um im Rahmen des schulischen Englischunterrichts Interkulturelle Kommunikative Kompetenzen zu fördern (vgl. Jäger 2011). Auch können grammatische Strukturen mithilfe der Übungen aus dem Improvisationstheater im Rahmen des ChunkAnsatzes gefestigt werden (vgl. Walter 2012a: 185f.).

\section{Zum Abschluss: Eine Ermunterung für die szenische Wortschatzvermittlung}

Trotz der aufgezeigten Hürden ist es durchaus sinnvoll, den Wortschatz mit den Techniken wie dem gesprochenen Bühnenbild zu vermitteln. Gibt es den idealen Zeitpunkt, um Bühnenbilder sprechend zu konstruieren? Auf welcher Niveaustufe man idealerweise mit der Technik beginnen kann, ohne Frustrationen hervorzuru-

\footnotetext{
${ }^{11}$ Der pädagogische und didaktische Hintergrund wird zudem in Kurtz 2008 auf prägnante Weise vertieft dargestellt. Die Fremdsprachendidaktikerin Michaela Sambanis diskutiert dieses Szenario aus einer neurodidaktischen Perspektive (vgl. Sambanis 2013: 122).
} 
fen, soll an dieser Stelle bewusst offen gelassen werden. Auch wenn die Wahl des Wartezimmer-Szenarios nahelegt, dass bereits früh im Anfängerbereich erfolgreich gearbeitet werden kann, wird diese Entscheidung dem erfahrenen Auge und dem geschulten $\mathrm{Ohr}$ der Lehrperson überlassen. Mit anderen Worten, hier ist gelebte Diagnostik im Kursraum vonnöten (vgl. Kubanek-German; Edelenboss 2004, Hallet 2006). Und das bedeutet, dass ein/e Lehrer/in nicht nur die Ergebnisse eines schriftlichen Tests oder eine längere Lerneräußerung in eine der sechs Schubladen des Gemeinsamen Europäischen Referenzrahmens zu stecken vermag. Erst wenn eine Lehrperson ein Bühnenbild in der oben dargestellten Weise in der Fremdsprache malt und zugleich die körpersprachlichen Zeichen der zuschauenden Lerner/innen adäquat zu deuten vermag, kann man das Potenzial der Technik ausschöpfen. Die Lerner/innen sind Zuschauer/innen und zumindest zum Teil auch Mitspieler/innen, die ein/e Bühnenbildner/in wahrnehmen muss, wenn die Improvisation erfolgreich sein soll. Das ist nicht für alle Lehrenden leicht, einige mühen sich ihr gesamtes Berufsleben erfolglos daran ab. Eine Beschäftigung mit den Techniken der Improvisation kann jedoch durch aktives Zuhören und Wahrnehmen die entsprechenden Türen öffnen. Auf diese Weise lässt sich vielleicht durch die Anwendung eines ästhetischen Verfahrens der Fremdsprachenunterricht effizienter und vor allem auch lustvoller für Lehrende und Lernende gestalten, mehr als gut gemeinte, in der Fachdidaktik vorgeschlagene Unterrichtsrezepte es vermocht haben. Impro-Spieler/innen bringen dies auf die kurze Formel des $A u$ ja! Und dieser Gedanke kann auch von erfahrenen Lehrpersonen akzeptiert werden.

\section{Literatur}

Boal, Augusto (1976): Theater der Unterdrïckten. Übungen und Spiele für Schauspieler und Nicht-Schauspieler. Frankfurt a.M.: Suhrkamp.

Bohn, Rainer (2000): Probleme der Wortschatzarbeit. Berlin: Langenscheidt.

Bormann, Hans-Friedrich; Brandstetter, Gabriele; Matzke, Annemarie (Hrsg.) (2010): Improvisieren. Paradoxien des Unvorbersebbaren. Kunst-Medien - Praxis. Bielefeld: transcript.

Brook, Peter (2009): Der leere Raum. Berlin: Alexander.

Dudenredaktion (Hrsg.) (2005): Bildwörterbuch. 6., neu bearbeitete und erweiterte Auflage. Mannheim: Dudenverlag.

Frost, Anthony; Yarrow, Ralf (2007): Improvisation in Drama. Basingstoke u.a.: Palgrave.

Funk, Hermann; Kuhn, Christina (2013): studio (21). Das Deutschbuch A1. Berlin: Cornelsen. 
Hallet, Wolfgang (2006): Didaktische Kompetenzen. Lehr- und Lernprozesse erfolgreich gestalten. Stuttgart: Klett.

Hallet, Wolfgang (2010): Performative Kompetenz und Fremdsprachenunterricht. In: Scenario: Sprache - Kultur - Literatur 4, 1, 1-18. Online: http:/ / publish.ucc.ie/ scenario/2010/01/hallet/02/de (Stand: 29.09.2010).

Jäger, Anja (2011): Improvisationen auf literarischer Grundlage zur Förderung von Interkulturellen Kommunikativen Kompetenzen. In: Küppers, Almut; Schmidt, Torben; Walter, Maik (Hrsg.): Inszenierungen im Fremdsprachenunterricht. Grundlagen. Formen, Perspektiven. Braunschweig: Schroedel; Diesterweg; Klinkhardt, 164-179.

Johnstone, Keith (1999): Theaterspiele. Spontaneität, Improvisation und Theatersport. Berlin: Alexander.

Johnstone, Keith (2002): Improvisation und Theater. Die Kunst, spontan und kreativ zu agieren. Berlin: Alexander.

Köster Lutz (2010): Wortschatzerwerb und Wortschatzvermittlung. In: Krumm, Hans-Jürgen; Fandrych, Christian; Hufeisen, Britta; Riemer, Claudia (Hrsg.): Deutsch als Fremd- und Zweitsprache. Ein internationales Handbuch. 2. Halbband. Berlin u.a.: de Gruyter, 1021-1032.

Kubanek-German, Angelika; Edelenbos, Peter (2004): Teacher assessment: The concept of „diagnostic competence“. In: Language Testing 21, 3, 259-283.

Kurtz, Jürgen (2001): Improvisierendes Sprechen im Fremdsprachenunterricht. Eine Untersuchung zur Entwicklung spontansprachlicher Handlungskompetenz in der Zielsprache. Tübingen: Narr.

Kurtz, Jürgen (2008): Szenische Improvisationen: theoretische Grundlagen und unterrichtliche Realisierungsmöglichkeiten. In: Ahrens, Rüdiger; Eisenmann, Maria; Merkl, Matthias (Hrsg.): Moderne Dramendidaktike für den Englischunterricht. Heidelberg: Universitätsverlag Winter, 409-424.

Lewis, Michael (1993): The lexical approach. The state of ELT and a way forward. Hove: Language Teaching Publications.

List, Volker (2012): Kursbuch Impro-Theater. Stuttgart u.a.: Klett.

Lösel, Gunter (2013): Das Spiel mit dem Chaos. Zur Performativität des Improvisationstheaters. Bielefeld: transcript.

Masemann, Sandra; Messer, Barbara (2009): Improvisation und Storytelling in Training und Unterricht. Weinheim: Beltz.

Meyer, Karl-A S. (2008): Improvisation als flüchtige Kunst und die Folgen für die Theaterpädagogik. Berlin u.a.: Schibri. 
Nation, I. S. Paul (2001): Learning vocabulary in another language. Cambridge u.a.: Cambridge University Press.

Neveling, Christiane (2004): Wörterlernen mit Wörternetzen. Eine Untersuchung zu Wörternetzen als Lernstrategie und als Forschungsverfahren. Tübingen: Narr.

Sambanis, Michaela (2013): Fremdsprachenunterricht und Neurowissenschaften. Tübingen: Narr.

Siebold, Jörg (Hrsg.) (2006): Let's talk: Lehrtechniken. Vom gebundenen zum freien Sprechen. Berlin: Cornelsen.

Siegemund, Anke (2003): Improvisation. In: Koch, Gerd; Streisand, Marianne (Hrsg.): Wörterbuch der Theaterpädagogik. Berlin u.a.: Schibri, 137-139.

Sim, Stephen (2013): Who Wants to Play? Stephen Sim at TEDxManitoba 2013. Online: http://tedxtalks.ted.com/video/Who-Wants-to-Play-Stephen-Sim-a (Stand: 28.12.2013).

Spolin, Viola (1997): Improvisationstechniken für Pädagogik, Therapie und Theater. Paderborn: Junfermann.

Stork, Antje (2003): Vokabellernen. Eine Untersuchung zur Effizienz von Vokabellernstrategien. Tübingen: Narr.

Stork, Antje (2010): Wortschatzerwerb. In: Hallet, Wolfgang; Königs, Frank G. (Hrsg.): Handbuch Fremdsprachendidaktik. Seelze-Velber: Klett; Kallmeyer, 104-107.

Streisand, Marianne (2006): Brecht und der Theatersport. In: Kleinschmidt, Sebastian; Hörnigk, Therese (Hrsg.): Brecht und der Sport. Brecht-Dialog 2005. Berlin: Theater der Zeit, 91-101.

Vlcek, Radim (2003): Workshop Improvisationstheater. Übungs- und Spielesammlung für Theaterarbeit, Ausdrucksfindung und Gruppenarbeit. Donauwörth: Auer.

Walter, Maik (2004): Grammatisches Hintergrundwissen für DaF. Oder warum Philosophen nicht die besseren Mediziner sind. In: Lüger, Heinz-Helmut; Rothenhäusler, Rainer (Hrsg.): Linguistik für die Fremdsprache Deutsch. Landau: Verlag Empirische Pädagogik, 53-84.

Walter, Maik (2011): Prosa in Szene setzen: Generation X trifft Generation Harry Potter. In: Küppers, Almut; Schmidt, Torben; Walter, Maik (Hrsg.) (2011), 117-130.

Walter, Maik (2012a): Theater in der Fremdsprachenvermittlung. In: Nix, Christoph; Sachser, Dietmar; Streisand, Marianne (Hrsg.): Theaterpädagogik. Berlin: Theater der Zeit, 182-188. 
Walter, Maik (2012b): Kooperatives Sehen lernen: Kritiken schreiben in der Fremdsprache. In: Zeitscbrift für Theaterpädagogik. Korrespondenżen 60, 59-60.

Wendlandt, Wolfgang (2013): Wenn Leichtigkeit misslingt - Stolpersteine auf dem Weg zum Improvisationstheater. In: Zeitschrift für Theaterpädagogik.

Korrespondenżen 64, 78-81.

Wilson, Ken (2008): Drama and improvisation. Oxford: Oxford University Press. 



\title{
Probieren geht über Studieren - Dramenpädagogische Reflektionen
}

\begin{abstract}
Siegfried Boehm
Im vorliegenden Beitrag geht es um die Einführung in die dramapädagogische Lehr-und Lernmethode und es wird dargelegt, wie diese Kunstform in den DaF-Unterricht miteinbezogen werden kann. Zunächst wird auf die Stellung der Dramapädagogik im Fremdsprachenunterricht eingegangen und es werden Vorteile von und Vorbehalte gegenüber der Methode erläutert. Anschließend werden Hilfsmittel und Techniken präsentiert sowie Empfehlungen zur Gruppendynamik. und der Rolle der Lehrkraft gegeben. Schließlich wird als Beispiel einer dramapädagogischen Unterrichtseinheit erläutert, wie eine kurze Szene mit den Lernenden eines A2-Niveaus an der Facultad de Estudios Superiores (FES) Acatlán der Universidad Nacional Autónoma de México (UNAM) durchgeführt wurde.
\end{abstract}

\section{Vorteile von und Vorbehalte gegenüber der dramapädagogischen Lehr- und Lernmethode im Fremdsprachenunterricht}

Obwohl Maley und Duff (1978), Schewe (1993) und Tselikas (1999) schon im letzten Jahrtausend die Dramapädagogik im Fremdsprachenunterricht wissenschaftlich untermauert haben, nimmt deren Bedeutung und Anwendung erst in letzter Zeit zu. Wenn wir das Erlernen einer Fremdsprache als einen mehrdimensionalen Prozess erfassen, der in einem soziokulturellen Umfeld stattfindet, so ist das dramapädagogische Vorgehen eine empfehlenswerte Methode, um eine fremde Sprache nicht nur geistig, sondern auch mit dem ganzen Körper zu erfassen und auszuprobieren. Nicht nur die vier Fertigkeiten können dabei auf natürliche Weise in den Unterricht mit einbezogen werden, sondern auch das nonverbale Verhalten, 
dem im traditionellen Sprachunterricht meist wenig Beachtung geschenkt wird. Aufmerksames Zuhören ist bei den meisten Aktivitäten wichtig, und Schreiben und Lesen sind Teile des In- und Outputs (vgl. Maley und Duff 2005: 1). Die Lernenden stehen im Mittelpunkt des Lernprozesses, kognitive und affektive Bereiche vermischen sich und fördern somit ganzheitliches Lernen (vgl. Tselikas 1999: 21).

Maley und Duff geben u.a. folgende Gründe für den Einbezug dramapädagogischer Aktivitäten im Sprachunterricht:

- By fully contextualising the language, drama brings the classroom interaction to life through an intense focus on meaning.

- The emphasis on whole-person learning and multi-sensory inputs helps learners to capitalise on their strengths and to extent their range. In doing so, it offers unequalled opportunities for catering to learner differences $[\ldots]$.

- It encourages an open, exploratory style of learning where creativity and the imagination are given scope to develop. This, in turn, promotes risktaking, which is an essential element in effective language learning.

- It has a positive effect on classroom dynamics and atmosphere, thus facilitating the formation of a bonded group, which learns together [...].

- It is low-resource. For most of the time, all you need is a ,roomful of human beings' (Maley und Duff 2005: 1f.).

Dennoch ist es verwunderlich, dass die Methode bis heute noch nicht den gewünschten Anklang gefunden hat und in den meisten Curricula des Fremdsprachenunterrichts nicht beachtet wird. Weiterhin gibt es, zumindest im Bereich Deutsch als Fremdsprache, noch kein Lehrbuch das dramapädagogische Übungen einbezieht. Das hat zur Folge, dass die Lehrkräfte ihren Unterricht selbst lenken und gut vorbereiten müssen, um performative Lehr- und Lernmethoden einzubringen. In vielen Institutionen werden die Lernenden gezielt auf Prüfungen vorbereitet, die sich nach dem Inhalt der zu behandelnden Themen des Lehrbuchs richten. So bleibt meist keine Zeit mehr für dramapädagogische Übungssequenzen. Im dramapädagogischen Unterricht kommt es oftmals zu Überraschungen. Vieles ist unvorhersehbar und Lehrkräfte sowie Lernende gehen Risiken ein. Besonders lehrbuchorientierte Lehrkräfte, die Zeit und Sprachbenutzung kontrollieren sowie auf Lehrbucheinheiten fokussiert sind, befürchten das Chaos einer großen Gruppe, die dramapädagogisch arbeitet. Die Angst, die Kontrolle über die Gruppe zu verlieren, ist ein wichtiger Grund, warum manche Lehrkräfte Vorbehalte gegenüber der Methode haben (vgl. Royka 2002: 3).

Schewe hat sogenannte „dreidimensionale Übungsformen“ (Schewe 1993: 145) in DaF-Lehrwerken untersucht und dabei ihr szenisches Potential kritisiert. Er versteht unter diesem Begriff 
Übungsformen mit szenischem Potential, mit denen bereits in die Richtung einer Sprachaneignung/-anwendung durch körperliche Bewegung im (Klassen-)Raum geschritten wurde (ebd.).

Er erwähnt, dass die vorherrschende dreidimensionale Übungsform in Lehrbüchern das sogenannte „Rollenspiel“ (ebd.) ist, das diese Bezeichnung nicht verdient, denn

- die Lernenden bekommen kaum Identifikationshilfen, es erfolgt keine reflektierte Einfühlung in die Situation, bzw. Person.

- der Aufbau des fiktiven Handlungsortes wird nicht ernst genug genommen.

Es erfolgt kaum eine Nachbereitung der Szene (vgl. ebd.: 154).

Weiterhin haben die kurzen Szenen der Lehrbücher keinen dramatischen Höhepunkt, Kreativität und Interesse der Lernenden werden nicht berücksichtigt (vgl. ebd.: 161). Ein Beispiel dafür ist folgende Arbeitsanweisung, die wir in vielen Lehrbüchern vorfinden werden:

Arbeiten Sie zu zweit oder zu dritt, wählen Sie eine Situation und spielen Sie den Dialog: Ihre 17-jährige Tochter verbringt jedes Wochenende in der Disko. Überzeugen Sie Ihre Tochter davon, weniger tanzen zu gehen, und machen Sie ihr einen Vorschlag, was sie stattdessen tun könnte (Dallapiazza u.a. 2002: 110).

Die Lernenden werden daraufhin eine Liste mit verschiedenen Aktivitäten erstellen und die Tochter, von der wir nur wissen, dass sie 17 Jahre alt ist, wird letztendlich einen anderen Vorschlag akzeptieren. Im besten Fall wird sie den Vater oder die Mutter mit Argumenten überzeugen, warum sie weiterhin in die Disko geht.

Dieselbe Situation könnte man interessanter machen und einer Dramatisierung anpassen, indem man Zusatzinformation zu den Charakteren gibt, wie z.B.:

Sie sind ein autoritärer Vater/autoritäre Mutter/Besitzer(in) einer Disko/haben Schulden beim Besitzer der Disko/religiöse(r) Fanatiker(in)/Terrorist(in), usw. Die Tochter ist die Freundin eines vor kurzem aus dem Gefängnis entlassenen DJs/hat drogensüchtige Freunde/übt in der Disko, um an einem Tanzwettbewerb teilzunehmen usw.

\section{Behutsamer Einstieg in die dramapädagogische Unterrichtsform}

Unter Rückgriff auf einen Unterrichtsvorschlag, auf dem der Workshop Probieren geht über Studieren basiert, wird im Folgenden die Einbindung von dramapädagogischen Mitteln skizziert. Zunächst geht es dabei um eine Aufwärmübung zum Kennenlernen, die an dieser Stelle beschrieben wird. Alle Teilnehmenden bewegen sich frei zur Musik im Raum. Nach einer Minute wird diese gestoppt und jeweils zwei 
nebeneinander stehende Teilnehmenden stellen sich Fragen zu ihren Namen, ihrer Herkunft, ihren Interessen usw. Dann wird die Musik weiter gespielt, wieder gestoppt usw. bis alle Teilnehmenden genug voneinander wissen. Danach stellen sie sich in einem Kreis auf und einer geht in die Mitte. Die restlichen Teilnehmenden stellen ihn oder sie vor und wenn einer sich nicht mehr an alle Aussagen erinnern kann, so gibt es andere, die weiterhelfen können.

Wie beim Sport ist auch im dramapädagogischen Unterricht die Aufwärmphase äußerst wichtig. Je besser die Gruppe aufgewärmt ist, d.h. körperlich, stimmlich und geistig ins Thema eingeführt wird, desto gelöster und kreativer wird sie sich an die Gestaltung der Aufgaben begeben. Tselikas beschreibt ein „PyramidenPrinzip“ (1999: 62) nach dem Körper, Bewegung und Rhythmus eine Einheit bilden. „Körper produziert Atem, Atem trägt Stimme, Stimme ermöglicht Sprache. Entsprechend ist es sinnvoll, z.B. Atemübungen vor Stimmübungen zu setzen und Stimmübungen vor Sprachübungen“ (ebd.). Die Autorin empfiehlt Aufwärmsequenzen nicht mehr als 10-15\% der Zeit des gesamten Treffens dauern zu lassen (vgl. ebd.: 61). Sie erwähnt folgende Funktionen des Aufwärmens:

- $\quad$ Einführung in das Thema und Schaffen eines gemeinsamen Spiel- und Erlebnisraumes

- Erwecken des Vertrauens innerhalb der Gruppe

- Schaffen eines Erlebnisraumes, um neue Techniken auszuprobieren

- Körperliche Bewegung als Impuls für geistige Bewegung

- Bereitschaft konventionelle Grenzen zu überwinden

- Wecken von Neugier und Kommunikationslust (vgl. ebd.).

Aufwärmübungen gehören nicht nur zur Dramapädagogik, sondern können jederzeit auch in anderen Sprachunterrichtseinheiten verwendet werden. Besonders bei Ermüdungserscheinungen der Lerner sind sie effektiv. Denn „,[durch] die Bewegung des Körpers und die Einbeziehung der Stimme kommen Geist und Sprache in Bewegung“ (ebd.: 63).

Royka empfiehlt den Lehrkräften mit noch wenig Erfahrung anfangs kurze Szenen in ihren Unterricht einzuführen und diese zu erweitern, wenn sie mehr Sicherheit dabei gewonnen haben. Sie sollten sich nicht wie die Vorführenden der Szene fühlen, sondern müssen verstehen, dass eine dramapädagogische Einheit nur durch die aktive Beteiligung aller erarbeitet werden kann (vgl. Royka 2002: 2ff.).

\section{Hilfsmittel und Rahmenbedingungen für dramapädagogisches Vorgehen}

Wie auch im bereits erwähnten Workshop gezeigt wurde, können verschiedene Hilfsmittel, wie beispielsweise Fotos, Zeitungsartikel, Holzfiguren und Gedichte, verwendet werden, um die Kreativität der Lernenden beim Ausarbeiten einer Szene zu wecken. Neelands und Goode weisen darauf hin, dass das Ausgangsmaterial 
für dramapädagogische Aktivitäten in der menschlichen Erfahrung verankert sein sollte. Für die Teilnehmenden kann diese wirklich, imaginär, nachempfunden oder historisch sein. Wichtig ist dabei, dass die ausgewählten Hilfsmittel Interesse und Motivation der Lernenden erwecken und angemessen in den Unterricht eingeführt werden (vgl. Neelands; Goode 2008: 99f.).

Eine beliebte Technik, um Schlüsselmomente einer Handlung zu visualisieren, sind Standbilder. Anhand von diesen können Szenen, Situationen, Gefühle, Rollen und Beziehungen sinnlich erfahrbar gemacht werden. Sie können zu Beginn der Aktivität eingesetzt werden, um beispielsweise eine Schlüsselszene zu beschreiben oder um literarische Texte auszukundschaften (vgl. Tselikas 1999: 173).

Sie können angewendet werden, indem

- man die Szene in einem bestimmten Moment stoppt und die Handlung einfriert.

- $\quad$ eine Gruppe der Lernenden das Standbild einer anderen Gruppe aufbaut.

- Teilnehmende die Figuren beschreiben, d.h. Zeit und Raum der Szene sowie den Vorfall festlegen, die Gedanken der Figuren aussprechen.

- $\quad$ eine Figur berührt wird und diese daraufhin ihre Situation beschreibt, bzw. ihre Gedanken und Gefühle ausspricht, bis sie erneut berührt und eingefroren wird.

Anschließend kommt die nächste Person dran.

Auch wenn Standbilder nicht immer leicht zu deuten sind, so eignen sie sich gut, um eine Situation zu verbalisieren. Jeder Lernende kann sie für sich interpretieren. Durch unterschiedliche, zum Teil widersprüchliche, Auslegungen kommen die Lernenden miteinander ins Gespräch.

Beim dramapädagogischen Lernen spielt die Atmosphäre eine besondere Rolle, um den Unterricht erfolgreich gestalten zu können. Sie schafft einen glaubwürdigen Kontext, in dem Gefühle und Gemütszustände der Teilnehmenden zum Ausdruck kommen sollen.

Folgende Empfehlungen können zur Schaffung einer adäquaten Atmosphäre beitragen:

- Große Klassenzimmer, in denen man Tische und Stühle zur Seite stellen kann, um sich frei bewegen zu können. Ein Teppich ist von Vorteil, um sich darauf setzen und entspannen zu können.

- Im Klassenzimmer bleiben und es je nach Bedarf einrichten und dekorieren. Der Fantasie sind dabei keine Grenzen gesetzt.

- Genug Hilfsmittel für die Dekoration und Hinweisschilder im Klassenzimmer bereitstellen. Eine Truhe mit diversen Requisiten und Verkleidungsstücken unterstützt die Lernenden in ihren Rollen.

- Die Aufführung mit Videokamera filmen (kann auch ein Lernender oder eine andere Lehrkraft tun) und den Mitwirkenden eine CD/DVD mit der aufgenommenen Szene zur Verfügung stellen. Erfahrungsgemäß wird 
dadurch die Motivation der Lernenden mehr angeregt als durch eine nicht dokumentierte Aufführung.

- $\quad$ Die Szene anhand der CD/DVD nachbereiten (vgl. Boehm 2013: 66).

\section{Gruppendynamik und die Rolle der Lehrkraft}

Die dramapädagogischen Ansätze basieren auf dem Konstruktivismus, d.h. der Lernprozess der Lernenden baut erheblich auf ihren Erfahrungen auf und ist stets an ihre Handlungen geknüpft. Das Lernen wird effektiver, wenn die Lernenden ihren Lemprozess weitgehend selbst steuern können. Die Lehrkraft wird zum Berater und Beobachter dieses Prozesses, schafft Lernangebote und stellt die Mittel dafür bereit. Der Unterricht ist lernerzentriert, der Raum gehört den Lernenden und alle arbeiten in Kleingruppen oder im Plenum.

In einem freien Raum können Lehrkräfte und Lernende zum Ausdruck bringen, was sie innerlich bewegt. Dabei arbeiten sie in fiktiv geschützten Kontexten, d.h. beim Spielen einer Person geben sie zwar indirekt etwas von sich preis, ihre eigene Identität wird aber geschützt. Gerade die bewusste Verfremdung der Wirklichkeit setzt nachhaltig wirksame Lernprozesse in Gang, die zu einem Neuverstehen der Realität führen (vgl. Schewe 1993: 401).

Es ist wichtig, dass die Lehrkraft auf den Zusammenhalt der Gruppe achtet. Die Lernenden müssen verstehen, dass die Szene ein Werk aller Teilnehmenden ist und dass Nebenrollen für die Handlung genauso tragend sind wie Hauptrollen. Unterschiede und Gemeinsamkeiten innerhalb der Gruppe müssen akzeptiert und Lösungen gemeinsam gefunden werden.

Die Lehrkraft muss die Rahmenbedingungen für eine positive Gruppendynamik schaffen, z.B. durch Übungen zur Vorstellung aller Teilnehmenden sowie durch Sozialformen wie Partner- oder Kleingruppenarbeit. Ebenso muss auf pünktliche und regelmäßige Anwesenheit aufmerksam gemacht werden. Ständiges Fehlen oder Dazukommen von neuen Mitgliedern beeinträchtigt die Gruppe. Eventuelle Konflikte müssen schnellstens beseitigt werden und es dürfen keine Lernenden anderen vorgezogen werden. Schüchterne Lernende sollten die Möglichkeit haben, sich anfangs etwas in Nebenrollen zu verstecken, bis sie mehr Selbstbewusstsein erreicht haben. Niemand darf sich ausgelacht oder kritisiert fühlen und fähigere Lernende sollten schwächeren helfen.

Erfahrungsgemäß empfiehlt es sich autoritäre Anweisungen zu vermeiden und Entscheidungen sollten mit der ganzen Gruppe getroffen werden. Bei der Planung der Szenen kann je nach Sprachniveau der Gruppe bei Deutsch als FremdspracheLernenden in Fremd- oder Muttersprache ${ }^{1}$ kommuniziert werden. Wichtig dabei ist, dass sich niemand unter Druck fühlen darf. Die Verwendung der Muttersprache hat den Vorteil, dass Missverständnisse vermieden werden können und die

\footnotetext{
${ }^{1}$ Im Fall homogener muttersprachlicher Lernergruppen. Bei sprachlich heterogenen Gruppen könnte die Kommunikation nur in der Fremdsprache erfolgen.
} 
Kreativität ungehemmten Ausdruck finden kann. Bei der Vorführung der Szenen bleibt noch genug Zeit für die Fremdsprache.

Im dramapädagogischen Unterricht ist die Funktion der Lehrkraft helfend und beratend. Sie muss der Gruppe Anstöße geben und Autonomie schaffen, damit sich die sprachlichen Aktivitäten entwickeln können. Je nach der spezifischen Situation kann sie eine Rolle übernehmen, um in der Gruppe integriert zu sein und die Szene aus dem Gesichtspunkt einer fiktiven Person heraus zu leiten sowie bestimmte sprachliche Äußerungen anzuregen. Als Spielleiterin steuert sie demnach nicht nur den Lernprozess, sondern kann auch als Animateurin, Mitspielerin, Gesprächspartnerin immer wieder aktiv in den Spielprozess eingreifen (vgl. Tselikas 1999: 47).

Die Lehrkraft, die dramapädagogisch arbeitet, muss Erfahrung, Sensibilität und „Lust zum Spielen“ (Scheller 1996: 30) haben. Vor allem dort, wo in Rollengesprächen intime Gefühle angesprochen werden, soll sie zurückhaltend sein (vgl. ebd.).

Es verstößt gegen die Grundprinzipien der Dramapädagogik die Lernenden während der Szene zu korrigieren, da dadurch die dramatische Realität unterbrochen wird. Die Lehrkraft kann Fehler notieren und eine Korrektur nach der Szene vornehmen. Fehler, die sich wiederholen, können auch im Plenum korrigiert werden (vgl. Boehm 2013: 63). Einerseits muss die Lehrkraft vor Beginn des Unterrichts Lernziel und Thema festlegen sowie zeitliche und räumliche Rahmenbedingungen berücksichtigen, andererseits beeinträchtigt zu strenges Festhalten an ein bestimmtes Schema den Verlauf der dramapädagogischen Übung (vgl. Copei 1966: 129). Wichtig dabei ist, dass genug Platz für Unvorhergesehenes besteht. Wenn die Entwicklung der Szene zu festgelegt ist, dann wird sich die Lehrkraft ärgern, wenn diese anders als geplant verläuft.

Die Strukturierung und Vorbereitung der Aktivitäten ist genauso wichtig wie genügend Freiheit für die Gruppe, damit diese ihre Kreativität ohne ständiges Eingreifen der Lehrkraft entwickeln kann. Gegenseitiges Vertrauen zwischen ihr und den Lernenden ist äußerst notwendig, um die gesetzten Ziele zu erreichen.

\section{Schaffung einer Szene im DaF-Unterricht}

Ein Beispiel einer dramapädagogischen Übung im DaF-Unterricht, das auch im o.g. Workshop vorgestellt wurde, ist die Schaffung der Szene In der U-Bahn. Diese wurde mit den Lernenden im Rahmen des an der Deutschabteilung der Facultad de Estudios Superiores (FES) Acatlán der Universidad Autónoma de México (UNAM) geförderten Projekts Dramapädagogik als Mittel zur Erlangung von interkultureller Sensibilität im Fremdsprachenunterricht durchgeführt und durch eine Videoaufzeichnung dokumentiert. Die Lernenden sollen anhand zehn fiktiver Alltagsszenen ${ }^{2}$, die sich in

\footnotetext{
2 Die Szenen wurden von mir aufgrund persönlicher Erfahrungen ausgearbeitet. Sie beziehen sich auf stereotype Werte und Normen der deutschen Gesellschaft, die allerdings in der Nachbesprechung relativiert werden.
} 
Deutschland abspielen, eine interkulturelle Sensibilität entwickeln, die ihnen beim späteren Aufenthalt im Zielsprachenland helfen soll, sich zurechtzufinden. Die Protagonisten sind ein mexikanisches Paar, Carlos und Olivia, die ein Stipendium für einen Studienaufenthalt in München bekommen haben und sich dort mit verschiedenen Alltagssituationen vertraut machen.

Bei den Szenen wurde besonders darauf geachtet, dass

- die Situationen authentisch sind und landeskundliche Information enthalten;

- die Aufführung nicht mehr als zehn-fünfzehn Minuten in Anspruch nimmt;

- $\quad$ sie einen dramatischen Höhepunkt enthalten;

- $\quad$ sie ein Ende haben, das die Lernenden selbst bestimmen können (vgl. Boehm 2011: 3f.).

Obwohl es in der Dramapädagogik sinnvoller ist, von einem Geschehen auszugehen und die Handlung anhand konkreter Situationen und Figuren aufzubauen (vgl. Oelschläger 2007: 2), wird bei den Szenen weniger Spielraum gelassen, da angenommen wird, dass die Lernenden weder mit allen Verhaltensweisen der Zielsprachengesellschaft noch ihrer sprachlichen Mitteln vertraut sind. Deshalb werden Dialoge mit kultureller Information vorgegeben, die einen dramatischen Höhepunkt haben und den Lernenden Gelegenheit geben, den Ausgang der Szene selbst zu bestimmen. Das offene Ende macht die Aktivität handlungsorientiert und fördert die Kreativität der Teilnehmenden.

Die vorgegebenen Dialoge müssen nicht auswendig gelernt werden, sondern dienen als Richtlinien. Die Teilnehmenden können Sprechkarten anfertigen, von denen sie die Aussagen ablesen. Wichtig bei diesen Szenen, die u.a. von Wohnungs- und Jobsuche, Benutzung der öffentlichen Transportmittel, Einladungen zum Essen, Einkauf und Diskothekenbesuchen handeln, ist letztendlich die Bewusstmachung der kulturellen Unterschiede bzw. Gemeinsamkeiten, wobei die Lernenden diese erst selbst identifizieren sollen und die Lehrkraft später auf die nicht erkannten aufmerksam macht (vgl. Boehm 2011: 4).

Die Lernenden, die an diesem Projekt teilnahmen, erklärten in der Nachbesprechung der Szenen, dass

- $\quad$ sich ihre Fertigkeiten im Deutschen erheblich verbessert hatten, vor allem fließendes Sprechen, Aussprache und Intonation. Sie hatten dabei auch viele typische Redewendungen gelernt und konnten den neuen Wortschatz besser behalten, da sie ihn in einem wirklichkeitsnahen Kontext gebraucht hatten.

- sie auf Normen, Werte, Verhalten und Bräuche der Zielkultur durch die übernommenen Rollen von Personen deutschsprachiger Länder aufmerksam gemacht wurden und Wissen über Institutionen, Transportmöglichkeiten, Lebensformen, Feste usw. erwarben. 
- im Gegensatz zum herkömmlichen Unterricht die nonverbale Kommunikation während den Proben besser geübt werden konnte. Gesten, Körperhaltungen, Lautstärke der Stimme, Kleidung, Distanz zwischen den Sprechern usw. machten einen bedeutenden Teil der Szenen aus.

- ihr Selbstbewusstsein und der Gruppenzusammenhalt bedeutend gestärkt wurde. Da sie aufgrund der Videoaufzeichnung der Szene Gelegenheit hatten sich selbst Deutsch sprechen zu sehen und zu hören, wurde ihr Vertrauen, sich in der Fremdsprache ausdrücken zu können, gestärkt.

Die Teilnehmenden lernten sich durch den ständigen Kontakt untereinander besser kennen und übernahmen mehr Verantwortung für die Aktivitäten (vgl. Boehm 2013: 158).

\section{Schlussfolgerungen}

In einer Zeit, in der sehr viel Wert auf Lernerautonomie und Kommunikationstechnologien gelegt wird, muss auch der Fremdsprachenunterricht lernerzentriert und handlungsorientiert gestaltet werden. Beide Prinzipien sind in der Dramapädagogik verankert. „Erst wenn ein sprachlicher Ausdruck mit einem sinnlichen Eindruck verknüpft werden kann, nimmt er für die Lernenden Bedeutung an" (Schewe 1993: 67). Ein Unterricht mit dramapädagogischen Aktivitäten fördert Kreativität, Spontaneität und Einfühlungsvermögen der Lernenden, was nötig ist, um sich sich in der Fremdsprache ähnlich wie in der Muttersprache ausdrücken zu können. Beim dramapädagogischen Vorgehen werden nicht nur die vier Fertigkeiten einer Sprache in einem wirklichkeitsnahen Kontext angemessen gelehrt, sondern auch nonverbale Kommunikation, welche den sprachlichen Ausdruck ständig begleitet. Eine Lehrkraft, die ihren Lernenden einen natürlichen Zugang zur Fremdsprache schaffen und das Lernen mit allen Sinnen fördern will, wird dramapädagogische Aktivitäten in ihrem Unterricht ausprobieren, um der fremden Sprache eine lebendige Form zu verleihen (vgl. ebd.: 429) sowie unvergessliche Momente in ihr Klassenzimmer zu bringen.

\section{Literatur}

Boehm, Siegfried (2011): Affektiv ist effektiv: Dramatische Aktivitäten als Hilfsmittel zur Erlangung einer interkulturellen Sensibilität im Fremdsprachenunterricht. In: Scenario V, 2. Online: http://research.ucc.ie/scenario/2011 /02/Boehm/05/de (Stand: 18.5.2013).

Boehm, Siegfried (2013): Aprender actuando. México D.F.: UNAM.

Copei, Friedrich (1966): Der fruchtbare Moment im Bildungsprozess. Heidelberg: Quelle \& Meyer. 
Dallapiazza, Rosa-Maria; Jan, Eduard von; Schönherr, Til (2002): Tangram. Deutsch als Fremdsprache. Ismaning: Hueber.

Maley, Alan; Duff, Alan (2005): Drama Techniques. Cambridge: Cambridge University Press.

Neelands, Jonathan; Goode, Tony (2008): Structuring Drama Work. Cambridge: Cambridge University Press.

Oelschläger, Birgit (2007): Rezension: Frühes Deutsch 15, 8, 2006 Theaterspielen: Vom Unterrichtsprinzip zum Unterrichtsereignis. In: Scenario 1. Online: http://publish.ucc.ie/scenario/2007/01/oelschlaeger/09/de (Stand: 1.9.2013).

Royka, Judith Gray: (2002): Overcoming the Fear of Using Drama in English Language Teaching. In: The Internet TESL Journal Vol. VIII, 6. Online: http://iteslj.org/Articles/Royka-Drama.html (Stand: 18.5.2013).

Scheller, Ingo (1996): Szenische Interpretation. In: Praxis Deutsch 136, 22-32.

Schewe, Manfred (1993): Fremdsprache inszenieren. Oldenburg: Carl von Ossietzky Universität.

Tselikas, Elektra (1999): Dramapädagogik im Sprachunterricht. Zürich: Orell Füssli. 


\section{Bildende Kunst}





\section{Die Sprache der Dinge: Ästhetisches Lernen und Visual Literacy in der Ausbildung von DaF-Lehrenden - Über die Arbeit mit Bildern und Objekten}

\section{Eva Veronika Chen}

Der Beitrag erörtert das Ästhetische Lernen als Wabrnebmungslernen - insbesondere die Visual Literacy - in seiner Bedeutung für Fremdsprachenlehrende und -lernende. Er konzentriert sich auf das Beispiel angehender Deutschlehrender im Studiengang Deutsch als Fremd-und Zweitsprache und zeigt auf, wie das Kulturelle Seben durch methodische Ansätze des sog. Inquiry Teaching in verschiedenen Unterrichtskontexten gefördert werden kann.

\section{1 Ästhetisches Lernen als Wahrnehmungslernen}

Wenn über Ästhetisches Lernen im Kontext von Lehre und Unterricht gesprochen wird, ist die Rede meist von ästhetischen Lernprozessen im engeren Sinne. Das heißt, es geht um die Auseinandersetzung mit „Musik - Kunst - Film - Theater Literatur", so wie es auch der Untertitel des Tagungsbands ausdrückt, in dessen Rahmen der vorliegende Artikel erscheint. Andere Definitionen fassen den Begriff der Ästhetik viel allgemeiner, indem sie an der Wortbedeutung des altgriechischen aisthesis ansetzen, das am besten mit sinnlicher Wahrnehmung zu übersetzen ist (vgl. Ehrenspeck 1996: 249f.). Im Zentrum dieses offeneren Ästhetikbegriffs steht die Beschäftigung mit „Wahrnehmungen aller Art, sinnenhaften ebenso wie geistigen, alltäglichen wie sublimen, lebensweltlichen wie künstlerischen“ (Welsch 1993, 9f.). Um die Diskussion kurz zusammenzufassen: Es wird argumentiert, dass „nichts, was die Kunst betrifft, mehr selbstverständlich ist, weder in ihr noch in ihrem Ver- 
hältnis zum Ganzen, nicht einmal ihr Existenzrecht“ (Adorno 1973: 3). Formulierte Friedrich Schiller im ausgehenden 18. Jahrhundert noch in seinem Werk Über die ästhetische Erziehung des Menschen, dass „die Vortrefflichkeit eines Kunstwerks [...] in seiner größern Annäherung zu jenem Ideale ästhetischer Reinigkeit bestehe[n]“ (Schiller 1995: 89), so wurden die Vorstellungen von der Kunst als dem Idealen und Schönen auf dem Weg in die Moderne immer weiter zurückgedrängt. Die einstmals vermeintlich klaren Grenzen zwischen künstlerischen und profanen Artefakten lassen sich heute nicht mehr aufrechterhalten. Kunstobjekte und Alltagsdinge sind einander näher gerückt, spätestens seit zu Beginn des 20. Jahrhunderts viele Kunstschaffende selbst den bisherigen Kunstbegriff in Frage stellten und unscheinbare Alltagsdinge in ihren Kunstwerken - etwa in Collagen und Installationen - integriert und verfremdet haben. Die mit der beginnenden Massenproduktion entstandene Debatte über die künstlerische und geschmackvolle Gestaltung von Gebrauchsgegenständen ist ein weiterer Beleg für die Überschneidung der Sphären Kunst und Alltag, sie spiegelt sich wieder in den Begriffen Kunstgewerbe und Kunsthandwerk (vgl. Pazaurek 2012: 2). Heute gilt: Erst die (künstlerische) Intention, die Verwendung und der Kontext sowie letzten Endes die Rezeption durch die Betrachtenden machen einen Gegenstand zum Kunstgegenstand.

Seither hat von der Ästhetischen Theorie aus auch die Theorie ästhetischer Bildung eine erhebliche Erweiterung erfahren. So formuliert Aissen-Crewett sie als „Ausbildung sinnlicher Wahrnehmungsmöglichkeiten, der Wahrnehmungskritik und des Wahrnehmungsgenusses“ (Aisen-Crewett 2000: 80). Es geht also um mehr als eine Wahrnehmungsschulung, die lediglich ein oberflächliches Erkennen und Beschreiben von Sinneswahrnehmungen beinhaltet. Kaspar H. Spinner verdeutlicht seine Unterteilung in eine zweckorientiert-pragmatische und eine ästhetische Wahrnehmung durch ein Beispiel:

Wenn ich am Morgen, nachdem es in der Nacht geschneit hat, einen Blick aus dem Fenster werfe und denke: ,Jetzt muss ich Schnee schippen und schauen, dass ich dann bei den zu erwartenden Straßenverhältnissen rechtzeitig mit dem Auto loskomme', dann nehme ich den Schnee im Horizont meiner zweckorientierten Alltagsbewältigung wahr. Wenn ich aber die Verwandlung des Gartens in eine weiße Welt einen Augenblick lang staunend betrachte, dann erlebe ich die Situation ästhetisch (Spinner 2008: 9).

In diesem Beispiel wird deutlich, dass eine ästhetische Erfahrung nicht nur durch ein Kunstwerk ausgelöst werden kann. Jede Erscheinung, die das oben beschriebene Staunen zu erwecken vermag, ist in der Lage, zum Gegenstand einer ästhetischen Erfahrung zu werden (vgl. Gärtner 2011: 41). Das Staunen kann beschrieben werden als ein Gefühl der Überraschung, Verwunderung und Faszination, das die Voraussetzung für die Öffnung zu neuen Erkenntnissen darstellt und das Anlass dazu bietet, in Reflexion über das Wahrgenommene zu kommen. Anders gesagt, es geht darum, dass ein Phänomen oder Objekt beziehungsweise die Art der Annähe- 
rung an dieses ,die durch Gewohnheit abgestumpfte Wahrnehmung erneuern kann“ (Jauß: 1972: 14).

Die Konzepte des Ästhetischen Lernens weisen eine große Nähe auf zu all jenen pädagogischen Richtungen, die das Erfahrungslernen und die Verbindung von Kognition und Emotion in den Mittelpunkt stellen und die auch in der Spracherwerbsforschung und der Fremdsprachendidaktik eine Rolle spielen (vgl. Wolff 2004: 88f.). Lerntheoretische Ansätze, wie beispielsweise das Task-Based-Learning, die ganzheitliche Lernprozesse postulieren, betonen die Notwendigkeit, abstrahierende mit erfahrungsorientierten Elementen zu verbinden (vgl. Müller-Hartmann; Schocker-v. Ditfurth 2005: 22ff.), und mit Erfahrung ist die Sinneserfahrung gemeint, denn über nichts anderes können wir die Welt erfahren als über unsere Sinne. Diese inzwischen nicht mehr nur als Ausgleich, sondern durch die Forschung sogar als notwendige Voraussetzung für Lernprozesse erkannte Dimension spielt eine zentrale Rolle im pädagogischen Diskurs, wenn auch leider nicht immer in der pädagogischen Praxis. Während in der Kleinkind- und Primarstufenpädagogik die Prinzipien des erfahrungsorientierten Lernens sich schon weitgehend durchgesetzt haben dürften (vgl. Zimmer 2004: 17), gerät deren Berücksichtigung mit dem zunehmenden Alter der Lernenden leider immer weiter aus dem Blickfeld. Man scheint von der völlig unbegründeten Annahme auszugehen, dass es ausreicht, wenn man im Kindesalter die vielfältige Sinneswahrnehmung fördert und trainiert, während später häufig nur noch auf vorwiegend textorientierte Lehrmethoden abgehoben wird.

Neben dieser generellen Begründung für ästhetisches Lernen als zentraler Bestandteil des ganzheitlichen Lernens gibt es einen weiteren Punkt, der dafür spricht, das ästhetische Lernen, und dabei besonders das Sehen, insbesondere für Lehrende und für Lernende von Fremdsprachen, systematisch einzubeziehen. In der Methodik des Fremdsprachenunterrichts wird traditionell verständlicherweise meist derjenige Sinn geschult, der auf eine erfolgreiche Sprachverarbeitung ausgerichtet ist: das Hören. Das Sehen spielt nur insofern eine Rolle, als es die notwendige Voraussetzung für die Kulturtechnik des Lesens und Schreibens bildet. Allerdings ist die gezielte Schulung des Sehens ebenfalls wichtig, weil darin die Grundlage für alle weiteren Prozesse des kulturbezogenen Lernens und Verstehens liegt. Denn der Sinn, der bei einem Aufenthalt in einem fremden Land zunächst im Vordergrund steht, ist verständlicherweise das Sehen als eine Art dominierender und primärer Sinn. Im Folgenden soll exemplarisch für eine bestimmte Zielgruppe aufgezeigt werden, wie das ästhetische Lernen anhand von Bildern und Objekten dazu beitragen kann, das Kulturelle Sehen, die Visual Literacy, zu schärfen. 


\section{Visual Literacy: Lernen mit Bildern als ästhetisches Lernen}

Die komplexe Frage Was ist ein Bild?, die von Kunsthistorikern, Medienwissenschaftlern und anderen Disziplinen jeweils unterschiedlich beantwortet wird, kann an dieser Stelle nur äußerst verkürzt angesprochen werden. ${ }^{1}$ Es scheint unmöglich, die Bedeutung des Begriffs zu erfassen, ohne dabei bereits auf bildliche Vokabeln zurückzugreifen. Hinzu kommt, dass wir in der deutschen Sprache keine Unterscheidungsmöglichkeit haben, wie sie beispielsweise im Englischen existiert, zwischen picture als dem einzelnen bildlichen Artefakt und image als der (kollektiven) bildlichen Vorstellung von etwas. Der materielle und der spirituelle Aspekt, so Gottfried Boehm, fallen im deutschen Wort Bild zusammen (vgl. Elkins; Naef 2011: 27). Bilder jeglicher Art stehen somit in einem Spannungsverhältnis zwischen ihrer Existenz als Abbild, als Repräsentation von etwas in der Welt und ihrer Fähigkeit zur Imagination, zum Hinausweisen über das in der Außenwelt Sichtbare.

Unter dem Stichwort Visual Literay - der Fähigkeit, Bilder zu lesen und zu verstehen - wird in jüngerer Zeit eine neue Kompetenzebene in den fremdsprachendidaktischen Fachdiskurs eingeführt. Dahinter steht die Erkenntnis, dass Bilder weder von selbst noch auf die gleiche Art und Weise zu den Rezipienten sprechen; ihre Wahrnehmung

hat gesellschaftliche wie individuelle Hintergründe, hängt von intellektuellen und psychologischen Faktoren, von langfristigen Sprachtraditionen und langlebigen Konnotationen ab (Bruhn 2009: 12).

Im Mittelpunkt steht nun die Beschäftigung mit den Bildern um ihrer selbst willen, weil zur Kenntnis genommen wurde, dass sie eine ganz eigene kommunikative Qualität in sich tragen, auch wenn sie nach wie vor in einem engen Bezug zu Sprache und Text stehen. Zum Verstehen von Kultur gehört die Beschäftigung mit „durch Symbole vermittelten Werte- und Normhorizonte[n] einer Gemeinschaft“ (Bisanz 2011: 185) und die Bilder zählen zu den „Medien der Erzeugung von kultureller Kommunikation, von Gedächtnis und Weltwahrnehmung“ (ebd.). Im Gegensatz zur Kunstpädagogik besteht das Hauptinteresse also nicht am einzelnen Bild (picture) als Kunstwerk, sondern an den images als kulturelle Vorstellungen, die in einem Bild dargestellt und erweckt werden. Begründet wird die Forderung nach der Berücksichtigung dieses Kulturellen Sehens mit der Diskursfähigkeit der Lernenden ,als Bildungsziel und als Leitziel des Fremdsprachenunterrichts“ (Hallet 2013: 220). Gesellschaftliche und kulturelle Diskurse, so Hallet, verlaufen stets unter Einbezug multimedialer und multimodaler Formen; sie nutzen nicht nur gesprochene und geschriebene Sprache sondern ebenso Videos, Postkarten, bebilderte Webseiten und Hörtexte, um nur einige Beispiele zu nennen. Die für Fremdsprachenlernende wichtige Diskursfähigkeit erstrecke sich damit auf die Partizipation

${ }^{1}$ Für weitere Ausführungen siehe Bruhn 2009, Elkins; Naef 2011, Boehm 1994. 
an diesen vielfältigen und somit auch visuellen, Kommunikationsformen, wie sie in verschiedenen Kulturen, Gesellschaften und Subkulturen genutzt werden (ebd.). Es geht also bei der Visual Literacy nicht mehr allein um die Frage, was Bilder jeweils leisten können, um unmittelbar verbales Verstehen und die Sprachproduktion der Lernenden zu unterstützen, indem sie beispielsweise genutzt werden, um Vokabeln, Dialoge oder grammatische Strukturen zu veranschaulichen. ${ }^{2}$ Bilder sind für die Fremdsprachendidaktik jetzt auch von Interesse aufgrund ihrer Zeichenhaftigkeit und ihres kulturellen Gehalts, aufgrund ihrer Fähigkeit, Kultur zu speichern und zu veranschaulichen.

Aus der Definition der Visual Literacy ergibt sich, dass zunächst einmal alle Arten von Bildern für die Bilddidaktik im Fremdsprachenunterricht in Frage kommen. $\mathrm{Ob}$ es sich bei einem Bild um eine Werbeanzeige, ein Urlaubsfoto oder ein Ölgemälde handelt, ist für seine Eignung als kulturelles Erkenntnismaterial zunächst nicht entscheidend. Es leuchtet allerdings ein, dass Bilder gegenständlichen Inhalts zunächst besser dafür geeignet scheinen, das Kulturelle Sehen zu fördern, denn den Lernenden soll ermöglicht werden, Dinge auf den Bildern zu entdecken, die sie in Bezug zu materiellen wie immateriellen Phänomenen der Außenwelt setzen können. Ästhetische Lernprozesse können angestoßen werden, indem ein Bild als Auslöser jenes Staunens fungiert, von dem aus eine neue Perspektive auf die Dinge möglich ist und das den Impuls dafür gibt, sich über die Neuentdeckungen auszutauschen.

\section{Visual Literacy und die Sprache der Dinge}

Bei näherer Betrachtung wird außerdem deutlich: Was für Bilder als Veranschaulichungsmittel von Kultur gilt, gilt zu großen Teilen ebenso für andere materielle Objekte und Gegenstände. Nicht nur Bilder fordern die Fähigkeit der Visual Literacy ein, sondern die gesamte materielle Umwelt spricht eine spezifische Sprache, die nach einer entsprechenden Lesekompetenz verlangt. Selbst gewöhnliche Alltagsobjekte bergen das Potential, durch einen genauen Blick auf sie zum Staunen und zum ästhetischen Lernen zu gelangen. Nach der Sprache der Dinge zu fragen, bedeutet, Dinge nicht lediglich hinsichtlich ihrer äußeren Erscheinung und ihrer Funktion zu betrachten, sondern weitere Betrachtungsebenen mit einzubeziehen. Hermann Bausinger macht anhand der Unterscheidung von drei Begriffen diese Ebenen deutlich (vgl. Bausinger 2004: 203). Er geht zunächst aus von der Materialität der Objekte, ihrer äußeren Form und stofflichen Beschaffenheit. Für das Verstehen von Kultur darf man an diesem Punkt jedoch nicht stehenbleiben, sondern muss zur Potentialität der Objekte übergehen. Diesen Begriff könnte man umschreiben als die Summe der Möglichkeiten an Funktionen und Bedeutungen, die einem Objekt im Laufe der Zeit zugewiesen wurden. Wichtig daran ist zum einen

2 Zur Nutzung von Bildern als Veranschaulichungshilfe im Fremdsprachenunterricht siehe Scherling; Schuckall 1992, Reinfried 1992, Macaire; Hosch 1996. 
die Erkenntnis, dass alle von Menschen geschaffenen Gegenstände nicht nur eine unmittelbar praktische Funktion haben, sondern auch die Fähigkeit besitzen, als Symbole zu fungieren. Bei vielen Dingen des Alltags überwiegt sogar der symbolische Gehalt bei weitem ihren praktischen Nutzen - man denke beispielsweise an Reisesouvenirs oder Eheringe. Wichtig zum anderen ist die Einsicht, dass Dinge nicht von sich aus eine Bedeutung in sich tragen, sondern dass ihnen die Bedeutungen von den Menschen zugewiesen wurden (vgl. Heidrich 2000: 14) und diese demnach dynamisch sind und kollektiven wie historischen Wandlungen unterliegen. Insofern kann man die Potentialität der Dinge auch als den kulturellen Kontext bezeichnen, in dessen Rahmen die jeweilige Aktualisierung, so die dritte Ebene Bausingers, stattfindet. Damit ist die konkrete situative Einbettung gemeint, in der ein Gegenstand seine je aktuelle Funktion und symbolische Aufladung erfährt. Was ein Ding bedeutet und wozu es genutzt wird, hängt also nicht allein von dessen historisch-kulturellem Hintergrund ab, sondern ist auch abhängig davon, unter welchen Umständen und von wem das Ding betrachtet und genutzt wird - zur kollektiven Zuschreibung tritt eine individuelle hinzu. Ein Beispiel zur Veranschaulichung: Im Thronsaal des Westflügels im Residenzschloss Ludwigsburg befindet sich das 1807 von König Friedrich I. von Württemberg aufgestellte Thronensemble. Die Materialität ist die stoffliche Beschaffenheit des Throns, sie repräsentiert - von eventuellen Umgestaltungen, Restaurierungen und Verfallserscheinungen abgesehen - den festen und unveränderlichen Bestandteil eines Objekts. In der Potentialität des Throns vereinigen sich unterschiedliche Aspekte: dessen Machtsymbolik, die historischen Regeln, wer sich wann und wie dem Thron nähern durfte, wie und zu welchen Gelegenheiten der Herrscher auf dem Thron saß, was mit dem Thron nach der Auflösung der Monarchie passierte, in welchen Kontexten Throne als Herrschaftssymbole jeweils vor und nach der Zeit Friedrich I. in Erscheinung traten, etwa in Form von Geschichten, Gesetzen, Redewendungen usw. In der Aktualisierung wird schließlich die Nutzung bzw. Bedeutungszuweisung des Throns durch eine einzelne Person wirksam, zum Beispiel durch einen Museumsbesucher, der mit seiner Reisegruppe eher widerwillig und uninteressiert den Raum betritt. Theoretisch ist denkbar, dass er, sofern das Aufsichtspersonal nicht in der Nähe ist, den Thron für eine dringend benötigte Ruhepause nutzt, um dort einen kleinen Snack einzunehmen. Die historische Potentialität des Throns als ein exklusiv für den Souverän bestimmtes Möbel wäre in diesem Moment für den Besucher genauso wenig relevant wie die aktuellere als ein kostbares, und insofern nur aus einem Mindestabstand heraus zu bewunderndes Zeitzeugnis und Museumsobjekt. Die drei Ebenen Materialität, Potentialität und Aktualisierung können zur Schulung der Visual Literacy im Fremdsprachenunterricht genutzt werden. Sich mit der unterschiedlichen äußeren Gestaltung von Dingen auseinanderzusetzen, scheint im Zeitalter von weltweit konsumierten gleichen Massenprodukten nur wenig Ansatzpunkte für den Unterricht zu bieten, doch bei genauerem Hinsehen kann man bereits hier einige interessante Beispiele für kulturspezifisch unterschiedliches Produktdesign finden. Spannender wird es, wenn man sich auf die Frage nach der 
unterschiedlichen Nutzung und Bedeutung der Dinge konzentriert und Lernende dazu auffordert, sich über ihre ganz persönliche Sicht auf und Erfahrung mit den Dingen zu äußern. Im Idealfall wird man im Unterricht versuchen, die Beschäftigung mit den Dingen und die Beschäftigung mit den Bildern zu verbinden, um beispielsweise auf historischen Gemälden oder Fotografien Dinge entdecken zu lassen und dann die Lernenden auf eine Suche nach der Nutzung und Bedeutung dieser Dinge in der heutigen Zeit zu schicken. Praktisch ist diese Kombination jedoch häufig nicht umsetzbar, weil es vor Ort weder die Möglichkeit gibt, die Objekte mit in den Klassenraum zu bringen, noch eine Exkursion zur Erkundung der Dinge außerhalb von Schule, Sprachinstitut oder Universität zu organisieren. In diesem Fall helfen die Bilder als Medium der Dinge weiter.

Abgesehen von ihrer Zeichenhaftigkeit und von ihrem Potential für die Schulung des ästhetischen Lernens und der Visual Literacy weisen Bilder und Objekte weitere Merkmale auf, die sie im Vergleich zu geschriebenen Texten besonders geeignet machen für einen lernerzentrierten und kommunikationsfördernden Unterricht. Für Fremdsprachenlernende ist der erste Zugang zu ihnen erleichtert, weil sie für ihre Rezeption zunächst noch keine fremdsprachliche Kompetenz einfordern. Erst in der zweiten Phase, der gemeinsamen Bedeutungserschließung, werden die Wörter gebraucht. Bilder appellieren durch ihre Komposition, die Wechselwirkung aus Farben und Formen, außerdem an die Emotionen, welche nach einer gängigen These der Emotionspsychologie die „motivationale[n] Orientierungen und Absichten [beeinflussen]“" (Hascher 2005: 610). Bilder und Objekte sind darüber hinaus „,unscharfe“ Zeichen“ (Hahn 2005: 122). Sie laden zu einer Vielzahl von Deutungen ein; dabei gibt es keine absolut richtigen oder falschen Vermutungen, sondern nur leichter oder schwieriger nachvollziehbare Interpretationen. Wenn den Lernenden dies bewusst gemacht wird, werden sie zu einer aktiveren Teilnahme am Unterricht ermutigt, weil sie keine Angst haben müssen, Fehler zu machen. Im Sinne der Kreativitätsförderung kann diese Herangehensweise somit dazu beitragen, „Hemmungen und Blockaden [...] abzubauen“ (Weiß 2008: 127). In ihrer Struktur sind Bilder und Objekte nicht-linear:

Ein Text ist diskursiv, da Sinneinheiten immer in zeitlicher Abfolge rezipiert werden müssen. Präsentativ sind dagegen Träger von Bedeutungen, deren Elemente nicht an eine bestimmte Reihenfolge gebunden sind (Hahn 2005: 123).

Bilder sind zwar in der Lage, den Blick der Betrachtenden ein Stück weit durch ihre Gestaltung zu lenken, aber es gibt keine feste Reihenfolge, in der sie gelesen werden. Das Gleiche gilt für alle materiellen Dinge. Diese Möglichkeit zur individuellen Lesart des Gesehenen unterstützt die Lernenden im Sinne der konstruktivistischen Lerntheorie dabei, die neu präsentierten Inhalte auf ihre jeweils eigene Weise zu strukturieren und zu organisieren (vgl. Wolff 2004: 93). 


\section{$4 \quad$ Visual Literacy in der Ausbildung von DaF-Lehrenden}

Damit die Förderung der Visual Literay im Fremdsprachenunterricht umgesetzt werden kann, ist die erste Voraussetzung, dass die Fremdsprachenlehrenden für dieses Lernziel sensibilisiert werden und ihre eigene Kompetenz auf diesem Gebiet geschult haben. Die Schulung der Visual Literacy ist an verschiedenen Stellen Bestandteil des Masterstudiengangs Deutsch als Fremd- und Zweitsprache der Universität Jena, denn sie stärkt Prozesse der Bewusstmachung, Wahrnehmung und Aufmerksamkeit, die den ersten wichtigen Schritt für das Verstehen oft komplexer kultureller Phänomene darstellen. Zum einen wird im Rahmen der mediendidaktischen Lehrveranstaltungen die Theorie und Praxis des Medieneinsatzes im Fremdsprachenunterricht vermittelt, und dabei spielen selbstverständlich auch die Bilder und visuellen Medien eine große Rolle. An dieser Stelle soll jedoch aufgezeigt werden, wie zum anderen speziell die landeskundlich-kulturwissenschaftlichen Seminare genutzt werden, damit die Lernenden beim Ausbau ihrer Visual Literacy Unterstützung finden.

Zunächst noch einige wichtige Hintergrundinformationen: Der seit seiner Gründung im Jahr 2002 sehr erfolgreiche Masterstudiengang Deutsch als Fremdund Zweitsprache an der Universität Jena ist ein Studiengang, der einen großen Schwerpunkt auf die Berufsorientierung legt, d.h. neben der Vorbereitung auf eine akademische Weiterqualifikation ist er speziell auf die Anforderungen an zukünftige Sprach- und Kulturmittler ausgerichtet. Innerhalb von vier Semestern Regelstudienzeit führt er zum Abschluss und berücksichtigt in seinem Curriculum in besonderer Weise auch die Bedürfnisse ausländischer Studierender (vgl. Barkowski; Funk; Kuhn 2006: 50f.). Im Jahr 2008 wurden im Rahmen der zentralen Universitätsreform die Modulstruktur sowie die Studien- und Prüfungsordnung überarbeitet. ${ }^{3}$ Die Nachfrage nach dem Studiengang ist anhaltend hoch, derzeit sind mehr als 240 Studierende eingeschrieben; er ist damit der größte DaF/DaZ-Masterstudiengang in Deutschland (Stand: September 2013). Zwischen 60 und 70 Prozent der Studierenden kommen aus dem Ausland, in einzelnen Lehrveranstaltungen liegt ihr Anteil noch deutlich darüber. Ein großer Teil der ausländischen Studierenden wiederum kommt aus nichteuropäischen Ländern. Auch wenn ein großer geographischer Abstand zum Zielsprachenland selbstverständlich nicht automatisch mit einer entsprechend großen kulturellen Distanz gleichzusetzen ist, wird man tendenziell doch davon ausgehen können, dass einige Studierende aus den weiter von Deutschland entfernten Ländern noch über vergleichsweise wenige Vorkenntnisse in Bezug auf die deutschsprachigen Länder verfügen. Sie bringen häufig nicht viele Anknüpfungspunkte für die Deutung hiesiger kultureller Phänomene und Eigenheiten mit. Zwar haben die Studierenden formal alle die gleiche Basisqualifikation - einen Bachelor-Abschluss in einem germanistischen Fach - die

\footnotetext{
${ }^{3}$ Eine gute Übersicht zum aktuellen Studienplan und zu den einzelnen Modulen wurde von Christina Kuhn erstellt. Vgl. Kuhn (o.J.). Online: http://www.uni-jena.de/unijenamedia/Downloads/faculties/ phil/inst_auslgerm/Aktuelles/MA_DaF_WiSe2012_13.pdf (Stand: 17.05.2014).
} 
vor Ort vermittelten Inhalte unterscheiden sich allerdings teils erheblich voneinander. Während an einigen ausländischen Universitäten der Schwerpunkt auf der Sprachpraxis liegt, liegt er an anderen Universitäten auf dem Übersetzen, und nach wie vor gibt es etliche Fakultäten, die ein traditionelles Curriculum mit Konzentration auf Literatur und Linguistik anbieten. Einige Studierende verfügen bereits über eigene Lehrerfahrungen, viele jedoch nicht. Nicht nur im Bereich der Sprachlehrmethodik und -didaktik im engeren Sinne bringen sie sehr unterschiedliche Vorkenntnisse mit, sondern auch auf dem Gebiet des landeskundlichen Wissens und der kulturdidaktischen Kompetenzen. Man kann sich leicht vorstellen, dass diese Heterogenität in den Seminargruppen einige Herausforderungen mit sich bringt. Besonders auf dem unüberschaubar großen Gebiet von Kultur und Landeskunde ist es weder möglich noch sinnvoll, ein kanonisiertes Wissen zu vermitteln.

Man ist sich im Fach einig, dass aufgrund der unüberschaubaren Themenvielfalt, der unterschiedlichen Lernkonzepte und Lerntraditionen, der stark voneinander abweichenden Zielgruppen mit verschiedenen Schwerpunktzielsetzungen sowie der sehr heterogenen didaktischen Rahmenbedingungen kein allgemeingültiger Themenkatalog erstellt werden kann (Koreik 2011: 593).

Da im Masterstudiengang alle für das Fach DaF/DaZ relevanten Kompetenzfelder angeboten werden, stehen innerhalb von 4 Semestern für die einzelnen Spezialgebiete, und damit auch für Kultur und Landeskunde, nur eine begrenzte Anzahl von Wochenstunden im Lehrprogramm zur Verfügung. Es ist nicht realistisch zu erwarten, dass die Studierenden ohne Impuls oder Hilfestellung von außen ihren Deutschlandaufenthalt dafür nutzen werden, ihre Kulturkenntnisse in ihrer Freizeit systematisch und gezielt zu erweitern. Somit steht zu befürchten, dass viele Studierende nach 2 Jahren in ihre Heimatländer zurückkehren, und zwar fachlich sehr gut ausgebildet sind, aber über Land und Leute nur wenig wissen, jenseits ihrer alltäglichen Erfahrungsebene zwischen Wohnheim, Supermarkt, Mensa und Seminarraum. Soweit spricht alles dafür, sich von einer Konzentration auf die vermeintlich wichtigsten landeskundlichen Inhalte zu lösen, und stattdessen darauf zu setzen, den Studierenden Strategien zu vermitteln, die sie beim eigenständigen Entdecken und Lesen ihrer Umwelt unterstützen. Im Kern geht es darum, das Kulturelle Sehen zu üben, Fragen an ein Thema zu entwickeln und damit auch eine methodische Basis für eigene Lehr- und Vermittlertätigkeiten aufzubauen. Die landeskundlich-kulturwissenschaftlichen Seminare dienen einerseits dazu, an exemplarischen Kulturthemen den Blick zu schärfen und handfeste Anknüpfungspunkte für eigene Weiterrecherchen außerhalb des Seminarraums zu bieten. Zum anderen werden innerhalb der Veranstaltungen sowohl explizit als auch implizit landeskunde- und kulturdidaktische Methoden und Aufgabenformen vorgestellt und erprobt. Dabei spielen Bilder und Objekte eine wichtige Rolle. 


\section{Methodisches: Inquiry Teaching und Visual Literacy}

Wie bereits erwähnt, zielt die Förderung der Visual Literacy auf Prozesse der Bewusstmachung, Wahrnehmungs- und Aufmerksamkeitsschulung; sie soll Lernende neugierig machen und sie dazu bringen, neue Perspektiven auf ihre Umwelt zu entwickeln. Nun stellt sich die Frage, wie die Lernenden dabei methodisch unterstützt werden können. Selbstverständlich spielt die Auswahl des zu erkundenden Objekts oder Bildes eine Rolle, denn in Abhängigkeit vom Vorwissen und von den Interessen der Lernenden sind manche Dinge allein durch ihre Betrachtung offenbar in der Lage, Diskussionen und Erkenntnisprozesse in Gang zu bringen. Generell gilt jedoch: ob ein Objekt im Jaußschen Sinne (vgl. Abschnitt 1) „die durch Gewohnheit abgestumpfte Wahrnehmung erneuern kann“ (Jauß 1972: 14), liegt nicht im Objekt selbst, sondern hängt von der Perspektive ab, mit der man sich einem Ding zuwendet. Es reicht nicht aus, allein auf die Aktivierungskraft durch die Gegenstände zu vertrauen und als Lehrkraft abzuwarten, ob und wie die Lernenden reagieren.

Der Ansatz des Inquiry Teaching erweist sich als besonders geeignet zur Förderung der Visual Literacy. Um Missverständnisse zu vermeiden, ist es notwendig, den Begriff kurz zu erklären. Im deutschsprachigen pädagogischen Diskurs existiert der Terminus fragend-entwickelnder Unterricht. Dieser Ansatz wird seit langen Jahren heftig kritisiert und oft abfällig als Osterhasenpädagogik bezeichnet, „,weil die Lehrperson ihr wertvolles Wissen versteckt und die Schülerinnen und Schüler es suchen müssen, was an österliche Bräuche erinnert" (Wahl 2006: 1). Die Lehrperson stellt den Lernenden zahlreiche Fragen zu einem Thema oder Lerngegenstand, um sie Schritt für Schritt auf bestimmte, vorher festgelegte Ergebnisse, also richtige Antworten hinzulenken (vgl. ebd.). Dadurch erinnert der Unterrichtsablauf an eine Quizshow, bei der die jeweils besten Lernenden gewinnen, also diejenigen, die bereits die meisten Vorkenntnisse zu einem Thema mitbringen, am schnellsten sind, oder die Absicht der Lehrperson am besten erraten.

Das Inquiry Teaching arbeitet zwar auch mit Fragen durch die Lehrperson, Vorgehen und Zielrichtung unterscheiden sich jedoch erheblich vom fragendentwickelnden Unterricht. Bereits der Begriff Inquiry verdeutlicht, dass die eingehende Untersuchung eines Gegenstandes das eigentliche Ziel der Fragen darstellt und nicht das Sammeln von richtigen Antworten. Offene Fragen, die an den Entdeckergeist und die persönliche Perspektive der Lernenden auf das Gesehene appellieren, sind der Schlüssel zum Inquiry Teaching. Die Kunst, Osterhasenfragen in Inquiry-Fragen zu verwandeln, besteht oft nur in einer feinen, jedoch wesentliche Unterschiede bewirkenden, Umformulierung. Schmidt (2004) gibt in ihrem Artikel Beispiele für diese Umformulierungen. Aus „what shape is this leaf?“ wird „what do you notice about this leaf?“, aus „what color is this?“ wird „,how would you describe this color?" und aus „who invented the first writing system?" wird „why do you think people invented writing?" (Schmidt 2004: 94). Wörter wie vermuten, glauben, könnte, würde und warum sind Indikatorenwörter für Inquiry-Fragen (vgl. 
ebd.). Solche Fragen lassen eine Vielzahl von Antworten zu, die zunächst unbewertet nebeneinander gestellt und gegebenenfalls in einem gemeinsamen Gespräch und durch weitere Fragen auf ihre Plausibilität überprüft werden. Außerdem sollte die Lehrperson den Lernenden großzügig Zeit geben, um Antworten zu finden und sich auch nicht mit sehr kurzen oder zu wenigen Antworten zufrieden geben. Wenn eine Schülerantwort zu wenig neuen Reflexionsstoff bzw. Anknüpfungspunkte bietet, ist es hilfreich, genauer nachzufragen: was fällt dir noch daఇu ein?, was genau meinst du mit...?, wie begründest du deine Antwort?. Dabei ist jedoch nicht ausgeschlossen, dass die eine oder andere Inhaltsfrage einbezogen wird, um das thematische Vorwissen der Lernenden mit einzubeziehen und auch um sicherzustellen, dass alle Lernenden notwendige Informationen für nachfolgende Untersuchungsschritte bekommen. Gelegentlich wird das Inquiry Teaching and Learning auch als Problem Based Learning bezeichnet (darin drückt sich die Nähe zu den Konzepten des Aufgaben- und Handlungsorienterten Lernens aus (vgl. Abschnitt 1). Die Rolle der Lehrperson ist in diesem Ansatz entscheidend. Dazu Hmelo-Silver:

In PBL [Problem Based Learning, EVC] the teacher/facilitator is an expert learner, able to model good strategies for learning and thinking, rather than an expert in the content itself. The facilitator scaffolds student learning through modeling and coaching, primarily through the use of questioning strategies (Hmelo-Silver 2004: 245).

In der Kunst- und Museumspädagogik in den USA wird das Inquiry Teaching bereits seit vielen Jahren angewendet. Als wegweisend ist hier insbesondere das Museum of Modern Art (MoMA) in New York zu nennen, das unter der Leitung von Lisa Mazzola auch den vierwöchigen internationalen E-Learning-Weiterbildungskurs Art and Inquiry: Museum Teacbing Strategies for your Classroom für Lehrende aller Fachrichtungen und Bildungsinstitutionen entwickelt hat. ${ }^{4}$ Im Kurs wurden pädagogische Materialien des MoMA zur Verfügung gestellt. Hier folgen ein paar ins Deutsche übersetzte Beispiele für Aufgaben und Leitfragen zu den ausgestellten Museumsobjekten, die das genaue Beobachten und die Reflexion fördern sollen: 1. Beschreibe das Bild/Objekt in deinen eigenen Worten. 2. Was weißt du schon über dieses Bild/Objekt? Was ist dir vertraut daran und kommt dir bekannt vor? Was an diesem Bild gibt dir Rätsel auf? 3. Notiere dir spontan ein paar Wörter, die dir einfallen, wenn du das Bild/Objekt anschaust. Warum sind dir diese Wörter eingefallen? 4. Welche Verknüpfungen von dem Bild zu etwas in deinem eigenen Leben/aus deinen eigenen Erfahrungen kannst du herstellen? 5. Wenn du dem Bild/dem Objekt eine Frage stellen könntest, was würdest du fragen? Überlege dir, was das Bild/Objekt darauf antworten könnte. 6. Beschreibe in einem Satz das Interessanteste für dich an diesem Bild/Objekt.

4 Der kostenlose Online-Kurs wurde über die Plattform www.coursera.org angeboten, fand vom 29.07. bis 31.08.2013 statt und wird meines Wissens regelmäßig wiederholt. Die Kursstruktur und die Kursmaterialien sind momentan nur für registrierte Teilnehmer einzusehen. 
Es fällt auf, dass nicht ausschließlich Fragen verwendet werden, um den Lernprozess in Gang zu bringen, sondern auch Aufgabenstellungen im Sinne der Handlungsorientierung einbezogen werden. Aus diesen Beispielen wird außerdem deutlich, dass für die Verwendung im Fremdsprachenunterricht eine entsprechende sprachliche Vorentlastung stattfinden muss, damit die Lernenden den Wortschatz und die Redemittel zur Verfügung haben, um ihre Antworten zu formulieren. Im folgenden Abschnitt werde ich zur weiteren Veranschaulichung drei Beispiele zum Inquiry Teaching und Visual Learning aus einem meiner Masterseminare geben. Durch entsprechende Bearbeitung können sie auch für die Aus- und Weiterbildung von Deutschlehrenden und -lernenden in anderen Ländern genutzt werden, also fern der sogenannten Zielsprachenkultur.

\section{Die Sprache der Dinge - drei Beispiele aus Seminar und Weiterbildung}

Das Masterseminar Die Sprache der Dinge - Symbole und Zeichen wird im Rahmen der Pflichtmodule im Wechsel mit anderen Lehrveranstaltungen, aber in der Regel mindestens einmal jährlich, angeboten. Wie der Titel bereits verrät, ist das Visual Learning ein wichtiges Lehrziel, allerdings nicht das einzige. Insgesamt bietet es eine Mischung aus Lektüre und Diskussion kulturwissenschaftlicher Texte, praktischen Übungen, thematischen kulturkundlichen Präsentationen (Beispielsweise zu den Themen Stüble und Sitzen, Statussymbole und Geschmack, Uhren und Zeit) sowie methodisch-didaktischen Praxiseinheiten, in denen Unterrichtsideen gemeinsam ausprobiert und weiterentwickelt werden.

Das Seminar beginnt in der ersten Sitzung mit einer Wahrnehmungsübung. Das Ziel ist, die Lernenden für die Zeichenhaftigkeit der materiellen Umwelt zu sensibilisieren, damit sie das Potential von Alltagsgegenständen für die Sprach- und Kulturvermittlung entdecken. Sie sollen die Erfahrung machen, dass es möglich ist, auch über zunächst unscheinbare Gegenstände wie einen Schlüssel, eine Räucherkerze oder ein Operationstuch ins Staunen zu kommen und von dort aus Fragen über kulturspezifische ebenso wie kulturübergreifende Nutzungen und Bedeutungen der Dinge zu ergründen. Die Lernenden bekommen alleine oder zu zweit einen Alltagsgegenstand in die Hand mit der Aufgabe, sich während dieser Phase keinesfalls über den Gegenstand zu unterhalten, sondern still zu überlegen, um was für ein Ding es sich handeln könnte. Wenn sie nicht wissen, was sie da jeweils vor sich liegen haben, sind sie ausdrücklich aufgefordert - ebenfalls im Stillen - sich trotzdem eine plausible Antwort auszudenken. Nach einigen Minuten findet eine gemeinsame Auswertung statt und Studierende präsentieren ihre Objekte und sprechen ihre Vermutungen dazu laut aus. Gemeinsam wird versucht, das Objekträtsel zu lösen. Falls die Gruppe sich am Ende nicht einig ist, projiziert die Lehrperson ein Bild des Objekts in Verwendung an die Wand - über diesen visuellen Input können die Lernenden (in den meisten Fällen) erraten, um was für ein Ding 
es sich handelt. Ansonsten hilft die Lehrperson mit einer abschließenden Erklärung weiter. Am Ende werden die Studierenden aufgefordert, sich ein paar Minuten Zeit zu nehmen und Thesen zur Sprache der Dinge zu formulieren, zum Beispiel, was sie allgemein über den speziellen Charakter der Sprache der Dinge gelernt haben und was alles notwendig ist, um diese Sprache zu deuten und zu verstehen. Die Thesen werden abschließend gesammelt und in den folgenden Seminarsitzungen mit den kulturwissenschaftlichen Thesen aus der Textlektüre verglichen und gegebenenfalls ergänzt. Für diese Übung ist sowohl die Auswahl der Gegenstände sehr wichtig als auch die Entscheidung, welcher Studierende jeweils welchen Gegenstand in die Hand bekommt. Wichtig ist, dass rätselhafte Situationen entstehen und zumindest ein paar Studierende auch ihnen völlig unbekannte Objekte in die Hand bekommen. Zum Beispiel erhält ein Lernender, der aus einem Land stammt, in dem klimatisch keine zentralgeheizten Wohnungen erforderlich sind, einen Heizungslüftungsschlüssel in die Hand. Mitteleuropäische Lernende werden mit einer Art Sortierstab überrascht, den routinierte Mah-Jongg-Spieler in Taiwan nutzen, um auf dem Spieltisch ihre Spielsteine ordentlich in eine Reihe zu schieben. Brasilianische Lernende, die erst vor kurzem in Deutschland angekommen sind, erhalten einen Plastikchip (samt Schlüsselanhänger) für den Einkaufswagen. Der Clou an der Übung ist, dass selbst Lernende aus den entsprechenden Kulturkreisen die Dinge oft nicht erkennen, weil der Kontext der Verwendung fehlt und sie selbst noch keine eigenen Erfahrungen damit gesammelt haben. Das führt natürlich zu entsprechenden Arbeitsthesen in der Abschlussphase der Seminarsitzung.

Eine andere Seminarsitzung widmet sich exemplarisch dem Kulturthema Stüble und Sitzen. Der Ablauf ist in Form eines klassischen Power-Point-Vortrags durch die Lehrperson, der allerdings fast ausschließlich mit Bildern und nur sehr wenig geschriebenem Text gestaltet ist. Außerdem werden zwischen wenigen kurzen informativen Einheiten viele längere interaktive Aufgaben- und Diskussionseinheiten zu den einzelnen Bildern dazwischengeschaltet. Im Folgenden schildere ich nur eine kurze Sequenz aus der Sitzung: Von der Lehrperson wird die Frage aufgeworfen, woher wir wissen können, worauf und wie Menschen zu früheren Zeiten gesessen haben. In Kleingruppen sollen die Studierenden möglichst viele Antworten auf diese Frage sammeln. Im Anschluss werden die Antworten diskutiert und auf ihre Plausibilität überprüft. Als nächstes wird den Lernenden eine Großansicht des Gemäldes Der Alchemist von Pieter Breughel dem Älteren präsentiert. Die Lernenden sollen das Bild anschauen und die verschiedenen Sitzgelegenheiten genau beschreiben. Danach sollen sie vermuten, woran es liegen könnte, dass auf der Abbildung keine der Personen einen Stuhl benutzt. Sie sollen überlegen, wer wann unter welchen Umständen auf welcher Sitzgelegenheit sitzen darf und eigene Beispiele aus ihrer eigenen Erfahrung finden. Im Laufe der Diskussion kommen die Lernenden von sich aus auf die Machtsymbolik des Sitzens, speziell des Sitzens auf einem einzelnen Stuhl, zu sprechen, im Gegensatz zum Sitzen auf Schemeln, Bänken und auf dem Boden. Es wird die Frage aufgeworfen, warum die meisten Menschen bis ins 19. Jahrhundert hinein normalerweise nicht auf einem Stuhl sitzen 
durften und warum im Gegensatz dazu die Studierenden im Seminarraum heute auf Stühlen sitzen. Die Diskussion wird durch die Veranschaulichung mit Gemälden und Fotografien begleitet. Da die Seminarteilnehmer aus verschiedenen Ländern und Kulturkreisen stammen, vergleichen sie die unterschiedlichen Sitzgewohnheiten in ihrer Heimat und erzählen, ob bzw. was ihnen an der aktuellen Sitzkultur in Deutschland aufgefallen ist.

Zum Thema Sprache der Dinge habe ich auch einen 4-stündigen Weiterbildungsworkshop für angehende brasilianische Deutschlehrende (Referendarinnen und Referendare) entwickelt. Die Zielgruppe befindet sich für einen 8-wöchigen Weiterbildungsaufenthalt an der Universität Jena. Nach einer praktischen und theoretischen Einführung in das Thema bekommen die Teilnehmenden die Aufgabe, sich für eine einstündige Fotosafari in die Stadt zu begeben. Sie sollen zu jeder der folgenden Leitfragen jeweils ein oder mehrere Fotos machen: 1. Fotografiere etwas, das dir Rätsel aufgibt; 2. Fotografiere etwas, das du so bislang nur in Deutschland gesehen hast; 3. Fotografiere etwas, was für dich typisch deutsch ist; 4. Fotografiere etwas, von dem man nicht erkennen kann, dass es in Deutschland aufgenommen wurde und das man so oder ähnlich auch in deiner Heimatstadt sehen könnte. Im Anschluss werden die Fotografien reihum vorgestellt, kommentiert und diskutiert. Die Referendarinnen und Referendare können das gesammelte Bildmaterial später für ihren eigenen Deutschunterricht nutzen.

Dies sind nur kurze Beispiele aus einer Fülle an Möglichkeiten, die das Arbeiten mit Objekten und Bildern für das ästhetische Lernen und die Förderung der Visual Literacy bietet. Dabei hoffe ich deutlich gemacht zu haben, dass die übergreifenden Lernziele des Nachdenkens über und des Entdeckens von Kultur das Entscheidende sind, und die einzelnen Lerninhalte jederzeit an die Interessen und Bedürfnisse der Lernenden angepasst und ausgetauscht werden können. Diese Vorschläge richten sich nicht auf das landeskundliche Lernen im engeren Sinne, bei dem es ausschließlich um landesspezifische und nationale Besonderheiten geht. Im Gegenteil, der Fokus ist hier auf das kulturübergreifende und verbindende Lernen gerichtet; es wird bewusst nach Gemeinsamkeiten und Verknüpfungen zwischen den Kulturen gesucht. Das liegt auch darin begründet, dass ein großer Teil der Objekte und Bilder - und speziell: Gemälde - keine nationalspezifischen Darstellungen aufweisen, sondern in der Regel in nationenübergreifende kulturelle Symboliken eingebunden sind, wenn man einmal vom Sujet der Historienmalerei absieht. Letzten Endes geht es weder um die Dinge noch um die Objekte per se, sondern um ihr Potential, das Unsichtbare in der Kultur zu veranschaulichen: Verhaltensregeln, Nutzungsweisen, Normen, Bewertungen und Weltbilder. Das sprachliche Zeichen mag arbiträr sein, das bildliche und materielle Zeichen ist es definitiv nicht, und das macht Bilder wie Gegenstände aus Kunst und Alltag so wertvoll für die Kulturvermittlung im Rahmen des Fremdsprachenunterrichts. 


\section{Literatur}

Adorno, Theodor W. (1973): Ästhetische Theorie. Frankfurt a.M.: Suhrkamp.

Barkowski, Hans; Funk, Hermann; Kuhn, Christina (2006): Der Internationale Masterstudiengang Deutsch als Fremd- und Zweitsprache in Jena. Curriculum, Erfahrungen und Empfehlungen. In: Casper-Hehne, Hiltraud; Koreik, Uwe; Middeke, Annegret (Hrsg.): Die Neustrukturierung von Studiengängen „Deutsch als Fremdsprache". Probleme und Perspektiven. Fachtagung 17.-19. November 2005 an der Universität Hannover. Göttingen: Universitätsverlag, 35-54.

Bausinger, Hermann (2004): Ding und Bedeutung. In: Österreichische Zeitschrift für Volkskunde LVIII, 107, 193-210.

Bisanz, Elize (2011): Kultur als symbolische Kommunikation. In: Treichel, Dietmar; Mayer, Claude-Hélène (Hrsg.): Lehrbuch Kultur. Lehr- und Lernmaterialien zur Vermittlung kultureller Kompetenæen. Münster u.a.: Waxmann, 185-189.

Ehrenspeck, Yvonne (1996): Der „Ästhetik“-Diskurs und die Pädagogik. In: Pädagogische Rundschau 50, 247-264.

Gärtner, Claudia (2011): Ästhetisches Lernen. Eine Religionsdidaktik zur Christologie in der gymnasialen Oberstufe. Freiburg: Herder.

Hahn, Hans Peter (2005): Materielle Kultur. Eine Einführung. Berlin: Dietrich Reimer.

Hallet, Wolfgang (2013): Die Visualisierung des Fremdsprachenlernens. Funktionen von Bildern und visual literacy im Fremdsprachenunterricht. In: Lieber, Gabriele (Hrsg.): Lebren und Lernen mit Bildern. Ein Handbuch zur Bilddidaktik. Baltmannsweiler: Schneider Verlag Hohengehren, 213-224.

Hascher, Tina (2005): Emotionen im Schulalltag. Wirkungen und Regulationsformen. In: Zeitschrift für Pädagogik 51, 610-625.

Heidrich, Hermann (2000): Facetten zu einer Theorie der Dinge. In: Heidrich, Hermann (Hrsg.): SachKulturForscbung. Gesammelte Beiträge der Tagung der Arbeitsgruppe Sachkulturforschung und Museum in der Deutschen Gesellschaft für Volkskunde vom 15. bis 19. September 1998 in Bad Windsheim. Bad Windsheim: Fränkisches Freilandmuseum, 8-17.

Hmelo-Silver, Cindy E. (2004): Problem Based Learning. What and How do Students Learn? In: Educational Psychology Review, 16, 3, 235-266. Online: http:// kanagawa.lti.cs.cmu.edu/olcts09/sites/default/files/Hmelo-Silver_2004.pdf (Stand: 17.05.2014).

Jauß, Hans Robert (1972): Kleine Apologie der ästhetischen Erfahrung. Konstanz: Universitätsverlag. 
Koreik, Uwe (2011): Zur Entwicklung der Landeskunde bzw. der Kulturstudien im Fach DaF/DaZ. Was haben wir erreicht, mit welchen Widersprüchen kämpfen wir und wie geht es weiter? In: Info DaF 6, 581-604.

Kuhn, Christina (o.J.): Internationaler Master Auslandsgermanistik - Deutsch als Fremdsprache - Deutsch als Zweitsprache. Online: http:/ /www.uni-jena.de/ unijenamedia/Downloads/faculties/phil/inst_auslgerm/Aktuelles/MA_DaF_ WiSe2012_13.pdf (Stand: 17.05.2014).

Müller-Hartmann, Andreas; Schocker-v. Ditfurth, Marita (2005): Aufgabenorientierung im Fremdsprachenunterricht: Entwicklungen, Forschung und Praxis, Perspektiven. In: Müller-Hartmann, Andreas; Schocker-v. Ditfurth, Marita (Hrsg.): Aufgabenorientierung im Fremdsprachenunterricht. Task-Based Language Learning and Teaching. Festschrift für Michael K. Legutke. Tübingen: Narr, 1-52.

Pazaurek, Gustav Edmund (2012): Guter und schlechter Geschmack im Kunstgewerbe. Nachdruck der Originalausgabe von 1912. Bremen: Dogma.

Schiller, Friedrich (1995): Über die ästhetische Erziehung des Menschen in einer Reibe von Briefen. Kommentar von Stefan Matuschek. Frankfurt a.M.: Suhrkamp.

Schmidt, Laurel (2004): Great Teachers Don't Take No (or Yes) for an Answer. Teaching by Asking Instead of Telling. In: Schmidt, Laurel (Hrsg.): Classroom Confidential. The 12 Secrets of Great Teachers. Portsmouth u.a.: Heinemann, 91-112.

Spinner, Kaspar H. (2008): Perspektiven ästhetischer Bildung. Zwölf Thesen. In: Vorst, Claudia; Grosser, Sabine; Eckhardt, Juliane; Burrichter, Rita (Hrsg.): Ästhetisches Lernen. Fachdidaktische Grundfragen und praxisorientierte Konzepte im interdisziplinären Kontext von Lehrerbildung und Schule. Frankfurt a.M. u.a.: Lang, 9-24.

Wahl, Diethelm (2006): Ergebnisse der Lehr-Lern-Psychologie. Textbeitrag im Rahmen der Fachtagung des Berliner Landesinstituts für Schule und Medien „Aktives und selbstgesteuertes Lernen gestalten - Fit fürs Lernen, Fit fürs Team " am 20.09. an der 1. staatlichen Fachschule für Sozialpädagogik, Berlin-Charlottenburg, 1-6. Online: http://www.dblernen.de/docs/Wahl_Ergebnisse-der-LehrLern-Psychologie.pdf (Stand: 17.05.2014).

Weiß, Sabine (2008): Kreativitätsförderung. In: Kiel, Ewald (Hrsg.): Unterricht sehen, analysieren, gestalten. Bad Heilbrunn: Klinkhardt, 119-142.

Welsch, Wolfgang (1993): Ästhetisches Denken. 3. Aufl. Stuttgart: Reclam. 
Wolff, Dieter (2004): Kognition und Emotion im Fremdsprachenerwerb. In: Börner, Wolfgang; Vogel, Klaus (Hrsg.): Emotion und Kognition im Fremdsprachenunterricht. Tübingen: Narr, 87-103.

Zimmer, Renate: Handbuch der Sinneswahrnehmung. Grundlagen einer ganzheitlichen Erziiehung. 12. Aufl. Freiburg: Herder. Online: http://www.schlossludwigsburg.de/schloss-garten/gebaeude/ordensbau-und-ordenskapelle/ (Stand: 17.05.2014). 



\title{
Kunstbilder im DaF-/DaZ-Unterricht - Die Porträts des Malers Gerhard Richter und seiner Kinder Betty, Ella und Moritz
}

\author{
Tristan Lay \\ Die Beschäftigung mit Kunstbildern erfolgt im Fremdsprachenunterricht selten. Künstlerische \\ Bildvorlagen besitzen jedoch das Potenzial, authentische sprachliche Äußerungen zu motivieren \\ und bieten ferner einen wichtigen Zugang zum kulturellen Lernen. Anhand ausgewäblter Famili- \\ enporträts des Künstlers Gerhard Richter werden im vorliegenden Beitrag Möglichkeiten des \\ Lebrens und Lernens mit Kunstbildern im DaF-/DaZ-Unterricht exemplifiziert.
}

\section{Kunstbilder im DaF-/DaZ-Kontext}

Es liegt die Vermutung nahe, dass die Arbeit mit Kunstbildern ${ }^{1}$ im Fremdsprachenunterricht keine Selbstverständlichkeit darstellt, denn in den gegenwärtig auf dem Buchmarkt erhältlichen DaF-/DaZ-Lehrbüchern aller Niveaustufen findet eine gezielte Arbeit mit Bildender Kunst nur marginal statt. ${ }^{2}$ Ein Blick in gängige Lehrbücher verdeutlicht, dass künstlerische Bildvorlagen im Wesentlichen zur Semantisierung, Visualisierung von Sprachstrukturen oder als Vorentlastung benutzt werden; oft dienen sie auch nur als Textdekoration (vgl. Sturm 1991: 7ff.).

\footnotetext{
${ }_{1}$ Unter Kunstbilder werden im Folgenden gemalte Bilder, grafische Werke, Kupferstiche, Radierungen, Zeichnungen, Lithografien und Holzschnitte zusammengefasst.

2 In einigen Lehrbüchern werden Kunstbilder thematisiert, z.B. in eurolingua Deutsch 3 (S. 144-149), DaF kompakt A1-B1 (S. 65), Mittelpunkt neu B2 (S. 44), Mittelpunkt neu C1 (S. 80-87) oder Tangram aktuell 2 (S. 106). In vielen aktuellen Lehrbüchern werden Kunstbilder jedoch gar nicht behandelt: Ja genau!, prima (Cornelsen); Lagune, Menschen, Schritte international plus, Ziel (Hueber); studio d (Klett); Aspekte, Netzwerk (Langenscheidt).
} 
Eine interdisziplinäre Verbindung künstlerischer Ausdrucksmittel mit dem Sprachunterricht erfolgt in den meisten Lehrbüchern selten.

In den letzten 25 Jahren wurden umfangreichere Didaktisierungsvorschläge lediglich zu einzelnen Künstlern vorgelegt. ${ }^{3}$ Die fachliche Auseinandersetzung mit dem Kunstbild im Kontext des Lehrens und Lernens fremder Sprachen weicht immer mehr der Erforschung audiovisueller und neuer Medien. Während in den 1980er- und Anfang der 1990er-Jahre noch diverse Fachveröffentlichungen zum Thema vorgelegt wurden, geht der Trend seit Mitte der 1990er-Jahre stetig über zum Einsatz audiovisueller Medien und dem Internet im Fremdsprachenunterricht. Dies belegt die hohe Anzahl an Publikationen zur Implementierung dieser Medien im Sprachunterricht ${ }^{4}$, die sicherlich auch als Reaktion auf die veränderten visuellen Perzeptionsgewohnheiten junger Erwachsener $\mathrm{zu}$ verstehen ist (vgl. Ballstaedt 2004: 3ff., Harms 2005: 247, Simonis 2012: 10). Während der Einfluss und die Relevanz von Filmen und Internet im Unterricht stetig zunehmen, ist seit Längerem die intensive und kritische Auseinandersetzung mit statischen Bildern im Kontext des Lehrens und Lernens fremder Sprachen in den Hintergrund getreten. Ein Kinobesuch scheint heutzutage für junge Erwachsene attraktiver zu sein als ein Museumsbesuch.

\section{Gründe für die Arbeit mit Kunstbildern}

Die Vorteile der Arbeit mit künstlerischen Bildvorlagen im fremdsprachlichen Unterricht liegen meines Erachtens darin, dass diese im Vergleich zu Texten unbelastet sind und durch handlungsorientierte Aufgabenstellungen zur Motivationssteigerung im Unterricht beitragen. Sie sind wesentlich offener und ermöglichen dadurch mehr Interpretationsmöglichkeiten. Einerseits erfordert die räumliche, zeitliche, soziale und kommunikative Offenheit des Bildes (vgl. Eichheim; Wilms 1980) bei der Betrachterin und dem Betrachter kreatives und selbständiges Denken. Andererseits kann die Beschäftigung mit Kunstbildern im Sprachunterricht an das Vorwissen und die ästhetischen Erlebnisse der Lernenden anknüpfen (vgl. Macaire; Hosch 1996: 60ff.).

Bilder, obwohl sie etwas zeigen, verschweigen dem Betrachter viel, auch wenn sie oft auf Ausgespartes verweisen (was uns nicht immer verständlich ist). Der hohe Grad an Unbestimmtheit ruft die Phantasie des Betrachters im wahrsten Sinne des Wortes ins Bild: er muss in der Imagination über den fruchtbaren Augenblick hinausgehen, muss ergänzen, konstruieren, Zu-

\footnotetext{
3 So z.B. zu Carl Spitzweg (Charpentier; Cros; Dupont; Marcou; Momenteau; Vrignaud; Wackwitz 1988), Caspar David Friedrich (Charpentier; Cros; Dupont; Marcou 1993a), George Grosz (Charpentier; Cros; Dupont; Marcou 1993b), Gustav Klimt (Perlmann-Balme; Schwalb; Weers 2011), Albrecht Dürer (Lay; Gertz; Then 2013) sowie Edward Hopper und Pablo Picasso (Wicke; Rottmann 2013).

${ }^{4}$ Für den Einsatz von Filmen im Fremdsprachenunterricht siehe die von Burger 2012 zusammengestellte chronologische Bibliografie.
} 
sammenhänge herstellen, kann sich aber auch ganz den Assoziationen hingeben, die in der Betrachtung des Bildes wachgerufen werden (Wangerin 2006: 29).

Wenn die Bildvorlage wohlüberlegt gewählt ist, spricht sie die Lernenden an; sie ist ihnen zugänglich und begreifbar, weil sie ihre Lebenswelt berührt. Ausgehend von einem konstruktivistischen Verständnis haben Lernende die Möglichkeit, im Klassenverband oder im Rahmen einer Museumsexkursion die Werke individuell mündlich bzw. schriftlich zu deuten. Persönlich bedeutsame Aspekte in ihrer kulturbedingten subjektiven Rezeption (vgl. Schwerdtfeger 1989: 32f., Hu 1996: 46ff.) führen erfahrungsgemäß bei fortgeschrittenen heterogenen Lernergruppen mit unterschiedlichen sozial vermittelten Wissensbeständen (kulturellen Deutungsmus$\operatorname{tern}^{5}$ ) zu einem lebendigen, interessanten und fruchtbaren Austausch, der den Fremdsprachenunterricht und das ästhetisch-kulturelle Lernen ${ }^{6}$ bereichert (vgl. Huber 2005: 1).

Durch den Einsatz von Kunstwerken im Unterricht werden die Lernenden weniger mit Instruktionen von Lehrenden konfrontiert; ihre Autarkie und Eigenaktivität werden stattdessen unterstützt und gefördert. Gleichzeitig nimmt bei der Beschäftigung mit Kunst der Spielraum für individuelle Stellungnahmen und Deutungen zu: Bildeindrücke können versprachlicht und eigene Vorstellungen bzw. Empfindungen frei formuliert werden, so dass die Lernerpersönlichkeit in ihrer Authentizität und Individualität durch aktive Deutungskonstruktionen adäquat zur Geltung kommt. Kunst bedarf stets der Interpretation:

\footnotetext{
${ }^{5}$ Geteilte Wissensvorräte, die im kulturellen Gedächtnis einer Gruppe gespeichert sind und ständigen Veränderungsprozessen unterliegen, werden auch als kulturelle Deutungsmuster bezeichnet. Kulturelle Deutungsmuster werden von Altmayer wie folgt definiert: „So weit es sich bei diesen Mustern um überlieferte, im kulturellen Gedächtnis einer Gruppe gespeicherte und abrufbare Muster von einer gewissen Stabilität handelt, spreche ich von ,kulturellen Deutungsmustern', und den Bestand an ,kulturellen Deutungsmustern', der einer Gruppe als gemeinsamer Wissensvorrat für die gemeinsame diskursive Wirklichkeitsdeutung zur Verfügung steht, nenne ich „Kultur ' dieser Gruppe“ (Altmayer 2006: 51). Kulturelle Deutungsmuster sind multifunktional: Sie sind notwendig, um Situationen zu deuten, zu bewerten und angemessen mit ihnen umgehen zu können; um der Wirklichkeit, die nicht an sich erfahrbar ist, subjektiv Sinn zuzuschreiben und um Diskurse zu verstehen und (affirmativ oder kritisch) dazu Stellung zu nehmen.

${ }^{6}$ Lernen ist an den Körper/Leib, die sinnliche Wahrnehmung (aisthesis) sowie soziale, kulturelle und symbolische Zeichensysteme gebunden (vgl. Schultheis 1998); Lernen ist somit auch immer kulturelles Lernen. Dieses kulturelle Lernen kann durch die Arbeit mit Kunstbildern im Fremdsprachenunterricht in ein ästhetisch-kulturelles Lernen überführt werden. Durch die intensive Auseinandersetzung mit ästhetisch-kulturellen Lerninhalten wird die Entwicklung der Sinnes- und Rezeptionstätigkeiten gestärkt und der Fremdsprachenunterricht könnte durch das Auslösen und die Vermittlung ästhetischer Erfahrungen (vgl. Wangerin 2006: 3) zur Förderung des Wahrnehmungspotentials der Lernenden beitragen. Denn „Kunst hat traditionell nicht unbedingt nur die Rolle, Unruhe zu stiften und für Aufregung zu sorgen. Sie hat vielmehr auch die Aufgabe, einen sowohl ästhetischen als auch ethischen Mehrwert zu schaffen, der bei seinen Betrachtern zu einer anderen, neuen, komplexeren Perspektive und Wahrnehmung führt" (Biesenbach 2006: 19). Neben der Entwicklung der Wahrnehmungsfähigkeit für komplexe soziale Zusammenhänge, wird durch das ästhetisch-kulturelle Lernen die Persönlichkeit weiterentwickelt und der individuelle Erfahrungsraum erweitert. Dazu sind kreativ-offene Lernumgebungen und Lernformen im Unterricht vonnöten, die bei der sinnlichen Wahrnehmung und Erfahrung der Lernenden ansetzen und ihre Imagination stimulieren.
} 
Häufig wollen künstlerische Bilder aber auch entschiedene Botschaften beim Betrachter induzieren, und das mit Ausdrucksmitteln der Farbe und Linienführung, die dem Kunstbild eigen sind und auch mit dem künstlerischen Foto nie zu erreichen sind. Demzufolge erwartet man bei der Beschäftigung mit Kunstbildern im Sprachunterricht, mehr als nur Sprechanlass zu sein. Sie muss über die erste affektive Rezeption hinausgehen und zu einer vertiefenden Interpretation führen. Bei der Berücksichtigung der ästhetischen Komponente werden die Schüler - im Rahmen des Fremdpsrachenunterrichts [sic] - für die der Kunst eigenen Ausdrucksmittel sensibilisiert und lernen über Kunst zu sprechen (Charpentier 1988: 8).

Im Unterricht wird den Lernenden vermittelt, dass die Bildaussage eine starke Intentionalisierung durch den Künstler/die Künstlerin erfährt. Durch den Dialog mit Bildern wird deutlich, dass diese bewusst gestaltet wurden und Teil eines individuell, soziokulturell gebundenen Rahmens sind.

Die gezielte und systematische Implementierung von Arbeit mit Kunst im fremdsprachlichen Unterricht führt ferner dazu, dass durch die individuelle Beschreibung, Analyse und Interpretation von Kunstwerken die „Visual Literacy“ (Elkins 2008: 1), d.h. der Erwerb kulturspezifischer Seherfahrungen und die bewusste Einordnung von Symbolen, Bildern und Zeichen, gestärkt wird. Dies entspricht der Erfassung ,impliziter Bedeutungen“ (Trim; North; Coste 2001: 35) als eines der wichtigen Lehr- und Lernziele auf Oberstufenniveau.

Bei jungen Erwachsenen, die oft durch die mediale Bilderflut im Alltag Inhalte kritiklos annehmen, ist die Förderung des Lesens und Verstehens von Bildern auf der einen Seite sowie die Stärkung und Differenzierung des Wahrnehmungsvermögens auf der anderen Seite umso relevanter.

\section{Familienporträts: Eingrenzung und Begründung}

In dem komplexen und mannigfaltigen Euvre von Gerhard Richter finden sich u.a. auf Amateurfotos oder selbst aufgenommenen Fotos basierende gegenständlich-figurative Gemälde, Stadtansichten, Landschaften, Seebilder, Wolkenstudien, monochrome Bilder sowie großflächige abstrakte Farbtafeln, Druckgrafiken, Glasarbeiten und Skulpturen.

Obwohl Richter in diversen Medien arbeitet, bildet die Malerei den Schwerpunkt seines Schaffensbereichs. Allein in diesem Medium ist die Anzahl der Werke so immens, dass jede Beschäftigung selektiv und partiell erfolgen muss. Für den Fremdsprachenunterricht ist es daher angemessen, einen besonderen Aspekt aus seiner Kunst herauszugreifen.

Im vorliegenden Beitrag sollen an ausgewählten Beispielen konkrete Übungsvorschläge zur Arbeit mit seinen Selbstporträts und den Porträts seiner Kinder Betty, Ella und Moritz, die auf fotografischen Vorlagen basieren, vorgestellt wer- 
den. ${ }^{7}$ Bei Richter haben Porträts von Familienmitgliedern eine lange Tradition und ziehen sich seit 1962 wie ein roter Faden durch sein gesamtes malerisches Werk. Gerade bei seinen intimen Familienbildern, die er teils in Auseinandersetzung mit Ikonen der Kunstgeschichte malte, schuf Richter klassische Meisterwerke der Gegenwartskunst. ${ }^{8}$ Seine persönlichen Porträts lassen in Bezug auf Bildkomposition, Farbigkeit, Atmosphäre und Maltechnik eine große Variationsbreite erkennen. Ihnen ist die genuine Ambiguität zu eigen, dass sie bei näherer Betrachtung zwischen Vertrautheit und Andersheit, zwischen Erscheinen und Verbergen, zwischen Nähe und Ferne oszillieren; sie laden somit zum Deutungslernen und dem Entdecken einer inneren Welt ein, die Neugier und Zweifel weckt und zugleich Überraschung und Paradoxie provoziert.

Die Thematisierung des familiären Umfeldes bietet für Deutschlernende zahlreiche Berührungspunkte zu ihrem Vorwissen und ihren lebensweltlichen Erfahrungen. Indem Lernende individuell auf die im Unterricht behandelten Bilder reagieren und mit anderen darüber diskutieren, werden sie mit ihrer persönlichen Denkweise und kulturellen Prägung konfrontiert. Sie können im Fremdsprachenunterricht durch das Deutungslernen und den plenaren Dialog über das Kunstbild neue Sichtweisen einnehmen und so ihre Eigenperspektivität relativieren.

\section{Unterrichtsvorschläge}

Bei den nachfolgenden Unterrichtsideen handelt es sich um praktische Arbeitsvorschläge auf Oberstufenniveau. Abhängig vom Sprachniveau können die in DaFKursen der Otto-Friedrich-Universität Bamberg und der University of Sydney erprobten Materialien in der vorliegenden oder in modifizierter, vereinfachter Form auch für Lerngruppen mit niedrigerem Sprachniveau im Unterricht eingesetzt werden.

Das methodische Vorgehen ist bei allen Übungsvorschlägen dreischrittig gegliedert: vor, während und nach der Bildbetrachtung.

Als Quelle für Materialien dient die offizielle Homepage von Gerhard Richter. ${ }^{9}$ Seine Kunstbilder können über das Internet für den Unterricht genutzt werden. ${ }^{10}$ Zusätzlich zu den Gemälden werden auf der Homepage umfangreiche Materialien bereitgestellt, die für die Beschäftigung mit seiner Kunst im Sprachunterricht gezielt eingesetzt werden können (Zitate, Biografie, Videoausschnitte etc.).

\footnotetext{
${ }^{7} \mathrm{Zu}$ seinem jüngsten Sohn Theodor, der 2006 geboren wurde, liegen bislang keine Gemälde vor.

8 Zum Beispiel Lesende (1994: 804), nach Jan Vermeers Brieflesendes Mädchen am offenen Fenster (um 1659).

${ }^{9}$ Online: http://www.gerhard-richter.com.

${ }^{10}$ Die integrierte Suchfunktion der Homepage erleichtert u.a. das Auffinden seiner Werke (am besten durch die Eingabe der Werkverzeichnisnummer/Catalogue Raisonné, WV (CR)-Nr.), die ohne nennenswerte Qualitätseinbußen vergrößert (Zoomfunktion) und so für den Unterricht im Klassenverband eingesetzt werden können.
} 


\subsection{Selbstporträts}

In Richters Catalogue Raisonné sind nur vereinzelt Selbstporträts zu finden. Die an dieser Stelle besprochenen zwei verwandten Selbstbildnisse entstanden im Jahre 1996, als Richter bereits einer der wichtigsten und einflussreichsten zeitgenössischen Künstler war.

Bevor den Lernenden die Selbstporträts von Richter nacheinander gezeigt werden, sollen die folgenden Fragenimpulse und der Lesetext zu Gerhard Richter in das Thema Kunst einführen. Es ist nicht notwendig und sinnvoll, alle aufgeführten Fragen im Plenum zu stellen. Lehrkräfte können anhand des Fragenkatalogs entscheiden, welche Fragen für ihre Lernergruppe als Sensibilisierung geeignet erscheinen. Der Text Zur Bedeutung von Gerhard Richter (siehe Anhang: Text 1) verdeutlicht die Relevanz und den Einfluss des Künstlers auf die zeitgenössische Malerei sowie seine internationale Stellung auf dem Kunstmarkt. Der Inhalt weckt Neugier und Interesse im Hinblick auf den Künstler und seine Werke. Gerhard Richter und seine Kunst sind der Lernerschaft in der Regel nicht bekannt. Die Lernenden stellen Vermutungen an, wie die Werke aussehen könnten und welche Motive und Themen in seinen Kunstbildern angesprochen werden. Beim Fragenkatalog handelt es sich um Fragenimpulse, die nicht chronologisch abgearbeitet werden müssen. Die Lernenden sollen die Selbstbildnisse Richters beschreiben, analysieren, miteinander vergleichen und Hypothesen bilden. ${ }^{11}$

Die unterschiedlichen Vorschläge für die mündliche und schriftliche Weiterarbeit nach der Bilderpräsentation rücken die Persönlichkeit des Künstlers ins Zentrum. Sie bieten die Möglichkeit zur individuellen Stellungnahme und Verbalisierung persönlicher Eindrücke.

\section{Vor der Bildbetrachtung}

Fragen:

- Interessieren Sie sich für Kunst?

- Welche Bedeutung hat Kunst im Alltag?

- Welchen Auftrag hat Kunst in Bildungsinstitutionen?

- Erinnern Sie sich an Ihren Kunstunterricht in der Schule? Erzählen Sie!

- Wie oft besuchen Sie Museen und Ausstellungen? Gehört ein Museumsbesuch dazu, wenn Sie im Urlaub/Ausland sind?

- Erinnern Sie sich an eine Ausstellung, die Ihnen besonders gut gefallen hat?

- Nennen sie ein Museum, das in Ihrem Heimatland berühmt ist? Was wird dort ausgestellt?

- Kennen Sie bekannte Künstler Ihres Landes? Was zeichnet sie aus?

- Welches Museum im deutschsprachigen Raum (DACHL) gefällt Ihnen?

\footnotetext{
${ }_{11}$ Die Bilder Selbstporträt (1996, CR-Nr. 836-1) sowie Selbstporträt (1996, CR-Nr. 836-2) sollen nacheinander betrachtet werden.
} 
- Welche Künstler aus dem deutschsprachigen Raum kennen Sie?

- Haben Sie einen Lieblingskünstler oder ein Lieblingsbild?

Aufgabe: Lesen Sie den Text Zur Bedeutung von Gerhard Richter (siehe Anhang: Text 1). Diskutieren Sie darüber, wie seine Werke aussehen und welche Motive und Themen in seinen Bildern eine Rolle spielen könnten. Wie erklären Sie sich die weltweite Popularität des deutschen Künstlers?

\section{Während der Bildbetrachtung}

Aufgabe: Sehen Sie sich nacheinander die Porträts an und lassen Sie diese auf sich wirken. Sammeln Sie drei passende Adjektive, um die abgebildete Person zu beschreiben. Vergleichen Sie anschließend im Plenum.

Fragen:12

- Aus welcher Zeit könnten die Bilder stammen?

- Was können Sie auf den Bildern erkennen bzw. nicht erkennen?

- Welchen Eindruck macht die Person auf Sie?

- Was sagt die Kleidung über sie aus?

- Welchen Beruf könnte die Person ausüben?

- Wie präsentiert sie sich?

- Wie sind die Kopfhaltung und der Blick?

- Vergleichen Sie beide Porträts. Gibt es Gemeinsamkeiten/Unterschiede in der Darstellung?

- Was suggerieren die Porträts?

- Wie sind die Bilder aufgebaut?

- Welche Atmosphäre vermitteln die Bilder?

- Welche Technik könnte der Künstler beim Malen eingesetzt haben und welche Wirkung wird dadurch evoziert?

- Welche Farben überwiegen? Welche Funktion könnten diese haben?

- Gibt es Auffälligkeiten beim Lichteinfall und der Schattierung?

- Kennen Sie Porträts anderer bekannter Künstler? Inwieweit unterscheiden sie sich von den beiden vorliegenden Selbstbildnissen?

\section{Nach der Bildbetrachtung}

Aufgabe: Bilden Sie Kleingruppen. Erarbeiten Sie acht Fragen in der Gruppe, die Sie dem Künstler gerne in einem Interview stellen würden. Eine andere Gruppe versucht die Fragen aus Sicht des Künstlers zu beantworten und stellt nach der Beantwortung der Fragen der anderen Gruppe ihre Fragen.

Aufgabe: Sehen Sie sich gemeinsam im Plenum entweder Ausschnitte aus dem Dokumentarfilm Gerhard Richter - Painting von Corinna Belz (2011) oder Videose-

\footnotetext{
${ }^{12}$ Sprachliche Hilfen für die Formulierung der persönlichen Meinungsäußerung in Bezug auf Kunst-
} bilder finden sich z.B. in Lay; Gertz; Then 2013: 77. 
quenzen auf der Homepage des Künstlers an (Online: http://www.gerhardrichter.com/videos/).

Schreiben Sie anhand der gesehenen Videoexzerpte Stichworte für eine Personencharakterisierung auf. Gehen Sie dabei auf folgende Punkte ein: äußere und innere Merkmale, Verhaltensweisen, Eigenschaften, Gewohnheiten, Schwächen und Vorlieben. Stellen Sie Ihre Charakterisierung mündlich vor.

Aufgabe: Verfassen Sie mithilfe der Biografie und Chronologie auf Richters Homepage einen Lexikonartikel ${ }^{13}$ über den Künstler.

\subsection{Betty}

Die Gemälde von Gerhard Richters älterer Tochter Babette (geb. 1966), genannt Betty, gehören zu den bekanntesten Motiven Richters. Was der Künstler jedoch mit seinen Betty-Bildern aussagen will, ist bis heute sowohl bei Betrachtern als auch bei Fachleuten äußerst umstritten (vgl. z.B. Härtel; Pazzini 2012.). Drei Porträts von ihr finden sich in Richters Werkskatalog. ${ }^{14}$

Die Einführung und Vorentlastung kann durch ein Assoziogramm erfolgen oder den Lernernden wird als Hausaufgabe aufgegeben, Kunstbilder in den Unterricht mitzubringen. Die Lernenden hätten so die Möglichkeit über Bilder, die ihnen gefallen, zu sprechen. Die ausgestellten Bilder haben also einen persönlichen Bezug und das Vorwissen kann gezielt für den Unterricht genutzt werden. Es wäre z.B. möglich die Bilder nach Epoche, Kunstrichtung, Motiv etc. gruppieren zu lassen.

Die subjektive Wahrnehmung des ausgesuchten Bildes von Richter soll anhand eines Bildtitels und einer Bildbeschreibung schriftlich festgehalten und miteinander verglichen werden. ${ }^{15}$ Die Fragenimpulse bieten die Möglichkeit, im Plenum über Gemeinsamkeiten und Unterschiede in den präsentierten Kunstbildern zu sprechen.

Die Hausaufgabe (Textproduktion) zeigt erfahrungsgemäß die unterschiedlichen Vorlieben der Lernenden in Bezug auf Motive und Themen in der Kunst Richters. Durch die Suche nach einem Bild, das ihnen persönlich gefällt oder missfällt, werden die Lernenden mit der künstlerischen Vielfalt von Richter konfrontiert.

\section{Vor der Bildbetrachtung}

Hausaufgabe: Zur Vorbereitung auf das Thema Kunst sollen die Lernenden als Hausaufgabe ein Bild ihres Lieblingsmalers auswählen und zum Unterricht mitbringen. Auf einem zweiten Blatt wird der Künstlername notiert. Die Blätter wer-

\footnotetext{
13 Ein Lexikonartikel ist ein Text, der in Kurzform die wichtigsten Informationen zu einer Person oder einem Sachverhalt enthält: Name, Lebensdaten, relevante Lebensstationen und Entwicklungsphasen, epochale Einordnung, bekannte Werke.

14 Betty (1977, CR-Nr. 425-4); Betty (1977, CR-Nr. 425-5); Betty (1988, CR-Nr. 663-5).

${ }^{15}$ Es handelt sich um folgende Bilder: Betty (1977, CR-Nr. 425-4); Betty (1988, CR-Nr. 663-5).
} 
den gemischt, im Klassenraum aufgehängt und die Lernenden ordnen die Werke den Künstlern zu.

Aufgabe: Überlegen Sie mit Ihrer Nachbarin oder Ihrem Nachbarn, was Sie mit Kunst verbinden. Sammeln Sie gemeinsam Begriffe und strukturieren Sie anhand einer Mind-Map Ihre Ergebnisse an der Tafel.

\section{Während der Bildbetrachtung}

Aufgabe: Finden Sie zuerst einen geeigneten Titel für eines der Betty-Bilder, das Ihre gewonnenen Wahrnehmungen zusammenfasst. Fertigen Sie nun eine Beschreibung zu diesem Bild an; gehen Sie dabei systematisch vor. Diktieren Sie anschließend Ihrem Partner oder Ihrer Partnerin Ihre Bildbeschreibung. Vergleichen Sie im Anschluss die Bildbeschreibungen miteinander.

Fragen:

- Was können Sie auf den Bildern erkennen?

- Wie alt könnte die Person sein?

- Wie wirkt die Körpersprache auf Sie?

- Was ist das Besondere an den Gemälden?

- Vergleichen Sie beide Porträts miteinander? Welche Gemeinsamkeiten und Unterschiede fallen Ihnen auf?

- Was könnte die Aufmerksamkeit der Person anziehen?

- Was strahlen diese Bilder aus?

- Wie finden Sie die Gemälde?

- Welche Fragen hätten Sie an die Bilder?

\section{Nach der Bildbetrachtung}

Aufgabe: In einem Interview von 2005 äußerte sich der Künstler über das abgewendete Porträt seiner Tochter (1988, CR-Nr. 663-5). Lesen Sie das folgende Zitat und beziehen Sie Stellung zu der Aussage von Gerhard Richter:

Der abgewendete Kopf bringt zwar etwas plakativ das Geheimnisvolle in das Porträt, aber das Eigentliche, was da zur Wirkung kommt, ist doch vielmehr eine schmerzliche Wehmut über Verlust und Trennung und was da so in die Richtung geht. Als ich es malte, war mir das natürlich gar nicht bewusst (Richter zitiert nach Moorhouse 2009: 130).

Hausaufgabe: Besuchen Sie die Homepage des Künstlers und entscheiden Sie sich für ein Gemälde, das Ihnen gefällt oder missfällt. Verfassen Sie eine Bildbeschreibung und erläutern Sie darin, warum Sie sich für das Bild entschieden haben, welche Erinnerungen bzw. Gefühle es in Ihnen weckt und welche Wirkung es auf Sie hat. Gehen Sie ebenso auf die verwendeten Farben, die Maltechnik und die Bildkomposition ein. 


\subsection{Ella}

Bei dem vorliegenden Kinderbildnis ist die jüngere Tochter des Künstlers, Ella Maria (geb. 1996), abgebildet. Das bereits 2007 entstandene Porträt wurde erst zwei Jahre später bei der großen Einzelausstellung in der National Portrait Gallery in London einer breiten Öffentlichkeit vorgestellt.

Der Text Unschärfe als Stilprinzip (siehe Anhang: Text 2) soll über eine charakteristische Technik in der Malerei Richters informieren: die Verwischung. Die Lernenden sollen nach dem Lesen über die Gründe und die Wirkung der Verwischung diskutieren.

Anhand eines Senryūs sollen die Lernenden die Wirkung des Bildes poetisch festhalten. Das Porträt von Ella ${ }^{16}$ wird mit Richters Selbstporträt (1996, CR-Nr. 8362) verglichen. Die Lernenden benennen hinsichtlich der Farben, Atmosphäre, Bildkomposition sowie Maltechnik Gemeinsamkeiten und Unterschiede.

Im Anschluss erfolgt eine Diskussion über Ästhetik in der Kunst. Die Lernenden können auch selbst künstlerisch tätig werden, indem sie gemeinsam ein Plakat für eine Ausstellung gestalten.

\section{Vor der Bildbetrachtung}

Aufgabe: Besitzen Sie Postkarten, Plakate, Kalenderblätter oder Bücher mit Gemälden und Zeichnungen von Gerhard Richter? Bringen Sie diese oder einen Ausdruck in den Unterricht mit und sprechen Sie darüber.

Aufgabe: Lesen Sie den Text Unschärfe als Stilprinzip (siehe Anhang: Text 2). Sprechen Sie über das Zitat von Richter und die charakteristische Unschärfe in seinen Werken.

\section{Während der Bildbetrachtung}

Aufgabe: Verfassen Sie ein Senryū ${ }^{17}$ zur subjektiven Wirkung des Bildes auf Sie.

Aufgabe: Vergleichen Sie das Porträt Ella mit Gerhard Richters Selbstporträt (1996: 836-2). Nennen Sie Gemeinsamkeiten und Unterschiede, die Ihnen auffallen.

\section{Nach der Bildbetrachtung}

Fragen:

- Was verbinden Sie mit dem Begriff Ästhetik?

- Welche Kriterien sollte ein Bild für Sie erfüllen, um als ästhetisch zu gelten?

- Existieren Ihrer Meinung nach universelle und zeitlose Kriterien für schöne Kunst?

\footnotetext{
${ }^{16}$ Das Bild Ella (2007, CR-Nr. 903-1) ist Gegenstand der Bildbetrachtung und -analyse.

17 Das Senryū ist eine dem Haiku sehr ähnliche japanische Gedichtform, das sich mit dem Persönlichen und Emotionalen befasst, während das Haiku eher der Natur zugewandt ist. Formal sind beide Gedichtformen identisch und bestehen aus drei Versen mit traditionell fünf, sieben und fünf Moren (Sprechzeiten).
} 
- Wirkt die Malerei von Richter ästhetisch auf Sie?

Aufgabe: Gestalten Sie in Kleingruppen gemeinsam eine Collage oder ein Plakat für eine geplante Richter-Ausstellung. Wählen Sie einen Titel für die Ausstellung, einen Zeitraum und einen geeigneten Ausstellungsort. Hängen Sie das Plakat auf und kommentieren Sie es.

\subsection{Moritz}

Unmittelbar nach der Geburt seines Sohnes Moritz im Januar 1995 porträtierte Gerhard Richter ihn gemeinsam mit seiner Frau Sabine in der achtteiligen Bilderfolge S. mit Kind (1995, CR-Nr. 827-(1-8)). Dieser Zyklus legt eine äußerst intime Situation aus seinem Privatleben offen.

Als Moritz fünf Jahre alt war, malte ihn Richter allein in einer dreiteiligen Bilderfolge (Moritz 2000, CR-Nr. 863-(1-3)). Auch diese Gemälde entstanden nach Fotos, die von Richter selbst aufgenommen wurden.

Vor, während und nach der Betrachtung: Bei den Porträts von Moritz handelt es sich um zwei mehrteilige Bilderfolgen, die zwar figurativ miteinander verbunden sind, jedoch in Bezug auf Darstellung, malerische Mittel, Technik etc. sehr große Unterschiede aufweisen. Im vorliegenden Beitrag sollen drei Abbildungen als Veranschaulichung der Gemäldezyklen dienen. ${ }^{18}$ Aufgrund methodisch-didaktischer Überlegungen fällt das dreischrittige Gliederungsprinzip (vor, während, nach der Bildpräsentation) bei den Bildnissen von Moritz (und seiner Mutter in S. mit Kind) zusammen.

Aufgabe: In Partnerarbeit soll nach vorheriger Absprache sowohl aus der achtteiligen ( $S$. mit Kind) als auch aus der dreiteiligen Serie (Moritz) eine Kurzpräsentation zu einem Bild als Hausaufgabe vorbereitet und anschließend mündlich im Unterricht vorgestellt werden.

Die Bilder sollen nach den Präsentationen gemeinsam in Bezug auf Bildkomposition, Perspektive, Farbe, Atmosphäre, Technik und ästhetische Wirkung miteinander verglichen werden.

Projektarbeit: Bei Kunstobjekten bietet es sich an, Werke der Künstler später auch im Original zu sehen und weiterführende Aufgaben zu stellen. Organisieren Sie doch gemeinsam mit Ihren Lernenden eine Exkursion zum Südquerhaus des Kölner Doms (Richter-Fenster) oder in eines der folgenden Museen, die Werke von Gerhard Richter ausstellen (Auswahl):

- Museum Ludwig: http://www.museum-ludwig.de

- Staatliche Kunstsammlungen Dresden (Albertinum): http://www.skd.museum

- Hamburger Kunsthalle: http://www.hamburger-kunsthalle.de

${ }^{18}$ Exemplarisch können folgende Bilder im Unterricht besprochen werden: S. mit Kind (1995, CR-Nr. 827-3); S. mit Kind (1995, CR-Nr. 827-7); Moritz (2000, CR-Nr. 863-1). 


\section{Schluss}

Anhand von Gerhard Richters Selbstporträts sowie den Porträts seiner Kinder Betty, Ella und Moritz wurden im vorliegenden Artikel Einsatzmöglichkeiten von Kunstbildern im DaF-/DaZ-Unterricht vorgestellt. Es wurde deutlich, dass die Arbeit mit künstlerischen Bildvorlagen eine sinnvolle Ergänzung zum herkömmlichen Fremdsprachenunterricht darstellt und wesentlich zum ästhetisch-kulturellen Lernen beiträgt. Da Kunstbilder im Gegensatz zu Printtexten im Unterricht seltener eingesetzt werden, kann angenommen werden, dass Lernende dieser Abwechslung aufgeschlossen gegenüberstehen. Diese Chance gilt es, im Unterricht durch didaktisch-methodische Vor- und Nachbereitung systematisch zu nutzen. Handlungsorientierte Aufgabenstellungen unterstützen und fördern die Selbstständigkeit und Eigenaktivität der Lernenden im Umgang mit Kunst. Die Zuweisung adäquater Arbeitsaufträge wirkt in einem hohen Grade motivierend und das Interesse an Bildender Kunst kann bei den Lernenden geweckt und gefördert werden.

\section{Literatur}

Altmayer, Claus (2006): Kulturelle Deutungsmuster als Lerngegenstand. In: Fremdsprachen Lebren und Lernen 35, 44-59.

Ballstaedt, Steffen-Peter (2004): Kognition und Wahrnehmung in der Informations- und Wissensgesellschaft. Konsequenzen gesellschaftlicher Veränderungen für die Psyche. In: Kübler, Hans-Dieter; Elling, Elmar (Hrsg.): Wissensgesellschaft. Neue Medien und ihre Konsequenzen. Bonn: Bundeszentrale für politische Bildung (CD-ROM).

Belz, Corinna (2011): Gerhard Richter - Painting, DVD. Studio: Indigo.

Biesenbach, Klaus (2006): Lieben wir die Kunst zu Tode. In: Frankfurter Allgemeine Sonntagszeitung, 06.08.2006, 19.

Burger, Günter (2012): Spielfilme im Fremdsprachenunterricht: Eine chronologische Bibliografie. Online: http://www1.uni-hamburg.de/Medien/berichte/arbeiten /0112_10.html (Stand: 17.05.2014).

Charpentier, Marc; Cros, Rotraud; Dupont, Ute; Marcou, Carmen (1993a): Sprechende Bilder. Deutsch lernen mit Kunstbildern. Caspar David Friedrich: Kreidefelsen auf Rügen. München: Klett.

Charpentier, Marc; Cros, Rotraud; Dupont, Ute; Marcou, Carmen (1993b): Sprechende Bilder. Deutsch lernen mit Kunstbildern. George Grosz: Querschnitt 1919/ 1920. München: Klett.

Charpentier, Marc; Cros, Rotraud; Dupont, Ute; Marcou, Carmen; Momenteau, Barbara; Vrignaud, Irene; Wackwitz, Gustav (1988): Bild als Sprechanlaß. Kunst- 
bild (Projekt Didaktik und Methodik für den Unterricht Deutsch als Fremdsprache in Frankreich, Heft 8). Paris u.a.: Goethe-Institut.

Dallapiazza, Rosa-Maria; Jan, Eduard von; Schönherr, Til; Schümann, Anja (2013): Tangram aktuell 2. Ismaning: Hueber.

Eichheim, Hubert; Wilms, Heinz (1980): Das Bild im Deutschunterricht. In: Goethe-Institut (Hrsg.): Deutsch als Fremdsprache heute. Lebren - Lernen - Informieren. München: Goethe-Institut, 105-120.

Elkins, James (2008): Introduction: The Concept of Visual Literacy, and Its Limitations. In: Elkins, James (Hrsg): Visual Literacy. New York: Routledge, 1-10.

Funk, Hermann; Koenig, Michael (1999): eurolingua Deutsch 3. Berlin: Cornelsen.

Grätz, Roland (1997): Kunst und Musik im Deutschunterricht. In: Fremdsprache Deutsch 2, 4-8.

Harms, Michael (2005): „TV is quite a big part of my life“. Konsequenzen aus der Dominanz von Bildlichkeit im Lerneralltag für den Fremdsprachenunterricht in Großbritannien. Regensburg: FaDaF.

Härtel, Insa; Pazzini, Karl-Josef (2012): „Frage-Antwort-Spiel“‘: Babette und Gerhard Richter. In: kunsttexte.de 3. Online: http:/ / edoc.hu-berlin.de/ kunsttexte/ 2012-3/haertel-insa-8/PDF/haertel.pdf (Stand: 17.05.2014).

Hu, Adelheid (1996): „Lernen“ als „Kulturelles Symbol“. Eine empirisch qualitative Studie zu subjektiven Lernkonzepten im Fremdsprachenunterricht bei Oberstufenschülerinnen und -schülern aus Taiwan und der Bundesrepublik Deutschland. Bochum: Brockmeyer.

Huber, Gabriele (2005): Mit Bildender Kunst Deutsch lernen? In: Zeitschrift für Interkulturellen Fremdsprachenunterricht 10, 3, 1-10. Online: https://zif.spz.tudarmstadt.de/jg-10-3/beitrag/Huber1.htm (Stand: 17.05.2014).

Lay, Tristan; Gertz, Armin; Then, Marion (2013): Bamberg - Kaleidoskop einer fränkischen Stadt. Bamberg: Selbstverlag.

Macaire, Dominique; Hosch, Wolfram (1996): Bilder in der Landeskunde. Berlin: Langenscheidt.

Moorhouse, Paul (2009): Die Porträts von Gerhard Richter. Köln: DuMont.

Perlmann-Balme, Michaela; Schwalb, Susanne; Weers, Dörte (2011): em neu 2008 Abschlusskurs. Deutsch als Fremdsprache für die Mittelstufe. Ismaning: Hueber.

Richter, Gerhard; Elger, Dietmar; Obrist, Hans Ulrich (Hrsg.) (2008): Gerhard Richter. Text 1961-2007: Schriften, Interviews, Briefe. Köln: Verlag der Buchhandlung Walther König.

Sander, Ilse; Braun, Birgit; Doubek, Margit; Fügert, Nadja; Vitale, Rosanna (Hrsg.) (2011): DaF kompaket A1-B1. Stuttgart: Klett. 
Sander, Ilse; Daniels, Albert; Köhl-Kuhn, Renate; Bauer-Hutz, Barbara; Mautsch, Klaus F.; Tremp Soares, Heidrun; Butler, Ellen; Estermann, Christian (Hrsg.) (2012): Mittelpunk.t neu B2. Stuttgart: Klett.

Sander, Ilse; Köhl-Kuhn, Renate; Mautsch, Klaus F.; Schmeiser, Daniela; Tremp Soares, Heidrun; Daniels, Albert; Dengler, Stefanie; Estermann, Christian; Lanz, Monika; Schlenker, Wolfram (Hrsg.) (2013): Mittelpunkt neu C1. Stuttgart: Klett.

Schultheis, Klaudia (1998): Leiblichkeit - Kultur - Erziehung. Zur Theorie der elementaren Erz̧iehung. Weinheim: Deutscher StudienVerlag.

Schwerdtfeger, Inge Christine (1989): Sehen und Verstehen. Arbeit mit Filmen im Unterricht Deutsch als Fremdsprache. Berlin u.a.: Langenscheidt.

Simonis, Annette (2012): Einleitung - Bilder, Medien, Schriftkultur. Das Zusammenspiel zwischen Medien und ihre Wechselwirkungen mit soziokulturellen Kontexten als Triebfedern von ästhetischen und kulturgeschichtlichen Transformationsprozessen. In: Simonis, Annette; Schröder, Berenike (Hrsg.): Medien, Bilder, Schriftkultur. Mediale Transformationen und kulturelle Kontexte. Würzburg: Königshausen \& Neumann, 7-20.

Sturm, Dietrich (1991): Das Bild im Deutschunterricht. In: Fremdsprache Deutsch 10, 4-11.

Trim, John; North, Brian; Coste, Daniel (2001): Gemeinsamer europäischer Referenzrahmen für Sprachen: lernen, lehren, beurteilen. Berlin: Langenscheidt.

Wangerin, Wolfgang (2006): Ästhetische Erfahrung jenseits der Begriffe? Musik und Bildende Kunst im Deutschunterricht. Eine Einführung. In: Wangerin, Wolfgang (Hrsg.): Musik und Bildende Kunst im Deutschunterricht. Baltmannsweiler: Schneider Verlag Hohengehren, 2-54.

Wicke, Rainer E.; Rottmann, Karin (2013): Musik und Kunst im Deutsch-als-Fremdsprache-Unterricht. Berlin: Cornelsen. 


\section{Anhang}

Text 1: Zur Bedeutung von Gerhard Richter

Gerhard Richter, geboren am 9. Februar 1932 in Dresden, zählt zu den weltweit führenden und einflussreichsten zeitgenössischen Künstlern. Einige seiner Gemälde stellen Hauptwerke der deutschen Nachkriegskunst dar und gehören zum aktuellen Kanon der Malerei. Seit geraumer Zeit werden ihm weltweit zahlreiche Ausstellungen gewidmet. Eine Auswahl der wichtigsten Ausstellungen der letzten zehn Jahre sei hier erwähnt: 2002 im Museum of Modern Art in New York, 2008 im National Art Museum of China in Peking, 2009 in der National Portrait Gallery in London. Zu seinem 80. Geburtstag würdigte im Februar 2012 die Tate Modern in London gemeinsam mit dem Centre Pompidou in Paris und der Neuen Nationalgalerie in Berlin einen bedeutsamen Ausschnitt seines breit gefächerten Euvres. Die Retrospektive Panorama zeigte 140 Gemälde sowie einige Skulpturen des Künstlers und ermöglichte so einen Einblick in die eindrucksvolle Vielschichtigkeit und Intensität von Richters künstlerischem Schaffen.

Gerhard Richter ist nicht nur einer der bedeutendsten und einflussreichsten Künstler, er gilt auch als einer der teuersten Gegenwartskünstler. Auf dem Kunstmarkt erzielen seine Werke regelmäßig Millionenbeträge: Im Oktober 2012 wurde das Werk Abstraktes Bild (1994) im Auktionshaus Sotheby's in London für 21,3 Million Pfund (rund 26,5 Millionen Euro) versteigert, im Mai 2013 sein Gemälde Domplatz, Mailand (1968) für eine Rekordsumme von 37,1 Millionen Dollar (knapp 29 Millionen Euro) bei Sotheby's in New York.

Text 2: Unschärfe als Stilprinzip

Unschärfe gilt in der allgemeinen ästhetischen Auffassung als Fehlleistung. Die zeitgenössische Bildproduktion wertet Unschärfe jedoch nicht als mangelhaft noch defizitär, vielmehr gilt sie als legitimes und wichtiges technisches Verfahren, um der Betrachterin und dem Betrachter anhand ihrer Ambiguität Freiheit zur Interpretation und Fantasieentfaltung zu ermöglichen. Gleichzeitig wird durch die Verwischung das Eigenleben der Malerei akzentuiert.

Die für Gerhard Richter charakteristische Unschärfe in seinen nach fotografischem Quellenmaterial gemalten Bildern entsteht durch die Technik der Verwischung. Den Verwischungseffekt erzielt der Künstler dadurch, dass er mit einem breiten trockenen Pinsel in der Regel horizontal oder vertikal die angetrockneten Ölfarben auf der Leinwand verwischt. Die Motive werden auf diese Weise partiell undeutlich und wirken durch die oberflächliche Weichzeichnung der Konturen verschwommen, so als wären sie in eine unscharfe Sphäre entrückt. Gerhard Richter äußerte sich zum Charakteristikum der Verwischung in seinen Gemälden folgendermaßen:

Ich verwische, um alles gleich zu machen, alles gleich wichtig und gleich unwichtig. Ich verwische, damit es nicht künstlerisch-handwerklich aussieht, 
sondern technisch, glatt und perfekt. Ich verwische, damit alle Teile etwas ineinander rücken. Ich wische vielleicht auch das Zuviel an unwichtiger Information aus (Richter; Elger; Obrist 2008: 33).

Das Verschwimmen der Konturen in seinen Werken besitzt eine ästhetische Wirkung; es fasziniert, irritiert und verunsichert zugleich. Geheimnisvoll wird durch die erzeugte Weichzeichnung das Dargestellte verschleiert. Seine Bilder führen durch die Unschärfe exemplarisch die Grenzbereiche visueller Wahrnehmung vor Augen. Weil sie zwischen dem Realismus einer Fotografie und dem Farbenspiel abstrakter Malerei changieren, erzeugen sie einen Eigenwert im neuen verfremdeten Erscheinungsbild. Sie konfrontieren die Betrachterin und den Betrachter einerseits mit der Frage nach der Wirklichkeit des Wahrgenommenen, andererseits mit der Funktion der Kunst für die menschliche Perzeption.

Durch den Akt der Verwischung und die damit erzielte Unschärfe werden im Gegensatz zur traditionellen Malerei die abgebildeten Figuren anonymisiert und entindividualisiert; Fotovorlagen werden von Richter Modellen vorgezogen und das Innenleben seiner Protagonisten ist für die Betrachterin und den Betrachter kaum noch ergründbar. Es entstehen auf diese Weise ambivalente Bilder, die durch den Akt der Distanzierung sich einer klaren Lesbarkeit entziehen. Die intendierte Verweigerung des emotionalen Gehalts lässt seine Gemälde ernst, distanziert, unpersönlich wirken und lädt so zu Diskussionen über die Werke, deren Entstehung, den Künstler und seine Gedankenwelt ein. 


\section{Musik}





\section{Text - Bild - Klang \\ Ästhetisches Lernen im mehrsprachigen Medienverbund}

\section{Camilla Badstübner-Kiritk}

Medienkombinationen können die in einzelnen Medien enthaltenen Impulse für ästhetisches Lernen potenzieren. Die Autorin geht zunächst auf die Ziele ästhetischen Lernens und ibre Relevanz für den Fremdsprachenunterricht ein. Sie zeigt Möglichkeiten für die Kombination ästhetischer Lerngegenstände in einem Medienverbund und erläutert dann mit Blick auf Deutsch als Fremdsprache am Beispiel der Dreigroschenoper, welche Möglichkeiten ein authentisch gewachsener mehrsprachiger Medienverbund für ästhetische Lernprozesse bietet.

\section{1 Ästhetisches Lernen im Fremdsprachenunterricht}

Als Ziel ästhetischen Lernens gilt, aus der Sicht eines Musikpädagogen, Lernenden

dazu zu verhelfen, aktiv handelnd, fühlend und reflektierend, in der Auseinandersetzung mit gestalteter Wirklichkeit und Kunst (als Teil dieser Wirklichkeit) ein bewussteres, offeneres Welt- und Selbstkonzept auf der Grundlage vermehrter Wahrnehmungsfähigkeit, kommunikativer, interaktiver und gestalterischer Kompetenz zu gewinnen (Bastian 1997: 124).

Dies hat fächerübergreifende Gültigkeit und zeigt Konstanten, die in den verschiedenen Versuchen, ästhetisches Lernen zu definieren, immer wieder aufgenommen werden $^{1}$ :

1 Vgl. z.B. zusammenfassend: http://www.uni-paderborn.de/institute-einrichtungen/plaz/plazorganisation/projektgruppen-und-forschungskollegs/forschungskolleg-aesthetisches-lernen/

(Stand: 02.10.2013). 
1. Ästhetisches Lernen fokussiert auf eine Förderung und Differenzierung der Wabrnehmungsfähigkeit. Dazu gehört zum einen die Reflexion (und ggf. Verschiebung) von Wahrnehmungsgrenzen, zum anderen die (Wiederentdeckung und) Schulung einer verweilenden oder verlangsamten Aufmerksamkeit, die Rede ist oft auch von Entschleunigung der Wabrnebmung. So sind Hin-Sehen und Hin-Hören, darüber hinaus aber auch Er-Fühlen oder Er-Riechen als Primärerfahrungen neu zu entdecken. Sie helfen dabei, Erfahrungen aus zweiter Hand und überwiegend kognitiv geprägte Lernprozesse zu kompensieren.

2. Ästhetisches Lernen fördert Emotionalität. Die Initiierung von persönlicher Anteilnahme, Involvement, Empathie und subjektiver Auseinandersetzung mit Lerninhalten ist in ästhetischen Lernprozessen beabsichtigt. Grundsätzlich sind sie auf den Ausbau und die Differenzierung von Gefühlswelten und Erlebnisfähigkeiten angelegt.

3. Ästhetisches Lernen setzt auf Vorstellungskraft, Phantasie und Kreativität. Diese werden u.a. dadurch freigesetzt, dass Fragen angeregt werden, die mehr als eine Antwort zulassen bzw. offen bleiben müssen. Ästhetische Lernprozesse berufen sich dabei rezeptiv und produktiv auf unterschiedliches (z.B. körperliches, bildnerisches, musikalisches, sprachliches) Ausdrucksvermögen und sein jeweiliges Repertoire, dieses wird als komplementär verstanden.

4. Ästhetisches Lernen ist auf Sozialität und Handeln ausgerichtet. Im Mittelpunkt stehen Erfahrungen von Gemeinschaft, Teilhabe und aktiver Gestaltungsmöglichkeit, begleitet von einem Wunsch nach Deutung. Die Begegnung mit anderen, grundsätzlich gleichberechtigten Vorstellungs-, Gefühls- und Interpretationswelten (AutorInnen/KünstlerInnen - RezipientInnen, RezipientIn A - RezipientIn B usw.) birgt intersubjektives und interkulturelles Potenzial. Die Handlungsausrichtung schließt eine breite Palette an Reaktionen ein, darunter Irritation und Distanz ebenso wie Identifikation oder Perspektivenübernahme. Ästhetische Lernprozesse wirken unter sozialer Ausrichtung sowohl nach innen (Selbsterkenntnis) wie nach außen (Empathie, Toleranz).

5. Ästhetische Lernprozesse fördern - auf der Grundlage von Wahrnehmung, Reflexion und Wissenserwerb - die Entwicklung von Interpretations- und Deutungskompetenzen. Entscheidend dafür ist beispielsweise eine immer wieder notwendige Ausbalancierung des Verhältnisses von Detail und Ganzem, Konkretem und Abstraktem, Bekanntem und Unbekanntem, Vertrautem und Neuem, Verständlichem und Unverständlichem, Eindeutigem und Mehrdeutigem, Eigenem und Fremdem.

6. Ästhetisches Lernen ist ganzheitlich angelegt: verschiedene Fächer, Künste, Sinne und Lebensbereiche greifen ineinander und ergänzen einander. Damit spiegeln ästhetische Lernprozesse die Realität und ermöglichen vielfältige Zugänge zu ihr.

Lernprozesse in diesem Sinne können durch Gegenstände angeregt werden, die im Ergebnis von (bewussten) Gestaltungsprozessen entstanden sind und deren Eigenschaften über unterschiedliche Sinneskanäle erfasst werden können (z.B. literarischer Lese-Text). In Hinsicht auf ihr Deutungs- und Handlungsangebot 
wohnt ihnen eine grundsätzliche Vielfalt, Mehrdeutigkeit und Offenheit inne. ${ }^{2}$ Sie sind authentisch, d.h., nicht eigens für Lernzwecke hergestellt oder von vornherein auf Lernverfahren hin angelegt und liegen in einer erfassbaren medialen Form vor (z.B. als gedrucktes Buch). Sie fungieren als Mittler in (unmittelbaren oder mittelbaren) Kommunikationsprozessen und kombinieren ein spezifisches Zeichen- und Symbolsystem (z.B. verschriftete Sprache) mit einer konkreten Präsentationsform (z.B. Papier). ${ }^{3}$ Dabei wird ihnen grundsätzlich ein Inhalt unterstellt, den sie formen und in Bezug auf den sie nicht neutral sind. Konkrete mediale Formen machen bestimmte Inhalte möglich (und andere unmöglich) und strukturieren sie. Sie gestatten jeweils eine bestimmte Art der Speicherung, des Transports durch Raum und Zeit, der (rezipierenden) Nutzung und der (produktiven) Be- und Verarbeitung. In Bezug auf die Realität wirken sie gliedernd, ordnend und reduzierend, sie helfen bei deren Verarbeitung und (symbolischer) Bewältigung. Medien fokussieren auf einzelne Sinneskanäle oder einen Kombination aus diesen (z.B. audialer und visueller Kanal beim Film). ${ }^{4}$

Die enge Relation zwischen ästhetischem Lernen und Medien macht gemeinsame Teilziele von Ästhetischer und Medien-Erziehung möglich. Dazu gehören insbesondere die komplementäre Wahrnehmungsschulung, die Reflexion der eigenen Wahrnehmung und die gezielte Förderung unterschiedlicher ästhetischer Erfahrungen (vgl. Heck 2013: 202f.). Vor allem im Bereich der Wahrnehmungsschulung bietet die Beschäftigung mit den Beziehungen zwischen den strukturellen Eigenschaften einzelner medialer Formate und dem durch sie übermittelten Inhalt die Chance, „Medienästhetiken (schnelle und langsame, diffuse und strukturierte, lineare und nicht-lineare, konkrete und abstrakte, diskursive und nicht-diskursive " (ebd.: 202) zu thematisieren. Medienspezifische Wahrnehmungsweisen und durch sie ausgelöste Wirkungen und Emotionen sollten erkannt, benannt und in ihrer Entstehung reflektiert werden. Nur so kann „ein von Alltagserfahrungen abweichendes Genuss-Erleben in seinen vielfältigen Ausprägungen wie Staunen, Identifikation, spielerischer Distanz oder intensivem Empfinden“ (ebd.) ermöglicht werden. Ästhetisches Lernen in diesem Sinne bedeutet, die Wechselwirkung zwischen vermitteltem Inhalt und dem ihn prägenden medialen Format zu reflektieren, also z.B. über folgende Fragen nachzudenken: Wie wird diese Geschichte als Text erzählt? Wie anders wird sie als Film erzählt? Ist das dieselbe Geschichte? Welche Wirkung hat die Geschichte als Text, welche hat sie als Film? Es geht darum, eine „Nachricht um ihrer selbst willen [zu] betrachten“ (Dobstadt; Riedner 2011: 9, auf

\footnotetext{
2 Dobstadt und Riedner sprechen nach Adolf Muschg von „,nie ganz auflösbare[r] Rätselhaftigkeit“ (Dobstadt; Riedner 2011: 8).

3 Vgl. zum Folgenden auch die kumulative Mediendefinition von Winkler 2004.

${ }^{4}$ Es liegt eine Fülle von Einteilungskriterien für Medien vor. So werden Medien beispielsweise als primär verstanden, wenn sie direkten Kontakt ermöglichen (Stimme, Körper), als sekundär gelten Informationsträger, die auf der Seite des Empfängers technische Geräte voraussetzen (z.B. Buch). Medien, die auf beiden Seiten des Kommunikationsprozesses technische Unterstützung brauchen (z.B. Radio, Fernseher, DVD), sind tertiäre Medien, als quartär werden die neuen Informations- und Kommunikationstechniken bezeichnet (vgl. Heck 2013: 201f.).
} 
der Grundlage von Roman Jakobson), hinter die erzählte Geschichte zu schauen. Für literarische Texte bedeutet das beispielsweise, danach zu fragen, was sie zu Literatur macht, d.h. konkret,

auf die sprachliche Oberfläche [zu] achten, auf den Klang, auf die Zusammenstellung der Worte, die nicht nur nach dem Kriterium der kommunikativen ,Richtigkeit' erfolgt, sondern auch (und manchmal vor allem) nach dem Kriterium eines (formalen) Zueinander-Passens. [...] Der Effekt dieses Verfahrens ist eine Verlagerung der Aufmerksamkeit weg von der Bedeutung, vom Sinn [d.h., der medial erzählten Geschichte]; es geht plötzlich [...] spielerischer, vielleicht auch weniger ernsthaft zu; aber doch nur auf den ersten Blick, denn diese Verlagerung der Aufmerksamkeit weg vom Sinn ist paradoxerweise zugleich eine Voraussetzung, dass Sinn neu erfahrbar wird beziehungsweise neu entstehen kann (Dobstadt; Riedner 2011: 9f.).

Diese Literarizität - hier verstanden als das Lesen über einen vordergründig kommunikativ verwertbaren Inhalt hinaus - ist auf andere mediale Formate übertragbar: in Bildern und Filmen geht es um das Bildliche bzw. Filmische, in Liedern und in Musikstücken um das Musikalische usw. Die Beziehungen zwischen dem Inhalt und der konkret gewählten medialen Ausdrucksweise sind dabei unterschiedlich komplex, auch in der Muttersprache nicht immer überzeugend zu verbalisieren ${ }^{5}$ und für didaktische Prozesse nicht gleich gut zu nutzen. Im Bereich der Fremdsprachendidaktik ist seit einiger Zeit eine verstärkte Hinwendung zur Literarizität zu verzeichnen, in vergleichbare Richtung läuft seit Jahren die didaktische Erfassung von Rezeptions- und Produktionskompetenzen in Bezug auf Bild- und Musikkunst (vgl. z.B. Badstübner-Kizik 2006, Hecke; Surkamp 20106). Medienübergreifendes Arbeiten fokussiert in der Fremdsprachendidaktik gern auf einen zentralen (literarischen) Lese-Text (vgl. z.B. Rymarczyk 2007, Blell 2007, Blell 2010). Die Nutzung des ästhetischen Potenzials von Bildender Kunst (v.a. Malerei, Fotografie) und Musik (v.a. Instrumentalmusik) wird allerdings auch weiterhin gern in andere Didaktiken verwiesen: Bilder und Musik werden, vor allem in der fremdsprachendidaktischen Unterrichtspraxis, nicht selten auf ihr sprachliches und inhaltliches Zuliefererpotenzial reduziert, nicht zuletzt auf Grund der Komplexität bild- und vor allem musikästhetischer Codes. Ihre Leistung bei der Förderung bewusster, intensiver Wahrnehmung, Empathie-, Erlebnis- und Reflexionsfähigkeit steht dennoch auch für die Fremdsprachendidaktik außer Frage. ${ }^{7}$

\footnotetext{
${ }^{5}$ Dobstadt und Riedner weisen am Beispiel der Literatur auf diese Problematik hin: „Wie diese Vielschichtigkeit [...] angemessen auch obne solche Deutungsgespräche erfahrbar gemacht werden kann, ist eine für die Fremdsprachendidaktik wichtige, aber noch nicht zufriedenstellend geklärte Frage“ (Dobstadt; Riedner 2011: 13, Hervorhebung der Autoren).

${ }^{6}$ Entscheidende Impulse gingen (und gehen) dabei von der prozessorientierten Mediendidaktik aus. Vgl. dazu z.B. Hellwig 2007.

${ }^{7}$ Vgl. ausführlich Badstübner-Kizik 2006, insbesondere 338-391.
} 


\section{2 Ästhetische Lerngegenstände im mehrsprachigen Medienverbund}

Gerade unter den Zielsetzungen ästhetischen Lernens kann die Kombination verschiedener medialer Textformate didaktisch hochpotente Lernangebote schaffen. ${ }^{8}$ Sie sprechen unterschiedliche Sinneskanäle an (Multimodalität), greifen auf unterschiedliche Codesysteme zurück (Multicodalität) und begünstigen - als eine mögliche Antwort auf die zunehmend vernetzte und hybride Realität - die Entwicklung von multiliteracies, eine Herausforderung, der sich der Fremdsprachenunterricht gegenüber sieht (vgl. u.a. Bland 2012: 141). Die Potenzierung und Verstärkung von ästhetischen Lernangeboten kommt einer allgemeinen Schwerpunktverlagerung im Fremdsprachenunterricht entgegen, von einer (pragmatisch verstandenen) Kommunikationsfähigkeit hin zu einer umfassenden Wahrnehmungsfähigkeit, vom interkulturellen zu einem ,umfassenden kulturbezogenen Lernen“ (Dobstadt; Riedner 2011: 7), von kommunikativer Kompetenz zu symbolischer Kompetenz. ${ }^{9}$ Wie ästhetische Merkmale in einer multimedialen Konstellation besonders deutlich und damit für die Reflexion besser zugänglich werden können, lässt sich exemplarisch an der Verfilmung literarischer Texte beobachten: Zum gedruckt vorliegenden Text kommen die simultanen Codes von Bild, Klang, ggf. Raum, Licht, Bewegung hinzu, die literarische Textvorlage wird zu einer Art Hypertext erweitert, der andere Rezeptionsflächen bietet. Kennzeichnend ist die Möglichkeit einer Visualisierung und Audialisierung von gedruckter Sprache: Ihrem Potenzial an „Begriffe[n] und kategorielle[n] Zuordnungen“" (Binder; Engel 2008: 42) steht die Fähigkeit des Films gegenüber, ,in der Form des Bildes das Konkrete besser vor Augen“ (ebd.) zu führen. Eine der häufig gewählten Möglichkeiten der Transformation $^{10}$ von Literatur in Film wird dabei als „Übertragung von Konzepten“ (Poppe 2007: 91) verstanden. Für ihr Gelingen steht das Auffinden von geeigneten funktionalen, auf eine vergleichbare Wirkung zielenden, aber keineswegs wörtlichen Entsprechungen im anderen Medium. Dabei verkürzt das Medium Film einerseits notwendigerweise die Vorstellungsbildung, indem es „konkrete Bilder an die Stelle von vergleichsweise deutungsoffenen schriftsprachlichen Zeichen“ (Neuhaus 2008: 13f.) setzt, andererseits trägt es zur „Demokratisierung der Welt der Fiktionen“ (ebd.) bei: Ein größeres Publikum kann einfacher und direkter erreicht werden. Zweifellos liegt darin die Chance, die Rezeption eines literarischen Textes über

\footnotetext{
${ }^{8}$ Vgl. grundlegend Hallet 2002; zum inhaltsorientierten Lernen im Medienverbund auch BadstübnerKizik 2007: 87-130, Badstübner-Kizik 2013.

9 Der Begriff geht auf Claire Kramsch zurück. Symbolische Kompetenz gilt als ,wichtiges Ziel für einen zeitgemäßen Fremdsprachenunterricht“. Sie „umfasst eine differenzierte Deutungskompetenz sowie die Fähigkeit, Bedeutungen im Prozess der sprachlichen Interaktion flexibel auszuhandeln“ (o.A. 2011: 70). Über die inhaltliche und formale (ästhetische) Erschließung von Literatur kann Bedeutungsbildung, Komplexität und Mehrdeutigkeit besonders nachvollziehbar werden. Vergleichbares gilt für andere mediale Formate.

10 Transformation bezeichnet den Übersetzungsvorgang von einem Medium in ein anderes (vgl. dazu Poppe 2007). Was hier für die Beziehung zwischen literarischem Text und Film formuliert wurde, gilt grundsätzlich auch für andere Medienkonstellationen.
} 
mediale, kulturelle und/oder sprachliche Grenzen hinweg leichter und unterhaltsamer zu machen, zugleich aber wird sie stärker konditioniert. Die Übersetzungsmöglichkeiten von einem Medium ins andere sind dabei vielfältig: neben einer analogen Wiedergabe (die literarische Botschaft als Filmtext) kann es sich um eine konzeptuelle Interpretation ${ }^{11}$ oder um eine eigenständige Transformation handeln. Im letzteren Fall wäre der literarische Text nur einer unter mehreren Bezugspunkten des Films.

Es gibt verschiedene Möglichkeiten, mediale Formate miteinander zu kombinieren und so ihr ästhetisches Potenzial im Vergleich und Kontrast zugänglich und deutlich zu machen. Wichtig sind aus meiner Sicht zum einen primäre Medienverbünde. Sie sind dadurch gekennzeichnet, dass konkrete mediale Formen gezielt in ein anderes Medium transformiert, durch ein solches begleitet, ergänzt oder kontrastiert werden. Das kann zeitgleich oder zu einem späteren Zeitpunkt, durch denselben, einen oder mehrere andere Autoren geschehen, entscheidend ist, dass die mediale Beziehung intendiert ist. Zu dieser Art Medienverbund gehören z.B. Illustrationen, Vertonungen oder Verfilmungen literarischer Textvorlagen, transmediale Rezeptionen (Cross-Over) und andere Formen von beabsichtigten Bearbeitungen. Die Bandbreite reicht dabei von bewusst gesuchter Unterordnung und Parallelität über das Zitat bis hin zur offenen Kontrastierung (Verfremdung, Parodie). Aussagekräftige Beispiele bieten unter zahllosen vertonten lyrischen Texten etwa die Liederzyklen der deutschen Romantik (z.B. Winterreise, Die schöne Müllerin), die im Allgemeinen auf eine Unterstützung und Potenzierung der Struktur und Aussage des unverändert bleibenden literarischen Textes setzen. Auf der anderen Seite des Spektrums stehen verfremdende Bearbeitungen literarischer, musikalischer oder auch bildkünstlerischer Texte (z.B. Schülerparodien zu klassischen literarischen Texten). Andere Möglichkeiten bieten sekundäre Medienverbünde, deren einzelne Bestandteile methodisiert, d.h., speziell für Erkenntnis- und Lernverfahren zusammengestellt werden (vgl. Würffel 2010: 1228). Diese Zusammenstellung kann unter verschiedenen Gesichtspunkten erfolgen. Eine Möglichkeit wäre z.B. die Fokussierung auf eine zeitliche und/oder inhaltliche Passung, eine andere die der (vermuteten) ästhetischen und strukturellen Parallelität.

Ästhetische Lernprozesse verlaufen in primären Medienverbünden entlang konkreter vorliegender Medienbeziehungen, häufig diachron und stärker medienübergreifend (z.B. literarische Vorlage und spätere Verfilmung). Daneben kann das kreative Potenzial Lernender genutzt werden, um neue konkrete Medienbeziehungen zu schaffen (z.B. Illustration eines literarischen Textes durch Lernende). Ein sekundärer (methodisierter) Medienverbund ist im Vergleich dazu potenziell sehr viel offener, unstrukturierter und auch subjektiver. Bei der Wahl seiner einzelnen Bestandteile können unterschiedlichste Kriterien greifen. Der Medienverbund kann stärker kulturentdeckenden Charakter annehmen (z.B. innerhalb eines bestimmten Zeit-

\footnotetext{
${ }^{11}$ Binder und Engel sprechen für diesen Fall von „Auswahl und Zuspitzung von Schlüsselkonzepten“" (Binder; Engel 2008: 46).
} 
raums), entlang formaler Merkmale erfolgen (z.B. innerhalb eines bestimmten Mediums oder Textgenres) oder Spezialinteressen berücksichtigen. Ästhetische Lernprozesse werden hier angeregt, wenn Texte, Bilder oder Klänge, die zunächst unabhängig voneinander existieren, aufeinander bezogen werden und die Art dieser Beziehung reflektiert wird. Das geschieht eher rezeptiv, wenn Zusammenstellungen nachvollzogen und ggf. begründet werden sollen, und nimmt eher produktiven Charakter an, wenn neue Kombinationen erstellt werden. Primäre und sekundäre Medienverbünde bieten immer die Möglichkeit, einander zu ergänzen, „flexible [...], Kontextnetze ${ }^{6}[\ldots]^{\prime \prime}$ (Schiedermair 2011: 29) zu bilden. Für die konkrete didaktische Arbeit können unterschiedliche Ausgangspunkte gewählt, unterschiedliche Erarbeitungswege beschritten und die Beziehungsnetze unterschiedlich dicht geknüpft werden. Dabei darf nicht aus den Augen verloren werden, dass es ,nicht um eine erschöpfende Besprechung, sondern um die Erfahrung [geht], dass der analytische Blick besser verstehen hilft und also die Lust am Text [oder an anderen medialen Formaten] steigert" (Bürner-Kotzam 2011: 45). Mehrfach ist in der einschlägigen Fachliteratur gezeigt worden, wie das leichtere Medium (z.B. Film) den Zugang zum schwierigeren (z.B. literarischer Text) erleichtert und die Wahrnehmungsfähigkeit für dessen ästhetische Codes schärft. ${ }^{12}$

\section{Die Dreigroschenoper als authentisch gewachsener mehrsprachiger Medienverbund für $\mathrm{DaF}$}

Die Dreigroschenoper von Bert Brecht und Kurt Weill (1928) stellt auf Grund ihrer besonderen Affinität für zeitgleiche wie nachgeordnete Rezeptions- und Transformationsversuche ein mediales Phänomen dar. Rund um den zentralen literarischen Text existiert ein mehrsprachiger multimodaler und multicodaler primärer Medienverbund, der vielfältige Möglichkeiten für sekundäre Erweiterungen beinhaltet. Er bietet unterschiedliche Ausgangspunkte für ästhetische Lernprozesse in zunehmend mehrsprachigen Lernkontexten, nicht zuletzt im Hinblick auf die weitgehende Etablierung von Deutsch als Fremdsprache nach Englisch bzw. im Kontext mit anderen (Fremd-)Sprachen. Ohne Anspruch auf Vollständigkeit und Originalität sei hier an wesentliche mediale Eckpfeiler erinnert, die vom 18. Jahrhundert bis in die unmittelbare Gegenwart reichen:

\footnotetext{
12 Diesen Weg beschreitet Bürner-Kotzam 2011, wenn sie mit Lernenden zunächst einzelne Merkmale der Filmsprache erarbeitet und diese dann auf literarische Texte anwenden lässt: Das Ziel ist der Text, wenn es darum geht, über die Beschäftigung mit Perspektiven, Einstellungsgrößen, Montageoder Schnitttechniken ,einen analytischen Zugang zu modernen Texten zu ermöglichen, der den Blick auch für sprachliche und literarische Gestaltungsmittel schärft. [...] Durch eine solche, auf die Filmerfahrungen und Filmbegeisterung der Lernenden zurückgreifende Herangehensweise kann Angst vor Literatur abgebaut, neues Interesse für literarische Texte [...] geweckt [...] werden“ (Bürner-Kotzam 2011: 46).
} 
- Text/Musik/Bild/Film/szenische Aufführung ${ }^{13}$ :

Das Theaterstück von Brecht und Weill knüpft an The Beggar's Opera von John Gay zur Musik von Johann Christoph Pepusch an (1728). Der Text der Opera liegt gedruckt und als e-Text im englischsprachigen Original und in Übersetzungen vor. Das Ereignis der Aufführung wurde durch William Hogarth malerisch illustriert (um 1728), die Oper selbst mehrfach verfilmt (1953, 1984, 1991). Von dem Gemälde Hogarths existiert wiederum ein Stich von William Blake (1790). Bis in die Gegenwart wird die Opera gespielt, z.T. mit neuerer Musik und in bearbeiteter Form.

- Text:

Brechts Bühnentext der Dreigroschenoper liegt in zahlreichen Auflagen im Original und in Übersetzungen gedruckt vor. 1934 veröffentlichte der Autor einen (Kriminal-)Roman zum selben Stoff (Dreigroschenroman).

- Klang-Musik-Kombination/Musik:

Das Theaterstück selbst enthält längere Gesangseinlagen (Songs) zur eigens komponierten Musik von Kurt Weill. Dieser gab 1929 zusätzlich eine Orchestersuite heraus (Kleine Dreigroschenmusik). Viele der Songs haben sich verselbständigt und existieren unabhängig vom Bühnenstück. Die Orchestersuite liegt, ebenso wie die gesamte Oper und einzelne Songs, in einer umfangreichen Diskographie aus verschiedenen Jahren und von verschiedenen Interpreten, ggf. in unterschiedlichen Sprachen, vor.

- Film:

Drei Jahre nach der Uraufführung im Theater am Schiffbauerdamm (heutiges Berliner Ensemble) wurde die Brechtsche Oper in prominenter Besetzung verfilmt (D, Regie: Georg Wilhelm Pabst 1931, u.a. mit Weills Ehefrau Lotte Lenya, Carola Neher sowie Ernst Busch als Moritatensänger). 1962 (D, Regie: Wolfgang Staudte, u.a. mit Curd Jürgens und Hildegard Knef), 1989 (Mack the Knife, USA, Regie: Menahem Golan), 1995 (TV) und 2004 (TV) folgten weitere Verfilmungen.

- Szenische Aufführung:

Bis heute wird das Theaterstück (bzw. Auszüge daraus) in verschiedenen Sprachen an professionellen Theatern und Kleinkunstbühnen sowie off-Theatern weltweit szenisch aufgeführt. ${ }^{14}$

\footnotetext{
13 Mit Text sind im Folgenden schriftlich vorliegende Texte zum Lesen gemeint (gedruckt oder als eText), Klang meint gesprochene Texte zum Hören (z.B. Hörbuch), Klang-Musik-Kombinationen bezeichnet die Aufzeichnung von musikalisch begleiteten Hörtexten (registrierte szenische Aufführung zum Hören, z.B. auf CD, auch als Hörspiel). Musik bezeichnet instrumentierte Passagen (ohne Text). In Film (aufgezeichnet) sind ebenso wie in der szenischen Auffïbrung (live) akustische (gesprochener Text, musikalisch begleiteter Text, Geräusch, textlose Musik) und visuelle Ebenen zusammengeführt. Zusätzlich käme bei der szenischen Aufführung eine (haptische) Raumwahrnehmung hinzu (Theatergebäude, Opernhaus usw.).
} 
- Klang/Text-Musik-Kombination:

Die Dreigroschenoper liegt als Hörbuch und Hörspiel vor.

- Text-Musik-Kombination/szenische Aufführung:

Einzelne Songs aus der Dreigroschenoper wurden/werden prominent gecovert, eine Spitzenposition nimmt die Moritat von Mackie Messer in verschiedenen Sprachversionen ein (u.a. Englisch, Französisch, Spanisch, Italienisch, Russisch, Tschechisch, Polnisch). ${ }^{15}$ Im Einzelfall handelt es sich um weitgehende Bearbeitungen, insbesondere des Textes (u.a. durch Rammstein). Neben Song-Rezeptionen gibt es unzählige professionelle und private medienübergreifende Verarbeitungen (Kombinationen von Musik und Text u.a. mit Tanz, Performance, Comic, Umsetzung als Lego-Videoclip usw.).

Dieser primäre Medienverbund kann durch einen sekundären ergänzt werden, z.B.:

\section{- Bild:}

In besonderer Weise bieten sich sozialkritische Graphiken und Gemälde der 1920er- und 30er-Jahre aus dem Umkreis von George Grosz, Otto Dix oder Karl Hubbuch an (Neue Sachlichkeit). Viele von ihnen zeigen inhaltliche und strukturelle Parallelen zu der in der Dreigroschenoper entworfenen Welt. ${ }^{16}$

- Klang-Musik-Kombination/Musik:

Weills Musik enthält viele Elemente historisierender (Barock, Klassik) und zeitgenössischer Musikentwicklung (Jazz), daraus ergeben sich unterschiedliche musikgeschichtliche Anknüpfungspunkte.

- Text/Klang/Klang-Musik-Kombination/Film/szenische Aufführung:

Verfremdungstechniken, wie sie auch in der Dreigroschenoper zum Tragen kommen (z.B. Erzähler-Moritatensänger, die Handlung unterbrechende Gesangseinlagen) sind in vielen anderen Werken Brechts präsent. Ebenso kann auf weitere gemeinsame Arbeiten von Brecht und Weill mit vergleichbarer Struktur zurückgegriffen

14 Die statistischen Angaben auf operabase verweisen für den Zeitraum seit Oktober 2011 auf 118 Aufführungen in 30 Städten weltweit (http://operabase.com/oplist.cgi?id=none\&lang=de\&is= Dreigroschenoper\&by $=\& l o c=\& s t y p e=a b s \& s d=2 \& s m=10 \& s y=2011 \&$ etype $=$ abs \&ed $=\& e m=\& e y=$ (Stand: 02.10.2013). Die Suche nach off-Aufführungen auf YouTube ergibt regelmäßig etwa 100 Treffer (darunter viele Schülertheater).

15 Das Stichwort Mackie Messer ergibt auf YouTube ca. 12300 verschiedensprachige Einträge, darunter prominente (klassische) Versionen (u.a. Louis Armstrong, Lotte Lenya, Ernst Busch, Ute Lemper, Sting, Robbie Williams) sowie zahllose weniger bekannte Darsteller und Privataufnahmen (Stand: 02.10.2013).

16 Neben dem Zyklus Ecce homo von George Grosz (1923) bietet sich z.B. Otto Dix' Triptychon Großstadt an (1928). Abgesehen von dem inhaltlichen Personal, das auch in vielen anderen zeitgenössischen bildkünstlerischen Arbeiten auftaucht (z.B. Bettler, Krüppel, Prostituierte, Polizisten) verfremden beide - analog zu Brecht und Weill (Oper, Ballade usw.) - klassische Bildtypen (hier: Bildtyp Zurschaustellung Christi, dreiteiliges Altargemälde) und z.T. traditionelle künstlerische Techniken. 
werden, allen voran Aufstieg und Fall der Stadt Mahagonny (1930). Sie bieten z.T. eine ähnliche multimediale und mehrsprachige Rezeption wie die Dreigroschenoper.

- Text/Klang-Musik-Kombination/szenische Aufführung:

Die für die Dreigroschenoper gewählten klassischen Formate (Oper, Ballade, Song oder Moritat) eröffnen den Blick in eine Fülle von älteren, zeitgenössischen und aktuellen Texten und Musikbeispielen zum Lesen, Hören und Sehen.

Im Schnittpunkt dieser medialen Formate ergeben sich - abgesehen von umfangreichen Gelegenheiten für kulturentdeckendes Lernen (insbesondere mit kultur- und literaturhistorischer Ausrichtung) - vielfältige Gelegenheiten für ästhetische Lernprozesse. Für besonders ergiebig halte ich vergleichende Analysen und Recherchen über Mediengrenzen hinweg sowie die Anwendung ästhetischer Codes auf andere mediale Formate. ${ }^{17}$ Zwischen einzelnen Bestandteilen des Medienverbundes ergeben sich allerdings beträchtliche Unterschiede, was den Abstraktionsgrad und damit verbundenen theoretisch-begrifflichen Aufwand betrifft, sowohl terminologisch wie auch rein lexikalisch (in der fremden und eigenen Sprache): Musikalische Strukturen im Song Mackie Messers zu erkennen und zu benennen, ist sehr viel ungewohnter und komplexer als die Reimform im dazugehörigen Text. Der analytischen Erarbeitung eines Bestandteils (Text, Bild, Musikstück, Filmaufnahme usw.) bzw. Fragments aus dem beschriebenen Medienverbund dienen z.B.:

- Beschreibung der äußeren Erscheinung (z.B. Länge, Größe, Bestandteile, Farben, Formen, Lautstärke usw.). Dabei können gezielt medienspezifische Merkmale herausgearbeitet werden.

- Benennen einzelner Elemente (z.B. sprachliche Bilder, dargestellte Personen, Gegenstände, Motive sprachliche und musikalische Formen usw.)

- Aufdecken von Beziehungen zwischen einzelnen Elementen (z.B. Erzählperspektiven, Fokalisierungen, Blickrichtungen, Über-/Unterordnungen, Wiederholungen usw.)

- Benennung von Emotionen (Sympathie, Antipathie, Irritation usw.), die während des Rezeptionsprozesses entstehen; Suche nach ihren Auslösern (z.B. konkretes Wort, Melodiefragment, Bilddetail) und Manifestationen diegetisch (unter den Protagonisten), extradiegetisch (auf die rezipierende Person), textabhängig oder textunabhängig (vgl. dazu u.a. Donnerstag; Wolff 2007)

\footnotetext{
17 Vgl. allerdings die berechtige Warnung Carola Surkamps vor einer Nutzung literarischer Texte als „Sprungbrett für kreativ-produktive Arbeiten“ (Surkamp 2007: 101), dies führe zu ihrer Beliebigkeit und schließlichen Entwertung. „Eine Möglichkeit, dieser Gefahr zu entgehen, liegt in der Verbindung von handlungs- und produktorientierten Aufgaben mit analytischen Verfahren" (ebd.), daneben sind „solide Textkenntnis“ (ebd.) und eine bewusste Rückbeziehung auf den Ausgangstext notwendig (ebd.). Analoges gilt aus meiner Sicht für andere mediale Formate. So müssten die von Grosz oder Dix gewählten Bildtypen im Verhältnis zu den in ihnen vermittelten Inhalten auf die Opernform bei Brecht und Weill bezogen werden.
} 
- Kennzeichnung von Stolpersteinen und Leerstellen (z.B. Mehrdeutigkeiten, Ambivalenzen, Widersprüche, fehlende Elemente; vgl. dazu auch Dobstadt; Riedner 2011: 11f.)

- Aufbau von assoziativen und/oder semantischen Netzen um einzelne Elemente (z.B. um Wörter, Bilddetails, Klangfiguren)

- Reproduktion von Ausschnitten und ggf. Verbalisieren/Kommentieren der damit verbundenen Vorgänge und Gefühle (z.B. Sprechen ${ }^{18}$, Aufführen, Singen, Ab-Zeichnen/Kopieren)

- Veränderung des medialen Formats unter Beibehaltung wesentlicher inhaltlicher Bestandteile (z.B. Bühnentext wird zum Einakter, Film wird zum Kurzfilm, szenische Aufführung wird zum Puppentheater)

- Veränderung/Verfremdung von strukturell wichtigen Eigenschaften (z.B. Perspektivenwechsel, Farbwechsel, elektronische Klangveränderung, Veränderung von Personenkonstellation, Raum- und Lichtverhältnissen usw.)

- kreativ-spielerische Weiterverarbeitung von Fragmenten, Motiven, Details usw. (z.B. Such- und Ratespiele, Text-, Bild-Puzzle, kreatives Schreiben, Malen, alternatives Instrumentieren usw.).

Während diese und ähnliche Aufgaben sich vorrangig innerhalb eines medialen Formats anbieten und die Aufdeckung medienspezifischer Strukturen fördern, implizieren die folgenden Möglichkeiten eher intertextuelles und intermediales Arbeiten. Dabei tragen viele von ihnen rezeptiven Charakter (Nutzung bereits bestehender intermedialer Beziehungen innerhalb des Verbundes), andere sind eher produktiv-kreativ ausgerichtet (Übertragung erkannter Strukturen auf andere Formate, kreative Veränderung, Verarbeitung). Von welchem Format dabei ausgegangen wird, ist u.a. abhängig von Rezeptionsgewohnheiten und -erwartungen. Durch die analytische und spielerische Beschäftigung mit Elementen eher zugänglicher (und attraktiver) Formensprachen kann die Bereitschaft erhöht werden, sich auch für schwierigere und ungewohntere zu öffnen. Folgende Verfahren bieten sich z.B. an:

- vergleichende Ausführung der oben genannten Verfahren zwischen zwei oder mehreren medialen Formaten (z.B. Vergleich von äußerer Erscheinung, Konstellationen im Text, Emotionen und ihren Auslösern, Perspektiven und Fokalisierungen, erzielter Wirkung)

- Auffinden von intertextuellen Verbindungen, Abhängigkeiten, Gemeinsamkeiten und Unterschieden (z.B. im Beziehungsgefüge Text-Text, TextMusik, Text-Film)

- Herausarbeiten komplementärer/kontrastierender bedeutungstragender Strukturen (z.B. im Beziehungsgefüge Film-Musik)

- Aufspüren von intertextuellen Leerstellen (z.B.: Was wird im Text gesagt, aber im Bild nicht gezeigt?), ggf. ihre Füllung

\footnotetext{
18 Auffällig ist beispielsweise die starke Rhythmisierung vieler Textpassagen, was besonders in den historischen Aufnahmen deutlich zum Vorschein tritt.
} 
- Vergleich einzelner (Text-)Fragmente in verschiedenen Sprachen im Hinblick auf ihre Konnotationen (z.B. in Songtexten und ihrer Übersetzung)

- vorübergehendes partielles Ausblenden/auch Umkehrung von offiziellen transmedialen Beziehungen innerhalb des Medienverbundes und Erarbeitung neuer/alternativer Lösungen (z.B. vom Film zum Theaterstück, von der Musik zum Text), ggf. Vergleich mit der offiziellen Version

- kreative Weiterverarbeitung von Fragmenten, Motiven, Details über Mediengrenzen hinweg und ggf. in neuen Formaten (z.B. Text-, Bild- und Musikcollagen, Werbespots)

- Auffinden von weiteren Beispielen für szenische Aufführungen, Adaptionen, Parodien usw. und ihre Einschätzung (z.B. nach dem Kriterium der Texttreue, der erzielten Wirkung, der optimalen Nutzung des gewählten medialen Formats)

- Schaffen komplementärer/fehlender medialer Angebote (z.B. Textillustrationen, Bilderbuch, Kurzgeschichte, Comic, Fotostory, Poster, Werbeangebot, Lernprogramm, Musikvideoclip, Internetseite usw.).

Der Erweiterung des primären Medienverbundes um sekundäre Elemente dienen vor allem Aktivitäten im Umkreis von Recherchen, sie erweitern die Medienkenntnisse, fördern eine kritische Rezeptionskompetenz und unterstützen eigenverantwortete Lernprozesse. Dabei können sie so gelenkt werden, dass (neben inhaltlichen) auch strukturelle Eigenschaften als Suchkriterien im Vordergrund stehen, z.B.:

- Auffinden von subjektiv als passend empfundenen Texten, Bildern, Musikstücken und Begründung der Wahl (z.B. nach dem Kriterium ihrer Passgenauigkeit zu einzelnen Text-, Musik- oder Filmfragmenten)

- Übertragen erkannter struktureller Eigenschaften auf selbst gewählte neue Stoffe (z.B. Stück mit Gesangseinlagen, Kurzfilm mit Erzähler; Adaption weiterer traditioneller Text-, Bild- oder Filmformate)

- Schaffen von Hypertexten aus vorliegenden und eigenen Bestandteilen, auch sprachübergreifend

- Konzeption und Durchführung von längerfristigen Projekten (auch fächerübergreifend) zu einzelnen Aspekten des Medienverbundes mit Schwerpunkt auf einzelnen medialen Formaten und/oder Medienbeziehungen (z.B. Verfilmte Literatur, Musik im Theater ${ }^{19}$.

Innerhalb all dieser - hier nur angedeuteten - Möglichkeiten, die natürlich weiter zu konkretisieren und zu ergänzen sind, gibt es unterschiedliche Abstraktionsgrade, verschiedene Stufen der Sprachrezeption und -produktion, unterschiedliche Antei-

\footnotetext{
19 Beispiele finden sich u.a. bei Schier 2011, die vorschlägt, im Rahmen von Projekten epochen-, genre- und medienübergreifend Texte aus Hoch- und Populärkultur rund um zentrale literarische Texte unter einem Themendach zu sammeln (sammeln zu lassen) und sie anschließend mit ganzheitlichem Methodenrepertoire zu erarbeiten (z.B. Männerbilder in der neueren deutschsprachigen Literatur von Frauen).
} 
le an spielerischen und kreativen Elementen und authentischer Mehrsprachigkeit. ${ }^{20}$ Gemeinsam ist ihnen, dass sie ein mediales Format mit seinen Eigenschaften ernst nehmen und diese als Teil der vermittelten Bedeutung verstehen (vgl. Dobstadt; Riedner 2011: 11). Wichtig ist dabei, dass der jeweilige Text oder Song, das Bild oder der Filmausschnitt als Teil eines natürlich gewachsenen Medienverbundes verstanden wird, dessen einzelne Bestandteile spezifische Eigenschaften haben und unterschiedliche Facetten eines Gesamtbildes übermitteln (können). „[L]iterarische Texte [bringen] prinzipiell alles mit [...], was den Zugang zu ihnen ermöglicht" (Dobstadt; Riedner 2011: 1121), „Kontext [könne daher in] eine weitere Ebene des Textes“ (ebd.) ausgelagert werden. Diese Argumentation, die grundsätzlich auch für Bilder, Musik und Filme gilt, würde ich ergänzen durch die Beobachtung, dass jedoch gerade eine mediale Kontextualisierung ästhetische Formate mit ihren spezifischen Eigenschaften besonders deutlich hervortreten lässt: Was kann ein literarischer Text, ein Musikstück, ein Bild, ein Film besonders gut und was kann er in Bezug auf die durch ihn übermittelte Botschaft eben nicht? Durch welche Mittel prägt er/es die von ihm übermittelte Botschaft? Der Vorteil des Medienverbundes ist, dass Vergleich und Kontrastierung auf der Grundlage eines aus verschiedenen Perspektiven wahrgenommenen Inhalts besonders gut möglich werden und es Lernenden einleuchten kann, wenn die Beschäftigung mit dem ästhetischen Potenzial eines medialen Formats - bei mehrfacher Auseinandersetzung mit dem Inhalt - ins Zentrum rückt. Aus didaktischer Perspektive kann überzeugen, dass es der Medienverbund gestattet, mediale Gewohnheiten und Präferenzen gezielt aufzugreifen und ggf. zu ergänzen. Bei Gelegenheit können verschiedene sprachliche Fertigkeiten (Hör-, Lese-, Hör-Sehverstehen, mündliche und schriftliche Fertigkeiten, Übersetzen) sowie performative Fähigkeiten gefördert werden. Nicht zuletzt ist natürlich die Einbeziehung von authentischer Mehrsprachigkeit ein motivierender Aspekt. Der Medienverbund Dreigroschenoper ist in diesem Sinne ausgesprochen vielseitig und attraktiv. Erfahrungen weltweit zeigen, dass mit einzelnen seiner Teile, und auch über Mediengrenzen hinweg, sehr erfolgreich im DaF-Kontext gearbeitet werden kann. ${ }^{22} \mathrm{Ihm}$ ergänzend an die Seite zu stellen wären andere, darunter solche, die insbesondere auch jüngere Lernende ansprechen. Exemplarisch seien etwa Janosch, Heidi oder auch, für erwachsene Lernende, Der Dritte Mann als multimediale, mehrsprachige und DaF-affine Medienverbünde genannt. Die Sensibilisierung für die Spezifik medialer Formate anhand mehrperspektivisch

\footnotetext{
${ }^{20}$ Die Texte im Medienverbund liegen genuin in verschiedenen Sprachen und mit unterschiedlichem Schwierigkeitsgrad vor. Zwischen Sprachen, Textformaten und Schwierigkeitsgrad kann frei navigiert werden.

${ }^{21}$ Dobstadt und Riedner beziehen den ,,sogenannte[n] Kontext“ (Dobstadt; Riedner 2011: 11) dabei auf Entstehung und Rezeption „wann, von wem, für wen, mit welcher Absicht und unter welchen historischen und gesellschaftlichen Umständen“ (ebd.) und schreiben ihm ,weniger Erklärungsfunktion für einen literarischen Text [und andere ästhetische Formate] zu als oft angenommen wird“ (ebd.).

22 Vgl. z.B. die szenische Umsetzung mit Studierenden in Zypern bei Baumann 2013.
} 
erarbeiteter authentischer Inhalte scheint mir jedenfalls ein gangbarer Weg für ästhetisches Lernen im Fremdsprachenunterricht zu sein.

\section{Literatur}

Badstübner-Kizik, Camilla (2006): Fremde Sprachen - fremde Künste? Bild- und Musikkunst im interkulturellen Fremdsprachenunterricht. Das Fallbeispiel Deutsch als Fremdsprache in Polen. Gdańsk: Wydawnictwo UG.

Badstübner-Kizik, Camilla (2007): Bild-und Musikkeunst im Fremdsprachenunterricht. Zwischenbilanz und Handreichungen für die Praxis, Frankfurt a.M.: Lang.

Badstübner-Kizik, Camilla (2013): Inhaltsorientiertes Fremdsprachenlernen in medialen Umgebungen. In: Chudak, Sebastian (Hrsg.): Fremdsprachenunterrichtomnimedial? Frankfurt a.M.: Lang, 33-45.

Bastian, Dietmar (1997): Bedingungen und Möglichkeiten interkulturellen Lernens im Musikunterricht. Beiträge zu einer gren₹überschreitenden Musikpädagogik. Ludwigsburg: Pädagogische Hochschule.

Baumann, Annedoris (2013): Die Dreigroschenoper im DaF-Unterricht - Vorstellung eines Unterrichtsprojekts. In: Grucza, Franciszek u.a. (Hrsg.): Vielheit und Einheit der Germanistik weltweit. Akten des XII. Internationalen Germanistenkongresses Warschau 2010. Bd. 19. Frankfurt a.M.: Lang, 215-219.

Binder, Eva; Engel, Christine (2008): Film und Literatur. Von Liebeleien, Konflikten und langfristigen Beziehungen. In: Neuhaus, Stefan (Hrsg.): Literatur im Film. Beispiele einer Medienbeqiehung. Würzburg: Königshausen \& Neumann, 31-48.

Bland, Janice (2012): Within and between Texts - Indeterminacy and Empowerment. In: Reinfried, Markus; Volkmann, Laurenz (Hrsg.): Medien im neokommunikativen Fremdsprachenunterricht. Einsat:formen, Inhalte, Lermerkompetenzen. Frankfurt a.M.: Lang, 141-154.

Blell, Gabriele (2007): Zum Wechselspiel von Text und Musik in einer intermedialen Literatur- und Kulturdidaktik. In: Hallet; Nünning (Hrsg.) (2007): 311-328.

Blell, Gabriele (2010): Der Leser als ,Grenzgänger‘: Entwicklung intermedialer Lese- und Sehkompetenzen. In: Hecke; Surkamp (Hrsg.) (2010): 94-109.

Bürner-Kotzam (2011): Literarisches und kinematographisches Erzählen. In: Fremdsprache Deutsch 44, 41-46. 
Dobstadt, Michael; Riedner, Renate (2011): Fremdsprache Literatur. Neue Konzepte zur Arbeit mit Literatur im Fremdsprachenunterricht. In: Fremdsprache Deutsch 44, 5-14.

Donnerstag, Jürgen; Wolff, Martina (2007): Literarische Texte und Emotionen im Fremdsprachenunterricht. In: Hallet; Nünning (Hrsg.) (2007): 143-164.

Hallet, Wolfgang (2002): Fremdsprachenunterricht als Spiel der Texte und Kulturen. Intertextualität als Paradigma einer kulturwissenschaftlichen Didaktik. Trier: WVT.

Hallet, Wolfgang; Nünning, Ansgar (Hrsg.) (2007): Neue Ansätze und Konžpte der Literatur- und Kulturdidaktik. Trier: WVT.

Heck, Bettina (2013): Ernst Jandl für eine Ästhetische und Medien-Erziehung. In: Schweiger, Hannes; Nagy, Hajnalka (Hrsg.): Wir jandln! Didaktische und wissenschaftliche Wege zu Ernst Jandl. Innsbruck: StudienVerlag, 201-218.

Hecke, Carola; Surkamp, Carola (Hrsg.) (2010): Bilder im Fremdsprachenunterricht. Neue Ansätze, Kompetenzen und Methoden. Tübingen: Narr.

Hellwig, Karlheinz (2007): Prozessorientierte Literatur- und Kulturdidaktik: Genese und Kontur eines Konzepts. In: Hallet; Nünning (Hrsg.) (2007): 295-309.

Neuhaus, Stefan (2008): Literatur im Film. Eine Einführung am Beispiel von Gripsholm (2000). In: Neuhaus, Stefan (Hrsg.) (2008): Literatur im Film. Beispiele einer Medienbeziehung. Würzburg: Königshausen \& Neumann, 11-29.

o.A. (2011): Symbolische Kompetenz. In: Fremdsprache Deutsch 44, 70.

Poppe, Sandra (2007): Visualität in Literatur und Film. Eine medienkomparatistische Untersuchung moderner Erzähltexte und ihrer Verfilmungen. Göttingen: Vandenhoeck \& Ruprecht.

Rymarczyk, Jutta (2007): Zum Wechselspiel von Text und Bildender Kunst in einer intermedialen Literatur- und Kulturdidaktik. In: Hallet; Nünning (Hrsg.) (2007): 329-350.

Schiedermair, Simone (2011): Literarische Texte als literarische Texte. Vieldeutigkeit, Anschaulichkeit, Kontextverbundenheit. In: Fremdsprache Deutsch 44, 28-34.

Schier, Carmen (2011): Perspektivenwechsel als Tür zu anderen Welten. Zum Potenzial von Literaturprojekten in Deutsch als Fremdsprache. In: Fremdsprache Deutsch 44, 53-59.

Surkamp, Carola (2007): Handlungs- und Produktorientierung im fremdsprachlichen Literaturunterricht. In: Hallet; Nünning (Hrsg.) (2007): 89-106. 
Winkler, Hartmut (2004): Mediendefinition. In: Medienwissenschaft - Rezensionen, Reviews 1, 104, 9-27. Online: http://homepages.uni-paderborn.de/winkler/ medidef.pdf (Stand: 30.09.2013).

Würffel, Nicola (2010): Deutsch als Fremd- und Deutsch-als-Zweitsprache-Lernen in elektronischen Lernumgebungen. In: Krumm, Hans-Jürgen; Fandrych, Christian; Hufeisen, Britta; Riemer, Claudia (Hrsg.): Deutsch als Fremd- und Zweitsprache. Ein internationales Handbuch. 2. Halbband. Berlin u.a.: de Gruyter, 1227-1243. 


\title{
Musik im DaF-Unterricht: Von der Sprache zur Musik - und zurück
}

\author{
Matthias Perner \\ Eingangs wird die enge Verbindung zwischen und sogar Identität von sprachlichen und musikali- \\ schen Konzepten nachgewiesen. Nach einem historischen Überblick über den Bezug zwischen \\ Musik und Sprachdidaktik werden im dritten Teil, basierend auf aktueller Forscbungsliteratur, \\ konkrete Umsetzungsmöglichkeiten für den Einsatz von Musik (RaP) im Bereich Deutsch als \\ Fremdsprache vorgestellt.
}

\section{Die Verbindung von Sprache und Musik}

Dass Musik eine enge, vielleicht sogar sehr enge Verbindung mit Sprache hat, wird schon durch die beiden Schlüsselbegriffe Sprachmelodie und Sprechrbythmus deutlich. Dabei bezieht sich der Begriff Melodie häufig auf die Intonation einer Äußerung, Rhythmus aber auf das individuelle Sprechen mit Bezug auf Segmentierung, Tempo und Pausen (vgl. Fischer 2007: 9, 11, 15); als spracbliche Korrektheit wird die Nähe zum Melodie- und Rhythmusgebrauch eines Muttersprachlers definiert (vgl. Patel 2008: 16).

Dieser Gebrauch suggeriert natürlich die Existenz von klaren Konzepten beider Bereiche - wohingegen Eva Lilja mindestens neun Definitionen des Konzepts Rhythmus etabliert (vgl. 2009: 273, vgl. Cummings 2012: 28). Ein ,allgemeines kognitives Desiderat" der Rhythmizität sieht auch Andreas Dufter (1997) in der fehlenden Verbindung zwischen „einfacher Strukturierung und Speicherung von Wahrnehmungsdaten" (ebd.).

Daher liegt der Fokus der weiteren Untersuchungen hier auch eher auf dem rhythmischen Aspekt des Sprechens zur Musik, weniger auf der (ebenso viel ver- 
sprechenden) Analyse von veränderter Sprachmelodie durch Rhythmen oder Lieder.

Ein kleiner Versuch mit minimaler technischer Unterstützung zeigt aber, dass Sprache und Rhythmus keineswegs nur eine enge Verbindung aufweisen, sondern in der Tat gemessen an Metrik und Tonumfang identisch sind; m.a.W. Sprache kann mit musikalischen Mitteln dargestellt werden:

Meine Kollegin am Fachsprachenzentrum formulierte, unwissend $\mathrm{zu}$ welchem Zweck, die naheliegende Aussage: Ich arbeite am Fachsprachenzentrum der Leibniz Universität Hannover.

Unter Zuhilfenahme der von der schwedischen Kungliga Tekniska högskolan (Königlich Technischen Hochschule, KTH) entwickelten freien Software WaveSurfer lässt sich die Aufnahme dieser Äußerung schnell analysieren und stellt neben Zeitstrahl, Wellenform und Stärke der Aussage auch die Tonhöhe in Hertz dar.

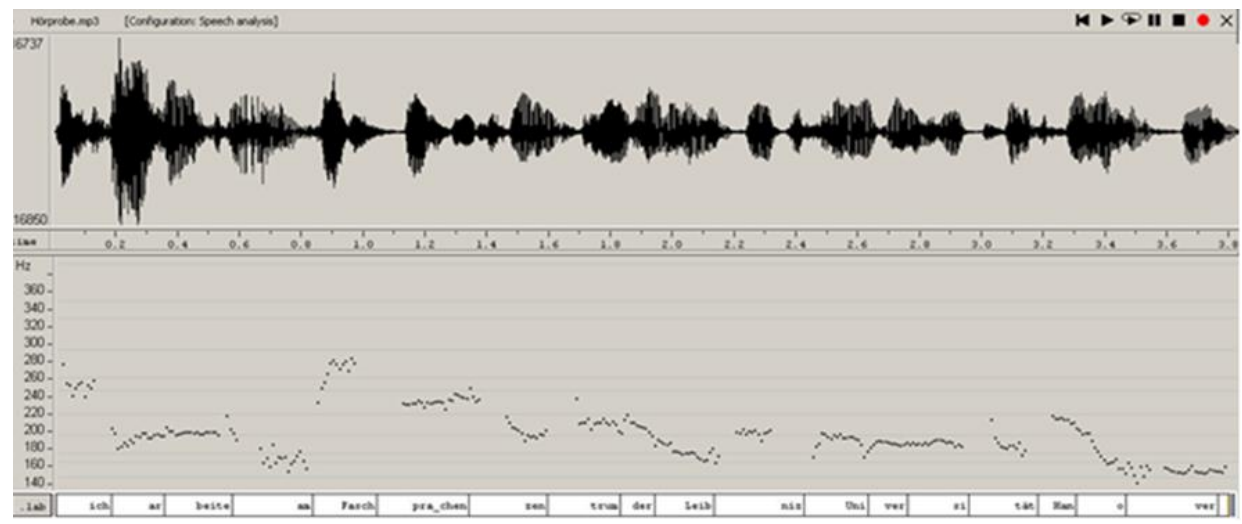

Abb. 1: WaveSurfer Analyse

Mittels der Daten lassen sich sehr direkte Schwerpunkte (Betonungen) in der Äußerung aufschlüsseln, die erwartungsgemäß (mehr oder weniger deutlich) auf die Silben Ich 'arbeite am 'Faschprachen'zentrum der Leibniz. Universi tät Hann'over fallen. Über den Zeitstrahl lässt sich ein Metrum ermitteln, indem die Abstände zwischen den Betonungspunkten gemessen werden $(0,65 s-1,15 s-1,4 s-0,5 s)$ und deren Summe als Annäherung an einen vollständigen musikalischen Takt $(2,55 \mathrm{~s})$ mit vier konstanten Taktschlägen gewertet wird: folglich erfolgt alle 0,64s ein ViertelTaktschlag, das einem musikalischen Metrum von 93,75 bpm (beats per minute) entspricht und der klassischen Tempobezeichnung Moderato entspricht.

Unterlegt man der Äußerung der Kollegin ein Metronom mit exakt dieser Geschwindigkeit, überrascht es nicht, dass dies die Rhythmik ihrer Äußerung überraschend markant in den Vordergrund rückt.

Da die Software darüber hinaus auch die Tonhöhe in Hertz angibt, lassen sich jeder Silbe über die Hertz-Zuordnungen auch konkrete Noten zuordnen (z.B. A3 
$=220 \mathrm{~Hz}^{1}$ ), die in Verbindung mit der metrischen Analyse als musikalische Melodie notiert werden können:

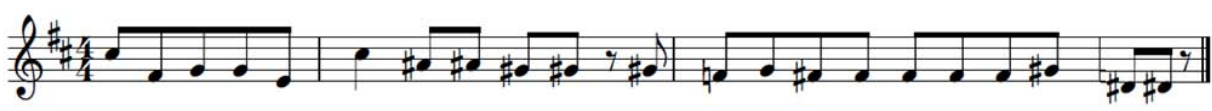

Abb. 2: Notierte Äußerung (um eine Oktave nach oben transponiert)

Die Art des unterlegten Rhythmus ist hier selbstverständlich belanglos: es kann ein gleichbleibendes Metronom sein oder aber auch ein RaP2-Loop, vorausgesetzt, das ermittelte Tempo wird beibehalten. Möglich wäre darüber hinaus auch eine Umspielung mit Akkordinstrumenten oder Nebenmelodien, da die Kollegin relativ nah an der Tonart D-Dur bleibt.

So überraschend leicht die Darstellung von Sprache mit musikalischen Mitteln ist - es ist natürlich kein Novum. Künstler wie Jason Moran haben bereits ähnlich gearbeitet, indem sie Äußerungen in Instrumentalimprovisationen harmonisch, rhythmisch und melodisch aufnahmen (z.B. Jason Moran, Artists Ought to be Writing auf dem Album Artist in Residence, 2006, Blue Note). Kürzlich überraschte Jonny König (2013) von der Popakademie Mannheim mit dem YouTube-Video Stoiber on Drums - eine silbenbezogene rhythmische Begleitung auf dem Schlagzeug zu Edmund Stoibers berüchtigter Rede über den Transrapid. Mit diesem unerwarteten Bezug schaffte es Jonny König sogar in die deutschen Tagesthemen.

Der Bezug von Sprache zu Musik ist also enger als häufig gedacht: Sprache lässt sich mit musikalischen Mitteln durchaus problemlos darstellen, sofern formalmusikalische Zugeständnisse mit Bezug auf das gleichbleibende Metrum gemacht werden (tempo rubato). Das Deutsche bietet sich hier aufgrund der Sprachcharakteristik mit akzentzählender Sprachrhythmusstruktur an - wobei allerdings Einschränkungen in der Sprachtypologie gemacht werden müssen: Die Unterscheidung zwischen silben- und akzentzählenden Sprachen (oder den Einflüssen der Muttersprache eines Komponisten vgl. Patel 2008: 131) ist komplizierter als häufig angenommen (ebd.).

Eine eher musikwissenschaftliche Frage, die sich logisch anschließt, ist der umgekehrte Fall: Lassen Lieder einen deutlichen Bezug zu gesprochener Sprache erkennen? Vermutlich wären es weit verbreitete, traditionelle Lieder mit hoher Produktivität, die verbal übermittelt wurden, bei denen eine solche Entwicklung nahe läge. Als ersten (und einzigen) Versuch habe ich den Text des ältesten mir bekann-

\footnotetext{
1 Dabei liegen (europäische) Männerstimmen zwischen $110-130 \mathrm{~Hz}$ und Frauenstimmen zwischen 200-230Hz (vgl. Künzel 1987: 115, vgl. Rodmonga 2011: 179) - auch dies wäre ein interessanter Untersuchungsgegenstand in Bezug auf den L1-Einfluss. Erste eigene Versuche haben ergeben, dass überraschender Weise Thai mit $104 \mathrm{~Hz}$ am tiefsten gesprochen wird (Grundfrequenz); US-Englisch mit $145 \mathrm{~Hz}$ am Höchsten.

2 Aufgrund der missverständlichen Pluralform wird RaP (für „Ryhthm and Poetry“) in dieser Form geschrieben. RaP ist nicht zu verwechseln mit HipHop, das im Gegensatz zu einer vollständigen Kultur (inkl. bildender Kunst, Tanz und Mode) lediglich eine Präsentationstechnik von Sprache zur Musik umfasst (vgl. Nowitzki 2006: 2).
} 
ten Wiegenlieds Schlaf, Kindlein, schlaf von einer computergenerierten Stimme sprechen lassen (der Text ist bei weitem zu bekannt, als dass er von einem Muttersprachler ohne melodiöse Einflüsse hätte gesprochen werden können). Nach der Texteingabe generierte der Computer eine Sprachmelodie, die sich nach identischer Analyse (s.o.) mit Wave Surfer mittels folgender Notation darstellen lässt:

\section{Schlaf, Kindlein, schlaf \\ gesprochen (computergeneriert)}

Allegro(156bpm)

Johann Friedrich Reichardt, 1781

nach einer Volksweise
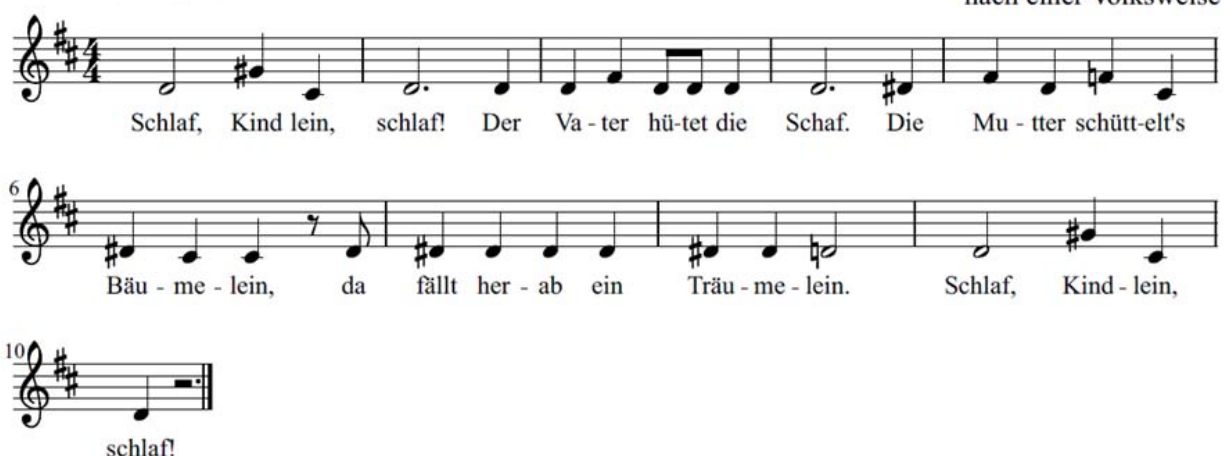

Abb. 3: Computergenerierte Sprechmelodie

Der direkte Vergleich mit der Originalversion des Liedes (entsprechend in die Tonart D-Dur transponiert) lässt erkennen, dass die gesprochene Version recht genau der tradierten Melodie folgt und häufig nur unwesentlich neben den tonarteigenen Tönen liegt:

\section{Schlaf, Kindlein, schlaf}

Originalversion, transponiert

Allegro (156bpm)

Johann Friedrich Reichardt, 1781

nach einer Volksweise
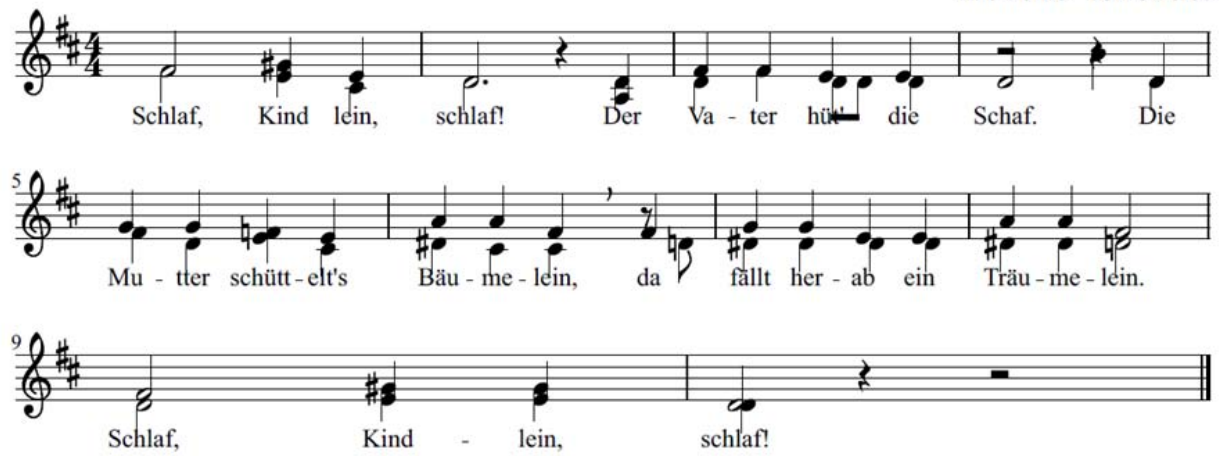

Abb. 4: Computergenerierte Sprachmelodie und traditionelle Notation 
Aufgrund der frappanten Ähnlichkeit drängt sich der Verdacht auf, dass dieses Lied in der Tat aus gesprochener Sprache entstanden sein könnte und sich in der mündlichen Weitergabe über die Generationen an musikformale Kriterien angepasst hat.

Spätestens hiermit wurde die selten beschrittene linguistische Grenze der Analysen erreicht ${ }^{3}$. Allerdings gibt es schon auf den ersten Blick einen klaren Bezug zum Bereich Deutsch als Fremdsprache: Wenn schon die Melodie einer gesprochenen Äußerung so aussagekräftig ist, dass sich Intervalle und Schwerpunkte davon ableiten lassen - gibt es dann nicht auch Bereiche, in denen nur die Melodie (also ohne Worte) eine definierte semantische Aussage hat? Und, falls das so ist, wie erlernen ausländische Sprechende des Deutschen diese Intervalle?

Etablierte DaF-Lehrwerke nehmen sich diesen non-verbalen Kommunikationssignalen mit durchaus semantischem Inhalt nur vereinzelt und begrenzt an: die Intonation sei ,gleichbleibend“ oder „steigend“ um „Überraschung“, „Freude“, „Nachdenklichkeit“ oder „Zustimmung“ (Digitales Wörterbuch der Deutschen Sprache) auszudrücken. Lediglich in der Forschungsliteratur stößt man z.B. bei Schilling und Stezano Cotelo (2007: 327) auf vier, bei Gardner (2003: 17) auf fünf definierte Arten der Intonationskontur ${ }^{5}$, unterteilt in ein- und zweisilbige Rezeptionssignale (vgl. Selting 1998: 93). Van Leeuwen spricht von „sound acts“ (1999: 92f.) und sieht semantische Bedeutungselemente von Intonationen als durchaus gegeben an.

Somit stand meinen Kollegen am Fachsprachenzentrum ein weiterer Test bevor: Über ein Headset bekamen sie diverse Fragen als Audio-Datei vorgespielt, auf die sie non-verbal antworten sollten; traditionell verschriftlicht als hm-hmmm. Fragen wie Freust Du dich auf den nächsten Urlaub?, Ist Dir Arbeit wichtiger als Deine Familie?, Was hältst Du von einem romantischen Abend mit Deinem Partner?, Bunte Kühe zablen seltener Steuern als blau'? oder Wie gut sprichst Du Französisch? wurden von den Kollegen und Kolleginnen mit hm-hmmm beantwortet und die Äußerung aufgezeichnet, wobei sich folgende Antworttypen und Intervalle tendenziell beobachten ließen:

\footnotetext{
3 Dabei haben medizinische Bereiche, wie z.B. die Neuropsychologie den Zusammenhang bereits lange etabliert: Bei Sprachstörungen sind ,rhythmische Strukturen (auch in nicht-sprachlichem Material)“ (Przybylski, Lauranne u.a. 2013: 121) geeignet, linguistische Strukturierungsprozesse zu beschleunigen (vgl. Patel 2008: 6, 9).

4 Tatsächlich wurde mir dieser Bezug von meiner Tochter vermittelt, der ich meine bisherigen Testergebnisse schilderte. Unbeeindruckt davon bestätigte sie diese mit den Worten, dass am heimischen Frühstückstisch zu früher Stunde ohnehin ohne Worte kommuniziert würde; häufig reiche für die grundlegenden Absprachen ein intoniertes hm-bmmm? - hm-hmm! (etwa: Noch Milch? - Hab noch!; das deiktische Element wird hier natürlich unterschlagen).

5 = Melodieverlauf innerhalb einer Äußerung (Aussagesatz: fallende Intonation; Fragesatz: steigende Intonation) (vgl. Landgraf 2003: 5).

${ }^{6}$ Dieser Frage würde im kommunikativen Zusammenhang einfaches Lachen oder aber komplexe Diskurselemente folgen (Rückfrage, Übernahme des nonsense-Kontextes, thematische nonsenseWeiterführung, etc). Auch als non-verbale Reaktion wurden diese Diskursmarkierungen ausgedrückt: entweder als Lachen oder als das eigene Verständnis bestätigendes hm-hmm!
} 


\section{hm-hmm}

\section{Testergebnis, $\mathrm{n}=4$}

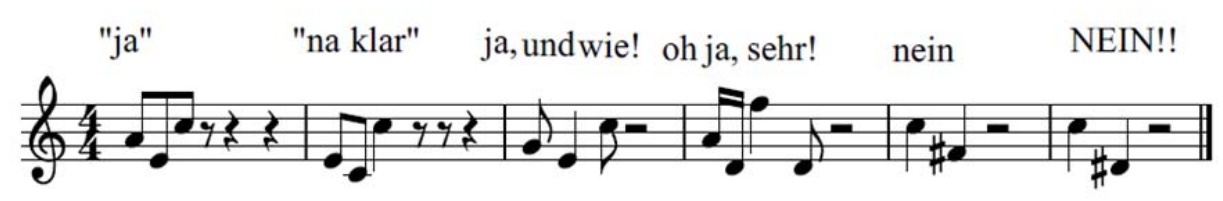

Abb. 5: Intervalle und Interpretation von nonverbalen Signalen

Diese Ausführungen zur engen Verknüpfung von Sprache und Musik bilden die Grundlage für einen weiteren Bezug zum DaF-Unterricht. Die Grundüberlegung ist: Wenn Sprache und Musik offensichtlich so eng miteinander verbunden sind, kann diese Verbindung nicht auch verstärkt im DaF-Unterricht genutzt werden?

Ein abschließendes rhythmisches Beispiel spielt hier sogar schmerzhaft in den Bereich der interkulturellen Sprachkompetenz hinein: Ein Vortrag in Mexiko sollte den Bezug zwischen Rhythmus und Semantik demonstrieren und begann mit einem international bekannten rhythmischen Klopfen, ursprünglich etabliert im Ragtime At a Darktown Cakewalk (Charles Hale, 1899), später (z.B. durch Looney Tunes Cartoons wie Who Framed Roger Rabbit) vokalisiert als Shave and a Hair CutTwo Bits:

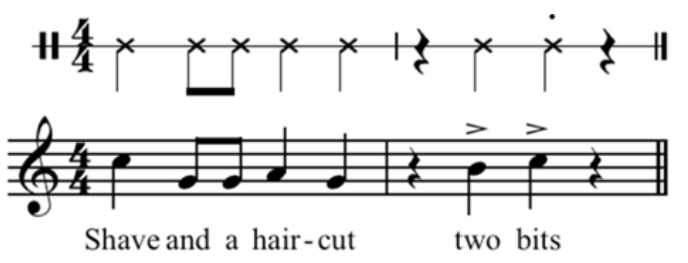

Abb. 6: Shave and a Hair cut - two bits

Die indignierte Reaktion des Publikums und spätere Erklärungen ließen den Redner erkennen, dass diese rhythmische Sequenz speziell in Mexiko zwar durchaus als Hupsignal bei Autos geläufig ist, aber eine entschieden pejorative Bedeutung hat (für den ursprüngliche Text shave and a baircut wird dabei die Phrase Cbinga tu madre eingesetzt).

Trotz der unterschiedlichen Semantik (im Wortschatzbereich würde man von false friends sprechen) wird das Bestehen klarer semantischer Bedeutung einzelner Rhythmen und/oder Melodien untermauert. 


\section{Musik im Unterricht}

„So sind Worte Gesang, wenn sie gleich nicht gesungen werden“, beobachtete bereits Johann Gottfried Herder mit durchaus deutlichem Bezug zur historischen Didaktik, denn „durch Gesänge lehrten sie“ (Cvetko 2009: 208)7. In der Tat übernahm Herder das griechische Konzept, die Musik ,selbst als Sprache, als Tonsprache“ (ebd.) zu definieren, die semantisch zwar eingeschränkt aber dafür emotional umso stärker wirkt. Auch schon früher wurde der Bezug deutlich formuliert, wie z.B. von Augustinus von Hippo im 12. Jahrhundert "Sprache IST Musik“ (Jourdain 2001: 293). Eine Übergangsstufe mag durchaus die Dichtung ${ }^{8}$ darstellen, die Metrik und Sprachmelodie im gesprochenen Vortrag sehr deutlich in den Vordergrund setzt. Es überrascht daher wenig, wenn sogar der deutsche Begriff Musik etymologisch einen bildenden Hintergrund hat: Die mousikè bezeichnet die Musenkunst im Altertum (500 v. Chr.) zum expliziten Zweck der (politischen) Bildung und mit großer erzieherischer Macht (vgl. Cvetko 2006: 208f.). In der Tat beinhaltete mousiké die klassischen drei Elemente Melodie (Intonation), Verse (Wörter) und Tanz (Körpersprache) (vgl. Stansell 2005: 5). Von der musikalischen Unterweisung der Ägypter bis zu den biblischen Psalmen der Hebräer bildet Musik, Gesang oder Sprache ein unteilbares Medium zur traditionellen Weitergabe von Lehrinhalten. Häufig war es der Sprechgesang, der die wahrhaftige Weitergabe der Inhalte garantierte und als Mnemo-Technik Verwendung fand (vgl. Cvetko; Knigge 2009: 2f.).

Abgesehen von allgemeiner Didaktik hat Musik auch im Fremdsprachenunterricht schon eine frühe, inzwischen vielfach vergessene Signifikanz erreicht: 1882 formulierte Wilhelm Viëtor (alias Quousque Tandem) mit Bezug auf den Hannoveraner Dialekt:

Gefällt [einem Lerner] aus musikalischen Rücksichten das spitze anlautende s-p und s-t der Hannoveraner besser, so wird nur dieser echt plattdeutsche Provinzialismus im Munde der Schüler für das schon vor Luthers Zeit allein hochdeutsche schp und scht geduldet (1882: 3).

Neben einem erstaunlich frühen liberalen Phonetikverständnis (tolerierte Alternativen zur Standardsprache) fällt hier natürlich die musikalische Charakterisierung von Aussprachevarianten auf, gefolgt von einer Forderung für reichere Unterrichtsmaterialien, insbesondere in Bezug auf Lyrik und Lieder, analog zu englischen Lehrbüchern:

Welch reichen Schatz an Reimen und Geschichten, Rätseln und Liedern bietet ja grade die englische Litteratur! [...] Nun denn: es gehört auch unsrer deutschen Jugend. ,Die Regentropfen am Fenster', ,Gute Nacht, Baby', die

\footnotetext{
${ }^{7}$ Herder äußerte dies mit Bezug zum antiken Griechenland (Herder zit. nach Cvetko 2009: 208).

8 Laut dem Reallexikon der dentschen Literaturwissenschaft ist das Konzept der Lyrik griech. ìje $\alpha$ (= ,Leier') an der Sangbarkeit der Verse orientiert (Fricke 2007: 499).
} 
Geschichte von ,der Spinne، [...] und hunderterlei anderes erkennt sie sofort als ihr Eigentum. Das ist verständlicher als ein Kapitel Nepos. Das wird besser gelernt als eine Seite Genus-regeln! (ebd.: 29).

Die damals noch ungewöhnliche Philosphie der Sprachdidaktik mit expliziten Bezug auf die Motivation und den Lernerfolg der Lernenden hat sich durchgesetzt. Das Metzler-Lexikon Fremdsprachendidaktike formuliert identische Beobachtungen unter dem Eintrag Musik wie folgt:

Obwohl eine direkte spracherwerbsfördernde enge Verbindung von Musik und Sprachenlernen bis heute erst in Anfängen nachweisbar ist, gehen Kognitionswissenschaftler und Neuropsychologen mehr und mehr davon aus, dass die Verarbeitung von M[usik] und Sprache ähnlichen Prozessen unterliegt und damit positive Wechselwirkungen zwischen beiden zu vermuten sind (Blell 2010: 227).

Dieser kleine Überblick soll den Übergang zwischen Sprache und Musik nur ansatzweise planieren und andeuten, wie viel DaF-Material zwischen den beiden Domänen liegen mag. Während reiner Gesang nicht auf jeden Sprachenlerners ungeteiltes Interesse stößt (,Musik im DaF-Unterricht kann mehr sein als ,Lieder singen!" - Fischer 2007: 5), gibt es durchaus attraktive, moderne Mischformen von Sprache und Musik, die der vorwiegend jugendlichen Zielgruppe genügend Motivation bieten. Allerdings setzt eine Prämisse, wie Nowitzki sie zieht, doch sehr viel positive Erfahrung mit dem Medium RaP und HipHop voraus:

Ich bin absolut davon überzeugt, dass wir als Fremdsprachenlehrer es uns kaum leisten können, nicht Rap und Hiphop in unseren Sprachunterricht einzubauen (2006: 1).

Nach Alicja Karyns Analyse von DaF-Lehrwerken bleibt allerdings noch (zu) viel dem Lehrenden und explizit auch den Lernenden überlassen: Welche Vorentlastung es wann in welcher Form geben soll, welchen Lerneffekt der Einsatz von Musik auf welche Fertigkeit hat und wie wichtig Authentizität ist - all diese Aspekte sind offensichtlich noch in der Findungsphase und Lehrwerke lassen den Lehrenden „ungewöhnlich viel Autonomie“ (2006: 552) ohne konkrete Didaktisierung. Allein die Bedeutung der Motivation scheint zugenommen zu haben, daher der Untertitel zu Karyns Aufsatz, der einem Lehrerhandbuch entstammt: „Wenn ihre Schüler Spaß am Rap haben, werden sie wissen, was zu tun ist" (ebd.: 547).

\section{Musik im DaF-Unterricht}

Mit Mitteln der Untersuchung von sprachlichen Merkmalen in der Musik oder vice versa können Problembereiche von ausländischen Sprechenden des Deutschen analysiert und eventuell sogar behoben werden - so zumindest der hier vorgestellte vielversprechende Ansatz. Das ist zwar kein völlig neues Konzept - bereits 1939 
nutzte Classé Leserhythmik im Sprachunterricht, nur um festzustellen, dass kein konstantes Metrum vorherrscht (vgl. Cummings 2012: 28) - aber das Konzept verdient aufgrund der sprachlichen Nähe genauere Beachtung.

In einem visualisierten Audio-Mitschnitt eines DaF-Prüfungsgesprächs z.B. werden prosodische und intonatorische Unterschiede zwischen der muttersprachlichen Prüferin und der asiatischen Kandidatin sehr deutlich:

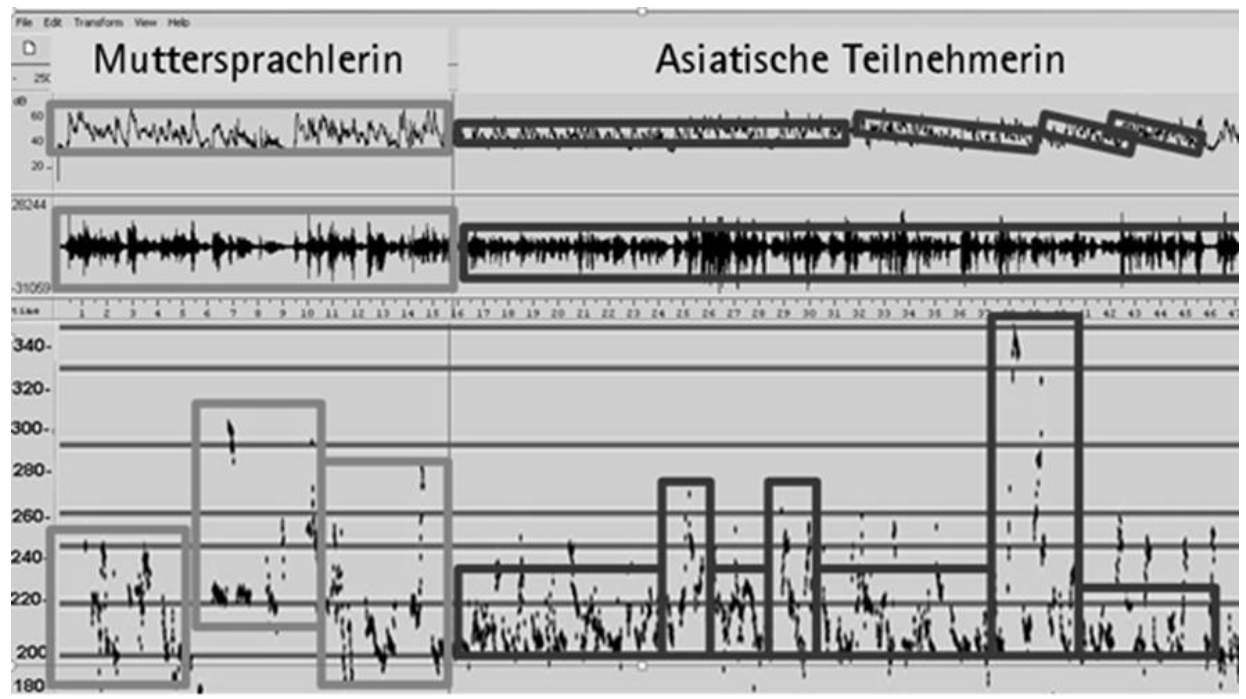

Abb. 7: Sonogramm eines Prüfungsgesprächs (Ausschnitt)

Auffällig ist, dass die Modulation, Lautstärke und auch Prosodie große Unterschiede zwischen den Personen aufweist: Während die muttersprachliche Prüferin sehr moduliert spricht, transferiert die asiatische Teilnehmerin offensichtlich den Sprechusus ihrer Muttersprache und moduliert wenig. Selbstverständlich kann diese Beobachtung nur ein erster Ansatzpunkt für weitere didaktisierte Übungen zum Sprechtraining sein. Allerdings drängt sich die Vermutung auf, dass mittels melodiösem Training, vielleicht in Form von Gesang oder RaP, gerade dieses Manko hätte behoben werden können. ${ }^{9}$

Es lässt sich an dieser Stelle nur ein grober Überblick über die Funktionen und einzelnen Forschungsbereiche von Musik im Fremdsprachenunterricht sagen. Gabriele Blell hat 2010 verschiedene Funktionen der Nutzung von Musik im Fremdsprachenunterrichtet aufgelistet, die auch von anderen Autorinnen und Autoren genannt werden. Zu diesen zählen unter anderem:

\footnotetext{
9 Den Bezug zwischen Grundfrequenz, suprasegmentalen Merkmalen und Rhythmus erläutert sehr
} differenziert Müller 2002: 152ff. 
1) Psychohygienische und emotionale Funktionen (mit Bezug auf Aufwärmund Entspannungsaktivitäten) (vgl. Fischer 2007: 6, Grzeszczakowska-Pawlikowska 2007: 17)

2) Sozialpsychologische Funktionen (z.B. Verstärkung der inter-/intrakulturellen Kommunikation unter den Lernenden) (vgl. Lilja 2009: 273, Cvetko; Knigge 2009: 9)

3) Förderung des unbewussten Lernens (z.B. Prosodisches Verständnis) (vgl. Cvetko; Knigge 2009: 9)

4) Förderung (sprachlich) kognitiver Prozesse (Vertonung von Texten) (vgl. Hallet 2007: 56)

Weiterhin werden Bereiche wie das enorm komplexe Hör-(Seh-)verstehen ${ }^{10}$ und viele weitere wichtige Aspekte genannt. Neben dieser Taxonomie von Funktionen besteht offensichtlich ebenfalls eine klare Verbindung zwischen dem Einsatz von Musik im DaF-Unterricht und verschiedenen wissenschaftlichen und didaktischen Bereichen:

Im Bereich des autonomen Lernens wird die Rolle der Teilnehmenden durch selbstbestimmtes Lernen natürlich stark aufgewertet (vgl. Bachel 2005: 24), die Lehrkraft tritt zurück (vgl. Mercadal-Sabbagh 2004: 14) und spricht im Durchschnitt nur 20\% $0^{11}$ - wovon 15\% durch den ,musikalischen Charakter der Sprache“ (Mora 2000: 147), nämlich Intonation, übermittelt werden (vgl. Stansell 2005: 5). Partnerinterviews, Erfahrungsaustausch in der Gruppe und Fragebögen sowie fortlaufende Selbsteinschätzungen können den autonomen Ansatz entsprechend des von Bachel (vgl. 2005: 5) erläuterten Grundmusters abrunden. Die Lehrzielorientierung liegt dann auch eher im Prozeduralen als in der Ergebnisabfrage (vgl. Blell 2010: 228). Und wie Erfahrungsberichte deutlich erkennen lassen, folgt der Spracherwerb schon ab unteren Niveaustufen natürlicher intrinsischer Motivation und den Inhalten (vgl. Cvetko; Knigge 2009: 10).

Selbst kognitive Aspekte werden durch Musik, insbesondere durch Strukturierung und Speicherung mittels Rhythmizität, belebt und fördern den Lernprozess. Rhythmizität wiederum belebt Bildlichkeit und Resonanz (vgl. Hallet 2007: 53). Auswirkungen eines solchen ganzheitlichen Ansatzes führen u.a. auch zu gesteigerten Gedächtnisleistungen und erleichtern den Spracherwerb als solchen (vgl. Fischer 2007: 2, Cvetko; Knigge 2009: 98, Cvetko 2011: 12, Patel 2008: 17).

Die Wahl nach konkreten musikalischen Umsetzungsmöglichkeiten sollte natürlich von der Interessenslage der Zielgruppe bestimmt werden, und nicht - wie so oft - von den musikalischen Ambitionen oder Interessen der/des Lehrenden. HipHop bzw. RaP entsprechen den medialen Sozialisierungen junger Menschen,

10 Durch audio-visuelle Rezeption „verdoppelt sich [...] gewissermaßen ein rezpetionsästhetischorientierter Höransatz“ (Blell; Lütge, 2012: 103), der zu verständnisfördernden synästhetischen „information loops“ (ebd.) führt (hier mit Bezug auf Filmmusik, aber unter Anlehnung an die Grundsätze der Schulung des Hör-Seh-Verstehens von Engelbert Thaler).

${ }_{11}$ Nach der Studie sprächen die Teilnehmer im Durchschnitt 20\% und der Dozent 80\% (vgl. Oebel 2003: 10). 
sie sind authentisch, tragen ein hohes Motivationspotential und bringen damit als angenehme Begleiterscheinung offensichtlich auch weniger Unterrichtsstörungen mit sich (vgl. Hallet 2007: 53, Fischer 2007: 1, 4, Oebel 2003: 2, Cvetko; Knigge 2009: 91, Cvetko 2011: 11).

Auch der Bereich des interkulturellen Lernens (vgl. Blell 2010: 229, Patel 2008: 6), die gemeinschaftsstiftende Partner- und Gruppenarbeit (vgl. Oebel 2003, Cvetko; Knigge 2009) und die prozessorientierte Projektarbeit sind davon positiv beeinflusst (vgl. Stöver-Blahak; Perner 2010: 312).

So spannend der musikalische Ansatz zu sein verspricht, für den Einsatz im Sprachunterricht müssen selbstverständlich messbare linguistische Vorteile nachgewiesen werden. Geschehen ist das bereits in folgenden Bereichen:

- Worterkennung, Textverständnis (vgl. McCarthy 1982: 238)

- Aussprache, Grammatik ${ }^{12}$, Wortschatz, Kultur (vgl. Hallet 2007)

- Hör-/Leseverstehen (vgl. House 2012: 46)

- $\quad$ subtilere Rezeption (vgl. Cvetko; Knigge 2009: 2)

- authentische Betonung der Sprache, grundlegend zum Sprachverständnis (vgl. Patel 2008: 6)

Auch in Einzelfalluntersuchungen bezogen auf Interferenzfehler (vgl. Grzeszcakowska-Pawlikowska 200713) lässt sich ein Bezug zur Musik in der Sprache eindeutig herstellen und eine Problembehandlung der L1-Einflüsse durch musikalische Methoden legitimieren: von Wortakzentfehler (weiterschl'afen), Wortgruppenakzentfehlern ('eine ,Qual), Silbenbetonung (Ursach'e) oder Vokalismus (Verlängerung von Kurzvokalen) (mo:rgen, We:cker, kli:ngelt, do:ch) (vgl. ebd.: 13ff.).

Die didaktischen Lösungsansätze bestehen nach aktuellem Forschungsstand aus folgenden wesentlichen Elementen: 1) Der Gegenüberstellung von sachlichneutralen und emotional erregten Ausdrucksformen; 2) Übungsformen zum Rhythmus (Lieder, etc.); 3) Bewusstmachung rhythmischer Gesetzmäßigkeiten durch versgebundene Sprache, wobei die Bewusstmachung sowohl implizit als auch explizit erfolgt (vgl. Brdar-Szabó 2010: 526).

Zusammenfassend erscheinen die Ergebnisse der Studien zum Einsatz von Musik oder konkreter RaP im DaF-Unterricht vielversprechend - Grund genug, sich dem Thema weiter zu widmen. ${ }^{14} \mathrm{RaP}$ (also Rhythm and Poetry, s.o.) unterstützt mit dem Rhythm die zeitliche Gliederung der Sprachäußerung, vorzugsweise durch ein vorgegebenes festes konstantes Metrum (als Rhythmus oder wiederkehrende rhythmische/melodische Schleife, Loop). Poetry wird quasi als literarisch ästhetische

\footnotetext{
${ }^{12}$ Dass Musik eine eigene Grammatik oder Syntax hat (i.S.v. Struktur) ist naheliegend. Selbstverständlich deckt sie sich nicht absolut mit sprachlicher Struktur - hat aber Patel zufolge eine ,psychologisch unbestreitbar [...] maßgebliche Verbindung“ (Patel 2008: 7, 12; Übersetzung MP), deren konkrete Signifikanz naturgemäß schwer nachzuweisen sei.

${ }^{13}$ Hier: L1 = Polnisch.

${ }^{14}$ Der konkrete Bezug zwischen RaP und Sprache wird auch in einem Artikel der Los Angeles Times (Landsberg, 2005) deutlich - während Musik oder Gesang zusätzliche musikalische Regeln befolgt, stellt Sprechgesang eine unmittelbare Verbindung von Sprache und Musik dar.
} 
Kunst getragen und transportiert semantische Inhalte..$^{15}$ Vorbehalte zu traditioneller Poetry werden z.B. von Wolfgang Hallet (vgl. 2007: 52f.) entkräftet, da diese modernen Formen der Lyrik sehr häufig im alltäglichen Sprachgebrauch anzutreffen seien - nicht nur im kulturellen Bereich.

Am Fachsprachenzentrum der Leibniz Universität Hannover wird das Seminar Sprachrbythmus bereits seit dem Wintersemester 2009/10 als semesterbegleitende Sprachpraxisveranstaltung für ausländische Studierende auf dem Niveau B1 angeboten (siehe beigefügten Ablaufplan Seminar Sprache \& Musik).

Dort wird den Teilnehmenden der Zusammenhang zwischen Sprache und Musik im Genre RaP praktisch vorgestellt - sehr schnell (noch in der ersten Seminarstunde) müssen Sie sich schon selbst vorstellen (Name, Heimatland, Studienfach, Hobbies); zuerst gesprochen, dann vor Publikum (Plenum) mit Mikrofonverstärkung und Rhythmus im Hintergrund.

Im weiteren Verlauf des Seminars werden die Teilnehmenden auf sehr vielen verschiedenen Ebenen tätig: Sie entdecken durch Workshops den Bezug von Sprache zum Rhythmus (z.B. gemeinsam gelesene kurze Gedichte um rhythmische Bezüge von Texten herauszuarbeiten, vgl. Hanser 2010), und auch die Bewusstmachung vom Rhythmus in der Sprache - Beatboxing, also das verbale Imitieren von Schlaginstrumenten, das deutlichen semantischen Bezug erhält, Beispiel: Böse Katze!! wobei drei Teilnehmergruppen ein aspiriertes $B^{b} \ddot{b} h$ als Bassdrum, das $K^{b} a t$ als Snaredrum und das tze als HiHat intonieren.

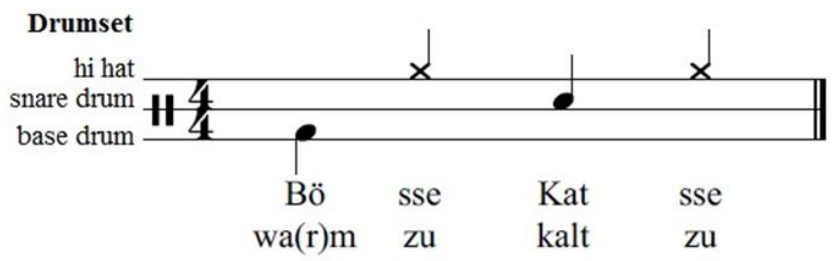

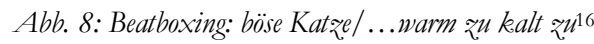

Der Rhythmuscharakter steht im Vordergrund, der semantische Bezug wird jedoch sehr schnell deutlich. Als darauf aufbauende Übung werden die sechs Silben Das Fach•spra・chen $\bullet$ zen $\bullet$ trum von sechs Personengruppen einzeln auf festgelegten Zählzeiten gesprochen - erst langsam, dann im umgangssprachlichen Tempo. Das anfängliche rhythmische Chaos weicht bald einem organisierten Sprechchor, der die betonten Silben auch tonal anpasst (höher spricht):

\footnotetext{
15 Wobei van Leeuwen auch Melodien als sound act explizite und sehr konkrete semantische Bedeutungen zuordnet (vgl. van Leeuwen 1999: 93f.).

16 Als kontextuelle Erklärung dient ein kurzer Bezug zum Wetter in Deutschland: Es ist zu warm oder zu kalt.
} 


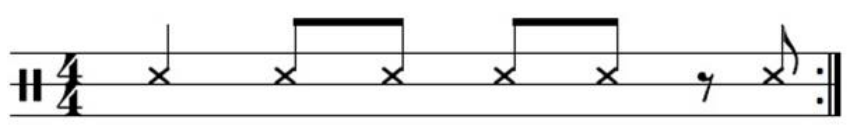

$$
\text { Fach - spra - chen - zen - trum Das }
$$

Abb.9: Das Fachsprachenzentrum

Begleitet von regelmäßigen Übungen zu Intonation, Atmung, Körperlichkeit, Präsentationstechniken und Aufwärmphasen werden die Teilnehmenden im Verlauf des Seminars in Gruppen eingeteilt, in denen eigene narrative Texte entwickelt werden (Concept Rapp ${ }^{17}$ ) - zuerst mit einem vorgegebenen vagen Thema (Deutschland oder Deutschland ist...), im zweiten Durchlauf nach Gruppenwechsel ohne Vorgaben. ${ }^{18}$

So haben die einzelnen international zusammengesetzten Gruppen nicht nur die Aufgabe, einen „gemeinsamen Status Quo“ (Mercadal-Sabbagh 2005: 10) zur Arbeitsgrundlage zu etablieren und einen kohärenten, bedeutungsvollen Text gemeinsam zu entwickeln, sondern ihn auch mit adäquatem Wortschatz in ein Versmaß zu bringen, was sich zum individuell für die und von der Gruppe erstellten Rhythmus sprechen lässt - auch dies ein Element, um die Motivation und Identifizierung der Gruppe mit dem Projekt zu verketten (vgl. Oebel 2003: 5). Zu guter Letzt werden Gruppenpräsentationen einstudiert, die aus dezenter Kostümierung und vager Choreographie ${ }^{19}$ bestehen und das Seminar mündet in eine öffentliche Abschlussveranstaltung, in der ausländische Studierende verschiedenster Studiengänge in einer Fremdsprache vor muttersprachlichem Publikum (bis zu 150 Besucher) rappen - eine ausgesprochen hohe, zugleich ungewöhnliche Leistung, die sehr schnell einen Vorteil für akademische Präsentationen anderer Art (Referate, Vorträge, Diskussionsbeiträge) zeitigt.

Das gesamte Seminar wird per Videoaufnahme dokumentiert, so dass ein Zusammenschnitt der Dokumentation die Progression einzelner Studierender verdeutlicht. Das inhärente Problem besteht selbstverständlich aus dem Erbringen eines messbaren Befundes. Hier stößt man auf das Dilemma: Was genau hat sich wodurch exakt verändert, idealer Weise verbessert? Die zu untersuchenden Bereiche wären u.a.: Aussprache, Prosodie/Intonation, Präsentationstechniken, Textproduktion, soziale Kompetenzen. Eine Analyse der umfangreichen Datenmenge und Erhebungen in einer Vergleichsgruppe stehen noch aus. Doch bereits ein

\footnotetext{
17 Texte, „die eine längere Geschichte erzählen, in der Regel in Form einer Ich-Erzählung“ (Nowitzki 2006: 3).

18 Ein ähnliches Ablaufkonzept wird auch von Nowitzki empfohlen (vgl. Nowitzki 2006: 6f.).

19 Der Bezug zwischen Sprache (Akzent), Sprechen und Körperlichkeit/Körpermotorik ist bereits lange etabliert, wird aber noch immer häufig unterschätzt (vgl. Grzeszczakowska-Pawlikowska 2007: 18, vgl. Bose 1995: 36, vgl. Hanke 1995: 12). Entsprechend weist Cummings darauf hin, dass sich kaum ein Musiker oder Musikliebhaber regungslos einem Musikstück hingibt und auch Sprache nicht modular, sondern stark körperbetont ist (vgl. 2012: 33).
} 
erster Blick auf die sprachliche Entwicklung Einzelner lässt zum Teil starke Verbesserungen in den genannten Bereichen erkennen.

Die teilnehmenden Studierenden sind ihrerseits sehr davon überzeugt, z.B. Sprechhemmungen abgebaut $\mathrm{zu}$ haben (insbesondere asiatische Studierende, vgl. Oebel 2003: 11). Entsprechende Kommentare hört man schon während des Semesters, wenn zeitgleich z.B. Referate im Fachstudium anstehen und sich die Teilnehmenden durch die Übungen besser dafür vorbereitet sehen. Dasselbe trifft auf die Abschlusskommentare der Studierenden zu, die das Seminar meistens als sprachlich sehr sinnvoll für Studium und Leben in Deutschland einschätzen unabhängig davon, dass sie vermutlich nie wieder öffentlich rappen werden.

Nach jüngsten Tests lässt sich ebenfalls ein deutlicher Bezug zum Vorlesen (nicht Leseverstehen) herstellen: Zwei Gruppen der Teilnehmenden lesen zwei von der Schwierigkeit her identische Texte in unterschiedlicher Reihenfolge laut vor: mit und ohne HipHop-Loop (über Kopfhörer eingespielt). Die Vorträge werden videographiert und mit Hinblick auf Pausen und Flüssigkeit analysiert, sowohl im Vergleich zwischen den Teilnehmenden als auch in Bezug auf die Reihenfolge des Lesens (zuerst ohne, dann mit Musik und umgekehrt).

Teilnehmende sequenzieren Lesetexte viel akkurater, wenn sie dies mit erlernten Methoden zum Rhythmus tun. Pausen sind zwar länger, aber semantisch verständlicher platziert (zwischen Bedeutungseinheiten) - und nicht vor unbekannten Wörtern, wie im freien Lesen - ein Befund, den auch Andreas Fischer festgestellt hat (vgl. 2007: 12). Auch die Aussprache, Flüssigkeit und Betonung wird bei der Leseübung verbessert. ${ }^{20}$ Der direkte Bezug von rezeptiven (Lesen) zu produktiven (Vorlesen) Sprachbereichen wird also durch den Einsatz von Rhythmus positiv beeinflusst. Als äußerst schwer zu messende, aber nichtsdestotrotz enorm wichtige Kriterien gelten die Selbstwahrnehmung und die Motivation. Beide werden von den Studierenden in einer abschließenden Evaluation durchgängig mit sehr gut bewertet, obwohl der ungewöhnliche Einsatz von RaP im DaF-Unterricht ein starkes Umdenken erfordert. Allein diese intrinsische Motivation, sich konkreter mit der Zielsprache zu befassen, hat einen bedeutenden Effekt auf den Spracherwerb, wie im schulischen Kontext bereits von Bernadette Furey nachgewiesen, die weniger Verhaltensauffälligkeiten, eine höhere Teamfähigkeit und einen generell besseren Lernerfolg beim Einsatz mit Musik beobachtet (vgl. 2006: 2). Grund genug, Musik und Fremdsprachenunterricht konkreter miteinander zu verbinden und innovative Wege zur produktiveren Sprachvermittlung zu beschreiten. Oder, um es präziser (mit Andreas Fischers Worten) zu sagen:

Die grundlegenden Klangmerkmale der deutschen Sprache - Melodie, Rhythmus und Akzentuierung - können kaum besser als mit derartigen Sprechtexten $[=\mathrm{RaP}]$ vermittelt werden (Fischer 2007: 9).

\footnotetext{
20 Vgl. Mizener 2008: 15, 21f., die zusätzliche positive Auswirkungen von Musik in Verbindung mit Lesen in den Bereichen Phonologie, Phonetik, phonemisches Bewusstsein, Textanalyse und diversen weiteren Bereichen erkennt.
} 


\section{Literatur}

Blell, Gabriele (2002): Audio Literacy/Musik. In: Surkamp, Carola (Hrsg.): Metzlers Lexikon: Fremdsprachendidaktik: Ansätze - Methoden - Grundbegriffe. Stuttgart: Metzler, 226-229.

Blell, Gabriele; Lütge, Christiane (2012): Musical Visions. Filmmusik im Rahmen der Entwicklung von Hör-Seh-Verstehen im Fremdsprachenunterricht. In: Reinfried, Marcus; Volkmann, Laurenz (Hrsg.): Medien im neokommunikativen Fremdsprachenunterricht. Einsatzformen, Inhalte, Lernerkompetenzen. Frankfurt a.M. u.a.: Lang, 99-110.

Bose, Ines (1995): Spielerisches zum Rhythmus. Aussprache. In: Fremdsprache Deutsch 12, 36-41.

Brdar-Szabó, Rita (2010): Nutzen und Grenzen der kontrastiven Analyse für Deutsch als Fremd- und Zweitsprache. In: Helbig, Gerhard; Götze, Lutz; Henrici, Gert; Krumm, Hans-Jürgen (Hrsg.): Deutsch als Fremdsprache. Ein internationales Handbuch. 1. Halbband. Berlin u.a.: de Gruyter, 518-530.

Cummings, Fred (2012): Looking for Rhythm in Speech. In: Empirical Musicology Review 7, 1-2, 28-35.

Cvetko, Alexander J. (2011): Der Sprechgesang in wissenschaftlicher Perspektive. Anregungen aus der Historischen Musikwissenschaft für die Musikpädagogik. In: Thomas Greuel; Kranefeld, Ulrike; Szczepaniak, Elke (Hrsg.): Singen und Lernen - Perspektiven auf schulische und außerschulische Vokalpraxis. Aachen: Shaker, 10-23.

Cvetko, Alexander J. (2006): „,... durch Gesänge lehrten sie ... “Johann Gottfried Herder und die Erziehung durch Musik. Mythos - Ideologie - Rezeption. Frankfurt a.M.: Lang.

Cvetko, Alexander J.; Knigge, Jens (2009). Musik- und (Fremd-)Sprachenunterricht - Interdisziplinäre Perspektiven in Schule und Forschung. In: Graf, Peter; Fernández-Castillo, Antonio (Hrsg.): Schulen auf dem Weg nach Europa. Interkulturelle Bildung und Mehrsprachigkeit. Göttingen: Vandenhoeck \& Ruprecht, 78-110.

Digitales Wörterbuch der Deutschen Sprache (DWDS). Online: http://www.dwds.de/ ?qu=hm (Stand: 18.02.2014).

Dufter, Andreas (1997): Ansätže zu einer rhythmologischen Sprachtypologie. Online: http://17.stuts.de/procs/dufter.html. (Stand: 18.02.2014).

Fischer, Andreas (2007): Deutsche Aussprache - Lernen mit Rhythmus. In: Zeitschrift für Interkulturellen Fremdsprachenunterricht 12, 2, 1-25.

Fricke, Harald; Peter Stocker (2007): Lyrik. In: Fricke, Harald (Hrsg.): Reallexikon der deutschen Literaturwissenschaft. Bd. II. Berlin u.a.: de Gruyter, 498-502. 
Gardner, Rod (2003): Rezipientenpartikeln in der englischen Konversation: Mm, $\mathrm{Mm} \mathrm{hm} \mathrm{(Uh} \mathrm{huh)} \mathrm{und} \mathrm{Yeah} \mathrm{ELiSe.} \mathrm{In:} \mathrm{Essener} \mathrm{Linguistische} \mathrm{Skripte} \mathrm{-} \mathrm{elektronisch}$ $3,1,15-29$.

Grzeszczakowska-Pawlikowska, Beata (2007): Probleme beim Rhythmuserwerb Ausgangssprache Polnisch und Zielsprache Deutsch. In: Zeitschrift für Interkulturellen Fremdsprachenunterricht 12, 2, 1-23.

Hallet, Wolfgang (2007): Literatur, Kognition und Kompetenz: die Literarizität kulturellen Handelns. In: Bredella, Lothar; Hallet, Wolfgang (Hrsg.): Handbuch L $i$ teraturunterricht, Kompetenzen und Bildung. Trier: WVT.

Hanser, Chiara; Wieland, Jeannine Sophie (2010): Vorläuferfähigkeit. Online: http:/ / www.logopaedieundpraevention-hfh.ch/webautor-data/33/2-Vorlaeuferfaehig keiten.pdf (Stand: 18.02.2014).

House, David (2012): Response to Fred Cummins: Looking for Rhythm in Speech. In: Empirical Musicology Review 7, 1-2, 45-48.

Hanke, Eva (1995): Körpersprache. Aussprache. In: Fremdsprache Deutsch 12, 12-15.

Jourdain, Robert (1997): Das wohltemperierte Gehirn. Wie Musik im Kopf entsteht und wirkt. Heidelberg: Spektrum.

Karyn, Alicja (2006): Lieder und Musik in DaF-Lehrwerken. „Wenn ihre Schüler Spaß am Rap haben, werden sie wissen, was zu tun ist". In: Info DaF 33, 547-556.

König, Jonny (2013): Stoiber on Drums. Online: http://www.youtube.com/watch?v $=9 \mathrm{Vg} 2 \mathrm{~h} \_n W 0 \mathrm{bA}$ (Stand: 18.02.2014).

Künzel, Hermann. J. (1987): Sprechererkennung - Grundzüge forensischer Sprachverarbeitung. Heidelberg: Kriminalistik-Verlag.

Landsberg, Mitchell (2005): Hip-Hop Unlocks the Meaning of Literary Classics. Online: http://articles.latimes.com/2005/jun/19/local/me-hiphop19/2 (Stand: 18.02.2014).

Landgraf, Kristin (2003): Steigende Intonationskonturenim Deutschen: Experimentalphonetische Untersuchungen zur auditiven Kategorisierung. Online: http://www.ipds.unikiel.de/kjk/pub_exx/kla2003/ma-landgraf-2003.pdf (Stand: 18.02.2014).

Leeuwen, Theo van (1999): Speech, Music, Sound. London: Macmillan.

Lilja, Eva (2009): Towards a Theory of Aesthetic Rhythm. In: Versatility in Versification - Berkeley Insights in Linguistics and Semiotics 74, 273-292.

McCarthy, William G. (1985): Promoting Language Development Through Music. In: Intervention in School and Clinic 21, 237-242. 
Mizener, Charlotte P. (2008): Enhancing Language Skills Through Music. In: General Music Today, 21, 11, 11-17.

Mora, Carmen Monseca. (2000): Foreign language acquisition and melody singing. In: ELT Journal 54, 2, 146-152.

Müller, Horst. M. (2002). Arbeitsbuch Linguistik. Paderborn: Schöningh.

Nowitzki, Werner (2006): Vom Fremdsprachenlerner zum Rapper. Online: http://www.musicisthelanguage.de (Stand: 15.08.2012).

Oebel, Guido (2003): Deutsche Populärmusik im DaF-Unterricht. Online: http://www.ldl.de/LDL_ALT/material/berichte/daf/oebel.pdf (Stand: 18.02.2014).

Patel, Aniruddh (2007): Music, Language, and the Brain. New York: Oxford University Press.

Patel, Aniruddh (2008): Language of Music. Online: http://www.loc.gov/today/ cyberlc/transcrip/2008/081107mus1800.txt (Stand: 18.02.2014).

Przybylski, Lauranne; Bedoin, Nathalie; Krifi-Papoz, Sonia; Herbillon, Vania; Roch, Didier; Léculier, Laure; Kotz, Sonja A.; Tillmann, Barbara (2013): Rhythmic Auditory Stimulation Influences Syntactic Processing in Children With Developmental Language Disorders. In: Neuropsychology 27, 1, 121-131.

Potapov, Rodmonga; Vsevolod Potapova (2011): Kommunikative Sprechtätigkeit: Russland und Deutschland im Vergleich. Köln: Böhlau.

Schilling, Andrea; Stezano Cotelo, Kristin (2008): Wie komm ich nur zu Wort? Redewechsel als Thema im DaF-Unterticht. In: Chlosta, Christoph; Leder, Gabriela; Krischer, Barbara (Hrsg.): Auf neuen Wegen. Deutsch als Fremdsprache in Forschung und Praxis. Beiträge der 35. Jahrestagung DaF 2007. Göttingen:

Universitätsverlag, 323-342.

Selting, Margret; Auer, Peter; Barden, Birgit; Bergmann, Jörg; Couper-Kuhlen, Elizabeth; Günthner, Susanne; Quasthoff, Uta; Meier, Christoph; Schlobinski, Peter; Uhmann, Susanne (1998): Gesprächsanalytisches Transkriptionssystem (GAT). In: Linguistische Berichte 173, 91-122.

Stansel, Jon Weatherford (2005): The Use of Music for Learning Languages: A Review of the Literature. Online: http://mste.illinois.edu/courses/ci407su02/students/ stansell/Jon_Stansell_The_Use_of_Music_in_Learning_Languages.pdf (Stand: 18.02.2014). 
Stöver-Blahak, Anke; Perner, Matthias (2010): RaP im Deutsch als FremdspracheUnterricht - „Es hat Spaß gemacht und trotzdem haben wir etwas gelernt.“ In: Hahn, Natalia; Roelcke, Thorsten (Hrsg.): Grenzen überwinden mit Deutsch. 37. Jabrestagung des Fachverbands Deutsch als Fremdsprache an der Pädagogischen Hochscbule Freiburg/Br. 2010. Göttingen: Universitätsverlag, 311-326.

Viëtor, Wilhelm (1882): Der Sprachunterricht muss umkehren! Ein Beitrag zur Überbürdungsfrage von Quousque Tandem. Heilbronn: Henninger. 


\section{Anhang}

Ablaufplan Seminar Sprache \& Musik ${ }^{21}$, Fachsprachenzentrum, Leibniz Univeristät Hannover

1. Sitzung: Begrüßungsrap durch Lehrkraft; Informationen zum Seminar; erste Rhythmusübungen in der Gruppe; Selbstvorstellung 1) Gesprochen 2) zu Rhythmus mit Mikrofon vor Plenum; Kurzes Interview: Name, Herkunft, Studium, Was erwarte ich vom Seminar?; Einstufungstest

2. Sitzung: Aufwärmen (Phonetik, Rhythmus, Bewegung); Beatboxing (Bhöse $K^{h} a T_{2}$ ); Sprechchor; gemeinsames Gedicht rhythmisch lesen;

Rhythmisches Sequenzieren von Silben (Fach•spra・chen $\bullet$ zen $\bullet$ trum $\bullet$ Das); Themengebundene Textproduktion (auch Hausaufgabe)

3. Sitzung: Aufwärmen (Zungenbrecher, Bewegung, Atemtechnik); Hausaufgabe Vortragen, Selbstanalyse und Gruppenfeedback; graphische Sequenzierung von Texten; Gruppenaufteilung für 1. Projekt (3-5 Pers.): Textproduktion zu Themenvorgabe Deutsches...; Gruppenarbeit mit Anleitung

4. Sitzung: Aufwärmen (Fantasiereise, Aussprache, Stehen); individualisierte Texte zur Ausspracheverbesserung; erste Ergebnisse der Gruppenarbeit; kurze Einführung in Notation/Rhythmus; kurze Einführung in Arten des Sprechgesangs; Absprache Gruppentermine

5. Sitzung: Aufwärmen (Rhythmen imitieren; Wir sind ein Schlagzeng); erste Präsentation der Gruppenprojekte, Analyse; Zeitungstexte vorlesen 1) mit Rhythmus (über Kopfhörer) 2) ohne Rhythmus + Analyse

6. Sitzung: Aufwärmen (Body-Percussion, Phonetik); Präsentation 1. Projekt aller Gruppen + Analyse; Gruppenaufteilung 2. Projekt (ohne Thema) + Teamwork

7. Aufwärmen (Gehen, Stehen, Atmen, laut sprechen); Lesen (mit/ohne Rhythmus); Vorstellung erste Projektergebnisse + Analyse; Absprache Gruppentermine

8. Aufwärmen (Gesichtsmuskulatur); Vorstellung und Analyse

Gruppenprojekte; Einteilung der Aufgaben für Abschlusspräsentation

9. Generalprobe, ggf. Audioaufnahme

10. Öffentliche Abschlusspräsentation

11. Kursevaluation

Auch die Teilnehmenden des Workshops durchliefen eine komprimierte Form dieses Ablaufs und wurden mit dem Dozenten-RaP begrüßt. Wichtig hierbei ist das gleichzeitige Hören und Lesen des Textes, insbesondere mit Bezug auf die graphische Textgestaltung (Betonungszeichen):

21 Videos der Abschlusspräsentation, Teilnehmerkommentare und Zwischenstände finden sich auf Youtube im Kanal von Matthias Perner. 


\section{Begrüßungs-RaP:}

[1'38] Achtung - Achtung - Gleich geht's los

[gesprochen] Guten Tag und heralich Willkommen im Seminar Musik und

Spracheäm Fachsprachenzentrum der Leibniz Universtät Hannover

[Verse]

Matthias |Perner ist mein | Name und ich | rappe eigentlich | nie

Doch | heute ist es $\mid$ anders und ich $\mid$ spreche hier für $\mid$ Sie.

| RAP ist | Rhythmus und | RAP ist Poe | sie

|RAP ist das Obj| ekt unsrer |Autopsie.

\section{[Bridge]}

|Jetzt zeig' ich | Ihnen, wie | leicht das von der |Zunge geht:

|Sprecht alle | mit | später ist's zu | spät!

|Sprecht alle | mit | später ist's zu | spät!

[Refrain]

|Sprache ist | Rhythmus und |Sprechen ist Mus | sik!

Mit |RAP lernt man es | schnell - sprecht | einfach alle |mit!

|Sprache ist |Rhythmus und |Sprechen ist Mus| sik!

Mit |RAP lernt man es | schnell - sprecht | einfach alle | mit!

[Verse]

|Macht Euch keine | Sorgen über |Aussprache und | Publikum.

Fühlt | einfach die Mu|sik - und wer nicht | mitmacht ist |dumm!

|Syntax, Se | mantik, | Kasus, Proso | die

- das |kommt von ganz al |leine, doch

ohne |Rhythmus | nie!

\section{[Bridge] \\ [Refrain]}

Erwartungsgemäß haben die Teilnehmenden entsprechend der Haltung von Studierenden nach den ersten Schrecksekunden belustigt mitgeklatscht und nach Möglichkeit den Refrain mitgesprochen. Es folgten drei Übungen, die generelle Probleme der Sprache und Körperlichkeit adressieren sollten:

Übung 1: Die Teilnehmenden bewegen sich ziellos im Raum und grüßen die anderen Personen (Freundlichkeit wird erwidert). Nach der Aufforderung, möglichst leise zu gehen (alle werden langsamer), folgt die Aufforderung, sehr laut aufzutreten. Die Teilnehmenden finden einen gemeinsamen Rhythmus und gehen ausnahmslos alle hintereinander im Kreis (Marsch). Analogie: In der Gruppe wird man lauter/sicherer/überzeugter, wenn man aufeinander eingeht und eine Richtung einschlägt.

Übung 2: Die Teilnehmenden stehen im Kreis. Kaum jemand steht aufrecht, mit beiden Füßen geerdet, die Hände/Arme hängen kaum (verschränkt, in Hosentaschen). Es folgt die Bewusstmachung des festen Standes, die Überwindung, Hände und Arme baumeln zu lassen und das Aufrichten durch 
einen imaginären Faden, der durch den Körper geht und sich ziehen lässt: Richtiges Stehen (geerdet sein) führt zu verbesserter Sprechweise.

Übung 3: Die Teilnehmenden treten vor die Kamera und sollen sich über eine Lautsprecherverstärkung (Mikrofon) selbst kurz vorstellen. Die eben erarbeiteten Erkenntnisse sind schnell wieder vergessen: Teilnehmende machen dieselben Fehler, die sie täglich bei Studierenden erleben:

- Sie beginnen mit dem Sprechen, bevor Sie sich dem Plenum zugewendet haben (auf dem Weg zum Sprechort)

- Sie verschränken die Arme/Beine und/oder stehen unsicher

- Blickkontakt zum Publikum/Kamera fehlt; häufig wird eine der oberen Zimmerecken angesprochen

- $\quad 80 \%$ der Äußerungen beginne mit Ja ... also ich bin

- Natürliche Körpersprache leidet

Wohlgemerkt, die Teilnehmenden waren durchweg erfahrene DaF-Lehrkräfte, die gewohnt sind, auch vor größeren Gruppen spontan zu sprechen. Das Plenum von Fachkolleginnen und -kollegen, der Umgang mit dem Mikrofon und die Kamera kreierten aber eine solch formale Situation, dass viele Teilnehmenden die Grundlagen des öffentlichen Sprechens vernachlässigten.

In der realen Unterrichtssituation mit ausländischen Studierenden an der Leibniz Universität Hannover wäre der Arbeitsverlauf bisher nur die Grundlage für das weitere Vorgehen, in dem die Ausdehnung auf sprachliche Bereiche erfolgt: Textinhalte (in Gruppenarbeit) erstellen, Textproduktionen strukturieren, rhythmisieren und diese letztendlich nach Überarbeitungen gemeinsam oder individuell mit einen RaP-Loop unterlegt vortragen. 



\title{
Neue Töne im Ausspracheunterricht
}

\author{
Kathrin Wild \\ Der vorliegende Beitrag stellt den Status quo der Forschung zu Aussprachevermittlungsmethoden \\ im Fremdsprachenunterricht dar und geht auf die Relation zwischen Musik und (Aus)Sprache \\ ein. Es werden mögliche Aussprachevermittlungsansätze, die Musik nutzen, vorgestellt. Anhand \\ einer empirischen Studie wird anfgezeigt, inwieweit Musik und Rhythmus als aisthetische Ele- \\ mente für den Ausspracheunterricht geeignet sein können und inwieweit sich der Ausspracheer- \\ werb zwischen musikalisch aktiven und nicht aktiven Lernenden unterscheidet.
}

\section{Status Quo der Forschung zu Aussprachevermittlungsmethoden im Fremdsprachenunterricht}

Viele Lehrkräfte verzichten im fremdsprachlichen Unterricht auf Aussprachekorrekturen bzw. korrigieren erst, wenn sie die Aussprache der Lernenden nicht verstehen und dies nicht länger ignorieren können (vgl. MacDonald 2002: 8). Dabei ist eine verständliche Aussprache ein wichtiger Teil der kommunikativen Kompetenz, sodass gerade diese Fertigkeit geschult werden muss (vgl. Reinke 2012: 4). In fast jedem neueren DaF-/DaZ-Lehrwerk sind inzwischen Ausspracheübungen enthalten. Auch gibt es eine immer größere Anzahl an reinen Phonetik-Lehrwerken'1. Darüber hinaus werden Ansätze verfolgt, die ästhetisch-aisthetische² Elemente

\footnotetext{
1 z.B. Cauneau 1992, Cauneau; Müller 1992, Frey 1995, Middleman 1996, Hirschfeld; Reinke 1998, Schäfermeier 1998, Kelz 1999, Dieling; Hirschfeld 2000, Behme-Gissel 2005, Hirschfeld u.a. 2007, Hirschfeld; Reinke 2009, Reinke 2011 \& 2012 und Rug 2012.

2 Gemäß Aissen-Crewett (1998: 29) unterscheiden wir zwischen Ästhetik als Einbeziehung der schönen Künste und Aisthetik als sinnliche Wahrnehmung und Erkenntnis.
} 
nutzen. ${ }^{3}$ In der Spracherwerbsforschung sind bisher noch keine Aussprachevermittlungsmethoden empirisch überprüft worden, sodass auf dieser Grundlage entsprechende Lehr- und Lernmaterialien entwickelt werden könnten. Auch in der Lehrerausbildung kommt der Aussprachedidaktik eine eher geringe Bedeutung zu - möglicherweise gerade, weil es an Forschung, die Theorie und Praxis verknüpft, mangelt (vgl. Hirschfeld; Trouvain 2007: 185f.).

Im Folgenden wird erörtert, warum sich ästhetisch-aisthetische Elemente für die Aussprachevermittlung eignen könnten.

\section{Aussprachevermittlung mithilfe des ästhetisch-aisthetischen Elements Musik}

Cranmer und Laroy (1992: 1) sind der Meinung, dass Musik als wesentlicher Bestandteil unserer Kultur nicht von Sprache zu trennen ist. ${ }^{4}$ Was aber sind die Gemeinsamkeiten von Musik und (Aus)Sprache, die die Nutzung von Musik im Ausspracheunterricht nahelegen? Musik und Sprache, vor allem Aussprache, sind Tonhöhe, Melodie, Klangfarbe, Rhythmus und Tempo gemein (vgl. Stokes 2001: 67, Fuchs; Röber-Siekmeyer 2002: 98f., Brandstätter 2008: 154). Falk (2009: 252) weist darauf hin, dass

Dauer, Tonhöhe, Klangfarbe und Lautstärke [...] in musik- und sprachprosodischen Äußerungen zwar unterschiedlich ausgeprägt [sind], sie [...] jedoch gleichermaßen allgemeinen Wahrnehmungsmechanismen des Hörsystems [folgen].

Der Nutzen von Musik und Kinästhetik wird in der Forschung zum Spracherwerb immer wieder hervorgehoben (vgl. u.a. Forschungsüberblick in Sposet 2008: 24, Stöver-Blahak; Perner 2011: 319, Schiffler 2012). Ziel ist dabei einerseits das Training der Diskriminierungsfähigkeit und andererseits eine bessere Verankerung im Langzeitgedächtnis (vgl. Lake 2002). Nardo und Reiterer (2009: 246) vermuten, dass bei der Verarbeitung von Musik und Sprache jeweils die gleichen kognitiven Prozesse ablaufen. Ermert u.a. (2003: 82) weisen darauf hin, dass Informationsverarbeitung im gesamten Körper stattfindet. Brandstätter (2008: 172, 179ff.) postuliert, dass es auf vielen verschiedenen Ebenen Brücken zwischen Musik und Körper gibt und dass sich im Sprechakt die Sprache mit dem Körper verbindet. Musik könne als eine körperliche Erfahrung beschrieben werden.

Unter Berücksichtigung dieser Annahmen kann man davon ausgehen, dass sich aisthetische Ansätze besonders gut für die Aussprachevermittlung eignen, weil sie durch die Verknüpfung von mentaler und körperlicher Erfahrung die Möglichkeit zur stärkeren Kognitivierung bieten (vgl. Schiffler 2012: 53) und zu nachhalti-

\footnotetext{
${ }^{3}$ Vgl. z.B. Kroemer 2000 und Fischer 2007.

${ }^{4}$ Vgl. den Beitrag von Matthias Perner in diesem Band.
} 
geren Lernerfolgen beitragen. Aisthetische Elemente können die Wahrnehmung fördern, die ein aktiver, bewusster Vorgang ist, der am Anfang eines jeden Lernens steht und kontinuierliche Übung erfordert (vgl. Aissen-Crewett 1998: 88f.). Rora und Wagener (2008: 19) weisen darauf hin, dass uns viele Wahrnehmungen im Alltag entgehen, weil wir sie nicht zum Gegenstand unserer Aufmerksamkeit machen. Gerade im Ausspracheunterricht können wir fehlende Wahrnehmungen von Ausspracheabweichungen beobachten. Hierfür sind etablierte Hörmuster verantwortlich. Das muttersprachlich geschulte Gehör ordnet die fremde Sprache in bestehende muttersprachlich ausgeformte Kategorien ein. Dieses Phänomen ist auch als phonologisches Sieb der Muttersprache bekannt (vgl. Dretzke 2009: 134f.). Wir nehmen vornehmlich das wahr, was wir bemerken wollen (vgl. Ermert u.a. 2003: 70f.). Viele Ausspracheprobleme entgehen nicht nur den Lernenden selbst, sondern auch den Lehrkräften, weil die Aussprache nicht in den Mittelpunkt gestellt wird. Ermert u.a. (ebd.: 72) weisen darauf hin, dass, wenn wir einen Druckfehler erst einmal entdeckt haben, dieser nicht mehr von uns zu übersehen ist. Ähnlich ist es auch mit der Aussprache. Es sollte also vielmehr Augenmerk auf die Förderung der bewussten Wahrnehmung gelegt werden, sodass eine Ausspracheabweichung überhaupt gefunden werden kann. Die Lehrkräfte sollten Aussprache stärker fokussieren und Vermittlungsmethoden wählen, die die Lernenden aktivieren. Durch die Aktivierung der/des Lernenden wird der Lernprozess vertieft und intensiviert (vgl. Hellwig 1996: 26).

Bei der Aussprache geht es vornehmlich um das Hören, auch wenn wir Phänomene in Form von Lautschrift und Zeichen sichtbar machen können. Es zeigt sich jedoch in der Praxis immer wieder, dass die Verschriftlichung von Aussprache allein nicht ausreicht, um dauerhafte Lernerfolge herbeizuführen. Zu flüchtig ist der visuelle Eindruck. Otto (1998: 29) nennt wichtige Aspekte des aisthetischen Lernens, die wir für die Ausspracheschulung unabdingbar halten:

Wahrnehmen ist nicht nur sehen, sondern heißt, so dicht an Dinge herangehen, dass ich sie für wahr nehmen kann, heißt vergewissern, aufspüren, hineinhören. Erfahren heißt in Erfahrung bringen, meint also handeln, erkunden, erinnern, befragen, prüfen, ausprobieren. [...] Erkennen steht mit Bedacht am Schluss. Aufgrund von Wahrnehmungen, von Erfahrungen durchschaue ich etwas, verstehe ich einen Zusammenhang, wird mir etwas klar.

Die Lernenden müssen also einen aktiven Lernprozess durchlaufen, der mit der Wahrnehmung sowie einem „genussvollen Staunen“ (Freeß 2002: 63) beginnt und in eine Kontextualisierung mündet.

Ein wichtiger Aspekt beim (Aussprache)Lernen ist die emotionale Beteiligung, die durch ästhetisch-aisthetische Elemente gefördert werden kann. Apeltauer (1997: 70) betont, dass es wichtig ist, dass Lernende mit ihrer Sprachproduktion positive Gefühle verbinden. Auch Riemer (1997: 236) gibt zu Bedenken, dass 
bei der Aufnahme und Verarbeitung von Information bzw. Aktivierung des Gedächtnisses [...] [seien] gleichermaßen neben kognitiven immer auch emotionale Prozesse beteiligt.

Emotionen bestimmen, was wir wahrnehmen und dies hängt von unseren Bedürfnissen, Wünschen und Zielen ab (vgl. Aissen-Crewett 1998: 159). Es ist also wichtig, dass Lernende emotional in ihren Lernprozess involviert sind, um zu aktiven Lernenden zu werden. Eine nachhaltige Aktivierung resultiert aus der Motivation, die die Verwendung von Musik im Unterricht bewirkt: „Es gibt $[\ldots]$ kaum einen Lernenden, der sich nicht in irgendeiner Form von Musik für das Fremdsprachenlernen motivieren ließe“ (Blell; Hellwig 1996: 7).

\section{Musik und Rhythmus integrierende Ansätze in der Aussprachevermittlung}

Sposets (2008: 91) Auswertung von 23 Studien zum Einsatz von Musik im Fremdsprachenunterricht ergab, dass nicht ganz eindeutig evaluiert werden kann, inwieweit sich Musik auf Lernprozesse auswirkt. Sie fasst jedoch zusammen, dass in 20 Studien Musik für mehr Freude am Lernen sorgte. Dieses stützt die Annahme von Blell und Hellwig (1996: 7).

Lake (2002) schildert aus seiner Unterrichtspraxis eine positive Auswirkung auf das nachhaltige Behalten von Wortschatz: „Adding rhythm and melody to chunks of language invites rehearsal and transfers words into long-term memory." Außerdem geht er auf die emotionale und bedeutungsgebende Wirkung von Musik sowie Ausspracheverbesserung durch Singen ein. So kann sie Geborgenheit geben (vgl. ebd., Blell; Hellwig 1996: 8). Von einem Vorschulkind, das im Vergleich zu anderen Kindern der Untersuchungsgruppe die deutsche Aussprache durch Singen schneller und problemloser zu erwerben scheint, berichtet auch Kuyumcu (2014: 131, 282ff.).

Im Folgenden werden verschiedene Ansätze vorgestellt, die das ästhetische Element Musik zur Ausspracheschulung nutzen. Dabei handelt es sich zumeist nicht um Ansätze, die bisher wissenschaftlich evaluiert worden sind, wenngleich auch kleinere Studien zum Einsatz von Liedern durchgeführt wurden.

\subsection{Lieder}

Lieder gelten als motivierend, auflockernd und entspannend und werden deshalb gerne im Unterricht verwendet. Lieder führen suprasegmentale Phänomene kontextuell eingebettet ein (vgl. Lems 2001). Je nach Sprachniveau können Lieder für unterschiedliche Zwecke wie der Übung von Aussprache, Wortschatz und Grammatik, Hörverstehen sowie für Kultur- und Landeskunde genutzt werden. Bei der Auswahl eines Liedes ist jedoch einerseits auf Korrektheit aller genannten Bereiche zu achten (vgl. Willis; Mason 1994: 104f.) und andererseits darauf, dass Lieder 
entsprechend ihres Unterrichtszwecks ausgesucht werden müssen (vgl. GattiTaylor 1980: 466).

Van Asselt (1970) untersuchte in einer 3. Klasse in Kansas mit 19 ProbandInnen über einen Zeitraum von zwölf Wochen, ob sich der Einsatz von Reim, Rhythmus und Melodie in Liedern und Gedichten positiv auf die Aussprache und die Verstehensleistung der Zielsprache Deutsch auswirkt. Er fand heraus, dass Reime, Rhythmus und Melodie sowohl die Lern- und Behaltensleistung fördern als auch zu einer besseren Aussprache führen (vgl. Sposet 2008: 54f.).

In einer Studie mit 25 erwachsenen, südostasiatischen Englischlernenden nutzte Karimer (1984) Lieder zur Verbesserung des phonologischen Kurzzeitgedächtnisses. Sie stellte in einem Posttest nach zwei Wochen Unterricht etwas bessere Ergebnisse für die Experimentalgruppe fest.

Wilcox (1996) führte eine Studie mit 50 Personen durch, um zu überprüfen, ob der Einsatz von Liedern und Singen zu einer Verbesserung der Ausspracheleistung und einer besseren Behaltensleistung von Wortschatz führt. Während es beim Wortschatzerwerb keine Leistungsunterschiede gab, erzielte die mit Musik lernende Gruppe höhere Ergebnisse in Flüssigkeit - zu der auch Aussprache zu zählen ist -, Erinnerungsvermögen und Verstehen (vgl. zu den Ergebnissen auch Sposet 2008: 62f.).

Die verschiedenen Studien und Beobachtungen weisen darauf hin, dass sich der Einsatz von Musik und Rhythmus positiv auf den fremdsprachlichen Ausspracheerwerb auswirken kann. Hierbei muss jedoch die unterschiedliche Materialauswahl und die Art der Aufbereitung beachtet werden. Es fehlt in den vorgestellten Studien zumeist an Transparenz des Untersuchungsdesigns. Deshalb kann hier keine Aussage über die Belastbarkeit der Untersuchungsergebnisse getroffen werden. Insgesamt ist weitere, transparente Forschung in diesem Bereich wünschenswert.

\subsection{Jazz Chants}

Jazz Chants wurden 1978 von Graham entwickelt um natürliche Betonung und Intonationsmuster im gesprochenen Amerikanischen Englisch zu verdeutlichen (vgl. Graham 1978: ix, 2001: vi, 2006: 5). Dabei wird die Verbesserung von Sprechen und Hörverständnis sowie die Verstärkung situationsspezifischer Strukturen fokussiert (vgl. Graham 1978: ix). Zu diesem Zweck werden auftaktige Lieder und Gedichte, die in verschiedenen Jazzrhythmen eingerichtet sind, genutzt. Jazz Chants basieren auf Wiederholung und gelernter Antwort. Dabei ist der klare, gleichmäßige Rhythmus wesentlich (vgl. ebd.: xi, 2001: vii). Graham (1992: 3) weist darauf hin, dass Jazz Chants vor allem die Imitation von MuttersprachlerInnen in natürlichen Sprechkontexten in den Mittelpunkt stellt. Jazz Chants sollen zur wachsenden Bewusstheit gegenüber der Zielkultur beitragen und somit für eine positive Haltung gegenüber der Zielsprache sorgen. Den größten Nutzen sieht Graham jedoch in der Steigerung der Lernfreude (vgl. ebd.: 43). Die Lernenden sollen die Wortakzente klatschen, um muttersprachlich bedingte Interferenzen zu 
reduzieren. Graham regt auch das Mitbringen von Rhythmus-Instrumenten an, damit diese anstelle von Klatschen gespielt werden (vgl. Graham 2001: vii). Unseres Wissens wurden bisher keine empirischen Untersuchungen zur Wirksamkeit von Jazz Chants durchgeführt.

Positiv hervorzuheben ist bei diesem Ansatz die Verknüpfung von Kinästhetik und Aussprache. Jazz Chants können spontan eingesetzt werden und nehmen nur wenige Minuten in Anspruch. Die Lehrkraft kann Rhythmusinstrumente mitbringen, um die Lernenden stärker zu involvieren und somit zu motivieren. Dies bedeutet allerdings auch einen höheren Vorbereitungsaufwand.

\section{3 Ästhetisch-aisthetische Ansätze}

Kroemer $(2000,2001)$ hat ein Konzept entwickelt, das Intonationsphänomene vereinfacht systematisiert. Ihre Methode vermittelt Intonation und Aussprache mithilfe von Instrumenten, rhythmischen Übungen mit Körpereinsatz und festen Schriftzeichen. Dabei werden auch Regeln thematisiert. Bei diesem mehrkanaligen Ansatz verwendet Kroemer zur Unterstützung des Hörprozesses eine Trommel für den Sprachrhythmus und eine Posaune für die Sprachmelodie. Es wird z.B. geklatscht, rhythmisch gegangen und es werden Tonhöhenmuster in die Luft gemalt. Durch die Ausführung der Bewegung steht die Aussprache nicht mehr im Vordergrund und ist somit auch nicht mehr so stark angstbesetzt. Sie geschieht eher beiläufig (vgl. 2001: 52). Während einer Studie, die Kroemer im Rahmen ihrer Masterarbeit durchführte, stellte sie anhand einer Fragebogen-Auswertung ${ }^{5}$ fest, dass der Lernzuwachs nicht davon abhänge, ob die Lernenden sich außerhalb des Unterrichts mit Musik beschäftigen oder zum besonders auditiven Typ gehören. Sie wies jedoch darauf hin, dass ihre Studie aufgrund der begrenzten Probandenanzahl nicht repräsentativ sei (vgl. ebd.: 53).

Positiv hervorzuheben ist der ganzheitliche, mehrkanalige Ansatz, in dem Rhythmus körperlich, mithilfe von Instrumenten und Musik sowie durch den Einsatz von eindeutigen, sich klar voneinander unterscheidenden Schriftzeichen erfahren und gelehrt wird. Die Übungen können ohne bzw. mit sehr wenigen Hilfsmitteln (CD-Player, CD) durchgeführt werden. Die Methode erfordert weder von der Lehrkraft noch von den Lernenden eine musikalische Vorerfahrung. Darüber hinaus wird die kognitive Ebene miteinbezogen, indem (vereinfachte) Regeln von den Lernenden zunächst erschlossen und dann zusammen mit der Lehrperson systematisiert werden. Die Möglichkeit, Regeln über die Intonation zu erschließen, ohne grammatische Gesetzmäßigkeiten abrufen zu müssen, kann Lernende zusätzlich zur Ausspracheschulung motivieren. Aus wissenschaftlicher Sicht stellt sich die Frage, ob die Regeln zur Intonation nicht zu sehr vereinfacht werden. In der Praxis

\footnotetext{
${ }^{5}$ Es ist kritisch anzumerken, dass mit Fragebögen nur Meinungen abgefragt werden. In Interviews hingegen könnte tiefer gehend nachgefragt werden.
} 
ist es aber sicherlich ein gutes und praktikables Handwerkszeug, das auch spontan und ohne Hilfsmittel eingesetzt werden kann.

Die von Fischer (2007) entwickelte Methoden- und Materialsammlung „Deutsch lernen mit Rhythmus - Der Sprechrhythmus als Basis einer integrierten Phonetik im Unterricht Deutsch als Fremdsprache" fokussiert den Primar- und Sekundarbereich auf dem Grundstufen-Niveau. Jedoch soll es auch möglich sein, die Übungen im Fortgeschrittenen-Bereich einzusetzen. Erwachsene Lernende werden dabei nicht explizit angesprochen. Bei Fischers Ansatz soll prosodische Richtigkeit vor artikulatorischer Korrektheit kommen. Dabei ist es ihm wichtig, Sprechlust zu wecken, Geläufigkeit herzustellen, Fortgeschrittene neu zu motivieren und ihnen neue Erfolgserlebnisse zu vermitteln. Die ganzheitlich orientierten Übungen sollen entkrampfend wirken, emotional ansprechen, zur unmerklichen Automatisierung der fremden Aussprache führen und somit für Nachhaltigkeit sorgen (vgl. ebd.: 7). Zusätzlich zu verschiedenen Sprechstücken, Rhythmen und Raps werden Unterrichtsvorschläge und Hinweise gegeben, wie man Material selbst erstellen kann.

Positiv hervorzuheben sind die Bausteine für eine integrierte Ausspracheschulung (vgl. ebd.: 29ff.), die auch Lehrenden, die sich bisher nicht näher mit Ausspracheschulung beschäftigt haben, einen guten Überblick über die Thematik verschaffen und ein Gerüst für die Durchführung von Ausspracheübungen bieten. Fischer ist in seiner Forderung zuzustimmen, dass die Beherrschung der richtigen Prosodie wichtiger ist als die Artikulation von Einzellauten. Für die angegebene Zielgruppe stellt sich aufgrund des vielfältigen und kreativ aufbereiteten Materials - es handelt sich dabei um richtiggehende Inszenierungen - sowie der Verwendung von unterschiedlichen Instrumenten sicherlich auch die beabsichtigte Motivation ein. Über die benötigten Instrumente und die Zeit, diese im Klassenraum einzuführen, wird jedoch kaum eine Fremdsprachenlehrkraft verfügen. Es darf angenommen werden, dass phonetische Gesten und Inszenierungen, wie Fischer sie vorschlägt, den Lernprozess günstig beeinflussen. Ihre Vermittlung und Durchführung nimmt jedoch viel Zeit in Anspruch. Wir sehen es als problematisch an, für lange und kurze Vokale die gleichen Notenwerte zu nutzen. Es entsteht dadurch der Eindruck, dass alle Vokale gleich lang gesprochen werden. Zudem werden betonte Silben nicht durch entsprechendes Klatschen, Klopfen oder Stampfen verstärkt. Vielmehr wird ein eigener Klopfrhythmus, der nicht dem natürlichen Sprachrhythmus folgt, gewählt. Fischers Methode ist nicht ohne Abstriche (z.B. das Weglassen der Instrumente) spontan und jederzeit einsetzbar, wenngleich auch eine Möglichkeit, gerade jüngere Lernende auf einem eher niedrigen Sprachniveau für die deutsche Sprache und Aussprache zu begeistern. Für die Vermittlung des Wortakzents scheint uns das Material weniger geeignet. 


\section{Empirische Studie zum Wortakzenterwerb}

Um zu erforschen, wie und inwieweit sich der Wortakzenterwerb bei jungen Erwachsenen durch den Einsatz von Musik und Rhythmus (z.B. rhythmisches Gehen, stampfen, klatschen, Raps erstellen) steuern lässt, wurde eine Längsschnittstudie durchgeführt. Diese wurde als Quasi-Experiment (vgl. Bortz; Döring 2006: 54, 114) angelegt, um möglichst viele Faktoren kontrollieren und intervenierende Faktoren eliminieren zu können. Hierdurch können Aussagen über eine größere Lernergruppe getroffen werden.

Untersucht wurden u.a. folgende Fragen:

1. Kann der Einsatz bestimmter rhythmischer Übungen früher zu Bewusstwerdungsprozessen im Bereich des Wortakzents führen?

2. Machen Lernende, die selbst musizieren, durchschnittlich weniger Fehler bei der Wortbetonung?

Folgende Hypothesen wurden überprüft:

1. Neu konzipierte rhythmische Übungen verbessern die Aneignung des deutschen Wortakzents im Vergleich zu konventionellen Übungen.

2. Lernende, die selbst musizieren, machen durchschnittlich weniger Wortakzentfehler im Deutschen.

\subsection{Probandengruppe}

Bei den 18-22-jährigen ProbandInnen handelt es sich um britische Studierende der Germanistik im ersten Studienjahr, die Deutsch als zweite bzw. dritte Fremdsprache lernen. Das Niveau lag zu Beginn des Studiums bei A2 bis B1 des Gemeinsamen Europäischen Referenzrahmens und es fielen viele fossilierte Wortakzentfehler auf. Die Muttersprache aller Studierenden ist Englisch. Viele sprechen weitere Fremdsprachen.

\subsection{Unterricht}

Die 32 ProbandInnen erhielten in Kleingruppen zwei Semester lang jeweils eine SWS Unterricht in mündlicher Sprachfertigkeit (insg. 22 UE à 50 Minuten), die auch Ausspracheübungen beinhaltete. Die Ausspracheübungen selbst umfassten je nach Kleingruppe 90-180 Minuten. Eine Hälfte der Studierenden wurde mithilfe von konventionellen Imitations- und Nachsprechübungen, die andere Hälfte mithilfe von neu konzipierten rhythmischen Übungen unterrichtet. ${ }^{6}$ Dabei diente die Gruppe, die konventionell unterrichtet wurde, als Kontrollgruppe, sodass die gewonnenen Daten vergleichbar sind.

\footnotetext{
${ }^{6}$ Hierbei handelt es sich z.B. um Gehen, Stampfen und Klatschen des Rhythmus sowie das Erstellen von eigenen Raps.
} 


\subsection{Datenerhebung}

Es wurden über zwölf Monate hinweg Daten erhoben. Zu vier Zeitpunkten beantworteten die ProbandInnen jeweils zunächst einen Fragebogen (MultipleChoice- und offene Fragen) und nahmen danach an einer Überprüfung zur Beherrschung des deutschen Wortakzentes (Lesetext und Dialogübung) teil. Zwischen den einzelnen Datenerhebungen lagen jeweils dreieinhalb bis viereinhalb Monate.

\subsection{Datenauswertung}

Zur Datenauswertung wurden verschiedene Verfahren angewendet. Dabei handelt es sich um

1. die statistische Auswertung der Fragebogen-Daten und Transkripte

2. die Erstellung individueller Ausspracheverläufe und

3. die Überprüfung der qualitativen Analysen anhand der quantitativen Daten.

Die gesamte Datenmenge der 32 untersuchten ProbandInnen wurde quantitativ ausgewertet. Bei den analysierten Daten handelt es sich um insgesamt 124 Fragebögen mit jeweils ca. 140 Variablen. Pro ProbandIn wurden etwa 40 Minuten Tonmaterial transkribiert. Das gesamte Tonmaterial der Überprüfungen zum Wortakzent umfasst ca. 21 Stunden.

Für acht ProbandInnen wurden anhand der Ergebnisse der Ausspracheüberprüfungen und der Angaben in den jeweils vorgeschalteten Fragebögen individuelle Ausspracheerwerbsverläufe erstellt.

Die gewonnenen Daten wurden quantitativ und qualitativ ausgewertet und die unterschiedlichen Forschungsergebnisse aufeinander bezogen. Die Ausspracheerwerbsverläufe und die Faktoren, die diese möglicherweise beeinflussen, wurden durch quantitative Analysen validiert, sodass eine Gesamtinterpretation der Daten möglich wurde. Durch die Verknüpfung von quantitativen und qualitativen Resultaten sollte festgestellt werden, ob die Forschungsergebnisse miteinander übereinstimmen, divergieren oder sich ergänzen.

\subsection{Untersuchungsergebnisse}

1. Kann der Einsatz bestimmter rhythmischer Übungen früher zu Bewusstwerdungsprozessen im Bereich des Wortakzents führen?

Die Angaben der ProbandInnen bezüglich der Fragestellung, ob sie Schwierigkeiten mit der Diskriminierung und Produktion des deutschen Wortakzents haben, sind in der Experimental- und der Kontrollgruppe zu allen Zeitpunkten fast iden- 
tisch. Da kein signifikanter Unterschied $(\mathrm{p} \leq 0,1)^{7}$ sichtbar wird, stellen wir fest, dass die neu konzipierten rhythmischen Übungen nicht zu einem früheren Bewusstwerdungsprozess für Wortakzentprobleme geführt haben. Hier scheint die Instruktionsart von geringer Bedeutung zu sein.

2. Machen Lernende, die selbst musizieren, durchschnittlich weniger Fehler bei der Wortbetonung?

ProbandInnen, die ein Instrument spielen, und besonders solche, die singen, machen unseren quantitativen Analysen folgend durchschnittlich signifikant weniger Wortakzentfehler. Ein besser trainiertes Gehör und eine höhere Wahrnehmungssensibilisierung als bei nicht musikalisch Aktiven sind naheliegende Gründe, denn Diskriminierungsfähigkeiten sind die Grundlage der korrekten Produktion.

Hypothese 1: Neu konzipierte rhythmische Übungen verbessern die Aneignung des deutschen Wortakzentes im Vergleich zu konventionellen Übungen.

Statistisch gesehen müssen wir die Hypothese, dass neu konzipierte rhythmische Übungen die Aneignung des Wortakzents im Vergleich zu konventionellen Übungen verbessern, zurückweisen, da sich die beiden Gruppen in ihren zielsprachlichen Wortakzentproduktionen und auch den Erwerbsverläufen nicht signifikant $(p \leq 0,1)$ voneinander unterscheiden. Jedoch verbessert sich die Experimentalgruppe ab dem zweiten Zeitpunkt etwas stärker als die Kontrollgruppe und überholt trotz ursprünglicher Unterlegenheit diese in der dritten Erhebung. Bei einer größeren Anzahl an ProbandInnen wäre möglicherweise ein signifikanter Unterschied nachzuweisen gewesen.

Hypothese 2: Lernende, die selbst musizieren, machen durchschnittlich weniger Wortakzentfehler im Deutschen.

Hypothese 2 kann bestätigt werden. Welcher Art der positive Transfer ist, sollte noch genauer untersucht werden. Ein wichtiger Faktor könnte die Sensibilisierung des Gehörs sein. Deshalb wäre u.a. interessant, welches Instrument die ProbandInnen spielen.

\section{Zusammenfassung und Ausblick}

Einige unserer Ergebnisse (vgl. Hypothese 1) lassen annehmen, dass rhythmische Übungselemente den Erwerb des deutschen Wortakzents fördern können. Als besonders wichtig erachten wir, dass durch den Einsatz von Musik und Rhythmus zum einen eine höhere intrinsische Motivation für den Lerngegenstand entstehen und zum anderen die Wahrnehmung geschult werden kann. Erfolgte Wahrnehmungen sollten dann von den Lernenden analysiert, systematisiert und kontextualisiert werden. Nur durch solch ein kognitiv orientiertes Vorgehen können nachhal-

\footnotetext{
${ }^{7}$ Aufgrund der verhältnismäßig kleinen Gruppengröße (32 ProbandInnen) wurde ein großzügigeres Signifikanzniveau gewählt.
} 
tige Lernerfolge entstehen. $\mathrm{Da}$ es sich beim aisthetischen Lernen oft um ein verlangsamtes und verweilendes Lernen (vgl. Aissen-Crewett 1998: 157) handelt, muss ein entsprechend hoher Zeitaufwand einkalkuliert werden. Es ist allerdings anzunehmen, dass dieser Zeitaufwand immer nötig ist, um nachhaltig zu lernen. Weitere Ergebnisse der empirischen Studie (vgl. Untersuchungsfrage 2 \& Hypothese 2) weisen darauf hin, dass musikalisch Aktive schon früher im Lernverlauf Fortschritte machen. Wir gehen davon aus, dass dafür eine höhere Sensibilisierung des Gehörs verantwortlich ist. Es scheint ein hohes Ziel zu sein, diese Sensibilisierung im fremdsprachlichen Unterricht auch bei musikalisch nicht Aktiven so zu fördern, dass dadurch nach wenigen Unterrichtseinheiten Ausspracheabweichungen (hier: im Bereich des Wortakzents) sicher und nachhaltig erkannt werden. Dennoch sollten sich Lehrende dazu ermutigt fühlen, Musik im (Aussprache-)Unterricht einzusetzen.

Ein Forschungsdesiderat ist die Untersuchung von Transfereffekten von Musik auf das Erlernen von Fremdsprachen, insbesondere von Aussprache (vgl. dazu auch Forderungen von Gembris 1998: 306). Hierbei sollte eine zentrale Frage sein, wie Musik und die Sprachperzeptions- und Sprachproduktionsfähigkeiten hirnphysiologisch zusammenhängen. Dadurch können sich für die Fremdsprachenerwerbsforschung interessante Perspektiven eröffnen, um eine empirisch fundierte Didaktik zu entwickeln. Darüber hinaus lohnt es sich, Musik als affektiven und kognitiven Faktor eingehender zu beleuchten. Auch die Wechselwirkung zwischen eigenem Musizieren und Ausspracheerwerb sollte näher untersucht werden. Dabei könnten vor allem Untersuchungen interessant sein, in denen neben Gesang auch nach Instrument unterschieden wird.

\section{Literatur}

Aissen-Crewett, Meike (1998): Grundriß der ästhetisch-aisthetischen Erriehung. Potsdam: Direktorium des Instituts für Grundschulpädagogik.

Apeltauer, Ernst (1997): Grundlagen des Erst-und Fremdsprachenerwerbs. Eine Einführung. Berlin: Langenscheidt.

Behme-Gissel, Helma (2005): Deutsche Wortbetonung. Ein Lehr- und Übungsbuch. München: iudicium.

Blell, Gabriele; Hellwig, Karlheinz (1996): Zur Einführung: Bildende Kunst und Musik im Fremdsprachenunterricht. In: Blell, Gabriele; Hellwig, Karlheinz (Hrsg.): Bildende Kunst und Musik. im Fremdsprachenunterricht. Frankfurt a.M.: Lang, 7-13.

Bortz, Jürgen; Döring, Nicola (2006): Forschungsmethoden und Evaluation. Für Humanund Sozialwissenschaftler. Heidelberg: Springer Medizin Verlag. 
Brandstätter, Ursula (2008): Grundfragen der Ästhetik. Bild - Musik - Sprache - Körper. Köln: Böhlau.

Cauneau, Ilse (1992): Hören, Brummen, Sprechen. Angewandte Phonetik im Unterricht Deutsch als Fremdsprache. Handbuch. München: Klett.

Cauneau, Ilse; Müller, Helmut (1992): Hören, Brummen, Sprechen. Angewandte Phonetike im Unterricht Deutsch als Fremdsprache. Begleitheft. München: Klett.

Cranmer, David; Laroy, Clement (1992): Musical openings. Using music in the language classroom. Canterbury: Longman; Pilgrims.

Dieling, Helga; Hirschfeld, Ursula (2000): Phonetik lehren und lernen. Berlin: Langenscheidt.

Dretzke, Burkhard (2009): Ausspracheschulung im Fremdsprachenunterricht. In: Jung, Udo (Hrsg.): Praktische Handreichung für Fremdsprachenlehrer. Frankfurt a.M.: Lang, 132-140.

Ermert, Karl; Gnahs, Dieter; Siebert, Horst (2003): Kunst-Griffe. Über Möglichkeiten künstlerischer Methoden in Bildungsprozessen. Wolfenbüttel: Bundesakademie für kulturelle Bildung.

Falk, Simone (2009): Musik und Sprachprosodie. Kindgerichtetes Singen im frühen Spracherwerb. Berlin: de Gruyter.

Fischer, Andreas (2007): Deutsch lernen mit Rhythmus. Der Sprechrbythmus als Basis einer integrierten Phonetik im Unterricht Deutsch als Fremdsprache; Methode und Material. Leipzig: Schubert.

Freeß, Doris (2002): Ästhetisches Lernen im fächerübergreifenden Sachunterricht. Naturphänomene wahrnehmen und deuten. Baltmannsweiler: Schneider Verlag Hohengehren.

Frey, Evelyn (1995): Kursbuch Phonetik. Lehr- und Übungsbuch. Ismaning: Hueber.

Fuchs, Mechthild; Röber-Siekmeyer, Christa (2002): Elemente eines phonologisch bestimmten Konzepts für das Lesen- und Schreibenlernen: die musikalische Hervorhebung prosodischer Strukturen. In: Röber-Siekmeyer, Christa; Tophinke, Doris (Hrsg.): Schrifterwerbskonzepte zwischen Sprachwissenschaft und Pädagogik. Baltmannsweiler: Schneider Verlag Hohengehren, 98-122.

Gatti-Taylor, Marisa (1980): Songs as a Linguistic and Cultural Resource in the Intermediate Italian Class. In: Foreign Language Annals 6, 13, 465-469.

Gembris, Heiner (1998): Grundlagen musikalischer Begabung und Entwicklung. Augsburg: Wißner.

Graham, Carolyn (1978): Jazz Chants. Rhythms of American English for Students of English as a Second Language. New York: Oxford University Press. 
Graham, Carolyn (1992): Singing, Chanting, Telling Tales. Arts in the Language Classroom. Englewood Cliffs u.a.: Prentice Hall Regents.

Graham, Carolyn (2001): Jazz chants old and new. New York: Oxford University Press.

Graham, Carolyn (2006): Creating Chants and Songs. Oxford: Oxford University Press.

Hellwig, Karlheinz (1996): Sehen und hören, empfindend verstehen und sprechen - Bild- und Musik-Kunst im Fremdsprachenunterricht. In: Blell, Gabriele; Hellwig, Karlheinz (Hrsg.), 15-31.

Hirschfeld, Ursula; Reinke, Kerstin (1998): Phonetik Simsalabim. Ein Übungskurs für Deutschlernende. Berlin: Langenscheidt.

Hirschfeld, Ursula; Reinke, Kerstin; Stock, Eberhard (2007): Phonothek intensiv. Aussprachetraining [Deutsch]. Berlin: Langenscheidt.

Hirschfeld, Ursula; Reinke, Kirstin (2009): 33 Aussprachespiele. Stuttgart: Klett.

Hirschfeld, Ursula; Trouvain, Jürgen (2007): Teaching prosody in German as a foreign language. In: Trouvain, Jürgen; Gut, Ulrike (Hrsg.): Non-native prosody. Phonetic description and teaching practice. Berlin: de Gruyter, 171-187.

Karimer, Lisa (1984): Can Southeast Asian Students Learn to Discriminate between English Phonemes More Quickly with the Aid of Music and Rhythm? Online: http:/ / eric.ed. gov/?id=ED263783 (Stand: 23.03.2014).

Kelz, Heinrich P. (1999): Deutsche Aussprache: praktisches Lebrbuch zur Ausspracheschulung für den Unterricht in Deutsch als Fremdsprache. Bonn: Dümmler.

Kroemer, Sandra (2000): Intonation und Aussprache. Ein Übungsprogramm für Deutsch als Fremdsprache.

Kroemer, Sandra (2001): Die Musik der Sprache. Rhythmus, Klang und Bewegung - ein neues Konzept zum Erlernen einer Sprache. In: DaZ Extraheft, 49-54.

Kuyumcu, Reyhan (2014): Sprach(en)entwicklung und Sprachreflexion: Drei Fallstudien zu zweisprachig aufwachsenden Vorschulkindern mit Erstsprache Türkisch und Zweitsprache Deutsch. Tübingen: Stauffenburg.

Lake, Robert (2002): Enhancing Acquisition through Music. In: The Journal of the Imagination in Language Learning VII. Online: http:/ / www.njcu.edu/cill/journalindex.html (Stand: 23.03.2014)

Lems, Kristen (2001): Using Music in the Adult ESL Classroom. ERIC Digest. Online: http://www.ericdigests.org/2002-3/music.htm (Stand: 23.03.2014).

MacDonald, Shem (2002): Pronunciation - views and practices of reluctant teachers. In: Prospect 3, 17, 3-18. 
Middleman, Doris (1996): Sprechen - Hören - Sprechen. Übungen zur deutschen Aussprache. Ismaning: Verlag für Deutsch.

Nardo, Davide; Reiterer, Susanne Maria (2009): Musicality and phonetic language aptitude. In: Dogil, Grzegorz; Reiterer, Susanne Maria (Hrsg.): Language Talent and Brain Activity. Berlin: de Gruyter, 213-255.

Otto, Gunter (1998): Lernen und Lehren zwischen Didaktik und Ästhetik. SeelzeVelber: Kallmeyer.

Reinke, Kerstin (2011): Einfach Deutsch aussprechen. [phonetischer Einführungskurs; Deutsch als Fremdsprache]. Leipzig: Schubert.

Reinke, Kerstin (2012): Phonetiktrainer A1-B1. Aussichten. Kurs- und Selbstlernmaterial mit 2 Audio-CDs. Stuttgart: Klett.

Riemer, Claudia (1997): Individuelle Unterschiede im Fremdsprachenerwerb. Eine Longitudinalstudie über die Wechselwirksamkeit ausgewählter Einflußfaktoren. Baltmannsweiler: Schneider Verlag Hohengehren.

Rora, Constanze; Wagener, Matthea (2008): Ästhetische Bildung: Musik. Frankfurt a.M.: Grundschulverband - Arbeitskreis Grundschule.

Rug, Wolfgang (2012): 77 Klangbilder gesprochenes Hochdeutsch. Übungen, Spiele, Tipps und Tricks zum phonetischen Training Deutsch als Fremdsprach; Sprachniveau B1 bis C2. Leipzig: Schubert.

Schäfermeier, Ingrid (1998): So klingt Deutsch. Übungen zur deutschen Standardaussprache im Bereich Deutsch als Fremdsprache. Münster: Lit.

Schiffler, Ludger (2012): Effektiver Fremdsprachenunterricht. Bewegung - Visualisierung Entspannung. Tübingen: Narr.

Sposet, Barbara A. (2008): The role of music in second language acquisition. A bibliographical review of seventy years of research, 1937-2007. Lewiston u.a.: E. Mellen Press.

Stokes, Jeffery D. (2001): Factors in the Acquisition of Spanish Pronunciation. In: IR AL: International Review of Applied Linguistics in Language Teaching, 2, 131, 63-84.

Stöver-Blahak, Anke; Perner, Matthias (2011): RaP im Deutsch als FremdspracheUnterricht - „Es hat Spaß gemacht und trotzdem haben wir etwas gelernt.“. In: Hahn, Natalia; Roelcke, Thorsten (Hrsg.): Grenzen überwinden mit Deutsch. 37. Jahrestagung des Fachverbands Deutsch als Fremdsprache an der Pädagogischen Hochschule Freiburg/Br. 2010. Göttingen: Universitätsverlag, 311-323.

van Asselt, Jan (1970): Music as an Aid to Teaching German in the Elementary Schools.

Washington: U.S. Office of Education, Bureau of Research. 
Wilcox, Wilma B. (1996): Music cues from classroom singing for second language acquisition: Prosodic memory for pronunciation of target vocabulary by adult non-native English speakers. Dissertation Abstracts Online, 56, 3318-A. Online: http://people. uwec.edu/rasarla/research/language/comdis.htm (Stand: 23.03.2014).

Willis, Bruce Dean; Mason, Keith (1994): Canciones en la clase: The Why and How of Integrating Songs in Spanish by English-Speaking and Bilingual Artists. In: Hispania, 1, 77, 102-109. 

V. Film 



\title{
Die Etablierung eines Geheimnisses - Titelsequenzen im Unterricht Deutsch als Fremdsprache
}

\author{
Tina Welke \\ In Titelsequenæen überlagern Vorspann und Exposition der Filmhandlung einander. Als Mini- \\ filme dienen sie der Bindung der Zuschauer und Zuschauerinnen und deren Einstimmung auf das \\ zu Erwartende. Neben ibrer rezeptionssteuernden Funktion sind sie in ibrer Verdicbtung durch \\ einen bohen Aufwand im Einsatz von kinematographischen Mitteln gekennzeichnet. Am Bei- \\ spiel des Kursspielfilms Hood (2001) zeigt der Beitrag, dass Kürze, Einführungscharakter und \\ mediensperifische Verfahren von Titelsequenzen für den Unterricht Deutsch als Fremdsprache \\ eine Quelle vielfältiger Zugänge an das Medium Film darstellt.
}

Der vorliegende Beitrag soll exemplarisch aufzeigen, wie gerade separate Filmsegmente als künstlerische Artefakte geeignet sind zum Thema eines Unterrichts Deutsch als Fremdsprache zu werden, der auf die subjektiven Erfahrungen der Lernenden aufbaut und zur Reflexion des Ich-Selbstverständnisses einlädt, ohne dabei die zentralen Aufgaben der Sprachentwicklung und Sprachvermittlung zu vernachlässigen. Der Ansatz versteht Filme als intendiert geformte Wirklichkeitsentwürfe, die im Unterricht einerseits zum Ausgangspunkt von Aushandlungsprozessen über Bedeutungszuschreibungen werden können, andererseits ebenso die Bedeutungskonstruktion durch die dem Medium Film eigenen Verfahren thematisieren. Am Beispiel der Titelsequenz des Kurz(spiel)films Hood (2001) wird dargelegt, wie das Zusammenspiel der audio-visuellen Codes den aktiven Rezeptions- 
prozess leitet und Lernende dazu anhält, ihr ästhetisches, symbolisches und kommunikativ-narratives Wissen an filmische Texte heranzutragen. ${ }^{1}$

Das angeführte Beispiel weist die Merkmale Beginn einer filmischen Narration und ausschnitthafter Charakter auf. Zum einen findet besonders an Filmanfängen eine dichte Informationsvergabe statt, auf deren Basis dann die Entwicklung der Figuren und der zentrale, die Handlung motivierende Konflikt, entfaltet werden. „Formen, Themen und Motive eines Films werden am Anfang etabliert, und der Filmanfang bildet damit so etwas wie einen textuellen Knotenpunkt" (Hartmann 1995: 102). Zum anderen soll deutlich werden, dass es nicht zwingend notwendig ist, im Unterricht mit vollständigen Werken zu arbeiten, um künstlerischen Formen gerecht zu werden. Gerade die Auseinandersetzung mit dem isolierten Fragment erlaubt es in die Tiefe zu gehen und darüber hinaus Neugierde zu wecken, die die eigenverantwortliche Beschäftigung mit dem ästhetischen Artefakt Film außerhalb des Unterrichts fördert (vgl. Bergala 2006: 10). Bei Interesse der Lernenden kann diese wiederum zyklisch in den Unterricht einfließen.

Erwähnenswert in diesem Zusammenhang scheint, dass die Gestaltung von Anfangs- und Abspannsequenz bei Langspielfilmen nicht selten an eigens darauf spezialisierte Produktionsfirmen übertragen wird, die diese dann in enger Absprache mit den Regisseurinnen und Regisseuren anfertigen (z.B. Soul Kitchen (2009), Drehbuch und Regie: Fatih Akin; Sophie Scholl - Die letrten Tage (2005), Drehbuch: Fred Breinersdorfer, Regie: Marc Rothemund). Analoges gilt für Trailer, maximal zweiminütigen Minifilmen, die als Teil der Marketingstrategie in der Vorproduktionsphase von selbstständigen Studios auf der Grundlage von Drehbuch und ungeschnittenen Szenen angefertigt werden, um ein potentielles Publikum aufmerksam und neugierig auf den in der Regel erst Wochen bis Monate später in den Verleih gelangenden Kinofilm zu machen. Die Akzeptanz und Relevanz von Trailern als eigene ambitionierte Kunstform schlägt sich nicht zuletzt darin nieder, dass mittlerweile die Kategorie Golden Trailer Oscar existiert.

Eine vergleichbare filmische Kurzform, wenn auch mit beschränkteren finanziellen Mitteln und an einen kleineren Rezipientenkreis gerichtet, sind die für das Fernsehen produzierten Programmankündigungen, sogenannte Teaser (vgl. Monaco 2001). Ebenso kommen natürlich die knappen geschlossenen Formen der Werbefilme und Kurz(spiel)filme für die Thematisierung der siebten Kunst im Unterricht in Frage, ohne dass Lehrende durch Reduktion und Auswahl in das künstlerische Artefakt eingreifen. Der Beitrag möchte jedoch zeigen, dass die Vorarbeit der Isolierung ermöglicht, Akzente in der konkreten Beschäftigung mit dem Medium Film zu setzen, die einer Sensibilisierung der Lernenden in Bezug auf ihre Wahrnehmungs- und Deutungskompetenz zugutekommen.

\footnotetext{
${ }^{1}$ Ein Langspielfilm mit einer Eröffnung durch Titelsequenz ist z.B. der oscarprämierte Film Der englische Patient (1996), USA, Drehbuch und Regie: Anthony Minghella.
} 


\section{Hood - ein modernes Schauermärchen}

Die im Folgenden vorgestellte Titelsequenz (1,40 Minuten) eröffnet den deutschen Kurz(spiel)film Hood aus dem Jahre 2001. Für Regie und Buch des fiktionalen Films ist die Nachwuchsregisseurin Sylvia Dahmen verantwortlich. Mit 27 Minuten gehört Hood zu den mittellangen Kurz(spiel)filmen. Auf der inhaltlichen Ebene handelt es sich bei dem Film um eine Adaption des Rotkäppchenstoffs. Die filmische Adaption folgt dem Handlungsgerüst des literarischen Ausgangsstoffs im Groben, erhöht aber die Komplexität durch Erweiterung des Figureninventars. In Hood verbündet sich die agile, ihrer Weiblichkeit bewusst seiende Großmutter mit der Enkelin gegen die bigotte, moralisierende Mutter. Die männliche Figurenwelt ist in Juwelier, Polizist, Jäger und Holzfäller aufgespalten. Daneben verkörpert eine amorphe Gruppe alkoholkonsumierender und kiffender Jugendlicher weitere Begehrlichkeiten und Gefahrenpotentiale. Die Rolle des Wolfes könn(t)en also durchaus mehrere Figuren innehaben. Abgesehen von diesen Anreicherungen hetzt ein leibhaftiger Wolf heulend durch den mondbeschienenen Filmwald. Es kommt zu transzendentalen Metamorphosen der Figuren, aus Regenpfützen werden Blutlachen. Das gerade Etablierte verschwimmt zu neuer, verzerrter Gestalt. Die filmische Repräsentation nimmt auf Bild- und Tonebene deutlich Anleihen am Genre des Horrorfilms mit Splatterelementen (vgl. Vossen 2004: 11). Hood aktualisiert und modernisiert so den bekannten Märchenstoff. Die adoleszente Protagonistin träumt davon aus der sozialen und sexuellen Kontrolle durch die Mutter und der tristen, engen Dorfgemeinschaft auszubrechen. Parallel dazu ermöglichen die zivilisatorischen und emanzipatorischen Errungenschaften des Gemeinwesens Rotkäppchen und Großmutter ihren Anspruch auf Selbstbestimmtheit zu behaupten. Hood spielt mit der Lust am Gruseln, ohne nachhaltig zu verstören. Die kathartische Wirkung des Schauermärchens beruht auf der Überwindung der Gefährdung, dem überschaubaren Handlungsraum und der surrealen Abwandlung des bekannten Stoffes, was den Film für den DaF-Unterricht mit (jungen) Erwachsenen interessant macht.

Die Titelsequenz von Hood ist segmentiert, indem Ein- bzw. Abblendungen von Credits (sieben) und Bildfolgen (sechs) einander abwechseln. Eröffnet wird sie mit dem Schriftzug Anne und Stephan Schesch zeigen, abgeschlossen mit dem Filmtitel Hood, wobei das Layout des , $\mathrm{H}^{\star}$ graphisch in Teile zerfällt. Die Credits erscheinen in roter Schrift in Majuskeln auf schwarzem Grund. Sie sind also deutlich von den bewegten Bildern abgegrenzt. Nach den Namen der Produzenten (00:01) folgen die Namen der Hauptdarstellerin (00.14), die der ersten Nebendarstellerin (00:24) und dann jeweils paarweise die weiterer NebendarstellerInnen. In Minute 01:02 ist In einem Film von Sylvia Dahmen zu lesen. Die kontrastive Farbgebung der Credits weckt Assoziationen an Blut und Nacht, gleichzeitig weist der Schrifttyp der Blockbuchstaben Ähnlichkeit zur Handschriftlichkeit auf und suggeriert eine kindliche Autorschaft. Auf der Tonebene ist durchgängig eine hohe metallische Klangkulisse nicht natürlichen Ursprungs zu vernehmen, die durch Geräusche des Win- 
des im Wald bzw. durch Sphärenklänge ergänzt wird. Ab Minute 01:02 überlagern Perkussionsinstrumente den anfänglichen Klangraum. Sie setzen der bedrohlichen Atmosphäre etwas Ungezwungenes entgegen. Im Rhythmus dieser Begleitmusik ${ }^{2}$ geht die Protagonistin nun die Dorfstraße entlang. Bis dahin folgte die Kamera dem rasanten Lauf eines Wolfes durch das Unterholz eines nächtlichen Waldes von links nach rechts. Die Bäume fliegen schemenhaft vorüber, in der Ferne ist eine Lichtung zu erahnen. Die Dunkelheit wird von grell-gelb-weißem Licht durchbrochen. Die Wirkung einer unmittelbaren Überwältigung auf der Sinnesebene ist durch den Einsatz diegetischen Wolfsgeheuls verstärkt. Die Credits Elaine Lüttich versprechen eine kurze Rast. Zugleich aber vermuten wir, dass nun die weibliche Hauptfigur auftritt, die in irgendeiner Beziehung zu dem jagenden oder fliehenden Wolf steht. Nach einer Aufblendung fährt die Kamera langsam auf eine Häuserfront zu, während sie dörfliches Kopfsteinpflaster erfasst. Sie fokussiert eine Auslage links im Bild, auf der Straße und dem Gehsteig liegen vereinzelt schmutzig-weiße Papierfetzen. Ansonsten besteht die Farbpallette aus rötlichen, braun-orangen Tönen. Rechter Hand über einem Geschäft hängt die Aufschrift Heidis Bistro. Neben dem lang gezogenen metallischen Anfangston ist ein leichtes Reiben zu vernehmen, eventuell Schritte auf grobem, unebenem Untergrund. Ein Eindruck von Patina und Stagnation dominiert die Szenerie. Ausgestorben scheint der Ort, den wir auf Grund der Credits der Hauptfigur zuordnen. Waren wir anfangs Rastlosigkeit und potentieller Gefahr ausgesetzt, herrscht nun die absolute Ereignislosigkeit. Credits unterbrechen den Gang zur Auslage, ein zweiter weiblicher Namen erscheint. Wir blicken unmittelbar in die dunkle Auslage eines Schmuckgeschäfts mit Perlenkette, Armreifen und anderem Schmuck aus mattglänzendem Gold und Silber. Unwirkliches Rauschen einer Unendlichkeit umfängt uns. Im Geschäftsinneren entnimmt jemand der Auslage - wir sehen nur die Hände - behutsam eine Schmuckkarte (Präsentationselement für Schmuck) mit einer Silberkette und drei Anhängern. Credits nennen die Namen einer Frau und eines Mannes. Das dunkelrote Präsentationsobjekt, nun mit einer Kette und einem christlichen Kreuz versehen, wird zurück in die Auslage geschoben. Zwei männliche Darstellernamen werden eingeblendet. Eine Detailaufnahme ${ }^{3}$ bietet die figurativen drei Silberanhänger dar: in der Mitte eine Patronenhülse, links eine Rasierklinge und rechts ein von einem Pfeil durchbohrtes Herz. Auf der Tonebene stoBen Metallteile klingend aneinander. Daumen und Zeigefinger beider Hände halten die Kette gespannt, zwei andere, zartere Hände, nehmen sie. Ein älterer Mann mit Brille in dunkelblauem Wollpullover und Hemd gekleidet - er ist wohl der Geschäftsinhaber - wendet sich diskret ab. Der Mann strahlt Vertrauenswürdigkeit

\footnotetext{
${ }^{2}$ Man unterscheidet zwischen ,,synchron' und ,asynchron“ - der Ton gehört entweder zum Bild, z.B. zu einem Dialog oder er kommt von außerhalb [...] (kurz ,on“ und ,off) “ (Klant; Spielmann 2008: 151).

${ }^{3}$ Detail (engl. Big close up/Detail): „Die Detailaufnahme zeigt einen Ausschnitt [...]. Die Detailaufnahme besitzt [...] eine hohe Suggestivkraft und zieht den Zuschauer in ihren Bann" (Klant; Spielmann 2008: 96).
} 
aus, die Atmosphäre im Raum hat etwas Geheimnisvolles. Im runden Handspiegel sind die untere Gesichtshälfte und der Hals eines jungen Mädchens zu sehen. Es hat die Kette umgelegt und streicht mit der rechten Hand über die phallisch geformte Patronenhülse. Fortwährend ist ein rauschender Ton zu hören. Die Einbettung des Namens der Regisseurin erklärt die Aufzählung der wichtigsten beteiligten Schauspielerinnen und Schauspieler für abgeschlossen. Uns erwartet eine Geschichte, in der drei Frauen und drei Männer handlungstragend sind, wobei zwei der weiblichen Figuren maßgeblicher als die anderen sind, sie fanden zuerst und jeweils singulär Erwähnung. Naheliegend ist die Erstgenannte, das junge Mädchen aus dem Spiegelbild, dessen Augen wir noch nicht sahen. Anzunehmen ist, dass sie in diesem Dorf lebt und das Geschäft sowie den Besitzer kennt. Die Symbolik der von ihr erworbenen Kette kreist um Glück, Tod und Liebe. Sie ist auf jeden Fall mit dem Verlust von Blut verbunden. Das christliche Symbol des Kreuzes, des Glaubens an Jesus Christus, bleibt in der Auslage zurück. Das Mädchen näherte sich gezielt heidnischen, teilweise auf Wehrhaftigkeit verweisenden Attributen. Offen bleibt noch die Verbindung zwischen dem wilden, dämonisierten Wolf und dem geschmückten, das Kreuz verschmähenden Mädchen. Beide müssen aber in einem Zusammenhang stehen, sonst würden sie nicht dergestalt aufeinander folgend präsentiert.

Die nun einsetzenden Perkussionseffekte eröffnen einen neuen Handlungsabschnitt. Das Mädchen - wir sehen vorerst nur flache feste Halbschuhe, dicke Strümpfe und einen knielangen dunklen Faltenrock auf sonnigem, schattengemustertem Gehsteig - nähert sich der Kamera. Ihr Gesicht streift durch das Bild. Sie geht vorüber als schreite sie im Rhythmus der Musik, wir hören ihre Schritte. Sie trägt ein ärmelloses, getupftes Shirt, eine Tasche schräg über den Körper und die Kette mit den Anhängern. Ihr offenes glattes Haar ist schulterlang und dunkelbraun. Wie schon zuvor dominieren braun-orange Farben die Zeichnung des Dorfes. Von den Hausfassaden bröckelt der Putz, der eingezäunte Bereich vor den Häusern liegt brach. Auf dem breiten Gehsteig stehen eingepflanzt lichte Bäume. Aus Distanz ertönt Stimmengewirr wie auf einer Party. Wir folgen dem Mädchen mit dem Auge der Kamera, betrachten es in Rückenansicht in der Halbtotalen ${ }^{4}$. An der Straßenecke im Hintergrund linker Hand lungern Jugendliche. Die Kamera hat den Abstand verringert. Als das Mädchen die Gruppe erreicht, die sie gestisch begrüßt - ihre Stimmen sind nach wie vor unverständlich - befindet sich die Kamera auf derselben Höhe. Das Licht der Abendsonne blendet das Kameraobjektiv, wodurch die Figuren der Jugendlichen unkenntlich sind und sich einer Abbildung entziehen. Die Kamera überholt nun die Gruppe. Das Mädchen wendet den Kopf in unsere Richtung, während die vier Jugendlichen auf die Halskette schauen und deuten. Die Lautstärke und Ungeordnetheit der Stimmen widerspricht der geringen Gruppengröße. Sie weisen den Jugendlichen einen enthemmten Status zu, der

\footnotetext{
${ }^{4}$ Halbtotale (engl. Medium long shot): „Hier wird die bildgewichtige Person bis zur vollen Größe gezeigt" (Klant; Spielmann 2008: 96).
} 
im Widerspruch zum Habitus des Mädchens steht. Nach einem Schnitt erscheint in Nahaufnahme ${ }^{5}$ das Gesicht eines jungen schnurbärtigen Mannes am Lenkrad eines Autos. In die Geräuschkulisse mischt sich ein sirenenhafter Klang. Der Mann betrachtet aus dem offenen Seitenfenster heraus Gruppe und Mädchen. Er hat den linken Arm auf den Rahmen des Autofensters gelegt, am Handgelenk ein breites Lederband. Er chauffiert lässig mit der rechten Hand, an der eine massive goldene Uhr glänzt. Der junge Mann trägt eine Art Uniform: ein hochgekrempeltes hellblaues Hemd und eine dunkle Schirmmütze. Zwischen ihm und dem Mädchen scheint es zu Augenkontakt gekommen zu sein. Die schweigende Begegnung oszilliert zwischen reiner Notiznahme und angedeutetem Interesse. Das Auto fährt langsam vorbei, der Mann dreht sich leicht zurück. Während des kurzen Auftritts bleiben einzelne seiner Gesichtspartien mehrfach im Schatten. Das Mädchen blickt ihm nach. Das polizeiartig lackierte Auto (unten dunkel, oben hell) entfernt sich von rechts gekommen nach links, auf der Fahrertür hat es einen Sheriffstern. Der Blick des jungen Mannes in den Seitenspiegel in Richtung zurückbleibende Gruppe ist das letzte Filmbild der Titelsequenz. Diese wird auf der visuellen Ebene mit der Präsentation des Schriftzuges mit dem Filmtitel Hood beschlossen, auf der Tonebene vom Rauschen und den bekannten Perkussionsklängen begleitet.

In den ersten Filmbildern der Titelsequenz jagte ein Wolf vom linken unteren Bildrand in Richtung rechten oberen Bildrand. In den die Titelsequenz abschlieBenden Bildern steuert ein Ordnungshüter sein Auto im Schritttempo vom unteren Bildrand nach links oben. Irgendwo fern am Horizont (der Lichtung?) könnten die Wege der beiden sich kreuzen. Das Mädchen ist die gesamte Titelsequenz über entweder in der rechten Bildhälfte positioniert oder bewegt sich dorthin. In Bezug zu den männlichen Figuren ist sie mittig angeordnet. Die Verortung des Mädchens und sein Verhältnis zu den beiden angedeuteten Handlungsdiagonalen ist der zentrale Konflikt der nun einsetzenden Geschichte.

\section{Anregungen für eine filmästhetische Wahrnehmungsschulung}

Die ausführliche Beschreibung der Titelsequenz sollte demonstrieren, wie informationshaltig selbst so kurze Filmausschnitte gestaltet sein können. Die Informationsfülle als solche wahrzunehmen, zu erkennen, wie Elemente der Bild- und Tonebene aufeinander abgestimmt sind und so in ihrer Verwobenheit die Dichte erst hervorbringen, erfordert die Bereitschaft und die Möglichkeit des genauen Sehens und Hörens. Zur Schulung der filmbezogenen Wahrnehmung muss der Flüchtigkeit der bewegten Bilder und Töne mit Mitteln der Verlangsamung entgegengewirkt werden. Wahrnehmungsschulung meint zuvorderst Spurenlesen, um darauf aufbauend die Fähigkeit zu entwickeln die temporalen Beziehungen und inhaltlichen

\footnotetext{
${ }^{5}$ Nah (engl. Medium close up): „Der Bildausschnitt rückt die Person vollständig in den Mittelpunkt. Der umgebende Raum spielt keine Rolle mehr [...] mimische Reaktion [soll] sichtbar werden" (Klant; Spielmann 2008: 96).
} 
Bedeutungen der präsentierten Bilder und Töne zu verstehen. Der bewusste Akt der Vergegenwärtigung dessen, was man erlebt hat, ist Voraussetzung sich anderen mitzuteilen und somit auch in sozialen Kontakt zu treten. Filme als plurimediale Darstellungsformen sind audio-visuelle Kompositionen, sie sind

ein virtueller Bewegungsraum, der uns nicht allein in Bewegungen des Sehens, sondern auch des Hörens: und mit ihnen in eine komplexe Bewegung des Verstehens versetzt (Keppler 2006:71).

Filme richten sich an Rezeptionsgemeinschaften, welche aus Gruppen von Individuen mit verschiedenen Vorlieben und Interessen bestehen. Die Spannbreite der Bedürfnisse reicht im Extremfall vom Wunsch nach untätiger Unterhaltung bis zu dem nach aktiver Anregung. Verstehen ist immer zuerst ein subjektiver Akt und damit von individuellen Voraussetzungen und Erfahrungen abhängig. In der Begegnung mit künstlerischen Artefakten gerade im unterrichtlichen Kontext, egal welcher Altersgruppe, ist das Recht auf Annäherung, unsanktionierten Zugang und letztlich Aneignung die zentrale Prämisse. Selbstverständlich können, um das intentionsgemäße Verstehen zu unterstützen, filmanalytische Instrumentarien zur Anwendung gelangen. Sie sind nützlich, Lernenden kollektive Rezeptionsprozesse nahe zu bringen oder auch Strategien der ideologischen Instrumentalisierung aufzudecken. Aber kognitiv-analytische Verfahren dürfen nicht auf Kosten von Kunst als Quelle von Inspiration und Genuss gehen und so affektiv-emotionale Zugänge verhindern (vgl. Blell; Lütge 2008: 129).

Häufig wird im Unterricht Deutsch als Fremdsprache auf das Modell der Filmanalyse, das Faulstich (2002: 26) vorschlägt, Bezug genommen. Er unterscheidet vier verschiedene Analyseebenen:

$W$ as: die Handlungsanalyse (Drehbuch, Filmprotokoll, Sequenzprotokoll, Zeit, Struktur, Phasen),

Wer: die Figurenanalyse (Konstellationen: Haupt- und Nebenfiguren, Protagonist und Held, Figurenpaarungen, Rollen, Typen, Setting/Ausstattung),

Wie: die Analyse der Bauformen, Kamera/Einstellung und Montage, Dialog und Geräusche, Musik, Raum, Licht, Farbe,

Wozu: die Analyse der Normen und Werte, Ideologie.

Teile dieses Modells dienen dann als Kategorien für die Arbeit mit den Lernenden. Im konkreten Fall könnte die Aufgabe lauten, zu überlegen, um welches Genre es sich bei dem durch die Titelsequenz eröffneten Kurz(spiel)film handelt und die Einschätzung mit Indikatoren der filmischen Präsentation zu belegen. Bei weniger filmgeschulten Gruppen kann vorher eine Auswahlliste mit Genres zur Verfügung gestellt werden, denen Merkmale zugeordnet werden müssen.

Ein figurenorientierter Ansatz würde, ausgehend von den Credits, die Zahl der Darsteller und Darstellerinnen und ihre Bedeutung für die Filmhandlung bestim- 
men lassen. Auf Grund dieser Bestimmung sollen mögliche Figurenkonstellationen (z.B. der böse Wolf - der gute Polizist) bzw. ein Figurennetz, das alle Darsteller/Darstellerinnen/Figuren in Beziehung zueinander setzt und verknüpft, (graphisch gestützt) angefertigt werden. Bei den visualisierten Figuren, insbesondere der Protagonistin, bietet sich die Erstellung eines Figurenprofils (Äußeres, Wesensmerkmale, Motivationen...) als Aufgabe an. Bei der Ausstattung liegt die Gegenüberstellung der nicht ausschließlich bipolaren Symbolik der beiden Halsketten nahe und die Frage, inwieweit sie mögliche Trägerinnen charakterisieren.

Ebenso ließe sich im Unterricht bei den Bauformen, hier z.B. dem dreigeteilten Farbspektrum, ansetzen. Dem schwarz-weiß-Kontrast, den warmen und kühlen Farben sind in der Titelsequenz jeweils bestimmte Handlungsräume und Figuren zugeordnet. Die gewählte Farbgebung dient nicht allein der Charakterisierung und Kenntlichmachung von Zugehörigkeit, sondern dramatisiert die in der Titelsequenz dargebotenen Elemente. Sie hat daneben über die Titelsequenz hinaus eine symbolische Bedeutung, auf die der Film rekurriert. Lernende sollten ermuntert werden zu reflektieren, was die Farben für sie verkörpern, bzw. welche Möglichkeiten der farblichen Kennzeichnung und Gestaltung ihnen aus anderen Filmen bekannt sind. (Zur Bedeutungskodierung von Farben im DaF-Unterricht vgl. den Artikel von Dieter Rall in diesem Band). In dem Bereich der Bauformen fallen auch die oben beschriebenen Aspekte der Bildkomposition. Eine Sensibilisierung für die akustischen Phänomene der Titelsequenz und ihren Beitrag zur Etablierung der Grundstimmung des Films könnte erfolgen, indem allein die Tonspur abgespielt wird und die Lernenden ihre Assoziationen dazu festhalten. Die Ergebnisse lassen sich wiederum zur Eingrenzung des Filmgenres verwenden.

Bei der Einblendung des Filmtitels bzw. dessen Nennung dürften einige Lernende der Überzeugung sein, es mit einer Abwandlung des Rotkäppchenstoffs zu tun zu haben. Deshalb sollte eventuell darauf verzichtet werden, ihn zu präsentieren, wenn filmspezifische Verfahren der Bedeutungskonstruktion im Zentrum der Aufmerksamkeit stehen. Der Titel übernimmt sonst die Funktion eines Filters, der die Möglichkeiten der Bedeutungszuschreibungen einengt und ausschließlich in eine Richtung lenkt. In weiterer Folge wird der Film unter Umständen lediglich als Illustration des bekannten literarischen Textes antizipiert und an dieser Bestimmung gemessen, was obendrein auch Verstörung und Abwehr auslösen kann, da Hood nicht ohne Weiteres übertragbar auf die kindlichen Welten der Erstrezeption des Märchens ist (vgl. Bettelheim 2006). Reizvoller und mehr Genugtuung versprechend ist es, ohne Kenntnis des Titels die gehegten Vermutungen auf ihre Plausibilität zu hinterfragen und der Titelsequenz zunächst mit erwachsenen Augen zu begegnen.

Obwohl die inhaltlich-thematisch orientierte Arbeit wohl die weit verbreitetste und akzeptierteste Form der Berücksichtigung des Mediums Film im DaFUnterricht ist, soll auch hierauf eingegangen werden. Im Anschluss an Aktivitäten, die auf die Gestaltung der Titelsequenz abzielten, könnte seitens der Lernenden der Versuch unternommen werden, in Gruppen Filmideen (sogenannte Pitching) 
zum Kurz(spiel)film Hood zu kreieren und diese dann als Story im Plenum zu präsentieren. Einzige Maßgabe ist, der Titelsequenz Rechnung zu tragen. Zu auf besondere Zustimmung gestoßenen Skizzen könnten in einem weiteren Schritt Exposees geschrieben werden. Die ein bis drei Seiten langen, in Prosa verfassten Entwürfe umreißen die Grundidee des Films, schildern die zentralen Figuren sowie den bestimmenden Konflikt. In der Phase der Vorproduktion von Filmen dienen Exposees dazu, bei Produzenten bzw. Redakteuren, Interesse an der Realisierung des Films zu wecken. Die in den entstandenen Texten angelegten Handlungsabfolgen und Figurenentwicklungen ließen sich extrahieren und ihre Plausibilität sowie narrative Kohärenz diskutieren.

Vermutlich werden die Lernenden wissen wollen, welche Geschichte der Kurz(spiel)film Hood tatsächlich erzählt. Um diesem Wunsch zu entsprechen, gleichzeitig sowohl dem Anliegen der Auseinandersetzung mit dem künstlerischen Medium als auch der Aufgabe der Sprachentwicklung und Sprachvermittlung gerecht zu werden, bietet sich z.B. die ungeordnete Präsentation von Ausschnitten aus dem Film an. Die Umsetzung der methodisch-didaktischen Forderung nach Strategien der Verlangsamung im Rezeptionsprozess ist dieser Präsentationsform immanent. Bei Hood sind es sechs bis sieben isolierte Sequenzen (Schlüsselszenen, Wendepunkte), deren chronologische Reihung es erlaubt, den Handlungsbogen der präsentierten Geschichte und die Entwicklung der Figuren zu rekonstruieren. Während der Sichtung sind die Lernenden dazu angehalten, die Sequenzabfolge gedanklich umzustellen und dabei die fehlenden Teile zu füllen. Die Montage kann haptisch in Kleingruppen an Laptops vollzogen werden, sofern ein Satz USBSticks mit den Sequenzen zur Verfügung steht. Die Füllung der vorenthaltenen, d.h. ausgesparten Sequenzen durch die Lernenden kann verbal (beschreibend, erzählend) oder szenisch (analog eines Drehbuchs), aber auch zeichnerisch als Teile eines Story Boards ${ }^{6}$ gestaltet werden.

Die Faszination von Adaptionen von Märchenstoffen und ihre breite Rezeption belegen zahlreich andere Filme der letzten Zeit. ${ }^{7}$ Ein unterrichtliches Konzept wie hier ansatzweise dargelegt, das die Auseinandersetzung mit künstlerischen Artefakten als integralen und selbstverständlichen Bestandteil begreift und es so versteht Imaginationsgabe, Neugier und Erfahrungen der Lernenden anzusprechen und in den Unterricht einzubinden, ist langfristig nachhaltig und reduziert Lernende nicht auf eine soziale Rolle ihrer Person.

\footnotetext{
6 , $[\mathrm{n}$ n der Phase der Vorproduktion für die Film- und Fernsehindustrie angefertigte Zeichnungen, die die einzelnen Szenen eines Drehbuchs visualisieren“ (Welke 2010: 312).

7 z.B. der Fantasy-Film Red Riding Hood - unter dem Wolfsmond, USA (2011), Regie: Catherine Hardwicke oder auch die ZDF-Reihe seit 2005 Märchenperlen (vgl. www.fernsehserien.de/maerchenperlen) und die ARD-Reihe seit 2008 Sechs auf einen Streich (vgl. www.fernsehserien.de/sechs-auf-einenstreich).
} 


\section{Literatur}

Abraham, Ulf (2013): Kurzspielfilme im Deutschunterricht. In: Praxis Deutsch. Zeitschrift für den Deutschunterricht 237, 4-14.

Beil, Benjamin; Kühnel, Jürgen; Neuhaus, Christian (2012): Studienhandbuch Filmanalyse. Ästhetik und Dramaturgie des Spielffilms. München: Fink.

Bergala, Alain (2006): Kino als Kunst. Filmvermittlung an der Schule und anderswo. Marburg: Schüren.

Bettelheim, Bruno (2006): Kinder brauchen Märchen. München: dtv.

Blell, Gabriele; Lütge, Christiane (2008): Filmbildung im Fremdsprachenunterricht: neue Lernziele, Begründungen und Methoden. In: Fremdsprachen Lehren und Lernen 37, 124-140.

Eick, Dennis (2005): Exposee, Treatment und Konzept. Konstanz: UVK.

Faulstich, Werner (2002): Grundkurs Filmanalyse. München: Fink.

Hartmann, Britta (1995): Anfang, Exposition, Initiation. Perspektiven einer pragmatischen Texttheorie des Filmanfangs. In: montage/av. Zeitschrift für Theorie \& Gescbichte audiovisueller Kommunikation 4, 2, 101-122.

Keppler, Angelika (2006): Die Einheit von Bild und Ton. Zu einigen Grundlagen der Filmanalyse. In: Mai, Manfred; Winter, Rainer (Hrsg.): Das Kino der Gesellschaft - die Gesellschaft des Kinos. Interdisziplinäre Positionen, Analysen und Zugänge. Köln: Herbert von Halem Verlag, 60-78.

Klant, Michael; Spielmann, Raphael (2008): Grundkurs Film 1. Kino, Fernsehen, Videokunst. Braunschweig: Schroedel.

Monaco, James (2001): Film verstehen. Kunst, Technik, Sprache, Geschichte und Theorie des Films und der Neuen Medien. Hamburg: Rowohlt.

Vossen, Ursula (2004): Filmgenres. Horrorfilm. Stuttgart: Reclam.

Welke, Tina; Faistauer, Renate (Hrsg.) (2010): Lust auf Film heißt Lust auf Lernen. Der Einsatz des Mediums Film im Unterricht Deutsch als Fremdsprache. Wien: Praesens.

Welke, Tina (2010): Story Board. In: Barkowski, Hans; Krumm, Hans-Jürgen (Hrsg.): Fachlexikon Deutsch als Fremdsprache. Tübingen u.a.: Francke, 312.

Welke, Tina (2007): Ein Plädoyer für die Arbeit mit Kurzfilmen. In: Sass, Anne (Hrsg.): Sehen (d) Lernen. Fremdsprache Deutsch. München: Hueber 36, 21-25.

\section{Filmographie}

Hood, 2001, Deutschland, Drehbuch und Regie: Sylvia Dahmen, 27 Minuten. 


\title{
Ästhetisierte Faktualität im Film. Über die filmisch- literarische Vermittlung von Initiationsszenen des bundesrepublikanischen Terrorismus in den beiden Filmen Wer wenn nicht wir (2011) und Der Baader Meinhof Komplex (2008) ${ }^{1}$
}

\begin{abstract}
Nils Bernstein
Literaturverfilmungen haben einen eigenen ästhetischen Anspruch. Besonders interessant wird die autarke filmische Gestaltungsweise im Vergleich mit der Literaturvorlage, wenn es nicht um fiktionale Literatur, sondern um Sachbücher geht. Uli Edel und Andreas Veiel zeigen in insgesamt drei Szenen zwei Initiationserlebnisse des bundesrepublikanischen Terrorismus der 60erund 70er-Jahre. Auf Faktualität lassen sich die Szenen nur bis zu einem gewissen Grad überprüfen. Im Beitrag soll daher der ästhetische und auf Fiktionalität berubende Eigenwert der Filme hervorgehoben und Methoden zur Vermittlung ästhetischer Medienkompetenz aufgezeigt werden.
\end{abstract}

\section{Einleitung}

Die Zeitspanne der bundesrepublikanischen Geschichte von 1967 bis 1977, vom Beginn der so genannten 68er bis zum so genannten Deutschen Herbst, gehört wohl zu einer der spannendsten Epochen der bundesrepublikanischen Nachkriegsgeschichte. Ebenso spannend gestaltet sich auch die Lektüre der Sachbücher über das Thema und der autobiographischen Zeugnisse aus jener Epoche. Diese

\footnotetext{
${ }^{1}$ Der vorliegende Beitrag wird in veränderter Form auch in dem Band Bermward Vesper, hrsg. von Thomas Richter und Julian Reidy (in Vorbereitung), erscheinen.
} 
lassen sich bei adäquater Didaktisierung für Zielgruppen der Lernenden im Landeskundeunterricht Deutsch als Zweit- und Fremdsprache, im Deutsch- oder Geschichtsunterricht ansprechend vermitteln.

Im Folgenden reflektiere ich den Umgang im Unterricht mit und die Analyse der beiden Filme Der Baader Meinhof Komplex (Deutschland, 2008, Regie: Uli Edel) und Wer wenn nicht wir (Deutschland, 2011, Regie: Andres Veiel), da ,in audiovisuellen Texten Potenziale ästhetischen Lernens [zu] entdecken“ (Maiwald 2010: 221) sind. Bei ersterem Film stammt die gleichnamige Literaturvorlage von Stefan Aust und erschien 1985. Bei der Neuauflage von 1990 hatte Aust durch den Fall der Mauer Zugang zu neuen Akten, derer er, laut eigener Aussage, „Tausende von Leitz-Ordnern durchsucht hat.“ (Aust 2012: 59). Die Vorlage zu Wer wenn nicht wir erschien, von Gerd Koenen verfasst, im Jahre 2003 unter dem Namen Vesper, Ensslin, Baader. Urszenen des deutschen Terrorismus. Hauptdarsteller wie Regisseur sind zudem vertraut mit Vespers Die Reise (vgl. Diehl 2011: 1). Wie ein kurzer Vergleich zeigen wird, sind beide Filme unterschiedlich strukturiert, folgen einer je eigenen Ästhetik und Form der Vermittlung und sprechen damit auch ein je eigenes Publikum an. Zunächst soll der unterrichtsmethodische Umgang mit dem historischen Kontext sowie den literarischen Bezugswerken, anschließend der heuristische Mehrwert einer filmisch-ästhetischen Vergegenwärtigung im Unterricht dargestellt werden.

\section{Zum unterrichtsmethodischen Umgang mit historischem Kontext und literarischen Bezugswerken}

Filme haben immer einen positiven Effekt auf Sprachproduktion, -rezeption und -reflexion, wie Fredering, Krommer und Maiwald in einer Einführung in die Mediendidaktik Deutsch unterstreichen:

Die Analyse von Radio-, Film- bzw. Fernseh-Sprache in den verschiedenen Sende- bzw. Produktionsformaten ist ein lohnendes Feld zeitgemäßer Sprachreflexion, die sich durch handelnd-produktive Erkundungen vertiefend erschließen können (2008: 77).

Setzt man einen handlungsorientierten Unterricht voraus, bei dem mittels Sprache authentische kommunikative Ziele erreicht werden sollen und der „im Sinne kommunikativen Alltagshandelns mit medial vermittelten Angeboten der Massenkommunikation" (Roche 2010: 1243) aufzufassen ist, so sind bei der Thematisierung der genannten Filme einige Vorentlastungen zu erfüllen. In Materialien beispielsweise zu Integrations- und Orientierungskursen, die auch zur Vermittlung landeskundlicher Informationen in Kursen fernab der Zielsprachenländer Verwendung finden können, wird die Relevanz der brisanten ausgehenden 60er- und dem Anfang der 70er-Jahre erkannt, ließe sich aber vertiefen. Die curricularen Vorgaben für dieses Kursformat setzen einen Fokus auf „die Entstehung und 
Entwicklung der Bundesrepublik Deutschland“ (Hartkopf 2010: 60). Insbesondere beleuchtet werden daher die Themen Nationalsozialismus und Beitritt der DDR zur BRD. Die aufgrund eines zeitlich eng gesetzten Rahmens nachvollziehbare Vernachlässigung des Themas Geschichte ist zwar verständlich, aber bedauerlich. ${ }^{2}$ In anderen Kursformaten außerhalb der Zielsprachenländer wiederum beinhaltet das internationale Phänomen 1968 vielerlei Anknüpfungsmöglichkeiten mit gegenseitig befruchtendem interkulturellem Austausch, weg von einer klassischen Landeskunde, hin zu einer zwischen Eigenem und Fremdem vermittelnden Kulturkunde, die auf gegenseitigem Austausch beruht. Bei einer auf diese Weise definierten Kulturkunde werden gleichermaßen ,interkulturelles Bewusstsein (deklaratives Wissen - savoir) und interkulturelle Fertigkeiten (prozedurales Wissen - savoir-faire)" (Kauzner 2008: 15) geschärft. Etwas umfangreicher, wenn auch nur mit kursorischem Blick auf das Phänomen 1968, ist das - mittlerweile vergriffene - Unterrichtsmaterial für Orientierungs- und Sprachkurse mit dem Titel miteinander leben. Unter der Überschrift „Wichtige Stationen der deutschen Geschichte bis 1990“ sind von den Lernenden Überschriften mit kurzen Informationstexten den entsprechenden Bildern zuzuordnen, z.B. ein Schaufenster nach der Währungsreform, ein Detail zum Thema des so genannten Wirtschaftswunders, der Volksaufstand in der DDR, eine Vietnamdemonstration in Westberlin, das RAF-Fahndungsplakat der Polizei Dringend gesuchte Terroristen (vgl. Feil; Hesse 2006: 318-323). Hierbei werden weitere historische Zusammenhänge beleuchtet, die teilweise vom Themenkomplex 1968 mit dessen Vorgeschichte nicht zu trennen sind. Durch das etwas breiter angelegte Material lässt sich eine Fokussierung mit den jeweils unterschiedlichen Interessen der Lernenden abstimmen.

Zur Vorentlastung und zum Einstieg bietet sich folgende Hausaufgabe oder Übung an, bei der erarbeitet werden soll, was mit den anschließend zu zeigenden, für den historischen Abschnitt wichtigen Abkürzungen/Begriffen zu verbinden ist: $^{3}$

\footnotetext{
2 Das Lehrwerk des Hueber-Verlages Zur Orientierung. Basiswissen Deutschland hat insgesamt 80 Seiten, davon vier Seiten zur Vertiefung Von der Teilung bis zur Wiedervereinigung (Gaidosch; Müller 2010: 34-37). Im Werk des Klett Verlages 45 Stunden Deutschland - der Titel illustriert perfekt die Lehrkraft und Lernenden drohende Zeitnot - werden auf drei Seiten „[w]ichtige Stationen in der Geschichte Deutschlands nach 1945“ (Kilimann; Kotas; Skrodzki 2012: 50-53) vermittelt. Im Langenscheidt-Verlag liegen zwei jeweils 64seitige Ausgaben vor, die Geschichte nach 1945 in ebenso knappen Kapiteln skizzieren: das Werk Orientierungskurs, das sich an Teilnehmende eines Orientierungskurses in Deutschland richtet und der" für Lernende außerhalb des Zielsprachenlandes. Im Kursheft Orientierungskurs des Cornelsen-Verlages gibt es auf drei Seiten Raum für das Thema „Die Jahre der Teilung 1949-1989“ (Schote 2011: 39ff.), auf denen die sechziger Jahre mit einem Absatz berücksichtigt werden.

${ }^{3}$ Die Paraphrasen entsprechen den jeweiligen Lemmata aus dem Brockhaus. Als Vorentlastung eignet sich ein Austausch in kleineren Gruppen zum internationalen Phänomen 1968. Anschließend lässt sich das Thema weiterhin durch eine kleine Internetrecherche oder Konsultation einer Enzyklopädie weiter vorentlasten. Dabei sollten in Gruppen v.a. die Biographien von Bernward Vesper, Gudrun Ensslin, Andreas Baader und Ulrike Meinhof gelesen und in Stichpunkten oder eigenen Worten nacherzählt werden.
} 
Aufgabe 1: Vorkenntnisse wecken/erarbeiten - Ordnen Sie zu:

SDS, RAF, Kommune 1, APO, Baader-Meinhof-Gruppe

- Locker organisierte studentische Bewegung mit neuartigen Demonstrationstechniken (Sit-Ins, Teach-ins)

- Linksextremistische terroristische Vereinigung

- Erste Generation einer terroristischen Vereinigung

- Lebens- und Wobngemeinschaft der Alternativkultur

- urspr. der SPD nahe stehende Studentenorganisation

In der eingangs angeführten Einführung Mediendidaktik Deutsch wird Medienkompetenz verstanden als

die kognitive Fähigkeit und Fertigkeit zum fachspezifischen Umgang mit Medien [...] sowie die [...] Bereitschaft und Fähigkeit, diese auf medienspezifische Fragen bezogenen Problemlösungen zielführend im Umgang mit Sprache und Literatur und ihren medialen Grundlagen zu verwirklichen. (Fredering; Krommer; Maiwald 2008: 89)

Geht man von einer solchermaßen verstandenen Medienkompetenz aus, so könnte auch die folgende Frage als Vorentlastung gelten - vorausgesetzt, die Lernenden sind mit den genannten Begriffen und den damit zu assoziierenden federführenden Persönlichkeiten und deren Aussehen vertraut. D.h. eines der berühmten Fahndungsfotos der RAF (vgl. z.B. Feil; Hesse 2006: 320) muss schon einmal im Unterricht gezeigt worden sein:

Aufgabe 2 (gezeigt werden die beiden Filmplakate der jeweiligen Filme): Wie werden die Schauspielerinnen und Schauspieler und die von ibnen verkörperten Figuren dargestellt? Welches Genre erwarten Sie? Woran liegt das (Farbe, Thema, Schriftart)?4

Wer wenn nicht wir arbeitet mit originalen Fotoaufnahmen im Hintergrund. Die Ähnlichkeit der Ensslin-Darstellerin (Lena Lauzemis) mit dem Foto von Gudrun Ensslin müssen die Lernenden selbst herstellen. Bereits im Plakat zum Film wird die Verwebung fiktionaler und von Schauspielern gespielten Passagen mit dokumentarischem Material angedeutet. Das Plakat zu Der Baader Meinhof Komplex hingegen spielt mit aggressiveren Farben in starkem Kontrast (schwarz und rot) und einer Schrifttype des Titels, die eher an Blockbuster-Kino erinnern. ${ }^{5}$ Die Ähnlichkeiten der Schauspielerinnen und Schauspieler mit den RAF-Fahndungsfotos wiederum müssen die Lernenden erkennen.

\footnotetext{
${ }^{4}$ Bei dieser Aufgabe wird von Lernenden sowohl in Grund- als auch Mittelstufenniveau zu Wer wenn nicht wir gelegentlich Romantik, Liebe oder Liebesfilm assoziiert, was dem dargestellten Freiheitsgefühl zumindest während des Kennenlernens von Ensslin und Vesper im Film entspricht. Jedoch ist es schwieriger, durch das im Hintergrund gezeigte Fahndungsfoto Dringend gesuchte Terroristen den im Film wahrnehmbaren Zusammenhang zu dokumentarischem Material herzustellen. Eine Seminargruppe ordnete dem Baader Meinhof Komplex tatsächlich Themen wie Action oder Krimi zu.

${ }^{5}$ Hierin lässt sich der Film mit einer Filmkritik assoziieren, in der der Film pejorativ als „Baller Meinhof" (Schulz-Ojala 2008: 29) bezeichnet wurde.
} 
Ein weiterer Ansatz mit reduziertem und unterrichtsorientiertem Textmaterial ist ein Vergleich zwischen Literaturvorlage und Adaptation. Generell sollte solch ein Vergleich keineswegs unter dem Motto laufen, welcher der beiden Filme näher am Original sei. ${ }^{6}$ Ein Film, ganz gleich, ob er eine literarische Vorlage hat und wie weit er von dieser entfernt ist, ist eine neue künstlerische Leistung, die eine eigene Rezeption erfordert. Hingegen ließe sich von den Lernenden bewerten, wie weit historischer Aufschluss durch die beiden Filme gegeben ist, durch welche ästhetischen Mittel sich beide unterscheiden (z.B. in Hinblick auf Schnitt, Musik, Einflechtung von dokument. Material) und was der jeweilige Unterschied der Bücher Koenens und Austs ist. Zu letzterem Aspekt ließe sich die Aufgabenstellung formulieren: Welche Unterschiede zwischen den beiden Büchern fallen Ihnen binsichtlich der Konzeption, der formalen Gestaltung und der Art der Recherche auf? Diese Beantwortung der Frage können die Lernenden durch die Lektüre von Textauszügen bewerkstelligen. ${ }^{7}$ Die Aufgabenstellung lässt sich folgendermaßen kursorisch beantworten:

Stefan Aust hat bei der Recherche zu Der Baader Meinhof Komplex in Archiven unter anderem das Archiv des Ministeriums für Staatsicherheit aufgesucht und dort nach eigener Auskunft „60 laufende Meter Akten“ (Aust 2008: 5) gesichtet. Er konstruiert einen dramaturgisch geschickten Spannungsbogen, beginnt mit dem Selbstmord der 1. Generation in Stammheim und endet mit dem Ende der 3. Generation der RAF. Nach dem Fall der Mauer war der Zugang zu weiteren Akten gegeben. Dadurch stellen sich Aust bei der Bearbeitung der ursprünglichen Erstfassung von 1985 unter anderem Fragen zu Hintergründen der SchleyerEntführung: Warum wurde er nicht befreit, wenn sein Aufenthaltsort bekannt war? Insgesamt ist das Buch tendenziell journalistisch orientiert. Faktualität wird dort suggeriert, wo sie nicht nachweisbar oder überprüfbar ist (s.u.). Der Autor bringt sich kurz an einer, von den anderen Passagen stilistisch kaum unterscheidbaren Stelle ein, an der er im historischen Geschehen tatsächlich teilgenommen hat: die durch ihn verhinderte Entführung der Kinder Ulrike Meinhofs nach Jordanien (vgl. Aust 2008: 134-138). ${ }^{8}$ Der Autor tut dies relativ bescheiden; die Passage ist vom übrigen Text kaum stilistisch unterscheidbar und es fällt weiterhin kaum auf, dass statt Persönlichkeiten aus dem Umfeld der RAF plötzlich das Autor-Ich als Akteur auftritt. Vergleichbar unprätentiös ist die Parallele im Film.

Gerd Koenen recherchierte bei der Konzeption von Vesper, Ensslin, Baader. Urszenen des deutschen Terrorismus hauptsächlich im Deutschen Literaturarchiv in Marbach. Er beleuchtet unter anderem literaturgeschichtliche Hintergründe zu Bernward Vespers posthum erschienenem Roman Die Reise und zitiert ausgiebig aus dem Nachlass und der Ensslin-Vesper-Korrespondenz, die mittlerweile unter

\footnotetext{
${ }^{6}$ Dieser Ansatz ist ohnehin problematisch, da es sich um Sachbücher handelt, bei denen die - so kaum berechtigte - Frage im Raum stehen kann, welches der beiden Bücher näher an der Realität orientiert ist.

7 Z.B. Aust 2008: 5ff.; 17. Weitere Vorschläge für Textauszüge s.u.

8 Bereits der Titel des betreffenden Kapitels ist mit „Kindergeschichten” ein beinahe schon kokettierendes understatement.
} 
dem Titel Notstandsgesetze von Deiner Hand. Briefe 1968/1969 zugänglich ist. Generell ist ein literarisches Interesse erkennbar, beispielsweise in der - gelegentlich übertriebenen - Parallelsetzung der Akteure mit dramatis personae aus der Literaturgeschichte oder den Kapitelüberschriften, die oftmals Geflügelte Worte oder bekanntere Zitate aus literarischen Werken sind. Insgesamt hat das Buch einen literarästhetischen Anspruch bei gleichzeitig vorhandenem dokumentarischem Charakter.

Außerdem ließe sich von den Lernenden - gerne weniger objektiv und als persönliche Meinung formuliert - die Leistung der Schauspieler kommentieren:

Aufgabe 3 (Fotos der Schauspieler und der historischen Figuren werden gegenüber gestellt: Baader gespielt von Moritz. Bleibtreu oder Alexander Febling; Vesper gespielt von August Diebl): Welche Ähnlichkeiten zwischen Schauspieler und historischer Person sehen Sie? An welchen Eigenschaften ibrer Charaktere knüpfen die Schauspieler an? Welche Ähnlichkeiten stellen sie ber? Mit welchen Stilisierungen spielen sie?

Insbesondere bei Andreas Baader gibt es signifikante Unterschiede, in Wer wenn nicht wir gespielt von Fehling, in Der Baader Meinhof Komplex gespielt von Bleibtreu. Während sich Bleibtreu in der Rolle eines Pistolen schwingenden, machohaften Draufgängers gefällt und dem „durchgeknallten Schnösel“ mehr als dem „Soziopath[en]" (Voss 2005: 67) gleicht, mimt Fehling einen effeminierten Baader mit Neigung zum Kajalstift, dem man gleichzeitig noch seinen „brutalen Charme“ (Aust 2008: 64) ansieht. Beide Interpretationen haben ihre Berechtigung. Allerdings lässt sich die Zeit Baaders vor den Frankfurter Kaufhausbrandanschlägen genauer nachzeichnen als die danach, wobei bereits diese „eher anekdotisch überliefert als dokumentarisch gesichert" (Koenen 2005: 106) ist. Und so lässt sich Fehlings Rolle als Baader in Wer wenn nicht wir ziemlich genau mit den knappen zusammenfassenden Charakterisierungen sowohl in Austs (2008: 24ff.) als auch in Koenens (2005: 106f.) Buch parallelisieren. Diese Textauszüge sollten den Lernenden bei der Bearbeitung von Aufgabe 3 unbedingt vorliegen. Sie eignen sich aufgrund der überschaubaren Textlänge und schildern den guten und vergleichenden Eindruck der beiden Autoren. Die Ähnlichkeiten zwischen August Diehl und Bernward Vesper bestehen zunächst in Frisur, Brille und eventuell Haltung. Hierbei wäre es außerdem hilfreich, die entsprechende Bildbeschreibung aus Koenen zu ergänzen. Doch die Verbindung zwischen Koenens Erklärung ,in schwarzer Existenzialistenkluft" (ebd.: 121) und dem sich im Kleidungsstil niederschlagenden Intellektualismus der damaligen Zeit lässt sich je nach Zielgruppe nur mit weiteren landeskundlichen Hinweisen herstellen. 


\section{Zum heuristischen Mehrwert einer filmisch-ästhetischen Auseinandersetzung}

Hat man die sehr unterschiedlichen Buchvorlagen bzw. die beiden literarischen Bezugspunkte von Stefan Aust und Gerd Koenen vor Augen, so ist es kaum verwunderlich, dass beide Filme dramaturgisch unterschiedlich umgesetzt werden: Uli Edel drehte mit Der Baader Meinhof Komplex einen am kommerziellen Erfolg orientierten Film, der Kurzweil auch ohne historische Vorkenntnisse verspricht und bei dem noch die kleinen Nebenrollen mit bekannten Schauspielerinnen und Schauspielern besetzt sind. Die Bildung einer eigenen Meinung hingegen ist in der Aneinanderreihung der Szenen nicht möglich. Andreas Veiel dagegen richtet sich in dem mit dokumentarischem Filmmaterial durchzogenen Film Wer wenn nicht wir eher an ein Publikum mit Vorwissen. Außerdem wählt er mit Bernward Vesper, gespielt von August Diehl, eine der Randfiguren in der Vorgeschichte der RAF, die einem breiten Publikum nicht unbedingt geläufig ist. In Der Baader Meinhof Komplex gibt es eine Szene, in der Bernward Vesper, gespielt von Thomas Winter, vorkommt und in einer Diskussion, die Ensslin mit ihren Eltern in deren Pfarrhaus in Schwaben führt, recht teilnahmslos auf dem Sofa sitzt und seiner Verlobten zu suggerieren scheint, sie solle ihr Verhalten mäßigen, auch wenn er ihren Standpunkt offenbar generell teilt. Die Vernachlässigung Vespers schlägt sich in Edels Film neben dieser wenig zu Vesper passenden Sachlichkeit oder gar Indolenz auch darin nieder, dass die Rolle von einem wenig bekannten Schauspieler übernommen wird. Jedenfalls passt es keineswegs zu dem Schriftsteller, der Bernd Neumann zufolge mit Die Reise angeblich den „Nachlaß einer Generation“ (1979: 121) verfasst habe. ${ }^{1}$ Sicherlich jedoch hat Vesper mittlerweile den von ihm angestrebten „unkündbaren Platz in der Literaturgeschichte“ (Voss 2005: 54) inne, den anzustreben er gegenüber seinem ehemaligen Mitbewohner einmal gestanden haben soll, auch wenn die Literaturwissenschaft Vespers Relevanz noch nicht gänzlich erkannt hat und ihn mit einer „,bemerkenswerten Nachlässigkeit“ (Reidy 2012: 61) goutiert.

Bemerkenswert an beiden Ver-Filmungen oder filmischen Adaptationen mit literarischen Vorlagen ist, dass es sich bei den Vorlagen bzw. Bezugswerken nicht um fiktionale Literatur, sondern um Sachbücher handelt. Was wir im Film sehen, hat sich tatsächlich einmal ereignet. Was wir im Film sehen, müsste einer historischen Überprüfung Stand halten können. Gleichzeitig gibt es aber einen ästhetischen Anspruch, einen Eigenwert der Filme. Bei Edel gibt es einige wenige und bei Veiel zahlreiche Ausschmückungen, deren Faktualität nicht überliefert ist und sich weder bestätigen noch widerlegen lässt. Trotz der eingewobenen dokumentarischen Szenen bei Veiel darf man nicht vergessen, dass auch hier Szenen geschildert

\footnotetext{
${ }^{1}$ Koenen kritisiert diese feuilletonistische Übertreibung, konzediert aber Vesper und dessen Werk Die Reise den Rang eines prototypischen Grundmusters „,der ,Vergangenheitsbewältigung“ der politischen Generation, als deren literarischer Repräsentant Bernward Vesper zu Recht gilt" (Koenen 2008: 281).
} 
werden, deren Authentizität nicht überprüfbar ist, auch wenn sie Authentizität suggerieren.

Diese Tendenz fällt in den Büchern sehr unterschiedlich aus. Stefan Aust leistet eine Aneinanderreihung überprüfbarer Fakten mit Ergänzung teils erfundener Details oder nicht belegbarer Dialoge. Es ist beispielsweise kaum verifizierbar, ob der Anstreicher Josef Bachmann am Tag seines auf Rudi Dutschke verübten Attentates erst „Schrippen und Wurst“ und zu Mittag dann „einen Teller Linsensuppe, danach noch zwei Buletten“ (Aust 2008: 69) gegessen hat, wie es Aust dem Leser auftischen will. Angeblich überlieferte Zitate werden nicht belegt - ein Verfahren, dass Koenen in seinem Buch wiederum entschieden kritisiert, einmal in einer Endnote, wo die Kritik weniger auffällt (vgl. Koenen 2005: 359) und einmal sehr dezidiert im Fließtext (vgl. ebd.: 124). ${ }^{2}$ Darüber hinaus gibt es kaum eigene Stellungnahmen von Aust. Das kann gelegentlich sogar zu Missvergnügen führen, etwa wenn in einem durch einen eigenen Absatz hervorgehobenen Abschnitt der ersten Begegnung zwischen Baader und Ensslin zu lesen ist: „Es wurde Haschisch geraucht. Andreas Baader war an diesem Abend dabei und lernte Gudrun Ensslin kennen“ (Aust 2008: 61). Warum hier Haschischkonsum, was in den 60er-Jahren durchaus kein Alleinstellungsmerkmal war, so hervorgehoben, überhaupt erwähnt wird, ist unklar.

So sind die wenigen deckungsgleichen Szenen, die bei Koenen geschildert werden, ungleich aufschlussreicher. Denn Koenens Darstellungen historisch überprüfbarer Ereignisse führen zu ausgiebigen Reflexionen, zu weiterer Darstellung von Hintergrundwissen und zu interessanten, wenn auch manchmal etwas zu offensichtlich an Freud geschulten Schlussfolgerungen Koenens. Zitate werden bei ihm übrigens genau belegt.

Fragt man nach dem Bezugsgeflecht von Fiktionalität und Faktualität, so ist diese Auseinandersetzung auch insofern eine müßige, als dass man es bei der Baader-Meinhof-Gruppe mit einer terroristischen Vereinigung zu tun hat, die gesteigerten Wert auf gefälschte Identitäten gelegt hat. Meinhof, Baader und Ensslin waren allesamt starke, nahezu auratische Charaktere, die ihr unmittelbares und ebenso ein nicht mit ihren politischen Gesinnungen übereinstimmendes Umfeld nachhaltig beeindruckt haben. ${ }^{3}$ Dies ist der Grund ihrer gewollten oder zugeschriebenen Stilisierungen, beispielsweise die der Ensslin als einer Jean d'Arc oder einer Else Lasker-Schüler (z.B. Koenen 2005: 171). Zudem gab es Zeiten, in denen selbst die Vertrauten der RAF nicht wussten, was einzelne Mitglieder taten und wo sie sich aufhielten. Während zweier Tage nach der Baader-Befreiung wusste bei-

\footnotetext{
2 Etwas unkonsequent jedoch zitiert Koenen wiederum ein RAF-Dokument nach Aust (vgl. Koenen 2005: 287).

${ }^{3}$ Man denke hierbei etwa an Ensslins Haft nach den Frankfurter Brandanschlägen auf Kaufhäuser und die Bezugspersonen, die sie während ihrer Haft betreut haben und im Nachhinein sehr positiv über sie berichten, z.B. Helga Einsele, die Direktorin des Frauengefängnisses (vgl. Koenen 2005: 177, 202) oder Prof. Heinitz, der ihr eine Assistentinnenstelle anbot (vgl. ebd.: 219). Auch ihre Eltern standen noch nach der Straffälligkeit durch die Brandanschläge hinter ihrer Tochter (vgl. ebd.: 184).
} 
spielsweise niemand etwas über den Aufenthaltsort von Ulrike Meinhof. Diese Lücken lassen Raum für Mutmaßungen, Spekulationen, Fiktionalisierungen bis hin zu Fantastereien und bieten sich zu filmisch-ästhetischen Gedankenspielen an.

Mit Aristoteles' berühmtem Zitat aus der Poetik liegt der Unterschied zwischen dem Geschichtsschreiber und dem Dichter darin „daß der eine das wirklich Geschehene mitteilt, der andere, was geschehen könnte" (Aristoteles 1982: 29, Vers 1451b). Dies führt jedoch keineswegs zu einer Abwertung sondern gerade zur Aufwertung der Dichtung, die deswegen auch ,philosophischer und ernsthafter als die Geschichte" (ebd.) sei, so Aristoteles. Hinsichtlich des Erkenntnisgewinns ist es nur an einigen Stellen hilfreich, wenn man aufzählt, wo nachweisliche Abweichungen zwischen Fakt und Fiktion in beiden Filmen zu finden sind: die in Filmkritiken ausgiebig kommentierte Hummersuppe, die Horst Herold, in Der Baader Meinhof Komplex gespielt von Bruno Ganz, vor seinen Ausführungen zur Rasterfahndung den Vertretern des Staatsapparates großzügig anbietet. Das gemeinsame Bad von Gudrun Ensslin und Peter Jürgen Boock in Anwesenheit Andreas Baaders, der Boock dann noch seine Lederjacke geschenkt hat. Beides ist tatsächlich passiert, aber nicht gleichzeitig (vgl. Koenen 2005: 238); es handelt sich um eine filmische Verdichtung um der Ökonomie willen. Auch hat Stokely Carmichael sein berühmtes Zitat nicht Bernward Vesper gegenüber geäußert, wie es in Wer wenn nicht wir gezeigt wird (01:12:00), sondern einem weißen US-amerikanischen Studenten entgegen geschrien. Den Ausspruch lieferte Carmichael auf einem Kongress mit dem Thema The Dialectics of Liberation in London, wo auch Vesper anwesend war. Im Kontext lautet er:

Wir sind die Mehrheit, wir, die farbigen Völker der Welt! Wir werden dem Imperialismus in seinem Herzland begegnen, und wenn wir nicht die Freiheit bekommen, Menschen zu sein, werden wir Amerika niederbrennen von einer Küste zur anderen! (Carmicheal nach Koenen 2005: 125)

Ein weißer Student fragte, wie er zu dieser Art der Revolution beitragen könne und erhielt die wenig hilfreiche Antwort: „Go home, kill father and mother, hang up yourself!" Der Humor dieses nicht gänzlich von Komik freien Paradoxes geht im Film leider unter. Das berühmte Zitat spielt aber im Film weiterhin eine wichtige Rolle. Vesper stellte es neben anderen Motti seiner Autobiographie Die Reise voran (vgl. Vesper 1983: 10). Die Verdichtung erfolgt, um zu zeigen, welchen Einfluss Carmichael auf den jungen Vesper und dessen Freundin Gudrun Ensslin ausübte.

In den feuilletonistischen Besprechungen schnitten gerade jene Passagen der Filme gut ab, deren Faktualität nicht nachgewiesen werden kann. Unzählbar die Besprechungen, die Bruno Ganz' Hummersuppen-Affinität lobten, oder aber belächelten. Es ist nicht überliefert, was sich in jenen Momenten ereignete, als Ulrike Meinhof oder Gudrun Ensslin entschieden, in den Untergrund zu gehen, was sich ereignete, als sie zum letzten Mal ihre kleinen Kinder gesehen haben. Die beiden betreffenden Filmausschnitte aus Wer wenn nicht wir (01:30:00 bis 01:31:50) und Der Baader Meinhof Komplex (40:10 bis 43:38) lassen sich perfekt im Unterricht unter 
dem Motto suggerierter Fiktionalität behandeln, als bewegender Moment im Leben der Protagonistinnen, der nicht allein deren eigenes Leben, sondern die gesamte Geschichte der Bundesrepublik Deutschland beeinflusst hat:

Aufgabe 4:

a) Vergleichen Sie die Filmszene der Befreiung Baaders aus Der Baader Meinhof Komplex (40:10 bis 43:38) mit der Vorlage von Aust (vgl. Aust 2008: 20-23). Welche Abweichungen finden Sie? Was könnte der Grund dafür sein? Welche Rolle spielt die Musik in der Szene?

b) Vergleichen Sie anschließend die entsprechende Szene aus dem Film Wer wenn nicht wir (01:53:22 bis 01:53:55). Welche Unterschiede in der dramaturgischen Konzeption fallen ibnen auf? Inwiefern ist die Stellungnabme Bernward Vespers (vgl. Vesper: 1983: 158) aufschlussreich? W arum glauben Sie, gibt er vor, Meinhof zu „, begreifen"?

c) In Wer wenn nicht wir gibt es eine weitere Schwellenszene (01:30:00 bis 01:31:50), die zugleich eine Initiation oder Urszene des Terrorismus bedeutet. Welchen Grund gibt Gudrun Ensslin vor, um nach Frankfurt zu gehen? Wie hätten Sie an der Stelle von Bernward Vesper gehandelt? Halten Sie der Szene zufolge einen anderen Ausgang der Geschichte für möglich? Hätte Vesper Ensslin beeinflussen können?

Der ästhetische Anspruch der jeweiligen Schwellen- und Urszenen ist sehr unterschiedlich. Während wir in der ganz privaten Szene zwischen Vesper und Ensslin bei Wer wenn nicht wir (Aufg. 4c) gar keine Zeugnisse darüber haben, was sich ereignete, lässt sich anhand von Polizeiberichten ziemlich genau verfolgen, was bei der Baaderbefreiung passiert ist. Der Ästhetik des Films von Edel entspricht es, dass die gesamte Befreiung des 14. Mai 1970 mit spannungsgeladener Musik unterlegt ist und anscheinend aus Sichtweise der angeblich verstörten Meinhof gezeigt wird. ${ }^{4}$ Zwar folgen die Schauspielerinnen und Schauspieler ziemlich genau den Dokumenten, die überliefert sind und Martina Gedeck als Ulrike Meinhof fragt gar die Polizisten und Institutsangehörigen nach deren Familie. Dennoch entsteht fälschlicher- oder gar ärgerlicherweise der Eindruck, Meinhof habe sich spontan entschieden, in den Untergrund zu gehen. ${ }^{5}$ Auch sprang sie wahrscheinlich nicht zuletzt aus dem Fenster (vgl. Aust 2008: 22). Hier stellt sich die Frage, warum wider die Faktenlage auf diese Weise inszeniert wird, wenn im Film ansonsten dokumentarische Gewissenhaftigkeit bis in kleinste Details an den Tag gelegt wird. Natürlich sieht Meinhofs Gang in den Untergrund viel spektakulärer aus, wenn der terroristische Initiationsritus mit einem Sprung durch ein Fenster und dem Überschreiten dieser Schwelle markiert wird.

Parallel dazu steht zunächst die Baaderbefreiungsszene aus Wer wenn nicht wir (01:53:22 bis 01:53:55, vgl. Aufgabe 4), die allein aus dokumentarischem Material

\footnotetext{
${ }^{4}$ Diese Beobachtung äußerten die Lernenden auch im Seminar.

5 Vgl. dagegen die richtigstellende Schilderung (z.B. Koenen 2005: 190). Wegen des geringen Textumfanges sind die Ergänzungen in Aust (21f.) und Vesper (158) eine sehr interessante und orientierende Grundlage für die Lernenden.
} 
besteht und einer Nachrichtensendung zu entstammen scheint. Sie zeigt den Tatort nach der Befreiung, während ein Zitat vorgelesen wird. ${ }^{6}$ Darüber hinaus lässt sich auch die (Tür-)Schwellenüberschreitung in Wer wenn nicht wir mit dem Fenstersprung von Meinhof in Der Baader Meinhof Komplex vergleichen. ${ }^{7}$ Der große Unterschied ist, dass es zu dieser Szene nun gar kein dokumentarisches Material gibt, das sich vergleichen ließe. Veiel muss daher keiner Vorlage folgen und kann den bemerkenswerten Leistungen der Schauspieler freien Lauf lassen. Dennoch orientiert sich Veiel an der Korrespondenz zwischen Ensslin und Vesper. Auf die Frage des Vesper-Darstellers August Diehl „Und was ist mit Felix?“ antwortet die EnsslinDarstellerin Lena Lauzemis: „Er bleibt bei dir. An ihm habe ich nie gezweifelt.“ Aus einem Brief an Vesper vom 2. Mai 1968 ist die Bemerkung Ennslins überliefert: „Es gibt Felix, an dem ich keinen Augenblick gezweifelt habe“ (zit. nach Koenen 2005: 157). Veiel folgt also auch hier dem Prinzip dokumentarischer Nachvollziehbarkeit, die er künstlerisch ausfüllt.

Bei seinem Blick auf Geschichte lässt sich das, was Veiel tut, mit Hayden Whites Gedanken von der Fiktion des Faktischen parallelisieren. Auch Klio, die Muse des Historikers, dichtet, so der US-amerikanische Historiker 1974 in seinem Aufsatz „Der historische Text als literarisches Kunstwerk“ (Volkmann 2001: 672). Geschichte lässt sich niemals objektiv nacherzählen. Es besteht eine formale Nähe zwischen Historiographie und Literatur, wenngleich der Historiographie der Anspruch auf Literarizität fehlt und Veiel dagegen in seinem historiographischdokumentarischen Erzählstil durchaus ästhetische Gestaltungskriterien verfolgt. Edel hingegen suggeriert dem Publikum in einem rasanten Narrationsstil, mit schnellen Schnitten und dramatischer Musik, zu wissen, was sich ereignet hat. Verirrt ist dabei die Suggestion, Meinhof hätte sich spontan, sozusagen in dem Moment der Befreiung, zum Weg in den Untergrund entschieden. Die Entscheidung wurde von ihr bereits früher getroffen, wahrscheinlich beeinflusst von Ensslins bereits erfolgten Entschluss, ihren Sohn Felix und Bernward Vesper zu verlassen (vgl. Koenen 2005: 190). Was man bei der Betrachtung solcher Szenen im Hinterkopf haben muss, ist, dass man Fragen vorschnell beantwortet, die offen bleiben müssen. Zwar muss man nicht gleich Springer als Repräsentant eines manipulativ berichtenden Medienkonzerns enteignen, wie es 1967 der SDS forderte. Doch ein mediendidaktisch geschulter Umgang mit Filmen führt zur kritischen Hinterfragung der Darstellungsweise in Medien und daher ,ist der Erwerb einer visual literacy in einer von Bildern dominierten Alltagskultur eine Bildungsaufgabe" (Maiwald

\footnotetext{
${ }^{6}$ Das Zitat setzt sich zusammen aus abgewandelten Auszügen aus der Erklärung zur Befreiung von Andreas Baader, die unter dem Titel Die Rote Armee aufbauen in der Zeitschrift Agit 883 vom 05.06.1970 erstmals publiziert wurde. Wahrscheinlich stammt der Text von Meinhof und Ensslin (vgl. Koenen 2005: 299) und wird daher im Film von der Stimme Lena Lauzemis, der Ensslin-Darstellerin, vorgetragen.

${ }^{7}$ Schwellenüberschreitungen, Tür- und Fenstermotive ziehen sich als literarisches Motiv durch die gesamte Literaturgeschichte. In Eduard Mörikes Gedicht Auf einer Wanderung (1846) finden sich Türund Fenstermotiv perfekt komponiert vereint und stellen das epiphanische Moment der Schwellenüberschreitung in eindringlich poetisierter Weise dar.
} 
2010: 221), die kaum zu unterschätzen ist. Gelegentlich muss man dem suggerierten Informationsgehalt mancher Medien misstrauen. Auf ein aktuelleres Ereignis bezogen, ist auch die Suggestionskraft der animierten Bilder, die wir etwa von der Tötung Osama bin Ladens kennen, durchaus manipulativ. Den Zuschauern wird in vermeintlicher Transparenz gezeigt, was sich angeblich zugetragen hat. Trotz einiger Vagheit in der Darstellung fühlt man sich informiert. Die Tötung wird nicht mehr hinterfragt, da auch der Stab im Weißen Haus Zeuge war und die Entscheidungen mitverfolgt hat - auch wenn es offenbar eine Unterbrechung der Verbindung im Moment der Tötung gegeben hat, die - ohne Konspirationstheorien Vorschub leisten zu wollen - allerdings ebenso Plan der Transparenz vorspiegelnden Berichterstattung hat sein können.

Somit beinhaltet der Begriff Medienkompetenz im Umgang mit Filmszenen, die Landeskunde vermitteln, auch, dass wir deren Inhalt stets hinterfragen, dass wir uns bewusst sind, dass es mehrere Quellen gibt und wir bei der Rezeption des mannigfaltigen Angebotes an Informationsquellen versuchen müssen, ein ganz eigenes, zwangsweise berechtigt subjektives Bild von vergangenen Sachverhalten zu erhalten. Darüber hinaus sind die Filme mit ihren literarischen Orientierungswerken ein unterstützendes Medium, die den Umgang mit umfangreichen Ganzschriften (v.a. Vesper und Aust, aber auch Koenen) erleichtern und gerade das lohnenswerte, literaturwissenschaftlich unterbeleuchtete Phänomen Bernward Vesper zugänglich machen. Denn Vespers Werk Die Reise hat für Lernende mit verschiedenen sozialen und kulturellen Hintergründen und Lernbiographien hohen Appellcharakter durch die ihm inne wohnende „kultur- und geistesgeschichtliche Fundiertheit“ (Reidy 2012: 173) und die „Intensität, mit der hier Tyrannei, Wehrlosigkeit, Existenznot, Unbehaustheit, Betäubungsverlangen, Kompaßlosigkeit und $\mathrm{Haß}$ in Sprache übertragen werden" (Voss 2005: 77).

\section{Literatur}

Aristoteles (1982): Poetik. Griechisch/Deutsch. Übersetzt und hrsg. von Manfred Fuhrmann. Stuttgart: Reclam.

Aust, Stefan (2012): Ulrike auf der Couch. Der schwedische Autor Steve SemSandberg hat einen Roman über die RAF geschrieben, der weit weniger spannend ist als die Wirklichkeit. In: Die Zeit 40, 27. September 2012, 59.

Aust, Stefan (2008): Der Baader-Meinhof-Komplex. München: Goldmann.

Brockhaus (2001): Die Enæylklopädie in 24 Bänden. Studienausgabe. 20. überarb. und akt. Aufl. Leipzig: Brockhaus.

Diehl, August (2011): „Innere Zerrissenheit kenne ich gut“. Der Schauspieler August Diehl über Bernward Vesper in Wer wenn nicht wir. In: Badische Zeitung, 09. 
März 2011. Online: http:/ / www.badische-zeitung.de/kino-neustarts / augustdiehl-innere-zerrissenheit-kenne-ich-gut--42360741.html (Stand: 29.05.2014).

Feil, Robert; Hesse, Wolfgang (2006): miteinander leben. Unterrichtsmaterial für Orientierungs- und Sprachkurse. München: iudicium.

Fredering, Volker; Krommer, Axel; Maiwald, Klaus (2008): Mediendidaktik Deutsch. Eine Einführung. Berlin: Erich Schmidt.

Gaidosch, Ulrike; Müller, Christine (2010): Zur Orientierung. Basiswissen Deutschland. München: Hueber.

Hartkopf, Dorothea (2010): Der Orientierungskurs als neues Handlungsfeld des Faches Deutsch als Fremdsprache. Münster: Waxmann.

Kaufmann, Susan; Rohrmann, Lutz; Szablewski-Çavuş, Petra (2007): Orientierungskurs Deutschland: Geschichte, Institutionen, Leben in Deutschland. Berlin u.a.: Langenscheidt.

Kauzner, Ulrike A. (2008): Grenzen überschreiten - Grenzen überwinden. Neue Herausforderungen an den DaF-Unterricht. In: Kauzner, Ulrike A. (Hrsg.): Der Fall der Kulturmauer. Wie kann Sprachunterricht interkulturell sein? Münster: Waxmann, 11-26.

Kilimann, Angela; Kotas, Ondřej; Skrodzki, Johanna (2012): 45 Stunden Deutschland. Orientierungskurs Politik, Geschichte, Kultur. Stuttgart: Klett.

Koenen, Gerd (2005): Vesper, Ensslin, Baader. Urszenen des deutschen Terrorismus. Frankfurt a.M.: Fischer.

Maiwald, Klaus (2010): Filmdidaktik und Filmästhetik - Lesen und Verstehen audiovisueller Texte. In: Frederking, Volker; Krommer, Axel; Meier, Christel (Hrsg.): Taschenbuch des Deutschunterrichts Bd. 2. Literatur- und Mediendidaktik. Baltmannsweiler: Schneider Verlag Hohengehren, 219-237.

Neumann, Bernd (1979): Die Wiedergeburt des Erzählens aus dem Geist der Autobiographie? Einige Anmerkungen zum neuen autobiographischen Roman am Beispiel von Hermann Kinders Schleiftrog und Bernward Vespers Die Reise. In: Basis 9, 91-121.

Reidy, Julian (2012): Vergessen, was Eltern sind. Relektüre und literaturgeschichtliche Neusituierung der angeblichen Väterliteratur. Göttingen: Vandenhoeck \& Ruprecht.

Roche, Jörg Matthias (2010): Audiovisuelle Medien. In: Krumm, Hans-Jürgen; Fandrych, Christian; Hufeisen, Britta; Riemer, Claudia (Hrsg.): Deutsch als Fremdsprache. Ein internationales Handbuch. 2. Halbband. Berlin u.a.: de Gruyter, 1243-1251.

Schote, Joachim (2011): Grundwissen Politik, Geschichte und Gesellschaft in Deutschland. Berlin: Cornelsen. 
Schulz-Ojala, Jan (2008): Extrem laut und unglaublich fern. In: Der Tagesspiegel, 18.

September 2008, 29. Online: http://www.tagesspiegel.de/kultur/kino/

baader-meinhof-komplex-extrem-laut-und-unglaublich-fern/1327390.html

(Stand: 29.05.2014).

Vesper, Bernward (1983): Die Reise. Reinbek bei Hamburg: Rowohlt.

Volkmann, Lutz (2001): White, Hayden V. In: Nünning, Ansgar (Hrsg.): Metzler

Lexikon Literatur- und Kulturtheorie. 2. überarbeitete und erweiterte Auflage.

Stuttgart: Metzler, 672-673.

Voss, Henner (2005): Vor der Reise. Erinnerungen an Bernward Vesper. Hamburg: Edition Nautilus.

\section{Filmographie}

Der Baader Meinhof Komplex, 2008, Deutschland, Regie: Uli Edel, 150 Minuten.

Wer wenn nicht wir, 2011, Deutschland, Regie: Andreas Veiel, 124 Minuten. 


\section{AutorInnenverzeichnis}

Camilla Badstübner-Kizik studierte Klassische Philologie, Germanistik und Kunstgeschichte in Jena und Berlin, ist seit 1990 im polnischen Hochschulwesen tätig und u.a. in der Aus- und Fortbildung von Lehrenden für DaF in Polen, Österreich und Deutschland engagiert. Seit 2008 hat sie eine Professur am Institut für Angewandte Linguistik der Adam-Mickiewicz-Universität Poznań inne. Ihre Forschungsschwerpunkte sind fremdsprachige Kultur- und Mediendidaktik, Didaktik und Methodik der Landeskunde $\mathrm{DaF}$, inhaltsorientiertes und fächerübergreifendes Fremdsprachenlernen, außerschulische Lernorte, multimediale und multimodale Lernarrangements sowie Medienlinguistik.

Nils Bernstein studierte Germanistik, Komparatistik, Theaterwissenschaft und Deutsch als Fremdsprache in Mainz und promovierte über Nicanor Parra und Ernst Jandl in Wuppertal. Nach einer DAAD-Sprachassistenz in Santiago de Chile und Lehraufträgen in Wuppertal und Hannover war er von 2011 bis 2013 als DAAD-Lektor an der UNAM in Mexiko-Stadt tätig. Aktuell ist er für die Koordination des DaF-Bereiches am Fachsprachenzentrum der Universität Hamburg zuständig.

Siegfried Boehm ist seit 29 Jahren an der Deutschabteilung des Sprachenzentrums der FES Acatlán der UNAM in Mexiko-Stadt tätig. Neben dem DaF-Unterricht ist er Tutor für zwei Online-Fächer der Licenciatura en Enseñanza de Lenguas Extranjeras, Autor von zwei Lesekursen.

Eva V. Chen ist seit 2009 als wiss. Mitarbeiterin am Institut für Auslandsgermanistik/Deutsch als Fremd- und Zweitsprache an der Friedrich-Schiller-Universität Jena tätig. Ihre Lehr- und Forschungsschwerpunkte sind: Kulturvermittlung, Kulturwissenschaften, interkulturelle Begegnung. Nach ihrem Studium der Europäischen Ethnologie, Geschichte, Germanistik und Deutsch als Fremdsprache in Würzburg, Marburg und Jena, promovierte sie 2006 am Lehrstuhl für Volkskunde/Empirische Kulturwissenschaft der Friedrich-Schiller-Universität Jena. Darüber hinaus hatte sie im Frühlingssemester 2013 die Max-Kade-Gastprofessur an der Michigan State University (USA) inne.

Julia Collazo schloss 2012 an der Technischen Universität Dresden (TUD) ihr Erstes Staatsexamen für Lehramt an Gymnasien u.a. im Fach DaF/DaZ ab. Im Jahr 2013 beendete sie ebenfalls an der TUD erfolgreich ihr Masterstudium in Romanistik und Germanistik. Sie war im Anschluss ein Jahr als Sprachassistentin 
des DAAD in Mexiko-Stadt tätig und arbeitet derzeit als Lehrerin an der Deutschen Schule La Herradura in Mexiko-Stadt.

Michael Dobstadt studierte in Bonn Germanistik und Geschichte und promovierte dort 2008 mit einer Arbeit über Georg Christoph Lichtenberg und Karl Philipp Moritz. Von 2000-2005 war er DAAD-Lektor in Salamanca. Seit 2006 arbeitet er am Herder-Institut der Universität Leipzig; von 2007 bis 2012 als Koordinator des binationalen Studiengangs Deutsch als Fremdsprache: Estudios contrastivos de lengua, literatura y cultura alemanas und seit 2011 als wissenschaftlicher Mitarbeiter im Bereich Kulturstudien.

Antje Dohrn absolvierte das 1. und 2. Staatsexamen in Deutsch, Französisch und Englisch sowie Zusatzqualifikationen in DaF und DaZ. Nach diversen Unterrichtserfahrungen an Berliner Gymnasien und dem Studienkolleg der FU Berlin arbeitete sie mehr als 11 Jahre lang als wissenschaftliche Mitarbeiterin an der TU Berlin im Fachgebiet Deutsch als Fremd- und Zweitsprache. Dort promovierte sie 1986 zum Thema Leseförderung mit literarischen Texten im DaZ-Unterricht. AuBerdem ist Antje Dohrn als Schulcoach für DaZ-Klassen und in der wissenschaftlichen Weiterbildung mit Seminaren zur interkulturellen Kommunikation mit verschiedenen Länderschwerpunkten tätig.

Susanne Even unterrichtet deutsche Sprache, Literatur und Kultur an der Indiana University in Bloomington, Indiana (USA) und bildet angehende Fremdsprachenpädagogen aus. Sie promovierte am University College Cork in Irland im Bereich Dramapädagogik, und ihr Buch Drama Grammatik - dramapädagogische Ansätze für den Grammatikunterricht Deutsch als Fremdsprache erschien 2003 im iudicium-Verlag.

Micha Fleiner lehrt und forscht im Rahmen eines binational strukturierten Graduiertenprogrammes am German Department des University College Cork in Irland sowie am Institut für Romanistik der Pädagogischen Hochschule Freiburg in Deutschland. Seine Forschungsschwerpunkte liegen im Bereich der Sprach-, Literatur- und Kulturdidaktik mit besonderem Bezug zu performativ-ästhetischen Formen des Lehrens und Lernens.

Magdalena Haftner studierte Pädagogik an der Universität Wien und Theaterpädagogik am Institut angewandtes Theater. Sie arbeitet als freischaffende Theaterpädagogin, Performerin, Improvisationstheaterspielerin und -trainerin im In- und Ausland. Als Ensemblemitglied der Gruppe artig ist sie seit 2011 u.a. auch im DaFBereich tätig und gibt spielendDeutsch Improvisationstheater-Workshops und -Fortbildungen für Deutschlernende und -lehrkräfte an diversen Sprachinstituten (Goethe-Institute, Österreich-Institute, Auslandsschulen etc.) in Europa, Asien, Afrika und Amerika. 
Heidi Hahn ist derzeit Akademische Oberrätin am Institut für deutsche Sprache und Literatur der Pädagogischen Hochschule Karlsruhe (Literaturwissenschaft und Literaturdidaktik). Zuvor absolvierte sie ihren Master in Schulmanagement und war mehrere Jahre als Lehrerin an Gymnasien im In- und Ausland (auch DaF) tätig. Ihre Arbeitsschwerpunkte sind: Deutschsprachige Literatur des 20. Jahrhunderts; Intertextualität/Intermedialität; Kinder- und Jugendliteratur; Literarisches Lernen (auch im DaF-/DaZ-Kontext) und Ästhetische Bildung.

Almut Hille ist Professorin für Deutsch als Fremdsprache an der Georg-AugustUniversität Göttingen, zuvor war sie Juniorprofessorin für Deutsch als Fremdsprache: Kulturvermittlung an der Freien Universität Berlin. Sie studierte Germanistik und Lateinamerikanistik an der Freien Universität Berlin, der Universität Córdoba/Argentinien und der New York University und war nach dem Studium in vielfältigen Kontexten im Bereich Deutsch als Fremdsprache tätig.

Christiane Hochstadt war mehrere Jahre lang als Lehrerin in Grund- und Hauptschulen tätig. Derzeit arbeitet sie als Akademische Mitarbeiterin im Fach Deutsch an der Pädagogischen Hochschule Heidelberg und promoviert im Bereich Grammatikdidaktik.

Anne-Marie Kuhfuß studierte an der Universität Wien Romanistik und Deutsch als Fremdsprache. Als Improvisationstheaterspielerin und Produzentin begann sie während ihres Studiums zu arbeiten und seit 2011 ist sie als Lehrende und Fortbildnerin von Deutsch als Fremdsprache tätig. An der Uraler Staatlichen Universität Jekaterinburg unterrichtete sie Methodik, Literatur, Konversation, sowie Improvisationstheater für Deutschstudierende. Als Ensemblemitglied entwickelte sie gemeinsam mit der Improvisationstheatergruppe artig das Konzept spielendDeutsch, mit dem sie bereits an div. Sprachinstituten Workshops und Fortbildungen (Goethe-Institute, Österreich-Institute, Auslandsschulen etc.) in Europa, Asien, Afrika und Amerika gab.

Tristan Lay studierte in Bochum Sprachlehrforschung und Sinologie. Seit 1999 ist er im DaF-/DaZ-Bereich tätig, zuletzt in der Funktion eines Lecturers (Level B) am Department of Germanic Studies der University of Sydney.

Charlotte Lerchner studierte Deutsch als Fremdsprache, Kommunikations- und Medienwissenschaft und Ethnologie an der Universität Leipzig. Nach ihrem Abschluss war sie als DAAD-Sprachassistentin an der FES Acatlán (UNAM) in Mexiko-Stadt tätig. Seit Juni 2011 arbeitet sie in der Bildungskooperation Deutsch am Goethe-Institut Mexiko. 
Johann Georg Lughofer arbeitet als Dozent an der Germanistikabteilung der Universität Ljubljana und als Lehrbeauftragter der Universität Wien. Nach seinem Studium in Wien, Granada, Nizza und Exeter unterrichtete er an der PekingUniversität, der University of Exeter, der Univerza v Mariboru, der Stellenbosch University, den Universitäten Wien und Innsbruck sowie an zahlreichen Schulen in verschiedenen Ländern.

Birgit Oelschläger hat Theaterwissenschaft und Theaterpädagogik in Berlin und Paris studiert. Sie ist seit mehr als 15 Jahren als Lehrerin für Deutsch als Fremdsprache und Fortbilderin mit dem Schwerpunkt Theater im Unterricht für die Goethe-Institute in Berlin sowie in aller Welt tätig. In den letzten 5 Jahren hat sie außerdem in diversen Ländern für Deutsch lernende Schüler Theaterprojekte konzipiert und Theaterworkshops durchgeführt.

Matthias Perner arbeitet als wissenschaftlicher Mitarbeiter an der Leibniz Universität Hannover in der zentralen Einrichtung Fachsprachenzentrum als DaFDozent und Projektmanager u.a. für englische Sprachnachweise. Er hat Anglistik und Germanistik in Hannover und England (University of Bristol) studiert.

Ulrike Pleß studierte von 2003 bis 2007 den Bachelor of Arts Mehrsprachige Kommunikation und im Anschluss von 2007 bis 2009 den Master of Arts Facbübersetzen an der Fachhochschule Köln. Im August 2010 begann sie eine einjährige DAAD-Sprachassistenz an der Universität Guadalajara in Mexiko, an der sie auch im Jahr darauf für ein Jahr als Gastdozentin tätig war und seit August 2012 als DAAD-Lektorin.

Dietrich Rall studierte Romanistik und Germanistik an den Universitäten Tübingen, Berlin, Innsbruck, Toulouse und Pau und promovierte 1968 in Tübingen über die Rezeption spanischer Literatur in Frankreich. Von 1975 bis 2007 war er Ordentlicher Professor für Deutsch als Fremdsprache, Germanistik und Komparatistik an der Universidad Nacional Autónoma de México. Er wurde im Jahr 2000 mit dem Premio Universidad Nacional für die Lehre in den Geisteswissenschaften ausgezeichnet und ist seit 2003 Mitglied der Academia Mexicana de Ciencias. Nach seiner Pensionierung erhielt er 2009 das Bundesverdienstkreuz für die Förderung der deutschen Sprache und Germanistik in Mexiko und Lateinamerika.

Renate Riedner studierte in München Deutsch als Fremdsprache/Transnationale Germanistik, Neuere deutsche Literatur und Ethnologie und promovierte dort 1996 mit einer Arbeit über Brigitte Kronauer. Von 2000 bis 2003 war sie Lehrbeauftragte und Wissenschaftliche Mitarbeiterin am Institut für Deutsch als Fremsprache/Transkulturelle Germanistik an der Universität München, von 1996-1999 und von 2003-2007 DAAD-Lektorin in Kairo. Seit 2007 arbeitet sie am Herder- 
Institut der Universität Leipzig; von 2007 bis 2013 als Koordinatorin des binationalen Masterstudiengangs Deutsch als Fremdsprache im arabisch-deutschen Kontext und seit 2011 als wissenschaftliche Mitarbeiterin im Bereich Kulturstudien.

Manfred Schewe lehrt Sprache, Literatur und Kultur an der germanistischen Abteilung der Universität Cork und bietet dort auch Lehrveranstaltungen im Fach Drama and Theatre Studies an. Schwerpunkt seiner zahlreichen Veröffentlichungen ist das Performative Lehren, Lernen und Forschen. Mit seinem Buch Fremdsprache inszenieren hat er die Dramapädagogik im deutschsprachigen Raum bekannt gemacht. Er ist Gründer der Fachzeitschrift SCENARIO und des internationalen Netzwerks SCENARIO FORUM for Performative Teaching, Learning and Research.

Carmen Schier ist seit 2012 Professorin für Kulturwissenschaften an der Hochschule für angewandte Wissenschaften Coburg. Nach ihrer Tätigkeit als DAADLektorin in der Ukraine, Portugal und Brasilien war sie von 2006 bis 2012 als Lehrkraft für besondere Aufgaben am Herder-Institut der Universität Leipzig tätig. Zudem leitete sie zahlreiche Lehrerfortbildungen im In- und Ausland und veröffentlichte Fachpublikationen und Vorträge zu kulturwissenschaftlichen Fragestellungen, zur interdisziplinären Arbeit im Sprach- und Landeskundeunterricht, zum ganzheitlichen Lernen und zur Behandlung von Gegenwartsliteratur in DaF.

Anke Stöver-Blahak war nach dem Zweiten Staatsexamen ein Jahr Lektorin in China. Seit 1989 arbeitet sie im Bereich Deutsch als Fremdsprache an der Leibniz Universität Hannover. Sie war im Vorstand des Fachverbands für Deutsch als Fremdsprache und ist zurzeit Koordinatorin des Sprachbereichs Deutsch am Fachsprachenzentrum in Hannover. Seit 2012 ist sie promoviert mit einer Arbeit zum Sprechen und Vortragen Lernen im Fremdsprachenunterricht.

Maik Walter absolvierte das Studium der Fächer Deutsch und Mathematik und das Zusatzstudium Deutsch als Fremdsprache an der Humboldt-Universität zu Berlin. Dort war er anschließend als Wissenschaftlicher Mitarbeiter tätig, bevor er für fünf Jahre an die Freie Universität und in der Folge zum Institut für Deutsche Sprache nach Mannheim wechselte. 2012 vertrat er den Lehrstuhl für deutsche Sprache der Gegenwart an der Universität Potsdam und ist seit vielen Jahren Lehrbeauftragter am Deutschen Seminar der Universität Tübingen. Daneben leitet er als Theaterpädagoge Workshops und Fortbildungen im In- und Ausland. Dies führte 2009 zur Gründung von Textbewegung: Theater und Sprache.

Angelika Weber ist seit 2001 Dozentin für $\mathrm{DaF}$ an der Universität Pretoria, Südafrika. Ihr Forschungsinteresse bewegt sich im Rahmen eines Sprachunterrichts für DaF-Lernende, der literarische Texte in den Grammatikunterricht integriert. Ihre Dissertation Die Textgrammatik Harald Weinrichs als Lernergrammatik des Deutschen als Fremdsprache befasst sich eingehend mit diesem Thema. 
Tina Welke ist derzeit Postdoc am Fachbereich DaF/Z am Institut für Germanistik der Universität Wien. Sie studierte Sprachwissenschaft, Politikwissenschaft und Deutsch als Fremdsprache. Aktuell ist sie in der LehrerInnenaus- und -fortbildung tätig mit dem Spezialgebiet: Film(vermittlung).

Kathrin Wild studierte Kultur- und Sprachmittlerin für Deutsch, Dänisch und Englisch in Dänemark, Finnland und Flensburg. Ihre Promotion zum Thema Einfluss rhythmischer Übungselemente auf den Erwerb des deutschen Wortakzents schloss sie 2013 an der Universität Flensburg ab. Nach sieben Jahren DaF- und DaZLehrtätigkeit in Slowenien, England, Dänemark und Deutschland lehrte sie von 2011 bis 2013 Englisch an der Pädagogischen Hochschule Süddänemark. Seit 2014 ist sie Akademische Rätin auf Zeit im Fachbereich DaF der Universität Bielefeld. 
Was hat Ästhetik mit Fremdsprachenunterricht zu tun und wie kann man verschiedene Kunstformen im Fremdsprachenunterricht einbringen? Dies waren Fragen, die 2013 auf dem Kongress „Ästhetisches Lernen im DaF-Unterricht. Musik-Kunst-Film-Theater-Literatur" an der UNAM (Universidad Autónoma de México) in Mexiko-Stadt thematisiert wurden. Ausgegangen wurde dabei von der These, dass die Einbindung der sinnlichen Wahrnehmung in Sprachlernprozesse einen interpretatorisch offenen und lebhaften Zugang zu Sprache und Kultur ermöglicht, der jenseits einer oftmals vorherrschenden Kompetenzorientierung liegt. Der vorliegende Band versammelt in ausgewogenem Theorie-Praxis-Verhältnis ausgewählte Kongressbeiträge und zusätzliche Artikel, in denen jeweils die verschiedenen Kunstformen unter Beachtung ihrer eigenen Ästhetik im Mittelpunkt stehen.

\section{fadaf}

fadaf.de

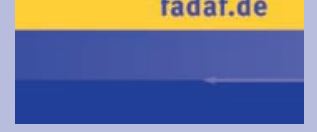

